\author{
UNIVERSIDADE DE SÃO PAULO \\ INSTITUTO DE GEOCIÊNCIAS
}

\title{
ESTUDO ISOTÓPICO DE U-Pb, Lu-Hf e Ti EM ROCHAS VULCÂNICAS ASSOCIADAS AOS SULFETOS MACIÇOS DA FAIXA PIRITOSA IBÉRICA (ESPANHA)
}

\author{
Caio Ribeiro de Mello
}

Orientador: Prof. Dr. Colombo Celso Gaeta Tassinari

TESE DE DOUTORAMENTO

Programa de Pós-Graduação em Geoquímica e Geotectônica

SÃO PAULO

2020 


\author{
UNIVERSIDADE DE SÃO PAULO \\ INSTITUTO DE GEOCIÊNCIAS
}

\title{
ESTUDO ISOTÓPICO DE U-Pb, Lu-Hf e Ti EM ROCHAS VULCÂNICAS ASSOCIADAS AOS SULFETOS MACIÇOS DA FAIXA PIRITOSA IBÉRICA (ESPANHA)
}

\author{
Caio Ribeiro de Mello \\ Orientador: Prof. Dr. Colombo Celso Gaeta Tassinari \\ TESE DE DOUTORADO \\ $N^{0} 623$ \\ COMISSÃO JULGADORA \\ Dr. Colombo Celso Gaeta Tassinari \\ Dra. Lena Virginia Soares Monteiro \\ Dra. Maria Helena Bezerra Maia de Hollanda \\ Dr. Miguel Angelo Stipp Basei \\ Dr. Saulo Batista de Oliveira \\ Dra. Lydia Maria Lobato
}

SÃO PAULO

2020 
Para minha querida avó Ursula, Para meus sobrinhos Gre, Lele, Juju e Lulu 
He who knows not, and knows not that he knows not - He is a fool, shun him.

He who knows not, and knows that he knows not - He is simple, teach him.

He who knows, and knows not that he knows - He is asleep, wake him.

He who knows, and knows that he knows - He is insufferable, use him.

He who knows, and knows when he knows not - He is wise, follow him.

Victor F. B. de Mello, modificado de um provérbio árabe anônimo 


\section{Agradecimentos}

Esta tese de doutorado encerra um ciclo da minha vida. São 12 anos estudando o nosso planeta e seus processos, desde o início da graduação em 2008 até aqui, o que significa que com certeza eu tenho muito mais a agradecer do que essas palavras serão capazes de demonstrar.

Começo agradecendo ao meu orientador ao longo do mestrado e doutorado, Prof. Colombo. Ao longo desses 6 anos trabalhando em conjunto foram diversas lições valiosas. Obrigado por abrir todas as portas para um jovem que estava perdido no final da graduação, sabendo que queria continuar estudando, mas sem foco quanto ao tema. Obrigado por abrir as portas para projetos incríveis, tanto no mestrado quanto no doutorado. E obrigado pela autonomia, é com ela que vem o crescimento verdadeiro.

Meus coorientadores também foram importantíssimos nessa jornada. Ao Dr. Fernando Tornos, geólogo espanhol que nos abriu as portas para trabalhar na Faixa Piritosa Ibérica, meus agradecimentos. Ao Prof. Dr. John Hanchar, da Universidade Memorial, em Newfoundland e Labrador, Canadá, meus mais sinceros agradecimentos também. Os três meses de convívio foram valiosíssimos tanto para este projeto quanto para a minha formação como indivíduo. À $\mathrm{Dr}^{\mathrm{a}}$. Carmen Conte, geóloga espanhola que trabalha junto com o Dr. Fernando Tornos, meus agradecimentos sinceros por sempre estar aberta a conversar e esclarecer questões relativas a geologia da região. Um abraço para o Dr. Mauricio Borba também, por todas as conversas no SHRIMP. Um agradecimento pela paciência e auxílio ao Vasco, Daniela e Nayara. E um forte abraço ao Dr. Kei Sato por todas as ajudas em várias sessões de análise no SHRIMP. Um muito obrigado especial para a Silvana também por me ajudar em todas as questões mais burocráticas, sempre me ensinando o caminho das pedras e me dando o peixe já pescado.

Aos meus amigos de graduação e pós-graduação o meu muito obrigado também. Sem vocês tudo teria sido mais difícil. Aquele abraço especial a turma 51! Vocês contribuíram mais do que qualquer outro professor da USP para meu aprendizado de mundo. Existem diversas outras pessoas de outras turmas do IGc-USP ou de outras faculdades que foram muito importantes, seja pelo convívio no instituto, seja pelos treinos de handball, basquete e futebol no CEPE ou nos tempos de BIFE e geoatlética. Seria impossível lembrar de todas elas, então fica um agradecimento geral (mas não menos sincero). 
Aos meus amigos de Disney, um abraço especial! Vocês foram importantíssimos para a evolução dessa tese. Guilherme e Renato, foi um prazer morar com vocês. Essa ideia que a gente comprou junto chamada Disney se tornou uma parte de nós (ou de mim pelo menos). Evandro, com você eu realmente entendi o que significa disciplina e trabalho duro. Kayano, muito obrigado por todas as conversas sobre a vida acadêmica, seja no IGc ou seja no IB, sem dúvidas elas me ajudaram muito no processo de amadurecimento que é necessário para a conclusão de um doutorado. Lorenzo, o verdadeiro labrador humano, quando eu crescer eu quero ser feliz como você cara! Vocês da Disney são irmãos e eu agradeço a vocês com toda a sinceridade.

Sem o apoio familiar nada disso teria sido possível e se eu consigo fazer qualquer coisa certo hoje em dia é só porque eu tive os dois melhores exemplos do mundo em casa. Sou realmente privilegiado de ter o pai e a mãe que eu tenho. Os melhores conselhos e as puxadas de orelhas necessárias sempre vieram de vocês. Com vocês eu aprendi tanto de tantas coisas que é impossível tentar fazer caber em uma sessão de agradecimentos só, mas basicamente vocês me construíram. Se eu conseguir ser metade do pai que eu tive e construir um lar para a minha família que seja metade do lar que eu tive eu já me considerarei um homem de sucesso.

Meus irmãos Gil e Maria também sempre foram exemplos de vida. Eu sempre aprendi e continuo aprendendo muito com vocês, e, mesmo que estes aprendizados não sejam relacionados a vida acadêmica propriamente dita, eles sempre foram valiosíssimos para mim. Os momentos com o Gre, Lele, Lulu e Juju sempre foram os momentos mais felizes ao longo desta caminhada. Ver o sorriso no rosto deles sempre foi o bastante para dissipar qualquer nuvem negra que estivesse pairando sob minha cabeça. Eles explicam o que é felicidades melhor que qualquer definição erudita.

O agradecimento mais especial de todos vai para a Clara, a mulher que segurou todas as barras ao meu lado. Que entrou nesse processo no início sem entender nada sobre os desafios da vida acadêmica e mesmo assim me deu apoio incondicional em todos os momentos. Que me escutou e conversou comigo sobre geologia mesmo sem entender um nada. Que tentou se interessar de verdade por isótopos, zircões e háfnio e essas coisas estranhas que eu resolvi estudar. Você é minha base, meu porto seguro, minha torre no alto da montanha onde eu me amarro para dar o salto. Obrigado por tudo. 


\section{RESUMO}

Neste trabalho são apresentados novos dados de isótopos de U-Pb, Ti e Lu-Hf obtidos a partir do estudo de amostras representativas de rochas vulcânicas félsicas associadas aos corpos de sulfeto maciço de diferentes regiões da Faixa Piritosa Ibérica (FPI). A FPI é dividida em duas regiões distintas, a Região Norte e a Região Sul, que apresentam diversas diferenças geológicas entre si, como o processo de formação dos sulfetos maciços, as rochas encaixantes, idades de formação, temperatura de cristalização e origem magmática das rochas vulcânicas félsicas associadas aos corpos de sulfeto maciço. Para estudar os isótopos de U$\mathrm{Pb}$ e de Ti foi utilizado o SHRIMP, enquanto que os estudos de Lu-Hf foram executados no LA-MC-ICPMS. A Região Norte é subdividida em dois setores de acordo com a geografia: Setor Central e Cinturão Norte.Os isótopos de U-Pb das rochas vulcânicas da Região Norte mostram que os depósitos desta região estão associados ao vulcanismo Tournaisiano, um intervalo posterior ao vulcanismo Struniano (Famenniano Superior) amplamente reconhecido em associação com os depósitos na Região Sul. As rochas do Cinturão Norte apresentaram intervalo associado aos corpos de sulfeto maciço entre 354-347 Ma. Enquanto que no Setor Central o depósito de La Zarza apresenta intervalo de 357-355 Ma. Em Rio Tinto, também no Setor Central, o estudo geocronológico foi mais aprofundado e caracterizou um amplo intervalo de pulsos intermitentes entre 358-339 Ma, com os depósitos de sulfeto maciços associados ao intervalo entre 352-348 Ma. As rochas da Região Sul apresentaram idades $\mathrm{U}-\mathrm{Pb}$ associadas aos corpos de sulfeto maciço entre 365-359 Ma. Outras idades no intervalo de 352-348 Ma também são calculadas na Região Sul em rochas plutônicas e em uma rocha vulcânica estéril em Las Cruces, mas estas amostras são estéreis e também diferem das rochas Strunianas em relação a temperatura de cristalização. A geocronologia da unidade relacionada ao vulcanismo félsico associado ao depósito de Rio Tinto foi estudada em maior detalhe e mostrou 3 períodos distintos: Unidade Félsica I, em $358 \mathrm{Ma}$, que marca o início do vulcanismo da Unidade Félsica na região de Rio Tinto. A Unidade Félsica II é a unidade relacionada com os corpos de sulfeto maciço e apresenta intervalo entre 352-348 Ma. O fim do vulcanismo félsico na região é marcado pela Unidade Félsica III, um corpo tardio que corta as demais unidades. As rochas vulcânicas Tournaisianas associadas aos corpos de sulfeto maciço apresentam temperaturas de ${ }^{49} \mathrm{Ti}$ inferiores a $760^{\circ} \mathrm{C}$, enquanto que as temperaturas das rochas vulcânicas Strunianas associadas aos sulfetos maciços que foram estudadas nesta tese e por outros autores são 
superiores a $800^{\circ} \mathrm{C}$. Estas temperaturas mais frias são inesperadas e complementam o cenário apresentado na literatura para os depósitos de sulfeto maciço da FPI e da literatura como um todo, que apresentam os corpos de sulfeto maciço associados a corpos vulcânicos de temperaturas mais elevadas $\left(\mathrm{T}>800^{\circ} \mathrm{C}\right)$ tanto na FPI quanto em análises mais amplas. $\mathrm{O}$ depósito de Rio Tinto, o maior depósito da FPI, apresenta as menores temperaturas calculadas nesta tese, com valores sempre inferiores a $730^{\circ} \mathrm{C}$. As assinaturas $\varepsilon_{\mathrm{Hf}}$ obtidas a partir dos isótopos de Lu-Hf também mostram diferenças entre os distintos setores da FPI. No Cinturão Norte da Região Norte ocorre contribuição de material mantélico em grande quantidade e o valor médio de $\varepsilon_{\mathrm{Hf}}$ é de $\sim-0.2$. O Setor Central apresenta contribuição de material mantélico em menor escala e apresenta assinatura média de $\varepsilon_{\mathrm{Hf}}$ de -3.2. A Região Sul espanhola possui $\varepsilon_{\mathrm{Hf}} \sim-5.2$, enquanto que a porção portuguesa da Região Sul apresenta $\varepsilon_{\mathrm{Hf}} \sim-7.97$. O Cinturão Norte possui uma unidade andesítica abundante e a interação de magmas ácidos e básicos deve estar correlaciona a esta assinatura menos crustal da região norte. Rochas plutônicas são escassas na FPI e nesta tese dois litotipos plutônicos foram estudados no Maciço de Gerena. Os resultados obtidos nestes litotipos mostram que o Maciço de Gerena está associado com o intervalo de 352-348 Ma, que, na Região Sul, é estéril. Os dados isotópicos de U-Pb, Ti e Lu-Hf associam o plutonismo do Maciço de Gerena com o vulcanismo Tournaisiano de Las Cruces e indicam que estas rochas plutônicas são as raízes plutônicas do vulcanismo do Complexo Vulcano Sedimentar nesta época e região.

Palavras chave: Faixa Piritosa Ibérica; FPI; U-Pb, Ti; Lu-Hf, Rio Tinto, Maciço de Gerena, VMS 


\section{ABSTRACT}

In this work, new $\mathrm{U}-\mathrm{Pb}, \mathrm{Ti}$ and $\mathrm{Lu}-\mathrm{Hf}$ isotope data are presented from the study of representative samples of the felsic volcanic rocks associated with the massive sulfide bodies of different regions of the Iberian Pyrite Belt (IPB). The IPB is a giant volcanogenic massive sulfide province divided into two distinct units, the Northern Region and Southern Region. The two regions are characterized by large geological differences, such as massive sulfide formation, host rock, ages, temperatures and magmatic sources. The $\mathrm{U}-\mathrm{Pb}$ and $\mathrm{Ti}$ isotopes studies were performed at SHRIMP, while Lu-Hf studies were performed at LA-MCICPMS.The Northern Region is subdivided into two different domains, the Central Sector and the Northern Belt. The U-Pb isotopes of the volcanic rocks of the Northern Region show this region is associated with Tournaisian volcanism, a later volcanic interval in comparison with the widely recognized Strunian volcanism in the Southern Region. The rocks of the Northern Belt had a range associated with the massive sulfide bodies between 354-347 Ma, while La Zarza in the Central Sector had a range of 357-355 Ma. In Rio Tinto, the geochronological study was more thorough and characterized a wide range of intermittent pulses between 358-339 Ma. The main interval is associated with the VMS formation and dated between 352-348 Ma. The rocks of the Southern Region showed U-Pb ages associated with massive sulfide bodies between 365-359 Ma. Other ages in the range of 352-348 Ma are also observed in the Southern Region in plutonic rocks and a barren volcanic rock in Las Cruces but these samples are barren and are also different from Strunian rocks in relation to the crystallization temperature. Tournaisian volcanic rocks associated with massive sulfide bodies have temperatures of ${ }^{49} \mathrm{Ti}$ below $760^{\circ} \mathrm{C}$, while the temperatures of Strunian volcanic rocks that have been studied in this thesis and by other authors are above $800^{\circ} \mathrm{C}$. These colder temperatures are unexpected and complement the scenario presented in the literature for the IPB massive sulfide deposits and the literature as a whole, which shows the massive sulfide bodies associated with higher temperature volcanic bodies $\left(\mathrm{T}>800^{\circ} \mathrm{C}\right)$. The Rio Tinto is the largest deposit of IPB and presents temperatures below $730^{\circ} \mathrm{C}$. The $\varepsilon_{\mathrm{Hf}}$ signatures obtained from the Lu-Hf isotopes also show the differences between the different IPF sectors. In the Northern Belt of the Northern Region there is a large amount of mantle material contributed and the average value of $\varepsilon_{\mathrm{Hf}}$ is $\sim-0.2$. The Central Sector still has a contribution of this mantle material and has an average $\mathrm{Hf}$ signature of $\sim-3.2$. The Southern Region has $\varepsilon_{\mathrm{Hf}} \sim-5.2$ in Spain, while the Portuguese portion has $\varepsilon_{\mathrm{Hf}} \sim-7.97$. The geochronology of the volcanic Felsic 
unit associated with the Rio Tinto deposit was studied in detail and showed three distinct periods: Felsic Unit I, at $358 \mathrm{Ma}$, which marks the onset of the Felsic Unit volcanism in the Rio Tinto region. The Felsic Unit II is the unit related to the massive sulfide bodies and has a range of 352-348 Ma. The Felsic Unit III, a late body that crosscuts the other units, marks the end of felsic volcanism in the region. Plutonic rocks are scarce in IPB and this thesis studied two plutonic lithotypes in the Gerena Massif. The results obtained in these lithotypes show the Gerena Massif is associated with the 352-348 Ma interval, which in the Southern Region is sterile. $\mathrm{U}-\mathrm{Pb}$, Ti and Lu-Hf isotopic data associate the Gerena Massif plutonism with the Las Cruces Tournaisian volcanism and indicate that these plutonic rocks are the plutonic roots of the Volcano-Sedimentary Complex volcanism at this time and region.

Key words: Iberian Pyrite Belt; IPB; U-Pb, Ti; Lu-Hf, Rio Tinto, Gerena Massif, VMS 


\section{Sumário}

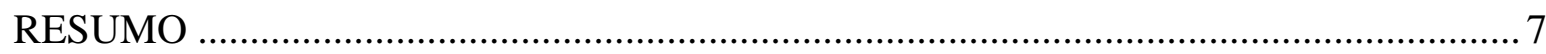

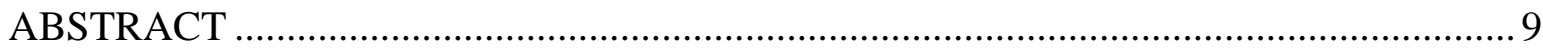

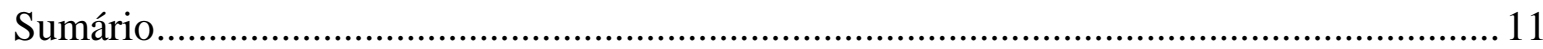

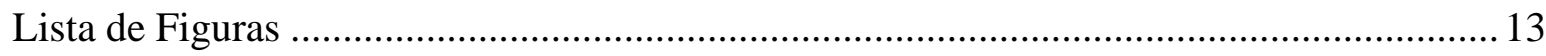

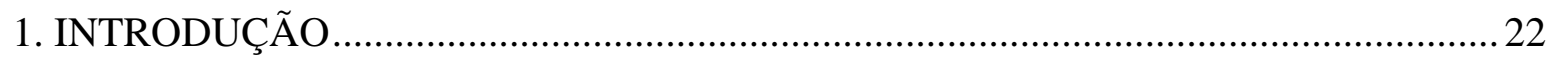

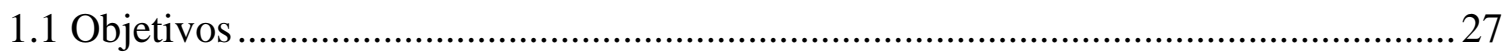

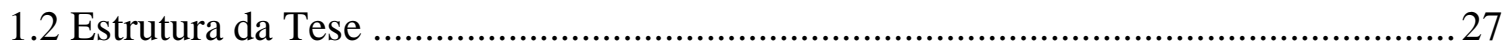

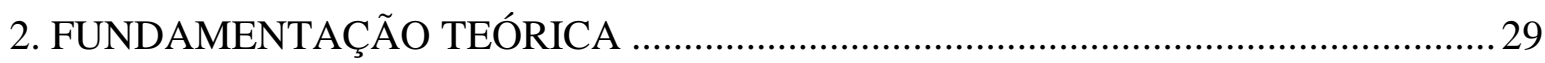

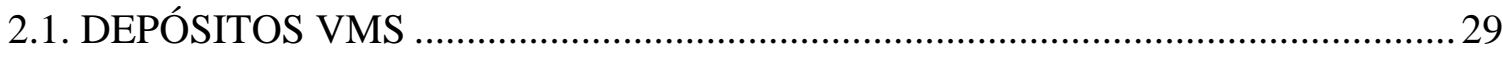

2.1.1. Fatores chave para a formação e preservação de um depósito VMS ........................ 33

2.1.2. Estilos de precipitação de sulfetos maciços vulcanogênicos ..................................... 35

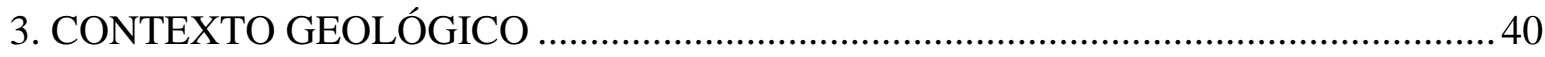

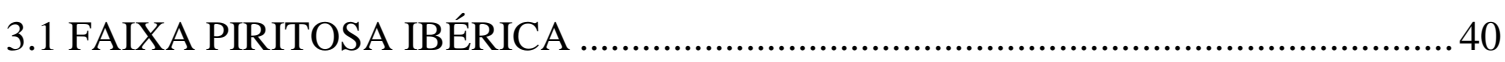

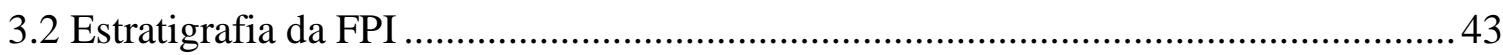

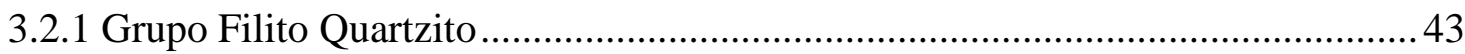

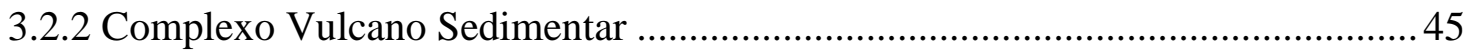

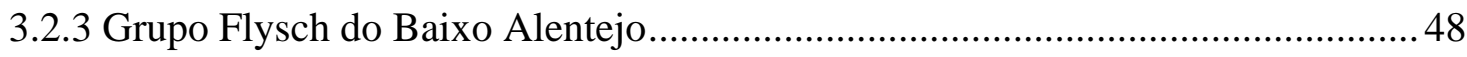

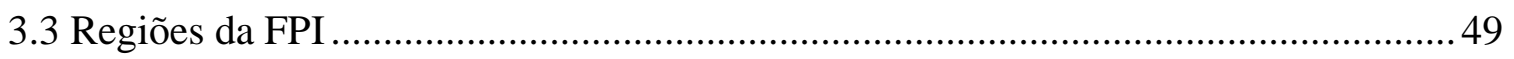

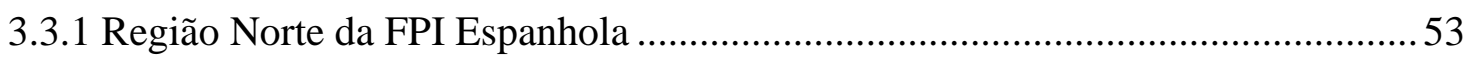

Cinturão Norte da Região Norte da FPI ....................................................................5

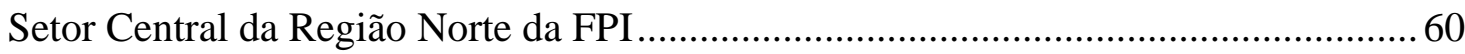

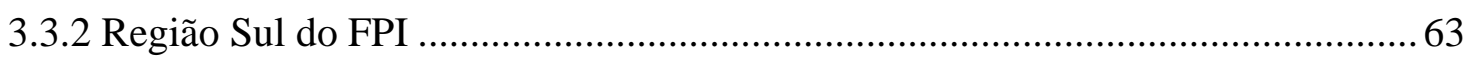

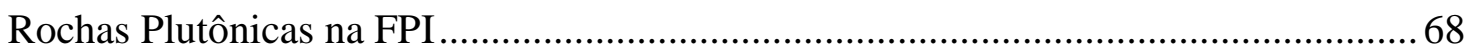

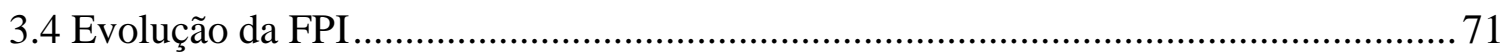

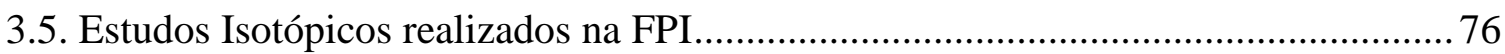




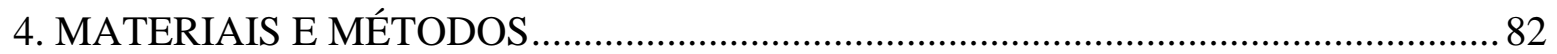

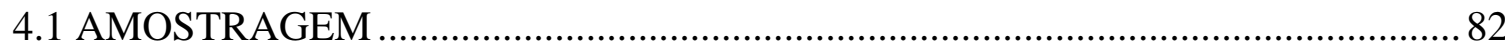

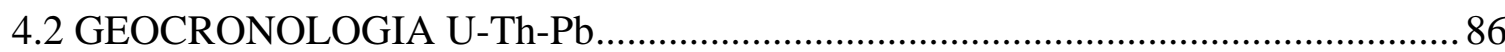

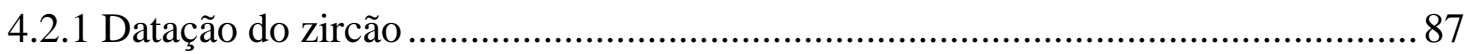

4.2.2 Geocronologia em depósitos de VMS .......................................................... 88

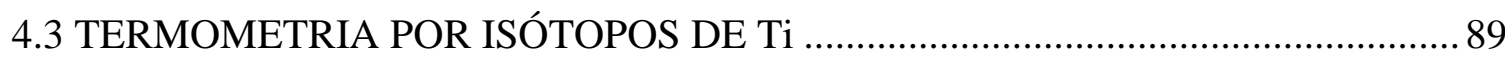

4.3.1 Por que Titânio? ........................................................................................ 89

4.3.2 O geotermômetro de Ti-em-zircão ......................................................... 89

4.3.3 Por que isótopos de Ti? ..................................................................... 91

4.3.4 Análises de isótopos de Ti por SHRIMP ..................................................91

4.4. ISÓTOPOS DE Lu-Hf ........................................................................... 93

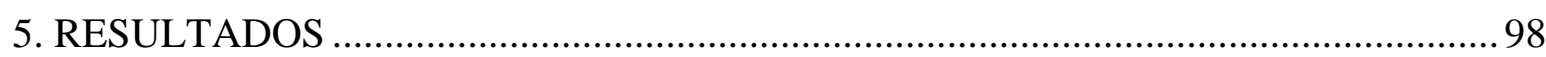

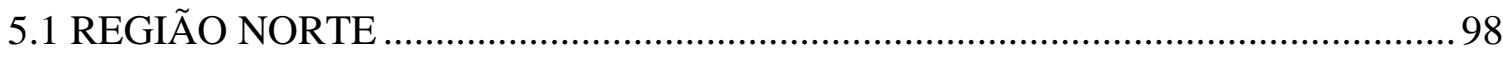

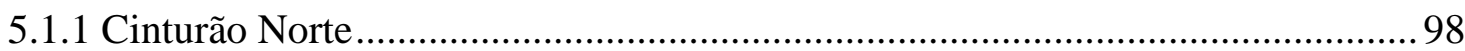

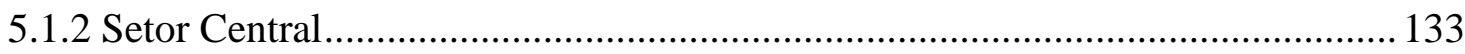

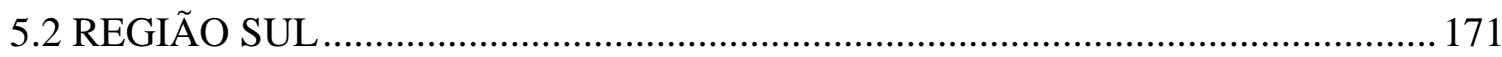

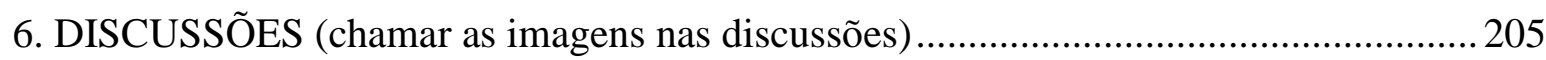

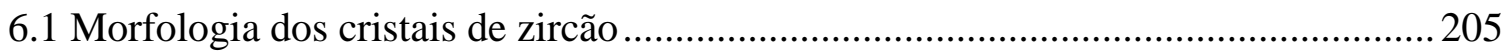

6.2 Idades no contexto regional da FPI............................................................ 206

6.2.2 Resultados de Ti-em-zircão no contexto regional da FPI....................................213

6.2.3 Resultados dos isótopos de Lu-Hf no contexto regional da FPI ...........................216

6.3 Diferenças entre a Região Norte e a Região Sul da Faixa Piritosa Ibérica............... 218

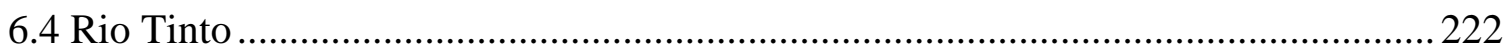

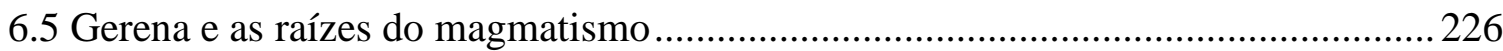

6.6 Temperatura de formação de depósitos de sulfeto maciço vulcanogênicos .............227

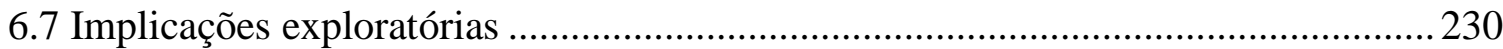




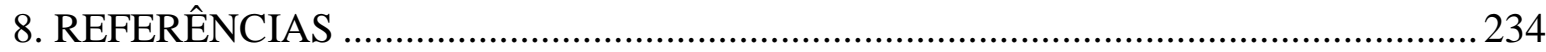

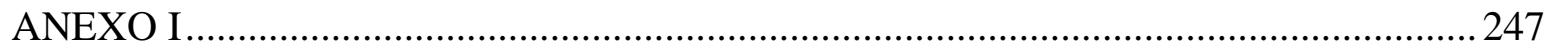

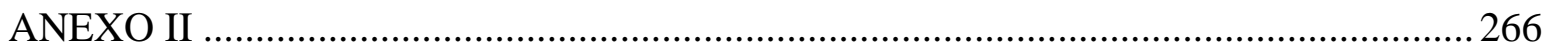

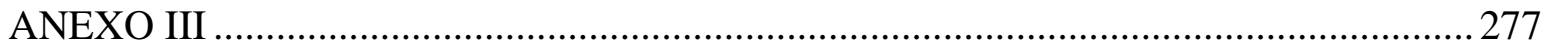

\section{Lista de Figuras}

FIGURA 1. LOCALIZAÇÃo dA FPI NA EXTREMIDADE SULDOESTE DA PENÍNSULA IBÉRICA.

FIGURA 2. COMPARATIVO ENTRE A TONELAGEM MÉDIA DE DEPÓSITOS VMS ENCAIXADOS EM ROCHAS BIMODAIS MÁFICOS, FÉLSICOS E MÁFICOS (MOSIER ET AL., 2009).

FIGURA 3. DIAGRAMA ESQUEMÁTICO COM AS PRINCIPAIS CARACTERÍSTICAS DOS TRÊS ESTILOS DISTINTOS DE MINERALIZAÇÃO: I) PRECIPITAÇÃO EM MOUND EM AMBIENTES OXIDANTES, II) SALMOURA EM BACIA RESTRITA, III) PRECIPITAÇÃO EM MOUND E SULFETOS ESTRATIFORMES EM AMBIENTES REGIONALMENTE ANÓXICOS (II E III SÃO PRECIPITAÇÕES EXALATIVAS QUE CORRESPONDEM AO MESMO ESTILO DE DEPOSIÇÃO EM AMBIENTES DISTINTOS) E IV) SUB-SEAFLOOR REPLACEMENT (TORNOS ET AL., 2015A)

FIGURA 5. BLOCO DIAGRAMA ESQUEMÁTICO DO AMBIENTE DE FORMAÇÃO DE UM DEPÓSITO VMS ASSOCIADO ÀS SALMOURAS, ISTO É, BACIAS COM CIRCULAÇÃO DE AGUA RESTRITA GERANDO CONDIÇÕES ANÓXICAS (TORNOS ET AL., 2015A).....

FIGURA 6. FEIÇÕES CARACTERÍSTICAS DE VMS PRECIPITADOS EM AGUAS ANÓXICAS NO ASSOALHO OCÊANICO A) SULFETO COM BANDAMENTO COMPOSICIONAL DEPOSICIONAL COM DEFORMAÇÃO SUPERIMPOSTA; B) BRECHA ESTRATIFORME COM FRAGMENTOS DE SULFETOS MACIÇOS E DE FOLHELHOS; C) PIRITA LAMINADA INTERCALADA COM FOLHELHOS NEGROS; E D) ASSOCIAÇÃO DE BARITA-PIRITA-ESFALERITA FORMADO EM CONDIÇÕES SUB ÓXICAS QUE JÁ NÃO PERMITEM O DESENVOLVIMENTO DE VMS BEM FORMADOS (TORNOS ET AL., 2015A).

FIGURA 7. BLOCO DIAGRAMA ESQUEMÁTICO MOSTRANDO AS PRINCIPAIS CARACTERÍSTICAS ASSOCIADAS A GERAÇÃO DE SULFETOS MACIÇOS ABAIXO DA SUPERFÍCIE. ESTE BLOCO DIAGRAMA TAMBÉM APRESENTA AS ZONAS DE ALTERAÇÃO HIDROTERMAIS DESENVOLVIDAS PELA PASSAGEM DOS FLUIDOS AQUECIDOS PELA ROCHA ENCAIXANTE (TORNOS ET AL., 2015A). ....

FiguRA 8. FEIÇÕES CARACTERÍSTICAS DE VMS RELACIONADOS A SUB-SEAFLOOR REPLACEMENT. A) SULFETO MACIÇO SUBSTITUINDO PERVASIVAMENTE O LITOTIPO ENCAIXANTE EM UMA ZONA DE STOCKWORK; B) SULFETO MACIÇO ESTRATIFORME DEVIDO A SUBSTITUIÇÃO SELETIVA DE ARENITOS VULCANOCLÁSTICOS EM UMA INTERCALAÇÃO COM FOLHELHOS NEGROS; C) CONTATO ENTRE ROCHA ENCAIXANTE E VMS ONDE O SULFETO SUBSTITUI QUASE QUE COMPLETAMENTE UMA BRECHA RICA EM PÚMICE; E D) CONTATO ENTRE O STOCKWORK E A ROCHA ENCAIXANTE, UMA BRECHA VULCANOCLÁSTICAS, NO DEPÓSITO DE LA ZARZA (TORNOS ET AL., 2015A). 
FIGURA 9 A) IMPORTÂNCIA DA FAIXA PIRITOSA IBÉRICA NO TOTAL DE MINERALIZAÇÕES VMS REGISTRADAS NA HISTÓRIA GEOLÓGICA DA TERRA (HUSTON ET AL., 2010); E B) DEPÓSITOS dO FPI QUE SÃo CONSIDERADOS GIGANTES E DE CLASSE

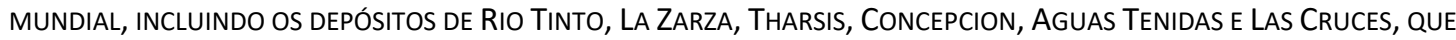
SÃO ESTUDADOS NESTA TESE (TORNOS, 2006).

FIGURA 10. MAPA GEOLÓGICO dA FAIXA PIRITOSA IBÉRICA COM A LOCALIZAÇÃO DOS DEPÓSITOS ESTUDADOS NESTA TESE E DE OUTROS DEPÓSITOS RELEVANTES REGIONALMENTE. OS DEPÓSITOS SÃO, OESTE PARA LESTE, REPRESENTADOS PELAS SEGUINTES SIGLAS: CA - CAVEIRA; AB - AZINHEIRA DE BARROS; LO - LOUSAL; AJ - ALUUSTREL; AL - ALberNOA; NC Neves Corvo; SB - Serra Branca; CH - ChançA; TH - Tharsis; ST - SAn Telmo; AT - Aguas Tenidas, LZ - LA Zarza; VA - Valverde; SO-MI - Sotiel-Migollas; SM - San Miguel; MA - MAgdalena; SV - SOlo Viejo; CO -

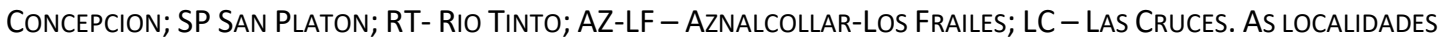
REGIONAIS DE GERENA (GR) e AGLOMERAdO dEL CERRo (AC) TAMBÉM FORAM ESTUdADAS NESTA TESE (MODIFICADO DE CAStROVIEJO ET AL., 2011) 44

FIgURA 12. A) SEPARAÇÃo dA FPI PROPOSTA POR MARTIN IZARD ET AL. (2016) E B) SEPARAÇÃO dA FPI PROPOSTA POR TORNOS

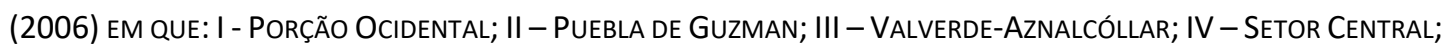
V-PAYMOGO; E VI - CINTURÃO NORTE 51

FIgURA 13. SEPARAÇÃo dAS DIFERENTES REGIÕES DA FPI AdOTADA NESTA TESE, BASEADA NO TRABALHO DE TORNOS (2006) E CONDE (2016). 52

FiguRA 14. Modelo de GÊNESE dos depósitos VMS dA FAIXA PIRITOSA IBÉRICA (TORNOS, 2006). 53

Figura 15. Coluna ESTRATIGRÁficA PROPOSTA POR CONDE (2016) E CONDE \& TORNOS (2019) PARA A REGIÃo do CINTURÃO NORTE DA FPI. 57

FIGURA 16. ILUSTRAÇÃO DE UM COMPLEXO DE DOMOS FÉLSICOS COM DESENVOLVIMENTO DE DEPÓSITOS VMS ASSOCIADOS (CONDE, 2016). 59

FIgURA 17. MAPA GEOLÓGICO dA REGIÃo NORTE dA FPI COM A loCALIZAÇÃo dOS DEPÓSITOS VMS dA REGIÃo (CONDE, 2016). 59

FIgURA 18. MAPA GEOLÓGICO DE RIO TINTO E SUAS DIVERSAS LENTES DE SULFETO MACIÇO (CONDE, 2016.). 62

FIGURA 18. ESTÁGIO INICIAL DA FORMAÇÃO DE UM DEPÓSITO DE SULFETO MACIÇO EM BACIA ANÓXICA (TORNOS ET AL., 2008 ) 64

FIGURA 20. ESTÁGIO PRINCIPAL DA PRECIPITAÇÃO DE UM CORPO DE SULFETO MACIÇO EXALATIVO, ONDE OS FLUIDOS OCEÂNICOS (MENOS DENSOS) JÁ FORAM EXPULSOS DA BACIA PELOS FLUIDOS HIDROTERMAIS EXALADOS (MAIS DENSOS) (TORNOS ET AL., 2008). 65

FIGURA 21. ESTÁGIO TARDIO ONDE OS SULFETOS JÁ FORAM PRECIPITADOS E COBERTOS POR FOLHELHOS ASSIM QUE A ATIVIDADE HIDROTERMAL CESSOU (TORNOS ET AL., 2008). 66

FIGURA 22. REPRESENTAÇÃO ESQUEMÁTICA DAS MUDANÇAS CATASTRÓFICAS ASSOCIADAS À FRONTEIRA DO DC E A FORMAÇÃO DOS DEPÓSITOS DA REGIÃo SUL dA FPI (MENOR-SALVÁN ET AL., 2010). 68

Figura 23. Afloramento do Maciço de Gerena na beira da estrada da ViLA de Gerena...... 69

Figura 24. Modelo APRESENTAdo POR RoSA (1992) PARA A ZONA DE INTERAÇÃo MAGMÁTICA do MACIÇO dE GERENA...... 70 
FIGURA 11. COMPOSIÇÃO ESQUEMÁTICA DA EVOLUÇÃO GEODINÂMICA DA FPI UTILIZANDO OS TRABALHOS DE A) SIMANCAS ET AL. (2003.) B) Mantero et Al. (2011), C) CAStroviejo (2011) e D) OnÉZIME et Al., (2002). OMZ É A Sigla dA ZonA de Ossa Morena, IPB é a sigla da fPI (Iberian Pyrite Belt) e SPZ é a Zona Sul Portuguesa. 75

FIgURA 25. IdAdES DA ATIVIDAdE MAGMÁtICA APRESENTAdOS POR A) BARRIE ET AL. (2002) E B) RoSA ET AL. (2009). ROSA ET AL. (2009) TAMBÉM UTILIZOU OS TRABALHOS DE BARRIE ET AL. (2002). 79

FIGURA 26. COMPILAÇÃO dOS DADOS APRESENTADOS POR CODEÇO ET AL (2015) COM A TEMPERATURA DE SATURAÇÃO DO ZIRCÃO E AS TEMPERATURAS OBTIDAS PELO MÉTODO DE TI EM ZIRCÃO. $\mu=$ MÉDIA, $\Sigma=$ DESVIO PADRÃO, M = MEDIANA, MAX = MÁXIMO, MIN = MÍNIMO E N = TOTAL DE ANÁLISES. 81

FIgURA 26. LOCALIZAÇÃO dOS DEPÓSITOS ESTUdAdOS NA FPI ESPANHOLA. AMOSTRAS DO CINTURÃO NORTE: ST = SAN TELMO, AT = AguAS TENIDAS, MA = MAgDALENA, SM = SAN MIGUEL, CO = CONCEPCION, SV = SOLOVIEJO E SP = SAN Platon. Amostras do Setor Central: AC = Aglomerado del Cerro, lZ = La Zarza e RT = Rio Tinto. Amostras DA REGIÃO SUL: TH = THARSIS, GR = MACIÇO DE GERENA E LC = LAS CRUCES 83

FIGURA 27. A) AMOSTRA LC-07 COLETADA EM TESTEMUNHO DE SONDAGEM, B), DETALHE DE AMOSTRA DE ROCHA VULCANOCLÁsticAs de AGUAS TENIDAS, C) CONTATO TECTÔNICO CARACTERÍSTICO DO CINTURÃO NORTE DA FPI obSERVAdO EM SOLO VIEJO; D) AFLORAMENTO DO MACIÇO DE GERENA A BEIRA DA ESTRADA NO VILAREJO DE GERENA; E)

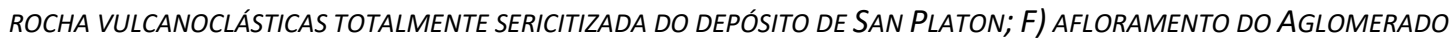

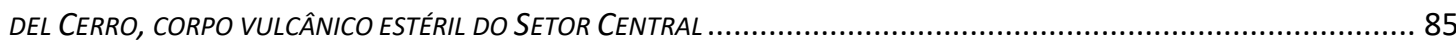

FIGURA 29. FotogRAFIAS DA AMOSTRA DA ROCHA FÉLSICA ENCAIXANTE (ST-03) ESTUDADA EM SAN TELMO. .....................99

FIGURA 30. A) IDADE ${ }^{206} \mathrm{~PB} /{ }^{238} \mathrm{U}$ MÉDIA E B) IDADE CONCÓRDIA OBTIDA PARA A POPULAÇÃO DE ST-03 ......................... 100

FIgURA 31. A) TEMPERATURAS ${ }^{49}$ TI E B) VALOR DE $\varepsilon_{\text {HFI }}$ OBTIDOS NA POPULAÇÃO DE ST-03 ...................................... 101

FIGURA 32. CRISTAIS DE ZIRCÃO ANALISADOS NA AMOSTRA ST-03 COM OS RESPECTIVOS RESULTADOS DAS ANÁLISES INDIVIDUAIS DE U-PB (IDADE ${ }^{238} \mathrm{U} /{ }^{206} \mathrm{~PB}$ ), TI-EM-ZIRCÃO (TEMPERATURA ${ }^{49} \mathrm{TI}$ ) E $\varepsilon_{\text {HFI }}$ CALCULADO COM A IDADE CONCÓRDIA OBTIDA VIA U-PB. 101

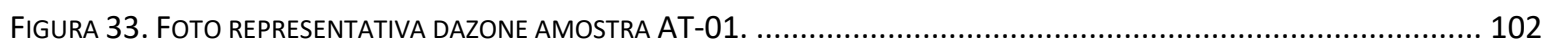

FIGURA 34. A) DADOS OBTIDOS, B) IDADE ${ }^{206} \mathrm{~PB} /{ }^{238}$ U MÉDIA E C) IDADE CONCÓRDIA OBTIDA NA AMOSTRA AT-01 .............. 104

FIGURA 35. A) TEMPERATURAS ${ }^{49}$ TI E B) VALORES DE $\varepsilon_{\text {HFI }}$ OBTIDOS NA AMOSTRA AT-01............................................ 105

FIGURA 36. COMPOSIÇÃO DAS IMAGENS DE CL COM OS RESULTADOS INDIVIDUAIS OBTIDOS NOS CRISTAIS DE ZIRCÃO ANALISADOS ATRAVÉS DE U-PB E TI-EM-ZIRCÃO VIA SHRIMP E LU-HF VIA LA-MC-ICPMS NA AMOSTRA DE ROCHA VULCANOCLÁSTICA (AT-01). 106

FIGURA 37. A) DADOS DE U-PB, B) IDADE ${ }^{206} \mathrm{~PB} /{ }^{238}$ U MÉDIA OBTIDA E C) IDADE CONCÓRDIA OBTIDA NA POPULAÇÃO DE AT-03 108

FIgURA 38. A) TEMPERATURAS ${ }^{49}$ TI E B) VALORES DE $\varepsilon_{\text {HFI }}$ OBTIDOS NA POPULAÇÃO DE AT-03 ..... 108

FIGURA 39. COMPOSIÇÃO DAS IMAGENS DE CL DA POPULAÇÃO DE ZIRCÃO DA AMOSTRA AT-03 COM SEUS RESULTADOS

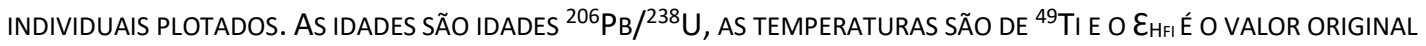

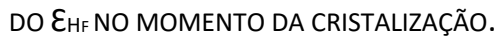


FIgURA 40. DETALHE dA AMOSTRA DE RIODACITO BRECHADO REPRESENTOU O DEPÓSITO DE MAGDALENA NESTE TRABALHO. AS FRATURAS SÃO PREENCHIDAS POR CLORITA, MINERAL RELACIONADO A FORMAÇÃO DOS SULFETOS MACIÇOS QUE OCORRE NA PORÇÃO DISTAL DO HALO DE ALTERAÇÃO GERADO PELO FLUIDO HIDROTERMAL. 110

FIgURA 41. A) DAdOS U-PB OBTIDOS NESTA AMOSTRA, B) IDADE CONCÓRDIA OBTIDA COM 13 CRISTAIS DESTA POPULAÇÃO E C) DADOS DE $\varepsilon_{\text {HFI }}$ OBTIDOS NA POPULAÇÃO DE MA-01

FIGURA 42. COMPOSIÇÃO COM AS IMAGENS DE CL COM OS RESULTADOS DAS ANÁLISES INDIVIDUAIS DE U-PB E LU-HF PARA A AMOSTRA MA-04. NO ZIRCÃO 9 O LASER DO LA-MC-ICPMS ATRAVESSOU O CRISTAL E COM ISSO O RESULTADO DESTA ANÁLISE NÃO É VÁLIDO. 113

FIGURA 43. AMOSTRA DO DACITO MACIÇO AFETAdO POR HIDROTERMALISMO DE SAN MIGUEL (SM-12) ......................... 114

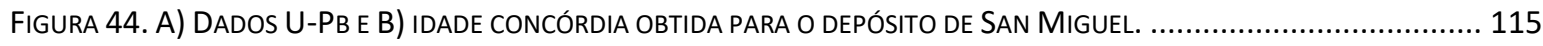

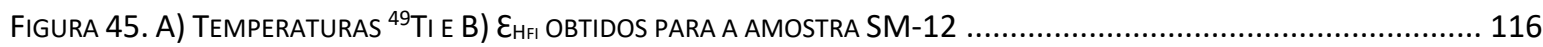

FIGURA 46. COMPOSIÇÃO DAS IMAGENS DE CL OBTIDAS NA AMOSTRA SM-12 COM OS DADOS DE CADA UMA DAS ANÁLISES INDIVIDUAIS DE U-PB, TI-EM-ZIRCÃO E LU-HF. 117

FIGURA 47. FotografiA DA AMOSTRA CO-04 DO DEPÓSITO DE CONCEPCION 118

FIGURA 48. A) DADOS DE U-PB E B ) IDADE CONCÓRDIA OBTIDA NA POPULAÇÃO DE CO-04 119

FIGURA 49. COMPOSIÇÃO DAS IMAGENS DE CL DOS CRISTAIS DE ZIRCÃO ESTUDADOS NA AMOSTRA CO-04 COM OS DADOS DE CADA UMA DAS ANÁLISES ISOTÓPICAS INDIVIDUAIS DE U-PB, TI E LU-HF.... 120

Figura 50. A) TeMPERATURAS ${ }^{49}$ TI E B) VALORES DE $\varepsilon_{\text {HFI }}$ OBTIDOS NA AMOSTRA CO-04 121

FIGURA 51. FotOGRAFIAS DA AMOSTRA SP-03, DE ONDE OS CRISTAIS DE ZIRCÃO DO DEPÓSITO DE SAN TELMO FORAM EXTRAÍDOS.

FiguRA 52. A) E B) MOSTRAM OS DAdOS DE U-PB E C) IDADE CONCÓRDIA OBTIDA PARA A POPULAÇÃO DE SP-03 ................ 122

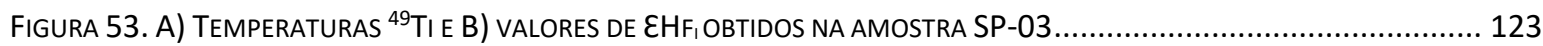

FIGURA 54. COMPOSIÇÃO DE IMAGENS CL DA POPULAÇÃO DE ZIRCÃO DA AMOSTRA SP-03. ...................................... 124

Figura 55. A) E B) REPRESENTAM A AMOSTRA SV-01, uM TUFO AUTOCLÁSTICO E C) E D) MOSTRAM A AMOSTRA DE DERRAME

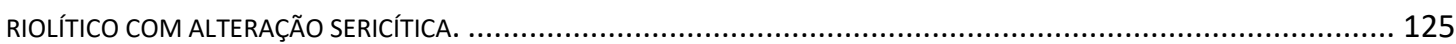

FIGURA 56. A) DADOS DE U-PB, B) IDADE ${ }^{206} \mathrm{~PB} /{ }^{238}$ U MEDIA E C) IDADE CONCÓRDIA OBTIDA NA AMOSTRA SV-01............. 126

FIGURA 57. A) TEMPERATURAS ${ }^{49}$ TI E B) VALORES DE $\varepsilon_{\text {HFI }}$ OBTIDOS NA POPULAÇÃO DA AMOSTRA SV-01 ..........................127

FIGURA 58. COMPOSIÇÃO DE IMAGENS CL DA AMOSTRA SV-01 COM OS DADOS INDIVIDUAIS DAS ANÁLISES DE U-PB, TI-EMZIRCÃO E LU-HF EXECUTADAS NESTA POPULAÇÃO 128

FIGURA 59. A) DADOS U-PB E B) IDADE CONCÓRDIA OBTIDA NA AMOSTRA SV-02 ................................................ 129

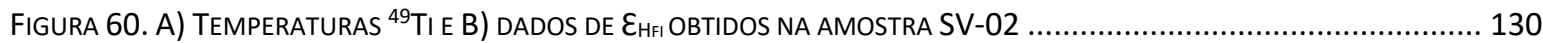

FIGURA 61. COMPOSIÇÃO COM OS DADOS OBTIDOS NAS ANÁLISES INDIVIDUAIS REALIZADAS VIA U-PB, TI-EM-ZIRCÃO E LU-HF NA POPULAÇÃO DE ZIRCÃO DA AMOSTRA SV-02. 130

Figura 62. A) E B) APRESENTAM OS VALORES DE $\varepsilon_{\text {HFI }}$ OBTIDOS NO CINTURÃO NORTE PLOTAdOS NA ESCALA DOS EVENTOS GEOLÓGICOS REGIONAIS (0.33-0.37 GA) E NA ESCALA GERALMENTE UTILIZADA EM OUTROS TRABALHOS (0.0- 1.0 GA) 131 
FIGURA 63. RÉGUA DE IDADES CONCÓRDIA OBTIDAS NOS DEPÓSITOS DO CINTURÃO NORTE. OS DEPÓSITOS ESTÃO PLOTADOS DE ACORDO COM A GEOGRAFIA E É POSSÍVEL NOTAR QUE EXISTE UMA TENDÊNCIA DOS DEPÓSITOS A OESTE DO CINTURÃO NORTE SEREM MAIS NOVOS QUE OS DEPÓSITOS MAIS A LESTE. 132

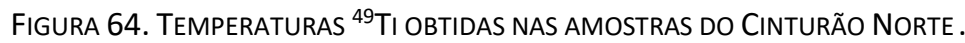
132

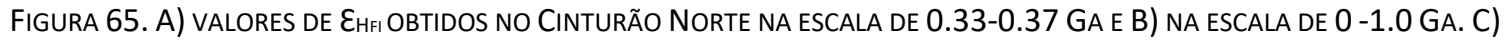
VALORES DE $\varepsilon_{\text {HFI }}$ OBTIDOS EM SOLO VIEJO

Figura 66. A) AMOSTRA ZA-3 E B) AMOSTRA ZA-4, DOIS DACITOS MACIÇOS. A DifERENÇA ENTRE ELAS SE DÁ, POIS, A AMOSTRA ZA-4 ESTÁ MOLHADA NA FOTO ENQUANTO A ZA-3 NÃO, E COM ISSO SEUS PORFIROCLASTOS ESTÃO MAIS VISÍVEIS. ....... 134

FIGURA 67. A) IDADE ${ }^{206} \mathrm{~PB} / 238 \mathrm{U}$ MÉDIA E B) IDADE CONCÓRDIA OBTIDAS NA AMOSTRA ZA-3 135

FIGURA 68. COMPOSIÇÃO DAS IMAGENS DE CL COM OS RESULTADOS INDIVIDUAIS DAS ANÁLISES EFETUADAS NA POPULAÇÃO DE ZIRCÃO DA AMOSTRA ZA-3 136

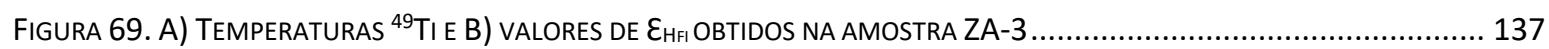

FIGURA 70. A) DADOS U-PB E B) IDADE CONCÓRDIA OBTIDA NA AMOSTRA ZA-4 .................................................... 138

Figura 71. A) TeMPERATURAS ${ }^{49}$ TI E B) VALORES De $\varepsilon_{\text {HFI }}$ OBTIDOS NA AMOSTRA ZA-4 ................................................. 138

FIGURA 72. COMPOSIÇÃO DE IMAGENS DE CL DA POPULAÇÃO DE ZIRCÃO DA AMOSTRA ZA-4 COM OS DADOS INDIVIDUAIS ..... 139

FIGURA 73. TEMPERATURAS ${ }^{49}$ TI OBTIDAS NAS AMOSTRAS ZA-3 E ZA-4 E PLOTADAS EM CONJUNTO ................................. 140

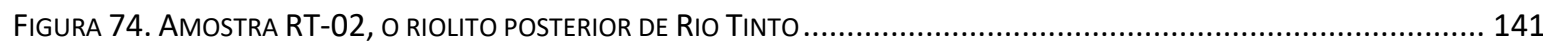

Figura 75. Contato entre o litotipo alterado hidROtermalmente de Filón NoRTe (RT-04) E UMA INTRUSÃo tARDia SEM

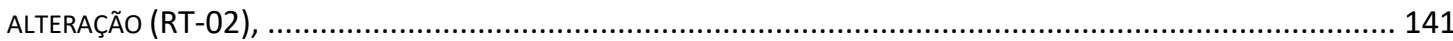

FIGURA 76. A) TODOS OS DADOS U-PB OBTIDOS, B) IDADE CONCÓRDIA ÚNICA GERADA COM ESTA POPULAÇãO. C) IDADE CONCÓRDIA DOS ANTECRISTAIS E D) IDADE CONCÓRDIA DOS AUTOCRISTAIS DA AMOSTRA RT-02 ................................ 142

FiguRA 77. A) TEMPERATURAS ${ }^{49}$ TI DA POPULAÇÃo de ANTECRISTAIS E B) TEMPERATURAS ${ }^{49}$ TI DA POPULAÇÃO dE AUTOCRISTAIS DA AMOSTRA RT-02. C) MOSTRA TODAS AS IDADES SENDO INTERPRETADAS EM CONJUNTO NESTA AMOSTRA. .............. 144

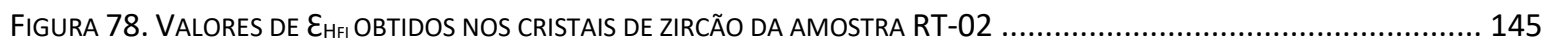

FIGURA 79. COMPOSIÇÃO DE IMAGENS CL DOS CRISTAIS DA AMOSTRA RT-02 COM OS DADOS DAS ANÁLISES INDIVIDUAIS DE U-PB,

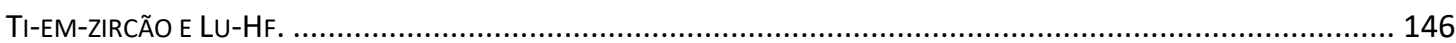

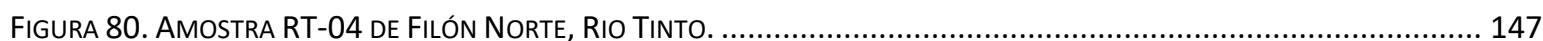

FIGURA 81. A) TODOS OS DADOS DE U-PB OBTIDOS, B) DADOS MAIS PRÓXIMOS AO EVENTO DA FPI E C) IDADE CONCóRDIA OBTIDA PARA A POPULAÇÃO DE ZIRCÃO DA AMOSTRA RT-04 148

FIGURA 82. COMPOSIÇÃO DE IMAGENS CL DA POPULAÇÃO DE ZIRCÃO PRESENTE NA AMOSTRA RT-04 COM OS DADOS DAS ANÁLISES INDIVIDUAIS DE U-PB, TI-EM-ZIRCÃO E LU-HF. 149

FIGURA 83. A) TeMPERATURAS ${ }^{49}$ TI E B) VALORES DE $\varepsilon_{\text {HFI }}$ OBTIDOS NA AMOSTRA RT-04 ............................................... 150

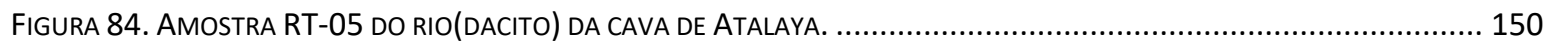

FIGURA 85. A) DADOS DA AMOSTRA RT-05 E B) IDADE CONCÓRDIA OBTIDA NOS CRISTAIS DE ZIRCÃO ESTUDADOS NESTA AMOSTRA.

FIGURA 86. A) TEMPERATURAS ${ }^{49}$ TI E B) VALORES DE $\varepsilon_{\text {HFI }}$ OBTIDOS NA POPULAÇÃO dE ZIRCÃO DE RT-05 ........................... 151 
FIGURA 87. COMPOSIÇÃO COM AS IMAGENS DE CL DA POPULAÇÃO ZIRCÃO ESTUDADA NA AMOSTRA RT-05 COM OS RESULTADOS INDIVIDUAIS OBTIDOS EM CADA ANÁLISE PLOTADOS NOS CRISTAIS DESSA POPULAÇÃO. 152

FIGURA 88. AMOSTRA DO ARENITO VULCANOCLÁSTICO DE ZARANDAS............................................................... 153

FIGURA 89. A) DADOS DE U-PB OBTIDOS, B) IDADE ${ }^{238}$ U/ ${ }^{206}$ PB MÉDIA E C) IDADE CONCÓRDIA DA POPULAÇÃO ZN-01......... 154

FIgURA 90. A) TEMPERATURAS ${ }^{49}$ TI E B) VALORES DE $\varepsilon_{\text {HFI }}$ OBTIDOS NA AMOSTRA ZN-01 ......................................... 155

FIGURA 91. COMPOSIÇÃO COM AS IMAGENS DE CL OBTIDAS COM OS CRISTAIS DE ZIRCÃO ESTUDADOS NA AMOSTRA ZN-01 COM OS RESULTADOS INDIVIDUAIS DE CADA ANÁLISE PLOTADOS NOS CRISTAIS ANALISADOS...................................... 156

FIGURA 92. FOTOGRAFIA DO DACITO MACIÇO AMOSTRADO EM ZARANDAS (ZN-02) ...............................................157

FIGURA 93. A) DADOS DE U-PB OBTIDOS, B) IDADE ${ }^{238}$ U/ ${ }^{206}$ PB MÉDIA E C) IDADE CONCÓRDIA OBTIDA NA POPULAÇÃO DE ZIRCÃO

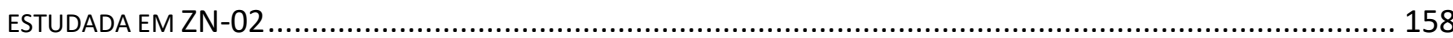

FIGURA 94. IMAGENS DE CL OBTIDAS NA POPULAÇÃO DE ZIRCÃO DA AMOSTRA ZN-02 COM OS RESULTADOS INDIVIDUAIS DAS

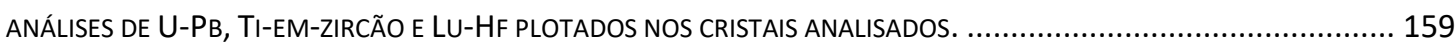

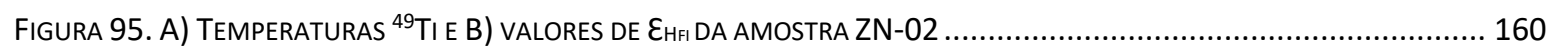

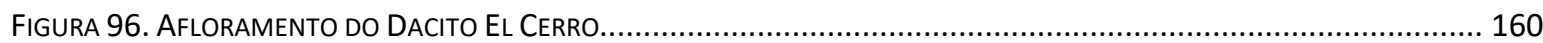

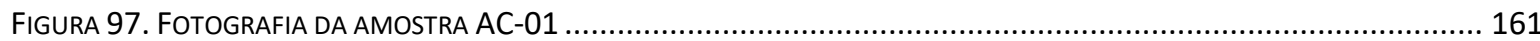

FIGURA 98. A) IDADE ${ }^{206} \mathrm{~PB} /{ }^{238}$ U MÉDIA E B) IDADE CONCÓRDIA DA POPULAÇÃO DE ZIRCÃO DE AC-01 ........................... 162

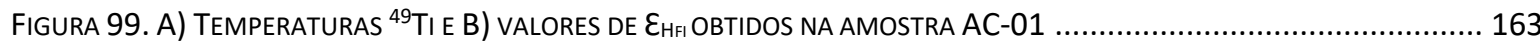

FIGURA 100. IMAGENS DE CL OBTIDAS NA POPULAÇÃO DE ZIRCÃO DA AMOSTRA AC-01 COM OS RESULTADOS DAS ANÁLISES DE UPB, TI-EM-ZIRCÃO E LU-HF PLOTAdOS NOS CRISTAIS ANALISADOS. ........................................................ 164

FIGURA 101. FotografIAS DA AMOSTRA AC-02 EM DOIS ÂNGULOS DIFERENTES............................................... 165

FIGURA 102. A) DADOS DE U-PB, B) IDADE ${ }^{238} \mathrm{U} /{ }^{206}$ PB MÉDIA E C) IDADE CONCÓRDIA OBTIDA NA POPULAÇÃO DE ZIRCÃO DE AC02 166

FIGURA 103. POPULAÇÃO DE CRISTAIS COM OS RESULTADOS INDIVIDUAIS DAS ANÁLISES DE U-PB, TI-EM-ZIRCÃO E LU-HF PLOTADOS 167

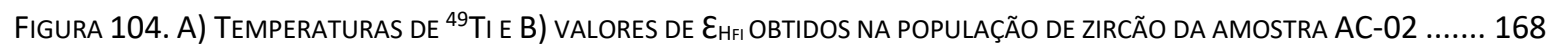
Figura 105. A) E B) APRESENTAM OS VALORES DE $\varepsilon_{\text {HFI }}$ OBTIDOS NO SETOR CENTRAL PLOTADOS NA ESCALA DOS EVENTOS GEOLÓGICOS REGIONAIS (0.33-0.37 GA) E NA ESCALA GERALMENTE UTILIZADA EM OUTROS TRABALHOS (0.0- 1.0 GA) 168 FIGURA 106. RÉGUA DE IDADES CONCÓRDIA OBTIDAS NOS DEPÓSITOS DO SETOR CENTRAL. ................................................

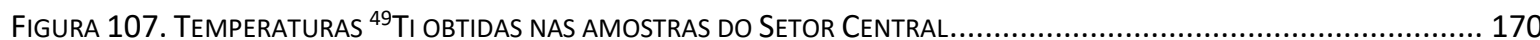

FIGURA 108.A) E B) VALORES DE $\varepsilon_{\text {HFI }}$ OBTIDOS NO SETOR CENTRAL DA FPI, QUE SÃO MAIS NEGATIVOS DO QUE OS VALORES DO CINTURÃO NORTE. 170

FIGURA 109. SESSÃO GEOLÓGICA DE THARSIS (TORNOS ET AL. 2008) COM FOTOGRAFIA DA AMOSTRA TH-04 EM DETALHE.... 171

FIGURA 110. A) DADOS DE U-PB OBTIDOS EM TH-04, B) IDADE ${ }^{206} \mathrm{~PB} /{ }^{238} \mathrm{U}$ MÉDIA E C) IDADE CONCÓRDIA OBTIDA NESTA

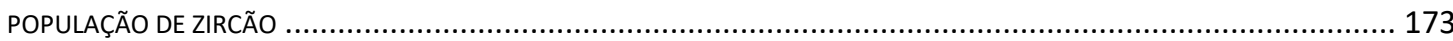

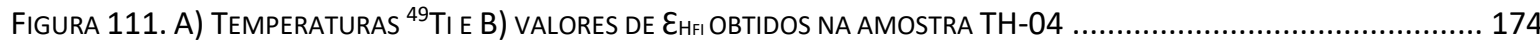

FIGURA 112. RESULtAdOS DAS ANÁLISES DE U-PB, TI-EM-ZIRCÃO E LU-HF EXECUTAdOS NA AMOSTRA TH-04................... 175 
Figura 113. Fotografia dos testemunhos de SONDAgEM AMOSTRAdo EM LAS CRUCES. A) É A AMOSTRA LC-07, QUE REPRESENTA A ROCHA ENCAIXANTE À MINERALIZAÇÃO DE LAS CRUCES, COM INTENSA ALTERAÇÃO SERICÍTICA E B) É O DACITO DISTAL (LC-09) SEM RELAÇÃO COM A MINERALIZAÇÃO. 176

FiguRA 114. SeSSÃo ESQUEMÁtICA do dePÓSITO de LAS CRUCES COM A ZONA DE CIMENTAÇÃo SECUNDÁRIA. HCH E HCL SÃO NOMENCLATURAS UTILIZADAS PELA COMPANHIA FIRST QUANTUM DE ACORDO COM O TEOR DE CU. 176

Figura 115. A) Todos os dados de U-PB obtidos neStA AMOSTRA. B) E C) DAdOS U-PB APÓS A EXCLUSÃo de Minerais COM

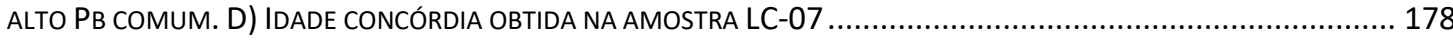

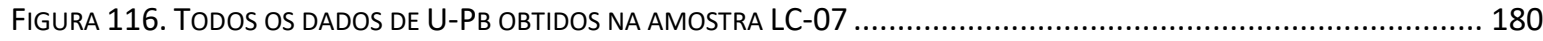

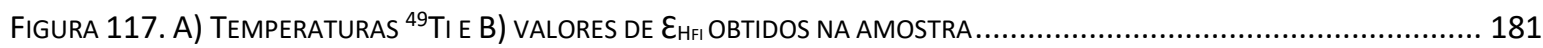

FIGURA 118. DAdOS DE U-PB QUE NÃO FORAM DESCARTADOS POR ALTO TEOR DE PB NESTA POPULAÇÃO DE ZIRCÃO. ........... 181

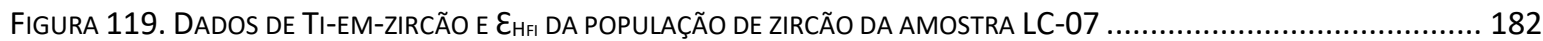

FIGURA 120. A) DADOS DE U-PB E B) IDADE ${ }^{206}$ PB $/{ }^{238}$ U MÉDIA OBTIDA NA AMOSTRA LC-09 ..................................... 183

FIGURA 121. IDADE CONCÓRDIA OBTIDA COM A POPULAÇÃO DE ZIRCÃO DA AMOSTRA LC-09 ....................................... 184

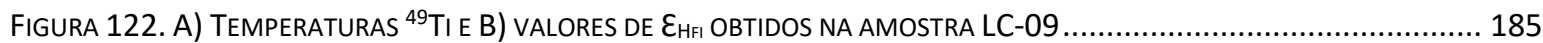

FIGURA 123. RESULTADOS INDIVIDUAIS OBTIDOS NAS ANÁLISES DE U-PB, TI-EM-ZIRCÃO E LU-HF EXECUTADAS NA POPULAÇÃO DA AMOSTRA LC-09. 186

FIGURA 124. A) TODOS OS DADOS DE U-PB OBTIDOS NESTA AMOSTRA E B) IDADE CONCÓRDIA OBTIDA A PARTIR DOS CRISTAIS DE

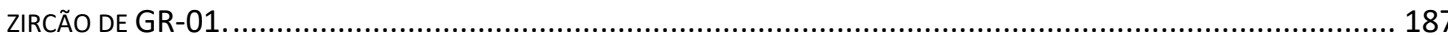

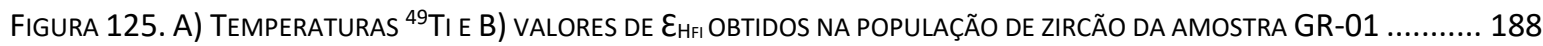

FIGURA 126. IMAGENS DE CL DA POPULAÇÃO DE ZIRCÃO DA AMOSTRA GR-01 COM OS RESULTADOS INDIVIDUAIS DE CADA ANÁLISE

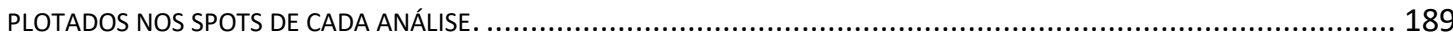

FigURA 127. A) TOdOS OS DAdOS OBTIDOS NA AMOSTRA GR-02. B) IDADE CONCÓRDIA OBTIDA COM 5 AUTOCRISTAIS DESTA POPULAÇÃO E C) IDADES DA POPULAÇÃO DE XENOCRISTAIS 191

FIgURA 128. A) TEMPERATURAS ${ }^{49}$ TI OBTIDAS NOS AUTOCRISTAIS E NOS XENOCRISTAIS DA AMOSTRA GR-02. B) VALORES DE $\varepsilon_{\mathrm{HFI}}$

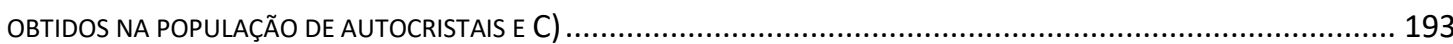

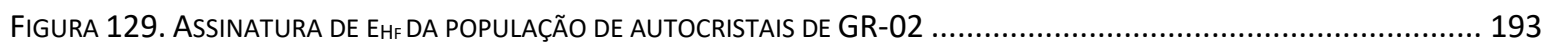

FIGURA 130. A) E B) APRESENTAM OS VALORES DE $\varepsilon_{\text {HFI }}$ OBTIDOS NO REGIÃO SUL PLOTADOS NA ESCALA DOS EVENTOS GEOLÓGICOS REGIONAIS (0.33-0.37 GA) E NA ESCALA GERALMENTE UTILIZADA EM OUTROS TRABALHOS (0.0- 1.0 GA) .... 193

FIGURA 131. POPULAÇÕES DE ZIRCÃO DA AMOSTRA GR-02 COM OS RESULTADOS INDIVIDUAIS DAS ANÁLISES DE U-PB, TI-EMZIRCÃO E LU-HF PLOTADOS NOS CRISTAIS DE ZIRCÃO. 194

FIGURA 132. RÉGUA DE IDADES CONCÓRDIA OBTIDAS EM DOIS DEPÓSITOS, UMA ROCHA ESTÉRIL E DUAS ROCHAS PLUTÔNICAS DA REGIÃO SUL 195

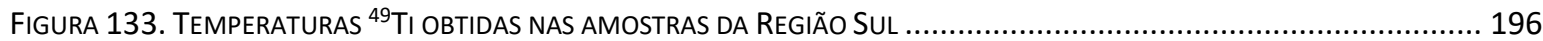

FIGURA 134. VALORES DE $\varepsilon_{\text {HFI }}$ OBTIDOS NA REGIÃo SUL dA FPI, QUE SÃO OS VALORES MAIS NEGATIVOS OBTIDOS NESTA TESE. 196 FIGURA 135. IDADES CONCÓRDIAS OBTIDAS NOS DEPÓSITOS DE SULFETO MACIÇO ESTUDADOS TANTO NA REGIÃO SUL QUANTO NA Região Norte e Seus subsetores (Setor Central e CinturÃo Norte). 198 
FIGURA 136. IDADES CONCÓRDIAS OBTIDAS NAS ANÁLISES U-PB EFETUADAS. AS DIFERENTES REGIÕES ANALISADAS ESTÃO MARCADAS EM CORES DIFERENTES. AS ROCHAS ASSOCIADAS AS MINERALIZAÇÕES DE SULFETO MACIÇO DA REGIÃO NORTE como um todo (Setor Central e Cinturão Norte) SÃo formadas entre o INTERVAlo de 355-347 MA, IDADE TOURNAISIANA, ENQUANTO QUE AS ROCHAS ASSOCIADAS AS MINERALIZAÇÕES DE SULFETO MACIÇO DA REGIÃO SUL SÃO MAIS ANTIGAS E ESTÃO ASSOCIADAS AO INTERVALO 365-359 MA, IDADE STRUNIANA.

FIGURA 137. TODAS AS TEMPERATURAS DE TI-EM-ZIRCÃO E ISÓTOPOS DE TI OBTIDAS NA FPI. AS TEMPERATURAS DESTA TESE FORAM OBTIDAS NA ESPANHA ENQUANTO AS TEMPERATURAS OBTIDAS POR CODEÇO ET AL. (2015) E CODEÇO ET AL. (2018) SÃO DE PORTUGAL.

Figura 138. Coluna estratigráfica do Cinturão NoRte PROPOSta POR CONDE (2016) e Conde \& ToRnOS (2019) COM AS IDADES OBTIDAS NOS DEPÓSITOS ASSOCIADOS ÀS UNIDADES LFU E UFU 208

FIGURA 139. IDADES OBTIDAS NESTA TESE PLOTADAS NA SEÇÃO GEOLÓGICA APRESENTADA POR MARTIN IZARD ET AL. (2016) COM OS DIFERENTES INTERVALOS MAGMÁTICOS MINERALIZADOS VSC 0 E VSC 2 209

FIGURA 140. IMAGENS DE CL DE BAIXA RESOLUÇÃO DOS CRISTAIS DE ZIRCÃO ESTUDADOS POR BARRIE ET AL. (2002) SÃO COMPARADAS COM AS IMAGENS DE CL OBTIDAS NESTA TESE. OS CÍRCULOS BRANCOS NAS IMAGENS DE CL DE BARRIE ET AL. (2002) SÃO INCLUSÕES. 210

FIGURA 141. IDADES OBTIDAS NESTA TESE PLOTADAS EM CONJUNTO COM IDADES OBTIDAS NA FPI PORTUGUESA 212

FIGURA 142. TODAS AS TEMPERATURAS DE TI-EM-ZIRCÃO E DE ISÓTOPOS DE TI OBTIDAS NA FPI COMO UM TODO. AS TEMPERATURAS OBTIDAS NESTA TESE SÃO DE LOCALIDADES ESPANHOLAS, ENQUANTO AS TEMPERATURAS OBTIDAS POR COdeço ET AL. $(2015,2018)$ SÃo de PoRTugal. 215

FIGURA 143. VALORES DE $\varepsilon_{\text {HFI }}$ OBTIDOS POR ROSA ET AL. (2009) PARA DEPÓSITOS PORTUGUESES DA FPI 216

FIGURA 144. INTERPRETAÇÃO DAS ASSINATURAS dE $\varepsilon_{\text {HFI }}$ NAS DUAS PORÇÕES DA REGIÃO NORTE. EM A) o CINTURÃO NORTE APRESENTA VALOR DE $\varepsilon_{\text {HFI }}$ MÉDIO DE -0.18, INDICANDO UMA SIGNIFICATIVA CONTRIBUIÇÃO MANTÉLICA ENQUANTO QUE EM

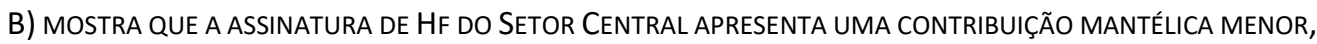

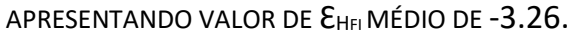

FIGURA 145. DAdOS DE U-PB E TI-EM-ZIRCÃO OBTIDOS NESTA TESE E NA LITERATURA (CODEÇO ET AL., 2015 REALIZOU AS ANÁLISES DE TI-EM-ZIRCÃO E ROSA ET AL., 2009 REALIZOU AS ANÁLISES DE U-PB). AS AMOSTRAS REPRESENTAM OS ROCHAS ENCAIXANTES DOS SEGUINTES DEPÓSITOS: TH-04 - THARSIS; LC-07 E LC-09 - LAS CRUCES; ZA-4 E ZA-3, LA ZARZA; CO-04 - CONCEPCION; SM-12 - SAN Miguel; AT-01 E AT-03 - AgUAS TENIDAS;RT-02, RT-04 E RT-05 RIO TINTO; SV-01 E SV-02 - SOLOVIEJO; ST-01 - SAN TELMO

FIGURA 146. CARACTERÍSTICAS DO MAGMATISMO EM 350 MA, O AUGE DO EVENTO MAGMÁTICO TOURNAISIANO NA FPI ESPANHOLA, PLOTADAS NO MODELO ESQUEMÁTICO DA FPI APRESENTADO POR TORNOS (2006).

FIGURA 147. DAdOS DE U-PB E TI-EM-ZIRCÃO OBTIDOS EM RIO TINTO E ZARANDAS, MOSTRANDO COMO A TEMPERATURA DO MAGMATISMO DO COMPLEXO VS NESTA REGIÃO SE MANTEVE ABAIXO DOS $750^{\circ} \mathrm{C}$ AO LONGO DE TODA SUA DURAÇÃO . 224

FIgURA 148. EVOLUção GEOCRONOLÓGICA do DEPÓSITO dE RIO TINTO COM OS 3 ESTÁGIOS DE EVOLUÇão (DE MELLO ET AL., IN PREP.) 


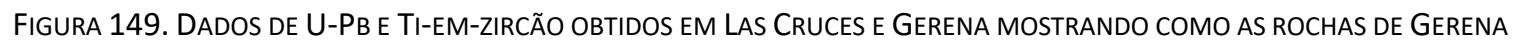
ESTÃO ASSOCIADAS AO MAGMATISMO TOURNAISIANO $\left[T\left({ }^{\circ} \mathrm{C}\right)<785^{\circ} \mathrm{C}\right]$, ENQUANTO QUE AS MINERALIZAÇÕES ESTÃO ASSOCIADAS AO MAGMATISMO STRUNIANO $\left[T\left({ }^{\circ} \mathrm{C}\right)>800^{\circ} \mathrm{C}\right]$. 


\section{INTRODUÇÃO}

A Faixa Piritosa Ibérica (FPI) é a maior província com depósitos de sulfetos maciços vulcanogênicos (VMS) do mundo e se estende desde Grândola, em Portugal até as proximidades de Sevilha, Espanha, com mais de $250 \mathrm{~km}$ de comprimento e 25 a $75 \mathrm{~km}$ de largura (Figura 1). Na FPI existem mais de 80 corpos de sulfetos maciços, sendo que 8 são depósitos classificados como gigantes (Rio Tinto, Neves Corvos, Aljustrel, La Zarza, Aznalcóllar, Sotiel-Migollas, Tharsis e Valverde) e 7 depósitos de classe mundial (Concepcion, Lousal, Aguas Tenidas, Magdalena, Las Cruces, La Romana e São Domingos), além de diversos outros depósitos de menor expressão ou prospectos não explorados, totalizando mais de $1600 \mathrm{Mt}$ de sulfetos maciços e $250 \mathrm{Mt}$ de sulfetos associados a zonas de stockwork, sendo que o sulfeto predominante é a pirita (Tornos, 2006, Conde \& Tornos, 2019).

A FPI é explorada intermitentemente desde a Idade do Bronze (século XII- IX a.C.) e já foi explotada por Tartessianos, Fenícios, Romanos, Árabes e, ao longo do século XIX e $\mathrm{XX}$, por companhias inglesas e espanholas. Uma revisão detalhada da origem histórica da região é apresentada por Conde (2016). Atualmente a maioria das jazidas estão exauridas e apenas alguns depósitos ainda estão operantes na Espanha (Rio Tinto, Aguas Tenidas, Magdalena e Las Cruces) (comunicação oral Tornos; Conde \& Tornos, 2019). O principal bem mineral da FPI é o cobre $(\mathrm{Cu})$ e geralmente os depósitos associados a sub-seafloor replacement possuem conteúdos mais elevados de chumbo $(\mathrm{Pb})$, zinco $(\mathrm{Zn})$ e alguns até mesmo de ouro (Au). Também ocorrem mineralizações de manganês (Mn) ao longo de toda a FPI, mas como estas possuem menor valor econômico elas não são desenvolvidas ou estudadas em maiores detalhes na literatura. Nesta tese apenas o depósito de Mn de Solo Viejo, o maior e mais bem estudado depósito de Mn da FPI, também foi estudado.

O contexto geológico da região é complexo e já foi alvo de diversos trabalhos regionais ao longo do tempo (Strauss et al., 1977; Routhier et el., 1980; Barriga 1990; Silva et al., 1990; Quesada et al., 1994; Sáez et al., 1996; Leistel et al., 1997; Mitjavila et al., 1997; Thieblemont et al., 1998; Tornos et al., 2000; Tornos, 2006; Tornos et al., 2008; Velasco et al. 2013; Conde, 2016; Martin Izard et al., 2016) e é composta por três unidades: o embasamento é formado pelo Grupo Filito-Quartzito (Grupo FQ), a unidade principal é o 
Complexo Vulcano Sedimentar (Complexo VS) e o Grupo Flysh do Baixo Alentejo representa a cobertura sedimentar posterior. $\mathrm{O}$ ambiente deposicional destes litotipos evoluiu de uma plataforma continental estável (durante a sedimentação do Grupo FQ) para um ambiente de bacias de pull apart resultantes de uma colisão oblíqua (gerando as rochas vulcânicas e sedimentação concomitante do Complexo VS) e posteriormente para uma bacia de antearco sin-orogênica com sedimentação tipo flysch (sedimentação das rochas do Grupo Flysch do Baixo Alentejo) (Silva et al., 1990; Quesada et al., 1994, Tornos, 2006). Os corpos de sulfeto maciço ocorrem sempre associados a horizontes do Complexo VS, mais especificamente a rochas vulcânicas e vulcanoclásticas nos depósitos da parte norte da FPI e a folhelhos nos depósitos da parte sul (Tornos, 2006, Conde, 2016, Martin Izard et al., 2016; Codeço et al., 2018).

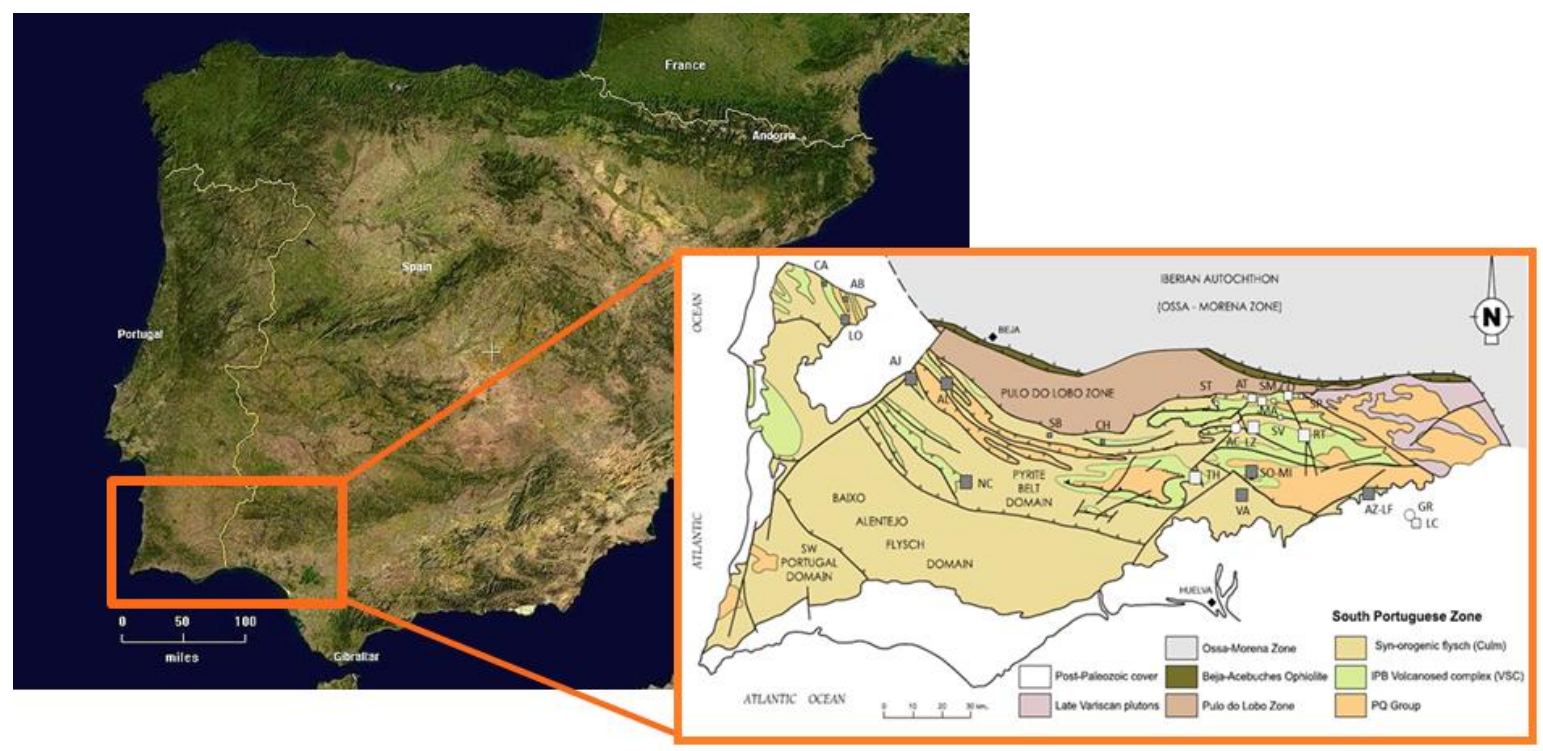

Figura 1. Localização da FPI na extremidade suldoeste da Península Ibérica.

Os depósitos de sulfetos maciços da FPI se formaram através de dois processos distintos:

1) sulfetos maciços foram precipitados quimicamente em bacias anóxicas no assoalho oceânico e ocorrem associados à folhelhos (Tornos, 2006, Tornos \& Heinrich, 2008, Tornos et al. 2008).

2) sulfetos que foram precipitados via substituição abaixo da superfície (sub-seafloor replacement) de litotipos reativos, geralmente rochas félsicas vulcanoclásticas (Tornos, 2006; Tornos et al., 2015a; Conde, 2016, Conde \& Tornos, 2019). 
Estes sulfetos com gêneses distintas podem ser organizados geograficamente em regiões. Basicamente, a FPI pode ser dividida entre:

1) uma região em que os depósitos de sulfeto maciço ocorrem associados às rochas félsicas vulcânicas e vulcanoclásticas no norte da FPI na Espanha. Essa região é aqui denominada Região Norte

2) uma faixa mais extensa de depósitos associados a folhelhos que ocupa o sul da FPI na Espanha e a totalidade da FPI em Portugal. Esta região é denominada Região Sul (Tornos, 2006, Conde 2016, Martin Izard et al., 2016).

A maioria dos depósitos importantes (Neves Corvo, Aljustrel, Aznalcóllar, SotielMigolas, Tharsis e Valverde) e dos depósitos de classe mundial (Lousal, Las Cruces, La Romana, São Domingo) estão associados a folhelhos na Região Sul da FPI e possuem altos tonelagens e baixos teores de metais de base (Tornos, 2006). Estudos palinológicos datam os folhelhos associados aos sulfetos maciços de Neves Corvo, Lousal, Caveira, Montinho, Aznalcóllar e Tharsis com idade Struniana, uma subdivisão do Fameniano reconhecida localmente na Europa (Matos et al., 2011; Oliveira et al., 2005; Oliveira et al., 2004; Pereira et al. 2008; Pereira et al. 2010; Gonzalez et al. 2002). A geocronologia das rochas vulcânicas félsicas associadas com os depósitos apresentam idades entre 362- 345 Ma, transição entre o Devoniano e o Carbonífero (Barrie et al. 2002; Rosa et al., 2009; Solá et al. 2015). Estas idades mostram que os depósitos estão associados aos mesmos processos regionais, mais especificamente ao magmatismo do Complexo Vulcano Sedimentar (CSV), o magmatismo relacionado com a colisão obliqua da Zona Sul Portuguesa (SZP) com o Terreno Autóctone Ibérico no fechamento do Oceano Rheic (Silva et al., 1990; Oliveira e Quesada, 1998; Tornos, 2006). As assinaturas de $\varepsilon_{\mathrm{Hfi}}$ das rochas do Complexo VS mostram origem crustal (0.2 e -14.4), provavelmente relacionado a fusão da base do embasamento regional, e o Grupo Filito-Quartzito (Grupo FQ), apresenta assinaturas semelhantes (Rosa et al., 2009).

Os depósitos da Região Sul podem ser divididos em 3 subdivisões dentro de uma mesma faixa E-W (Tornos, 2006):

1) A zona ocidental, que são os depósitos de Portugal, onde ocorrem dois depósitos gigantes (Neves Corvo e Aljustrel) e de classe mundial (Lousal e São Domingos);

2) A região Puebla de Guzman, onde o depósito gigante de Tharsis está inserido; 
3) A região de Valverde-Aznalcóllar, onde existem 3 depósitos gigantes (SotielMigollas, Valverde e Aznalcóllar) e o de classe mundial de Las Cruces.

Na Região Sul da FPI os folhelhos associados aos horizontes mineralizados apresentam biomarcadores de atividade biogênica em larga escala, em contraste com as assinaturas de rochas relacionadas a bacias oxidantes a sub oxidantes que apresentam poucos biomarcadores (Menor-Salván et al., 2010). Isto implica que as mineralizações desta região não estão somente associadas com o vulcanismo sincrônico, como também são controladas pelo aporte de matéria orgânica continental. Menor-Salván et al. (2010) propõe que a formação dos corpos de VMS está relacionada a diversos processos geológicos e biológicos atuando em conjunto: 1) colisão continental que leva a geração das bacias de $3^{\mathrm{a}}$ ordem e ao vulcanismo do Complexo VS; 2) degradação dos ecossistemas costeiros devido à combinação de diversos fatores (mudanças climáticas, vulcanismo, variações no nível do mar e erosão em escala regional); 3) destruição significativa da biomassa continental e aumento do aporte de matéria orgânica no ambiente marinho; 4) condições anóxicas que resultam em grande sucesso para microrganismos redutores de sulfato.

Em contraste com os depósitos da Região Sul, os depósitos da Região Norte estão sempre associados a rochas vulcânicas. A Região Norte pode ser dividida em 3 setores com alinhamentos paralelos E-W (Tornos, 2006): 1) o Setor Central, onde ocorrem 2 depósitos gigantes (La Zarza e Rio Tinto); 2) Região de Paymogo, com o depósito de classe mundial de La Romanera; e 3) o Cinturão Norte, região com 3 depósitos de classe mundial (Aguas Tenidas, Magdalena e Concepcion).

O conhecimento geológico é menos avançado na Região Norte da FPI, onde somente o depósito de Rio Tinto é bem estudado. O depósito de Rio Tinto já foi alvo de diversos estudos que caracterizaram sua evolução, suas unidades vulcânicas e sedimentares e geologia estrutural (García Palomero, 1980; Boulter, 1993, Mellado et al., 2006; Tornos, 2006; González Clavijo \& Díez Montes, 2010; Marin Izard et al., 2015). A atividade vulcânica relacionada com a formação dos sulfetos maciços também foi alvo de estudo de litogeoquímica e geocronologia (Barrie et al., 2002; Dunning et al., 2002; Valenzuela et al., 2011; Conde, 2016; Mello et al. in prep.).

O Cinturão Norte é pouco estudado pois os seus depósitos apresentam menores tonelagens, mas, apesar disto este cinturão ainda representa um dos alvos mais interessantes 
para exploração devido ao seu conteúdo elevado de metais de base e metais precioso (Conde \& Tornos, 2019). A mineralogia e geoquímica das rochas vulcânicas do Cinturão Norte já foi estudada em alguns depósitos (San Telmo, San Miguel e Peña del Hierro) por Sanchez España (2000). A partir do estudo de inclusões fluidas e isótopos estáveis, Sanchez España (2000) interpreta que os sulfetos maciços da região foram formados a partir da circulação de água marinha modificada com um significativo componente magmático (Sanchez España, 2000; Sanchez España et al., 2000; Sanchez España et al., 2003).

Conde (2016) e Conde \& Tornos (2019) caracterizaram a geologia e a litogeoquímica do Cinturão Norte através de um mapeamento detalhado em conjunto com de testemunhos de sondagem dos depósitos de Aguas Tenidas e Lomero Poyatos, além de petrografia detalhada. O depósito de Aguas Tenidas também foi alvo de estudos de petrografia e litogeoquímica de Bobriwicz (1995), Mckee et al (2001, 2003) e Hidalgo et a. (2003).

Existem muitas questões em aberto em relação ao vulcanismo félsico do Complexo VS que está associado aos sulfetos maciços, especialmente na porção espanhola da FPI. Isto é especialmente verdade para as rochas do Cinturão Norte e Setor Central, onde somente o depósito de Rio Tinto já vou alvo de estudos geocronológicos. Pouco se sabe sobre a temperatura de formação destas rochas félsicas e os únicos dados disponíveis apontam para temperaturas relativamente baixas, pois o estudo litogeoquímico efetuado por Conde (2016) mostra diversas rochas com menos de 200ppm de Zr. Além disso também não existem trabalhos que dão conta da origem desde magmatismo félsico na porção espanhola da FPI.

Esta tese caracteriza o vulcanismo félsico do Complexo VS associado aos corpos de sulfeto maciço na Região Norte e compara os resultados com os dados obtidos na Região Sul, além de dados da literatura. Para tanto seis depósitos do Cinturão Norte (San Telmo, Aguas Tenidas, Magdalena, San Miguel, Concepcion, San Platon e Solo Viejo) e dois depósitos do Setor Central (La Zarza e Rio Tinto) foram estudados e comparados com dois depósitos da Região Sul (Tharsis e Las Cruces), além de dados colhidos na literatura. O depósito de Rio Tinto foi estudado em maior detalhe, visando estabelecer a evolução do vulcanismo félsico do Complexo VS relacionado aos sulfetos maciços na localidade em conjunto com os dados de Conde (2016).

Os dados litogeoquímicos de conteúdo de $\mathrm{Zr}$ nas rochas vulcânicas de Rio Tinto obtidos por Conde (2016), bem como trabalhos mais recentes (Piercey et al., 2014; Pilote \& 
Piercey, 2018) indicam depósitos VMS associados a magmas frios. O que contrasta com o modelo geológico (Piercey 2011) e com o resto da literatura (Lentz, 1998, 1999; Whalen et al., 1998, Piercey et al., 2001; Piercey 2003; Piercey 2008; Piercey 2011) que associa os depósitos VMS a magmas quentes. Nesta tese a temperatura das rochas félsicas associadas aos depósitos também foram estudadas via isótopos de Ti visando caracterizar as temperaturas do magmatismo félsico ao longo da FPI.

A origem do magmatismo félsico do Complexo VS associado aos depósitos de VMS foi estudada via isótopos de Lu-Hf por Rosa et al. (2009) em depósitos da Região Sul de Portugal. Nesta tese este par isotópico também foi utilizado para caracterizar a origem do magmatismo félsico em toda a FPI espanhola.

\subsection{Objetivos}

O objetivo desta tese foi caracterizar isotopicamente as rochas vulcânicas félsicas que ocorrem associadas as mineralizações de VMS da FPI espanhola. Os isótopos de U-Pb foram usados para a geocronologia, os isótopos de Ti foram utilizados para a termometria e os isótopos de Lu-Hf foram utilizados para a caracterização da origem do vulcanismo.

A maioria dos trabalhos da literatura na FPI foram executados em depósitos da Região Sul, então nesta tese foram estudados mais depósitos da Região Norte (Cinturão Norte e Setor Central). Assim um quadro geral mais completo de toda a FPI pôde ser desenhado.

No depósito de Rio Tinto o trabalho foi mais aprofundado e visou caracterizar toda a extensão do vulcanismo félsico relacionado as mineralizações.

Os depósitos VMS são depósitos hidrotermais que ocorrem associados temporalmente e especialmente com vulcanismo. Os sulfetos maciços da FPI são predominantemente pirita e a datação direta da mineralização, seja pelo método $\mathrm{Pb}-\mathrm{Pb}$, seja pelo método Re-Os, não apresenta valores confiáveis. Portanto nesta tese as rochas vulcânicas que estão temporal e espacialmente associadas a estes depósitos são estudadas como forma indireta de se caracterizar a formação dos depósitos de VMS da FPI.

\subsection{Estrutura da Tese}

Esta tese possui 8 capítulos, além de 3 anexos, estruturados da seguinte forma: 
1. INTRODUÇÃO tem a missão de contextualizar o leitor para a melhor compreensão desta tese, os temas abordados, os dados obtidos e seus significados. Aqui os objetivos da tese são descritos bem como o que foi feito para se chegar a eles.

2.FUNDAMENTAÇÃO TEÓRICA trata dos processos de formação dos corpos de sulfeto maciço vulcanogênicos de uma maneira geral, seus processos de formação e seu modelo geológico mais amplo.

3. CONTEXTO GEOLÓGICO trata da FPI como um todo e depois faz uma breve contextualização das diferenças entre a Região Norte e a Região Sul. Aqui também estão os resultados isotópicos obtidos por outros autores na FPI.

4. MATERIAIS E MÉTODOS trata da amostragem e dos métodos isotópicos de U-Pb e Ti via SHRIMP na Universidade de São Paulo (USP) e Lu-Hf por LA-MC-ICPMS na Memorial University of Newfoundland (MUN), Canadá.

5. RESULTADOS apresenta os resultados obtidos nas análises isotópicas de U-Pb, Ti e Lu-Hf estruturados de acordo com a geografia da FPI.

6. DISCUSSÕES traz uma síntese dos resultados e seus significados, tanto em relação a geocronologia, quanto em relação a termometria de isótopos de Ti e origem via assinaturas de $\varepsilon_{\mathrm{Hf}}$.

7. CONCLUSÕES resumo das discussões, fazendo uma breve síntese do significado dos dados obtidos nesta tese.

8. REFERÊNCIAS apresenta os trabalhos consultados que embasam esta tese.

Os ANEXOS apresentam as tabelas com os resultados de todas as análises efetuadas nos cristais de zircão estudados. Em ANEXO I estão os dados isotópicos de U-Pb, ANEXO II contém os dados isotópicos de Ti e em ANEXO III estão contidos os dados isotópicos de Lu-Hf obtidos. 


\section{FUNDAMENTAÇÃO TEÓRICA}

\subsection{DEPÓSITOS VMS}

Os depósitos aqui descritos são depósitos de sulfeto temporal e espacialmente associados a processos vulcânicos submarinos. Estes depósitos são conhecidos de diferentes maneiras na literatura, como sulfetos vulcanogênicos, sulfetos maciços, sulfetos maciços exalativos, sulfetos maciços vulcanogênicos, sulfetos maciços vulcanogênicos entre outros. O termo mais utilizado atualmente é sulfetos maciços vulcanogênicos (VMS), tanto do meio acadêmico (Tornos et al., 2015a; Piercey, 2011) como no meio prático (USGS Volcanogenic Massive Sulfide Ocurrence Model - Shanks \& Thurston, 2012). Os depósitos de sulfetos maciços vulcanogênicos (VMS) são fontes importantes mundiais de cobre $(\mathrm{Cu})$, chumbo $(\mathrm{Pb})$, zinco $(\mathrm{Zn})$, ouro $(\mathrm{Au})$ e prata $(\mathrm{Ag})$ (Tornos, 2006, Piercey 2011, Shanks \& Thurston, 2012). Os minerais de minério geralmente são os próprios sulfetos e sulfossais com conteúdo de $\mathrm{Cu}, \mathrm{Pb}, \mathrm{Zn}, \mathrm{Ag}$ e $\mathrm{Au}$. Os minerais de ganga são compostos principalmente por quartzo e por sulfetos sem valor econômico como a pirita e a pirrotita (Mosier et al., 2009; Koski \& Mosier 2012; Tornos et al., 2015a). Mas mesmo esses minerais que supostamente não possuem valor comercial por vezes são explotados visando a produção de ácido sulfúrico $\left(\mathrm{H}_{2} \mathrm{SO}_{4}\right)$, como ocorre com as piritas do Distrito de Rio Tinto (Conde, 2016).

Existem depósitos VMS descritos em diversos ambientes geodinâmicos convergentes, divergentes e associados a plumas (Huston et al., 2010). Estes depósitos ocorrem um em amplo espectro de ambientes tectônicos distintos e alguns trabalhos separam os depósitos VMS de acordo com seus ambientes tectônicos (Mosier et al., 2009; Huston et al., 2010).

Os depósitos VMS são formados em associação com diversas rochas encaixantes, em especial com rochas vulcânicas máficas e félsica e em rochas sedimentares de granulação fina. Após a sua formação, estes depósitos podem sofrer metamorfismo, alterando os protolitos encaixantes da mineralização. Essa pluralidade de rochas encaixantes fez com que diversos subtipos de depósitos VMS fossem descritos. Os depósitos VMS são subdividos descritivamente de acordo com a rocha encaixante, o que deu origem a nomenclatura utilizada pela USGS e alguns pesquisadores (Siliciclastic-felsic, bimodal-felsic, bimodalmafic, pelite-mafic, mafic) (Mosier et al., 2009; Piercey 2011; Koski \& Mosier 2012). Entretanto, estes depósitos VMS que ocorrem em rochas distintas apresentam tonelagem 
muito semelhantes (Figura 2), com variação nos teores de $\mathrm{Cu}, \mathrm{Zn}, \mathrm{Pb}, \mathrm{Au}$ e $\mathrm{Ag}$ (Mosier et al., 2009). Essa semelhança de tonelagem em rochas encaixantes tão distintas mostra que os fatores determinantes na gênese dos depósitos VMS não são as rochas associadas e que outros fatores são mais relevantes na formação destes depósitos.

Abordagens descritivas geram vieses nos programas de pesquisa mineral e recentemente tem ocorrido uma mudança de paradigma que leva em conta o sistema mineral como um todo (McCuaig et al., 2010; McCuaig \& Hronsky, 2014). Tornos et al., (2015) utiliza esta abordagem e classifica os depósitos VMS de acordo com as condições com que os sulfetos foram precipitados e que permite compreender melhor os processos de formação relacionados com a gênese de depósitos VMS

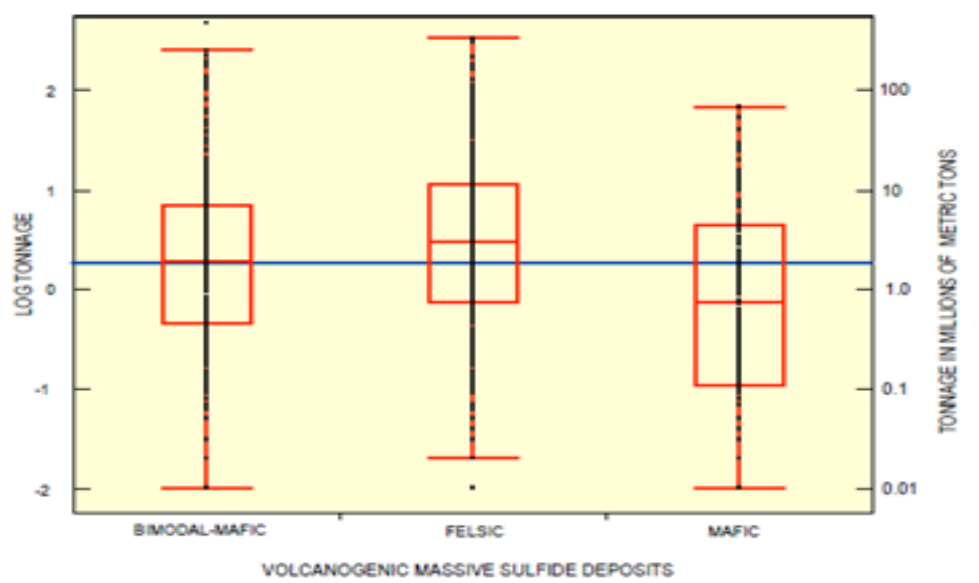

Figura 2. Comparativo entre a tonelagem média de depósitos VMS encaixados em rochas bimodais máficos, félsicos e máficos (Mosier et al., 2009).

São descritos três estilos de precipitação de sulfetos maciços (Figura 3, Tornos et al., 2015a):

1) mounds e chaminés relacionadas

2) corpos exalativos estratiformes

3) substituições abaixo da superfície oceânica (sub-seafloor replacement)

Esses três estilos correspondem às distintas maneiras com que sulfetos maciços são precipitados no fundo do mar, substituem as rochas abaixo da superfície e representam os 
distintos processos de precipitação que podem gerar corpos de VMS. Um mesmo depósito pode possuir um ou mais destes estilos ocorrendo simultaneamente e diversos depósitos VMS apresentam mais de um destes processos. No modelo clássico dos depósitos tipo Kuroku, por exemplo, ocorre um mound cercado por precipitações de sulfeto, com um stockwork também mineralização ocorrendo abaixo (Ohmoto, 1996).

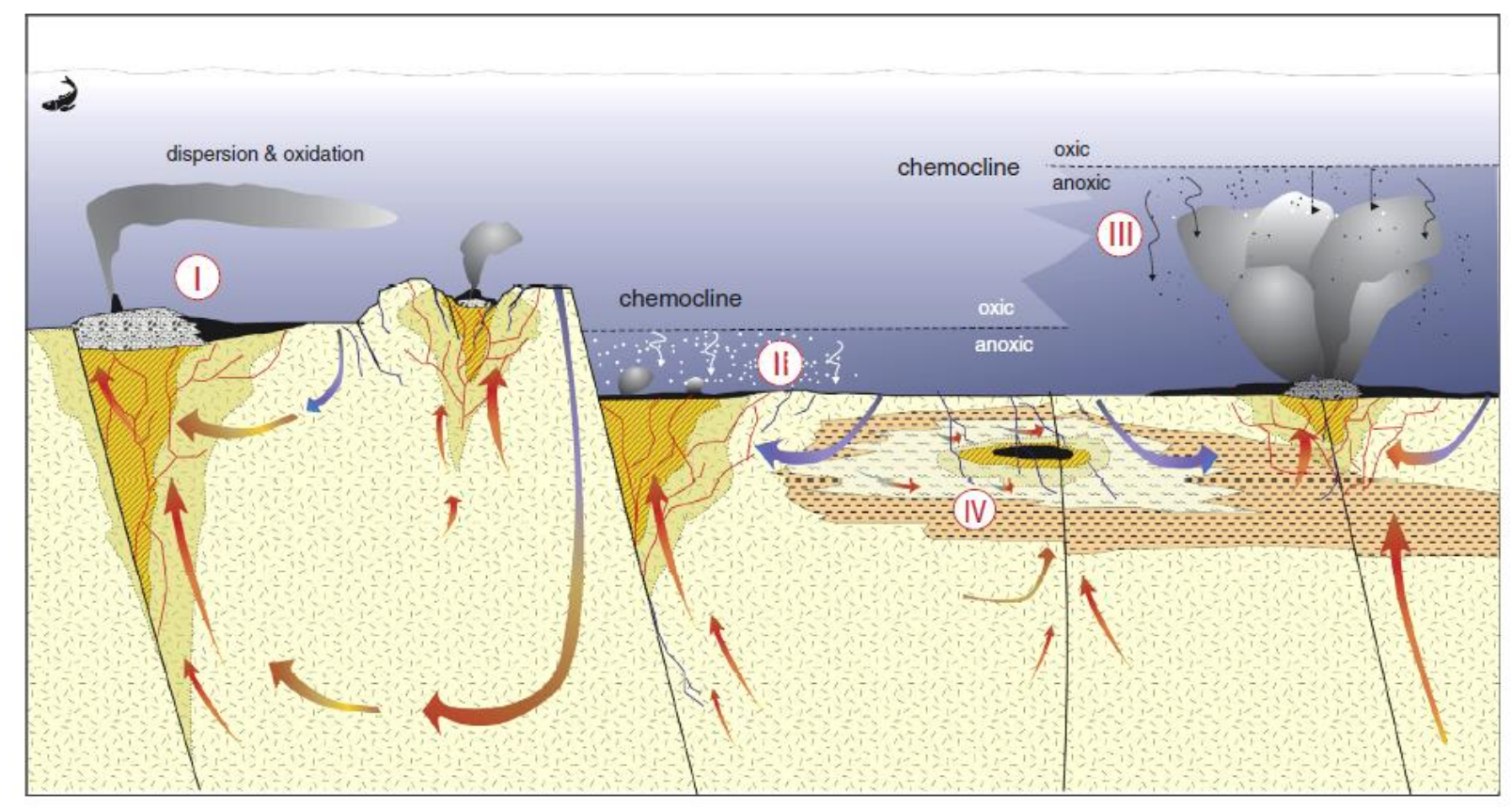

Figura 3. Diagrama esquemático com as principais características dos três estilos distintos de mineralização: I) precipitação em mound em ambientes oxidantes, II) salmoura em bacia restrita, III) precipitação em mound e sulfetos estratiformes em ambientes regionalmente anóxicos (II e III são precipitações exalativas que correspondem ao mesmo estilo de deposição em ambientes distintos) $e$ IV) sub-seafloor replacement (Tornos et al., 2015a).

Os sulfetos precipitados ocorrem como laminações plano paralelas, apresentam variação granulométrica e outras feições sedimentares quando são precipitados quimicamente no leito do oceano. Estas precipitações podem ocorrer distais a fonte de exalação dos fluidos hidrotermais. Chaminés e stockwork também são produtos de fluido hidrotermal, mas são proximais, sendo que a exalação do fluido hidrotermal ocorre nas chaminés e o stockwork fica em subsuperficie, podendo substituir litotipos reativos (Tornos et al., 2015a). Diversos processos convergem para fazer com que a geometria geral dos depósitos VMS seja horizontal. São eles: 
1) precipitação de sulfeto em uma salmoura em bacia restrita;

2) precipitação a partir de um fluido denso e de alta salinidade e acumulação em baixos topográficos;

3) sedimentação de sulfetos clásticos erodidos de um alto topográfico;

4) precipitação química na parte proximal $(<500 \mathrm{~m})$ de exalações hidrotermais;

5) sub-seafloor replacement de unidades mais permeáveis e/ou reativas (Schulz, 2012, Tornos et al., 2015a).

Os depósitos de sulfetos maciços são o resultado da concentração e precipitação de sulfetos a partir de fluidos hidrotermais aquecidos por uma atividade vulcânica, atividade que ocorre restrita a certos intervalos de tempo. Na maioria dos ambientes tectônicos de arco, o pico da extensão e o rifteamento possuem vida curta e geralmente ocorrem associados com rochas com alto conteúdo de sílica (dacitos a riolitos) (Schulz, 2012). Estes intervalos tendem a durar menos de 2-3 Ma e estão associados com a formação dos depósitos VMS. Os dois principais fatores que controlam o fluxo do fluido, duração da descarga e vida de um sistema hidrotermal são 1) a natureza, profundidade e tamanho da fonte de calor e 2) a permeabilidade das rochas a seu redor (Schulz, 2012). Simulações de sistemas VMS sugerem que essa descarga de fluidos hidrotermais aquecidos $\left(>150^{\circ} \mathrm{C}\right)$ podem durar entre 400 anos até mais de 200.000 anos (Schardt \& Large, 2009).

Os depósitos de sulfetos maciços se formam na superfície ou abaixo da superfície com relação espacial, temporal e genética com vulcanismo na localidade. As principais relações entre os depósitos VMS e a atividade vulcânica incluem: a) controle de localização dos depósitos em estruturas vulcânicas e litologias associadas; b) produção de alto gradiente térmico que alimenta a convecção do fluido hidrotermal (Schardt \& Large, 2009) e 3) contribuição de metais e enxofre a partir dos fluidos hidrotermais e dos elementos liberados em reações do fluido com a rocha encaixante (Schulz, 2012). Estudos realizados nos dias de hoje em locais de dorsais oceânicas demonstram que fumarolas de alta temperatura quase universalmente estão associadas a presença de magma. As rochas aquecidas e fontes de calor não-magmáticas são consideradas insuficientes para manter uma atividade hidrotermal de alta temperatura (Baker, 2009). 
Os sulfetos podem se encontrar associados a certas fácies vulcânicas. Os fluidos hidrotermais ascendentes são focados ao longo de zonas mais permeáveis, geralmente rochas vulcanoclásticas porosas, e a precipitação de sulfetos ocorre abaixo do nível do mar. Os depósitos também podem ocorrer associados a rochas sedimentares, geralmente folhelhos. Como estes depósitos são superficiais para que ocorra sua preservação é necessário que haja uma alta taxa de sedimentação e/ou vulcanismo que sele o depósito VMS, evitando assim sua oxidação e erosão.

Os fluidos hidrotermais geradores de depósitos VMS interagem com as rochas abaixo da superfície de duas maneiras distintas. Em unidades favoráveis eles precipitam sulfetos e substituem a litologia original (como descrito acima) e afetam em escala mais ampla rochas vulcânicas associadas com a mineralização, gerando um amplo processo de alteração hidrotermal. Pode ser generalizado que esta alteração hidrotermal substitui vidros vulcânicos e plagioclásio por minerais de alteração estáveis entre $150-400^{\circ} \mathrm{C}$, geralmente filossilicatos como a clorita, caolinita, illita, sericita, pirofilita, além de quartzo (Shanks \& Thurston, 2012). A alteração é gradacional e nas porções mais distais só afeta alguns minerais mais reativos e minerais da matriz. Rochas com muito vidro vulcânico são particularmente suscetíveis a alteração e apresentam intensa silicificação, cloritização ou sericitização. Em porções altamente alteradas a rocha não preserva as feições do protolito. Regiões de stockwork e intenso fluxo de fluidos também podem estar altamente silicificadas e não apresentarem mais indícios de seu protolito (Shanks \& Thurston, 2012).

\subsubsection{Fatores chave para a formação e preservação de um depósito VMS}

Como mencionado previamente, os depósitos VMS podem ser formados em uma ampla variedade de rochas encaixantes e diferentes ambientes tectônicos. Ou seja, fatores que geralmente são utilizados para o estabelecimento de modelos descritivos de depósitos minerais não devem ser aplicados para os depósitos VMS. Nos últimos anos tem ocorrido uma mudança de paradigma em relação a interpretação de modelos de depósitos, que tem avançado no sentido de se entender o sistema mineralizante e seus processos geológicos, e não apenas de uma maneira descritiva (McCuaig et al., 2010; McCuaig \& Hronsky, 2014). O sistema vulcânico-hidrotermal marinho responsável pela precipitação dos VMS foi estudado em detalhes por Tornos et al. (2015), que considera como principais fatores que geram a formação e preservação de um depósito de VMS: 
1 - Estruturas que focam a descarga do fluido hidrotermal (falhas, brechas e alimentadores subvulcânicos) em locais restritos.

2 - Características físico-químicas dos fluidos hidrotermais (como temperatura, composição química e condições de oxirredução) devem ser compatíveis com o transporte dos metais e enxofre.

3 - A profundidade da região de descarga dos fluidos hidrotermais deve ser superior a 1500m para que a pressão hidrostática da coluna de água permita que o fluido chegue até o assoalho oceânico sem sofrer boiling, processo que desencadearia a precipitação dos sulfetos.

4 - As rochas encaixantes, geralmente vulcânicas e em alguns casos sedimentares, precisam possuir litotipos adequados (reativos e/ou porosos) para que ocorra a substituição e precipitação abaixo da superfície (sub-seafloor replacement)

5 - Como os depósitos VMS são facilmente oxidados e erodidos uma alta taxa sedimentar e/ou de vulcanismo que cubra os sulfetos é importante para a proteção e preservação dos mesmos.

6 - A topografia do leito marinho também é um fator chave, pois é ela que determina se os metais se acumularão em depressões ou serão dispersos no oceano pelas correntes marinhas. Depressões como bacias de segunda e terceira ordem, bem como caldeiras vulcânicas são locais favoráveis para a formação dos VMS

7 - O ambiente marinho precisa ser anóxico e isolado de corpos de água oxidados.

8 - Água marinha com características físico-químicas que sirvam de gatilho para a precipitação dos metais quando ocorrer a mistura do fluido hidrotermal com ela no local de exalação do fluido.

A diferença de intensidade entre estes oito fatores determina as características dos depósitos VMS gerados. Outro fator chave para a formação de depósitos de grande porte é a longevidade da célula de circulação hidrotermal, uma vez que ela que determina a quantidade de metais transportados e concentrados em uma determinada área de descarga em um sistema VMS (Tornos et al., 2015a). 


\subsubsection{Estilos de precipitação de sulfetos maciços vulcanogênicos}

Os sulfetos maciços vulcanogênicos são precipitados associados a rochas vulcânicas, vulcanoclásticas e sedimentares. Tornos et al. (2015) reconhece três gêneses distintas para os corpos VMS no ambiente marinho superficial associados ao fluido hidrotermal proveniente de agua marinha que infiltra em subsuperficie e entra na célula de convexão gerada por uma fonte magmática. Como as chaminés geralmente não são preservadas no registro geológico, o que de fato ocorre na Faixa Piritosa Ibérica, aqui só serão tratados os corpos exalativos estratiformes e a sub-seafloor replacement.

\section{Corpos Exalativos Estratiformes}

A maioria dos corpos de VMS precipitados na superfície do oceano não apresentam evidências de oxidação em seus minerais ou associações minerais, o que implica que o contato entre as águas marinhas (oxidadas) e o fluido hidrotermal (reduzido) é desprezível. Mas também podem ocorrer casos em que os fluidos hidrotermais interagem com a água marinha e neste cenário os fluidos hidrotermais são dispersos e oxidados e a formação de uma lente estratiforme não ocorre. O ambiente tem papel decisivo na formação dos depósitos de sulfeto maciço e condições anóxicas são particularmente favoráveis para a formação de depósitos de sulfeto maciço de grande escala (Goodfellow et al., 2003) como é o caso dos depósitos da Faixa Piritosa Ibérica de Tharsis, Las Cruces, Aznalcóllar-Los Frailes e SotielMigolas (Tornos et al., 2015a).

Existem cinco paleoambientes descritos nos quais condições de anoxia prevaleceram no registro geológico: 1) oceanos em geral entre o Mesoarqueano e o Paleoproterozoico, antes do evento de grande oxidação (Huston et al., 2010); 2) períodos de anoxia oceânica regionalmente extensos relacionados a períodos de aquecimento global e mudança do padrão de circulação das correntes oceânicas (Arthur \& Sageman, 1994); 3) em regiões onde a circulação das correntes marinhas é restrita, como em caldeiras vulcânicas e bacias restritas (Ohmoto, 1996); 4) em fiordes e bacias isoladas, com conexão restrita com o mar, como o Mar Negro e 5) anoxia auto induzida causada pela exalação de fluidos hidrotermais imiscíveis em relação à água oceânica e se acumulam em bacias de terceira ordem (Tornos et al., 2015a).

No registro geológico são encontrados exemplos de sulfeto maciço em ambientes de anoxia regional, salmouras em bacias de circulação restrita (Tornos, et al., 2015a). O 
mecanismo de precipitação dominante nestes depósitos é a mistura dos fluidos hidrotermais com a água de mar. Geralmente a fonte dos metais são as rochas lixiviadas pelo fluido hidrotermal com o qual ele interage (Tornos et al., 2015a; Conde, 2016), enquanto que o enxofre pode ter diversas origens: 1) enxofre lixiviado das rochas pelos fluidos hidrotermais, 2) enxofre proveniente da degaseificação do magma, 3) enxofre reduzido termoquimicamente e 4) enxofre reduzido biogenicamente (Tornos et al., 2008). Como as rochas estudadas nesta tese são do Carbonífero, período em que os oceanos já estão oxidados, aqui só serão tratadas as salmouras de ambientes restritos.

\section{Salmouras em ambientes restritos}

Salmouras em ambientes restritos são formadas pela acumulação de fluidos hidrotermais densos em baixos topográficos. A presença de baixos topográficos é crucial para a formação deste estilo de VMS, uma vez que a mistura dos fluidos reduzidos com fluidos oxidados impede a precipitação e a preservação dos sulfetos com valor econômico (Tornos et al., 2015a). Estas salmouras são associadas a fluidos salinos, com salinidades superiores a $\sim 7 \%$ wt.\% $\mathrm{NaCl}$ eq. (Conde, 2016).

O depósito moderno de salmoura em ambiente restrito mais conhecido atualmente é o Atlantis II Deep, no Mar Vermelho (Anschutz et al, 2000), onde o fluido está estratificado em camadas de diferentes salinidades e temperatura. Devido ao ambiente em que são formados, estes depósitos se preservam melhor que as chaminés e com isso sua ocorrência no registro geológico é superior (Figura 4). Existem diversos exemplos de depósitos de VMS precipitados em salmouras de fluidos hidrotermais, incluindo os depósitos da Região Sul da Faixa Piritosa Ibérica estudados nesta tese (Tharsis e Las Cruces).

Os sulfetos maciços formados nestas condições apresentam diversas fácies sedimentares como bandamento, laminação entre pirita e siderita e brechas heterolíticas com fragmentos de sulfetos maciços (Figura 5). 


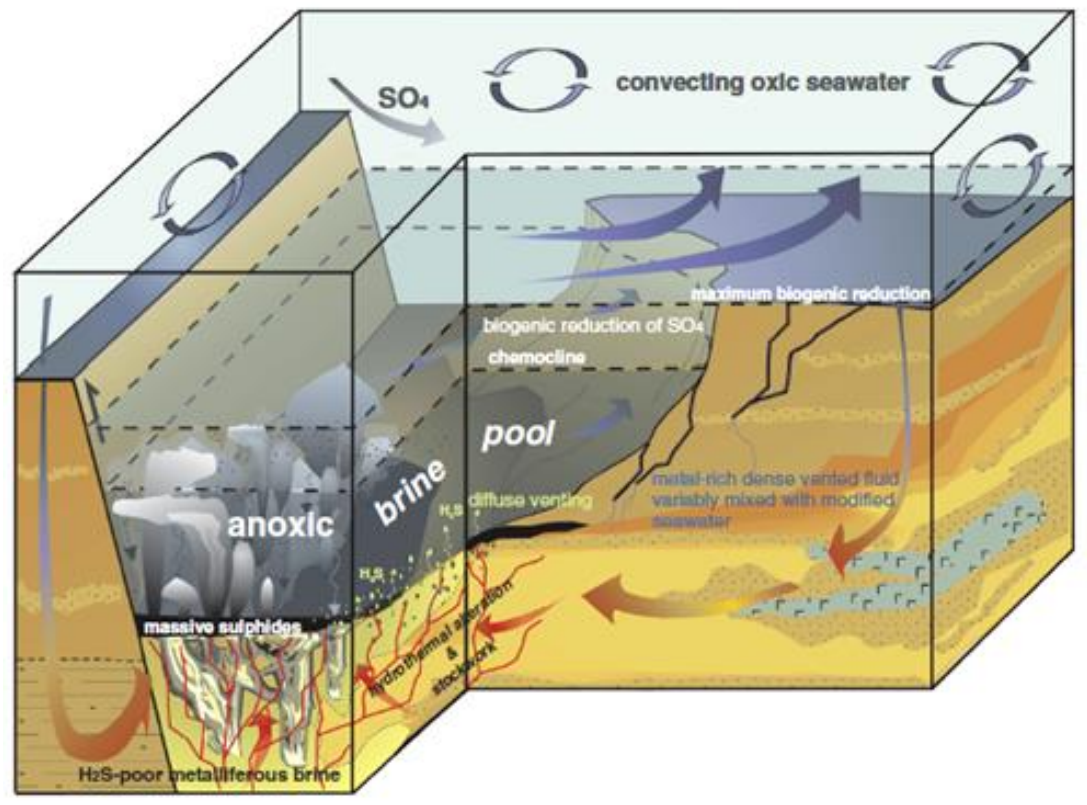

Figura 4. Bloco diagrama esquemático do ambiente de formação de um depósito VMS associado às salmouras, isto é, bacias com circulação de água restrita gerando condições anóxicas (Tornos et al.,

\section{5a)}
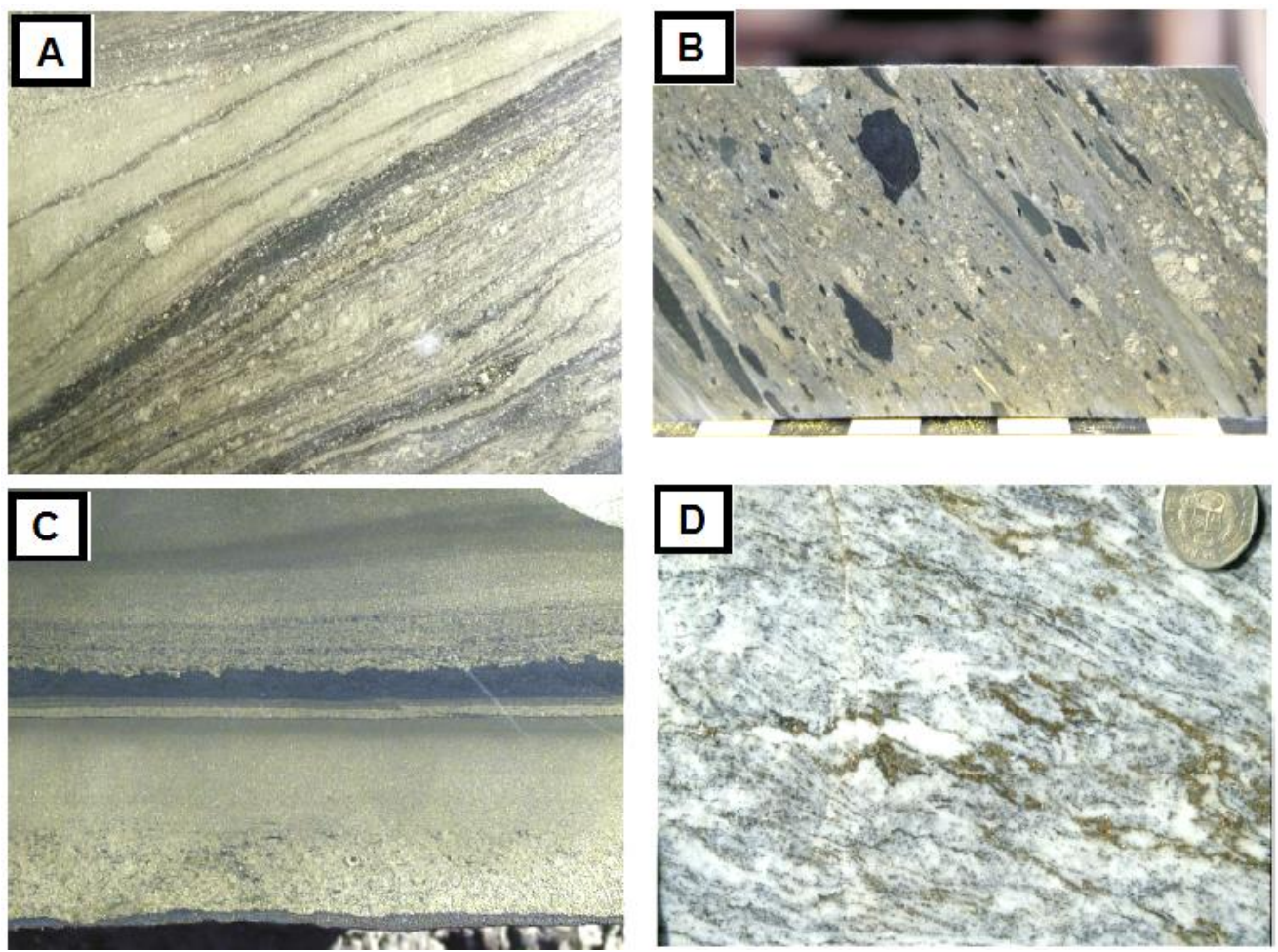

Figura 5. Feições características de VMS precipitados em aguas anóxicas no assoalho ocêanico A) sulfeto com bandamento composicional deposicional com deformação superimposta; B) brecha estratiforme com fragmentos de sulfetos maciços e de folhelhos; C) pirita laminada intercalada com folhelhos neg ros; $e$ 
D) associação de barita-pirita-esfalerita formado em condições sub óxicas que já não permitem o desenvolvimento de VMS bem formados (Tornos et al., 2015a)

\section{Sub-seafloor replacement}

Mineralizações de sulfetos maciços vulcanogênicos não se formam somente no assoalho oceânico, mas também abaixo dela. Diversos depósitos apresentam, inclusive, a maioria da sua mineralização associada a processos de substituição abaixo da superfície oceânica, como é o caso de todos os depósitos de sulfeto maciço da Região Norte da FPI estudados nesta tese (San Telmo, Aguas Tenidas, Magdalena, San Miguel, Concepcion, San Platon, La Zarza e Rio Tinto) (Tornos, 2006). Essa substituição ocorre em litotipos porosos e/ou reativos, como rochas vulcanoclásticas ricas em púmice, vidro e carbonato, e é desprezível em outros litotipos, como sedimentos químicos e folhelhos. Esses sulfetos podem ser estratiformes ou discordantes, de acordo com a morfologia do protolito. Como esse estilo de precipitação de sulfetos ocorre abaixo da superfície ela é menos afetada por processos superficiais como erosão e oxidação e apresenta uma chance maior preservação (Figura 6; Tornos et al., 2015a).

A substituição da rocha encaixante pelos sulfetos maciços vulcanogênicos quase sempre é parcial, o que significa que este estilo de precipitação apresenta feições heterogêneas. Essa substituição parcial por vezes deixa relictos e estruturas do protolito. A substituição ocorre com a substituição de vidro vulcânico e minerais menos estáveis (Piercey, 2015; Tornos et al., 2015a). Os fluidos hidrotermais que circulam pelos litotipos porosos precipitam minerais em fraturas, interstícios e cavidades abertas.

Estes sulfetos de substituição apresentam como características: 1) geometria irregular, 2) associação com rochas porosas e/ou reativas, 3) auréola de alteração hidrotermal das rochas encaixantes, 4) contato transicional entre os sulfetos e a rocha encaixante e os sulfetos maciços. A Figura 7 exemplifica uma variedade de feições de corpos VMS de sub-seafloor replacement como substituição pervasiva do litotipo encaixante em uma zona de stockwork; sulfeto maciço estratiforme devido a substituição seletiva de rochas vulcanoclásticas em uma intercalação com folhelhos negros; contato entre rocha encaixante e VMS onde o sulfeto substitui quase que completamente uma brecha rica em púmice; e contato entre o stockwork e a rocha encaixante no depósito de La Zarza. Zonas de substituição extensas, de dezenas a centenas de metros, podem se desenvolver em litotipos favoráveis. Estas zonas ocorrem 
associadas ao vulcanismo e servem como passagem para os fluidos hidrotermais. Estruturas de pipe são intrínsecas às zonas de stockwork e os sulfetos de substituição estratiformes provavelmente representam paleo-aquíferos, nos quais a mistura dos fluidos ocorreu (Tornos et al., 2015a).

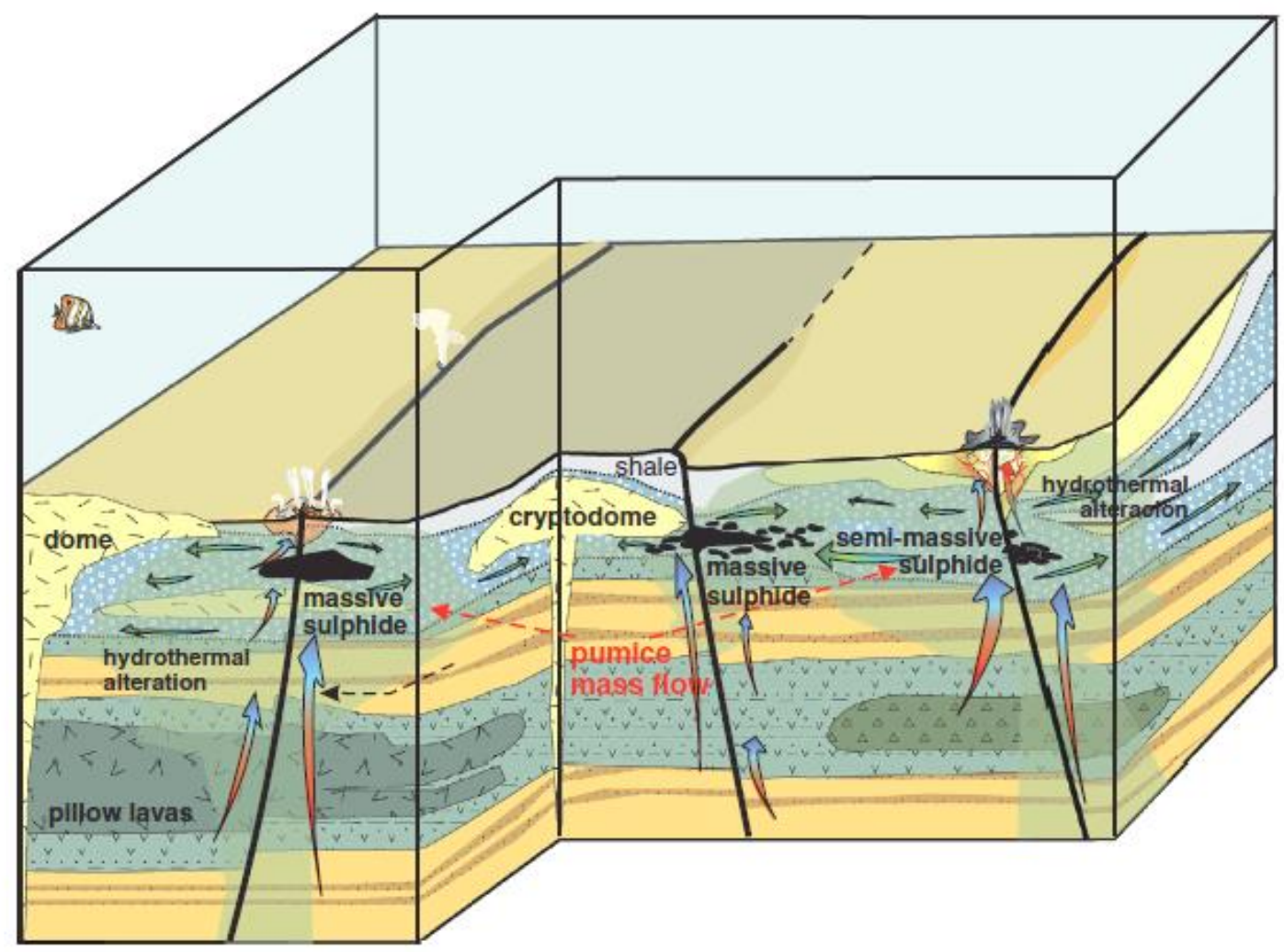

Figura 6. Bloco diagrama esquemático mostrando as principais características associadas a geração de sulfetos maciços abaixo da superfície. Este bloco diagrama também apresenta as zonas de alteração hidrotermais desenvolvidas pela passagem dos fluidos aquecidos pela rocha encaixante (Tornos et al., 2015a). 

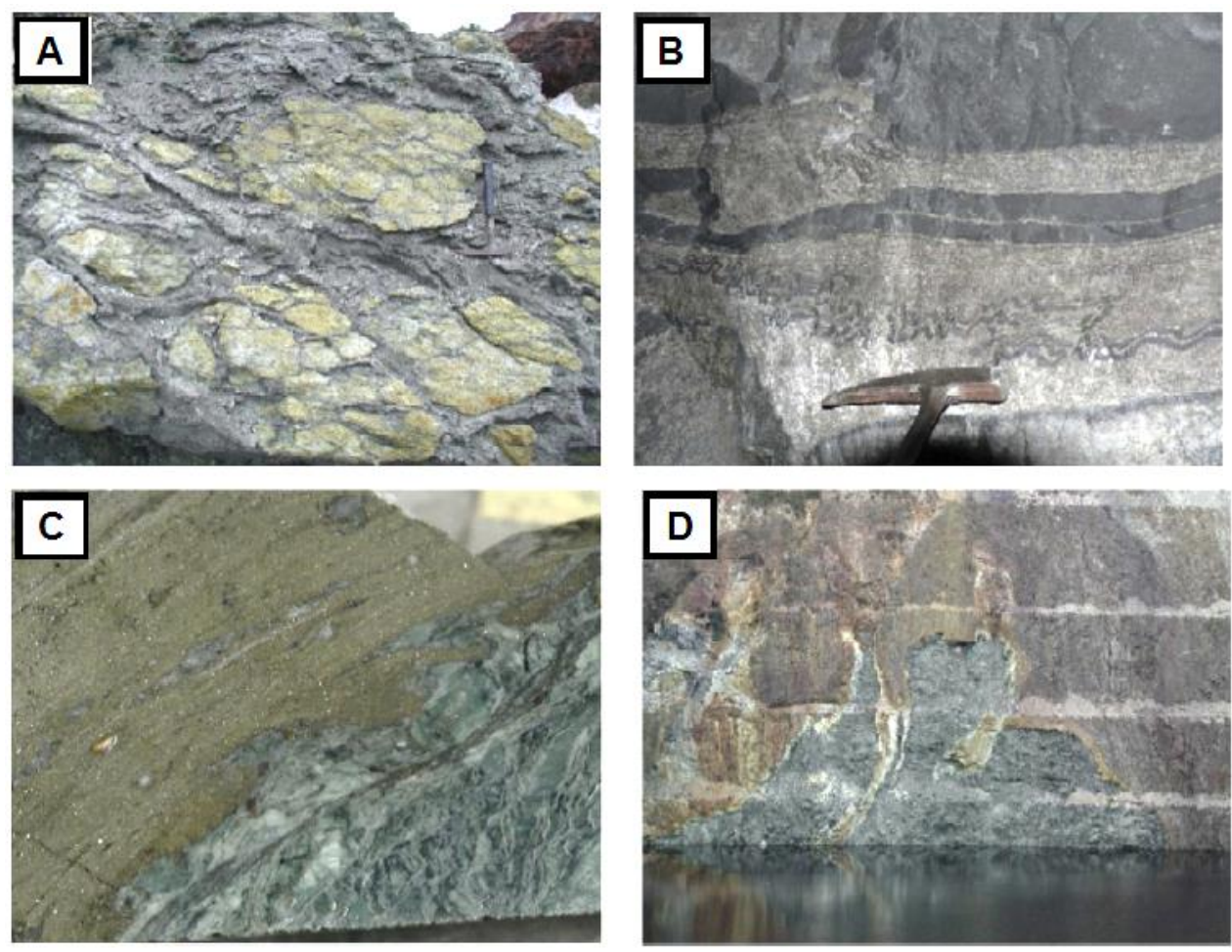

Figura 7. Feições características de VMS relacionados a sub-seafloor replacement. A) Sulfeto maciço substituindo pervasivamente o litotipo encaixante em uma zona de stockwork; B) sulfeto maciço estratiforme devido a substituição seletiva de arenitos vulcanoclásticos em uma intercalação com folhelhos negros; C) contato entre rocha encaixante e VMS onde o sulfeto substitui quase que completamente uma brecha rica em púmice; e D) contato entre o stockwork e a rocha encaixante, uma brecha vulcanoclásticas, no depósito de La Zarza (Tornos et al., 2015a).

\section{CONTEXTO GEOLÓGICO}

\subsection{FAIXA PIRITOSA IBÉRICA}

A Faixa Piritosa Ibérica (FPI) tem sido explorada há mais de 4500 anos, desde tempos pré-Romanos, e contém uma das maiores concentrações de sulfetos na crosta terrestre, com mais de $1600 \mathrm{Mt}$ de sulfetos maciços e mais de $250 \mathrm{Mt}$ associados aos stockworks distribuídos em diversos depósitos gigantes e de classe mundial (Leistel et al., 1997; Tornos, 2006). Estes depósitos caracterizam a FPI como a maior província de VMS preservada no registro geológico (Huston et al., 2010). A FPI abriga mais de 80 minas ativas e exauridas, sendo que $22 \%$ dos depósitos VMS de classe mundial ou gigantes estão inseridos nela (Tornos et al., 2000, Laznicka, 1999; Figura 8A e B). Apesar da alta tonelagem (8 dos 
depósitos apresentam tonelagem >100 Mt de sulfetos maciços), a maioria destes depósitos é rico em pirita e somente 11 depósitos podem ser considerados grandes no que diz respeito aos teores de $\mathrm{Cu}-\mathrm{Zn}-\mathrm{Pb}$ (Laznicka, 1999, Tornos, 2006). A maioria destes depósitos consiste em várias lentes de sulfeto maciço concentradas em uma pequena área de poucos quilômetros quadrados. Lentes individuais podem atingir até 170 Mt, como é o caso do depósito de La Zarza, mas geralmente os depósitos gigantes (Neves Corvo, Aljustrel, Tharsis, SotielMigollas, Rio Tinto e Aznalcóllar-Los Frailes) são formados por lentes isoladas. Em alguns casos essas lentes são interpretadas como uma única lente de grande porte desmembrada (Rio Tinto - Solomon et al., 1980; Tharsis - Tornos et al., 1998; Aznalcóllar-Los Frailes e SotielMigollas - Santos et al., 1996; Aljustrel, Dawson \& Caessa, 2003) enquanto que existem lentes que provavelmente se formaram próximas (Neves Corvo - Relvas, 2000). Entre os depósitos estudados neste doutorado estão os depósitos gigantes de Rio Tinto, La Zarza e Tharsis, e os depósitos de classe mundial de Concepcion, Aguas Tenidas, Magdalena e Las Cruces. 

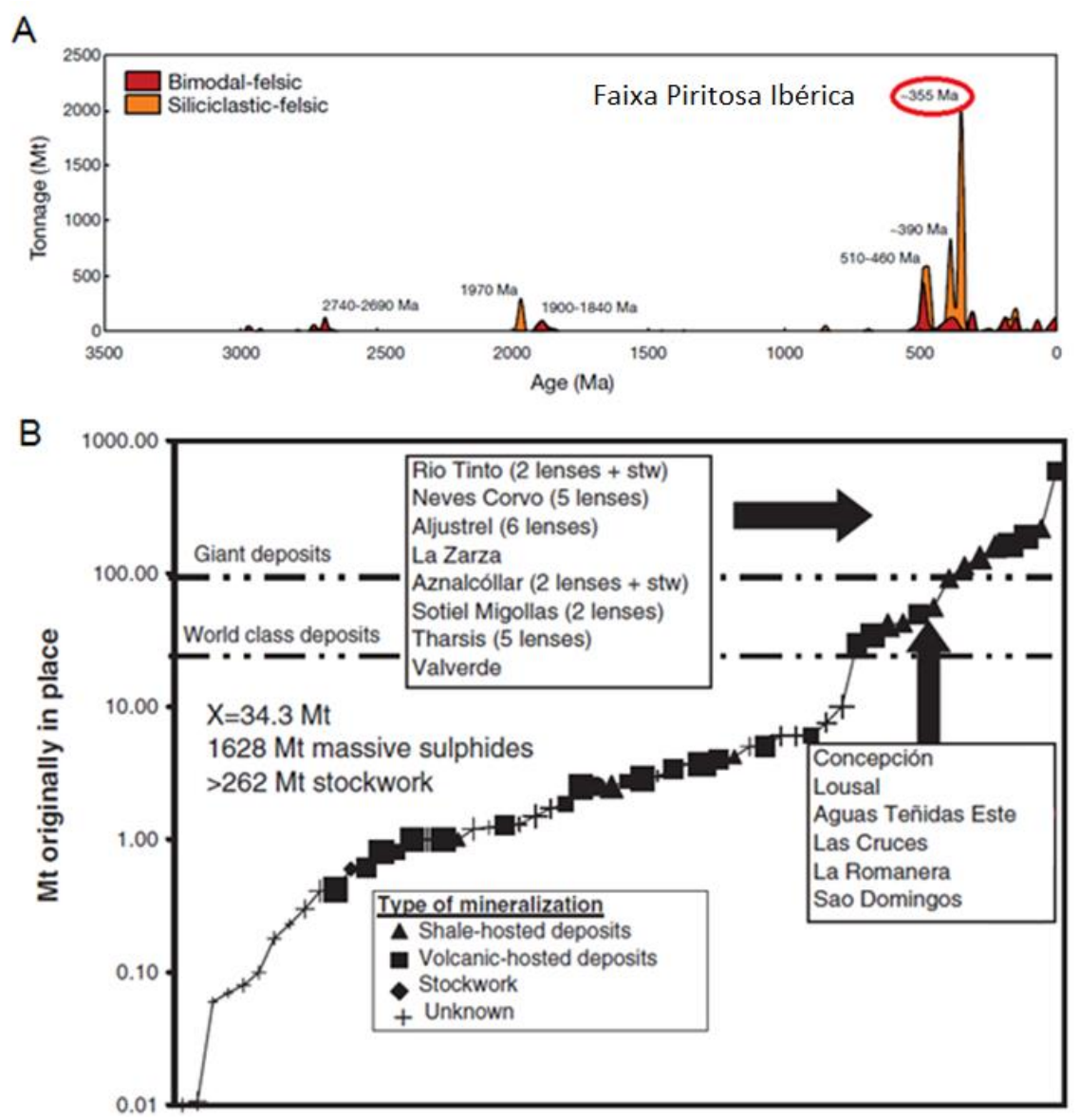

Figura 8 A) Importância da Faixa Piritosa Ibérica no total de mineralizações VMS registradas na história geológica da terra (Huston et al., 2010); e B) depósitos do FPI que são considerados gigantes e de classe mundial, incluindo os depósitos de Rio Tinto, La Zarza, Tharsis, Concepcion, Aguas Tenidas e Las Cruces, que são estudados nesta tese (Tornos, 2006).

Os litotipos que compõe a FPI estão inseridos em um terreno conhecido como Zona Sul Portuguesa (ZSP), o terreno mais ao sul do Maciço Ibérico. A ZSP compõe, juntamente com a Zona Ossa Morena (ZOM), a porção sudoeste do Cinturão Variscano do Sudoeste Ibérico. A ZOM compõe a parte sul do Terreno Autóctone Ibérico e ainda é considerada um terreno gondwânico, que foi acrescido na margem sul do Maciço Central Ibérico, um terreno autóctone, na Orogenia Cadomiana (Proterozoico superior - Cambriano inferior) (Abalos et al. 1991; Ochsner, 1993). O Cinturão Variscano do Sudeste Ibérico é o resultado da amalgamação de terrenos peri-gondwanicos (OMZ) e da Laurussia (ZSP) ao longo da orogenia Variscana (Devoniano tardio a Viseano tardio) gerando um cinturão de empurrões e cavalgamentos que se propagou para sul por cima de um descolamento crustal (Silva et al., 1990, Tornos, 2006). O fechamento do Oceano Rheic nesta região ao longo do 
Sherpukoviano-Pensilvaniano coloca as unidades da ZSP em contato com as unidades da ZOM (Tornos, 2006; Tornos et al., 2015b). A região desta sutura Variscana entre a ZSP e a ZOM é definida pelo Terreno Pulo do Lobo e pelo ofiolito de Beja Acebuches (Silva et al., 1990; Quesada et al., 1994). O Terreno Pulo do Lobo é um terreno oceânico composto por sedimentos de um prisma acrescionário, enquanto que o ofiolito de Beja Acebuches é resultado da obducção parcial de uma bacia pré-Famenniana (Silva et al., 1990).

\subsection{ESTRATIGRAFIA DA FPI}

O ambiente deposicional destas unidades evoluiu de uma plataforma continental estável (ao longo da sedimentação do Grupo FQ) para um ambiente de bacias de pull apart resultantes de uma colisão oblíqua (formação das rochas do Complexo VS) e posteriormente para uma bacia de antearco sin-orogênica com sedimentação tipo flysch (sedimentação das rochas do Grupo Flysch do Baixo Alentejo) (Silva et al., 1990; Quesada et al., 1994). A geologia simplificada da FPI pode ser consultada no mapa geológico da Figura 9.

\subsubsection{Grupo Filito Quartzito}

O Grupo Filito Quartzito (Grupo FQ) é constituído por uma sequência monótona de mais de $2000 \mathrm{~m}$ de espessura e base desconhecida, composta por sedimentos detríticos compostos predominantemente por folhelhos e quartzitos depositados no Devoniano tardio (Givetiano-Famenniano) (Tornos, 2006). Este ambiente deposicional é interpretado como o registro de uma plataforma continental rasa com sedimentação por vezes associada a tempestades. Ocorre uma mudança abrupta de fácies no topo da sequência, onde debri flows, barras de areia, lentes de carbonato e sedimentos de plataforma são comuns (Moreno et al., 1996). Estas fácies de alta energia do topo do Grupo FQ são datadas no Fammeniano e indicam a segmentação e colapso de uma plataforma estável perto da fronteira entre o Devoniano e o Carbonífero (Moreno et al., 1996). Esta situação de estabilidade tectônica teve longa duração e os sedimentos do Grupo FQ são interpretados como resultados da erosão de um continente que teria existido entre $2.0 \mathrm{Ga}$ e $0.4 \mathrm{Ga}$ (Onézime et al., 2002). 


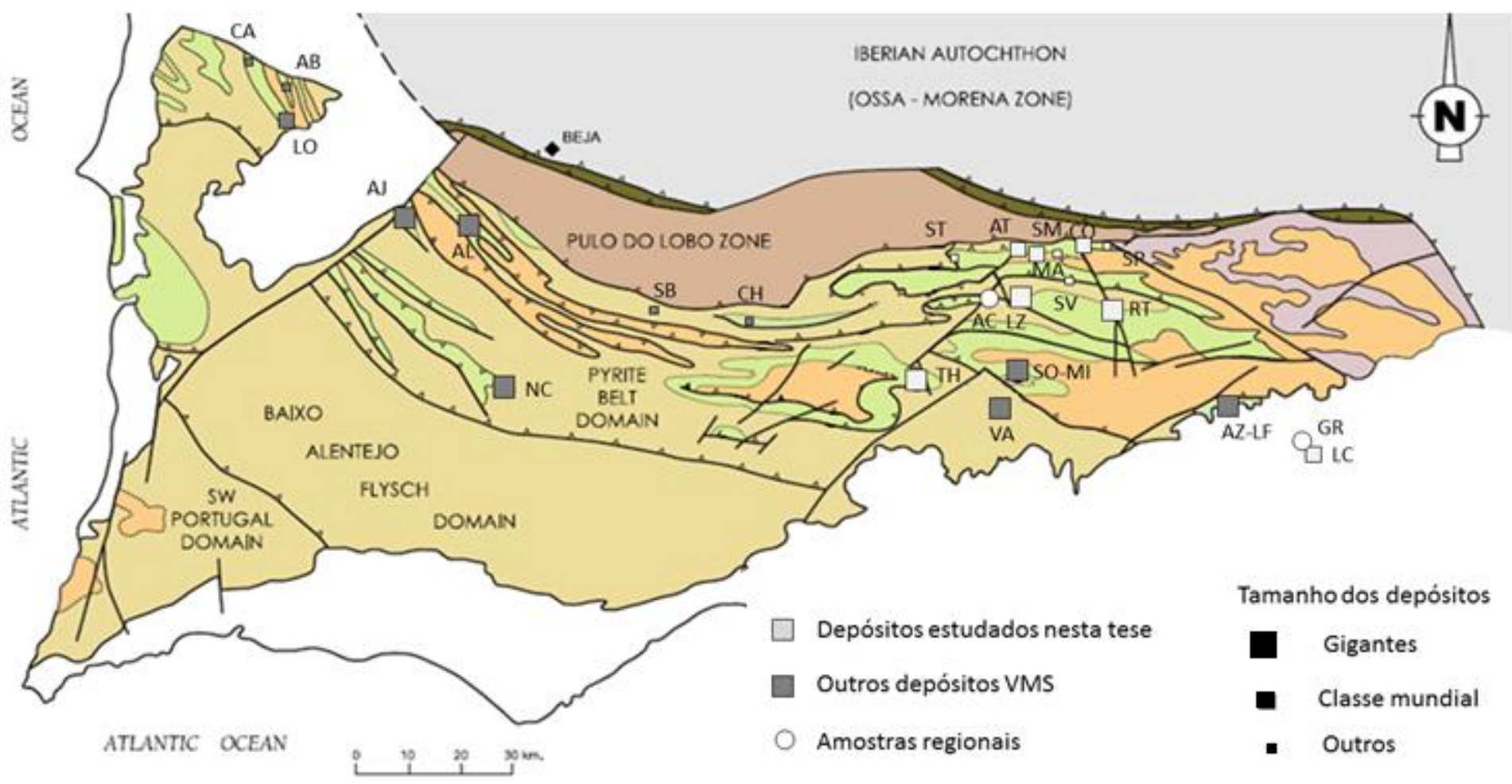

\section{Zona Sul Portuguesa}

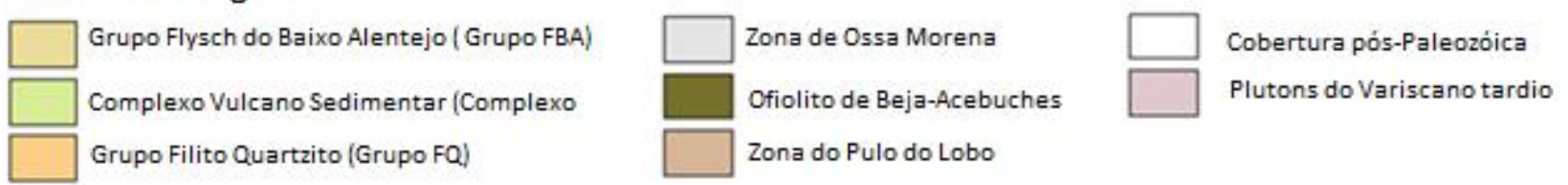

Figura 9. Mapa geológico da Faixa Piritosa Ibérica com a localização dos depósitos estudados nesta tese e de outros depósitos relevantes regionalmente. Os depósitos são, oeste para leste, representados pelas seguintes siglas: CA - Caveira; AB - Azinheira de Barros; LO - Lousal; AJ-Aljustrel; AL-Albernoa; NC Neves Corvo; SB - Serra Branca; CH - Chança; TH - Tharsis; ST - San Telmo; AT - Aguas Tenidas, LZ - La Zarza; VA - Valverde; SO-MI - Sotiel-Migollas; SM San Miguel; MA - Magdalena; SV-Solo Viejo; CO-Concepcion; SP San Platon; RT-Rio Tinto; AZ-LF-Aznalcollar-Los Frailes; LC-Las Cruces. As localidades regionais de Gerena (GR) e Aglomerado del Cerro (AC) também foram estudadas nesta tese (modificado de Castroviejo et al., 2011) 
Estas características relacionadas ao final da deposição do Grupo FQ estão relacionadas a instalação da Orogenia Variscana (Tornos, 2006). O colapso desta plataforma estável gerou o desenvolvimento de várias bacias de $3^{\mathrm{a}}$ ordem que constituem o ambiente de deposição dos folhelhos do Complexo VS. Um ambiente de riftes altamente compartimentalizado, com bacias com subsidência variada, caracteriza o paleo-ambiente em que os processos mineralizantes ocorreram (Tornos et al., 2002). Esta paleogeografia também é sustentada pela ausência de continuidade lateral nas camadas vulcanossedimentares, o que implica em variações abruptas de fácies lateral e verticalmente (Oliveira, 1990). Neste tipo de ambiente variações na profundidade do mar e na taxa de sedimentação são esperadas e algum grau de heterogeneidade não implica em mudança de unidade.

Os modelos atuais indicam que o Grupo FQ é a fonte principal de fluidos e metais das mineralizações VMS do Complexo VS. A desidratação termicamente induzida, a maturação diagenética e metamorfismo de baixo grau, provavelmente relacionado ao afinamento crustal e a compactação do Grupo FQ são os processos associados a estes fluidos e metais (Tornos, 2006)

\subsubsection{Complexo Vulcano Sedimentar}

O Grupo FQ é recoberto por uma sequência de rochas vulcanossedimentares com espessura entre $0-1300 \mathrm{~m}$, mas que geralmente não ultrapassam $600 \mathrm{~m}$, denominadas de Complexo Vulcano Sedimentar (Complexo VS). Esta unidade é altamente heterogênea, com variações de fácies abruptas tanto lateral quanto verticalmente. As fácies vulcânicas do Complexo VS incluem membros extrusivos e intrusivos, de natureza maciça ou vulcanoclásticas. As rochas vulcânicas variam entre riolitos a basaltos, mas são essencialmente riodacitos, e são observadas tanto em aspecto maciço quanto fragmentadas e brechadas. As rochas maciças incluem sills, domos e criptodomos félsicos e, em menor escala, derrames e diques de basalto. Estas rochas vulcânicas ocorrem intercaladas com folhelhos, sedimentos clásticos e sedimentos químicos como cherts, exalitos ricos em manganês e sulfetos maciços vulcanogênicos (Mitjavila et al., 1997; Thieblemont et al., 1997; Valenzuela et al., 2011; Conde, 2016; Conde \& Tornos, 2019). O vulcanismo é bimodal, com uma clara predominância de rochas félsicas (riolitos a dacitos) em relação as rochas máficos, mas a FPI é heterogênea e algumas regiões apresentam proporcionalmente mais rochas máficas que outras regiões. 
A abundância relativa das rochas máficas possivelmente aumenta em profundidade, o que diversos trabalhos de geofísica voltados para a exploração mineral não publicados indicam (Codeço et al., 2018). As rochas máficas podem ser tanto alcalinas quanto toleíticas enquanto que as rochas félsicas são cálcio-alcalinas (Mitjavila et al., 1997; Thieblemont et al., 1998; Tornos, 2006). Alguns autores enfatizam os sills como a fácies predominante do magmatismo (Boulter, 1993; Soriano \& Martí, 1999), o que é rejeitado pela maioria dos trabalhos na região. Mesmo que os sills sejam as fácies vulcânicas mais abundantes em determinadas localidades, isto é um fenômeno local e não reflete o magmatismo da FPI como um todo. Domos e criptodomos félsicos, rochas hialoclásticas e abundantes mass flows que por vezes são ricos em púmice e outras vezes em cristais e são os litotipos geralmente associados as mineralizações VMS da FPI (Tornos et al., 2002; Rosa et al., 2004; Tornos, 2006; Rosa et al. 2010; Tornos et al., 2015a; Conde, 2016; Conde \& Tornos, 2019). Rochas intermediárias resultantes da interação de magmas máficos com magmas félsicos são observadas principalmente na região mais a norte da FPI espanhola, enquanto que em outras regiões da FPI os magmas máficos e félsicos não interagiram entre si gerando andesitos intermediários (Conde \& Tornos, 2019).

A tectônica transpressional oblíqua gera como resposta falhas crustais profundas. Estas falhas favoreceram a ascensão de magmas félsico pouco fracionados, superaquecidos e empobrecidos em água até níveis crustais rasos. Estes magmas são o resultado da anatexia crustal ou da fusão parcial de rochas quartzo-feldspáticas do embasamento, processo que teria sido induzido pela colocação de magmas máficos na base da crosta (Munhá, 1983; Mitjavila et al., 1997; Thieblemont et al., 1998). Essa profundidade crustal rasa somado a natureza empobrecida em água desse sistema magmático félsico torna improvável a exsolução de grandes quantidades de fluidos magmáticos, indicando que os fluidos hidrotermais são predominantemente água do mar que infiltrou neste sistema hidrotermal através de falhas e foi incorporada como parte da célula convectiva (Tornos et al., 2002).

Possivelmente a única exceção é o depósito de Neves Corvo, em Portugal, onde é observada a contribuição de fluidos magmáticos na geração da mineralização. Este depósito possui geoquímica dos minerais de minério distinta também, com altos teores de $\mathrm{Cu}$ e $\mathrm{Zn}$. Estas anomalias de Neves Corvos são explicadas levando em conta as múltiplas fontes de metais e fluidos deste depósito. Dados de estrôncio ( $\mathrm{Sr})$, neodímio $(\mathrm{Nd})$ e chumbo $(\mathrm{Pb})$ são consistentes com esta hipótese e indicam a incorporação de fluido magmático e/ou de um 
fluido metamórfico em um sistema mineralizante dominado por água do mar (Relvas et al., 2001), os isótopos de oxigênio e hidrogênio indicam o mesmo (Relvas, 2000).

O cenário geodinâmico da FPI, com seu contexto transpressional com gradiente geotérmico anormalmente alto, evoluiu de acordo com a propagação da anomalia térmica ao longo das falhas normais de grande escala. Essas estruturas canalizaram o calor das zonas mais profundas até profundidades mais rasas, gerando o grande volume de fluido hidrotermal responsável pelas mineralizações.

As rochas do Complexo VS são heterogêneas ao longo de toda a FPI. Na região sul da FPI o Complexo VS é caracterizado pela presença abundante de rochas sedimentares, principalmente folhelhos, enquanto que na região norte da FPI rochas vulcânicas e vulcanoclásticas predominam (Conde, 2016; Conde \& Tornos, 2019). A formação dessas unidades vulcânicas tem início com o desenvolvimento das bacias de pull apart relacionadas com um underplating de magmas máficos e a descompressão relacionada à fusão da crosta (Tornos, 2006; Conde, 2016).

A arquitetura dos centros vulcânicos inclui lavas e domos félsicos, unidades piroclásticas, intrusões félsicas e subordinadamente unidades máficas. A diversidade de fácies vulcânicas ao longo das diferentes regiões da FPI reflete variações de proximidade com o centro vulcânico e diferenças no estilo de erupção. Essas sequências vulcânicas são dominadas por lavas e domos félsicos, entretanto unidades piroclásticas também são abundantes e ocorrem espacialmente relacionadas aos domos e lavas. As porções distais dos centros vulcânicos são dominadas por folhelhos, o que faz com que o Complexo VS seja dominado por essas rochas sedimentares, numa proporção aproximada de 3:1 com as rochas vulcânicas (Tornos, 2006). A arquitetura do Complexo VS ao longo de toda a FPI é uma combinação e proporção destas distintas fácies vulcânicas de acordo com a proximidade e distância dos centros vulcânicos (Rosa et al., 2010).

Rochas plutônicas são escassas na FPI, com a exceção do batólito de Sierra Norte, na região nordeste da província, e pouco se sabe sobre a relação entre essas rochas plutônicas e as rochas vulcânicas e vulcanossedimentares (Onézime et al., 2003). Alguns autores interpretam que estas rochas do batólito de Sierra Norte e as rochas do Complexo VS pertencem a mesma suíte magmática, sendo que os granitoides representam as raízes do Complexo VS (Thieblemont et al., 1997). Existe também quem interprete que as rochas 
intrusivas são mais recentes (Simancas et al., 2003). Dados de U-Pb mais recentes indicam que a primeira hipótese está correta e as rochas do batólito de Sierra Norte foram datadas entre 354 Ma e 346 Ma (Barrie et al., 2002 - 346.23 + 0.81 Ma; Dunning et al., 2002 - 354.4 $\pm 4 \mathrm{Ma}, 353 \pm 2 \mathrm{Ma}$ e $347.5 \pm 1.5 \mathrm{Ma}$ ), que são semelhantes as idades mais jovens observadas nas rochas vulcânicas do Complexo VS (Valenzuela et al., 2011)

\subsubsection{Grupo Flysch do Baixo Alentejo}

O Grupo Flysch do Baixo Alentejo (Grupo FBA), que em alguns trabalhos na porção espanhola é denominado Grupo Culm (Tornos, 2006), é uma sequência turbidítica formada por folhelhos, grauvacas e conglomerados, com espessura de até 3000m. Esta unidade registra a acumulação sin-orogênica de sedimentos flysch depositados na bacia de antearco da ZSP (Moreno, 1993). Sedimentos flysch são sedimentos que progridem de origem de águas profundas e fluxos turbidíticos para folhelhos e arenitos de águas rasas. A transição de um regime distensivo relacionado ao magmatismo do Complexo VS para um regime compressivo do Grupo FBA ocorre no Viseano tardio e o Grupo FBA é sedimentado até o início do intervalo Westphaliano, um estágio europeu do Carbonífero entre 313 e 304 Ma (Mantero et al., 2007), que na Internation Chronostratigraphic Chart corresponde ao Pennsylvaniano.

O metamorfismo regional é de baixa intensidade, variando entre as fácies prehnitapumpelita a fácies xisto verde, e afeta mais as rochas da porção norte da FPI (Munhá, 1993). Este metamorfismo é mais intenso nas proximidades de grandes zonas de cisalhamento, onde o esforço costuma se concentrar (Sanchez España et al., 2003). A evolução da geologia estrutural da região apresenta três episódios principais de dobramentos e falhamentos (Onézime et al., 2002; Soriano \& Casas, 2002). O primeiro destes episódios apresenta cavalgamentos e empurrões de alinhamento E-W sincrônicos ao metamorfismo regional e com vergência para o sul. As estruturas relacionadas ao segundo episódio são as mais bem desenvolvidas na FPI e são compostas por empurrões e dobras com vergência para o sul, que ocorrem sub paralelamente as estruturas do primeiro episódio. O terceiro episódio de deformação gera interferência nos episódios anteriores e desenvolve lineações com alinhamento E-W. A estrutura dominante deste terceiro episódio é um empurrão sincrônico com a formação do Grupo Flysch do Baixo Alentejo (Onézime et a., 2002; Soriano \& Casas, 2002; Conde 2016). 
As alterações hidrotermais observadas na região são associadas aos fluidos hidrotermais mineralizantes que percolam nas rochas vulcânicas e vulcanoclásticas encaixantes. Esta interação entre as rochas encaixantes e os fluidos hidrotermais ocorre sincronicamente com a deposição dos sulfetos maciços na superficie e abaixo da superfície marinha (Sanchez-España et al., 2000; Tornos, 2006). Gossans são comuns na região e geralmente são formados associados com sulfetos maciços e por conta disso são utilizados como guias na exploração de corpos de VMS (Andrew, 2000). Eles são desenvolvidos a partir dos sulfetos maciços quando estes são soerguidos e águas superficiais lixiviam elementos solúveis para depois os precipitar formando minerais secundários. Geralmente a zona inferior dos gossans apresenta os maiores enriquecimentos em elementos como enxofre (S), arsênio (As), fósforo $(\mathrm{P})$, chumbo $(\mathrm{Pb})$, estanho $(\mathrm{Sn})$, antimônio $(\mathrm{Sb})$, prata $(\mathrm{Ag})$ e ouro $(\mathrm{Au})$ (Velasco et al., 2013).

O embasamento da FPI não aflora em nenhuma região. Evidências geofísicas indicam que existe uma descontinuidade crustal de grande expressão entre $10-15 \mathrm{~km}$ de profundidade. Existem autores (Mitjavila et al., 1997) que acreditam que este embasamento é composto de rochas continentais pré-cambrianas que apresentam idades modelo menores que 1.2 Ga. Rosa et al. (2009) propõe, utilizando assinaturas de $\varepsilon_{\mathrm{Hf}}$ do Grupo FQ e das rochas do Complexo VS, que o Grupo FQ é o embasamento local e que a fusão parcial em suas partes mais profundas originou o magmatismo do Complexo VS. A composição química do Grupo FQ é similar a composição dos fluidos hidrotermais e com isso este fluido não gera alterações hidrotermais no Grupo FQ. A partir disto Tornos (2006) interpreta que o Grupo FQ representa a origem dos fluidos hidrotermais mineralizantes.

\subsection{REGIÕES DA FPI}

A Faixa Piritosa Ibérica é subdividida em diferentes regiões de maneiras distintas de acordo com as características das rochas presentes no Complexo VS (Tornos, 2006; Conde, 2016; Martin Izard et al., 2016; Codeço et al., 2018). Com base no mapeamento do depósito de Rio Tinto (Martin Izard et al., 2015) e na compilação de estudos regionais, Martin Izard et al. (2016) propõe que a FPI seja subdividida em 3 setores distintos: o Setor Norte, que engloba os depósitos relacionados a sub-seafloor replacement, o Setor Central, que engloba os depósitos relacionados a exalação marinha (com exceção de Neves Corvo) e o Setor Sul, que seria representado somente pelo depósito de Neves Corvo (Figura 10A). Esta subdivisão relaciona as diferentes regiões da FPI a magmatismos félsicos distintos e os depósitos do 
Setor Norte ocorrem sempre relacionados come o vulcanismo ácido denominado $\mathrm{VSC}_{2}$, enquanto que o Setor Central é associado com o vulcanismo intermediário $\mathrm{VSC}_{0}$ e vulcanismo básico $\mathrm{VSC}_{1}$. O magmatismo $\mathrm{VSC}_{0}$ e $\mathrm{VSC}_{1}$ já foram datados em diversos trabalhos apresentam idades Strunianas, entre 365-359 Ma (Solá et al., 2015; Rosa et al., 2009; Barrie et al., 2002)

A compartimentação proposta por Martin Izard et al. (2016) é questionada por Tornos (comunicação oral) pois, além do trabalho de mapeamento ser escasso, os depósitos são interpretados de acordo com a posição das rochas na estratigrafia (que por si só é questionável, visto que diversos contatos são tectônicos) e não em relação aos ambientes de formação dos sulfetos. Além do mais, para Conde (2016) e Conde \& Tornos (2019) rochas vulcânicas intermediárias (andesitos) só são representativas no Cinturão Norte e são escassos nas demais regiões da FPI, e, especialmente, na Região Sul, onde, para Martin Izard et al. (2016) ocorre o vulcanismo intermediário $\mathrm{VSC}_{0}$.

Tornos (2006) separa a FPI de uma maneira diferente. Para Tornos (2006) a Região Norte pode ser subdividida em 2 setores distintos: a Região de Paymogo na porção oeste da Região Norte e o Cinturão Norte, que representa os depósitos mais próximos da região da sutura entre a ZSP e a ZOM. O Setor Central, relacionado com os maiores depósitos de substituição subsuperficie da FPI, é considerado uma região distinta em Tornos (2006) e considerado parte da Região Norte em Conde (2016) devido as características geológicas dos depósitos. A Região Sul pode ser subdividida em 3 regiões distintas: a Região Ocidental, relacionada com os depósitos portugueses, a Região de Puebla de Guzman ocorre na porção central da Região Sul, e a Região de Valverde-Aznalcóllar na porção leste da FPI (Figura 10B). Nesta tese a separação de Tornos (2006) é utilizada em conjunto com a interpretação dada por Conde (2016) de que os depósitos do Setor Central fazem parte de uma $3^{\mathrm{a}}$ subdivisão da Região Norte e com isso a FPI é dividida em 2 macrorregiões, a Região Sul e a Região Norte (Figura 11). 


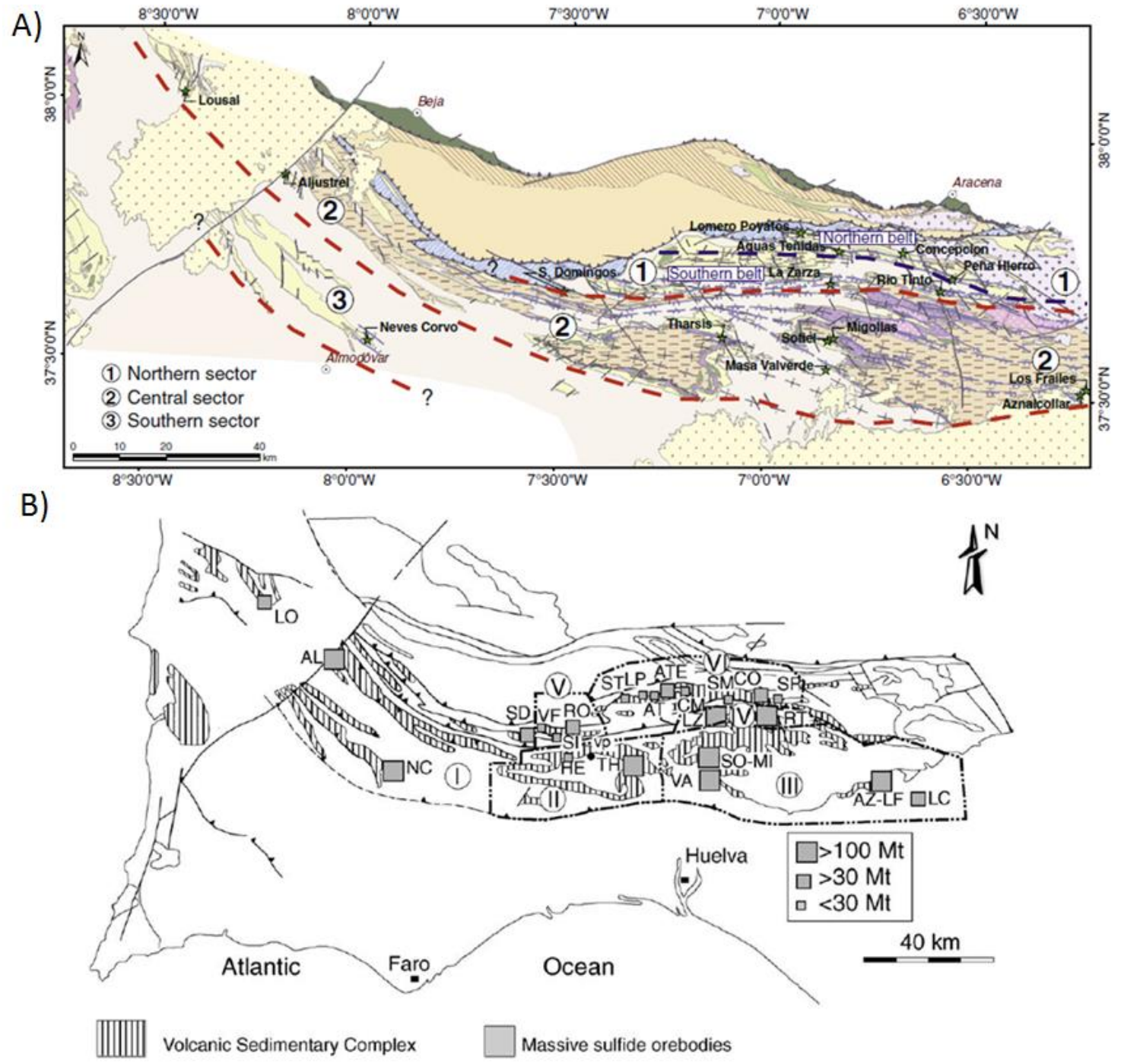

Figura 10. A) Separação da FPI proposta por Martin Izard et al. (2016) e B) separação da FPI proposta por Tornos (2006) em que: I - Porção Ocidental; II - Puebla de Guzman; III - ValverdeAznalcóllar; IV - Setor Central; V-Paymogo; e VI-Cinturão Norte 


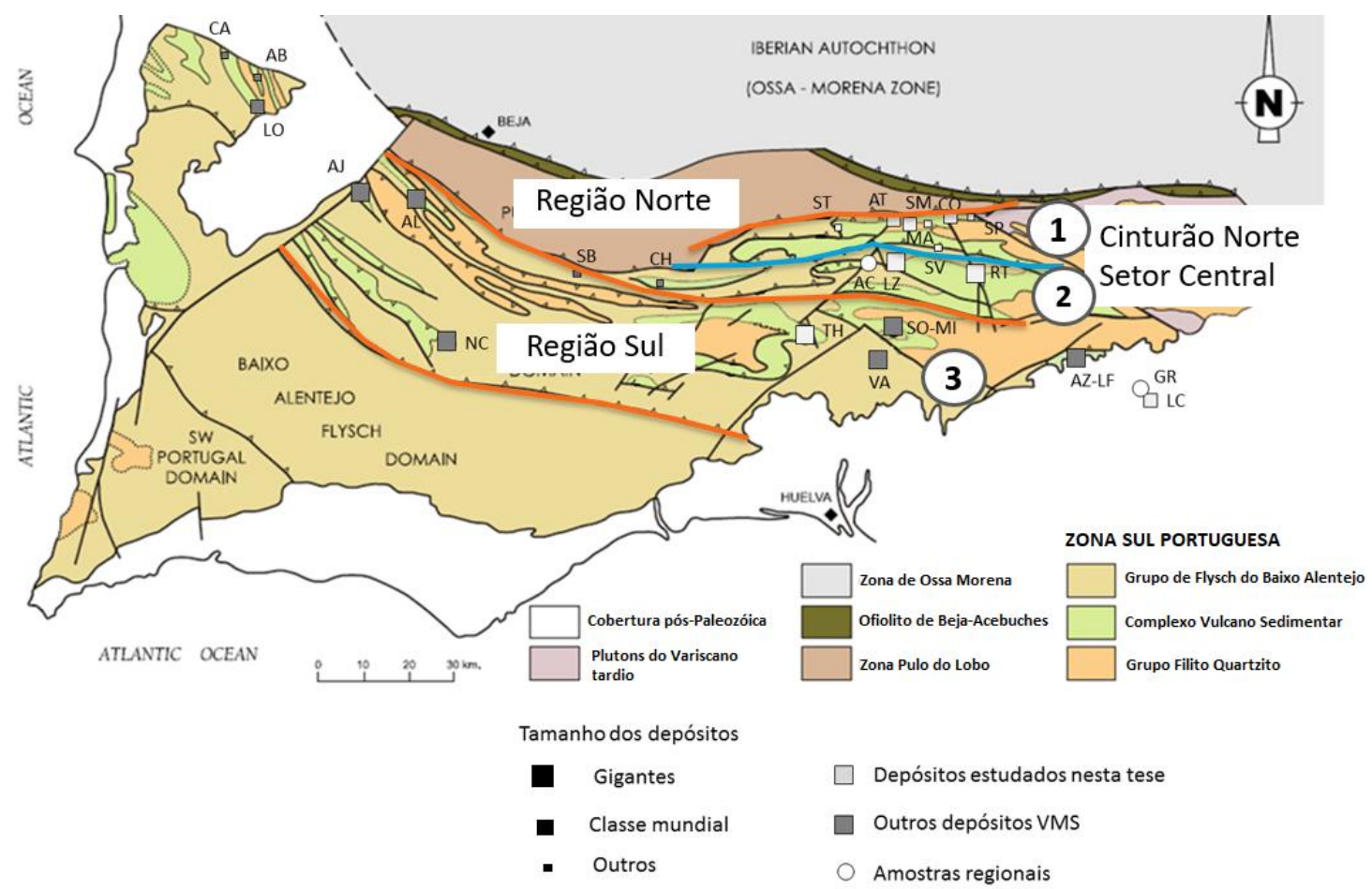

Figura 11. Separação das diferentes regiões da FPI adotada nesta tese, baseada no trabalho de Tornos (2006) e Conde (2016).

Na Região Sul, que engloba os depósitos portugueses e a os depósitos mais ao sul da Espanha, os depósitos de VMS são exalativos e ocorrem associados a folhelhos e são precipitados em bacias anóxicas (Figura 12). Rochas vulcânicas e vulcanoclásticas são escassas nesta região e estes depósitos são formados em um curto intervalo de tempo, tendo sido datados via palinologia com idades do Struniano (Famenniano Superior) (Gonzalez et al. 2002; Oliveira et al., 2004; Oliveira et al., 2005; Pereira et al. 2008; Pereira et al. 2010; Matos et al., 2011).

A Região Norte engloba os depósitos do norte da Espanha e o depósito de Chança, na fronteira com Portugal com a Espanha. Nesta região os depósitos são formados pela substituição subsuperficie que os fluidos hidrotermais mineralizantes causam em rochas vulcanossedimentares reativas e também em hialoclastitos em cima e ao lado de domos e criptodomos félsicos (Figura 12). Nesta região os folhelhos são escassos ou ausentes na coluna estratigráfica (Conde \& Tornos, 2019).

Os depósitos da Região Sul ocorrem isolados geograficamente, enquanto os depósitos da Região Norte geralmente ocorrem em cinturões com orientação W-E, como ocorre da Região de Paymogo e no Cinturão do Norte. La Zarza e Rio Tinto, dois depósitos do Setor 
Central, divergem do Cinturão Norte e da Região de Paymogo e ocorrem isolados geograficamente, sem nenhum depósito nas proximidades e nenhum alinhamento aparente.

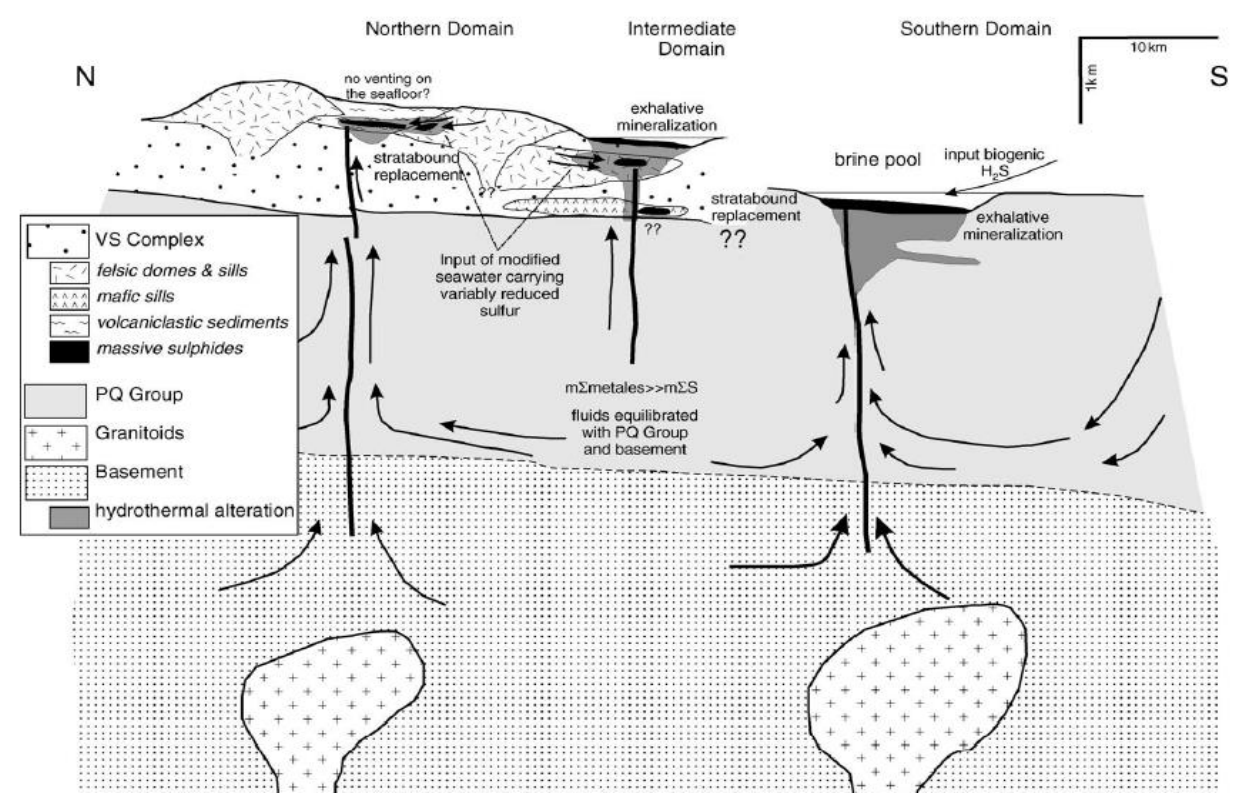

Figura 12. Modelo de gênese dos depósitos VMS da Faixa Piritosa Ibérica (Tornos, 2006).

\subsubsection{Região Norte da FPI Espanhola}

Neste trabalho a Região Norte da FPI é subdividida em 3 regiões distintas: o Cinturão de Paymogo (Tornos, 2006), que não foi estudada nesta tese; o Cinturão Norte (Conde \& Tornos, 2019) e o Setor Central (Tornos, 2006). Os depósitos do Cinturão Norte apresentam concentrações mais elevadas de metais de base $(\mathrm{Cu}, \mathrm{Pb}$ e $\mathrm{Zn})$ porém tendem a ser de menor tonelagem. O Cinturão Norte apresenta depósitos de classe mundial (Aguas Tenidas e Magdalena) e outros depósitos de porte menor (Concepcion, San Miguel, Lomeros Poyatos e San Telmo), ao passo que a Setor Central apresenta os depósitos gigantes de La Zarza e Rio Tinto (Sánchez-España et al., 2000; Tornos, 2006; Conde, 2016; Conde \& Tornos, 2019).

Os corpos de VMS da Região Norte do FPI ocorrem associados a complexos de domos e criptodomos félsicos (Sáez et al., 1996; Tornos, 2006; Rosa et al., 2011; Conde, 2016; Conde e Tornos, 2019). As rochas encaixantes são predominantemente rochas piroclásticas, com lavas félsicas e brechas associadas que são interpretadas, no contexto da FPI, como produtos de um vulcanismo explosivo em um ambiente marinho raso.

Pouco é realmente conhecido sobre a estratigrafia dessa região devido a mudanças de fácies laterais e verticais abruptas ao longo de toda sequência, ao intenso grau de deformação, 
com contatos tectônicos entre as unidades, e ao intenso processo de alteração hidrotermal associado as mineralizações que mascaram as feições iniciais (Conde, 2016; Conde \& Tornos, 2019). Os corpos de minérios da região geralmente são tabulares a lenticulares, com associação mineral normalmente composta predominantemente por pirita e esfalerita, com calcopirita e galena em menores proporções. Em alguns depósitos (Aguas Tenidas, San Miguel e Concepcion) uma zona de stockwork enriquecida em $\mathrm{Cu}$ com intensa alteração hidrotermal associada são observadas abaixo dos sulfetos maciços. A base dos corpos de minério tabulares acima dos stockworks também é enriquecida em $\mathrm{Cu}$, enquanto que as zonas superiores são enriquecidas em Zn, Pb, Ag e Au (Sánchez-Espana et al., 2000; Conde, 2016; Tabela 1). Atualmente apenas os depósitos de Aguas Tenidas, Magdalena e Rio Tinto estão sendo explorados na região e a maioria dos depósitos já está exaurida (Conde, 2016; Conde $\&$ Tornos, 2019).

Tabela 1. Tonelagem total estimada para depósitos da Região Norte da FPI, considerando as reservas já explotadas e as que ainda não foram explotadas (Conde, 2016).

\begin{tabular}{|c|c|c|c|c|c|c|c|}
\hline Deposit & Mt & $\% \mathrm{Cu}$ & $\% \mathrm{~Pb}$ & $\% \mathrm{Zn}$ & $\mathrm{Ag} g / \mathrm{t}$ & Au $g / t$ & Reference \\
\hline Old Aguas Teñidas ${ }^{1}$ & 0.42 & 5.66 & & & & & Pinedo (1963) \\
\hline \multicolumn{8}{|l|}{ Aguas Teñidas Mine ${ }^{1}$} \\
\hline cupriferous & 9.43 & 2.40 & 0.20 & 0.90 & 28.30 & 0.40 & Iberian Minerals Corp \\
\hline pollymetalic & 10.12 & 1.10 & 2.50 & 8.20 & 77.80 & 0.90 & (2009) \\
\hline stockwork & 1.36 & 2.25 & 0.06 & 0.25 & 7.1 & 0.06 & \\
\hline Carpio & 3.35 & 0.50 & 0.12 & 2.77 & & & Leistel et al. (1998) \\
\hline Concepción & 55.85 & 0.57 & 0.19 & 0.48 & 6.68 & 0.21 & Leistel et al. (1998) \\
\hline Cueva de la Mora & 4.2 & 1.45 & 0.26 & 0.73 & & & Pinedo (1963) \\
\hline La Zarza & 171.6 & 1.24 & 1.09 & 2.49 & 45 & 1.79 & Tornos (2006) \\
\hline Lomero Poyatos & 15.45 & 1.35 & 1.12 & 3.76 & 83.48 & 3.25 & Tornos (2006) \\
\hline Monte Romero & 0.8 & 2.0 & 2.5 & 5.0 & & & IGME (1982) \\
\hline Río Tinto ${ }^{2}$ & 707.2 & 0.39 & 0.12 & 0.34 & 22 & 0.36 & Tornos (2006) \\
\hline San Platón & 2.5 & 1.5 & 0.2 & 5.6 & 31 & 0.9 & Tornos (2006) \\
\hline San Miguel & 1.3 & 3.0 & & & & & Pinedo (1963) \\
\hline San Telmo & 4 & 1.2 & 0.4 & 12 & 60 & 0.8 & IGME (1982) \\
\hline
\end{tabular}

\section{Cinturão Norte da Região Norte da FPI}

Na região do Cinturão Norte o Complexo VS é dominado por rochas magmáticas félsicas, predominantemente andesitos, riolitos, riodacitos e dacitos. Os sulfetos maciços são associados as rochas vulcanoclásticas, domos e criptodomos de composição dacítica a 
riolítica. Com base em trabalhos de campo e testemunhos de sondagem a coluna estratigráfica representativa deste cinturão foi estabelecida (Conde, 2016; Conde \& Tornos, 2019; Figura 13).

Nesta região, mais de $95 \%$ do Complexo VS é composto por rochas vulcânicas, enquanto que os folhelhos são menos de 5\% (Conde, 2016; Conde \& Tornos, 2019). Estas rochas vulcânicas são predominantemente félsicas, com quantidade considerável de rochas de composição intermediárias e rochas máficas escassas. As fácies vulcânicas são variadas e incluem: a) fácies coerentes, como domos, criptodomos e sills, b) fácies porosas, como brechas autoclásticas nas margens e no topo destes domos e c) fácies vulcanoclásticas relacionadas a resedimentação das fácies autoclásticas, com rochas piroclásticas associadas e vidros vulcânicos e d) fácies epiclásticas como brechas, arenitos e folhelhos, produtos da resedimentação das rochas vulcânicas primárias (Conde, 2016; Conde \& Tornos, 2019; Figura 14).

As rochas do Complexo VS foram descritas na mina de Aguas Tenidas por Bobrowicz (1995) e posteriormente Conde (2016) e Conde \& Tornos (2019) mapearam o Complexo VS na região dos depósitos de San Telmo, Lomeros Poyatos e Aguas Tenidas. O mapeamento e dados geoquímicos levaram Conde \& Tornos (2019) a dividirem o Complexo VS em 6 unidades, da base para o topo:

Unidade Félsica Inferior (Lower Felsic Unit - LFU) - é a base da sequência, com 200 a 400m de espessura. Esta unidade é composta por complexo de domos e criptodomos riolíticos e dacíticos, com pequena quantidade de sills e diques porfiríticos de riodacito e riolitos. A LFU também é rica em rochas hialoclasticas e vulcanoclásticas ricas em púmice e vidro vulcânico. Unidade Vulcano Sedimentar (Volcano-Sedimentary Unit - VSU) - unidade de até 300m de espessura composta por derrames basálticos, rochas vulcanoclásticas máficas e sedimentos epiclásticos máficos. Estas rochas são intercaladas por finas camadas de folhelhos. A porção basal desta unidade apresenta deformação intensa e é composto por milonitos.

Unidade Félsica Intermediária (Midler Félsica Unit - MFU) - é uma unidade heterogênea com espessura entre 250 e 300m composta por rochas vulcanoclásticas félsicas intercaladas com brechas polimíticas e monomíticas de composição félsica, folhelhos e arenitos vulcanoclásticos. Sills félsicos são comuns e intrusões máficas são raras. 
Unidade Sedimentar (Sedimentary Unit - SU) - Sequência intensamente deformada com espessura de até $150 \mathrm{~m}$, composta por folhelhos finos intercalados com arenitos epiclásticos. Esta unidade apresenta textura milonítica ubíqua ao longo de toda sua extensão, o que sugere que esta unidade pode ser uma mélange entre duas outras unidades.

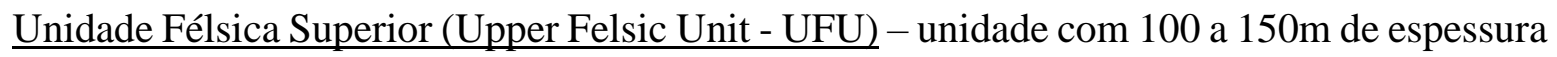
composta por brechas epiclásticas e arenitos intrudidos por sills dacíticos. Alguns domos félsicos também ocorrem associados com brechas ricas em púmice. A UFU e a LFU apresentam assinaturas semelhantes de $\mathrm{Zr}$, com conteúdo abaixo de 200ppm, valores significativamente inferiores ao conteúdo de 200 a 750ppm obtidos na HFU. A partir desta assinatura geoquímica e das semelhanças litológicas entre as unidades Conde (2016) e Conde \& Tornos (2019) propõe que a UFU e a LFU provavelmente são partes desmembradas de um mesmo complexo vulcânico, enquanto que a unidade HFU representa um pulso diferente de magma derivado da mesma fonte profunda.

Unidade Andesítica (Andesite Unit - AU) - rochas intermediárias marcam o topo da sequência do Complexo VS na região. Elas formam uma unidade de 100 a 200m de espessura composta por andesitos maciços e brechas andesíticas intercalados com sedimentos epiclásticos de mesma composição. Essa é a única região de toda a FPI em que rochas básicas são abundantes, o que implica em maior interação manto-crosta na geração das rochas do Complexo VS nesta região em relação as outras regiões da FPI (Tornos, comunicação oral)

Os depósitos mais significativos da região são os depósitos de San Telmo, Lomero Poyatos, Magdalena e Aguas Tenidas e todos os depósitos da região são formados através da substituição abaixo da superficie oceânica de litotipos reativos presentes nas unidades félsicas da região (Conde \& Tornos, 2019). 

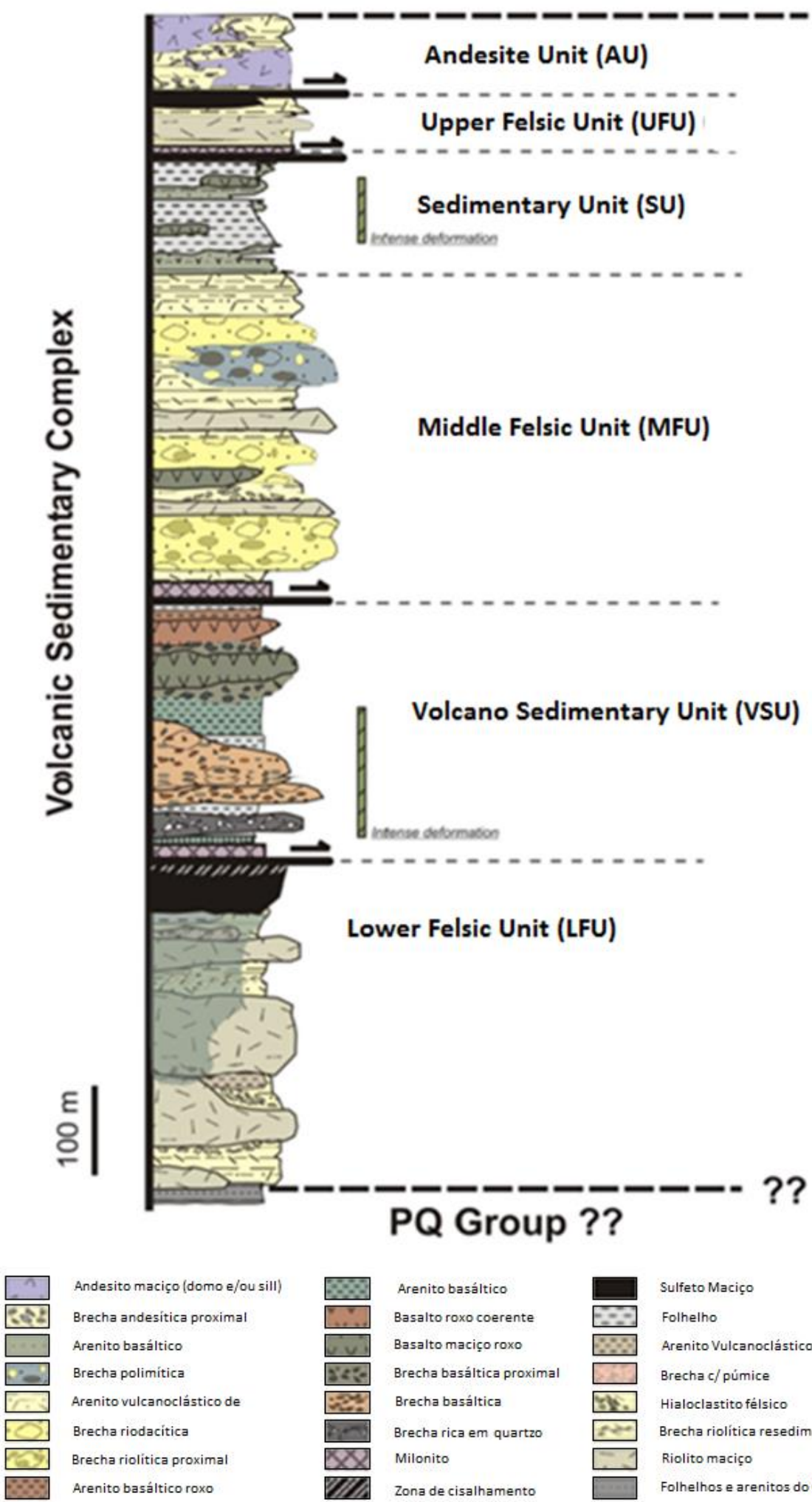

Arenito basáltico Basalto roxo coerente Basalto maciço roxo Brecha basáltica proximal

Brecha basáltica Brecha rica em quartzo Milonito

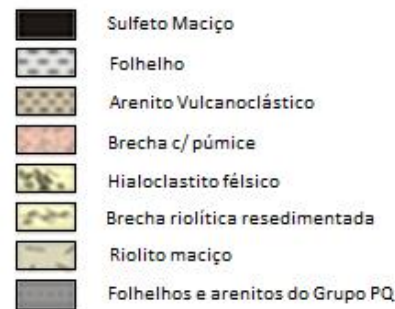

Figura 13. Coluna estratigráfica proposta por Conde (2016) e Conde \& Tornos (2019) para a região do Cinturão Norte da FPI. 
A região estudada por Conde (2016) e Conde \& Tornos (2019) não inclui os depósitos de Concepcion, San Platon e San Miguel e estes depósitos são pouco estudados na literatura. Os corpos de Concepcion e San Platon também são relacionados a substituição e possuem como rocha encaixante rochas vulcanoclásticas hidrotermalmente alteradas, com poucos folhelhos e diques basálticos associados (Tornos, 2003).

A região é intensamente afetada por tectonismo que frequentemente mascara as relações estratigráficas originais. Esta atividade tectônica é acompanhada de remobilização dos metais nas proximidades das zonas de cisalhamento e consequente alguns dos depósitos do Cinturão Norte apresentam enriquecimento em $\mathrm{Cu}, \mathrm{Zn}, \mathrm{Pb}$ e $\mathrm{Au}$ (Tornos et al., 2005), como é o caso de Aguas Tenidas Este, Lomero Poyatos ou Concepcion (Velasco et al., 2000; Tornos, 2006).

A LFU aparece em porções distintas de colunas estratigráficas dos diferentes depósitos mapeados por Conde (2016) devido ao tectonismo. Relações de contato observadas, dados de geoquímica e análise estrutural executada por Conde (2016) sugerem que a sequência vulcânica está invertida. Dados litogeoquímicos mostram que as rochas provavelmente representam a formação em locais diferentes de um mesmo magma contemporâneo (Conde, 2016; Conde \& Tornos, 2019). Existem poucos dados geocronológicos nas rochas do Cinturão Norte, mas os dados existem aparentam confirmar esta hipótese pelo menos em escala de depósito, o que Valenzuela et al. (2011) mostrou ao estudar rochas das unidades félsicas do depósito de Rio Tinto e região do Rio Odiel. O mapa geológico do Cinturão Norte é apresentado na Figura 15. 


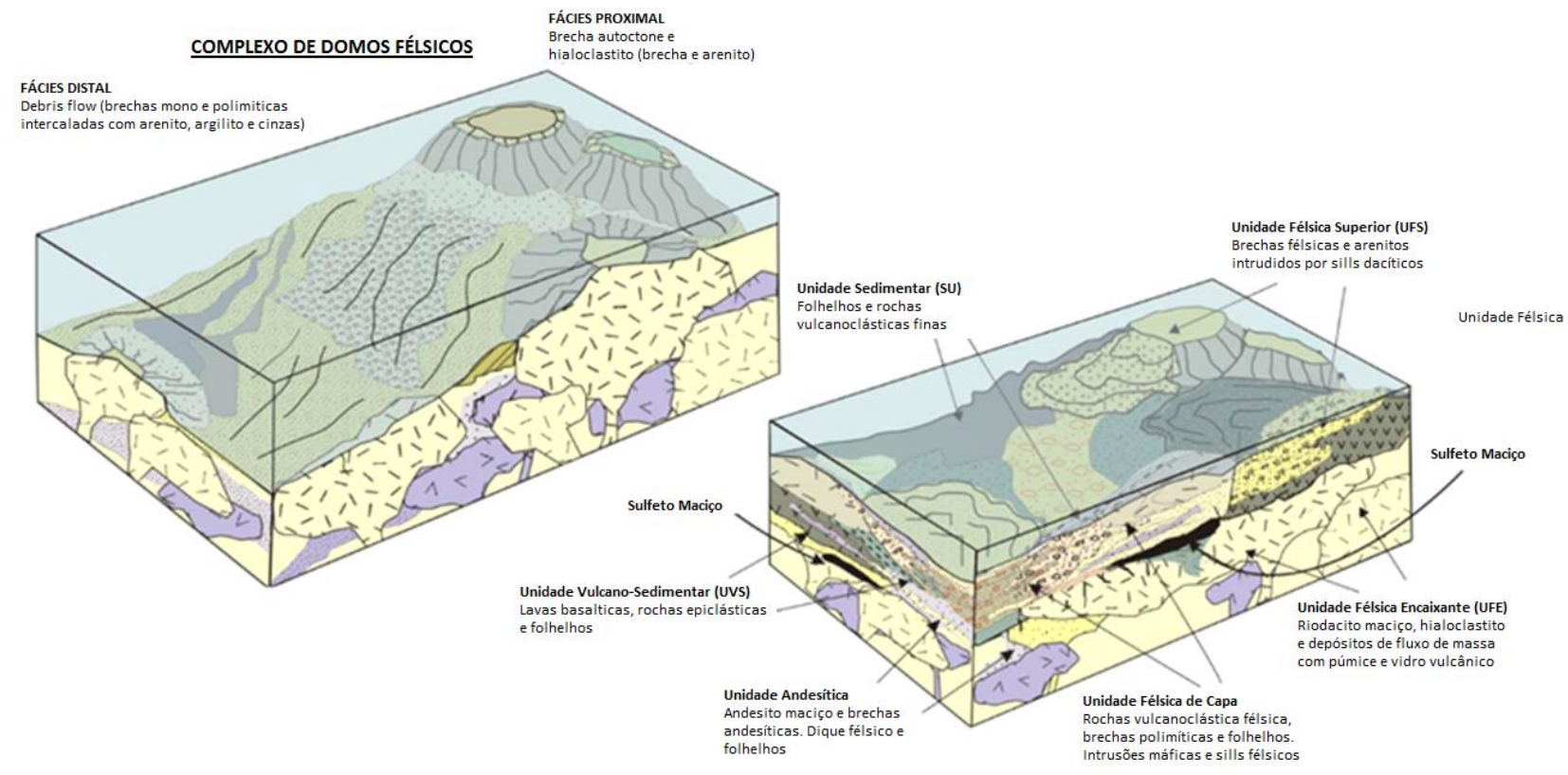

Figura 14. Ilustração de um complexo de domos félsicos com desenvolvimento de depósitos VMS associados (Conde, 2016).

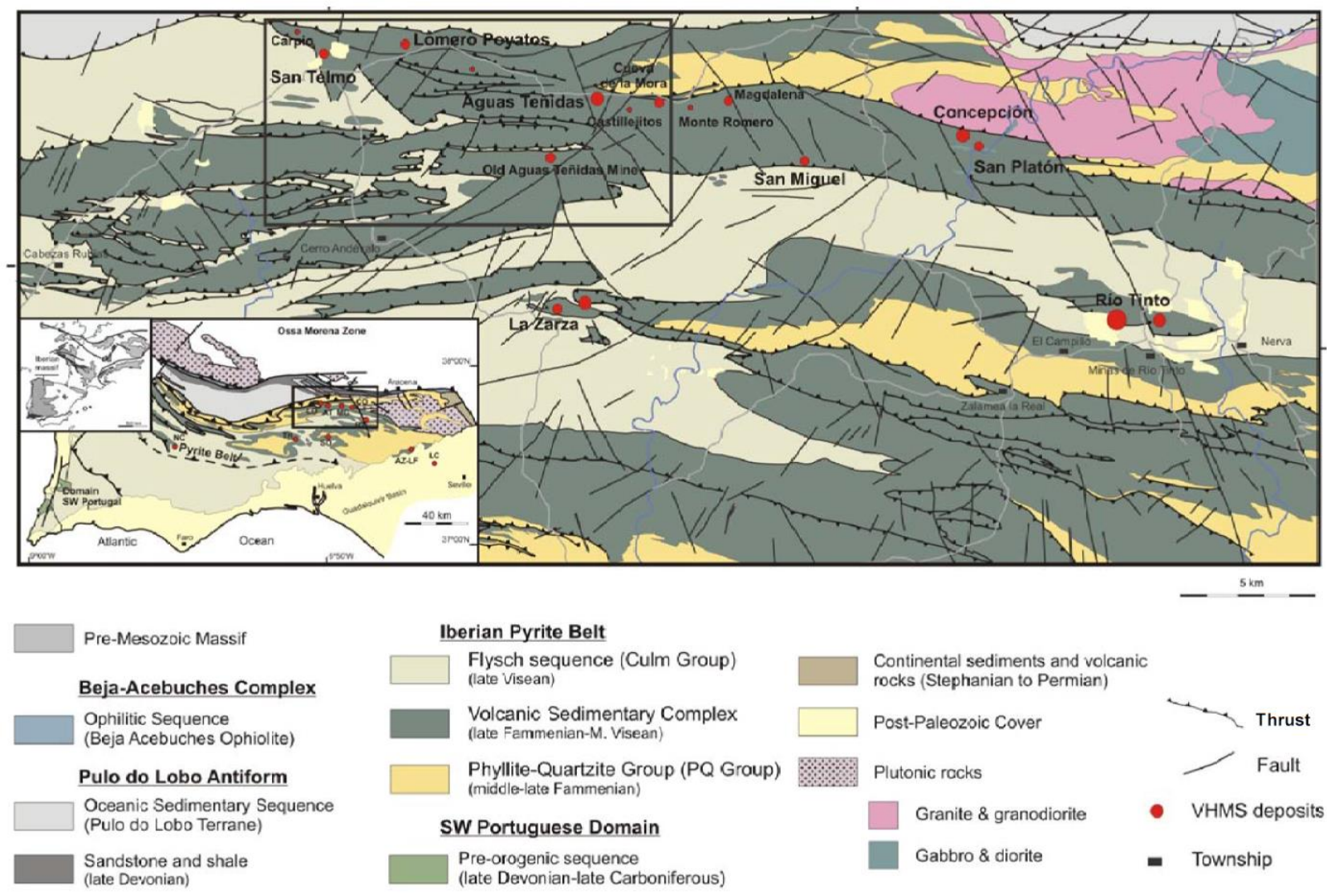

Figura 15. Mapa geológico da Região Norte da FPI com a localização dos depósitos VMS da região

(Conde, 2016). 
Setor Central da Região Norte da FPI

O Setor Central da Região Norte da FPI é composto por dois depósitos de VMS gigantes: La Zarza e Rio Tinto. Diferentemente que os outros setores da Região Norte da FPI, aqui os depósitos não ocorrem em cinturões e sim isolados geograficamente.

\section{$\underline{\text { Rio Tinto }}$}

O depósito de Rio Tinto é o maior e mais conhecido depósito da FPI e possivelmente é a maior concentração de sulfeto maciço do mundo (Tornos 2006). A quantidade total de minério extraída de Rio Tinto é desconhecida, mas compilações tanto científicas (Pinedo, 1963 apud Conde, 2016) quanto das companhias exploradoras indicam que até 2001 aproximadamente $241 \mathrm{Mt}$ foram extraídas, sendo que mais de $50 \%$ na última metade do século XX. A mais recente reavaliação feita pela companhia EMED-Tartessys relevou reservas de $123 \mathrm{Mt}$ com teor de $\mathrm{Cu}$ de $0.46 \%$ (www.emed-tartessus.com).

As rochas de Rio Tinto apresentam alteração hidrotermal por vezes intensa, que mascaram suas feições originais. Devido a isso estudos sobre lá também estudam as rochas de duas localidades distintas, denominadas Rio Odiel e Zarandas, onde a mesma sequência vulcânica aflora sem a presença do hidrotermalismo. Com a utilização destes dados adicionais a interpretação da evolução geológica do Distrito de Rio Tinto é descrita como uma região estruturalmente complexa, similar a outras áreas do FPI (Tornos et al., 1999) com extensão inicial e posterior compressão desenvolvendo um cinturão de dobramentos pouco espessos (González Clavijo \& Diez Montes, 2010). Os sulfetos presentes em Rio Tino são tanto exalativos, relacionados a folhelhos, quanto de substituição, relacionados a domos félsicos, o que o torna distinto dos demais depósitos da FPI (Tornos, 2006). O mapa geológico feito por Conde (2016) pode ser observado na Figura 16.

A rocha encaixante destes sulfetos maciços é composta por um espesso pacote vulcanossedimentar, similar ao Complexo VS em outras regiões do FPI (Tornos, 2006, Conde, 2016). Em geral, as rochas vulcânicas de Rio Tinto têm sido consideradas lavas extrusivas e fluxos piroclásticos (Rambaud, 1969; Lecolle, 1977; García Palomero, 1980, 1992 apud Conde, 2016). Boulter (1993), por outro lado, propõe que os hialoclastitos da localidade sugeririam que na localidade o Complexo VS é composto por um sill encaixado em sedimentos rasos. A interpretação mais recente a respeito das unidades encaixantes aos sulfetos maciços indica que estas, são na realidade um conjunto de domos félsicos de 
composições dacíticas e riolíticas superimpostos (Tornos, 2006; Valenzuela et al., 2011; Conde, 2016).

O Complexo VS apresenta espessura de até 1000m na região e uma estratigrafia simples que é complicada pela presença de diversos empurrões e falhas tectônicas, além de um processo de alteração hidrotermal pervasiva. A estratigrafia básica do Complexo VS foi estabelecida por Conde (2016) na região a partir de extensor mapeamento e é composta por:

Unidade Máfica Siliciclástica possui espessura de até $450 \mathrm{~m}$ e é constituída por uma intercalação de folhelho, siltito e basalto, sendo que a base da unidade é dominada pelos basaltos. Esta unidade é cronologicamente equivalente aos folhelhos que abrigam os sulfetos maciços da parte sul da FPI (Matos et al., 2011), mas aqui esta unidade é estéril e não apresenta alteração hidrotermal que sugeriria a ocorrência de algum processo exalativo e/ou de substituição (Conde, 2016).

Unidade Sedimentar Inferior ocorre logo acima da Unidade Máfica-Siliciclásticas, é composta por folhelhos negros, siltitos e grauvacas com características conglomeráticas na parte superior da sequência. Os clastos vulcânicos provavelmente derivam dos corpos vulcânicos marginais a estas bacias de $3^{\mathrm{a}}$ ordem onde estes conglomerados se formaram (Conde, 2016).

Unidade Félsica, composta por uma sequência de domos e criptodomos (dacitos e riodacitos) intercaladas com escassos folhelhos, e espessura variável entre 10 a 500m. Esta é a unidade predominante em Rio Tinto, mas suas feições se encontram intensamente alteradas por um processo de alteração hidrotermal e deformação tectônica. A base desta unidade é composta por grandes fluxos de massas com fragmentos de púmice e riodacito maciço, ambos intrudidos por sills de mesma composição geoquímica (Valenzuela et al., 2011; Conde, 2016).

Estas rochas incluem várias lentes de sulfetos maciços, sempre associados a rochas intensamente alteradas que correspondem aos membros mais ricos em vidro vulcânico da Unidade Félsica, possivelmente hialoclastitos que ocorrem acima dos domos félsicos (por exemplo em Filón Norte, uma das áreas explotadas no distrito de Rio Tinto). Assim como em outros depósitos da FPI, estas rochas félsicas ocorrem subjacentes aos corpos de sulfeto 
maciço. Os sulfetos maciços apresentam granulação grossa e sempre apresentam contatos irregulares característicos da substituição com as rochas vulcânicas encaixantes (Conde, 2016). Encaixado nas rochas vulcânicas da Unidade Félsica também está encaixado o stockwork.

Os corpos de sulfetos maciços estão relacionados a diferentes litotipos da coluna estratigráfica e que afloram em diferentes locais. Existem sulfetos maciços associados a precipitação exalativa em Filón Sur, nos corpos de sulfetos maciços de San Dionísio, Salomón e Lago. Também existem corpos de minério associados ao stockwork de Cerro Colorado e sulfetos de sub-seafloor replacement como é o caso dos sulfetos maciços de Filón Norte, San Antonio e Quebradahuesos (Conde, 2016).

Localmente (na cava de Atalaya e em Filón Sur), a Unidade Félsica ocorre tectonicamente abaixo de uma segunda sequência sedimentar conhecida como Sequência

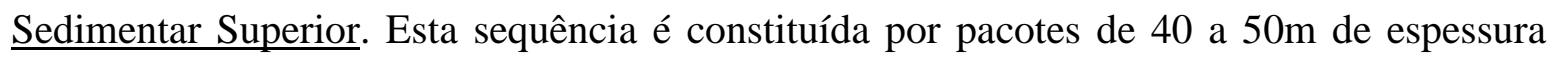
compostos por folhelhos verdes com esporádicas intercalações com arenitos vulcanoclásticas, argilitos e folhelhos negros (Conde, 2016).

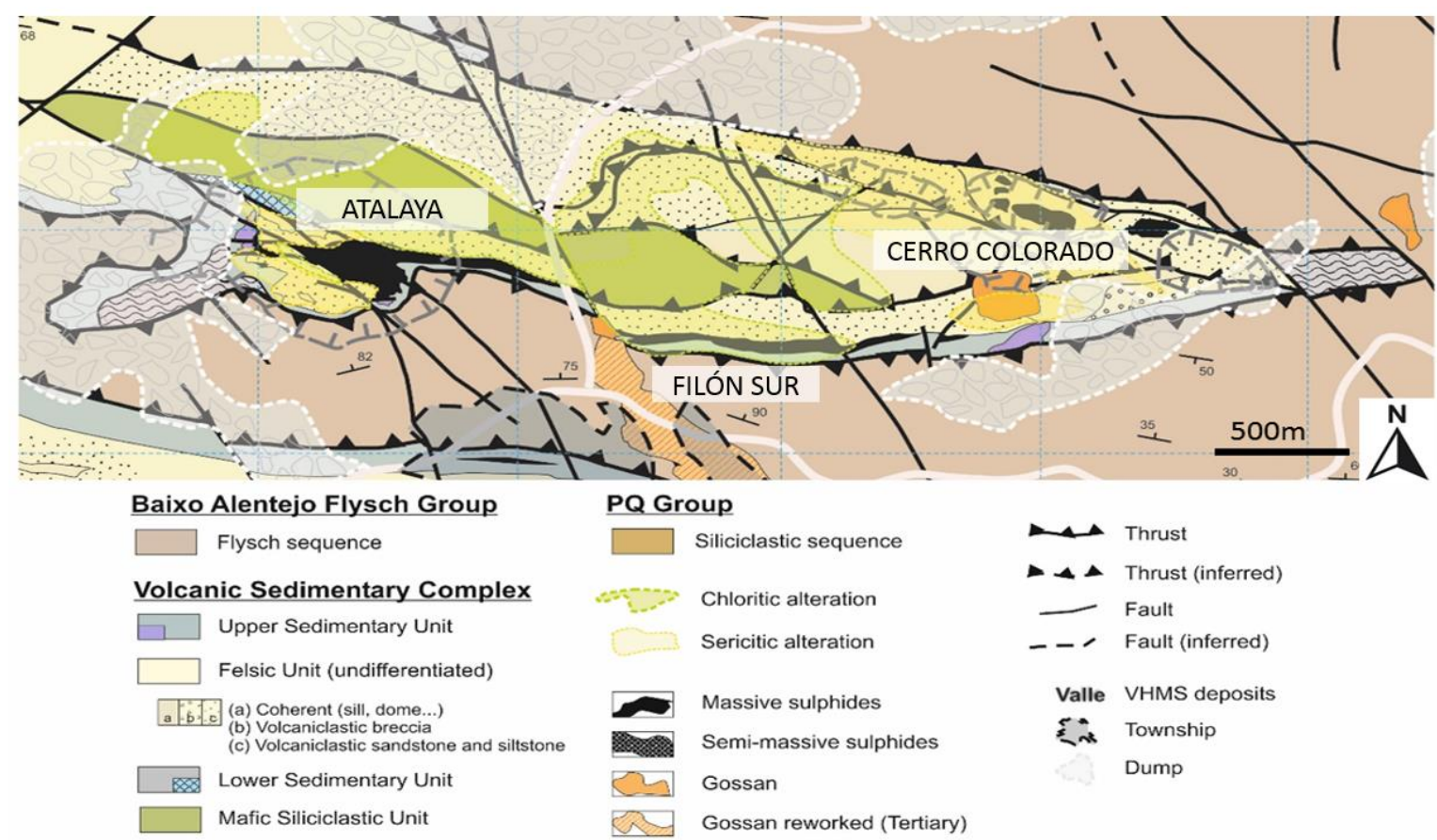

Figura 16. Mapa geológico de Rio Tinto e suas diversas lentes de sulfeto maciço (Conde, 2016.). 


\subsubsection{Região Sul do FPI}

Os processos de gênese dos corpos de sulfeto maciço são diferentes entre a Região Norte e a Região Sul da FPI. Na Região Sul a formação destes depósitos está associada a mineralizações de sulfetos geradas por fluidos hidrotermais exalados em águas anóxicas, incluindo os depósitos gigantes de Aznalcollar-Los Frailes, Sotiel-Migollas, Masa Verde e Tharsis na Espanha e Neves Corvo e Aljustrel em Portugal, além dos depósitos de classe mundial de Las Cruces, na Espanha, e Lousal, La Romana e São Domingos em Portugal. Estes depósitos do Sul representam a maioria dos depósitos gigantes (>100 Mt) da FPI (Tornos, 2006). As mineralizações ocorrem distantes entre si, sem relação óbvia com algum eixo vulcânico como ocorre na Região Norte.

As idades palinológicas obtidas nesta região (Matos et al., 2011) mostram uniformidade temporal na gênese dessas bacias anóxicas e, consequentemente, uma uniformidade temporal na formação destes depósitos. Os dados geocronológicos (U-Pb em zircão) obtidos em diversos depósitos também indicam idades 365 - $355 \mathrm{Ma}$, com maior concentração de idades por volta de 360 Ma (Barrie et al., 2002; Rosa et al., 2009; Solá, 2015).

Os sulfetos gerados por fluidos hidrotermais exalados em águas anóxicas geram feições predominantemente sedimentares, por vezes estando associados a stockworks que alimentam as exalações de fluidos hidrotermais que se precipitam em ambientes com sedimentação por decantação. O processo de deposição dos sulfetos maciços relacionados aos folhelhos da parte sul da FPI foi discutido extensamente por diversos autores. Almodóvar et al., (1998) e Sáez et al. (1999) propõem que estes sulfetos maciços foram formados por substituição dos argilitos e folhelhos enquanto que Barriga \& Fyfe (1997) também acreditam em uma origem subsuperficie, mas relacionada a acumulação abaixo de uma camada impermeável de chert. Outros autores consideram que os sulfetos estão relacionados a exalações no leito oceânico (Solomon et al., 2002; Boulter, 1993) ou ainda a combinação dos dois processos (Relvas, 2000). Tornos et al. (1997), por sua vez, propõe que os sulfetos foram precipitados em uma bacia restrita em condições anóxicas e Tornos (2006) estendem este conceito para os outros depósitos associados à folhelhos na FPI. As inclusões fluidas estudadas por Solomon et al. (2002) mostram que o fluido exalado pelos stockworks são mais densos e não seriam misturados na agua marinha, mas sim se concentrariam no fundo, 
especialmente com a existência de bacias restritas, como é descrito na FPI (Tornos et al., 1997; Tornos et al., 2008).

Nos depósitos da Região Sul ocorrem altas concentrações de pirita e baixas concentrações de metais base $(\mathrm{Cu}, \mathrm{Pb}$ e $\mathrm{Zn})$, quando comparados aos depósitos da Região Norte. A exceção é o depósito de Neves Corvo, em Portugal, que possui alto teor de Cu e Sn (Tornos 2006).

Os depósitos da Região Sul da FPI diferem dos depósitos tipo Kuroko clássico pois possuem tamanho maior, morfologia estratiforme, abundancia de pirita framboidal e granulação muito fina predominante (Solomon et al., 2004). Tornos et al. (2008) propôs o modelo para a precipitação dos sulfetos em bacia restrita gerando o distrito de Tharsis (Figura 17; 18 e 19), modelo que depois foi expandido regionalmente para diversos outros depósitos da região sul da FPI por Tornos (2006). O modelo consiste em três estágios distintos. São eles: a) estágio inicial, b) estágio principal e c) estágio tardio.

Estágio Inicial - O estágio inicial do modelo de precipitação em bacias restritas anóxicas mostra a exalação inicial precipitando uma associação mineral composta por pirita \pm marcassita \pm óxido de $\mathrm{Fe} \pm$ sulfatos em resposta a interação com a água marinha oxidante presente no ambiente (Tornos et al., 2008, Figura 17).

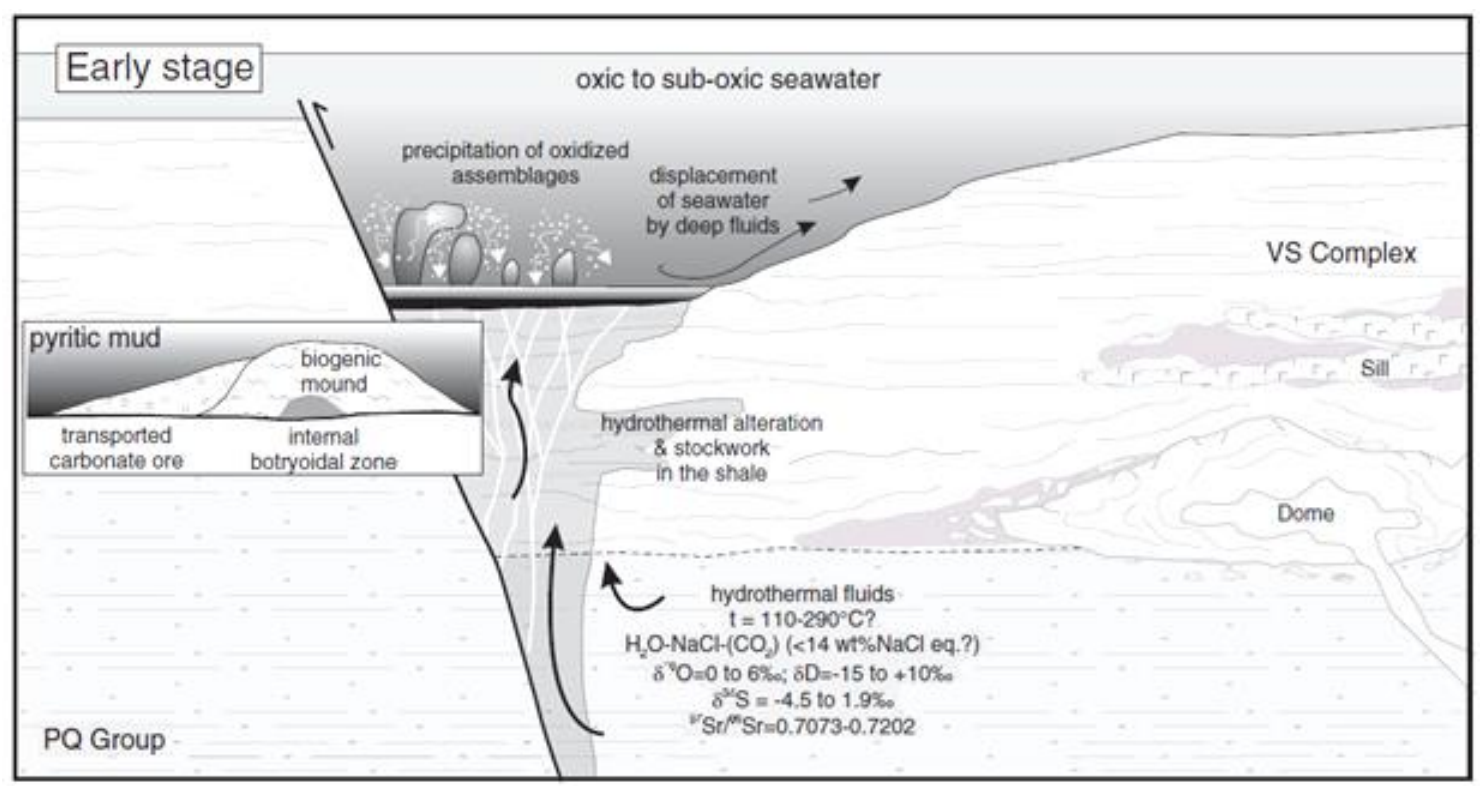

Figura 17. Estágio inicial da formação de um depósito de sulfeto maciço em bacia anóxica (Tornos et al., 2008) 
Estágio Principal - A exalação contínua gradualmente enche a bacia restrita com o fluido resultante da mistura de água oceânica com fluidos hidrotermais. Com o passar do tempo a composição do fluido se torna cada vez mais próximo do fluido hidrotermal, uma vez que os líquidos exalados são mais densos e vão gradativamente expulsando a água oceânica da bacia. Os fluidos exalados são ricos em metais, mas pobres em enxofre, pois eles perdem todo são conteúdo de $\mathrm{H}_{2} \mathrm{~S}$ a partir da precipitação de sulfetos abaixo da superfície oceânica. Uma porção significativa do sulfeto reduzido precipitado em Tharsis tem origem biogênica. Neste modelo de gênese o fator limitante é o suprimento de enxofre reduzido que a bacia possui, uma vez que os grandes depósitos minerais da FPI são grandes concentrações de sulfetos (Tornos et al., 2008). Os sulfetos maciços formados apresentam fácies sedimentares características, como brechamento sedimentar ou bandamento composicional, e também substituem folhelhos se tornando sulfetos maciços e semi maciços (Figura 18).

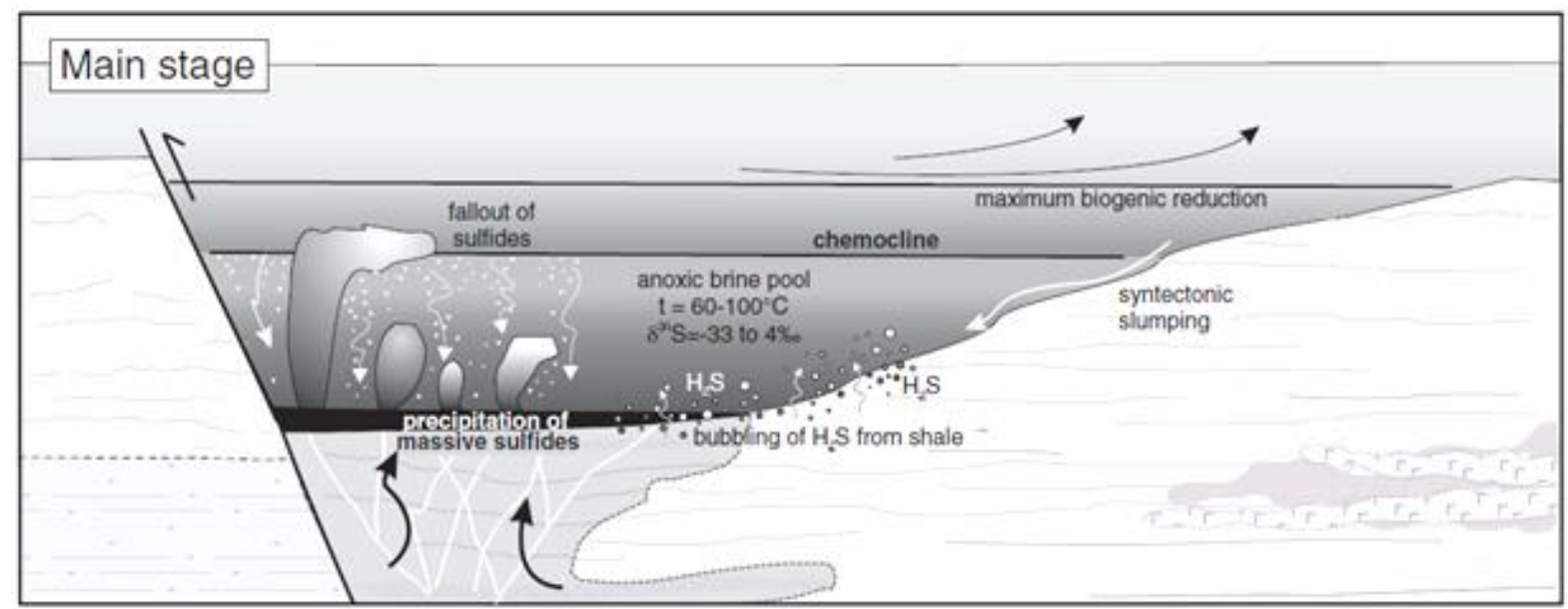

Figura 18. Estágio principal da precipitação de um corpo de sulfeto maciço exalativo, onde os fluidos oceânicos (menos densos) já foram expulsos da bacia pelos fluidos hidrotermais exalados (mais densos)

(Tornos et al., 2008).

Estágio Tardio - Quando a exalação e subsequente precipitação de sulfetos cessa volta a ocorrer a sedimentação de folhelhos na bacia. Estes folhelhos inicialmente apresentam características anóxicas, mas gradualmente se tornam folhelhos de ambientes oxidantes. Este folhelho de ambiente anóxico depositado acima dos corpos de sulfeto maciço são os responsáveis pelo selamento e preservação dos depósitos (Tornos et al., 2008; Figura 19). 


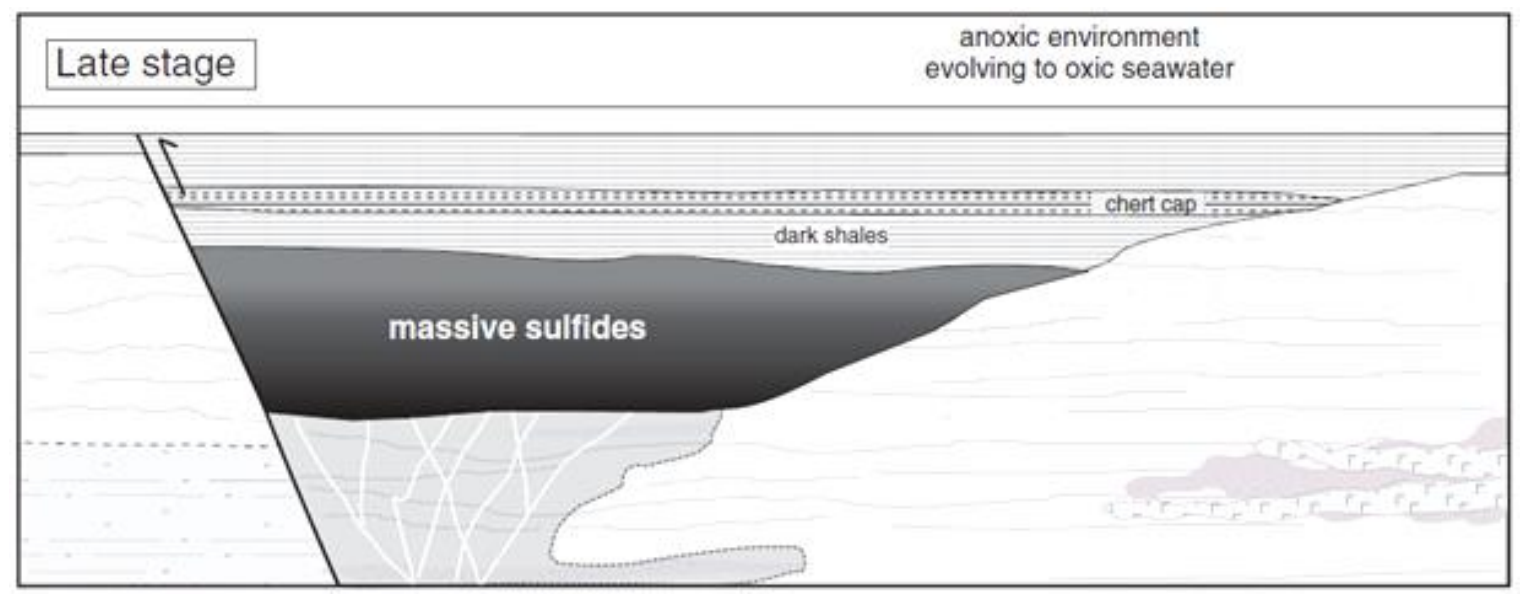

Figura 19. Estágio tardio onde os sulfetos já foram precipitados e cobertos por folhelhos assim que a atividade hidrotermal cessou (Tornos et al., 2008).

Na Região Sul da FPI os folhelhos associados aos horizontes mineralizados contem biomarcadores que indicam uma importante atividade biogênica, em contraste com as assinaturas de rochas relacionadas a bacias oxidantes a sub oxidantes que apresentam poucos biomarcadores (Menor-Salván et al., 2010). O que implica que as mineralizações desta região não estão somente associadas com o vulcanismo sincrônico, mas também são controladas pelo aporte de matéria orgânica continental. Menor-Salván et al. (2010) propõe que a formação dos VMS está relacionada a diversos processos geológicos e biológicos atuando em conjunto:

1) colisão continental que leva a geração das bacias de $3^{a}$ ordem e ao vulcanismo do Complexo VS.

2) degradação dos ecossistemas costeiros devido a combinação de diversos fatores (mudanças climáticas, vulcanismo, variações no nível do mar e erosão em escala regional)

3) destruição significativa da biomassa continental e aumento do aporte de matéria orgânica no ambiente marinho.

4) condições anóxicas que resultam em grande sucesso para microrganismos redutores de sulfato.

Nestas condições particulares a exalação de um fluido hidrotermal rico em metal e pobre em enxofre se mistura com uma coluna d'água anóxica rica em enxofre nesta região da FPI entre 363 - 359 Ma (Struniano), dando origem aos depósitos de sulfeto maciço da Região 
Sul (Menor-Salván et al., 2010). Estes depósitos foram formados em associação com uma crise paleoclimática que produziu explosão na atividade dos microrganismos relacionada com o aporte significativo de matéria orgânica (árvores, principalmente) continental.

O período da atividade hidrotermal e da destruição desta biomassa coincide com a fronteira entre o Devoniano e o Carbonífero (DC), momento em que ocorreu uma grande extinção em massa. O evento da fronteira DC está relacionado com o desaparecimento de $21 \%$ da biota marinha (Caplan \& Bustin, 1999; Sepkoski, 1996). Menor-Salván et al. (2010) interpreta que o vulcanismo de $\sim 360$ Ma ocorre associado a mudanças climáticas dramáticas em escala regional. O início do extensivo vulcanismo teria sido acompanhado por um aumento do gradiente geotérmico e a formação de grandes nuvens de cinzas vulcânicas, gerando chuvas ácidas e menor incidência solar na região, o que por sua vez geraram a devastação de grandes florestas, ampliando ainda mais a erosão. Este processo produziu uma diminuição acentuada da biomassa continental, a eutrofização do oceano, a formação das bacias anóxicas e consequente redução biogênica do enxofre dissolvido na água do mar (Figura 20). Outra alternativa viável é que mudanças rápidas na topografia das bacias relacionada a colisão oblíqua, com submersão e soerguimento de áreas extensas, levou ao desflorestamento devido a reconfiguração fluvial regional (Menor-Salván et al., 2010). Todos estes processos distintos ocorreram em um espaço restrito de tempo, provavelmente menor que 1 Ma (Menor-Salván et al., 2010; Tornos, 2006). 


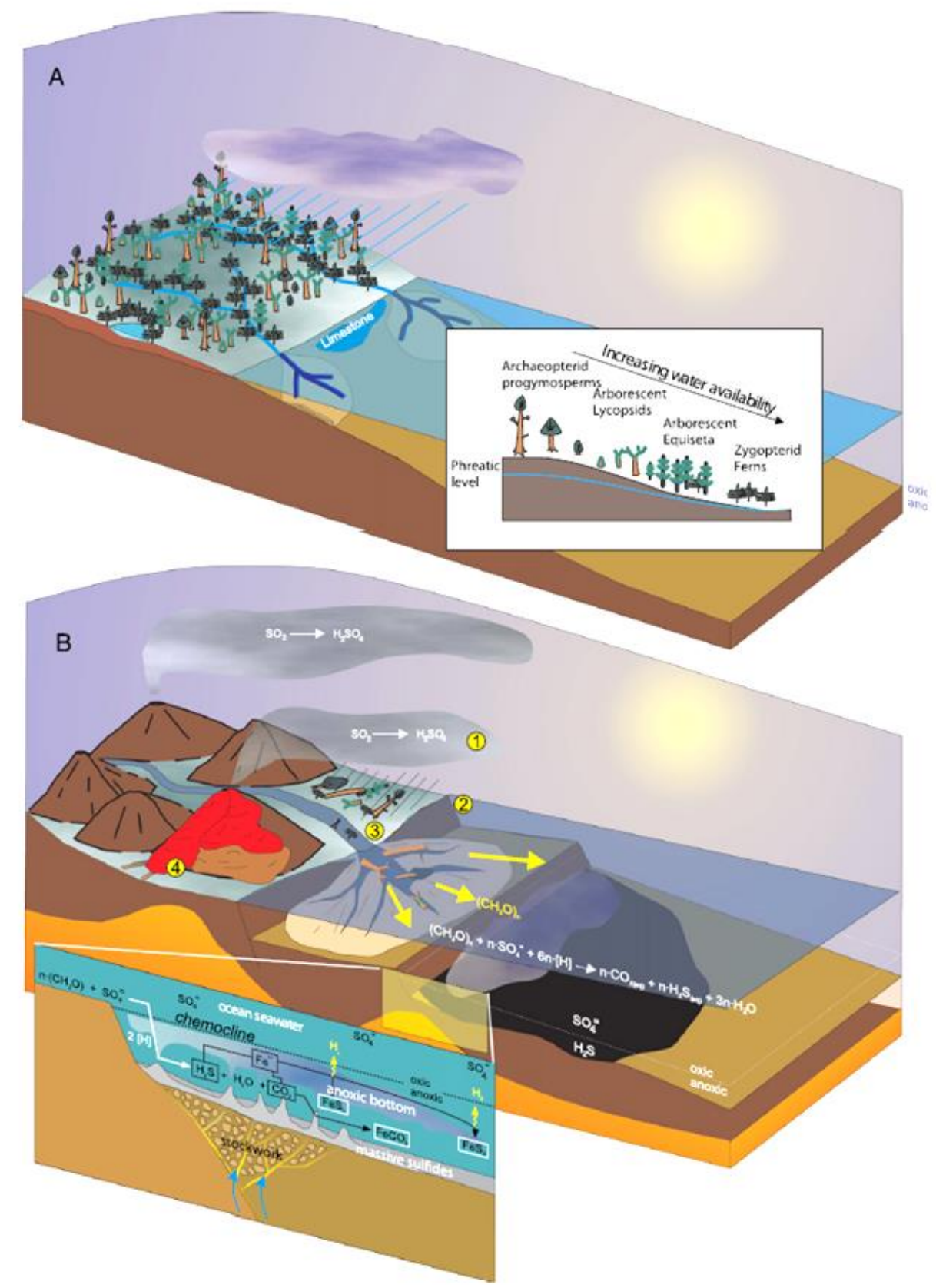

Figura 20. Representação esquemática das mudanças catastróficas associadas à fronteira do DC e a formação dos depósitos da Região Sul da FPI (Menor-Salván et al., 2010).

\section{Rochas Plutônicas na FPI}

O Maciço de Gerena aflora na vila de Gerana, localizada a $5 \mathrm{~km}$ do depósito de Las Cruces, e é coberto por materiais neógenos da Bacia de Guadalquivir. Este maciço é um dos poucos corpos plutônicos conhecidos na FPI. Ele é composto por granodioritos e tonalitos que representam a zona de interação entre os magmas félsicos e máficos na região (Rosa, 
1992; Castro et al., 1990; Figura 21). São descritos três tipos principais de rochas neste maciço: 1) tonalitos e quartzo-diorito, 2) biotita-leucogranito e 3) granodioritos híbridos.

Os tonalitos e quartzo-dioritos são diques sin-plutônicos e fragmentos destes diques envoltos no granitoide encaixante. Estas rochas são finas, por vezes porfiríticas, e apresentam essencialmente plagioclásio, hornblenda e quartzo, enquanto que biotita, apatita, albita, titanita e zircão são minerais acessório. As bordas sempre apresentam minerais mais finos, indicando que este tonalito foi intrudido em um magma granítico, sofrendo resfriamento devido a diferença de temperatura entre ambos. Os granodioritos híbridos aparecem como largas bandas homogêneas ou nas proximidades dos diques sin-plutônicos fragmentados. A rocha encaixante félsica é um leucogranito de granulação média com quartzo, k-feldspato e plagioclásio como minerais principais e biotita, allanita, apatita, hornblenda e zircão como acessórios (Rosa, 1992; Castro et al., 1990).

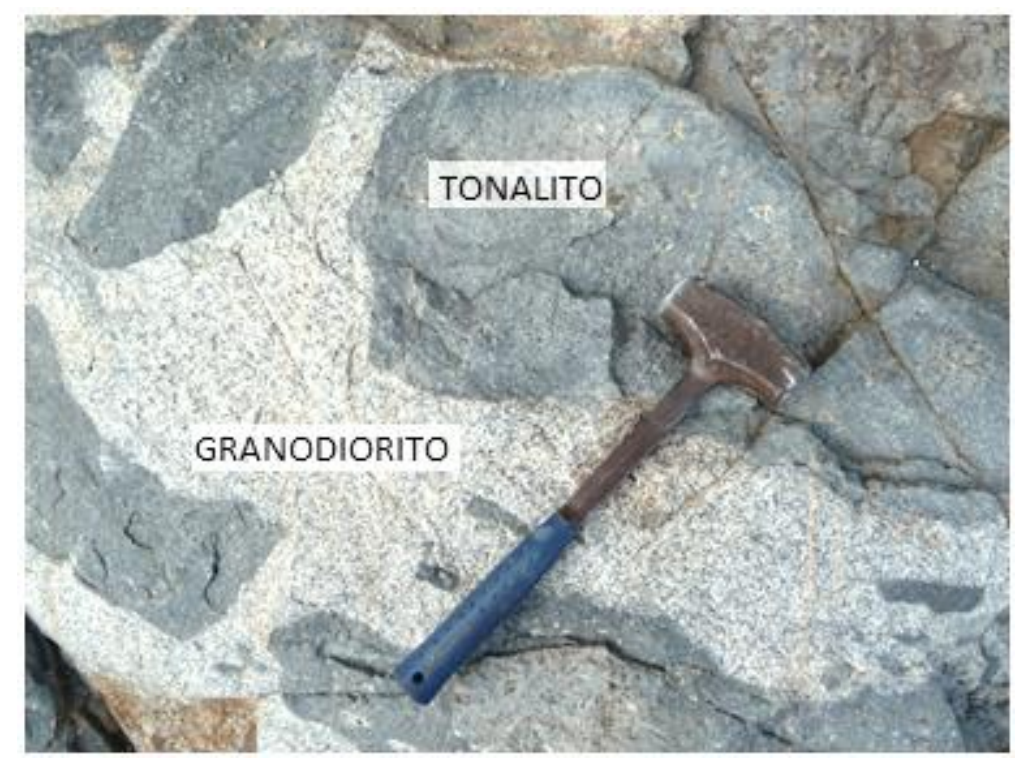

Figura 21. Afloramento do Maciço de Gerena na beira da estrada da vila de Gerena

As relações de campo indicam que o magma máfico intrudiu o magma máfico e a maioria dos diques máficos foi rompida pelo fluxo magmático. Após a cristalização de alta temperatura do magma máfico os dois magmas entraram em equilíbrio térmico, fase em que a ruptura do tonalito em regime de alta energia neste complexo subvulcânico resulta na dispersão de fragmentos do tonalito e de cristais no leucogranito, gerando o granodiorito hibrido. Essa mistura de magmas é o resultado final do processo em que dois magmas distintos interagem física e quimicamente (Figura 22). A diferença de temperatura destes 
magmas é da ordem de $200-400^{\circ} \mathrm{C}$, o que gera as bordas de resfriamento no magma máfico mais quente (Rosa, 1992; Castro et al., 1990).

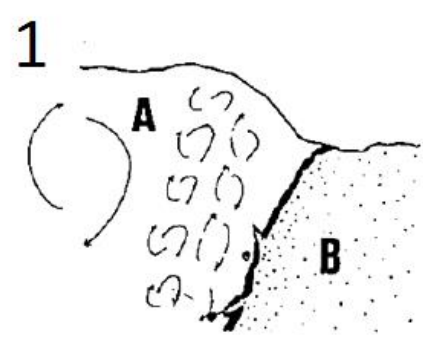

4

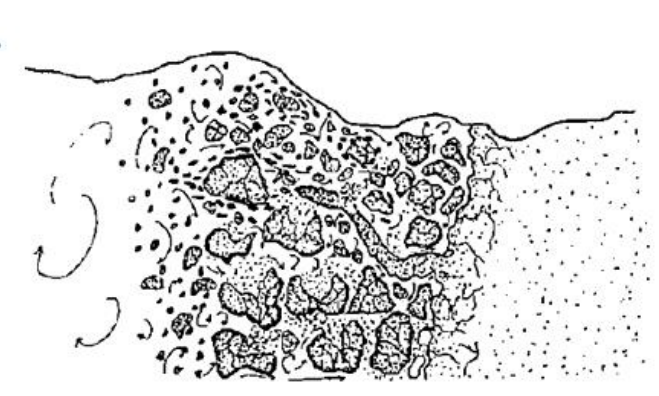

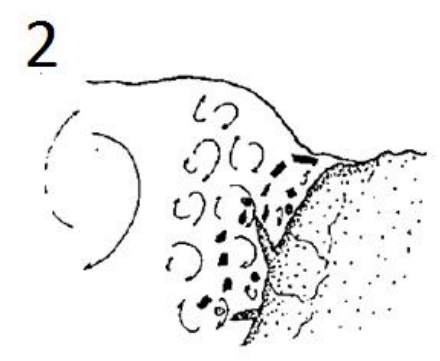
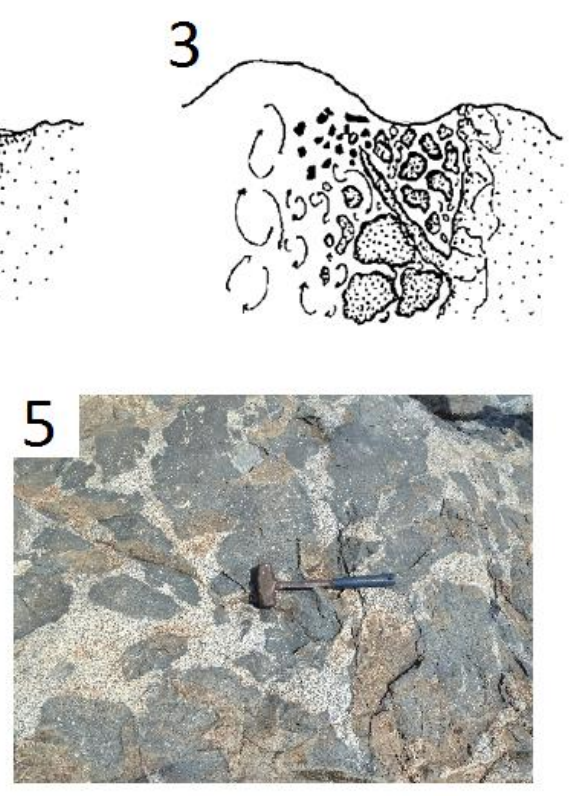

Figura 22. Modelo apresentado por Rosa (1992) para a zona de interação magmática do Maciço de Gerena. 


\subsection{EVOLUÇÃO DA FPI}

As características do magmatismo Variscano na FPI envolveram fusão crustal em baixas pressões, o que requer uma tectônica extensional com alto gradiente térmico (Tornos et al., 2002). O ambiente de formação da FPI é interpretado como uma bacia extensional de antearco induzida pela colisão oblíqua entre as rochas da Zona Ossa Morena (ZOM) e os terrenos autóctones ibéricos no início da orogenia Variscana (Silva et al., 1990, Quesada, 1997). Este contexto tectônico difere significativamente do contexto tectônico descritos em trabalhos sobre o modelo de gênese de corpos de VMS (Piercey, 2011, Huston 2010), o que torna comparação entre a Faixa Piritosa Ibérica e outras províncias mais difícil (Tornos et al., 2002).

O IBERSEIS, um programa de mapeamento geofísico executado na ZSP (Zona Sul Portuguesa, onde a FPI está inserida) e na ZOM (Zona de Ossa Morena, um terreno a norte) indicam diferenças notáveis entre estas duas regiões. A ZOM apresenta uma intrusão máfica de grande proporção no seu embasamento. Já a SPZ não possui evidências de intrusões máficas e os empurrões estão enraizados em um descolamento basal (Simancas et al., 2003). Para Simancas et al. (2003) uma pluma esteve ativa embaixo da ZOM durante o período de 355-335 Ma e está relacionada com todo o magmatismo da ZOM, além de contribuir com o vulcanismo de mesma idade da ZSP.

Orógenos relacionados a subducção e margens ativas são ambientes rico em mineralizações. Nestes ambientes processos tectônicos, magmáticos e hidrotermais relacionados a subducção de uma placa oceânica e a subsequente colisão arco de ilha continente ou continente - continente são responsáveis pela formação de diversos tipos de depósitos (depósitos do tipo pórfiro, depósitos epitermais, skarns e depósitos VMS, por exemplo). Estes processos são conhecidos em diversos cinturões orogênicos (Camus \& Dilles, 2001; Heinrich \& Neubauer, 2002, Huston et al., 2010; Piercey, 2011, Shanks \& Thurston, 2012), e os depósitos estão relacionados a ambientes extensionais que ocorrem localmente dentro de um contexto compressivo mais amplo. No entanto, nem toda margem colisional apresenta o mesmo comportamento e os modelos simplistas de subducção-colisão não dão conta de todos os processos mineralizantes que ocorrem (Onézime et al., 2002).

Os litotipos que compõe a Faixa Piritosa Ibérica estão inseridos em um terreno conhecido como Zona Sul Portuguesa (ZSP), o terreno mais ao sul do Maciço Ibérico. A ZSP 
compõe, juntamente com a ZOM, a porção sudoeste do Cinturão Variscano do Sudoeste Ibérico (SW Iberian Variscan Belt). A ZOM compõe a parte sul do Terreno Autoctone Ibérico e ainda é considerada um terreno peri-gondwânico, que foi acrescido na margem sul do Maciço Central Ibérico, um terreno autóctone, na orogenia Cadomiana (Neoproterozoico Cambriano inferior) (Abalos et al. 1991; Abalos \& Egiuluz, 1992; Ochsner, 1993). O Cinturão Variscano do Sudeste Ibérico é o resultado da amalgamação de terrenos perigondwanicos (ZOM) e da Laurussia (ZSP) ao longo da orogenia Variscana (Devoniano tardio a Viseano tardio) gerando um cinturão de empurrões e cavalgamentos que se propagou para sul por cima de um descolamento crustal (Silva et al., 1990).

O modelo mais aceito atualmente propõe que a ZSP foi subductada na ZOM, com posterior obducção de ofiolitos e colisão continental (Oliveira \& Quesada, 1998; Egiuluz et al. 2000; Onézime et al., 2002, entre outros). Esta subducção é interpretada como o fechamento de parte do Oceano Rheic, que teria ocorrido ao longo do SherpukovianoPensilvaniano, e que coloca as unidades da ZSP em contato com as unidades da Ossa Morena Zone (Tornos et al., 2015a). Dados geológicos, geocronológicos e geofísicos indicam que as mineralizações da ZSP e as mineralizações da ZOM estão associadas a este evento tectônico (Onézime et al., 2002; Tornos et al., 2005).

A zona desta sutura Variscana entre a ZSP e a ZOM é definida pelo Terreno Pulo do Lobo e pelo ofiolito de Beja Acebuches (Silva et al., 1990; Quesada et al., 1994). O Terreno Pulo do Lobo é um terreno oceânico composto por sedimentos de um prisma acrescionário, enquanto que o ofiolito de Beja Acebuches é resultado da obducção parcial de uma bacia préFamenniana (Silva et al., 1990).

A FPI é constituída por uma série de bacias marinhas desenvolvidas por falhamentos sinistrais transcorrentes gerados pela subducção obliqua entre Laurentia e Gondwana ao longo do Variscano (Devoniano Superior- Carbonífero; Silva et al., 1990; Quesada et al., 1991; Leistel et al., 1997; Oliveira \& Quesada, 1998, Matte, 2001). Este cinturão de empurrões e dobramentos com vergência para sul relacionado a deformações em tectônica thin skinned (Silva et al., 1990; Soriano, 1996; Quesada, 1998, Tornos, 2006) gerou as bacias da margem passiva de Laurentia, terreno que hoje é conhecido como Zona Sul Portuguesa (Tornos et al., 2008). Isto ocorre pois os empurrões não são ortogonais a zona de sutura e com isso a resposta tectônica que ocorre na região é a formação de bacias transtensionais de 
$2^{\mathrm{a}}$ e $3^{\mathrm{a}}$ ordem. A geologia e geoquímica das rochas ígneas da FPI são compatíveis com o cenário que envolve afinamento crustal, intrusão generalizada de magmas máficos, underplaing induzindo fusão parcial e rápida ascensão de magmas félsicos superaquecidos até a crosta superior (Mitjavila et al., 1997; Solomon \& Quesada, 2003; Tornos, 2006)

A formação dos depósitos de sulfeto maciço da FPI ocorreu ao longo do Devoniano Superior (mais especificamente no Struniano, uma subdivisão do Fammeniano) e o início do Carbonífero (mais especificamente no Tournaisiano) (Tornos, 2006, Matos et al., 2011). Esses depósitos foram formados em um contexto tectônico que é distinto dos contextos tectônicos relacionados a outros sistemas VMS (ativos ou fósseis) que são associados as bacias de retro-arco geradas pela subducção e ao antearco, além de plumas e dorsais oceânicas (Barrie e Hannington, 1999; Huston et al., 2010; Piercey, 2011, Shanks \& Thurston, 2012).

A partir dos resultados da geofísica, Simancas et al. (2003) reconstruíram a evolução geodinâmica da região da ZSP e ZOM. Esta evolução pode ser compreendida melhor em 4 estágios distintos (Figura 23).

1 - Incialmente, há cerca de $400 \mathrm{Ma}$, os terrenos que vieram a formar a ZSP e a ZOM ainda não estavam acrescidos em Gondwana. A subducção da ZSP na ZOM ocorreu concomitantemente a subducação da ZOM no Maciço Central Ibérico (um terreno autóctone gondwânico)

2 - Com o avanço da subducção da ZSP na ZOM o prisma acrescionário (Pulo do Lobo e Beja Acebuches) começa a ser formado entre 385-365 Ma.

3 - O regime tectônico começa a apresentar componentes laterais e extensionais (transtensional) no final do Fammeniano (Struniano) e início do Tournasiano, entre 360-350 Ma. Neste estágio a ZOM é intrudida por um corpo básico-ultrabásico que possivelmente representa uma pluma que atuou na região neste período. Mesmo sem a presença de corpos intrusivos o magmatismo da ZSP foi até mais expressivo que o magmatismo da ZOM. Este magmatismo da ZSP está relacionado com as mineralizações de VMS.

4 - Entre 345 e 300 Ma o encurtamento transpressional foi predominante, gerando a morfologia final deste orógeno variscano. 
Destes 4 estágios somente o 3 está relacionado com a formação das rochas vulcânicas da FPI e, portanto, somente ele está relacionado com as mineralizações de sulfeto maciço. De forma que deste ponto em diante esta tese tratará apenas deste estágio, o qual será referido como "estágio transtensional".

Estágio Transtensional: Na Zona de Ossa Morena o estágio transtensional está relacionado com a colocação de um corpo intrusivo básico-ultrabásico denominado de IRB (Iberseis Reflective Body, Simancas et al., 2003). Este corpo é interpretado como uma pluma mantélica e ajuda a explicar diversas características da ZOM, como a quantidade abundante de rochas máficas observadas na região (Capdevila et al., 1973), litogeoquímica e geoquímica isotópica associada a alto fluxo térmico (Tornos et al., 2001, Salman, 2004) e fácies granulíticas e anfibolíticas de alta temperatura e baixa pressão que afloram no sul da ZOM (Bard, 1969). Esta pluma teria sido atuante entre 355-335 Ma, idade da maioria das rochas máficas variscanas da região.

Na Zona Sul Portuguesa esta pluma não é observada e existem divergências sobre a importância dela na formação do vulcanismo, e consequentemente, na gênese das mineralizações. Simancas et al. (2003) propõem que esta pluma mantélica teria contribuído para o desenvolvimento de um regime transtensivo em meio a uma colisão e que esta pluma estaria relacionada ao alto gradiente térmico da região e à origem dos metais. Tornos (2006), por outro lado, cita as assinaturas crustais de $\mathrm{Pb}\left(\mu\right.$ entre 9.8 e 10; Marcoux, 1998) e $\varepsilon_{\mathrm{Nd}}(<-$ 5.5; Relvas et al., 2001) e a homogeneidade destes dados para argumentar que os metais foram lixiviados de uma fonte homogênea ou foram homogeneizados no transporte hidrotermal. Para Tornos (2006) é improvável que as rochas vulcânicas sejam as fontes de metal. Este autor argumenta que as rochas do Grupo FQ possuem conteúdos muito mais elevados de metais e que a lixiviação desta unidade que está relacionada com os metais.

Mais abaixo as diferenças geológicas internas da FPI serão tratadas, mas basicamente a esta província possui duas regiões com características geológicas distintas que estão relacionadas aos depósitos VMS. Estas características geológicas distintas estão associadas a duas etapas diferentes do estágio transtensional (360-350 Ma) na região. 
A)

Variscan evolution of Southwest lberia

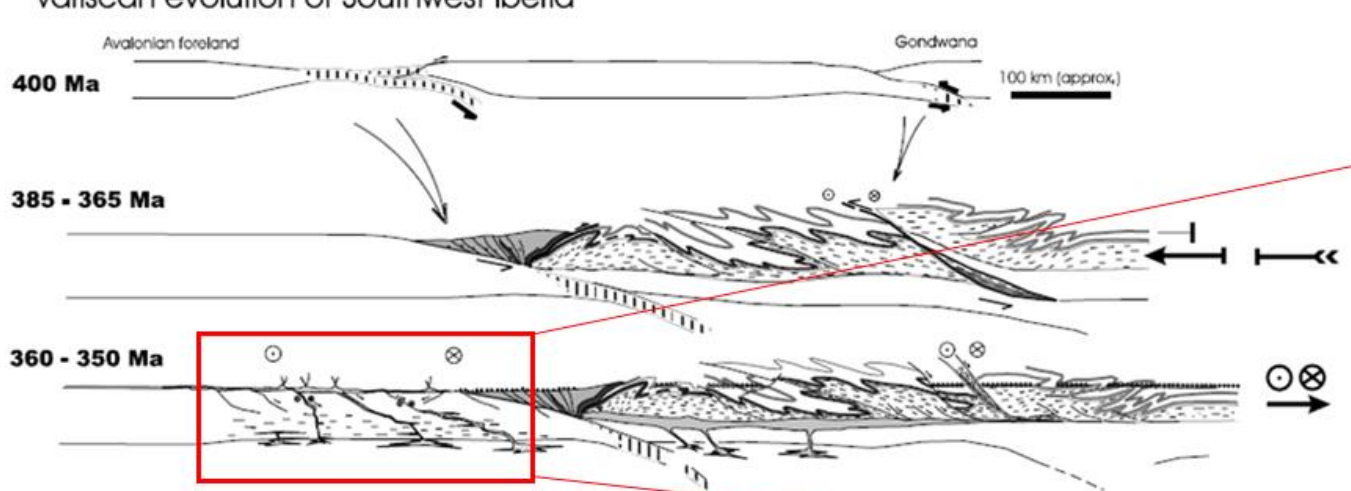

B) Zoom in

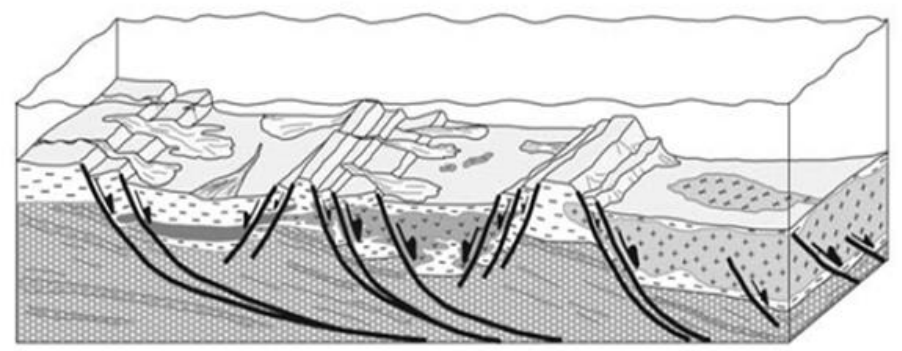

C) Em planta

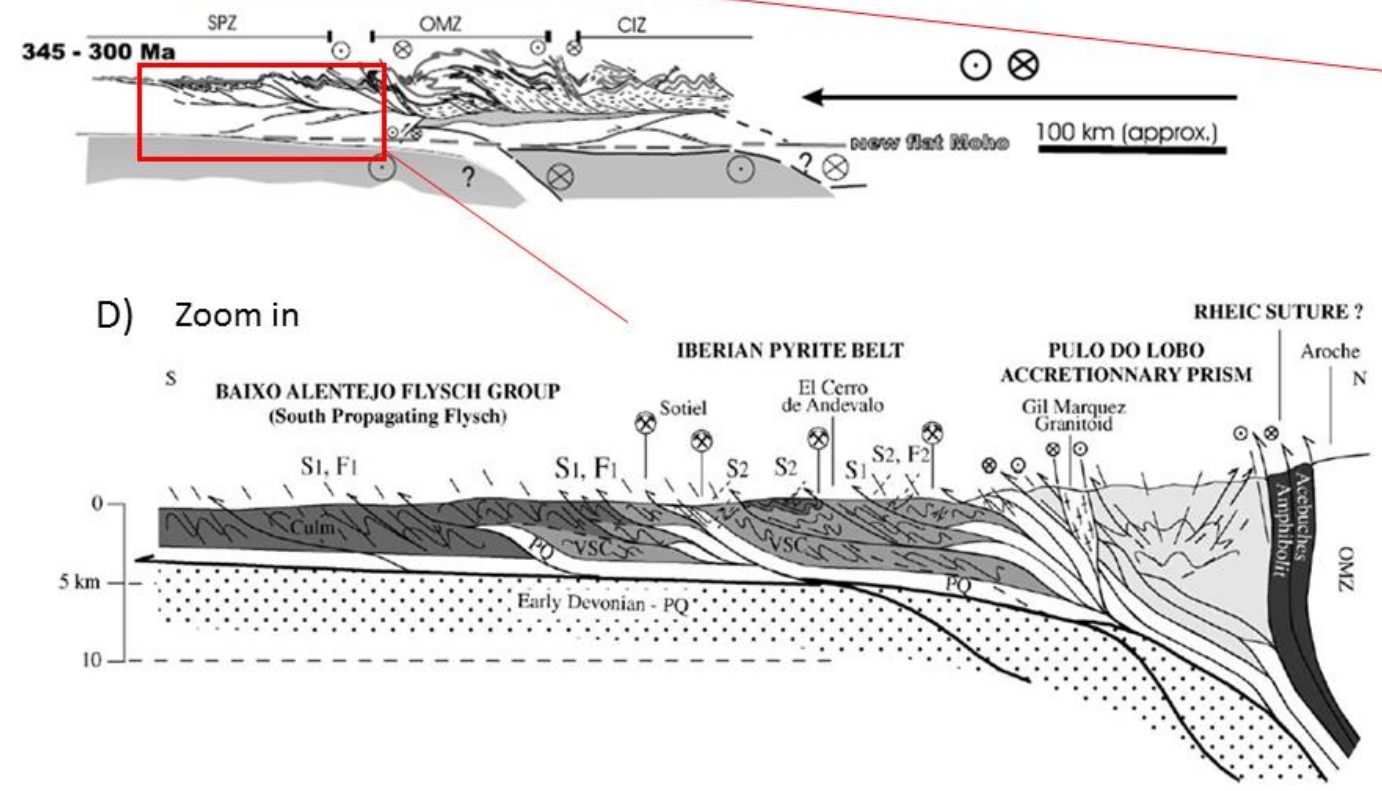

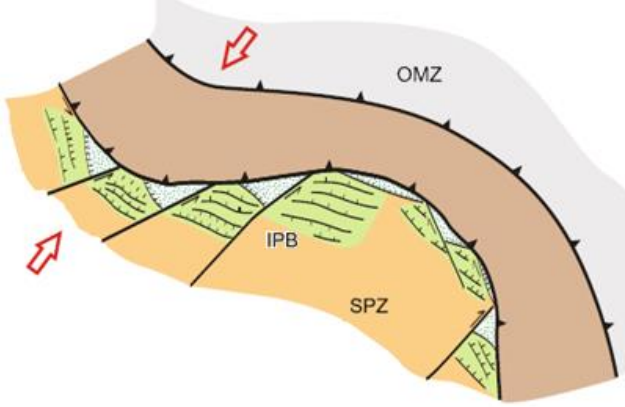

Figura 23. Composição esquemática da evolução geodinâmica da FPI utilizando os trabalhos de A) Simancas et al. (2003.) B) Mantero et al. (2011), C) Castroviejo (2011) e D) Onézime et al., (2002). OMZ é a sigla da Zona de Ossa Morena, IPB é a sigla da FPI (Iberian Pyrite Belt) e SPZ é a Zona Sul Portuguesa. 
Inicialmente a transtensão gerou bacias de pull apart de $2^{\mathrm{a}}$ ordem que abrigaram os corpos de VMS relacionados a folhelhos Strunianos ( 360 Ma) e interpretados como precipitação no leito do oceano. A segunda etapa de mineralizações é mais recente e ocorre somente na região norte da FPI espanhol. Ela está relaciona a domos e criptodomos félsicos Tournaisianos ( 350 Ma), momento em que o ângulo da subducção fica mais acentuado e o magmatismo da FPI migra para norte. Este segundo evento de mineralização não ocorre relacionado a bacias de $3^{\text {a }}$ ordem, mas está diretamente relacionado aos riodacitos, sugerindo um controle magmático nas mineralizações (Tornos et al., 2015b)

Nestas bacias de $2^{\mathrm{a}}$ ordem falhamentos locais com tendência E-W e NE-SW geram bacias menores (de $3^{\mathrm{a}}$ ordem). Estas bacias de $3^{\mathrm{a}}$ ordem estão diretamente relacionadas com as mineralizações exalativas da FPI (Saez et al., 1999; Tornos et al., 2002; Tornos

2006). Geralmente estas bacias apresentam morfologia de meio graben e taxas de subsidência variáveis que geram regiões anóxicas (Oliveira, 1990; Moreno et al., 1996). As estruturas tectônicas provavelmente controlam a ascensão do fluido hidrotermal mineralizante (Quesada, 1997; Solomon et al., 2004).

A tectônica thin skinned levou ao empilhamento das lentes de VMS e dos corpos de stockworks em estruturas de duplex, resultando no espessamento dos corpos de VMS e aumentando a tonelagem dos depósitos da FPI. O resultado disso é a redistribuição do metal, que por vezes é remobilizado, gerando enriquecimento em zonas de cisalhamento dúctil e corpos de pirita maciça estéreis (Tornos, 2006; Castroviejo et al., 2011).

\subsection{ESTUDOS ISOTÓPICOS REALIZADOS NA FPI}

Alguns estudos isotópicos já foram executados na sessão espanhola da Faixa Piritosa Ibérica ao longo das últimas décadas (Marcoux, 1997; Mathur et al., 1999, Nesbitt et al., 1999; Barrie et al., 2002; Rosa et al., 2009; Valenzuela et al., 2011; Solá, 2015). Geralmente os estudos foram realizados em escala regional escolhendo alguns depósitos representativos da região, como Rio Tinto, Tharsis ou Las Cruces, por exemplo. A síntese destes estudos pode ser observada na Tabela 2.

Marcoux (1997) realizou um amplo trabalho regional de caracterização do comportamento dos isótopos de $\mathrm{Pb}$ em 86 amostras de 26 depósitos da FPI portuguesa e espanhola. Foram estudados sulfetos maciços, gossans e rochas vulcânicas associadas. As 
razões ${ }^{206} \mathrm{~Pb} /{ }^{204} \mathrm{~Pb},{ }^{207} \mathrm{~Pb} /{ }^{204} \mathrm{~Pb}$ e ${ }^{208} \mathrm{~Pb} /{ }^{204} \mathrm{~Pb}$ apresentam valores homogêneos com exceção do depósito de Neves Corvos, que apresenta assinaturas mais dispersas e espalhadas. Estas assinaturas isotópicas indicam que tanto os fluidos hidrotermais quanto as rochas vulcânicas possuem a mesma fonte ou uma fonte magmática principal que gera um fluido hidrotermal que interage e homogeneíza as diferentes rochas magmáticas encaixantes, com exceção de Neves Corvo, que apresenta mais de uma fonte de fluidos. Os resultados mostram $\mathrm{Pb}$ de origem essencialmente crustal (Marcoux 1997).

Tabela 2.Idades obtidas por outros autores na FPI. As idades de Rosa et al., (2009) foram obtidas via ID-TIMS em rochas vulcânicas associadas aos VMS, as idades palinológicas são obtidas em folhelhos e as idades de Re-Os de Mathur et al. (1999) foram obtidas nos sulfetos maciços

\begin{tabular}{|c|c|c|c|c|}
\hline Região & Depósito & Idade (Ma) & Método de datação & Autor \\
\hline \multirow{21}{*}{ 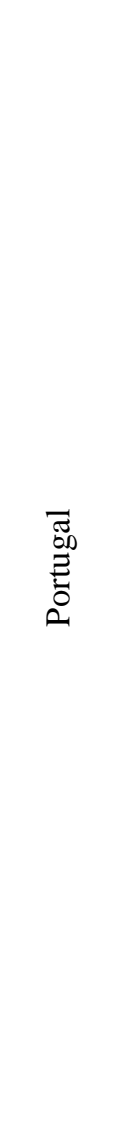 } & Cercal & $374 \pm 2$ & $\mathrm{U}-\mathrm{Pb}$ & Rosa et al., (2009) \\
\hline & & $371 \pm 1$ & $\mathrm{U}-\mathrm{Pb}$ & Rosa et al., (2009) \\
\hline & & $372 \pm 1$ & $\mathrm{U}-\mathrm{Pb}$ & Rosa et al., (2009) \\
\hline & & $370 \pm 1$ & $\mathrm{U}-\mathrm{Pb}$ & Rosa et al., (2009) \\
\hline & Caveira & $361 \pm 4$ & $\mathrm{U}-\mathrm{Pb}$ & Rosa et al., (2009) \\
\hline & & Struniano tardio & Palinologia & Pereira et al. 2010 \\
\hline & Azinheira de Barros & $362 \pm 4$ & $\mathrm{U}-\mathrm{Pb}$ & Rosa et al., (2009) \\
\hline & Lagoa Salgada & $356 \pm 1$ & $\mathrm{U}-\mathrm{Pb}$ & Barrie et al. (2002) \\
\hline & Aljustrel & $355 \pm 2$ & $\mathrm{U}-\mathrm{Pb}$ & Rosa et al., (2009) \\
\hline & & $356 \pm 1$ & $\mathrm{U}-\mathrm{Pb}$ & Rosa et al., (2009) \\
\hline & & $357 \pm 2$ & $\mathrm{U}-\mathrm{Pb}$ & Rosa et al., (2009) \\
\hline & & $364 \pm 2$ & $\mathrm{U}-\mathrm{Pb}$ & Rosa et al., (2009) \\
\hline & & $352 \pm 2$ & $\mathrm{U}-\mathrm{Pb}$ & Barrie et al. (2002) \\
\hline & Albernoa & $355 \pm 3$ & $\mathrm{U}-\mathrm{Pb}$ & Rosa et al., (2009) \\
\hline & & $356 \pm 2$ & $\mathrm{U}-\mathrm{Pb}$ & Rosa et al., (2009) \\
\hline & Serra Branca & $366 \pm 2$ & $\mathrm{U}-\mathrm{Pb}$ & Rosa et al., (2009) \\
\hline & & $357 \pm 5$ & $\mathrm{U}-\mathrm{Pb}$ & Rosa et al., (2009) \\
\hline & Chança & $354 \pm 1$ & $\mathrm{U}-\mathrm{Pb}$ & Rosa et al., (2009) \\
\hline & & $349 \pm 5$ & $\mathrm{U}-\mathrm{Pb}$ & Rosa et al., (2009) \\
\hline & Montinho & Struniano tardio & Palinologia & Matos et al. (2011) \\
\hline & Lousal & Struniano tardio & Palinologia & Matos et al. (2011) \\
\hline \multirow{7}{*}{ 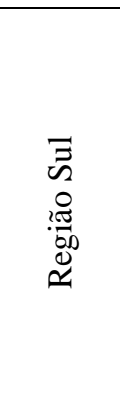 } & Neves Corvo & $\sim 363-358 \mathrm{Ma}$ & $\mathrm{U}-\mathrm{Pb}$ & Solá et al. (2015) \\
\hline & & 353-349 Ma & $\mathrm{U}-\mathrm{Pb}$ & Solá et al. (2015) \\
\hline & & Struniano tardio & Palinologia & Pereira et al. 2008 \\
\hline & Aznalcóllar & Struniano tardio & Palinologia & Pereira et al. 1996 \\
\hline & Los Frailes & $346 \pm 5$ & $\mathrm{U}-\mathrm{Pb}$ & Nesbitt et al. (1999) \\
\hline & Las Cruces & $354 \pm 1$ & $\mathrm{U}-\mathrm{Pb}$ & Barrie et al. (2002) \\
\hline & Tharsis & $353 \pm 44$ & $\mathrm{Re}-\mathrm{Os}$ & Mathur et al. (1999) \\
\hline
\end{tabular}




\begin{tabular}{|c|c|c|c|c|}
\hline & Tharsis & Struniano tardio & Palinologia & Gonzalez et al. (2002) \\
\hline \multirow{8}{*}{ 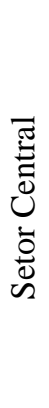 } & Rio Tinto & $350 \pm 1$ & $\mathrm{U}-\mathrm{Pb}$ & Barrie et al. (2002) \\
\hline & & $348 \pm 1$ & $\mathrm{U}-\mathrm{Pb}$ & Valenzuela et al. (2011) \\
\hline & & $350 \pm 1$ & $\mathrm{U}-\mathrm{Pb}$ & Valenzuela et al. (2011) \\
\hline & & $345 \pm 26$ & Re-Os & Mathur et al. (1999) \\
\hline & Rio Odiel & $352 \pm 1$ & $\mathrm{U}-\mathrm{Pb}$ & Valenzuela et al. (2011) \\
\hline & & $349 \pm 1$ & $\mathrm{U}-\mathrm{Pb}$ & Valenzuela et al. (2011) \\
\hline & & $346 \pm 1$ & $\mathrm{U}-\mathrm{Pb}$ & Valenzuela et al. (2011) \\
\hline & Campofrio & $346 \pm 1$ & $\mathrm{U}-\mathrm{Pb}$ & Barrie et al. (2002) \\
\hline
\end{tabular}

O estudo de Mathur et al. (1999) realizou datações via isótopos de Re-Os em amostras de pirita para os depósitos de Rio Tinto e Tharsis, obtendo idades de $345 \pm 26$ Ma e $353 \pm 44 \mathrm{Ma}$, que são idades com erros muito elevados. Os sulfetos da FPI ainda não foram datados em nenhum outro trabalho de maneira direta. Os valores iniciais de ${ }^{187} \mathrm{Os} /{ }^{188}$ Os obtidos são similares, levando os autores a propor que ambos devem possuir a mesma fonte de metais. Esses valores são considerados muito radiogênicos $(0.376 \pm$ 0.056) e levaram os autores a propor que a fonte dos metais é crustal, provavelmente relacionada com o Grupo FQ. Nesbitt et al. (1999) executou as primeiras datações U-Pb em depósitos da FPI ao datar uma amostra com população de zircão associada a alteração clorítica do depósito de Los Frailes. A idade concórdia obtida foi de $346 \pm 5$ Ma. A idade de Los Frailes não é uma idade confiável devido as razões discutidas por Barrie et al. (2002): 1) essa idade foi calculada usando somente a razão ${ }^{206} \mathrm{~Pb} /{ }^{238} \mathrm{U}$ e utilizando um erro $2 \sigma$ de $4.4-5.4 \%$, o que corresponde a um erro $2 \sigma$ para as idades individuais de ${ }^{206} \mathrm{~Pb} /{ }^{238} \mathrm{U}$ de $\pm 15-18 \mathrm{Ma}$, tornando este dado muito mais incerto que as demais idades $\mathrm{U}$ $\mathrm{Pb}$ obtidas na FPI; 2) é incerto se os cristais de zircão analisados são hidrotermais ou ígneos devido à ausência de imagens de CL no trabalho; e 3) o próprio Nesbitt et al. (1999) comenta que a essa idade U-Pb é mais de 7 Ma mais jovem que a idade palinológica de Los Frailes obtida por Pereira et al. (1996).

Um estudo de geocronologia U-Pb (TIMS) das rochas vulcânicas associadas aos depósitos da FPI foi executado por Barrie et al. (2002) em rochas de Rio Tinto, Las Cruces, Aljustrel, Lagoa Salgada, e no corpo tonalítico rico em biotita que aflora em Campofrio (3.5km de distância de Rio Tinto). O riolito datado na mina de Atalaya, em Rio Tinto apresentou idade concórdia de 349.76 £ 0.9 Ma. Os depósitos portugueses de Aljustrel e Lagoa Salgada foram datados em $352 \pm 1.9$ Ma e 356.4 $\pm 0.8 \mathrm{Ma}$, enquanto o tonalito possui idade de $346 \pm 0.8 \mathrm{Ma}$. Outro estudo de geocronologia U-Pb (LA-ICPMS) 
e geologia isotópica a partir de isótopos de Lu-Hf (o único estudo com este sistema isotópico executado na FPI) foi executado por Rosa et al., (2009).

Este estudo foi realizado em 7 depósitos da porção portuguesa da FPI, além de uma região estéril. Foram estudados, de oeste para leste: a região estéril de Cercal (374 $\pm 2 \mathrm{Ma}, 371 \pm 1 \mathrm{Ma}, 372 \pm 1 \mathrm{Ma}, 370 \pm 1 \mathrm{Ma}$ ), e os depósitos de Caveira (361 $\pm 4 \mathrm{Ma}$ ), Azinheira de Barros (362 $\pm 4 \mathrm{Ma})$, Aljustrel $(355 \pm 2 \mathrm{Ma}, 356 \pm 1 \mathrm{Ma}, 357 \pm 2 \mathrm{Ma}, 364$ $\pm 2 \mathrm{Ma})$, Albernoa (355 $\pm 3 \mathrm{Ma}, 356 \pm 2 \mathrm{Ma})$, Serra Branca $(366 \pm 2 \mathrm{Ma}, 357 \pm 5 \mathrm{Ma}) \mathrm{e}$ Chança (354 \pm 1 Ma, $349 \pm 5 \mathrm{Ma})$. Essas idades mostram uma migração do magmatismo de SW para Ne, perpendicularmente a sutura tectônica. Esse modelo de migração do magmatismo é diferente do apresentado por Barrie et al. (2002) (Figura 24). Algumas amostras ainda apresentaram xenocristais com idades variando entre o Neoproterozoico superior, Paleoproterozoico e Arqueno.
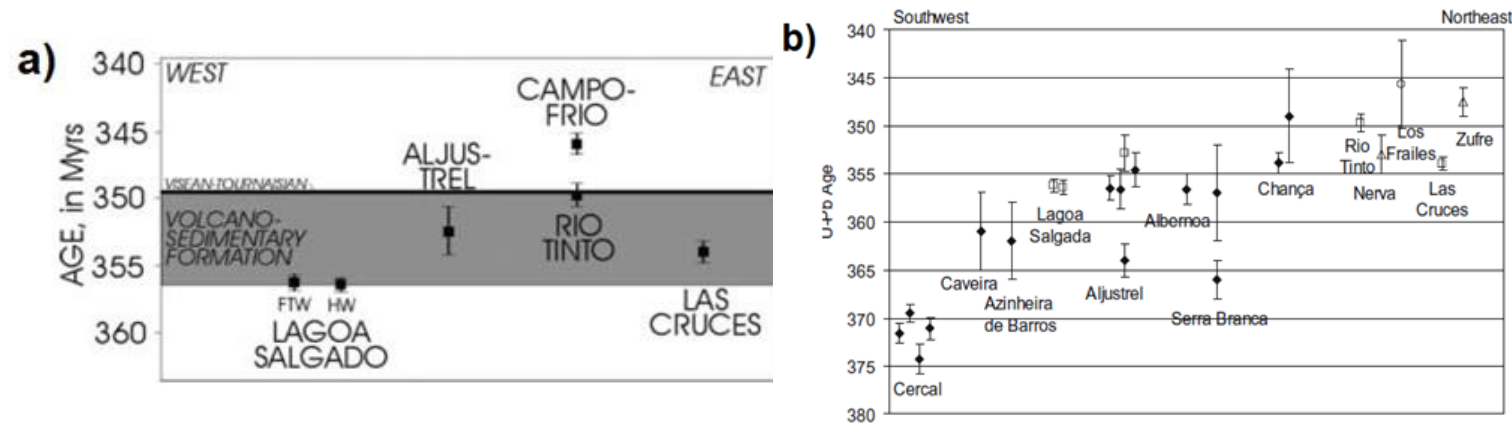

Figura 24. Idades da atividade magmática apresentados por a) Barrie et al. (2002) e b) Rosa et al. (2009). Rosa et al. (2009) também utilizou os trabalhos de Barrie et al. (2002).

Todas as populações de zircão das amostras estudadas por Rosa et al. (2009) também tiveram os isótopos de Lu-Hf analisados. As populações de zircão magmáticas (autocristais e xenocristais) apresentaram valores de $\varepsilon_{\mathrm{Hf}}$ entre -6.8 e -7.4 . $\mathrm{O}$ zircão Neoproterozoico apresentou valor de $\varepsilon_{\mathrm{Hf}}$ de 4.3. Também foi analisado um zircão da sequência basal denominada Grupo FQ, que apresentou $\varepsilon_{\mathrm{Hf}}$ de -6.9. Estes valores de $\varepsilon_{\mathrm{Hf}}$ obtidos para os dois tipos de zircão magmáticos apontam para um cenário sem mistura de magmas e com idades modelo Mesoproterozoicas (1.4 Ga). Não são conhecidas fontes crustais juvenis na FPI e o Grupo FQ possui mais de 2000m de espessura, sem ter a base conhecida e neste grupo foram datados cristais de zircão Neoproterozoicos, Paleoproterozoicos e Arqueanos. A fusão destes cristais de zircão daria justamente a idade modelo de $1.4 \mathrm{Ga}$ e os xenocristais de zircão nas rochas vulcânicas também apresentam idades Neoproterozoicos, Paleoproterozoicos e Arqueanas. Levando estes dados em conta Rosa et al. (2009) interpreta que o Grupo FQ é a fonte do magmatismo da FPI. 
As rochas da unidade Riotinto-Nerva, unidade em que o depósito de Rio Tinto está inserido, foram alvo de estudo com isótopos de U-Pb (TIMS) e Sm-Nd efetuado por Valenzuela et al. (2011). Nele foram utilizados litotipos da mina de Atalaya de Rio Tinto (duas amostras) e em rochas do Complexo VS em uma localidade próxima do depósito de Rio Tinto conhecida como Rio Odiel (3 amostras). As idades obtidas para as rochas

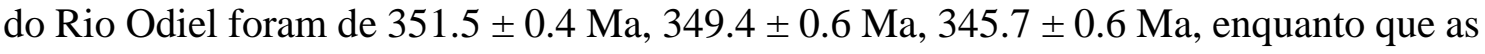
rochas encaixantes dataram em $348.4 \pm 0.7 \mathrm{Ma}$ e $349.5 \pm 0.4 \mathrm{Ma}$.

Nestas mesmas amostras os isótopos de Sm-Nd também foram estudados, visando a utilização como traçador da fonte das rochas ígneas, uma vez que este par isotópico não é afetado pelos processos hidrotermais superimpostos a estas rochas. Os resultados dos dois litotipos mais antigos de Rio Odiel apresentam $\varepsilon_{\mathrm{Nd}}$ levemente positivo, entre $+0.3 \mathrm{e}$ +0.4. Por outro lado, as rochas associadas à mineralização de Rio Tinto, assim como a rocha mais jovem de Rio Odiel apresentam $\varepsilon_{N d}$ negativos, entre -1.7 e -2.8. Os valores levemente positivos das rochas do Rio Odiel indicam que estas rochas se formaram por fusão parcial de um manto empobrecido ou pela fusão parcial de uma crosta máfica juvenil. Por outros lados os valores de $\varepsilon_{\mathrm{Nd}}$ negativos indicam que essas rochas são derivadas da fusão parcial de matéria crustal (Valenzuela et al., 2011), o que está de acordo com a interpretação de Rosa et al. (2009) para a geração do vulcanismo associado a mineralização associado a fusão de rochas do Grupo FQ.

Codeço et al., (2015) estudou a temperatura dos magmas da FPI através da temperatura de saturação de zircão no magma e das temperaturas obtidas a partir da utilização do geotermômetro de Ti-em-zircão na parte portuguesa da Faixa Piritosa Ibérica. Os resultados obtidos podem ser consultados abaixo (Figura 25) e sugerem que os magmas riolíticos relacionados aos centros vulcânicos associados aos corpos de VMS são resultado de magmas insaturados em zircão, com temperaturas acima de $800^{\circ} \mathrm{C}$. Em contraste, as sequências vulcânicas estéreis estão associadas a magmas de riodacíticos a dacíticos gerados em temperaturas mais baixas (menor que $800^{\circ} \mathrm{C}$, com cluster entre 700 $750^{\circ} \mathrm{C}$ ) que são supersaturados em zircão (Codeço et al., 2015). Esta interpretação está de acordo com a literatura, em que Piercey (2011 e referências internas) associa os corpos de VMS com magmatismo de alta temperatura através de temperaturas de saturação de zircão.

Para Codeço et al. $(2015,2018)$ estes dois conjuntos de rochas vulcânicas possuem origens distintas. O magma de composição riolítica é o resultado da fusão parcial 
moderada a intensa da crosta superior $(<10 \mathrm{~km}$ de profundidade e $<2.5 \mathrm{kbar}$ de pressão) causada pela ascensão rápida de magmas basálticos para câmaras superficiais. Em condições adequadas (temperatura-densidade-viscosidade) estes magmas riolíticos são facilmente separados do restito e ascendem até a superfície e um pouco abaixo dela, onde eles podem causar vulcanismo explosivo recorrente e sustentar uma vigorosa e duradoura atividade hidrotermal. Os magmas dacíticos a riodacíticos, em contraste, são gerados em profundidades equivalentes (ou um pouco mais profundas, se influenciados por fluidos) mas com grau menor de fusão parcial. Isso implica que a chance destes magmas atingir câmaras magmáticas rasas (e, portanto, gerar a atividade vulcânica e hidrotermalismo) é mais limitada. A partir deste raciocínio estes autores concluem que o magmatismo da FPI está relacionado aos magmas de temperaturas mais elevadas da região (Codeço et al., 2015, Codeço et al., 2018).

Luz et al. (2019) estudou as sequencias metassedimentares associadas aos sulfetos maciços e estéreis do Complexo VS da região portuguesa de Albernoa. A partir de geoquímica elementar e isotópica ( $\mathrm{Sr}, \mathrm{Pb}$ e $\mathrm{Nd}$ ) estes autores mostraram que existe um vetor de proximidade associado à razão ${ }^{87} \mathrm{Sr} /{ }^{86} \mathrm{Sr}_{(360 \mathrm{Ma})}$, que diminui com a proximidade de corpos de sulfetos maciços. $\mathrm{O} \varepsilon_{\mathrm{Nd}(360 \mathrm{Ma})}$ aumenta com a proximidade dos corpos de sulfetos maciços, assim como as razões isotópicas ${ }^{207} \mathrm{~Pb} /{ }^{204} \mathrm{~Pb}$ e ${ }^{206} \mathrm{~Pb} /{ }^{204} \mathrm{~Pb}$.

Zircon saturation temperature

\begin{tabular}{lcccccc}
\hline & $\boldsymbol{\mu}$ & $\boldsymbol{\sigma}$ & $\boldsymbol{m}$ & Max & Min & $\boldsymbol{n}$ \\
\hline $\begin{array}{l}\text { Serra } \\
\text { Branca }\end{array}$ & 738 & 55 & 729 & 856 & 614 & 47 \\
\hline Albernoa & 709 & 72 & 695 & 930 & 620 & 53 \\
\hline $\begin{array}{l}\text { Ervidel- } \\
\text { Roxo }\end{array}$ & 827 & 71 & 811 & 999 & 725 & 15 \\
\hline Aljustrel & 829 & 73 & 833 & 994 & 634 & 134 \\
\hline $\begin{array}{l}\text { Lagoa } \\
\text { Salgada }\end{array}$ & 810 & 59 & 813 & 935 & 676 & 22 \\
\hline $\begin{array}{l}\text { Neves- } \\
\text { Corvo }\end{array}$ & 767 & 88 & 770 & 977 & 566 & 22 \\
\hline Lousal & 866 & 93 & 905 & 942 & 677 & 86 \\
\hline Riotinto & 780 & 54 & 797 & 903 & 737 & 68 \\
\hline Aznalcöllar & 787 & 79 & 779 & 915 & 565 & 24 \\
\hline
\end{tabular}

$\mathrm{Ti}$ in zircon

\begin{tabular}{lllllll}
\hline & $\boldsymbol{\mu}$ & $\boldsymbol{\sigma}$ & $\boldsymbol{m}$ & $\mathrm{Max}$ & $\operatorname{Min}$ & $\boldsymbol{n}$ \\
Roxo & 866 & 76 & 868 & 991 & 736 & 14 \\
Albernoa & 908 & 54 & 921 & 1002 & 765 & 17 \\
Figueirinha & 849 & 68 & 825 & 981 & 778 & 6 \\
Aljustrel & 851 & 78 & 821 & 979 & 736 & $\mathbf{7}$ \\
Entradas & 930 & 45 & & 978 & 884 & 2 \\
\hline
\end{tabular}

Comparison of data

\begin{tabular}{lll} 
Deposit & Tzircsat & Ti in zircon \\
\hline Roxo & $827 \pm 71$ & $866 \pm 76$ \\
\hline Albernoa & $709 \pm 72$ & $908 \pm 54$ \\
\hline Aljustrel & $829 \pm 73$ & $851 \pm 78$
\end{tabular}

Figura 25. Compilação dos dados apresentados por Codeço et al (2015) com a temperatura de saturação do zircão e as temperaturas obtidas pelo método de Ti em zircão. $\mu=$ média, $\sigma=$ desvio padrão, $m=$ mediana, Max = máximo, Min = mínimo $e$ $n=$ total de análises 


\section{MATERIAIS E MÉTODOS}

\subsection{AMOSTRAGEM}

Como em todo estudo geocronológico e de geoquímica isotópica, a amostragem é uma parte crítica, uma vez que o controle geológico rigoroso garante que os resultados obtidos realmente são representativos. Neste projeto a amostragem durou uma semana, onde foram coletadas diversas amostras de 11 depósitos, além de 2 litotipos plutônicos do Maciço de Gerena e 2 litotipos estéreis da região. Esta etapa do trabalho contou com o auxílio do Dr. Fernando Tornos, maior especialista na FPI espanhola e da Dr ${ }^{\mathrm{a}}$. Carmen Conde (Figura 27).

Os depósitos estudados nesta tese de doutorado foram escolhidos em conjunto com o Dr. Fernando Tornos por serem representativos e também pela possibilidade de acesso, seja porque a mina está desativada (como é o caso de Tharsis, por exemplo), seja porque a empresa autorizou a amostragem (como é o caso das empresas First Quantum Minerals LTD. em Las Cruces e Matsa Minning no depósito de Aguas Tenidas).

Foram amostrados depósitos de três regiões distintas da FPI espanhola. No Cinturão Norte foram estudadas amostras dos depósitos de San Telmo (n=1), Aguas Tenidas $(n=2)$, Magdalena $(n=1)$, San Miguel $(n=1)$, Concepcion $(n=1)$ e San Platon $(\mathrm{n}=1)$. Também foram coletadas amostras do depósito de Mn de maior expressão da FPI, o depósito de Solo Viejo (2).

No Setor Central da FPI foram amostrados os depósitos de La Zarza (2) e Rio Tinto (5), enquanto que na Região Sul os depósitos de Tharsis (1) e Las Cruces (2) foram amostrados. Na Região Sul o Maciço de Gerena (2) também foi amostrado. Diferentemente dos depósitos do Norte, que ocorrem próximos um dos outros, os depósitos centrais e do Sul ocorrem isoladamente entre si. Em algumas das amostras estudadas não foi possível a obtenção de cristais de zircão para os estudos isotópicos e essas amostras foram desconsideradas. A localização dos depósitos estudados, bem como a lista de amostras podem ser observados na Figura 26 e Tabela 3. Exemplos dos litotipos amostrados podem ser observados na Figura 27 


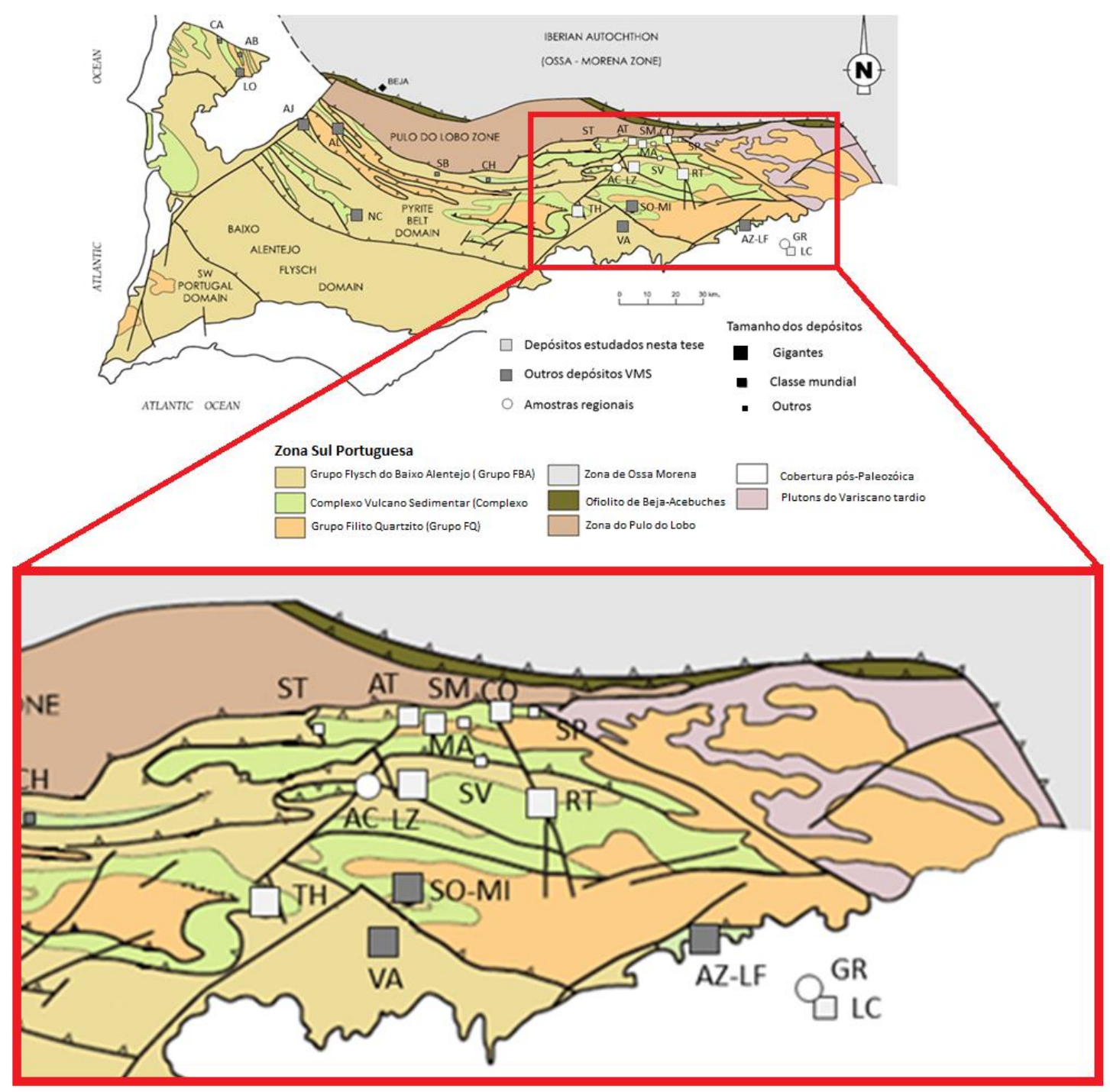

Figura 26. Localização dos depósitos estudados na FPI espanhola. Amostras do Cinturão Norte: $S T=$ San Telmo, $A T=$ Aguas Tenidas, $M A=$ Magdalena, $S M=$ San Miguel, $C O=$ Concepcion, $S V=$ Soloviejo e SP = San Platon. Amostras do Setor Central: $A C=$ Aglomerado del Cerro, $L Z=L a$ Zarza e RT = Rio Tinto. Amostras da Região Sul: $T H=$ Tharsis, GR = Maciço de Gerena e LC = Las Cruces . 
Tabela 3. Amostras estudadas nesta tese e sua localização na FPI

\begin{tabular}{|c|c|c|}
\hline Localização & Amostras & Região da FPI \\
\hline San Telmo & ST-03 & Cinturão Norte \\
\hline Aguas Tenidas & AT-01 e AT-03 & Cinturão Norte \\
\hline Magdalena & MA-01 & Cinturão Norte \\
\hline San Miguel & SM-12 & Cinturão Norte \\
\hline Concepcion & CO-04 & Cinturão Norte \\
\hline San Platon & SP-03 & Cinturão Norte \\
\hline Solo Viejo & SV-01 e SV-02 & Cinturão Norte \\
\hline Aglomerado el Cerro & AC-01 e AC-02 & Setor Central \\
\hline La Zarza & ZA-3 e ZA-4 & Setor Central \\
\hline Rio Tinto & RT-02, RT-04 e RT-05 & Setor Central \\
\hline Zarandas & ZN-01 e ZN-02 & Setor Central \\
\hline Tharsis & TH-04 & Região Sul \\
\hline Las Cruces & LC-07 e LC-09 & Região Sul \\
\hline Gerena & GR-01 e GR-02 & Região Sul \\
\hline
\end{tabular}




\section{A)}
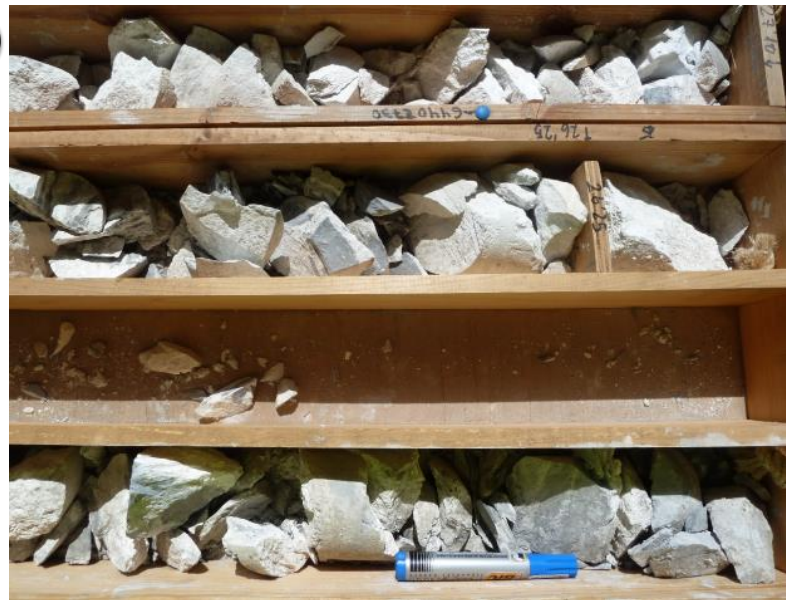

C)

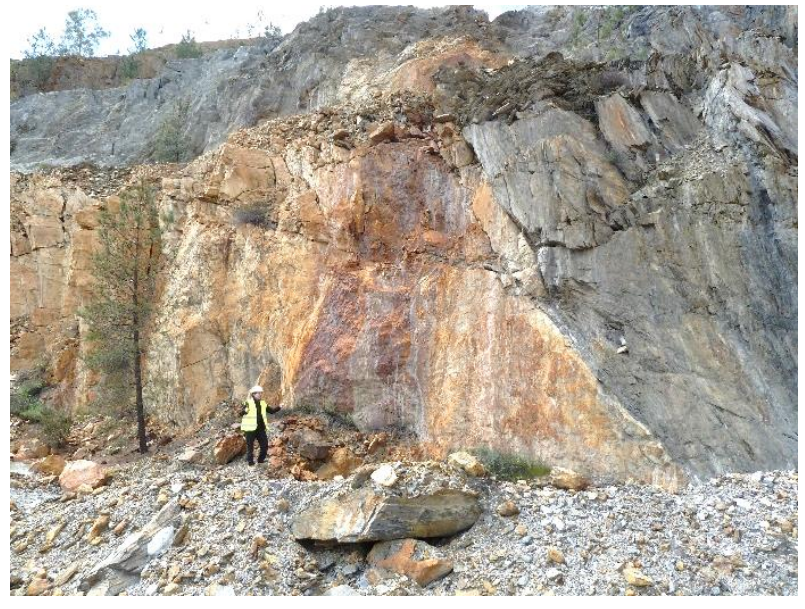

E)

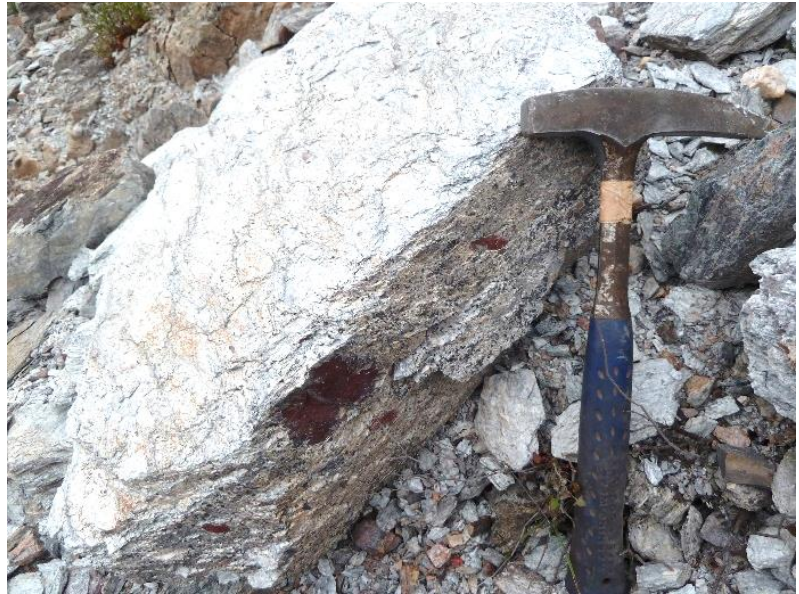

B)

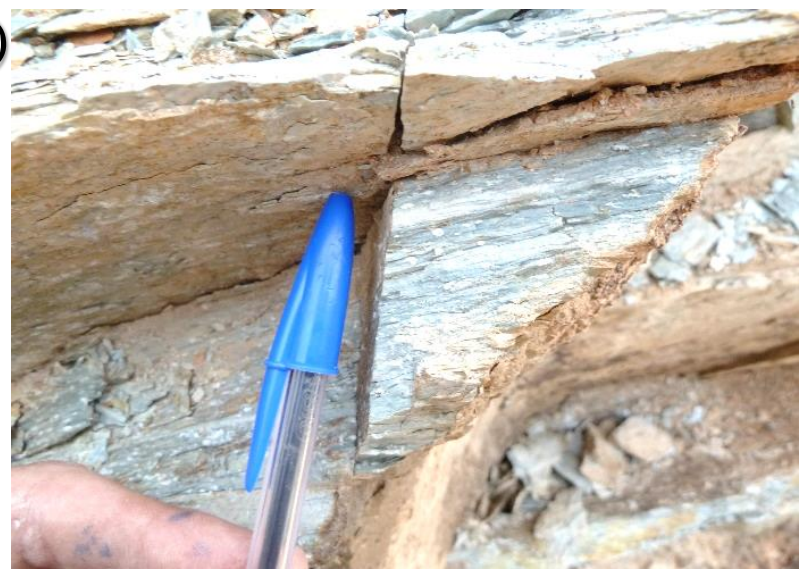

D)

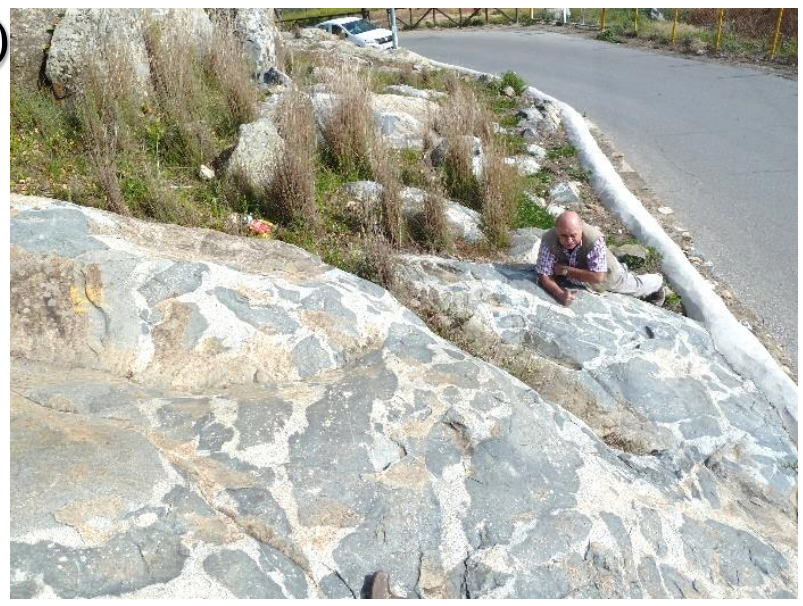

F)

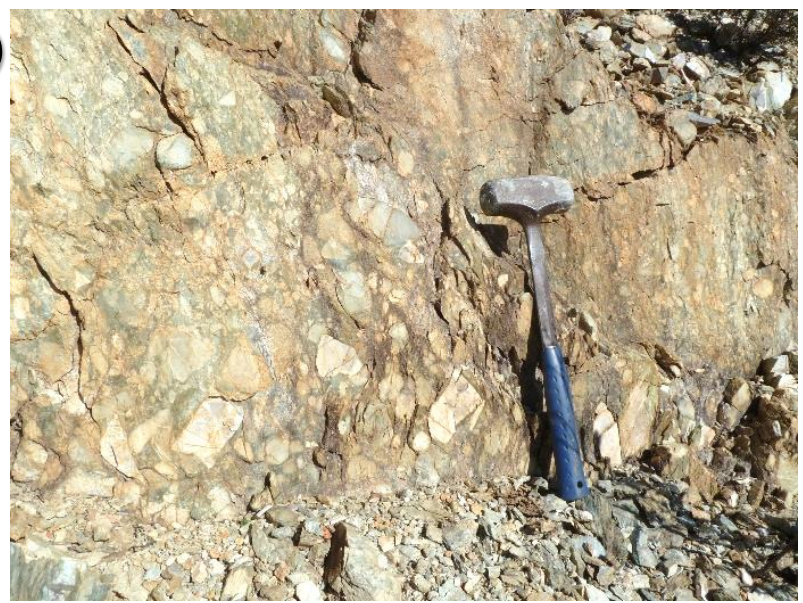

Figura 27. A) amostra LC-07 coletada em testemunho de sondagem, B), detalhe de amostra de rocha vulcanoclásticas de Aguas Tenidas, C) contato tectônico característico do Cinturão Norte da FPI observado em Solo Viejo; D) afloramento do Maciço de Gerena a beira da estrada no vilarejo de Gerena; E) rocha vulcanoclásticas totalmente sericitizada do depósito de San Platon; F) afloramento do Aglomerado del Cerro, corpo vulcânico estéril do Setor Central 


\subsection{GEOCRONOLOGIA U-Th-Pb}

Os decaimentos dos elementos urânio (U) e tório (Th) para isótopos estáveis radiogênicos de chumbo $(\mathrm{Pb})$ geram geocronômetros distintos que compõe o sistema isotópico $\mathrm{U}-\mathrm{Th}-\mathrm{Pb}$.

O método U-Pb é utilizado para datação de minerais com alto teor de $\mathrm{U}$ e Th e baixo teor de $\mathrm{Pb}$ normal. Este método se baseia em duas reações de decaimento radioativo de $\mathrm{U}$ e em uma reação de decaimento radioativo de Th em isótopos radiogênicos de $\mathrm{Pb}$. Estas três reações permitem o estabelecimento de três geocronômetros distintos $\left({ }^{238} \mathrm{U} /{ }^{206} \mathrm{~Pb},{ }^{235} \mathrm{U} /{ }^{207} \mathrm{~Pb}\right.$ e $\left.{ }^{232} \mathrm{Th} /{ }^{208} \mathrm{~Pb}\right)$.

O isótopo de urânio ${ }^{238} \mathrm{U}$ é o isótopo mais abundante e corresponde a $99.2743 \%$ do total de átomos de U existentes. Ele possui meia vida de $4.468 \times 10^{9}$ anos e decai para ${ }^{206} \mathrm{~Pb}$ em uma reação em cadeia de diversas etapas. O isótopo ${ }^{235} \mathrm{U}$ representa $0.7200 \%$ do total de elementos U existentes. Ele possui meia vida de $0.7038 \times 10^{9}$ anos e decai para ${ }^{207} \mathrm{~Pb}$ em outra reação em cadeia com diversas etapas. O elemento Th só ocorre na forma ${ }^{232} \mathrm{Th}$. Ele possui meia vida $14.010 \times 10^{9}$ e decai para ${ }^{208} \mathrm{~Pb}$ em uma reação em cadeia de diversas etapas (Steiger \& Jäger, 1972).

Estes três geocronômetros $\left({ }^{238} \mathrm{U} /{ }^{206} \mathrm{~Pb},{ }^{235} \mathrm{U} /{ }^{207} \mathrm{~Pb} \mathrm{e}{ }^{232} \mathrm{Th} /{ }^{208} \mathrm{~Pb}\right)$ são utilizados em conjunto para a obtenção de idades U-Pb e Th-Pb. Para que minerais possam ser datados utilizando estes isótopos é necessário que: a) os minerais mantenham seus retículos cristalinos fechados para $\mathrm{U}$, Th e todos os elementos intermediários da reação em cadeia, b) que os valores iniciais para os isótopos de $\mathrm{Pb}$ sejam conhecidos, c) que as constantes de decaimento sejam conhecidas com precisão e acurácia, d) que a composição isotópica de U não tenha sido afetada por fracionamento isotópico e e) que os resultados analíticos sejam acurados (Faure \& Mensing, 2005). A diferença entre as meias-vida dos isótopos ${ }^{238} \mathrm{U}$ e ${ }^{235} \mathrm{U}$ implica que o geocronômetro ${ }^{238} \mathrm{U} /{ }^{206} \mathrm{~Pb}$ é mais preciso que o ${ }^{235} \mathrm{U} /{ }^{207} \mathrm{~Pb}$ para idades mais jovens, uma vez que resta mais material inicial de ${ }^{238} \mathrm{U}$ do que de ${ }^{235} \mathrm{U}$ para rochas mais recentes $(>\sim 600 \mathrm{Ma})$.

O mineral mais utilizado para a determinação de idades é o zircão, uma vez que este se distribui amplamente em rochas crustais, possui quantidades consideráveis de U e Th e não apresenta perdas significativas de nenhum elemento presente nas cadeias de reação U-Th- $\mathrm{Pb}$. O zircão possui uma temperatura de fechamento elevada $\left(\sim 800^{\circ} \mathrm{C}\right)$ o que faz com que seu reticulo cristalino não seja aberto mesmo em eventos metamórficos, 
preservando informações sobre protolitos de processos metamórficos. Outros minerais que também podem ser utilizados são: titanita, monazita, granada, rutilo, apatita, badeleita e xenotima (Faure \& Mensing, 2005).

\subsubsection{Datação do zircão}

O passo inicial no processo de datação dos cristais de zircão é a documentação dos mesmos via imagens de catodoluminescência (CL). As imagens de CL mostram padrões de crescimento do zircão e são utilizadas como ferramenta auxiliar no processo de datação pois elas permitem distinguir populações distintas, visualizar inclusões, cristais de zircão metamíticos e sobrecrescimento metamórfico (Hanchar e Miller, 1993; Corfu et al., 2003). As imagens de CL são ótimas ferramentas para diferenciação de populações de zircão, como por exemplo grãos herdados de outros magmas, os chamados xenocristais (Miller et al., 2007). Quando cristais de zircão são herdados em um mesmo evento magmático (como por exemplo cristais de zircão de um pulso anterior que são absorvidos por um pulso posterior em um ambiente magmático) eles apresentam padrões de crescimento indistinguíveis via CL e só a datação permite separar os grãos de zircão em eventos precisos. Miller et al. (2007) utiliza a nomenclatura "antecristais" para os cristais de zircão originados em um $1^{\circ}$ pulso que é absorvido e a nomenclatura "autocristais" para os cristais de zircão da rocha cristalizada. Essa nomenclatura é originalmente utilizada para sistemas plutônicos e neste trabalho ela é utilizada para a atividade magmática/vulcânica do Complexo VS quando ocorrem duas populações de zircão em uma mesma amostra.

As amostras selecionadas para a datação U-Pb são fragmentadas e os cristais de zircão são separados usando as técnicas tradicionais de preparação e separação de amostras, ou seja: britador $\rightarrow$ moinho de disco $\rightarrow$ mesa vibratória wilfley $\rightarrow$ separação magnética no Franz $\rightarrow$ líquidos densos (bromofórmio e iodeto de metileno). O material resultante é analisado em uma lupa e os cristais de zircão são separados manualmente e colocados em um mount em conjunto com cristais de zircão do padrão internacional TEMORA-2 (Black et al., 2004) e posteriormente polidos para revelar o interior dos cristais. Os cristais de zircão são documentados por imagens de catodoluminescência (CL) para revelar suas estruturas internas a partir da variação no conteúdo de U nos cristais. As imagens de CL foram obtidas em um Microscópio Eletrônico de Varredura (MEV) FEI Quanta 250 e detector XMAX CL (Sato et al., 2014). Essas imagens são utilizadas para a seleção da fase de cristalização do zircão que será datada e para que 
cristais de zircão metamíticos ou com inclusões não sejam datados. As imagens de CL de todos os cristais de zircão analisados são apresentadas mais abaixo em conjunto com os resultados obtidos em cada análise executada em cada um dos cristais de zircão.

As análises geocronológicas são executadas no Laboratório de Geocronologia de Alta Resolução utilizando a Microssonda SHRIMP IIe (Sensitive High Resolution Ion Micro Probe) do Instituto de Geociências da Universidade de São Paulo (IGc-USP). O SHRIMP IIe é um tipo de espectrômetro de massas de íons secundários (SIMS) acoplado a uma microssonda iônica de alta resolução e a um sistema de detectores multicoletores. O SHRIMP IIe mede as diferentes razões isotópicas de U-Th- $\mathrm{Pb}$ com alta acurácia e precisão. Os spots analisados possuem tamanho de $30 \mu \mathrm{m}$ refletindo o diâmetro do feixe primário e a cada análise são medidas as massas de ${ }^{196}\left(\mathrm{Zr}_{2} \mathrm{O}\right),{ }^{206} \mathrm{~Pb},{ }^{207} \mathrm{~Pb},{ }^{208} \mathrm{~Pb},{ }^{238} \mathrm{U}$ e ${ }^{248}(\mathrm{ThO})$. A calibração da idade ${ }^{206} \mathrm{~Pb} /{ }^{238} \mathrm{U}$ é feita utilizando a idade do zircão de referência TEMORA que é de 417 Ma (Black et al., 2004). Todos os dados de U-Pb apresentados nesta tese foram reduzidos com o programa SQUID 2.05 utilizando a correção de chumbo comum usando os isótopos de ${ }^{207} \mathrm{~Pb}$ e ${ }^{204} \mathrm{~Pb}$. Os resultados analíticos foram calculados no software Isoplot versão 4.0 (Ludwig, 2009), onde é possível plotar as idades Concordia, Tera Wasserburg, idade média, histogramas de frequência e curvas de probabilidade relativa. Os parâmetros técnicos do SHRIMP IIe do IGc-USP, bem como os procedimentos analíticos utilizados são descritos em detalhe em Sato et al. (2014).

\subsubsection{Geocronologia em depósitos de VMS}

As rochas e, consequentemente os minerais, presentes em depósitos de sulfeto maciço podem ser subdivididos em duas categorias: I) os minerais de minérios, que são os sulfetos maciços e semi maciços e II) as rochas encaixantes, formadas ou por rochas vulcânicas ou por rochas sedimentares.

A datação de minerais de minérios pode ser aplicada para se obter a idade das mineralizações. Entretanto diversos depósitos de sulfeto maciço apresentam predominantemente pirita, o que afeta a precisão das datação executadas neles. De fato, a primeira datação de idade das mineralizações que foi tentada na FPI foi através do par isotópico de Re-Os em piritas (Rio Tinto e Tharsis foram datados em $345 \pm 26$ Ma e 353 $\pm 44 \mathrm{Ma}$ ), porém as idades obtidas apresentaram erros muito elevados. 
Uma outra maneira possível de se datar os depósitos de sulfeto maciço é a partir da datação das rochas vulcânicas que ocorrem associadas a eles. Os depósitos de sulfeto maciço estão sempre relacionados com fluidos hidrotermais que são aquecidos pelo magmatismo/vulcanismo que forma as rochas encaixantes. Estima-se que estes corpos vulcânicos (dacitos e riolitos) possuam vida curta, entre 2 e 3 Ma e, portanto, os depósitos de sulfeto maciço se formam também neste período de tempo (Schulz, 2012). Como este intervalo de 2 a 3 Ma está dentro do erro analítico da geocronologia efetuada no SHRIMP, nesta tese foi utilizada esta inferência que a idade do vulcanismo também representa a idade do hidrotermalismo gerador de depósitos de sulfeto maciço.

\subsection{TERMOMETRIA POR ISÓTOPOS DE Ti}

\subsubsection{Por que Titânio?}

O zircão serve como hospedeiro para uma variedade de elementos traços que são altamente compatíveis com o retículo cristalino do zircão e poderiam ter sido utilizados para a calibração de um geotermômetro baseado em zircão. No entanto todos estes

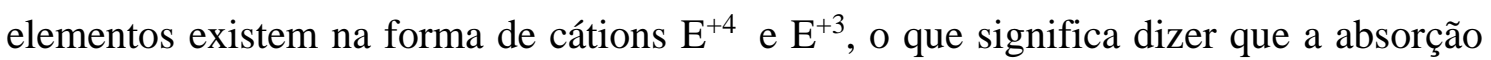
deles no zircão pode ser influenciada por outros componentes do sistema. Isto, e o fato do potencial de atividade química de certos elementos ainda não estarem bem estabelecidos os torna inapropriado para a calibração de um geotermômetro (Watson et al., 2006).

O titânio (Ti), por outro lado, ocorre sempre na forma do cátion tetravalente $\left(\mathrm{Ti}^{+4}\right)$, fazendo com que seu comportamento seja melhor definido. De fato, cálculos executados por Harrison et al. (2005) mostram que $\mathrm{Ti}^{+4}=\mathrm{Si}^{+4}$ é a substituição dominante para temperaturas encontradas na Terra. A maior vantagem na utilização de Ti é que o seu potencial de atividade químico é bem delimitado e com isso as variações observadas podem ser interpretadas com maior confiança. A quantidade de Ti em um cristal de zircão depende da temperatura de formação deste cristal e é praticamente imune a variações de pressão, o que o torna um ótimo geotermômetro (Watson et al., 2006).

\subsubsection{O geotermômetro de Ti-em-zircão}

A temperatura é um parâmetro fundamental que afeta o comportamento reológico e a evolução da cristalização de magmas e melts de fusões parciais. Tradicionalmente são utilizados geotermômetros baseados nos minerais gerados nestes magmas. Existem 
diversos geotermômetros distintos, como óxidos de $\mathrm{Fe}-\mathrm{Ti}$, piroxênio-horblenda e piroxênio-piroxênio (Anderson et al., 2008), no entanto estes geotermômetros possuem limitações na sua aplicabilidade, uma vez que estes minerais são suscetíveis à reequilíbrios, alterações hidrotermais, metamorfismo e intemperismo. O zircão, por outro lado, é extremamente resistente e praticamente não sofre reequilibro e nem é afetado por alterações hidrotermais, metamorfismo e intemperismo posteriores. Essa resistência, em conjunto com a facilidade de se analisar a conteúdo de Ti em seu retículo, fazem do zircão o mineral ideal para a averiguação da temperatura em diferentes magmas e melts.

A utilização da composição de Ti no zircão como um geotermômetro foi proposta por Watson \& Harrison (2005) e Watson et al. (2006). Este geotermômetro pode ser amplamente utilizado, uma vez que o zircão é um mineral que ocorre em abundância na maioria dos litotipos e desde que este geotermômetro foi proposto os modelos petrogenéticos se tornaram cada vez mais dependentes dele (Siégel et al., 2018).

A base termodinâmica do geotermômetro de titânio em zircão é a reação $\mathbf{T i O}_{2}$ $\left(\right.$ rutilo) $=\mathbf{T i O}_{2(\text { zircão) }}$, que possui constante de equilíbrio $\boldsymbol{k}_{1}=\boldsymbol{\alpha}_{\text {TiO2 }}^{\text {zircon }} / \boldsymbol{\alpha}_{\text {TiO2 }}^{\text {rutilo }}$. Como o rutilo é praticamente $\mathrm{TiO}_{2}$ puro, então a atividade de TiO $\boldsymbol{\alpha}_{\text {Tio2 }}^{\text {rutilo }} \cong \mathbf{1}$ e $\mathbf{k} \sim \boldsymbol{\alpha}_{\text {TiO2 }}^{\text {zircão }}$.

Portanto $\alpha_{\text {TiO2 }}^{\text {zircão }}=\gamma_{\text {TiO2 }}^{\text {zircão }} X_{\text {TiO2 }}^{\text {zircão }} \exp \left[\frac{-\Delta G_{1}^{0}}{R T}\right]$ Onde $\alpha$ é o coeficiente de atividade, $X$ é a fração molar de $\mathrm{TiO}_{2}$ no zircão, $-\Delta G_{1}^{0}$ é a energia livre para a reação, $\mathrm{R}$ é a constante dos gases e T é o valor da temperatura absoluta (Watson et al., 2006).

Watson et al. (2006) obtém as temperaturas ao utilizar atividades químicas iguais para $\mathrm{TiO}_{2}$ e $\mathrm{ZrO}_{2}$ em fases que coexistem. Esta é uma simplificação útil, mas que não representa o efeito da variação da atividade $\left(\alpha \mathrm{TiO}_{2}\right.$ e $\left.\alpha \mathrm{ZrO}_{2}\right)$ dos componentes nas substituições, o que é resolvido com a interpretação de que $\mathrm{TiO}_{2}$ e $\mathrm{ZrO}_{2}$ não são fases válidas no zircão pois eles não variam independentemente em uma solução sólida de zircão (Ferry \& Watson, 2007). Para estes autores a solubilidade de Ti no zircão depende não somente da temperatura e do $\alpha_{\mathrm{TiO} 2}$, mas também do $\alpha_{\mathrm{SiO} 2}$. A calibração revista estende a aplicação do Ti-em-zircão para situações sem quartzo e rutilo. Os valores de atividade $\alpha_{\mathrm{TiO} 2}$ em magmas silicáticos variam tipicamente entre 0.6-0.9 e uma mesma análise vária o resultado entre $\sim 750^{\circ} \mathrm{C}$ e $820^{\circ} \mathrm{C}$ de acordo com a variação do valor da atividade $\alpha_{\mathrm{TiO} 2}$ entre 0.5 e 1.0 (Ferry \& Watson, 2007). 


\subsubsection{Por que isótopos de Ti?}

Os trabalhos atuais com a metodologia de termometria via Ti-em-zircão utilizam o conteúdo total de Ti obtido para calcular a temperatura de cristalização (Watson et al., 2006; Watson \& Harrison, 2005; Fu et al., 2008; Codeço et al., 2018). Entretanto, existem cinco isótopos de $\mathrm{Ti}\left({ }^{46} \mathrm{Ti},{ }^{47} \mathrm{Ti},{ }^{48} \mathrm{Ti},{ }^{49} \mathrm{Ti}\right.$ e $\left.{ }^{50} \mathrm{Ti}\right)$ e praticamente todos eles apresentam interferência de massa com outros elementos com número de massa iguais, como o ${ }^{46} \mathrm{Ca}$, ${ }^{48} \mathrm{Ca},{ }^{50} \mathrm{Cr},{ }^{94} \mathrm{Zr}^{2+}$ (massa $\left.=47\right),{ }^{96} \mathrm{Zr}^{2+}$ (massa $\left.=48\right)$ e ${ }^{98} \mathrm{Mo}^{2+}$ (massa = 49). Dentre os isótopos de $\mathrm{Ti}$, os isótopos ${ }^{49} \mathrm{Ti}$ e ${ }^{50} \mathrm{Ti}$ são os que menos sofrem interferências e, se utilizados independentemente dos outros isótopos de $\mathrm{Ti}\left({ }^{46} \mathrm{Ti},{ }^{47} \mathrm{Ti},{ }^{48} \mathrm{Ti}\right)$, apresentam dados mais confiáveis de Ti para a termometria (Sato, comunicação oral).

A razão de ${ }^{50} \mathrm{Ti} /{ }^{49} \mathrm{Ti}$ é relativamente constante em um zircão TEMORA, com valor aproximado de 0.969. Esta razão padrão é utilizada como comparação com as razões ${ }^{50} \mathrm{Ti} /{ }^{49} \mathrm{Ti}$ obtidas em cada grão de zircão analisado. Esta comparação entre a razão real e a razão ideal de ${ }^{50} \mathrm{Ti} /{ }^{49} \mathrm{Ti}$ permite eliminar análises individuais com valores muito discrepantes de 0.969, valores estes que indicariam enriquecimento em $\mathrm{V}$ ou $\mathrm{Cr}$ e, portanto, interferência no conteúdo de ${ }^{50} \mathrm{Ti}$ obtido. Como o isótopo ${ }^{49} \mathrm{Ti}$ não apresenta interferência com outros elementos ele é utilizado como geotermômetro principal e a temperatura obtida por ele é mais precisa que a temperatura obtida pelo ${ }^{50} \mathrm{Ti}$ (Sato, comunicação oral). Neste trabalho foram obtidas as temperaturas obtidas nos geotermometros ${ }^{49} \mathrm{Ti} \mathrm{e}{ }^{50} \mathrm{Ti}$. A temperaturas de ${ }^{50} \mathrm{Ti}$ foram usadas somente para controle e as temperaturas apresentadas nesta tese são as temperaturas do geotermômetro de ${ }^{49} \mathrm{Ti}$

\subsubsection{Análises de isótopos de Ti por SHRIMP}

As análises de isótopos de Ti desta tese foram executadas no SHRIMP IIe do IGcUSP nos mesmos grãos de zircão previamente datados através do U-Pb também no SHRIMP IIe do IGc-USP. Nesta tese foi utilizada a nomenclatura de "Ti-em-zircão" para as análises de conteúdo total de Ti em zircão (Watson \& Harrison, 2005; Watson et al., 2006; Ferry \& Watson, 2007; Codeço et al., 2015; Codeço et al., 2018) e a nomenclatura de "isótopos de $\mathrm{Ti}$ " para as análises que diferenciam os isótopos ${ }^{49} \mathrm{Ti}$ e ${ }^{50} \mathrm{Ti}$. Os procedimentos analíticos utilizados são os apresentados em Sato et al. (2018). Em cristais de zircão a concentração de vanádio $(\mathrm{V})$ e crômio $(\mathrm{Cr})$ raramente ultrapassam os 10ppm, mas a sua presença afeta diretamente a medida do ${ }^{50} \mathrm{Ti}$, e, portanto, estes elementos são monitorados nas análises. O isótopo ${ }^{52} \mathrm{Cr}$ é medido para a correção do isótopo ${ }^{50} \mathrm{Cr}$ de acordo com a equação ${ }^{50} \mathrm{Cr}={ }^{52} \mathrm{Cr}_{\mathrm{m}} \times \mathrm{0} 0519$, enquanto que o isótopo de ${ }^{51} \mathrm{~V}$ é medido 
para a correção do isótopo ${ }^{50} \mathrm{~V}$ de acordo com a equação ${ }^{50} \mathrm{~V}={ }^{51} \mathrm{~V}_{\mathrm{m}} \mathrm{x} 0,002508$, sendo que $\mathrm{Cr}_{\mathrm{m}}$ e $\mathrm{V}_{\mathrm{m}}$ representam os valores obtidos nas análises. A correção resultante para o isótopo ${ }^{50} \mathrm{Ti}$ é ${ }^{50} \mathrm{Ti}={ }^{50} \mathrm{Ti}_{\mathrm{m}}-{ }^{50} \mathrm{Cr}-{ }^{50} \mathrm{~V}$. Para que as correções necessárias sejam efetuadas em conjunto com os cristais de zircão amostrados, também foi analisado o vidro padrão NIST 610, que é o padrão utilizado em análises isotópicas de Ti (Sato et al., 2018).

Para evitar contaminação superficial o raster é mantido por 150 segundos. Como alguns cristais de zircão são outliers e apresentam altas concentrações de Ti que não estão diretamente relacionadas as temperaturas, as medidas foram baseadas nos isótopos ${ }^{49} \mathrm{Ti} \mathrm{e}$ ${ }^{50} \mathrm{Ti}$. Diferenças de concentração considerando este par isotópico foram sempre menores que $5 \%$ e as medidas com razão ${ }^{50} \mathrm{Ti} /{ }^{49} \mathrm{Ti}$ discrepantes foram descartadas. A razão de ${ }^{50} \mathrm{Ti} /{ }^{49} \mathrm{Ti}$ foi sistematicamente conferida para verificar a acurácia da redução dos dados e se manteve sempre próxima do seu valor real de 0.9690 .

Watson et al. (2006) calibrou sua equação utilizando $\alpha \mathrm{TiO}_{2} \sim 1$, ou seja, assumindo que o magma está saturado em rutilo. Porém magmas saturados em rutilo são extremamente raros e, em magmas félsicos o $\alpha \mathrm{TiO}_{2}$ é aproximadamente fixo em valores $>0.5$ e com base nisso Claiborne et al. (2006) ajustou a equação de Watson \& Harrison (2005) para refletir $\alpha \mathrm{TiO}_{2} \sim 0.7$, apropriado para a saturação de titanita e titanomagnetita. Incertezas quanto ao valor verdadeiro de $\alpha \mathrm{TiO}_{2}$ podem introduzir uma variação de dezenas de graus célsius na temperatura absoluta, mas enquanto o $\alpha \mathrm{TiO}_{2}$ permanecer aproximadamente constante, ou seja, enquanto o magma estiver saturado com uma fase de Ti os erros serão sistematicamente os mesmos e a diferença de temperatura relativa apresentada pelo termômetro de Ti será real (Claiborne et al., 2006). As rochas vulcânicas félsicas da FPI estudadas nesta tese são essencialmente riolitos, riodacitos e dacitos em composição, o que é consistente com a utilização da correção de Claiborne et al. (2006) para a equação de Watson \& Harrison (2005) e, portanto, Codeço (2015) e Codeço et al. (2018) utilizam o valor de $\alpha \mathrm{TiO}_{2}=0.7$ nos cálculos de temperatura via Ti-em-zircão na Faixa Piritosa Ibérica. Como estes trabalhos são os únicos que já utilizaram o Ti-emzircão na FPI nesta tese foi utilizada o valor de $\alpha \mathrm{TiO}_{2}=0.7$ para o cálculo das temperaturas, assim comparações entre os resultados obtidos aqui e na literatura são possíveis.

A utilização de uma atividade de Ti incorreta pode gerar variação de até $\sim 70^{\circ} \mathrm{C}$ na temperatura, o que Ferry \& Watson (2007) demonstraram ao calcular as temperaturas com variação de $\alpha \mathrm{TiO}_{2}$ entre 1 a 0.6 (Ferry \& Watson, 2007). Por sua vez, a ablação de 
inclusões ricas em Ti (por exemplo rutilo ou ilmenita) ou fraturas preenchidas por $\mathrm{Ti}$ podem aumentar drasticamente a temperatura obtida (Siégel et al., 2018)

Após as análises terem sido efetuados os resultados foram interpretados levando em conta a proporção entre a razão entre o ${ }^{50} \mathrm{Ti}$ e o ${ }^{49} \mathrm{Ti}$, e quando esta razão variou abaixo de 0.94 ou acima de 1.00 os resultados foram desconsiderados. Temperaturas irreais foram descartadas de acordo com os experimentos em magmas félsicos, que indicam uma faixa entre 620 a $970^{\circ} \mathrm{C}$ (Scaillet et al., 2016), o que torna temperaturas inferiores a $620^{\circ} \mathrm{C}$ questionáveis (Siégel et al., 2018). Temperaturas muito elevadas também estão via-deregra associadas a valores muito elevados de Ti e também podem representar algum enriquecimento posterior, alguma inclusão rica em Ti ao uma fratura em que o Ti se acumulou posteriormente. Estas análises também foram descartadas.

\subsection{ISÓTOPOS DE Lu-Hf}

Os elementos lutécio (Lu) e háfnio (Hf) são elementos terra raras (ETR). O Lu possui 2 isótopos, o ${ }^{176} \mathrm{Lu}$ e o ${ }^{175} \mathrm{Lu}$. Destes dois somente o isótopo ${ }^{176} \mathrm{Lu}$ é radioativo e decai para ${ }^{176} \mathrm{Hf}$, este decaimento possui de $1,94 \times 10^{-11}$ ano- $^{-1}$, o que equivale a uma meia vida de 37,8 Ga. Estes isótopos são fracionados nos processos de fusão mantélica. O Hf tende a ficar na parte líquida, enquanto que o Lu permanece no restituo. Com isso o manto é enriquecido em isótopos de ${ }^{176} \mathrm{Hf}$ em relação à crosta (Faure \& Mensing, 2005).

O elemento Hf apresenta raio iônico de 0.81 Å, valor muito similar ao raio iônico do zircônio $(\mathrm{Zr})$, que é $0,81 \AA$ A. Com isso os minerais como o zircão possuem altos teores de Hf. No entanto o raio iônico do Lu é grande $(0,93 \AA$ A) e o retículo cristalino do zircão não comporta bem este elemento, resultando em baixas razões $\mathrm{Lu} / \mathrm{Hf}$ em zircão. Isto exclui a necessidade de correção da razão ${ }^{176} \mathrm{Hf} /{ }^{177} \mathrm{Hf}$ medida, pois não há geração de $\mathrm{Hf}$ radiogênico se não existir $\mathrm{Lu}$ inicial. Com isso a razão ${ }^{176} \mathrm{Hf} /{ }^{177} \mathrm{Hf}_{\text {inicial }}$ se mantem constante após a cristalização e reflete as características do ambiente em que o zircão foi cristalizado.

Os elementos Lu e Hf, assim como ocorre com os elementos Sm e Nd, apresentam comportamento distinto no processo de fusão parcial mantélica, com o Hf sendo o mais incompatível de ambos. Isso significa que a partir de um ponto inicial de composição homogenea de um manto primitivo hipotético (denominado CHUR, chondritic uniform reservoir) dois reservatórios com assinaturas $\mathrm{Lu} / \mathrm{Hf}$ distintas foram gerados: 1) a crosta, com $\mathrm{Lu} / \mathrm{Hf}_{\text {crosta }}<\mathrm{Lu} / \mathrm{Hf}_{\mathrm{CHUR}}$ e 2) o manto empobrecido, com Lu/Hf $\mathrm{Hanto}_{\text {mo }}>\mathrm{Lu} / \mathrm{Hf}_{\mathrm{CHUR}}$. Assim como ocorre com o $\mathrm{Nd}$ um parâmetro petrogenético denominado $\varepsilon_{\mathrm{Hf}}$ também foi 
estabelecido a partir da comparação entre as razões de ${ }^{176} \mathrm{Hf} /{ }^{177} \mathrm{Hf}$ de uma determinada amostra com a razão do CHUR (Eq. 1).:

$$
\varepsilon_{\mathrm{Hf}}(\mathrm{t})=\left[\left({ }^{176} \mathrm{Hf} /{ }^{177} \mathrm{Hf}\right)_{\operatorname{amostra}}(\mathrm{t}) /\left({ }^{176} \mathrm{Hf} /{ }^{177} \mathrm{Hf}\right)_{\mathrm{CHUR}}(\mathrm{t})-1\right] \times 10000 \text { Eq. } 1
$$

Este parâmetro é utilizado em estudos de evolução crustal. Um zircão com valor de $\varepsilon_{\text {Hf }}$ positivo é enriquecido em ${ }^{176} \mathrm{Hf}$ radiogênico em relação ao $\mathrm{CHUR}$ e, portanto, deve ter se cristalizado em uma rocha com razão Lu/Hf maior que a do reservatório condrítico, (por exemplo, um magma juvenil). De mesma forma, um zircão com $\varepsilon_{\mathrm{Hf}}$ negativo foi cristalizado a partir da fusão de material crustal.

As análises de Lu-Hf foram executadas na Memorial University of Newfoundland (MUN) com um espectrômetro de massa Finnigan NEPTUNE de foco duplo, alta resolução e multi coletores em conjunto com o espectrômetro de massa (MC-ICPMS) com um sistema de laser Geolas 193nm Ar-F excimer acoplado (LA), seguindo a metodologia apresentada por Fisher et al. (2011). As análises de Lu-Hf foram executadas nos mesmo cristais de zircão analisados previamente por SHRIMP (U-Pb e Ti-em-zircão), ou diretamente em cima dos spots deixados pelas análises pretéritas ou o mais próximo possível disso. Como o tamanho e a profundida das crateras deixadas pelo LA-MCICPMS são consideravelmente maiores (diâmetro de $50 \mu \mathrm{m}$ e cratera profunda), e, portanto, mais destrutivas, que as crateras deixadas pelo SHRIMP (diâmetro e profundidade de $20 \mu \mathrm{m}$ e cratera superficial), as análises de Lu-Hf foram as últimas analises executadas nos cristais de zircão. A configuração do LA-MC-ICPMS da MUN apresenta oito coletores Faraday, o que permite a coleta simultânea das seguintes massas de Lu, Yb e Hf: ${ }^{171} \mathrm{Yb}$ (coletor inferior 4); ${ }^{173} \mathrm{Yb}$ (coletor inferior 3); ${ }^{174}(\mathrm{Hf}+\mathrm{Yb}$ ) (coletor inferior 2); ${ }^{175} \mathrm{Lu}$ (coletor inferior 1$) ;{ }^{176}(\mathrm{Hf}+\mathrm{Yb}+\mathrm{Lu})$ (coletor axial); ${ }^{177} \mathrm{Hf}$ (coletor superior 1); ${ }^{178} \mathrm{Hf}$ (coletor superior 2); e ${ }^{179} \mathrm{Hf}$ (coletor superior 3). Os cristais de zircão da FPI foram analisados juntamente com os cristais de zircão de referência FC-1 (Woodhead \& Hergt, 2005; Vervoort, 2010), R33 (Vervoort, 2010), com os cristais de zircão sintéticos B142, B144 (Fisher et al., 2011) e com o zircão Plesovice (Sláma et al., 2008). Com isto a acurácia e precisão das análises de Lu-Hf no LA-MC-ICPMS são controladas ao longo das análises.

Cada análise no LA-MC-ICPMS consiste em 30 segundos de coleta de dados do gás de background seguidos por 60 segundos de ablação, com feixe de laser com diâmetro de $49 \mu \mathrm{m}$ (este diâmetro pode variar de acordo com o tamanho do cristal analisado, mas nos grãos de zircão da FPI somente foi utilizado o diâmetro de $49 \mu \mathrm{m}$ ), o laser disparou 
com uma frequência de $10 \mathrm{~Hz}$ utilizando $5 \mathrm{~J} / \mathrm{cm}^{2}$ de energia. O gás carregador utilizado na célula de ablação foi o hélio (He) e foi usado a uma taxa de 0.9-1.0 litro/min, com um fluxo adicional do gás de nitrogênio $\mathrm{N}_{2}$ de 4.0-7.5 mililitro/min adicionados ao fluxo de argônio (Ar) de 0.7 litros/min. Cada pico de análise durou 1 segundo e cada análise tipicamente leva 60 segundos.

Os dados coletados foram processados utilizando o software Iolite v.3.71 no Laboratório de Geoquímica Experimental da MUN. O processamento dos dados no Iolite permite que os dados sejam corrigidos visualmente utilizando as plotagens de tempo vs. intensidade e tempo vs. razão isotópica. Esta abordagem permite integrar seletivamente diferentes porções do sinal obtido pelo espectrômetro, uma vez que mudanças na razão ${ }^{176} \mathrm{Hf} /{ }^{177} \mathrm{Hf}$ podem ocorrer devido a presença de inclusões, ou quando o laser atravessa o zircão analisado e atinge o mount, o que ocorreu com certa frequência nos grãos de zircão mais finos. A redução dos dados obtidos utiliza o "Data Reduction Scheme" ("Hf_isotopes_MUN.ipf") escrito pelo Dr. Christopher M. Fisher baseado na planilha de Excel "MCTOOL-Hf.xls" da Dr. Rebecca Lam, a responsável pelas análises de Lu-Hf no laboratório. Na redução dos dados todos os sinais em estudo bruto são corrigidos com base no branco usando um valor base inserido no manualmente no Iolite. O cálculo da baseline utilizou 20-30pts obtidos. Para obter os dados dos cristais o usuário seleciona um intervalo de até 50pts cobrindo os dados obtidos pela ablação do laser na amostra. Análises com menos de 20pts ( 20s de abração) foram descartadas devido a imprecisão que estão associadas as menores quantidades de material coletado. As razões isotópicas utilizadas para as correções de enviesamento de massa foram: ${ }^{179} \mathrm{Hf} /{ }^{177} \mathrm{Hf}=0.7325$ (Patchett \& Tatsumoto, 1980); ${ }^{173} \mathrm{Yb} /{ }^{171} \mathrm{Yb}=1.1302 \mathrm{e}{ }^{176} \mathrm{Yb} /{ }^{171} \mathrm{Yb}=0.7938$ (Segal et al., 2003)

$\mathrm{O}$ fator $\beta$ é utilizado para o cálculo do enviesamento de massa para o $\mathrm{Hf}$ e o $\mathrm{Yb}$ onde o sinal medido (ms) é o branco da análise enquanto que o valor corrigido (corr) é o valor esperado para estas razões. Os enviesamentos de massa de Yb e Hf (Eq.2 e Eq.3) são calculados de acordo com as Eq. 1 e Eq. 2 a seguir: 


$$
\begin{aligned}
& \beta(Y b)=\frac{\ln \left[\frac{\left(\frac{{ }^{173} Y b}{{ }^{171} Y b}\right)_{c o r r}}{\left(\frac{{ }^{173} Y b}{{ }^{171} Y b}\right)_{m s}}\right]}{\ln \left(\frac{M_{173(Y b)}}{M_{171(Y b)}}\right)} \quad E q .2 \\
& \beta(H f)=\frac{\ln \left[\frac{\left(\frac{{ }^{179} H f}{{ }^{177} H f}\right)_{c o r r}}{\left(\frac{{ }^{179} H f}{{ }^{177} H f Y b}\right)_{m s}}\right]}{\ln \left(\frac{M_{173(H f)}}{M_{171(H f)}}\right)} E q .3
\end{aligned}
$$

Onde $\mathrm{M}$ é a massa do isótopo em questão. O sinal obtido para a massa atômica 176 é uma combinação de ${ }^{176} \mathrm{Hf},{ }^{176} \mathrm{Lu}$ e ${ }^{176} \mathrm{Yb}$, o que significa que para calcular o ${ }^{176} \mathrm{Hf}$ é necessário subtrair a quantidade de ${ }^{176} \mathrm{Lu}$ e ${ }^{176} \mathrm{Yb}$. Estes dois isótopos contribuem para a massa medida no sinal 176 de acordo com as equações 4,5 e 6 a seguir:

$$
\begin{gathered}
{ }^{176} Y b_{m s}={ }^{173} Y b_{m s} \times\left(\frac{{ }^{176} Y b}{{ }^{173} Y b}\right)_{c o r r} \times\left(\frac{M_{173(Y b)}}{M_{176(Y b)}}\right)^{\beta(Y b)} E q .4 \\
{ }^{176} L u_{m s}={ }^{175} L u_{m s} \times\left(\frac{{ }^{176} L u}{{ }^{175} L u}\right)_{c o r r} \times\left(\frac{M_{173(Y b)}}{M_{176(L u)}}\right)^{\beta(Y b)} E q .5 \\
{ }^{176} H f_{m s}={ }^{176}(H f+Y b+L u)_{m s}-{ }^{176} Y b_{m s}-{ }^{176} L u_{m s} \quad E q .6 \\
\text { O valor da razão }{ }^{176} \mathrm{Lu} /{ }^{175} \mathrm{Lu} \text { utilizado é } 0.02656, \text { seguindo o valor obtido por Chu }
\end{gathered}
$$
et al. (2002). O ${ }^{176} \mathrm{Hf} /{ }^{177} \mathrm{Hf}$ é calculado para do enviesamento de massa de acordo com a Eq. 7:

$$
\left(\frac{{ }^{176} H f}{{ }^{177} H f}\right)_{c o r r}=\left(\frac{{ }^{176} H f}{{ }^{177} H f}\right)_{m s} \times\left(\frac{M_{176(H f)}}{M_{177(H f)}}\right)^{\beta(H f)} \quad E q .7
$$

Este cálculo é feito para cada ponto da análise. O resultado final da ${ }^{176} \mathrm{Hf} /{ }^{177} \mathrm{Hf}$ corrigida para "final mass bias and interference" é a média dos $\sim 50$ pts do intervalo selecionado pelo usuário. Outliers são excluídos quando estão acima de 2 desvios padrões da média (2SD rejection). $\mathrm{O}{ }^{176} \mathrm{Hf} /{ }^{177} \mathrm{Hf}_{\text {corr }}$ é normalizado utilizando o valor referência de ${ }^{176} \mathrm{Hf} /{ }^{177} \mathrm{Hf}=0.282482$ obtido para o zircão Plesovice (Slama et al., 2008). Essa correção 
geralmente é negligenciável, e o valor de ${ }^{176} \mathrm{Hf} /{ }^{177} \mathrm{Hf}_{\text {corr }}$ do Plesovice analisado tipicamente fica entre 0.000010 do valor utilizado como referência. A correção do zircão Plesovice é calculada de acordo com a Eq 8:

$$
\left(\frac{{ }^{176} \mathrm{Hf}}{{ }^{177} \mathrm{Hf}}\right)_{\text {std_corr }}=\frac{0.282482}{\text { média }\left(\frac{{ }^{176} \mathrm{Hf}}{{ }^{177} \mathrm{Hf}}\right)_{\text {corr }} \text { Plesovice analisados }} \times\left(\frac{{ }^{176} \mathrm{Hf}}{{ }^{177} \mathrm{Hf}}\right)_{\text {corr }} \text { Eq.8 }
$$

Os parâmentros $\varepsilon_{\mathrm{Hf}}$ foram calculados na Memorial University of Newfoundland (MUN) com uma planilha Excel feita pelo Prof. John Hanchar e utilizada por seus alunos e demais pessoas que fazem análises de Lu-Hf na MUN e alguns destes parâmetros também foram calculados a mão para confirmar a precisão dos cálculos da planilha. Nesta planilha os valores de ${ }^{176} \mathrm{Hf} /{ }^{177} \mathrm{Hf}$ e ${ }^{176} \mathrm{Lu} /{ }^{177} \mathrm{Hf}$ obtidos no Iolite são inseridos após a redução dos dados e a correção dos mesmos. Os parâmetros de Lu-Hf utilizados nos cálculos de $\varepsilon_{\mathrm{Hf}}$ são os obtidos por Bouvier et al. (2008) para a constante de decaimento do ${ }^{176} \mathrm{Lu}=1.867 \times 10^{-11}$, valor atual do ${ }^{176} \mathrm{Lu} /{ }^{177} \mathrm{Hf} \mathrm{CHUR}=0.0336$ e valor atual do ${ }^{176} \mathrm{Hf} /{ }^{177} \mathrm{Hf} \mathrm{CHUR}=0.282785$. Os parâmetros ${ }^{176} \mathrm{Hf} /{ }^{177} \mathrm{Hf} \mathrm{e}{ }^{176} \mathrm{Lu} /{ }^{177} \mathrm{Hf}$ obtidos no Iolite e os $\varepsilon_{\mathrm{Hf}}$ obtidos na planilha de cálculo para todas as amostras estudadas podem ser consultados em Anexo III. 


\section{RESULTADOS}

Nesta tese foram empregados 3 métodos isotópicos (U-Pb, Ti e Lu-Hf) em populações de zircão provenientes de diversos depósitos de sulfeto maciço, um depósito de $\mathrm{Mn}$ e rochas regionais. Visando a clareza da apresentação dos resultados eles foram organizados e discutidos de acordo com cada localidade e não de acordo com cada metodologia, assim evitam-se redundâncias descritivas e otimiza-se a compreensão dos resultados. Os resultados são apresentados de acordo com a separação geográfica da FPI entre Região Norte (Cinturão Norte e Setor Central) e Região Sul. Os resultados analíticos dos isótopos de U-Pb, Ti e Lu-Hf encontram-se, respectivamente, nos ANEXO I, II e III. Para facilitar a leitura, os resultados analíticos também estão apresentados de forma mais sucinta nas Tabela 5 e 5 no final deste capítulo

\subsection{REGIÃO NORTE}

\subsubsection{Cinturão Norte}

San Telmo

O depósito de San Telmo é um depósito de sulfeto maciço rico em $\mathrm{Cu}-\mathrm{Zn}$ abandonado que se localiza na extremidade leste do Cinturão do Norte da FPI. Originalmente esta mina possuía 4.0Mt com teores de $1,2 \% \mathrm{Cu}, 0,4 \% \mathrm{~Pb}, 12 \% \mathrm{Zn}, 60 \mathrm{~g} / \mathrm{t}$ Ag e 0,8g/t Au que já foram explotados (Sanchez-España et al., 2000). A geologia local é composta por um domo félsico com lentes de sulfetos associadas as rochas mais externas ao domo (hialoclastitos). A parte superior da mineralização é bandada e apresenta um alto teor de $\mathrm{Cu}$ e $\mathrm{Zn}$ enquanto a parte inferior é composta por um stockwork com menor presença de Zn (Tornos, 2007). No depósito de San Telmo a transição entre sulfeto maciço, semi maciço e rocha félsica é clara, e está relacionada a distância entre a rocha e a fonte dos fluidos hidrotermais. A zona de stockwork com sulfeto semi maciço foi amostrada. Esta rocha se encontra totalmente alterada hidrotermalmente de modo que as suas características primárias não estão preservadas, e o seu protolito foi considerado como arenito vulcanoclástico rico em púmice ou epiclasto (Conde, 2016).

Os cristais de zircão foram concentrados a partir de uma amostra da rocha vulcânica associada aos sulfetos maciços (ST-03), que apresenta silicificação e precipitação de sulfetos disseminados relacionados a atividade hidrotermal (Figura 28). Os cristais de zircão foram imageados por catodoluminescência (CL) em microscópio eletrônico de varredura visando caracterizar diferentes populações de zircão presente na 
amostra, bem como inclusões, estágios distintos de cristalização e danos ao retículo cristalino. Grande parte dos cristais de zircão apresentam zoneamentos oscilatórios no interior dos cristais, que são típicos de grãos de zircão ígneos. Diversos cristais de zircão desta amostra apresentam bordas afetadas por alterações tardi-magmáticas. Estas bordas, quando datadas, apresentaram a mesma idade dos zoneamentos oscilatórios presentes no interior dos cristais. Os cristais de zircão são prismáticos, com comprimento variando entre 80 e $150 \mu \mathrm{m}$. Os zoneamentos oscilatórios são relativamente homogêneos e as bordas destes cristais de zircão apresentam um aspecto corroído, indicando que estas sofreram processos de reabsorção no magma, o que mostra que este magma atingiu a saturação de $\mathrm{Zr}$ e se tornou insaturado posteriormente, o que faz com que os cristais de zircão comecem a ser reabsorvidos.
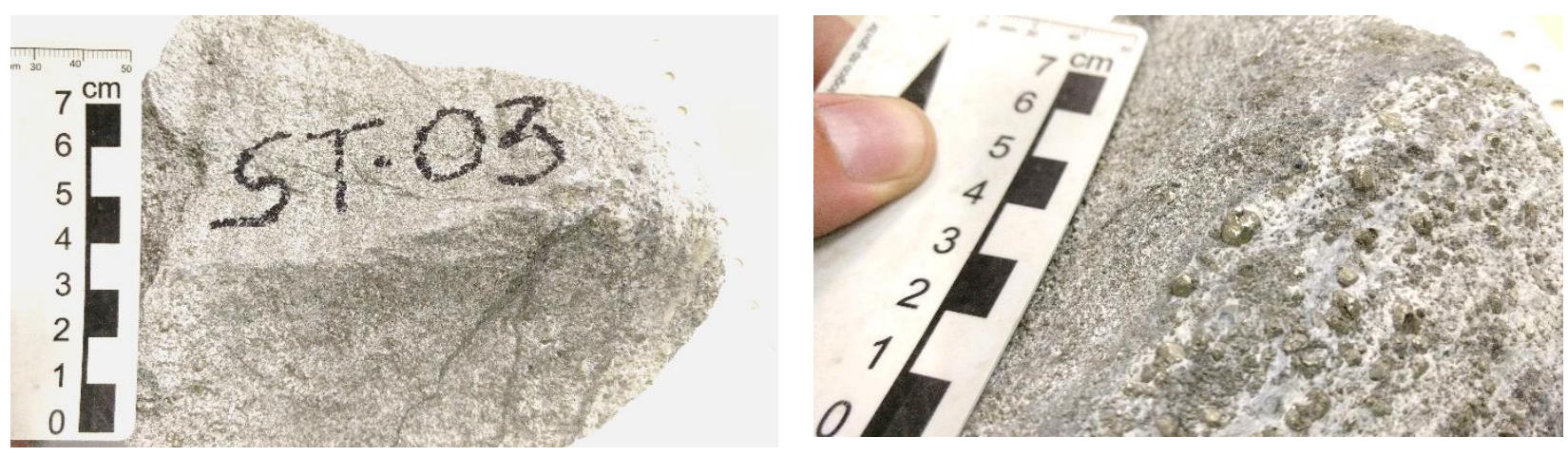

Figura 28. Fotografias da amostra da rocha félsica encaixante (ST-03) estudada em San Telmo.

Nesta amostra 24 análises de U-Pb por SHRIMP foram realizadas em 24 cristais de zircão. As análises são caracterizadas por uma pequena variação nos conteúdos de U (78 - 197 ppm) e razões Th/U entre 0.447 e 0.756, razões típicas de grãos de zircão ígneos. As análises foram executadas predominantemente em zoneamentos oscilatórios no interior dos cristais de zircão. As idades individuais ${ }^{206} \mathrm{~Pb} /{ }^{238} \mathrm{U}$ das 24 análises variaram entre 335 e $358 \mathrm{Ma}$ e, em conjunto, apresentaram uma idade média de $347 \pm 2 \mathrm{Ma}$. Em um diagrama concórdia 21 análises definiram uma idade concórdia de $347 \pm 2 \mathrm{Ma}$, com MSWD de 0.22 (Figura 29). 

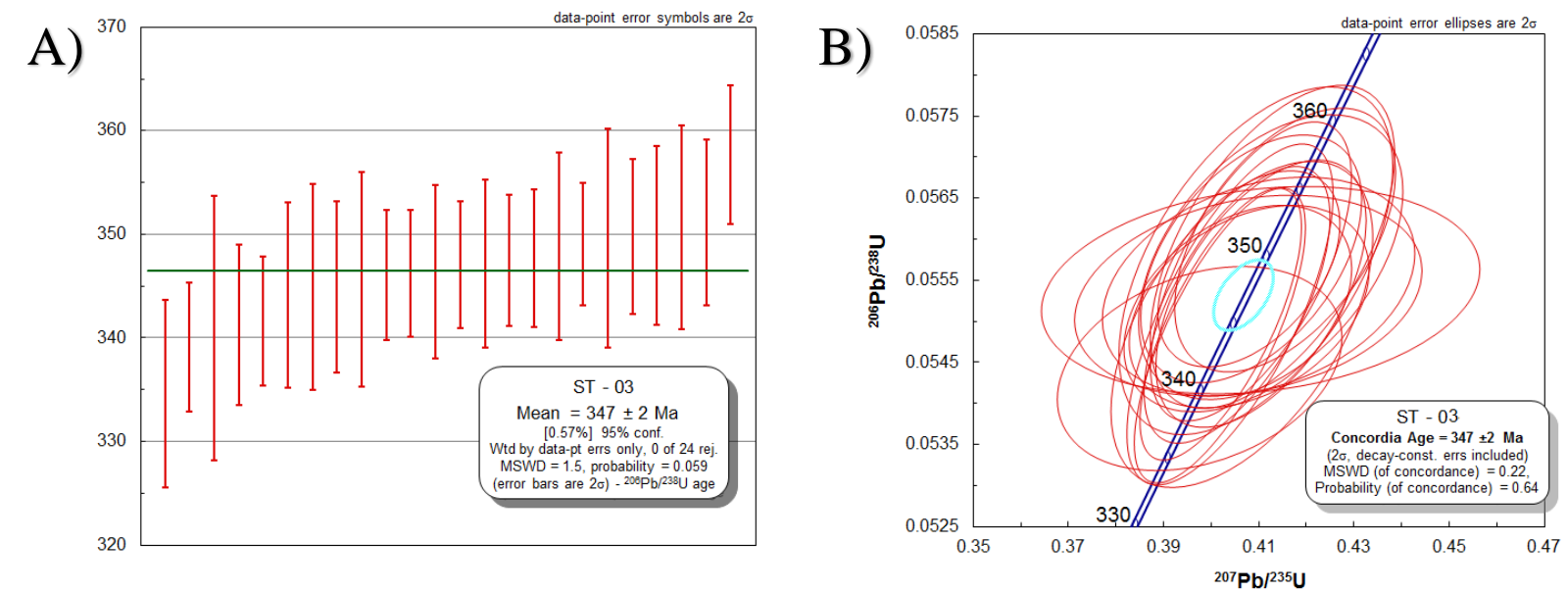

Figura 29. A) idade ${ }^{206} \mathrm{~Pb} /{ }^{238} U$ média e B) idade concórdia obtida para a população de ST-03

Dentre os cristais de zircão desta amostra, 10 grãos foram utilizados em análises dos isótopos de Ti via SHRIMP com o intuito de caracterizar a temperatura de cristalização desses minerais no magma. A razão média de ${ }^{50} \mathrm{Ti} /{ }^{49} \mathrm{Ti}$ nos grãos de zircão analisados é de 0.96, com 6.9 ppm de ${ }^{49} \mathrm{Ti}$ e $6.7 \mathrm{ppm}$ de ${ }^{50} \mathrm{Ti}$. Com 9 cristais de zircão apresentam uma temperatura média de $742 \pm 25^{\circ} \mathrm{C}$ no ${ }^{49} \mathrm{Ti}$ e temperatura média de $739 \pm$ $23{ }^{\circ} \mathrm{C}$ no ${ }^{50} \mathrm{Ti}$ (Figura 30A), enquanto um zircão é um outlier enriquecido em Ti com 69.4 ppm de ${ }^{49} \mathrm{Ti}$ e $70.0 \mathrm{ppm}$ de ${ }^{50} \mathrm{Ti}$. Nesta amostra 19 cristais de zircão também foram analisados pelo método Lu-Hf por LA-MC-ICPMS. Os valores presentes de ${ }^{176} \mathrm{Hf} /{ }^{177} \mathrm{Hf}_{\mathrm{o}}$ variaram entre 0.282895 e 0.282823 , com os valores de $\varepsilon_{\mathrm{Hfo}}$ correspondentes variando entre 3.89 e 1.34, e valor médio de 2.55. Utilizando a idade concórdia de 347Ma obtida nesta amostra para o cálculo do valor inicial de ${ }^{176} \mathrm{Hf} /{ }^{177} \mathrm{Hf}_{\mathrm{i}}$ os novos valores variam entre 0.282893 e 0.282822 , sendo que o valor de $\varepsilon_{\mathrm{Hfi}}$ correspondente varia entre 4.59 e 2.08 , com média em 3.28 (Figura 30B). Os resultados de todas as análises isotópicas individuais de U-Pb, Ti e Lu-Hf podem ser vistos na Figura 31 com as imagens de CL com a localização das análises e o resultado plotados juntos. 
A)

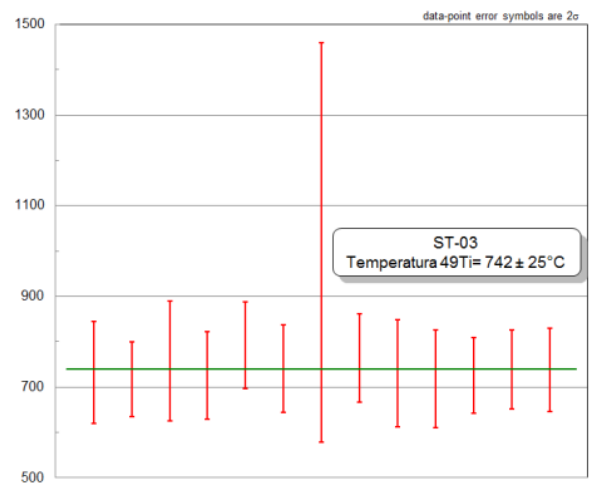

B)

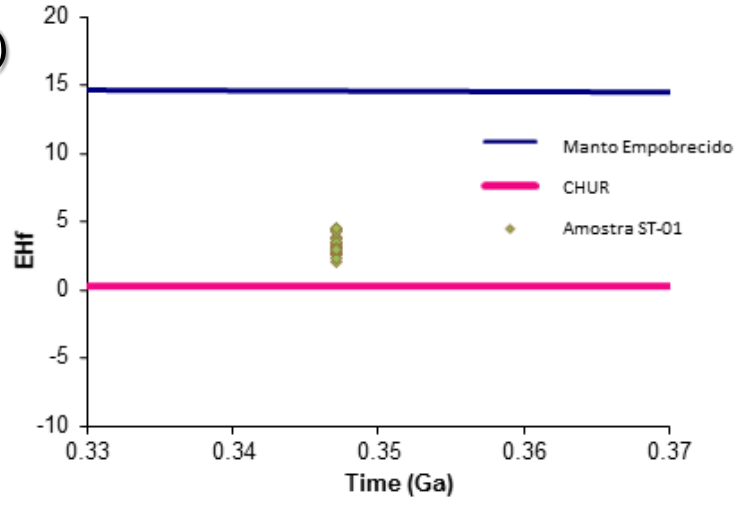

Figura 30. A) temperaturas ${ }^{49}$ Ti e B) valor de $\varepsilon_{H f i}$ obtidos na população de ST-03

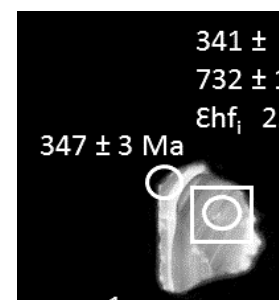

1.

2

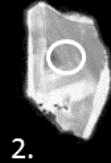

$358 \pm 3 \mathrm{Ma}$ Ehf $_{\mathrm{i}} 4.52$

$740 \pm 13^{\circ} \mathrm{C}$ Ehf $_{\mathrm{i}} 3.80$

7.

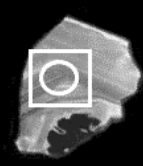

$349 \pm 5 \mathrm{Ma}$

Ehf $_{\mathrm{i}} 3.24$

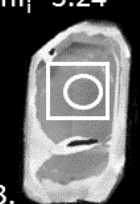

13.

$346 \pm 3 \mathrm{Ma}$

Ehf $_{\mathrm{i}} 2.08$

19.

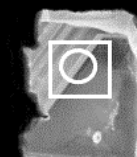

8.

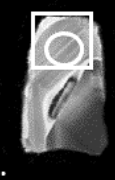

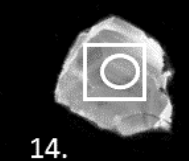

3.

$\begin{array}{lll}349 \pm 3 \mathrm{Ma} & 339 \pm 3 \mathrm{Ma} & 350 \pm 4 \mathrm{Ma} \\ 718 \pm 11^{\circ} \mathrm{C} & 757 \pm 17^{\circ} \mathrm{C} & 725 \pm 13^{\circ} \mathrm{C} \\ \text { Ehf } 3.88 & \end{array}$

$349 \pm 3 \mathrm{Ma} \quad 339 \pm 3 \mathrm{Ma} \quad 350 \pm 4 \mathrm{Ma}$

हhf $_{\mathrm{i}} 2.74 \quad$ हhf $_{\mathrm{i}} 3.42$

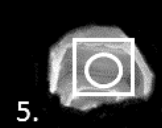

$346 \pm 3 \mathrm{Ma}$

$792 \pm 12^{\circ} \mathrm{C}$

हhf $_{\mathrm{i}} 2.57$

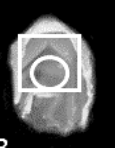

$345 \pm 5 \mathrm{Ma}$ $740 \pm 13^{\circ} \mathrm{C}$ Ehf $_{\mathrm{i}} 4.38$

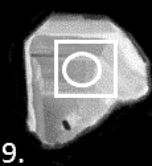

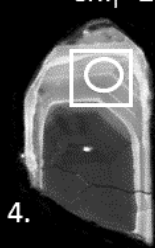

$350 \pm 4 \mathrm{Ma}$ $1019 \pm 43^{\circ} \mathrm{C}$ Ehf $_{\mathrm{i}} 3.04$

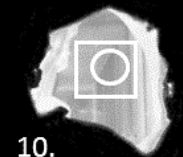

10.

6.

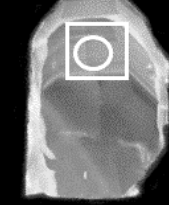

$345 \pm 4 \mathrm{Ma}$

$764 \pm 13^{\circ} \mathrm{C}$

$335 \pm 5 \mathrm{Ma} \quad$ हhf $_{\mathrm{i}} 3.43$

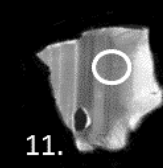

12

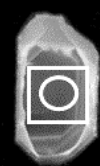

$342 \pm 3 \mathrm{Ma} \quad 351 \pm 5 \mathrm{Ma}$ $731 \pm 16^{\circ} \mathrm{C} \quad 719 \pm 15^{\circ} \mathrm{C}$ Ehf $_{\mathrm{i}} 3.14$ Ehf $_{\mathrm{i}} 2.61$
$347 \pm 3 \mathrm{Ma}$ غhf $_{\mathrm{i}} 2.70$
$346 \pm 4 \mathrm{Ma}$ غhf $_{\mathrm{i}} 2.90$
$348 \pm 3 \mathrm{Ma}$ Ehf $_{\mathrm{i}} 3.14$

15.

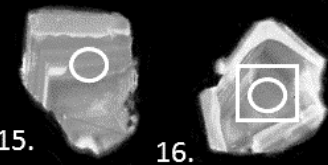

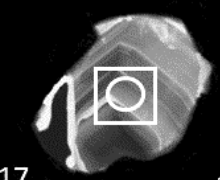

17.

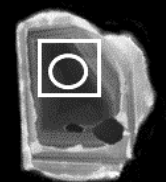

18.

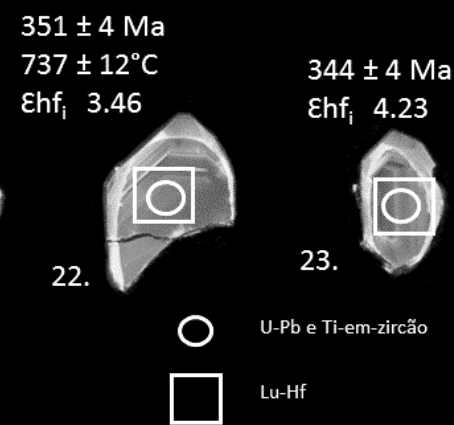

$351 \pm 4 \mathrm{Ma}$ $738 \pm 12^{\circ} \mathrm{C}$ Ehf $_{\mathrm{i}} 3.74$ $726 \pm 12^{\circ} \mathrm{C}$ Ehf $_{\mathrm{i}} 2.36$

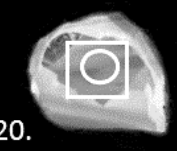

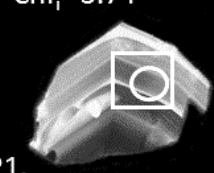

21. CPGeo

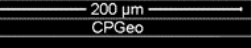

\section{$737 \pm 12^{\circ} \mathrm{C}$}

3.46 \begin{tabular}{|c|c|c|c|c|c|}
\hline det & HV & WD & pressure & spot & mag $\mathrm{⿴囗十}$ \\
PMD & $15.00 \mathrm{kV}$ & $17.0 \mathrm{~mm}$ & $1.10 \mathrm{e}-4 \mathrm{~Pa}$ & 6.0 & $285 \mathrm{x}$ \\
\hline
\end{tabular}

Figura 31. Cristais de zircão analisados na amostra ST-03 com os respectivos resultados das análises individuais de $\mathrm{U}$-Pb (idade ${ }^{238} \mathrm{U}^{206} \mathrm{~Pb}$ ), Ti-em-zircão (temperatura ${ }^{49} \mathrm{Ti}$ ) e $\mathcal{E}_{\mathrm{Hfi}}$ calculado com a idade concórdia obtida via U-Pb. 


\section{Aguas Tenidas}

O depósito de Aguas Tenidas é o maior depósito do Cinturão Norte da FPI, com mais 41.4 Mt de sulfetos maciços e 21.2 Mt de stockwork mineralizado (Conde \& Tornos, 2019). Nele duas amostras distintas foram estudadas (AT-01 e AT-03). Ambas são rochas vulcanoclásticas de composição félsica que são as porções distais de domos félsicos da região de acordo com estudos regionais (Conde, 2016) e de faciologia do vulcanismo félsico na FPI (Rosa et al., 2010). Estas porções distais são colocadas acima e abaixo dos corpos de VMS pela deformação variscana que afetou mais intensamente a região norte da FPI (Sanchez Espana et al., 2000; Conde, 2016). As duas amostras são rochas foliadas com amplo processo de alteração hidrotermal no qual a litologia anterior está parcial a totalmente substituída por clorita e sericita, além de quartzo (Figura 32).

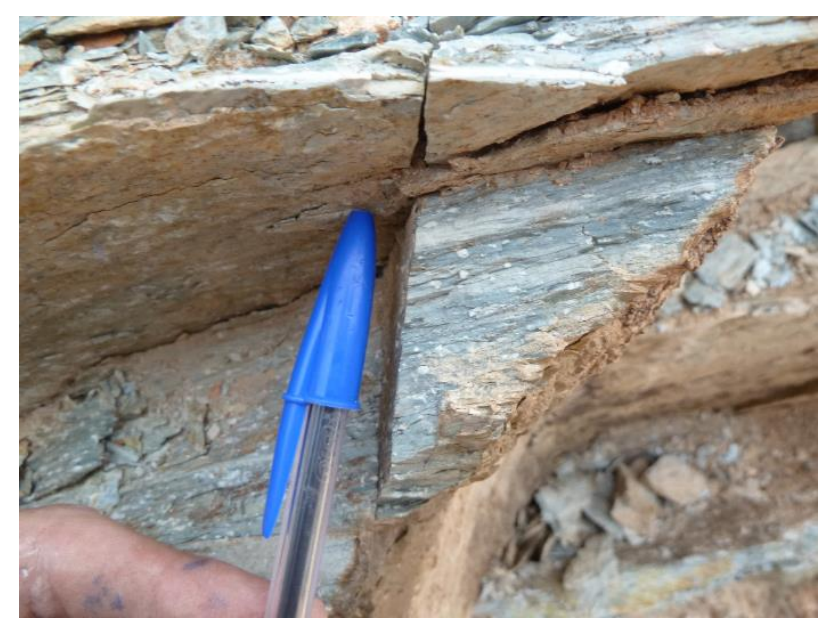

Figura 32. Foto representativa dazone amostra AT-01.

A amostra AT-01 apresenta grãos de zircão prismáticos que variam de comprimento entre 100-150 $\mu \mathrm{m}$. As imagens de CL obtidas mostram grãos de zircão ígneos com zoneamento oscilatório geralmente escuro, e pouca variação composicional. Diversas bordas reabsorvidas são observadas, indicando que o magma teve períodos de insaturação em Zr após a cristalização destes cristais. Geralmente as bordas apresentam luminescência esbranquiçada que indica que estes grãos sofreram alteração tardimagmática.

Foram executadas 16 análises geocronológicas de U-Pb por SHRIMP em 16 grãos de zircão da população concentrada em AT-01. Nas análises os conteúdos de U variaram entre 123 - 509 ppm e as razões Th/U entre 0.50 e 1.08, razões estas típicas de cristais de zircão ígneos. As análises isotópicas foram realizadas predominantemente nas porções 
com zoneamento oscilatório, caracterizando a idade de cristalização magmática. Em um diagrama concórdia 10 análises definiram uma idade concórdia de $352 \pm 3$ Ma com valor de MSWD de 0.0107 (Figura 33C) a partir de análises com idades ${ }^{206} \mathrm{~Pb} /{ }^{238} \mathrm{U}$ individuais entre 346 Ma e 358 Ma. Esta idade concórdia de $352 \pm 3$ Ma é a idade de cristalização magmática desta rocha vulcanoclástica. Das 16 análises executadas 6 não foram utilizadas no cálculo da idade concórdia. Destas, 3 foram excluídas por apresentarem conteúdo de $\mathrm{Pb}$ comum elevado (\% $\mathrm{Pb}$ comum > 2, nesta amostra pelo contexto da população de zircão) (Figura 33A). Outras 3 análises também não foram utilizadas no cálculo da idade concórdia pois suas idades ${ }^{206} \mathrm{~Pb} /{ }^{238} \mathrm{U}$ eram de $311 \pm 8 \mathrm{Ma}, 335 \pm 5 \mathrm{Ma}$ e $434 \pm 7 \mathrm{Ma}$ (Figura 33B). As duas idades mais jovens (311 e $335 \mathrm{Ma}$ ) foram obtidas em spots com feições tardi-magmáticas associadas, enquanto que a idade mais antiga é considerada um xenocristal herdado de outro vulcanismo. 

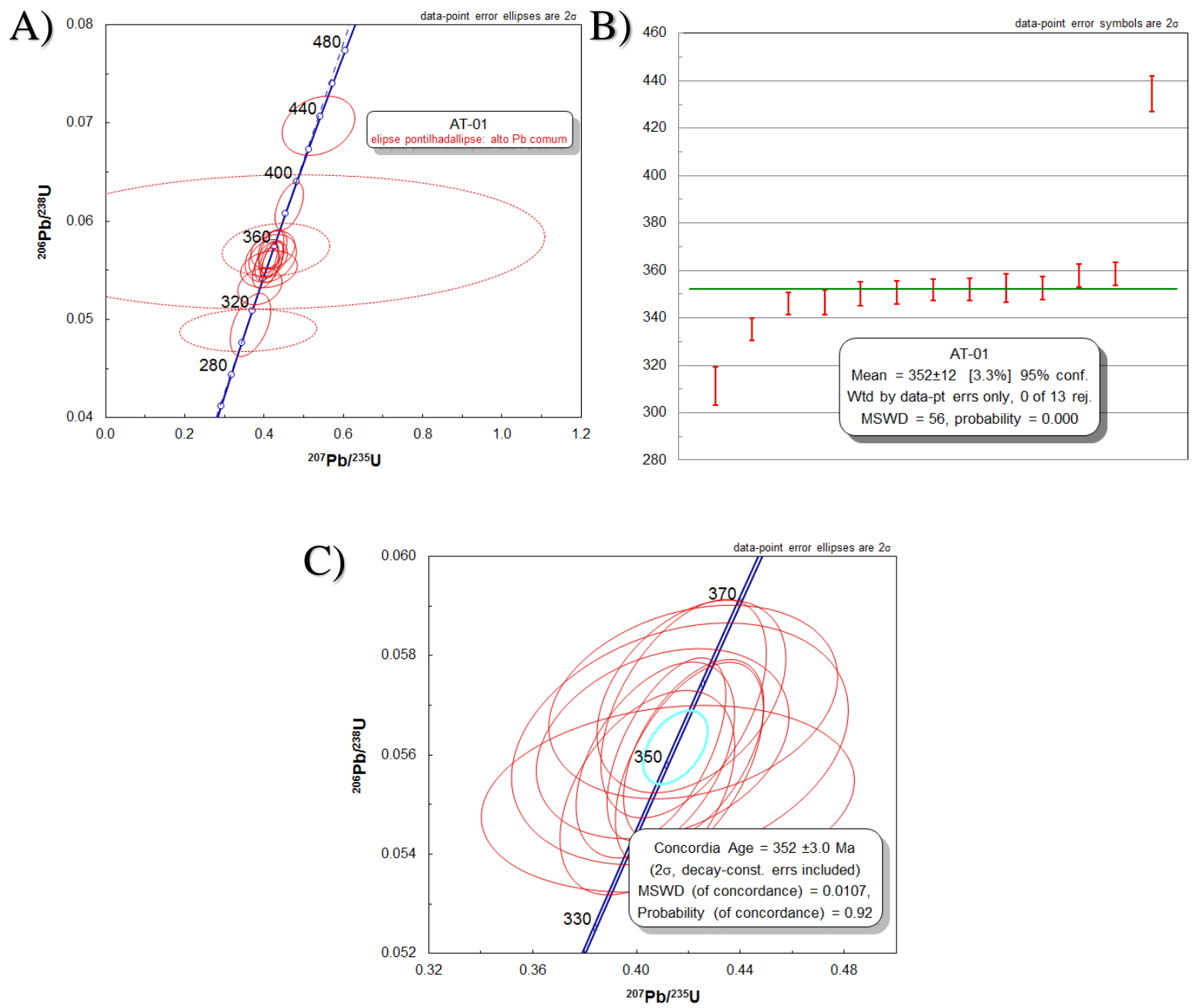

Figura 33. A) dados obtidos, B) idade ${ }^{206} \mathrm{~Pb} /{ }^{238} \mathrm{U}$ média e C) idade concórdia obtida na amostra AT-01

A temperatura de cristalização dos grãos de zircão desta amostra foi estudada em 10 destes grãos a partir do estudo do conteúdo isotópico de Ti por SHRIMP. A razão média de ${ }^{50} \mathrm{Ti} /{ }^{49} \mathrm{Ti}$ da população analisada é de 0.95 , com $8.6 \mathrm{ppm}$ de ${ }^{49} \mathrm{Ti}$ e $8.6 \mathrm{ppm}$ de ${ }^{50} \mathrm{Ti}$. Com isso as temperaturas médias obtidas foram de $759 \pm 42{ }^{\circ} \mathrm{C}$ no ${ }^{49} \mathrm{Ti}$ e de $759 \pm$ $42^{\circ} \mathrm{C}$ no ${ }^{50} \mathrm{Ti}$ (Figura 34A). Os isótopos de Lu-Hf de AT-01 foram analisados por LAMC-ICPMS em 20 cristais de zircão desta população. Essa população de zircão apresentou valores de ${ }^{176} \mathrm{Hf} /{ }^{177} \mathrm{Hf}_{\mathrm{o}}$ entre 0.282795 e 0.282698 , o que corresponde a valores de $\varepsilon_{\mathrm{Hfo}}$ entre 0.35 a -3.08, com valor médio de -0.71. Utilizando a idade concórdia de $352 \mathrm{Ma}$ obtida nesta população de zircão os valores iniciais de ${ }^{176} \mathrm{Hf} /{ }^{177} \mathrm{Hf}_{\mathrm{i}}$ foram de 0.282793 a 0.282697 , com $\varepsilon_{\mathrm{Hfi}}$ entre 1.07 e -2.33 , e valor médio de 0.01 (Figura 34B). Um dos cristais de zircão analisados é um xenocristal e seus valores de Hf não são 
representativos desta população, e, portanto, esta análise não foi considerada (AT-012.1). Todos os resultados individuais das análises efetuadas na amostra AT-01 podem ser vistos na Figura 35.
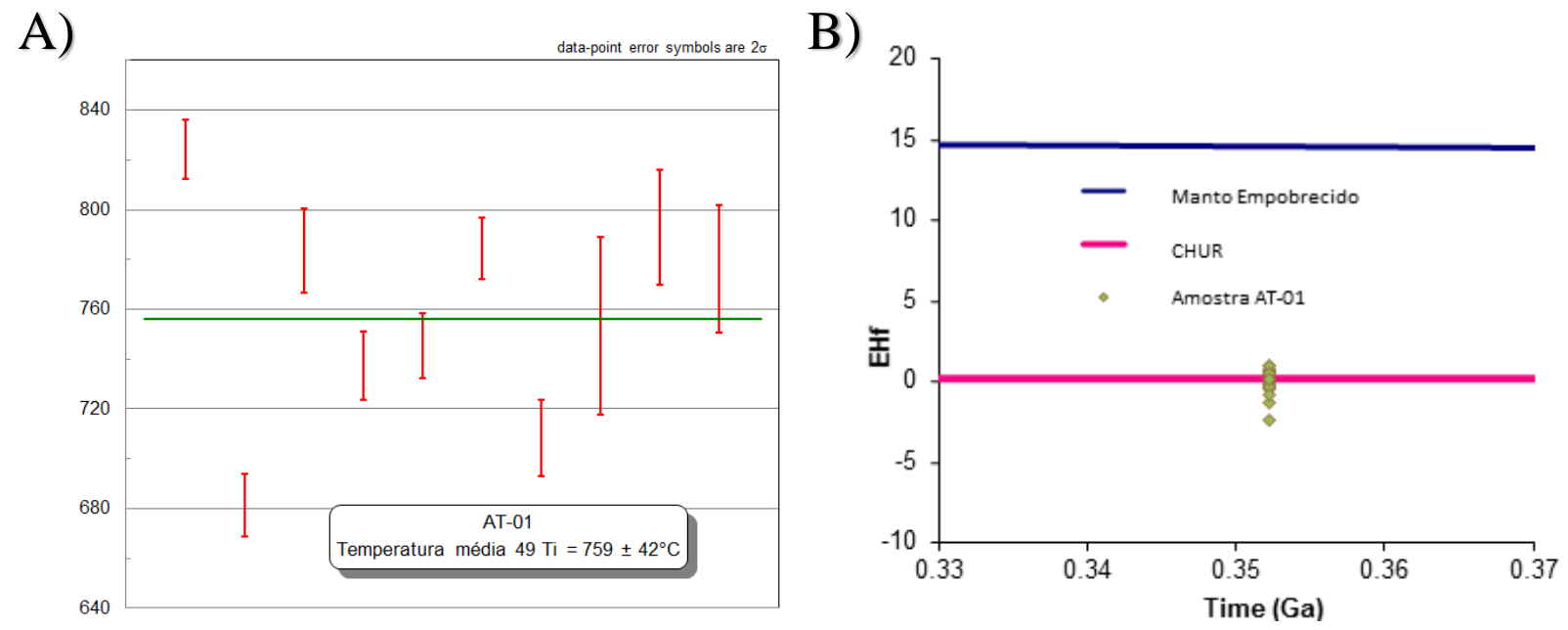

Figura 34. A) Temperaturas ${ }^{49}$ Ti e B) valores de $\mathcal{E}_{H f i}$ obtidos na amostra AT-01 

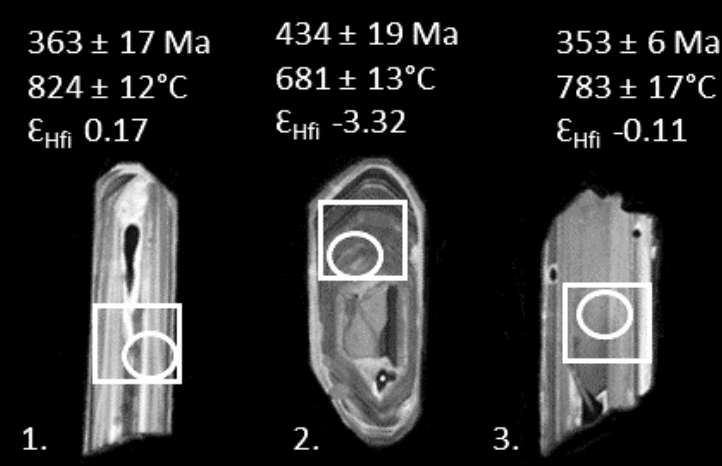

\title{
$353 \pm 5 \mathrm{Ma}$ \\ $737 \pm 14^{\circ} \mathrm{C}$ \\ $\varepsilon_{\mathrm{Hfi}} 0.17$
}

$358 \pm 7 \mathrm{Ma}$
$\varepsilon_{\mathrm{Hfi}} 1.07$

$346 \pm 5 \mathrm{Ma}$

$\varepsilon_{\mathrm{Hfi}}-0.47$

1.

2.
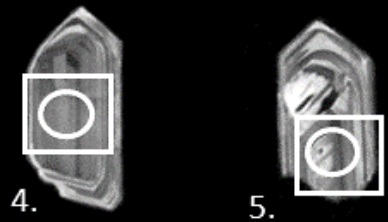

5.

6.
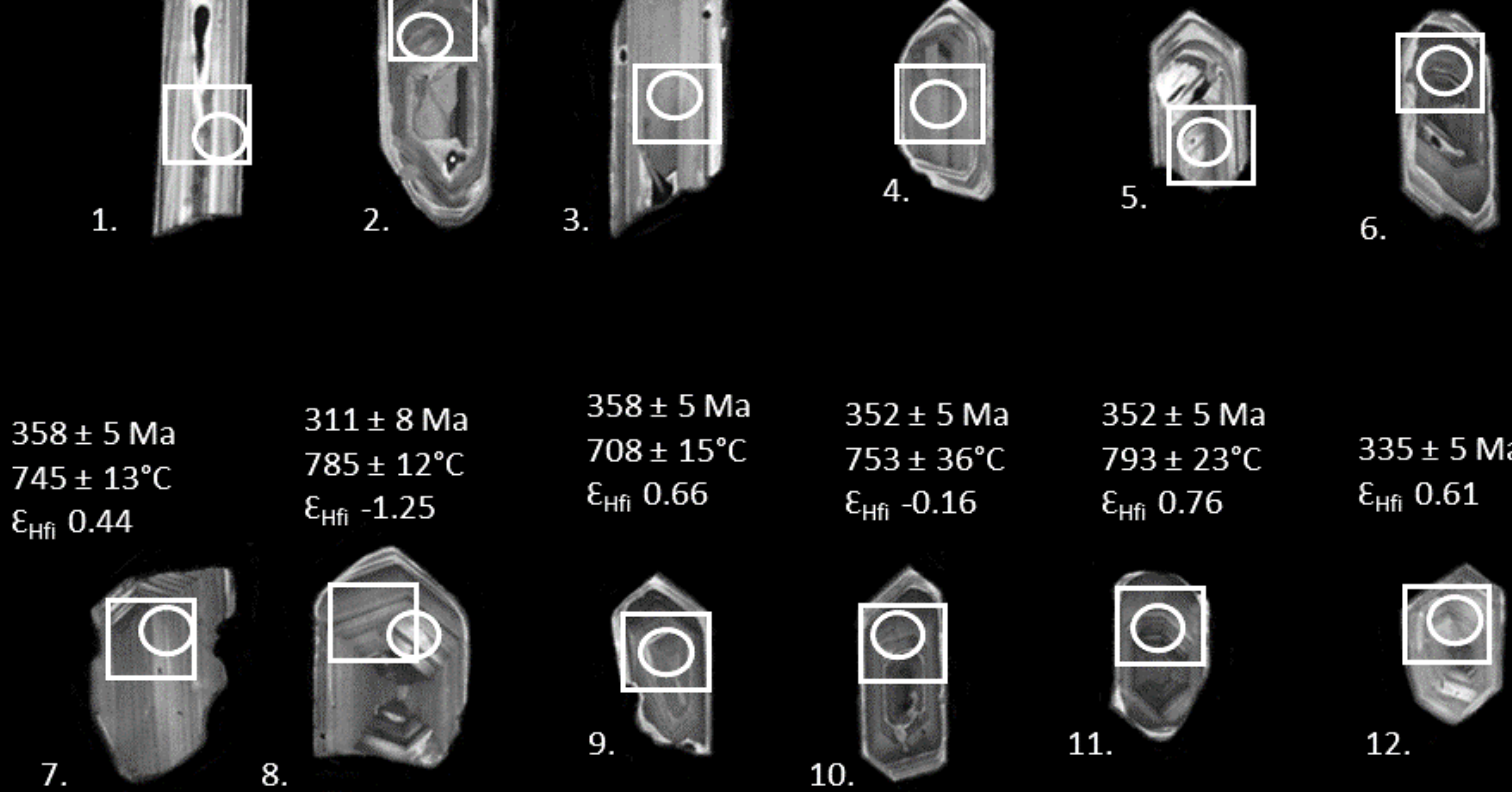

\begin{abstract}
$311 \pm 8 \mathrm{Ma}$ $\varepsilon_{\mathrm{Hfi}}-1.25$
\end{abstract}

$358 \pm 5 \mathrm{Ma}$ $708 \pm 15^{\circ} \mathrm{C}$

$352 \pm 5 \mathrm{Ma}$ $753 \pm 36^{\circ} \mathrm{C}$ $\varepsilon_{\mathrm{Hfi}} 0.66$ $\varepsilon_{\mathrm{Hfi}}-0.16$

$352 \pm 5 \mathrm{Ma}$ $793 \pm 23^{\circ} \mathrm{C}$

$335 \pm 5 \mathrm{Ma}$

8.
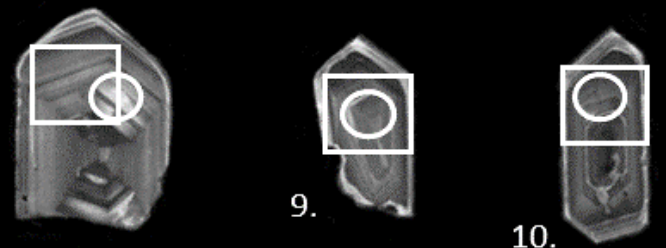
$\varepsilon_{\mathrm{Hfi}} 0.76$ $\varepsilon_{\mathrm{Hfi}} 0.61$

10.
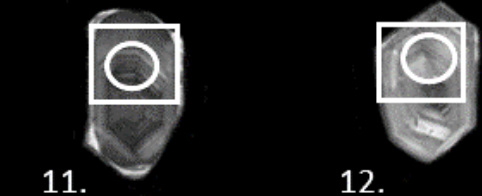

12.

\section{$350 \pm 5 \mathrm{Ma}$}

$776 \pm 26^{\circ} \mathrm{C}$

$\varepsilon_{\mathrm{Hfi}} 0.96$

$$
\begin{aligned}
& 347 \pm 5 \mathrm{Ma} \\
& \varepsilon_{\mathrm{Hfi}} 0.16
\end{aligned}
$$

\section{$351 \pm 5 \mathrm{Ma}$ $\varepsilon_{\mathrm{Hfi}}-0.27$}

$308 \pm 5 \mathrm{Ma}$

Alto $\mathrm{Pb}$

Alto $\mathrm{Pb}$

$\varepsilon_{\mathrm{Hfi}}-0.80$

$\varepsilon_{\mathrm{Hfi}} 0.56$

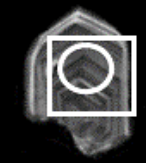

13.

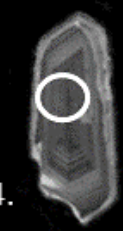

15.
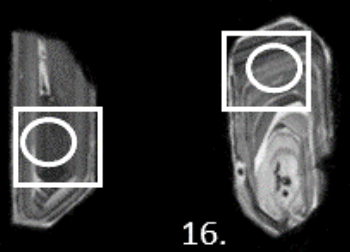

17.

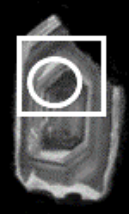

18.
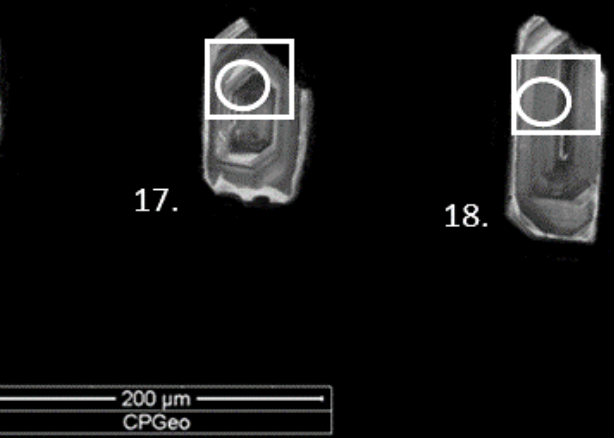

CPGeo

Figura 35. Composição das imagens de CL com os resultados individuais obtidos nos cristais de zircão analisados através de U-Pb e isótopos de Ti via SHRIMP e Lu-Hf via LA-MC-ICPMS na

amostra de rocha vulcanoclástica (AT-01).

Os grãos de zircão concentrados na amostra AT-03 variam entre 100-150 $\mu \mathrm{m}$. Na maioria dos casos, os núcleos dos grãos de zircão são mais escuros que as bordas. $\mathrm{O}$ padrão do zoneamento oscilatório mostra certa homogeneidade composicional, com bandas variando de maneira sutil em diversos cristais. Na maioria dos grãos de zircão as bordas apresentam coloração esbranquiçada, indicando que os cristais foram afetados por 
alterações tardi-magmáticas. Diversos cristais de zircão também apresentam bordas reabsorvidas, indicando que entre a sua cristalização e o estágio final de formação desta rocha vulcânica o magma passou por estágios de insaturação em Zr.

Foram executadas 19 análises de U-Pb em 19 cristais de zircão na amostra AT03. As análises são caracterizadas por uma grande variação nos conteúdos de U (257 1174 ppm) e razões Th/U entre 0.49 e 1.14 , razões que são típicas de grãos de zircão ígneos. 15 destas análises apresentaram idades ${ }^{206} \mathrm{~Pb} /{ }^{238} \mathrm{U}$ variando entre $343 \mathrm{Ma}$ e 356 Ma e, em conjunto, definiram a idade concórdia de $349 \pm 3$ Ma com valor de MSWD de 5.1 (Figura 36C). Uma das análises foi descartada devido ao alto teor de $\mathrm{Pb}$ comum obtido (AT03-7.1) e outras duas análises foram abortadas pelo mesmo motivo, enquanto outra análise obteve uma idade ${ }^{206} \mathrm{~Pb} /{ }^{238} \mathrm{U}$ de $335 \pm 8$ (AT03-3.1) (Figura 36A e B).

Nesta amostra a termometria foi analisada a partir dos isótopos de Ti por SHRIMP em 5 grãos de zircão. A razão média de ${ }^{50} \mathrm{Ti} /{ }^{49} \mathrm{Ti}$ dos 4 cristais é de 0.95 , com 6.7 ppm de ${ }^{49} \mathrm{Ti}$ e $6.4 \mathrm{ppm}$ de ${ }^{50} \mathrm{Ti}$. Esses resultados indicam que a cristalização desta população de zircão se deu em temperaturas médias de $737 \pm 40^{\circ} \mathrm{C}$ no ${ }^{49} \mathrm{Ti}$ e de $73435^{\circ} \mathrm{C}$ no ${ }^{50} \mathrm{Ti}$ (Figura 37A). Uma das análises foi descartada por apresentar conteúdos anômalos de Ti (29.8 ppm de ${ }^{49} \mathrm{Ti}$ e $29.8 \mathrm{ppm}$ de ${ }^{50} \mathrm{Ti}$ ).
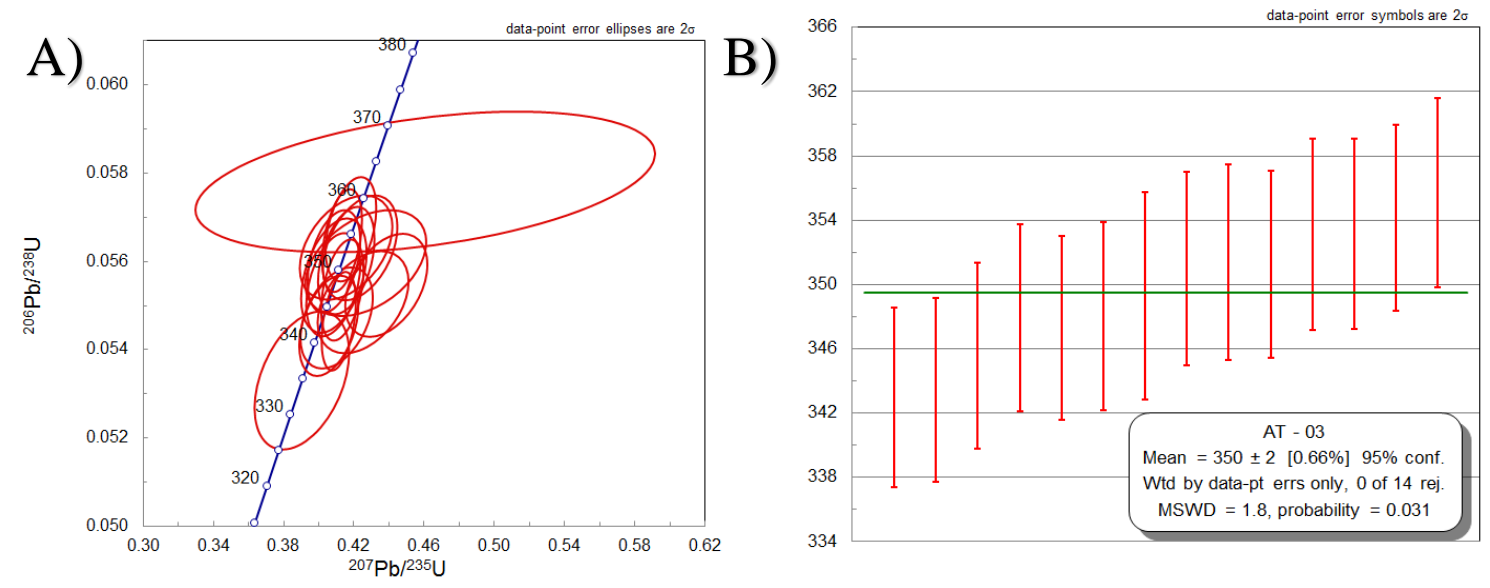


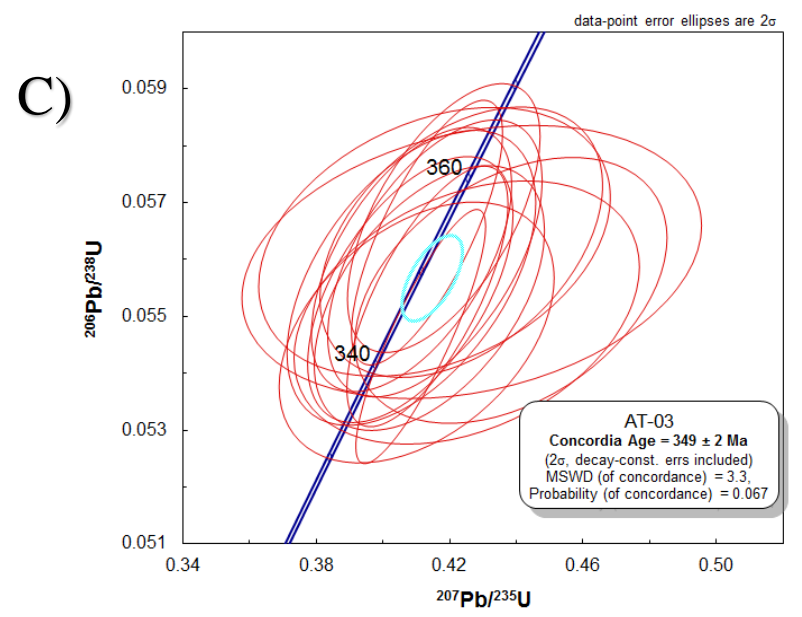

Figura 36. A) dados de $U-P b, B)$ idade ${ }^{206} \mathrm{~Pb} /{ }^{238} U$ média obtida e C) idade concórdia obtida na população de AT-03

Os cristais de zircão desta população também tiveram os isótopos de Lu-Hf analisados por LA-MC-ICPMS. Os valores presentes das razões de ${ }^{176} \mathrm{Hf} /{ }^{177} \mathrm{Hf}_{\mathrm{o}}$ variaram entre 0.282866 e 0.282630 , resultando em valores de $\varepsilon_{\mathrm{Hfo}}$ entre 2.86 a -5.48 , com valor médio de -0.66. Quando o valor de Hf inicial é calculado com a idade concórdia de 349 Ma obtida em AT-03, os valores iniciais de ${ }^{176} \mathrm{Hf} /{ }^{177} \mathrm{Hf}_{\mathrm{i}}$ variam entre $0.282863 \mathrm{e}$ 0.282628 , o que corresponde a $\varepsilon_{\mathrm{Hfi}}$ entre 3.55 e -4.77 , com valor médio de 0.02 (Figura 37B). O resultado das análises individuais de U-Pb, Ti-em-zircão e Lu-Hf podem ser vistos na Figura 38.
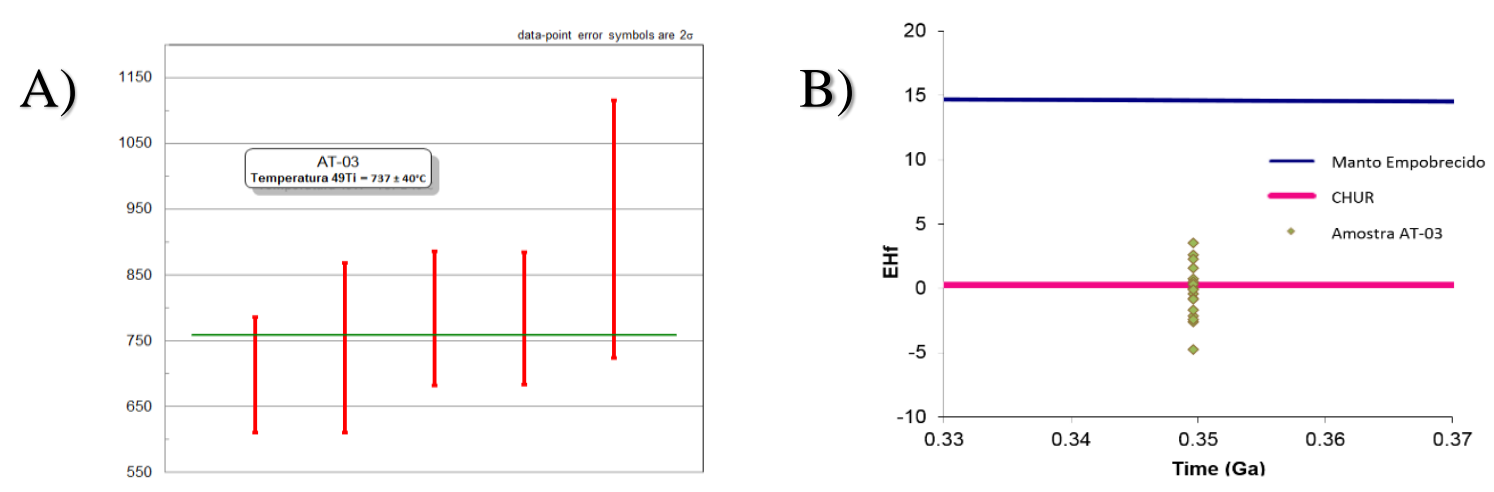

Figura 37. A) Temperaturas ${ }^{49}$ Ti e B) valores de $\mathcal{E}_{H f i}$ obtidos na população de AT-03 


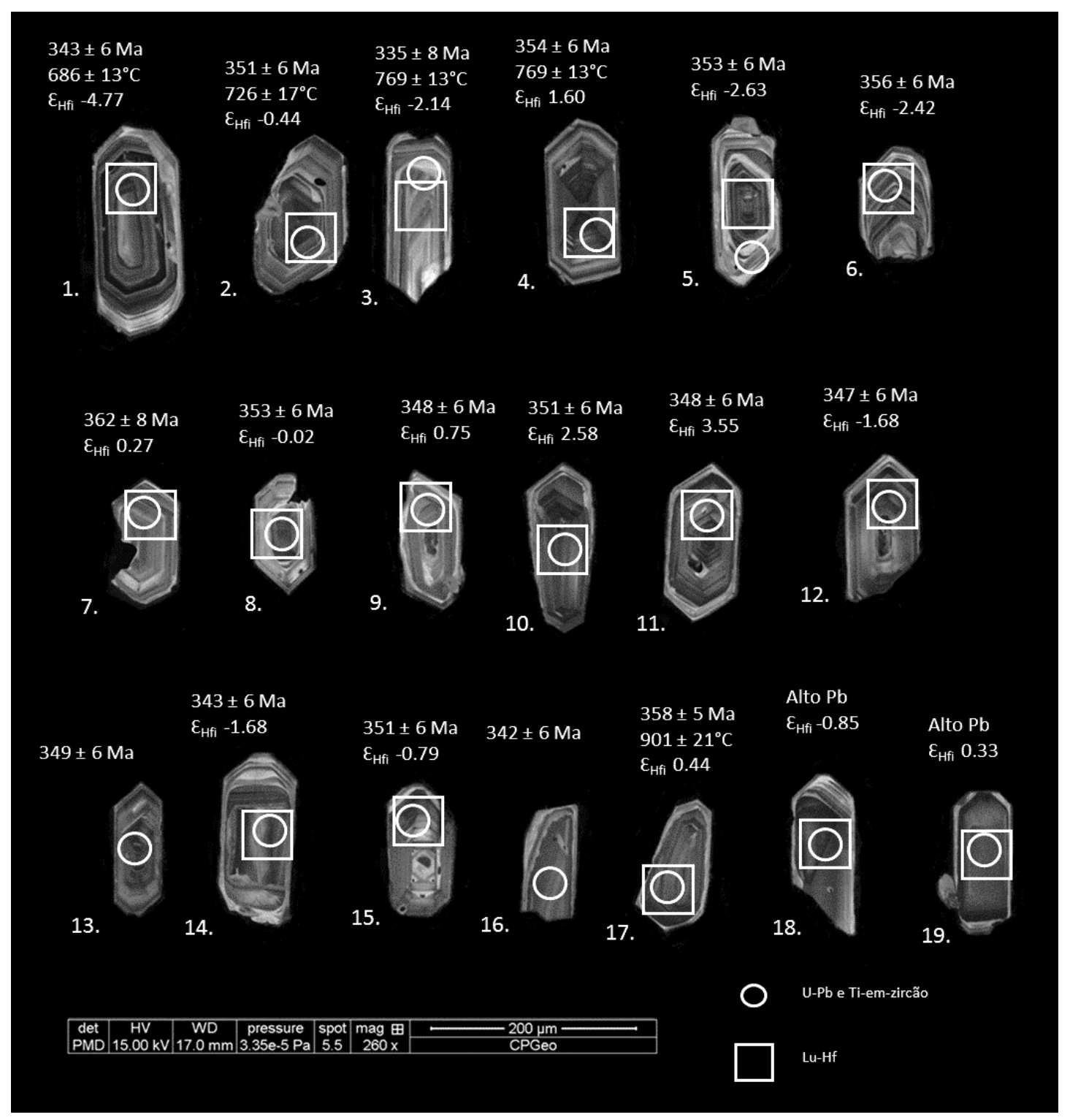

Figura 38. Composição das imagens de CL da população de zircão da amostra AT-03 com seus resultados individuais plotados. As idades são idades ${ }^{206} \mathrm{~Pb} /{ }^{238} \mathrm{U}$, as temperaturas são de ${ }^{49} \mathrm{Ti}$ e o $\varepsilon_{\text {Hfi }}$ o valor original do $\mathcal{E}_{\mathrm{Hf}}$ no momento da cristalização

\section{Magdalena}

O depósito de Magdalena não aflora e o material estudado nesta tese foi coletado em testemunhos de sondagem na litoteca da Matsa Minning em Aguas Tenidas. A amostra estudada é um riodacito brechado que nas sondagens aparece em contato com os sulfetos maciços. Como descrito anteriormente este depósito acabou de ser descoberto, de modo que ainda não existem artigos que lidem com a geologia deste depósito na literatura além do artigo que descreve o processo geofísico de descoberto deste depósito e uma breve menção em outro artigo de escopo mais amplo (Granda et al., 2016; Conde \& Tornos, 2019). 


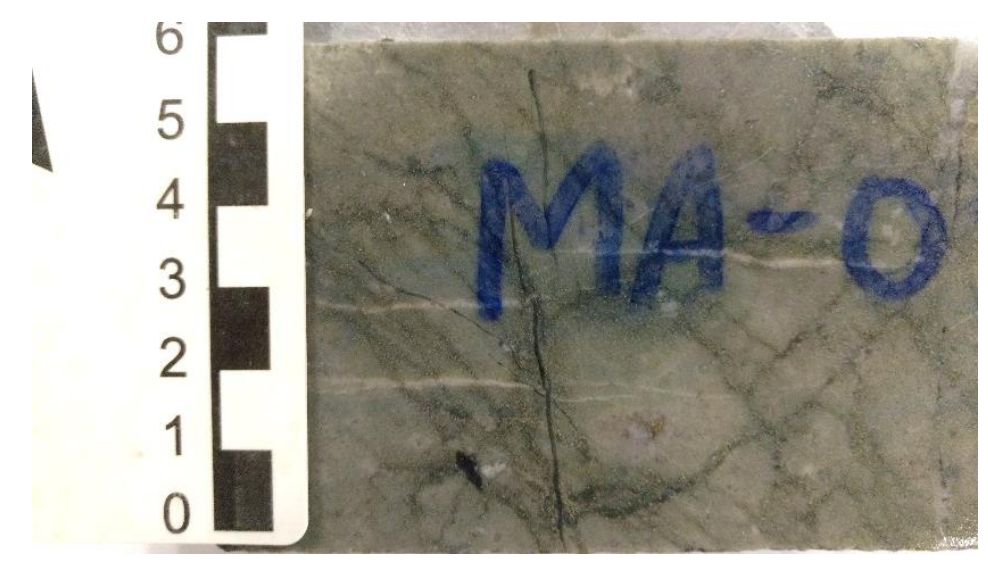

Figura 39. Detalhe da amostra de riodacito brechado representou o depósito de Magdalena neste trabalho. As fraturas são preenchidas por clorita, mineral relacionado a formação dos sulfetos maciços que ocorre na porção distal do halo de alteração gerado pelo fluido hidrotermal.

Nesta amostra de riodacito as fraturas são preenchidas por clorita, mineral relacionado a formação dos sulfetos maciços que ocorre na porção distal do halo de alteração gerado pelo fluido hidrotermal. Foram concentrados 13 cristais de zircão, eles usualmente são subeuhedrais, com morfologia subarredondada, e variam entre 100 e 180 $\mu \mathrm{m}$ em comprimento. Esta população de zircão apresenta alguns cristais com o núcleo mais escuro e bordas mais claras e outros cristais mais homogeneamente claros/esbranquiçados. Diversas inclusões minerais de tamanhos variados são observadas, estas inclusões possuem composição distintas, com a maioria de coloração escura nas imagens de CL, enquanto outras são claras. Diversos cristais também apresentam bordas reabsorvidas, indicativas de um período de instauração de Zr no magma ao longo da formação desta população. Além de bordas reabsorvidas alguns cristais também apresentam bordas corroídas, indicando que estes foram afetados no processo de circulação do fluido hidrotermal mineralizante. Diversos cristais também apresentam alterações associadas a altas pressões, como um padrão difuso e irregular de zoneamento denominado de auroral light por Corfu et al. (2003). As características desta população indicam uma história complexa para estes cristais de zircão, com origem magmática e processos subsequentes superimpostos.

As análises de U-Pb via SHRIMP da amostra MA-01 mostram um subconjunto principal de dados entre $\sim 340-360$ Ma e outro conjunto em 400 Ma (Figura 40A). As análises são caracterizadas por uma variação significativa nos conteúdos de U (102 - 504 ppm) e razões Th/U entre 0.47 e 1.17 , razões que são típicas de cristais de zircão ígneos. 
Mas quando os dados são comparados com a posição dos spots fica claro que este conjunto de 400 Ma é proveniente de dados menos confiáveis, que foram alterados em eventos tardi-magmáticos. Estas idades mais "antigas" foram geradas pois, como poucos cristais foram concentrados nesta amostra, regiões dos cristais que geralmente não seriam analisadas tiveram que ser para aumentar o conjunto de dados e obter maior relevância estatística. No entanto a datação destes spots não seria feita normalmente pois as imagens de CL mostravam que essa porção dos cristais de zircão não estavam bem preservadas. A idade concórdia foi obtida em 13 cristais e apresentou valor de $354 \pm 2 \mathrm{Ma}$, com valor de MSWD de 0.52 (Figura 40B). As idades ${ }^{206} \mathrm{~Pb} /{ }^{238} \mathrm{U}$ destes 13 cristais variam entre 345 Ma e 362 Ma.

A população de zircão de Magdalena não teve os isótopos de Ti analisados, enquanto que os isótopos de Lu-Hf foram analisados por LA-MC-ICPMS. Os valores presentes de ${ }^{176} \mathrm{Hf} /{ }^{177} \mathrm{Hf}_{\mathrm{o}}$ obtidos estão no intervalo de 0.282886 a 0.282744 , o que corresponde a valores de $\varepsilon_{\mathrm{Hfo}}$ entre 3.57 e -1.45 , com valor médio de 1.24 . A idade concórdia de $354 \mathrm{Ma}$ foi utilizada no cálculo dos valores iniciais de ${ }^{176} \mathrm{Hf} /{ }^{177} \mathrm{Hf}_{\mathrm{i}}$, e os valores obtidos variaram entre 0.282884 e 0.282743 . Estes valores correspondem a valores de $\varepsilon_{\mathrm{Hfi}}$ entre 4.3 e -0.71 , com valor médio de 1.98 . O resultado das análises individuais pode ser visto na Figura 41 com as imagens de CL com a localização das análises e o resultado plotados juntos. 

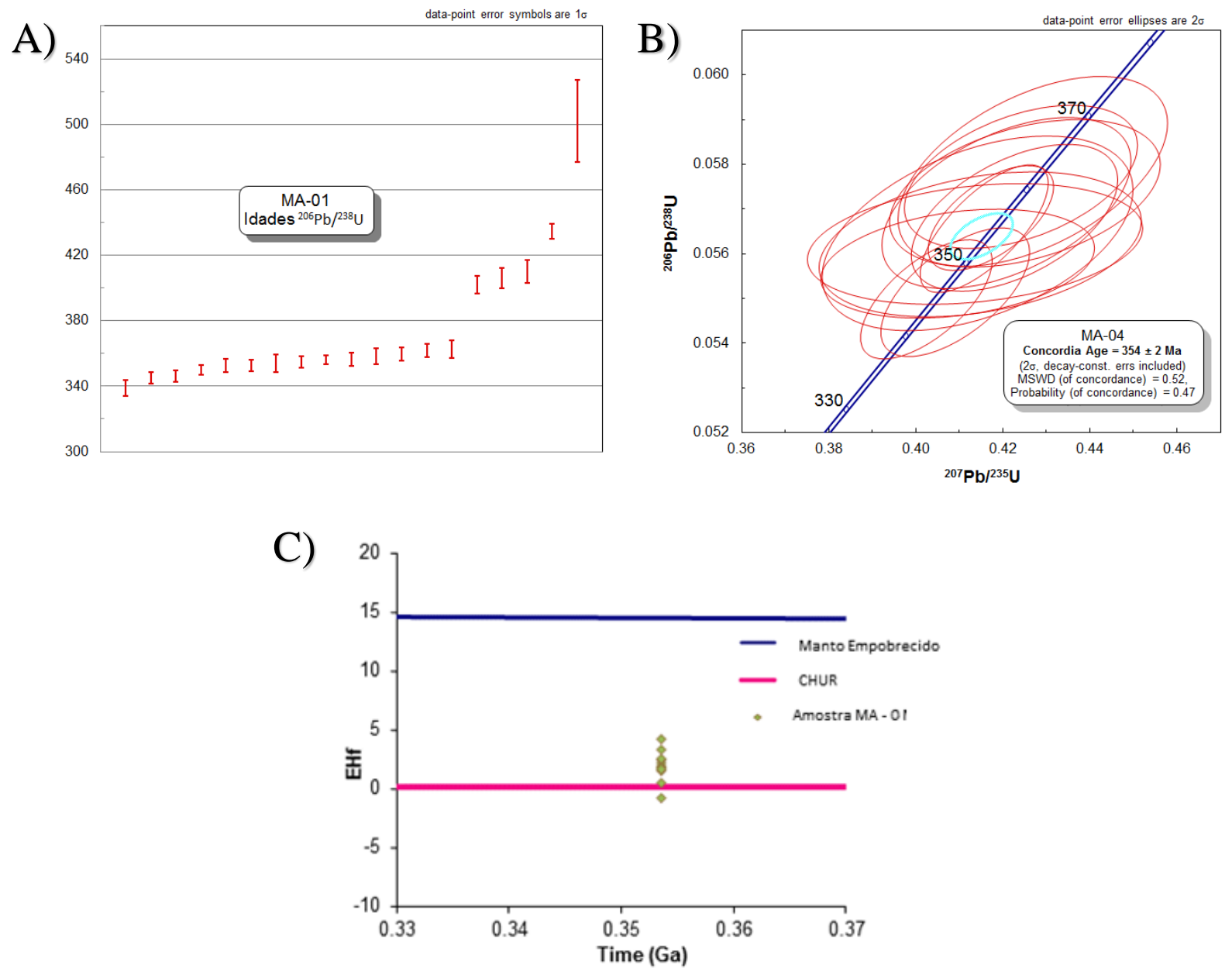

Figura 40. A) Dados U-Pb obtidos nesta amostra, B) idade concórdia obtida com 13 cristais desta população e C) dados de $\mathcal{E}_{H f i}$ obtidos na população de MA-01 


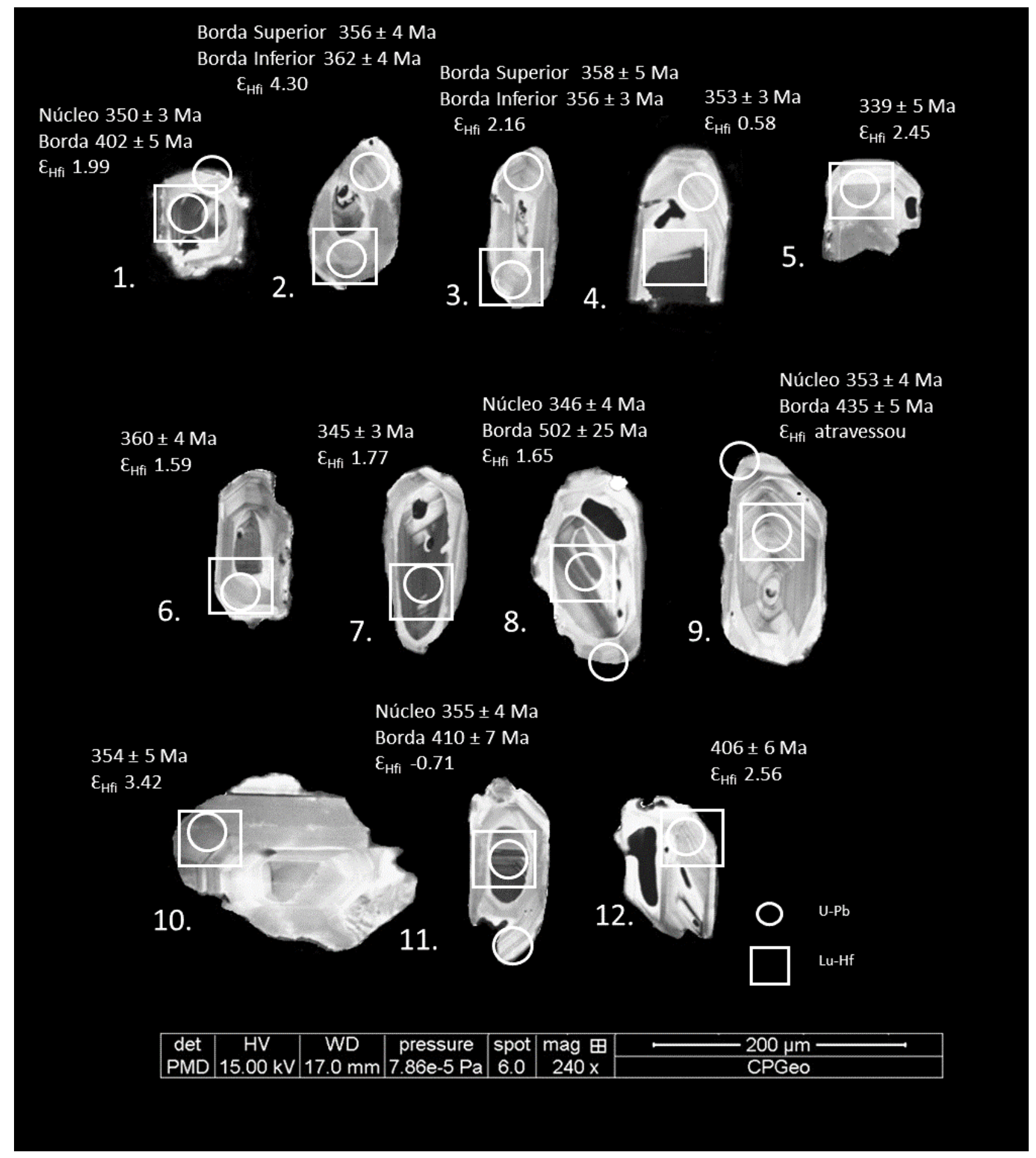

Figura 41. Composição com as imagens de CL com os resultados das análises individuais de UPb e Lu-Hf para a amostra MA-04. No zircão 9 o laser do LA-MC-ICPMS atravessou o cristal e com isso o resultado desta análise não é válido. 


\section{San Miguel}

San Miguel é uma mina abandona da borda sul do Cinturão Norte da FPI. Originalmente este corpo possuía 1.3 Mt com teor de 3\% de Cu que já foram explotados (Sanchez-España et al., 2000). Nesta localidade um dacito maciço coletado representa a rocha encaixante à lente de sulfeto maciço (Figura 42). Esta rocha apresenta um amplo processo de alteração hidrotermal onde a associação mineral original é substituída por filossilicatos, principalmente clorita e sericita, e também sofre silicificação. Esta rocha é a carapaça in situ de um domo félsico. Os cristais de zircão concentrados nesta amostra são prismáticos, com comprimento entre 180-50 $\mu \mathrm{m}$. O zoneamento oscilatório é bem marcado na maioria dos cristais, indicando variação composicional ao longo do processo de cristalização dos cristais. Alguns destes cristais de zircão apresentam bordas reabsorvidas e também algumas bordas levemente corroídas, indicando que o magma apresentou condições de insaturação de Zr após a cristalização destes cristais.

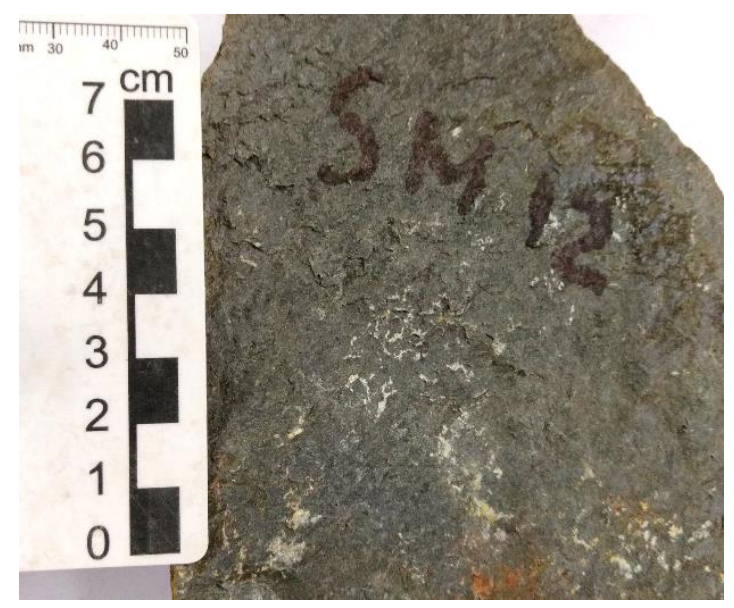

Figura 42. Amostra do dacito maciço afetado por hidrotermalismo de San Miguel (SM-12)

As 24 análises de U-Pb via SHRIMP foram executadas em 24 cristais de zircão desta população. Essas análises são apresentaram grande variação nos conteúdos de U (131 - 1444 ppm) e razões Th/U entre 0.54 e 1.36, razões típicas de grãos de zircão que são ígneos. No diagrama concórdia 14 cristais de zircão com idades ${ }^{206} \mathrm{~Pb} /{ }^{238} \mathrm{U}$ individuais entre 349 Ma e 361 Ma geraram uma idade concórdia de $353 \pm 2$ Ma, com valor de MSWD de 0.47 (Figura 43B). Outros 5 grãos são mais antigos e apresentam idades ${ }^{206} \mathrm{~Pb} /{ }^{238} \mathrm{U}$ de $368 \pm 3 \mathrm{Ma}, 369 \pm 4 \mathrm{Ma}, 372 \pm 3 \mathrm{Ma}, 374 \pm 10 \mathrm{Ma}, 391 \pm 9 \mathrm{Ma}$, enquanto outro zircão é um xenocristal de $477 \pm 6$ Ma. Estas idades não geram uma concórdia mas mostram atividade magmática por volta de $\sim 370 \mathrm{Ma}$, assim como heranças mais antigas. 
Outras 3 análises apresentaram idades ${ }^{206} \mathrm{~Pb} /{ }^{238} \mathrm{U}$ de $318 \pm 4 \mathrm{Ma}, 327 \pm 5$ Ma e $344 \pm 4$ Ma (Figura 43A).

A temperatura de formação destes cristais de zircão foi analisada em 15 grãos de zircão a partir dos isótopos de Ti. Dentro deste conjunto, 14 apresentaram razão média de ${ }^{50} \mathrm{Ti} /{ }^{49} \mathrm{Ti}$ de 0.96 , com $7.3 \mathrm{ppm}$ e $7.6 \mathrm{ppm}$ de ${ }^{49} \mathrm{Ti} \mathrm{e}^{50} \mathrm{Ti}$ em média, respectivamente. As temperaturas médias obtidas foram de $739 \pm 49^{\circ} \mathrm{C}$ no ${ }^{49} \mathrm{Ti}$ e de $741 \pm 54^{\circ} \mathrm{C}$ no ${ }^{50} \mathrm{Ti}$ (Figura 44A). A outra análise restante não foi utilizada por apresentar enriquecimento em Ti, com 72.3 ppm de ${ }^{49} \mathrm{Ti}$ e $75.1 \mathrm{ppm} \mathrm{de}{ }^{50} \mathrm{Ti}$.
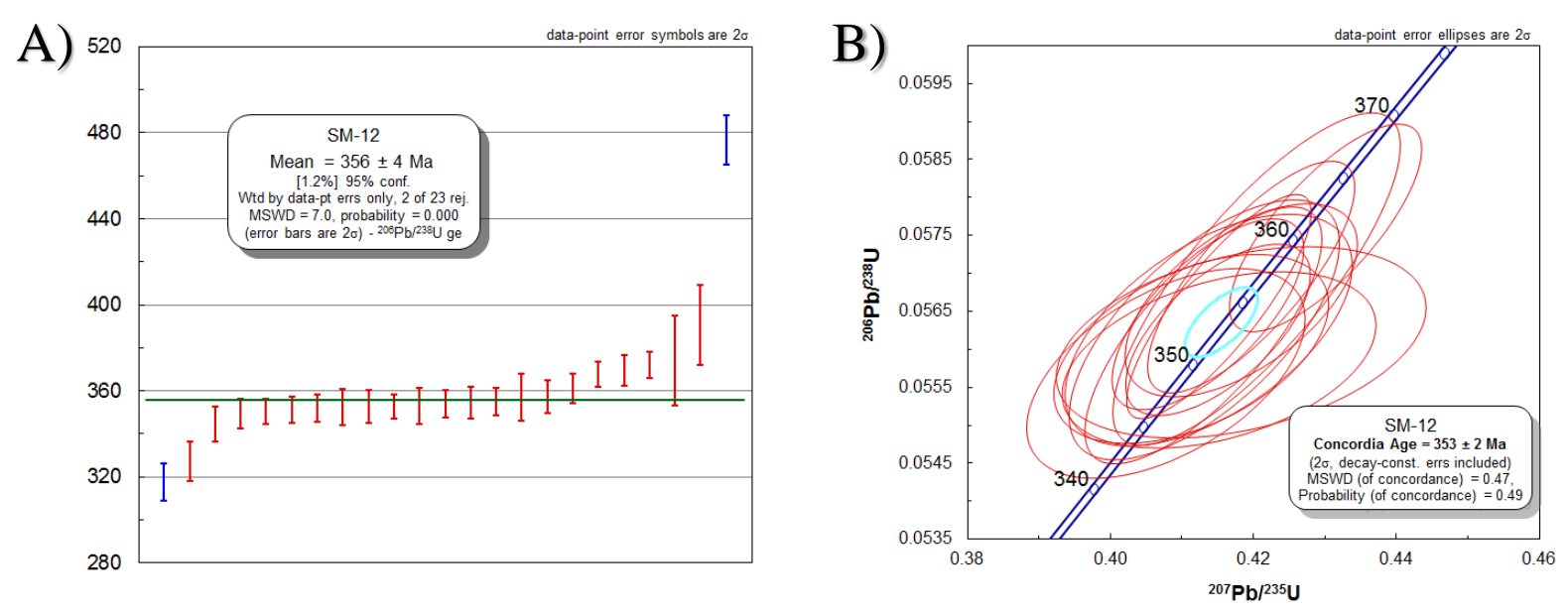

Figura 43. A) Dados U-Pb e B) idade concórdia obtida para o depósito de San Miguel.

As análises de Lu-Hf por LA-MC-ICPMS executadas nesta população apresentaram valores de ${ }^{176} \mathrm{Hf} /{ }^{177} \mathrm{Hf}_{\mathrm{o}}$ variando entre 0.282815 e 0.282691 , o que corresponde a valores de $\varepsilon_{\mathrm{Hfo}}$ entre 1.06 e -3,32, com valor médio de -1.36. A idade concórdia de $353 \mathrm{Ma}$ foi utilizada no cálculo dos valores iniciais de ${ }^{176} \mathrm{Hf} /{ }^{177} \mathrm{Hf}_{\mathrm{i}}$. Estes valores variaram entre 0.282813 e 0.282690 , uma variação de 1.76 a -2.58 no $\varepsilon_{\mathrm{Hfi}}$, com valor médio de $\mathrm{EHf}_{\mathrm{i}}$ de -0.63 nestes cristais (Figura 44B). Os valores mais baixos de $\varepsilon_{\mathrm{Hfo}}$ e $\varepsilon_{\mathrm{Hfi}}(-5.91$ e -5.17 , respectivamente) estão associados a um zircão (zircão 3) com alteração tardi-magmática e com uma inclusão mineral, que podem ter afetado especialmente a análise de Hf, uma vez que o spot do LA-MC-ICPMS é maior e mais profundo que o spot do SHRIMP. O resultado das análises individuais efetuada nos cristais de zircão desta população de San Miguel pode ser visto na Figura $45 \mathrm{com}$ as imagens de CL com a localização das análises e o resultado plotados juntos. 
A)

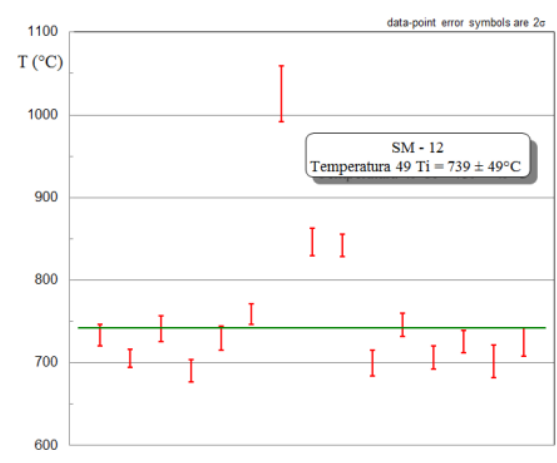

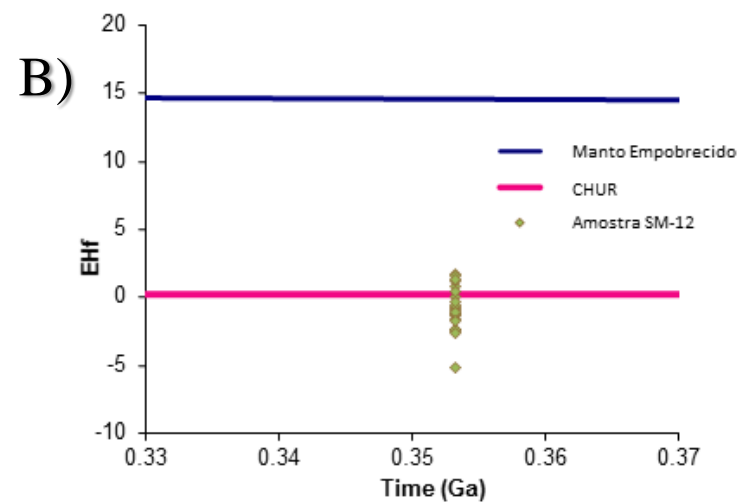

Figura 44. A) Temperaturas ${ }^{49} \mathrm{Ti}$ e B) $\mathcal{E}_{H f i}$ obtidos para a amostra SM-12 


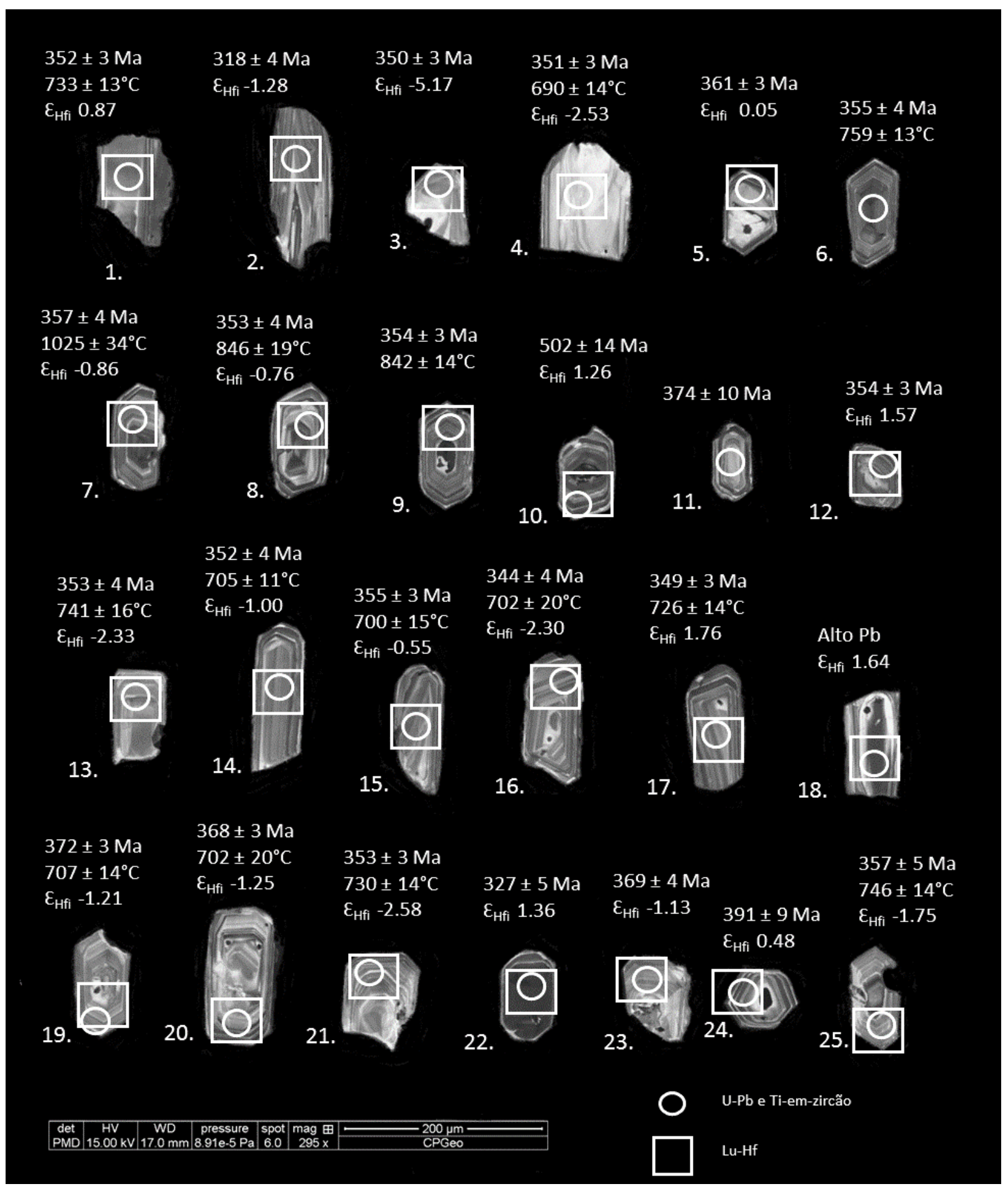

Figura 45. Composição das imagens de CL obtidas na amostra SM-12 com os dados de cada uma das análises individuais de $\mathrm{U}$-Pb, Ti-em-zircão e $\mathrm{Lu}-\mathrm{Hf}$ 


\section{Concepcion}

O depósito de Concepcion é composto por um corpo de sulfeto maciço associado a tufos riolíticos, riodacíticos e brechas (Sanchez-Espana et al., 2000). A mineralização foi formada via substituição do litotipo vulcânico pelos sulfetos, processo comum nos depósitos do Cinturão Norte da FPI. Atualmente a mina de Concepcion está abandonada e com a cava inundada. A amostragem foi executada na litoteca da Matsa Minning, onde os testemunhos de Concepcion estão armazenados. A amostra de Concepcion (CO-04) estudada nesta tese é um tufo hidrotermalizado que é interpretado como a feição maciça das brechas ricas em vidro vulcânico descritas na literatura (Figura 46).

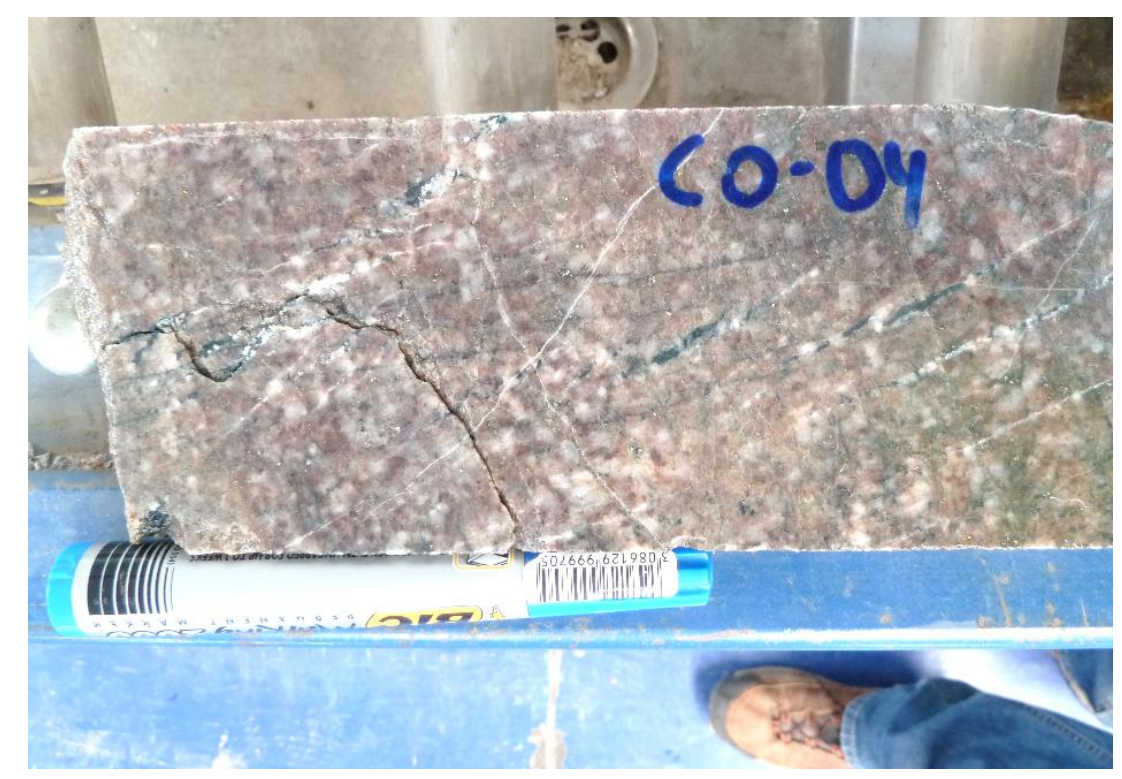

Figura 46. Fotografia da amostra CO-04 do depósito de Concepcion

Os grãos de zircão concentrados nesta amostra são prismáticos, com comprimento variando entre 100 e $150 \mu \mathrm{m}$. As imagens de CL obtidas mostram a maioria dos grãos de zircão desta população com zoneamento oscilatório sútil, indicando baixa variedade composicional ao longo da cristalização. Alguns dos cristais apresentam zoneamento setorial. Diversos cristais apresentam feições tardi-magmáticas e alguns deles também apresentam feições de recristalização em alta pressão denominadas de auroral light por Corfu et al. (2003). Existem diversas inclusões minerais de tamanhos variados e algumas das feições tardi-magmáticas aparentam estar associadas com algumas das inclusões, indicando processo de annealing. Diversos cristais apresentam bordas reabsorvidas, indicando período de insaturação de Zr no magma após a cristalização destes cristais. 
Nesta amostra 23 análises U-Pb via SHRIMP foram executadas em 22 cristais de zircão (Figura 47A). As análises são caracterizadas por uma grande variação nos conteúdos de U (125 - 1451 ppm) e razões Th/U entre 0.31 e 0.82 , razões que são típicas de grãos de zircão ígneos. As análises foram executadas nos núcleos dos cristais de zircão, visando caracterizar a idade da cristalização magmática deles. Dentre os 23 cristais de zircão analisados, 18 destes cristais tiveram idades ${ }^{206} \mathrm{~Pb} /{ }^{238} \mathrm{U}$ entre $340 \mathrm{Ma}$ e $365 \mathrm{Ma}$ e foram utilizados para o cálculo da idade concórdia de $354 \pm 3$ Ma com valor de MSWD de 0.111 (Figura 47B). Um xenocristal de zircão apresentou idade de $400 \pm 9$ Ma. Outras 2 análises feitas em 2 cristais de zircão apresentaram idades ${ }^{206} \mathrm{~Pb} /{ }^{238} \mathrm{U}$ de $322 \pm 76 \mathrm{Ma}$, $330 \pm 6 \mathrm{Ma}$. Um dos cristais com sobrecrescimento apresentou idades ${ }^{206} \mathrm{~Pb} /{ }^{238} \mathrm{U}$ de 335 $\pm 6 \mathrm{Ma}$ e $339 \pm 6 \mathrm{Ma}$ (núcleo e sobrecrescimento respectivamente).

A)

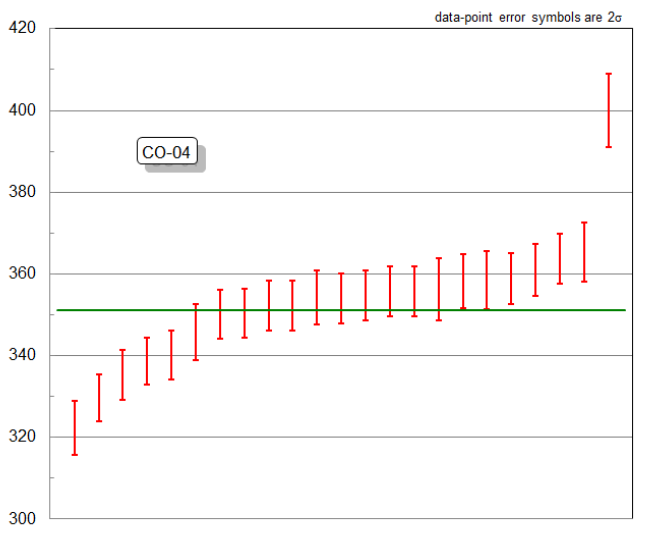

B)

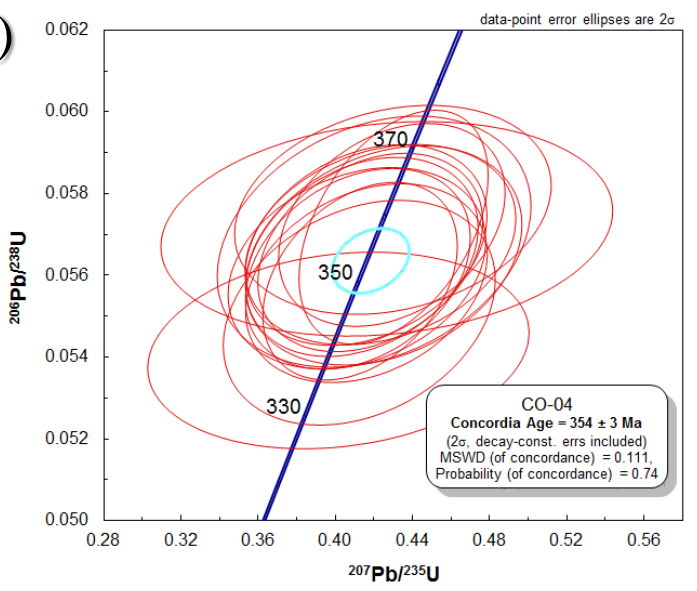

Figura 47. A) Dados de U-Pb e B ) idade concórdia obtida na população de CO-04

Nesta amostra de Concepcion 10 grãos de zircão tiveram seu conteúdo isotópico de Ti analisados por SHRIMP. A razão média de ${ }^{50} \mathrm{Ti} /{ }^{49} \mathrm{Ti}$ dessa população de zircão analisados é de 0.96 , com $6.1 \mathrm{ppm}$ de ${ }^{49} \mathrm{Ti}$ e $6.0 \mathrm{ppm}$ de ${ }^{50} \mathrm{Ti}$. Nesta amostra 8 análises restantes apresentaram teor médio de 49Ti e 50Ti de 5.58 e $5.51 \mathrm{ppm}$ respectivamente e apresentam temperaturas médias de $724 \pm 12{ }^{\circ} \mathrm{C}$ no ${ }^{49} \mathrm{Ti}$ e $723 \pm 12^{\circ} \mathrm{C}$ no ${ }^{50} \mathrm{Ti}$. Outras duas análises apresentaram temperaturas mais elevadas (Figura 49A), mas como ambas apresentam razão ${ }^{50} \mathrm{Ti} /{ }^{49} \mathrm{Ti}$ abaixo de 0.94 (0.90 e 0.92), estas análises foram descartadas.

Os cristais de zircão de Concepcion também foram analisados pelo método Lu-Hf por LA-MC-ICPMS. Foram analisados em 21 cristais de zircão e as razões ${ }^{176} \mathrm{Hf} /{ }^{177} \mathrm{Hf}_{\mathrm{o}}$ obtidas variaram entre 0.282883 e 0.282703 , o que corresponde a valores de $\varepsilon_{\mathrm{Hfo}}$ entre 3.47 e -2.90 , sendo que o valor médio foi de -0.02 . Ao utilizar a idade concórdia de 354 
Ma para calcular os valores iniciais ${ }^{176} \mathrm{Hf} /{ }^{177} \mathrm{Hf}_{\mathrm{i}}$ foram obtidos valores entre $0.282881 \mathrm{e}$ 0.282701 , uma variação de 4.18 a -2.18 nos valores de $\varepsilon_{\mathrm{Hfi}}$, que teve valor médio de -0.83 (Figura 49B). O resultado das análises isotópicas individuais de U-Pb, Ti e Lu-Hf podem ser vistos na Figura 48 com as imagens de CL com a localização das análises e o resultado plotados juntos.

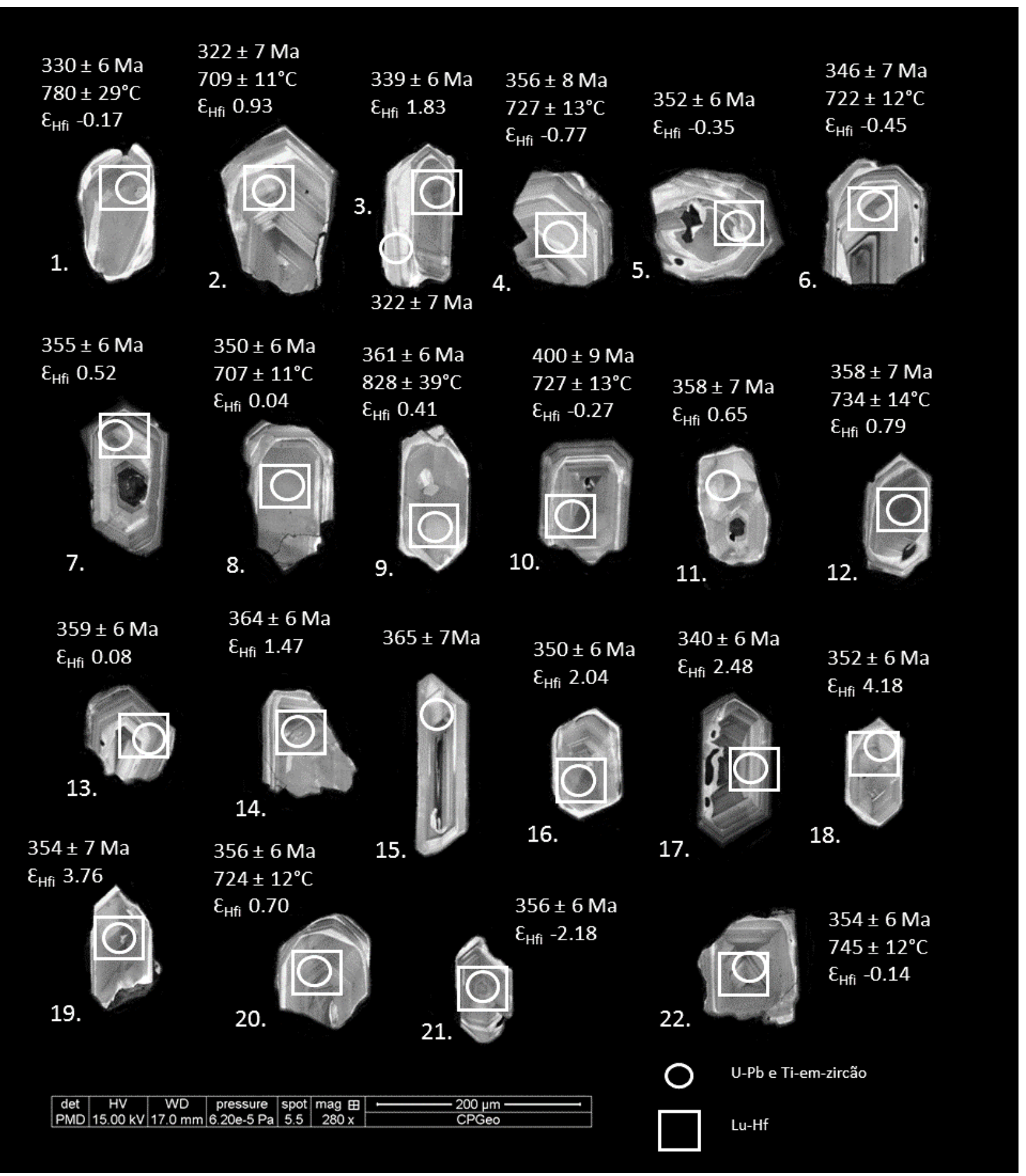

Figura 48. Composição das imagens de CL dos cristais de zircão estudados na amostra CO-04 com os dados de cada uma das análises isotópicas individuais de U-Pb, Ti e Lu-Hf 

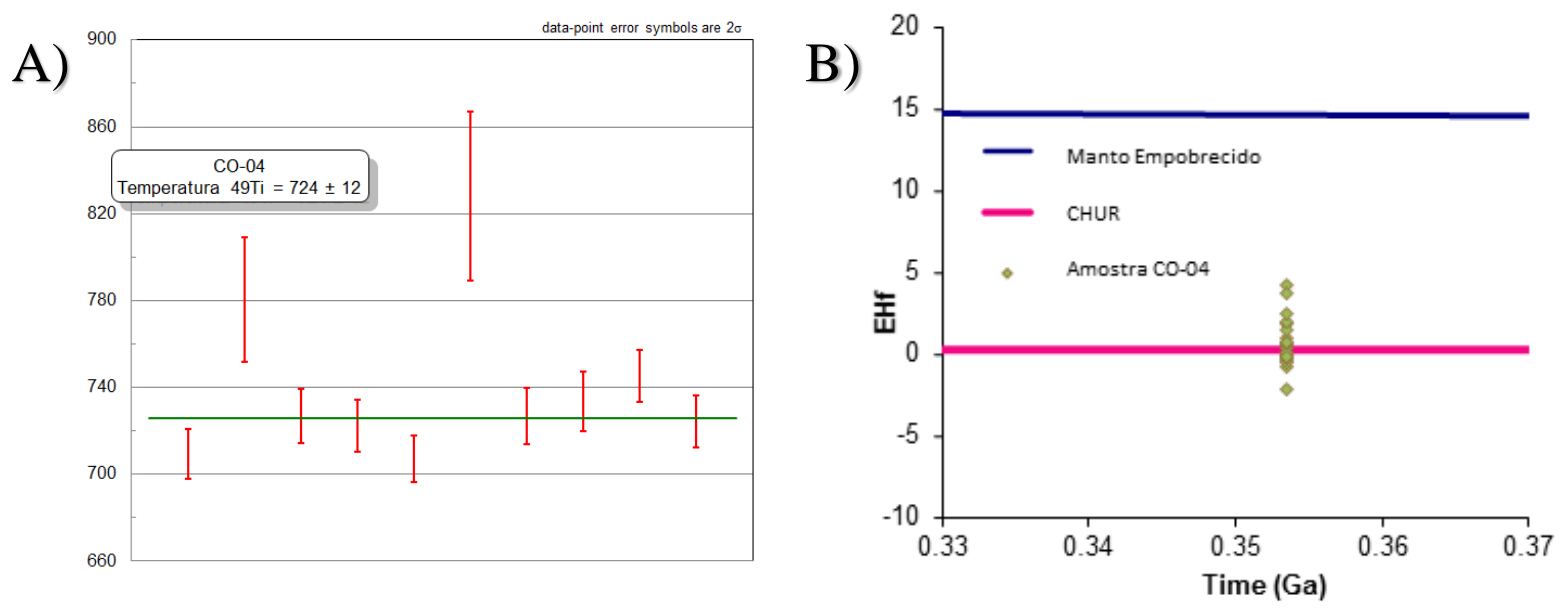

Figura 49. A) Temperaturas ${ }^{49}$ Ti e B) valores de $\varepsilon_{H f i}$ obtidos na amostra CO-04

\section{$\underline{\text { San Platon }}$}

San Platon é uma mina abandonada nas proximidades da mina de Concepcion. A geologia da região, assim como nos outros depósitos do Cinturão Norte é composta por domos riolíticos e rochas vulcanoclásticas associadas a precipitações dos sulfetos maciços e semi maciços. Aqui a amostragem foi efetuada na porção distal do domo, onde os fluidos hidrotermais percolaram intensamente a rocha, gerando intenso processo de sericitização. A amostra SP-03 é uma amostra da rocha encaixante que corresponde a rocha vulcanoclástica foliada rica em púmice e altamente sericitizada, com presença abundante de sulfetos, especialmente pirita, associados ao intenso processo de alteração hidrotermal associado a mineralização (Figura 50).

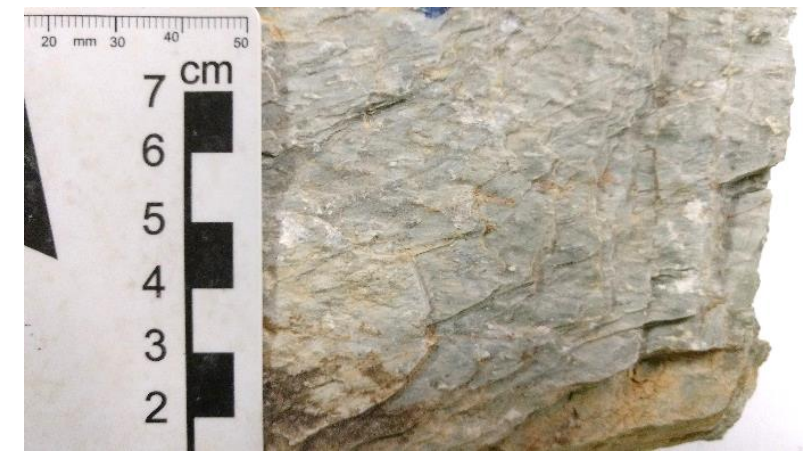

Figura 50. Fotografias da amostra SP-03, de onde os cristais de zircão do depósito de San Telmo foram extraídos.

Os 18 cristais de zircão concentrados nesta amostra são prismáticos, com comprimento variável entre 150 e $70 \mu \mathrm{m}$. Esta população de zircão apresenta zoneamento oscilatório sútil, com baixa variação composicional ao longo da cristalização desta população. Alguns cristais apresentam o núcleo levemente mais escuro nas imagens de 
CL. A borda de diversos cristais está reabsorvida e os cristais de zircão apresentam algum esbranquiçamento indicativo de feições tardi-magmáticas.

As 19 análises de U-Pb por SHRIMP foram executadas em 18 cristais de zircão. Essas análises são caracterizadas por uma pequena variação nos conteúdos de U (100 $254 \mathrm{ppm}$ ) e razões $\mathrm{Th} / \mathrm{U}$ entre 0.57 e 1.15, razões típicas de grãos de zircão ígneos. As análises isotópicas foram executadas predominantemente nos zoneamentos oscilatórios dos grãos de zircão. Com 16 análises foi calculada uma idade concórdia de $338 \pm 3 \mathrm{Ma}$ com valor de MSWD de 0.34 , com idades ${ }^{206} \mathrm{~Pb} /{ }^{238} \mathrm{U}$ variando entre 319 Ma e $352 \mathrm{Ma}$ (Figura 51C). Dois dos cristais de zircão desta população apresentaram idades ${ }^{206} \mathrm{~Pb} /{ }^{238} \mathrm{U}$ de $396 \pm 8 \mathrm{Ma}$ e outro idade ${ }^{206} \mathrm{~Pb} /{ }^{238} \mathrm{U}$ de $285 \pm 8 \mathrm{Ma}$ (Figura $51 \mathrm{~A}$ e B). Como pode ser visto, a idade de 285 Ma está associada a uma região com alteração tardi-magmática enquanto que a idade de 396 Ma representa um xenocristal.
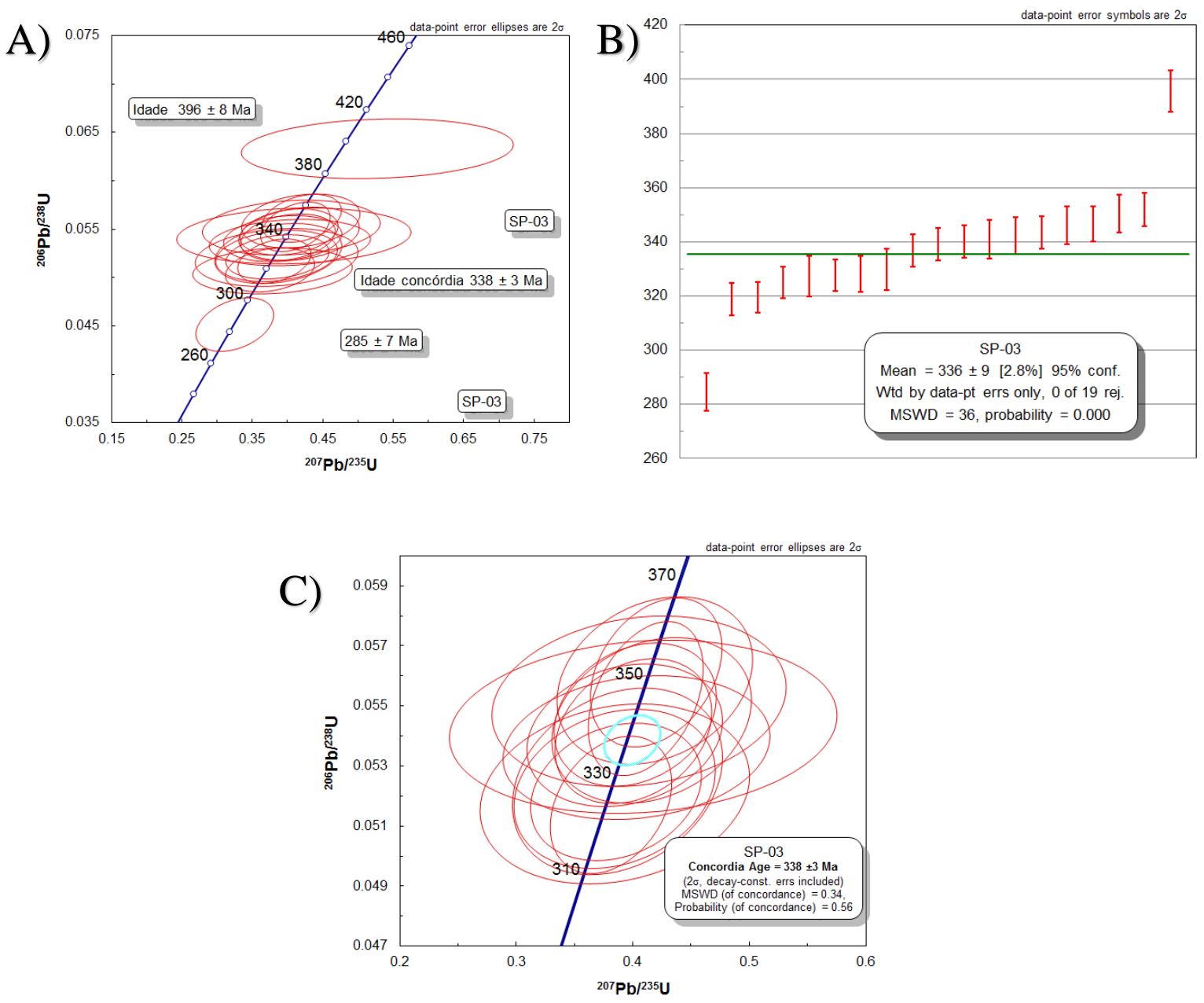

Figura 51. A) e B) mostram os dados de $U$-Pb e C) idade concórdia obtida para a população de SP-O3 
Nesta amostra 5 cristais de zircão foram analisados pelo método Ti-em-zircão via SHRIMP. Três destes cristais apresentaram razão média de ${ }^{50} \mathrm{Ti} /{ }^{49} \mathrm{Ti}$ de 0.96 , com conteúdo médio de ${ }^{49} \mathrm{Ti}$ e ${ }^{50} \mathrm{Ti}$ de $5.7 \mathrm{ppm}$ e 5.5 ppm respectivamente. Estes teores de Ti refletem temperaturas médias de $726 \pm 9^{\circ} \mathrm{C}$ no ${ }^{49} \mathrm{Ti}$ e $738 \pm 6^{\circ} \mathrm{C}$ no ${ }^{50} \mathrm{Ti}$. Outros dois outros cristais apresentaram conteúdos anômalos de Ti, com valores de ${ }^{49} \mathrm{Ti} \mathrm{e}{ }^{50} \mathrm{Ti}$ em 20.6 e 21.1 ppm para um dos cristais e 42.8 e 42.3 ppm para o outro. Estes dois cristais foram desconsiderados. Vale ressaltar que estes valores de $2 \sigma$ baixos $\left( \pm 6^{\circ} \mathrm{C} \mathrm{e} \pm 9^{\circ} \mathrm{C}\right)$, indicam a falta de número relevante de análise e não a precisão da análise em si (Figura $52 \mathrm{~A})$.

Essa amostra também teve os seus grãos de zircão analisados pelo método Lu-Hf via LA-MC-ICPMS. Os valores presentes ${ }^{176} \mathrm{Hf} /{ }^{177} \mathrm{Hf}_{\mathrm{o}}$ variaram entre $0.282737 \mathrm{e}$ 0.282684 , o que corresponde a valores de $\varepsilon_{\mathrm{Hfo}}$ entre -1.70 e -3.57 , sendo que o valor médio foi de -2.78 . Ao utilizar a idade concórdia de 338 Ma obtida nesta amostra para calcular os valores de ${ }^{176} \mathrm{Hf} /{ }^{177} \mathrm{Hf}_{\mathrm{i}}$ foram obtidos valores entre 0.282735 e 0.282684 , uma variação de -1.00 a -2.87 nos valores de $\varepsilon_{\mathrm{Hfi}}$, que apresentou valor médio de -2.07 (Figura 52B). O resultado das análises individuais pode ser visto na Figura $53 \mathrm{com}$ as imagens de CL com a localização das análises e o resultado plotados juntos.
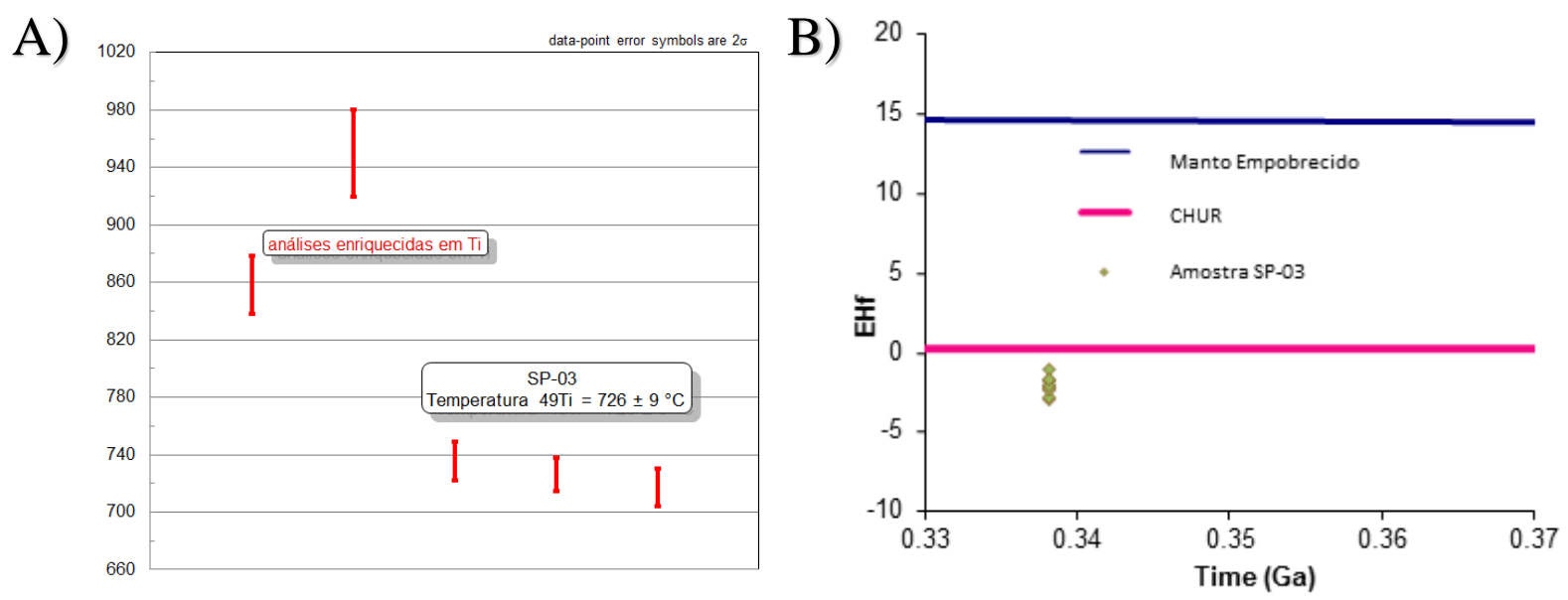

Figura 52. A) Temperaturas ${ }^{49}$ Ti e B) valores de $E H f_{i}$ obtidos na amostra SP-03 


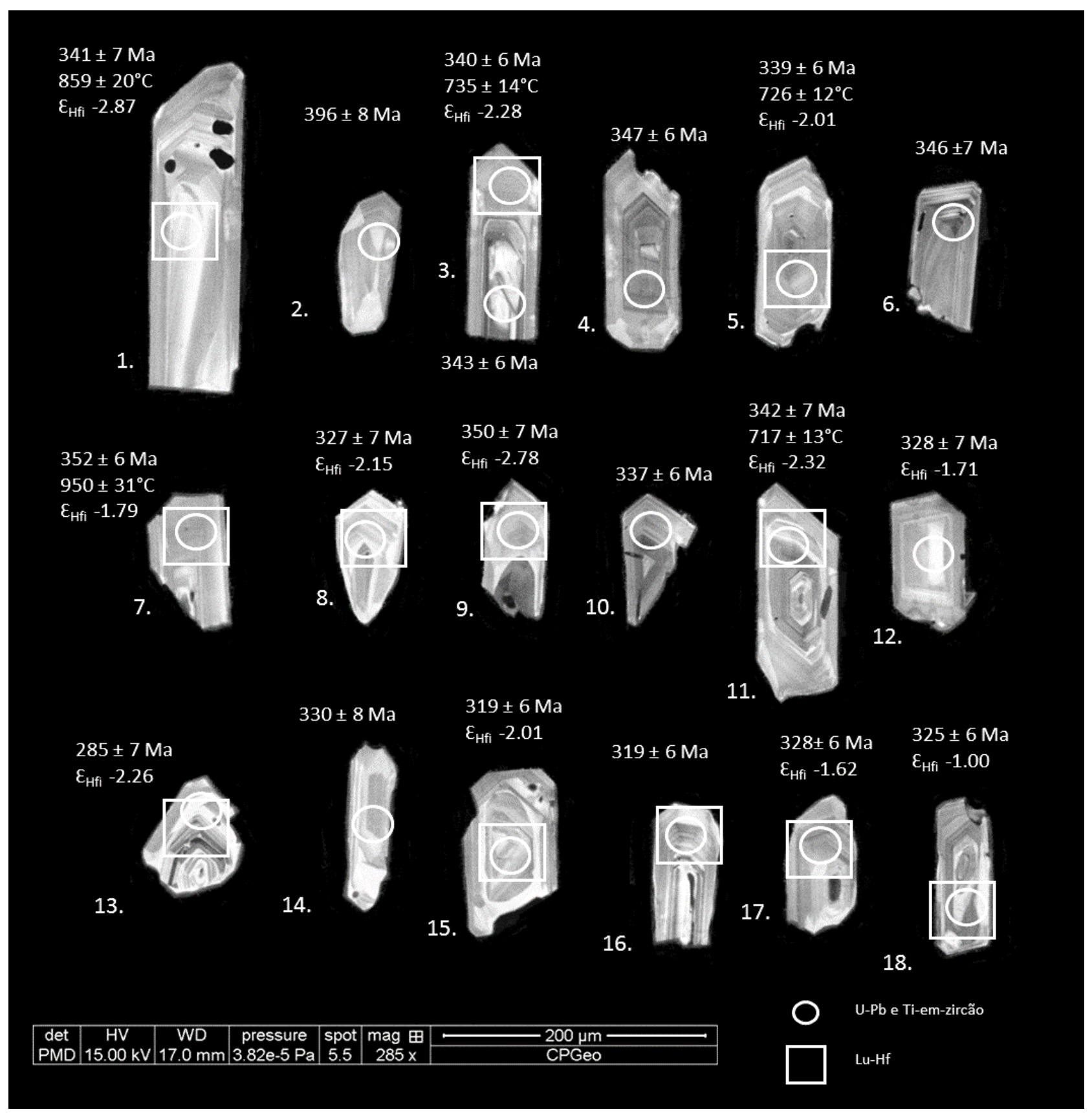

Figura 53. Composição de imagens CL da população de zircão da amostra SP-03.

\section{Solo Viejo}

Solo Viejo é uma mina de Mn abandonada na borda sul do Cinturão Norte da FPI. Nesta localidade foram coletadas duas amostras, um tufo autoclástico associado aos cherts e jaspers mineralizados (SV-01) e um derrame riolítico (SV-02). A amostra SV-01 está totalmente alterada hidrotermalmente e posteriormente por intemperismo (Figura 54 A, B) enquanto que a amostra SV-02 sofreu forte processo de sericitização (Figura 54 C, D). 
A)

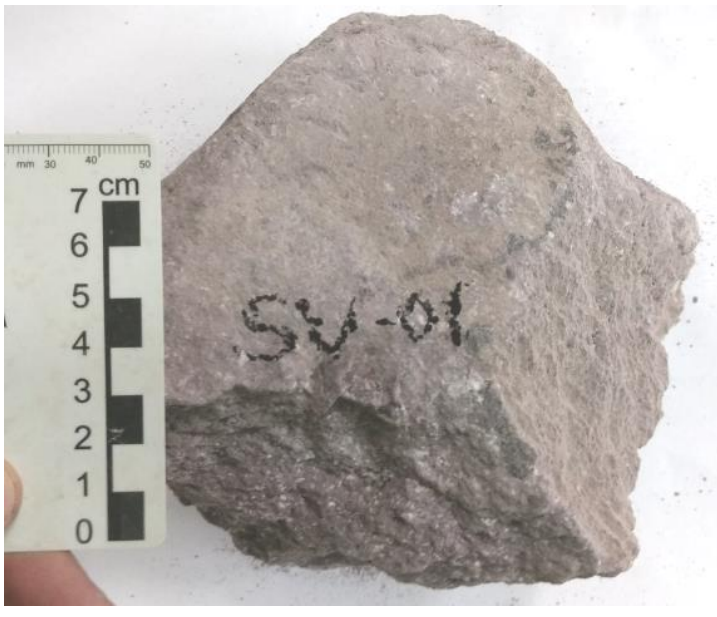

C)

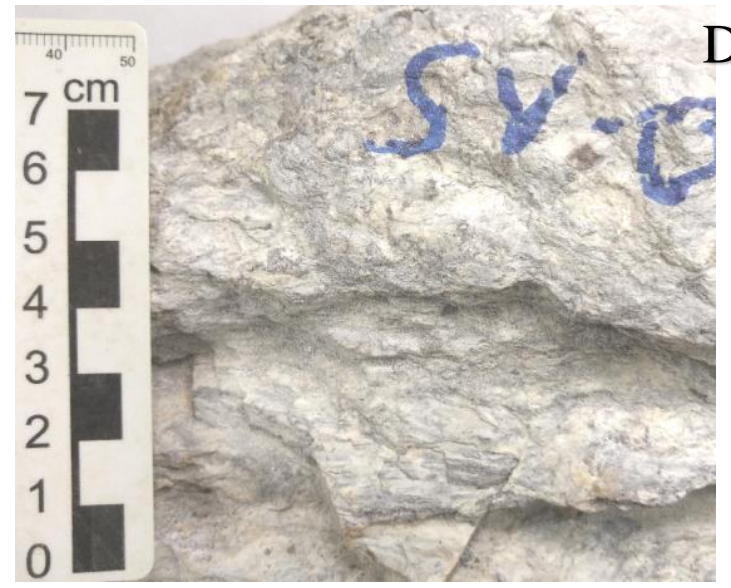

B)

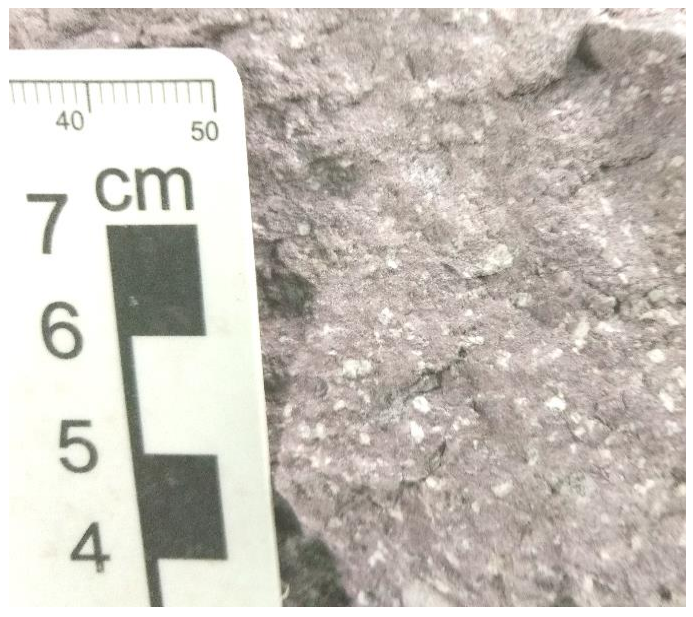

D)

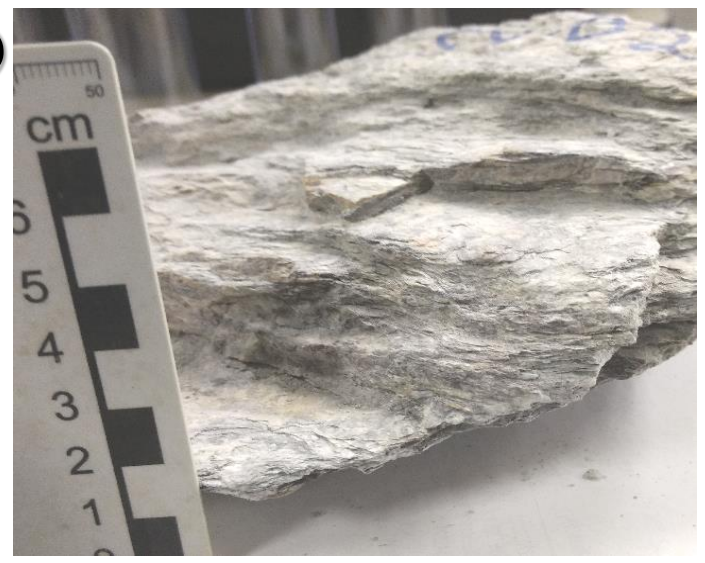

Figura 54. A) e B) representam a amostra SV-01, um tufo autoclástico e C) e D) mostram a amostra de derrame riolítico com alteração sericítica.

Os cristais de zircão concentrados na amostra SV-01 são prismáticos, geralmente com comprimento de 250 a $120 \mu \mathrm{m}$. Os zoneamentos oscilatórios são bem marcados, mostrando um amplo intervalo composicional nestes cristais magmáticos. Diversos grãos apresentam bordas reabsorvidas. Alguns grãos também apresentam inclusões, geralmente associadas a partes esbranquiçadas dos cristais, o que é indicativo de alterações tardimagmáticas.

Na amostra SV-01 foram executadas 24 análises de U-Pb em 23 cristais de zircão. As análises são caracterizadas por uma grande variação nos conteúdos de U (69 - 1031 ppm) e razões Th/U entre 0.41 e 1.33, razões típicas de grãos de zircão ígneos. Com 19 destas análises, que apresentaram idades ${ }^{206} \mathrm{~Pb} /{ }^{238} \mathrm{U}$ entre $340 \mathrm{Ma}$ e $354 \mathrm{Ma}$, foi possível calcular uma idade concórdia de $349 \pm 2$ Ma com valor de MSWD de 2.0 (Figura 55C). Nesta população outros 2 cristais apresentaram idades ${ }^{206} \mathrm{~Pb} /{ }^{238} \mathrm{U}$ de $322 \pm 4$ Ma e $334 \pm$ $6 \mathrm{Ma}$ (Figura 55B). A idade de 322 Ma está associada a um cristal com a parte com 
alteração tardi-magmática e a idade de 334 Ma está associada a um zircão hidrotermalizado presente nesta amostra. Outros dois cristais desta população apresentaram idades ${ }^{206} \mathrm{~Pb} /{ }^{238} \mathrm{U}$ Neoproterozoicas de $609 \pm 9$ e $622 \pm 9 \mathrm{Ma}$, idades relacionadas a Orogenia Cadomiana (Figura 55A).

Os isótopos de Ti desta amostra foi estudado em 12 cristais de zircão. 9 análises apresentaram razão média de ${ }^{50} \mathrm{Ti} /{ }^{49} \mathrm{Ti}$ de 0.95 , com conteúdo médio de ${ }^{49} \mathrm{Ti}$ de $5.1 \mathrm{ppm}$ e conteúdo médio de ${ }^{50} \mathrm{Ti}$ de $5.2 \mathrm{ppm}$. As temperaturas médias obtidas com essas 9 análises foram de $711 \pm 36^{\circ} \mathrm{C}$ no ${ }^{49} \mathrm{Ti}$ e $714 \pm 34^{\circ} \mathrm{C}$ no ${ }^{50} \mathrm{Ti}$ (Figura 56A). Duas outras análises foram descartadas por apresentarem conteúdos anômalos de $\mathrm{Ti}$, com o ${ }^{49} \mathrm{Ti}$ de 6105.9 e 28506.5 ppm e conteúdo de ${ }^{50} \mathrm{Ti}$ de 2006 e 2988 ppm respectivamente. Outras duas análises foram descartadas por apresentar razões ${ }^{50} \mathrm{Ti} /{ }^{49} \mathrm{Ti}$ de 0.88 e 0.89 , que são significativamente inferiores a 0.94 .
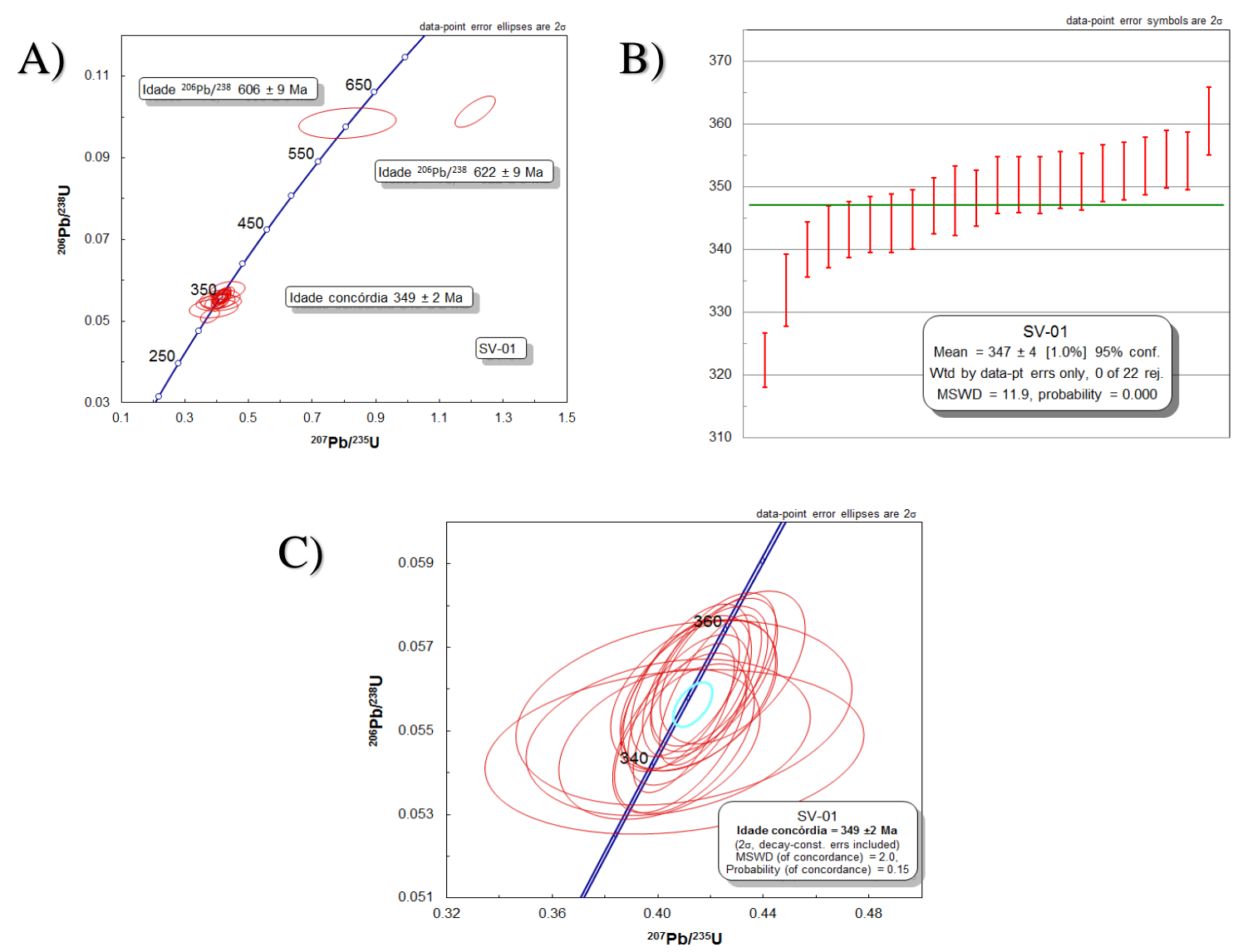

Figura 55. A) Dados de $U-\mathrm{Pb}, \mathrm{B})$ idade ${ }^{206} \mathrm{~Pb} /{ }^{238} \mathrm{U}$ media e C) idade concórdia obtida na amostra SV-01 
Na amostra SV-01 os isótopos de Lu-Hf foram estudados via LA-MC-ICPMS e os valores presentes ${ }^{176} \mathrm{Hf} /{ }^{177} \mathrm{Hf}_{\mathrm{o}}$ variaram entre 0.282821 e 0.282485 , o que corresponde a valores de $\varepsilon_{\mathrm{Hfo}}$ entre 1.27 e -10.61 , sendo que o valor médio foi de -5.27 . Ao utilizar a idade concórdia de $349 \mathrm{Ma}$ obtida para calcular os valores de ${ }^{176} \mathrm{Hf} /{ }^{177} \mathrm{Hf}_{\mathrm{i}}$ foram obtidos valores entre 0.282818 e 0.282484 , uma variação de 1.95 a -9.87 no $\varepsilon_{\mathrm{Hfi}}$, que teve valor médio de -4.54 (Figura 56B). Os resultados das análises individuais podem ser vistos na Figura 57 com as imagens de CL com a localização das análises e o resultado plotados juntos.
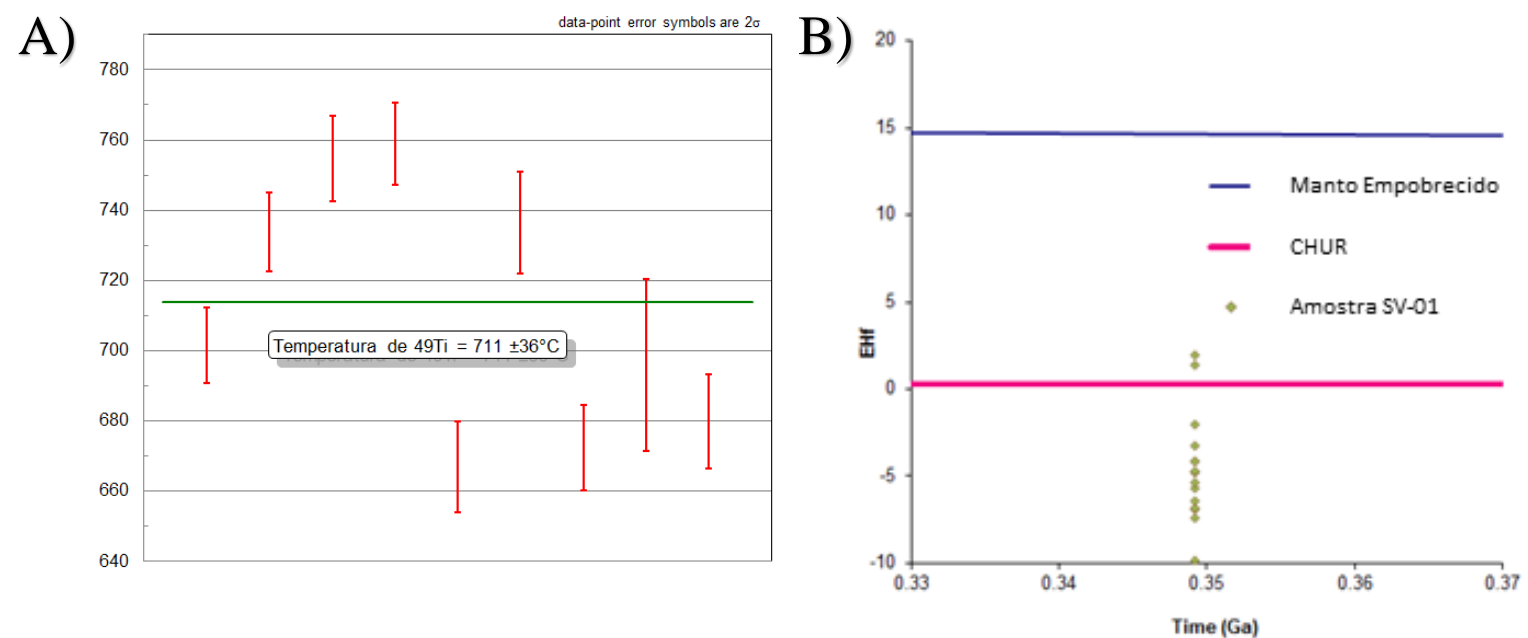

Figura 56. A) Temperaturas ${ }^{49}$ Ti e B) valores de $\varepsilon_{H f i}$ obtidos na população da amostra SV-01

A maioria dos cristais de SV-02 apresentam núcleo escuro com zoneamento oscilatório sútil nas imagens de CL. As bordas são esbranquiçadas, indicando alteração tardi-magmática. Alguns cristais apresentam inclusões associadas as regiões esbranquiçadas, indicando que as inclusões possivelmente são minerais de origem tardimagmática ou que elas sofreram annealing. Ocorrem também bordas reabsorvidas em diversos cristais, indicando um período de insaturação de $\mathrm{Zr}$ no magma em que esta população se cristalizou. 


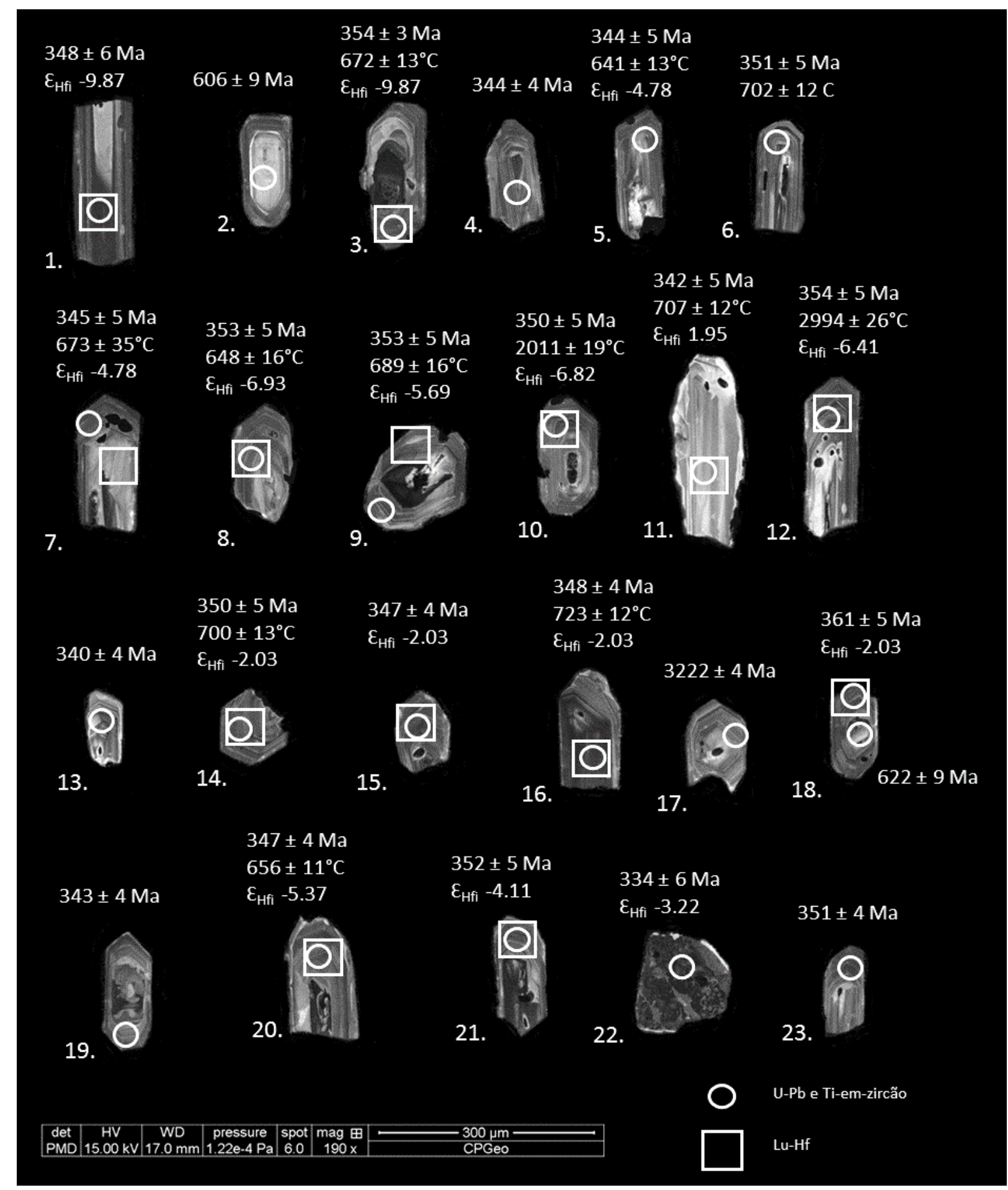

Figura 57. Composição de imagens CL da amostra SV-01 com os dados individuais das análises de $\mathrm{U}$-Pb, Ti-em-zircão e Lu-Hf executadas nesta população

Na amostra SV-02 foram executadas 25 análises em 18 cristais de zircão via SHRIMP com análises em núcleos e bordas pois diversos cristais aparentavam ter núcleos e bordas. As análises são caracterizadas por uma grande variação nos conteúdos de U (99 - 749 ppm) e razões Th/U entre 0.49 e 1.08, razões típicas de grãos de zircão ígneos. Com 
19 análises, que tiveram as idades ${ }^{206} \mathrm{~Pb} /{ }^{238} \mathrm{U}$ variando entre $344 \mathrm{Ma}$ e $354 \mathrm{Ma}$, foi calculada uma idade concórdia de $349 \pm 2$ Ma com o valor de MSWD de 0.100 (Figura 58B). Três análises apresentaram enriquecimento em $\mathrm{Pb}$ comum $(20.03 \%, 4.43 \%$, e $15.15 \%$ de ${ }^{204} \mathrm{~Pb} /{ }^{206} \mathrm{~Pb}$ ) e foram descartadas (Figura 58A). Outras 3 análises em bordas apresentaram conteúdo de $\mathrm{Pb}$ comum normal e idades individuais ${ }^{206} \mathrm{~Pb} /{ }^{238} \mathrm{U}$ de $332 \pm 2$ Ma, $338 \pm 2$ Ma e $332 \pm 2$ Ma. Como descrito acima, as bordas de diversos cristais de zircão desta população estão esbranquiçadas, feição característica de alterações tardimagmáticas, o que explica estas idades nas bordas dos cristais.
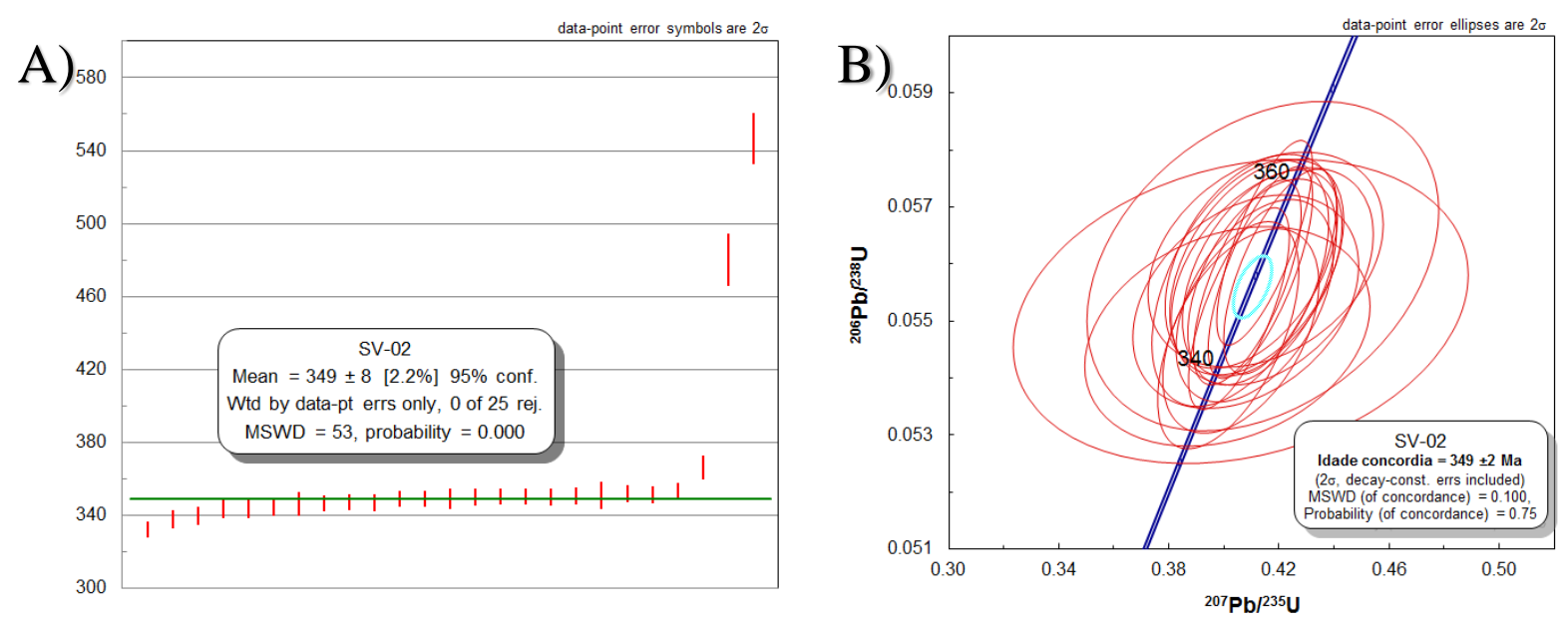

Figura 58. A) Dados U-Pb e B) idade concórdia obtida na amostra SV-02

O conteúdo de Ti-em-zircão da amostra SV-02 foi estudado em 12 cristais de zircão. Destes, 8 apresentaram razão média de ${ }^{50} \mathrm{Ti} /{ }^{49} \mathrm{Ti}$ de 0.97 , com conteúdo médio de ${ }^{49} \mathrm{Ti}$ de $6.6 \mathrm{ppm}$ e conteúdo médio de ${ }^{50} \mathrm{Ti}$ de $6.7 \mathrm{ppm}$. As temperaturas médias obtidas em 8 análises foram de $740 \pm 16^{\circ} \mathrm{C}$ no ${ }^{49} \mathrm{Ti}$ e $741 \pm 13^{\circ} \mathrm{C}$ no ${ }^{50} \mathrm{Ti}$ (Figura 59A). Dois cristais tiveram suas análises descartadas pois a razão de ${ }^{50} \mathrm{Ti} /{ }^{49} \mathrm{Ti}$ obtida foi de 1.5 e 0.8 enquanto que os outros dois cristais estavam enriquecidos em Ti com 25.1 e $12.5 \mathrm{ppm}$ de ${ }^{49} \mathrm{Ti}$ e 25.9 e 12.6 ppm de ${ }^{50} \mathrm{Ti}$. Nesta amostra 8 cristais de zircão tiveram os isótopos de Lu-Hf e analisados por LA-MC-ICPMS. Os valores presentes das razões ${ }^{176} \mathrm{Hf} /{ }^{177} \mathrm{Hf}_{\mathrm{o}}$ variaram entre 0.282815 e 0.282485 , valores correspondentes a $\varepsilon_{\text {Hfo }}$ entre 1.06 e 0.18 , sendo que o valor médio foi de 0.70 . Ao utilizar a idade concórdia de 349 Ma obtida para calcular os valores de ${ }^{176} \mathrm{Hf} /{ }^{177} \mathrm{Hf}_{\mathrm{i}}$ foram obtidos valores entre 0.282812 e 0.282484 , uma variação de 1.73 a 0.92 no $\varepsilon_{\mathrm{Hfi}}$, que teve valor médio de 1.42 (Figura 59B). 
A)

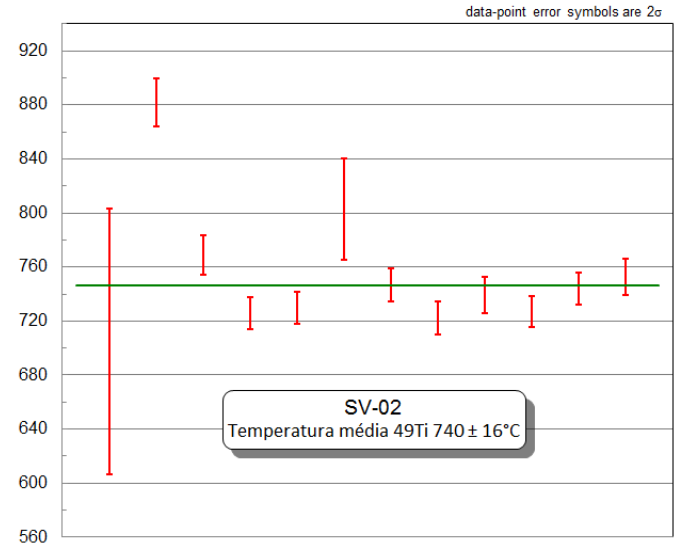

B)

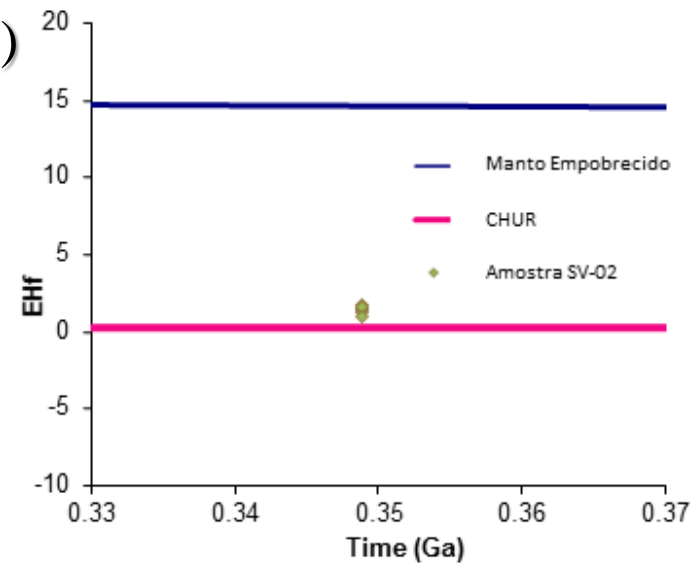

Figura 59. A) Temperaturas ${ }^{49} \mathrm{Ti}$ e B) dados de $\mathcal{E}_{\mathrm{Hfi}}$ obtidos na amostra SV-02

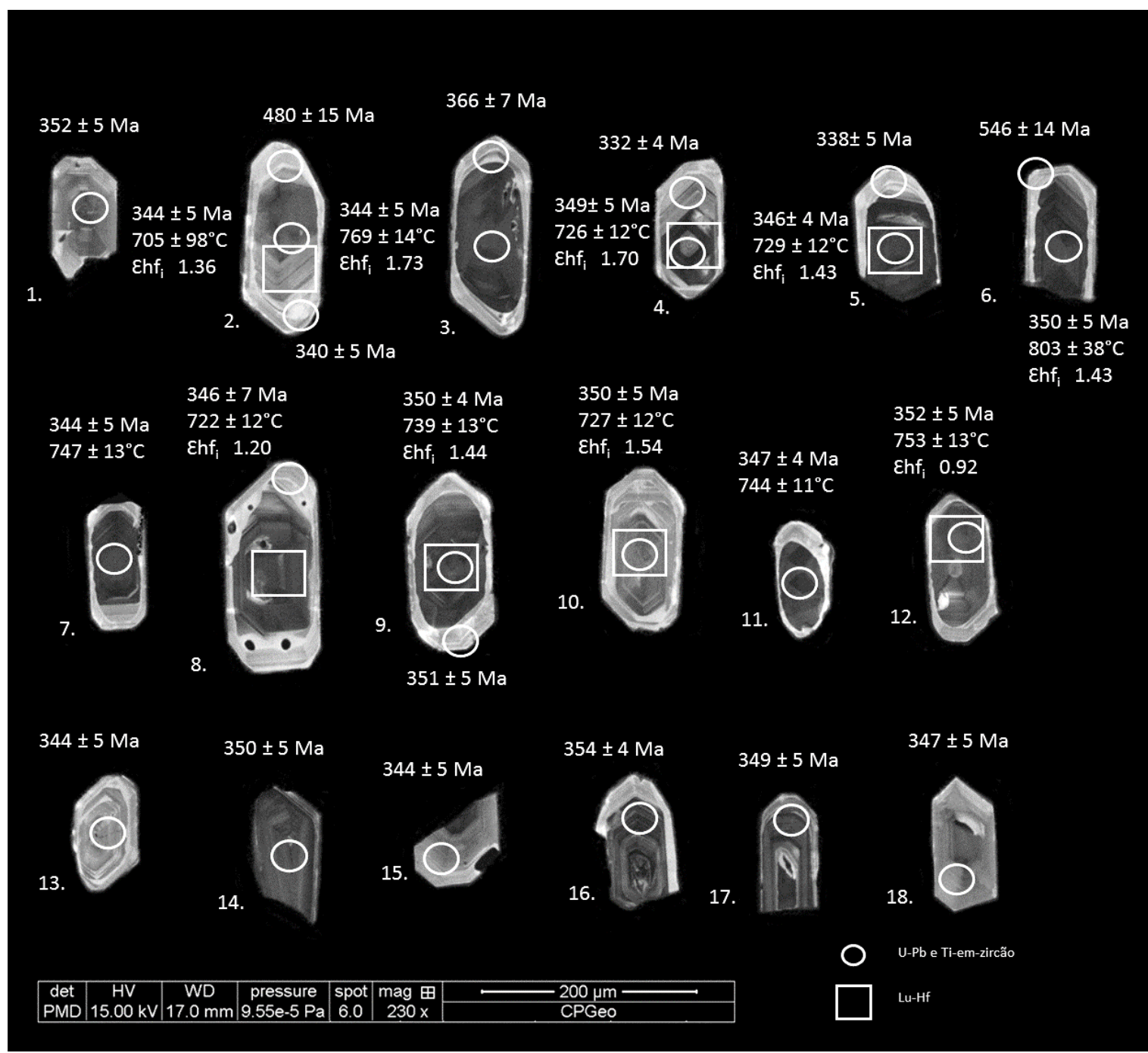

Figura 60. Composição com os dados obtidos nas análises individuais realizadas via $\mathrm{U}-\mathrm{Pb}$, Tiem-zircão e Lu-Hf na população de zircão da amostra SV-02. 
O resultado das análises individuais pode ser visto na Figura $60 \mathrm{com}$ as imagens de CL com a localização das análises e o resultado plotados juntos. A Figura 61 mostra todos os dados de $\varepsilon_{\mathrm{Hfi}}$ obtidos plotados em dois eixos de tempo distintos para auxiliar a compreensão. Ao longo dos resultados o autor desta tese optou por utilizar as imagens com escala temporal entre 0.33 e 0.37 Ga pois ela representa melhor os eventos da Faixa Piritosa Ibérica (Figura 61A), enquanto o Prof. Dr. John Hanchar recomenda a utilização da escala entre 0.0 e $1.0 \mathrm{Ga}$, que é a escala geralmente adotada em trabalhos utilizando os isótopos de Lu-Hf (comunicação oral, Figura 61B).

A)

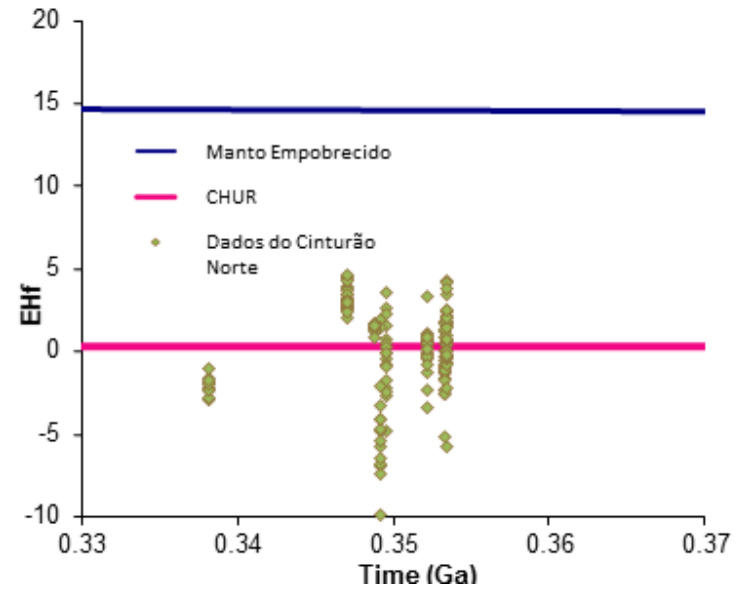

B)

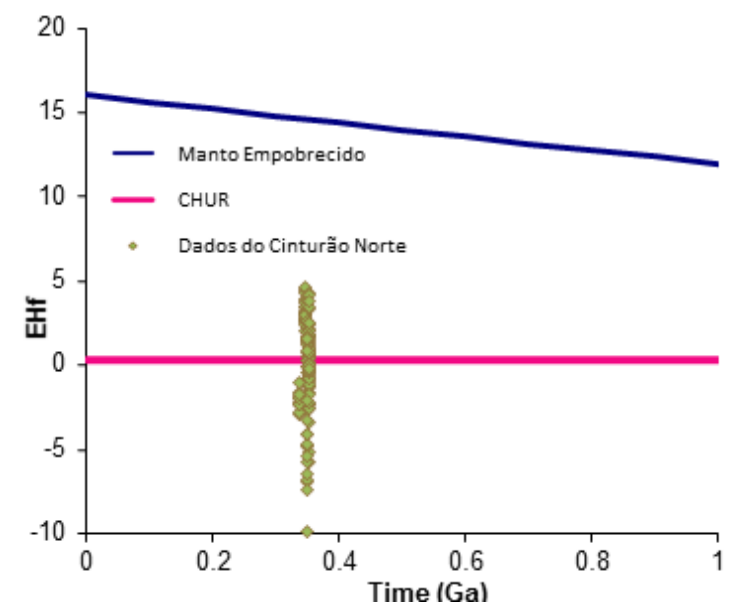

Figura 61. A) e B) apresentam os valores de $\mathcal{E}_{H f i}$ obtidos no Cinturão Norte plotados na escala dos eventos geológicos regionais (0.33-0.37 Ga) e na escala geralmente utilizada em outros trabalhos (0.0$1.0 \mathrm{Ga})$

As idades concórdia obtidas no Cinturão Norte da FPI variam entre $354 \pm 2$ Ma e $338 \pm 3$ Ma. As rochas vulcânicas associadas aos corpos de sulfetos maciços de San Telmo, Aguas Tenidas, Magdalena, Concepcion e Solo Viejo foram formadas no intervalo entre 354 - $347 \mathrm{Ma}$, todas idades do Tournaisiano. A amostra estudada em San Platon apresentou idade de $338 \pm 3 \mathrm{Ma}$, que Ma é interpretada como um corpo tardio que foi colocado em contato com o corpo de sulfeto maciço. Esta interpretação é apoiada na geologia regional do Cinturão Norte, uma região intensamente afetada por tectonismo na qual todos os contatos são tectônicos, assim como na datação e geologia do riolito tardio de Rio Tinto que será discutido abaixo.

As temperaturas do magma foram obtidas via isótopos de Ti em 8 amostras estudadas no Cinturão Norte da FPI espanhola que variaram entre $759^{\circ} \mathrm{C}$ e $711^{\circ} \mathrm{C}$, sendo que a temperatura média entre estes depósitos foi de $736 \pm 30^{\circ} \mathrm{C}$. 
Considerando que o depósito de Solo Viejo não é um depósito de sulfeto maciço e sim um depósito de Mn é possível separar os resultados em dois grupos:

I) depósitos de sulfeto maciço com temperaturas entre $759^{\circ} \mathrm{C}$ e $726^{\circ} \mathrm{C}$, com temperatura média de $738^{\circ} \mathrm{C}$.

II) depósito de $\mathrm{Mn}$ com temperatura de $711^{\circ} \mathrm{C}$ no tufo associado a mineralização.

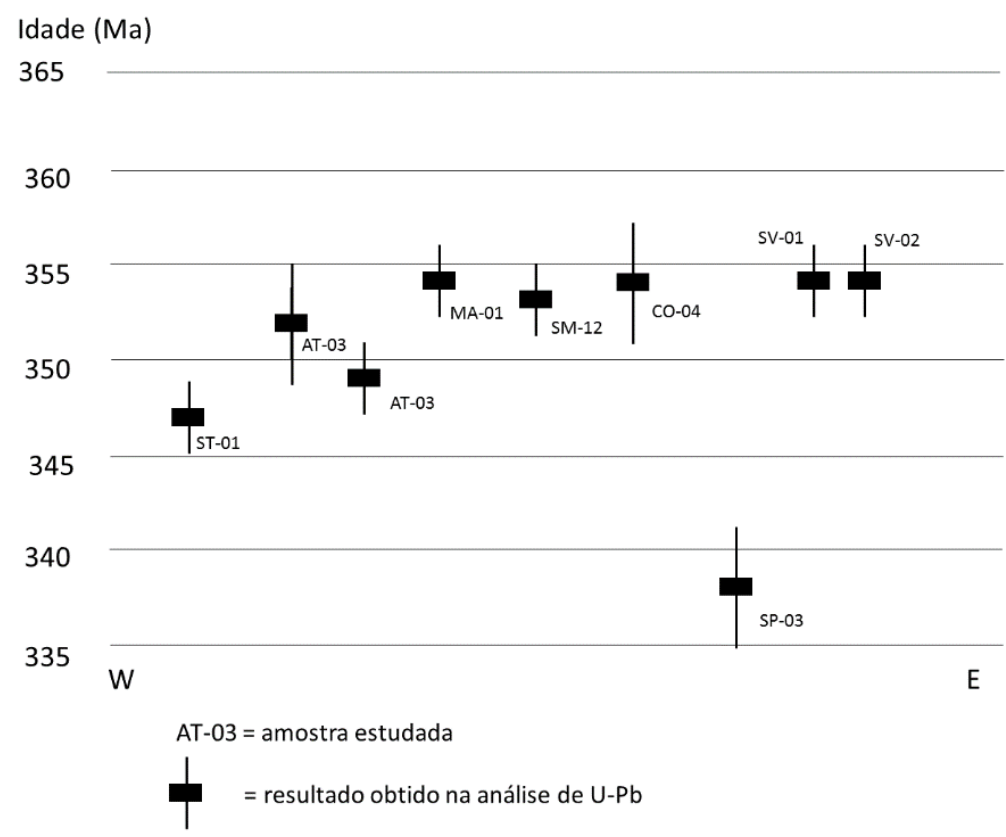

Figura 62. Régua de idades concórdia obtidas nos depósitos do Cinturão Norte. Os depósitos estão plotados de acordo com a geografia e é possível notar que existe uma tendência dos depósitos a oeste do Cinturão Norte serem mais novos que os depósitos mais a leste

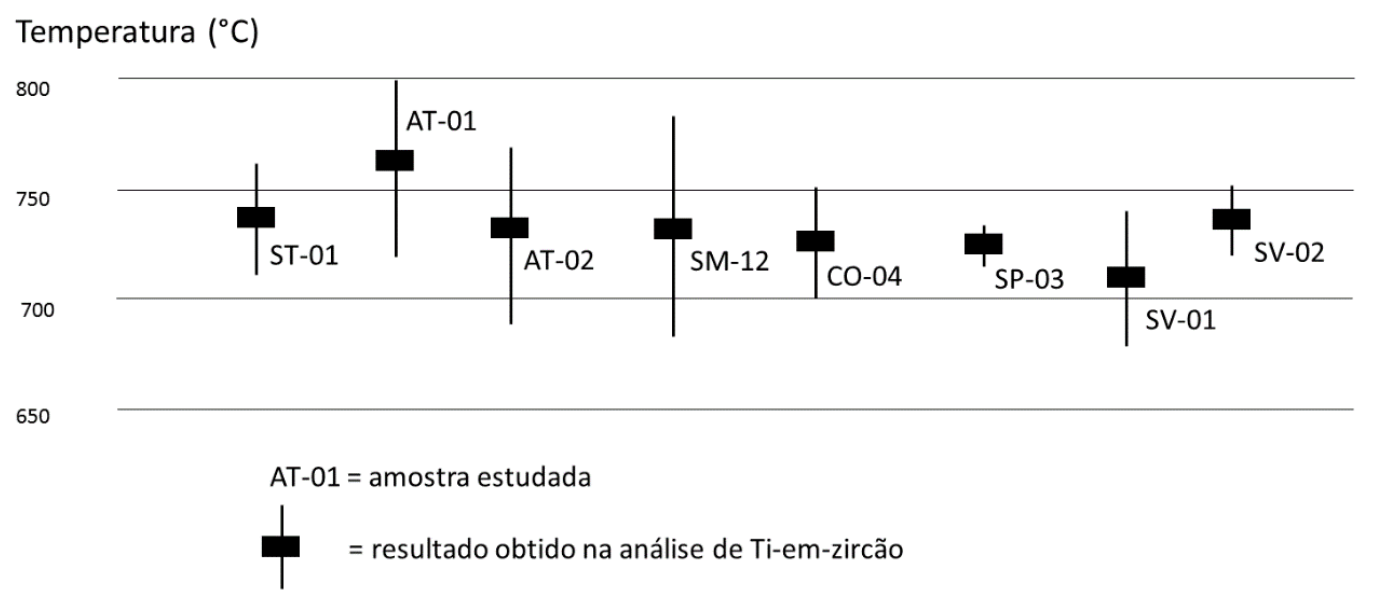

Figura 63. Temperaturas ${ }^{49}$ Ti obtidas nas amostras do Cinturão Norte 
Os isótopos de Lu-Hf foram analisados em 9 amostras do Cinturão Norte. Os valores de $\varepsilon_{\mathrm{Hfi}}$ obtidos nas rochas vulcânicas destas amostras variaram entre 3.28 e -4.54, com valor médio de $\varepsilon_{\mathrm{Hfi}}$ de -0.18 nesta região (Figura 64A e B).

As amostras estudadas em Solo Viejo mostram origem distinta entre si. A amostra do tufo autoclástico (SV-01) apresentou valor médio de $\varepsilon_{\mathrm{Hfi}}$ de -4.54 , indicando origem predominantemente crustal, enquanto que a lava riolítica (SV-02) apresentou valor médio de $\varepsilon_{\mathrm{Hfi}}$ de 1.42 , indicando que esta amostra possui material de origem mantélica. A dispersão dos dados obtidos nestas duas amostras também chama a atenção e os dados individuais de $\varepsilon_{\mathrm{Hfi}}$ de SV-01 (o tufo autoclástico) variam entre 1.95 a -9.87 enquanto que os valores individuais de $\varepsilon_{\mathrm{Hfi}}$ de SV-02 (o derrame riolítico) variam entre 1.73 e 0.92 (Figura 64C). Estes resultados obtidos em Solo Viejo mostram magmatismo com origens distintas em unidades félsicas distintas, o que já havia sido descrito por Conde (2016) a partir de litogeoquímica de elementos pesados em outros depósitos. Nos demais depósitos do Cinturão Norte apenas a amostra diretamente relacionada a mineralização foi estudada e com isso não existem dados comparativos que ilustrem origens distintas nos demais depósitos, como é o caso em Solo Viejo.

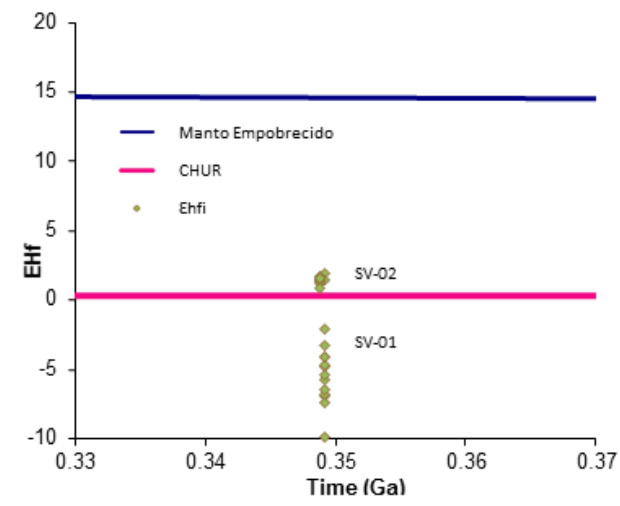

Figura 64. A) valores de $\varepsilon_{H f i}$ obtidos no Cinturão Norte na escala de 0.33-0.37 Ga e B) na escala de 0 -1.0 Ga. C) valores de $\mathcal{E}_{\mathrm{Hfi}}$ obtidos em Solo Viejo

\subsubsection{Setor Central}

O Setor Central da Faixa Piritosa Ibérica é a porção sul da Região Norte de acordo com a divisão adotada nesta tese. No Setor Central amostras provenientes de dois depósitos (La Zarza e Rio Tinto) e uma localidade sem mineralizações (Aglomerado del Cerro) foram analisadas. 


\section{$\underline{\text { La Zarza }}$}

O depósito de La Zarza é um dos depósitos gigantes da FPI que é explorado desde tempos romanos e se encontra exaurido hoje em dia. O corpo de sulfeto maciço La Zarza é a maior lente individual de toda a FPI, com extensão total de $2900 \mathrm{~m}$, espessura superior a $100 \mathrm{~m}$ e largura de mais de 500m. Duas amostras (ZA-3 e ZA-4, Figura 65A e B, respectivamente) consideradas representativas do dacito maciço encaixante foram analisadas nesta tese. As duas amostras são dacitos altamente afetados pela alteração hidrotermal, o que transforma diversos minerais da sua associação mineral original em filossilicatos, mais especificamente sericita e clorita, além dos sulfetos maciços.
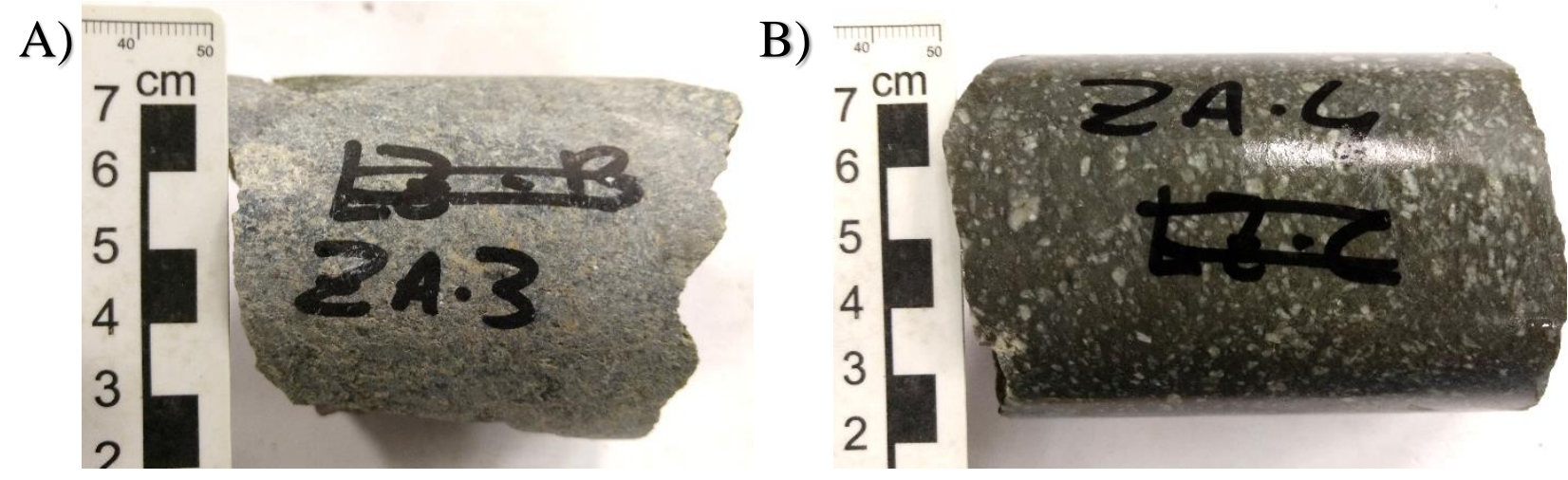

Figura 65. A) amostra ZA-3 e B) amostra ZA-4, dois dacitos maciços. A diferença entre elas se dá, pois, a amostra ZA-4 está molhada na foto enquanto a ZA-3 não, e com isso seus porfiroclastos estão mais visíveis.

Os cristais de zircão concentrados na amostra ZA-3 foram catalogados via imagens de CL. Em geral estes cristais são prismáticos, possuem comprimento entre 80 e $200 \mu \mathrm{m}$. A maioria dos cristais apresentam zoneamento oscilatório bem determinado, mostrando que a composição química do magma variou ao longo do processo de cristalização. Diversos cristais apresentam bordas reabsorvidas, o que indica condições de insaturação de $\mathrm{Zr}$ pós-cristalização dos cristais. Diversos cristais apresentam esbranquiçamento leve nas bordas associado a alterações tardi-magmáticas, que, nesta amostra, são mais sutis e leves comparativamente a outras populações de zircão já descritas (por exemplo, SV-01 e SV-02). Algumas inclusões são observadas nesta população e estão, via de regra, associadas ao processo de annealing. Um dos cristais é claro e foge de diversos padrões desta população (zircão 1), o que pode indicar a presença de um xenocristal. 
Nesta amostra 17 análises foram efetuadas em 17 cristais de zircão via SHRIMP. As análises são caracterizadas por uma pequena variação nos conteúdos de U (46 - 392 ppm) e razões Th/U entre 0.39 e 0.85 , razões típicas de grãos de zircão ígneos. Em um diagrama concórdia 14 análises que tiveram idades ${ }^{206} \mathrm{~Pb} /{ }^{238} \mathrm{U}$ variando entre $348 \mathrm{Ma} \mathrm{e}$ 366 Ma geraram uma idade concórdia de $357 \pm 2$ Ma e valor de MSWD de 0.32 (Figura 66B). O cristal com aspecto diferente de fato não pertence a esta população e apresentou uma idade ${ }^{207} \mathrm{~Pb} /{ }^{206} \mathrm{~Pb}$ Riaciana de $2090 \pm 22 \mathrm{Ma}$. Outros dois cristais apresentaram idades ${ }^{238} \mathrm{U} /{ }^{206} \mathrm{~Pb}$ de $328 \pm 8 \mathrm{Ma}, 339 \pm 9 \mathrm{Ma}($ Figura $66 \mathrm{~A})$.
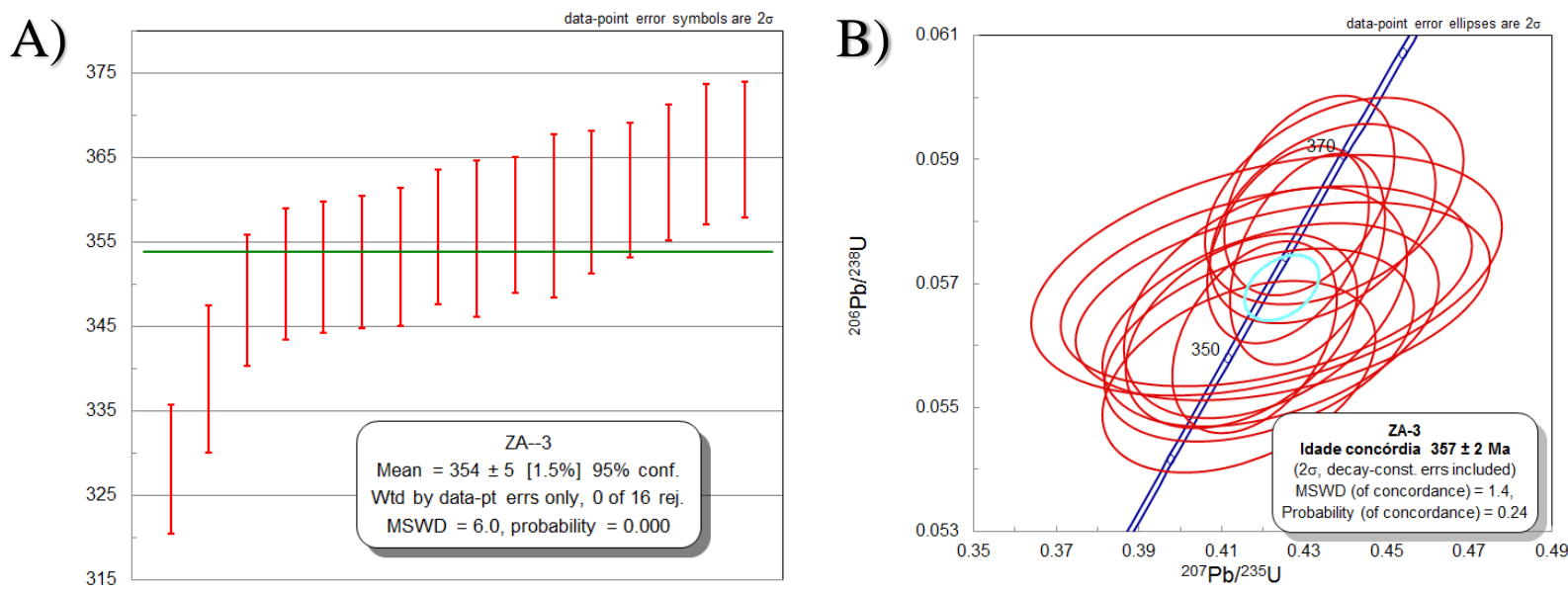

Figura 66. A) Idade ${ }^{206} \mathrm{~Pb} /{ }^{238} \mathrm{U}$ média e B) idade concórdia obtidas na amostra ZA-3

O conteúdo de Ti-em-zircão da amostra ZA-3 foi analisado por SHRIMP em 5 cristais de zircão. Em conjunto, 4 análises apresentaram razão média de ${ }^{50} \mathrm{Ti} /{ }^{49} \mathrm{Ti}$ de 0.97 , com conteúdo médio de ${ }^{49} \mathrm{Ti}$ de $7.6 \mathrm{ppm}$ e conteúdo médio de ${ }^{50} \mathrm{Ti}$ de $7.8 \mathrm{ppm}$. As temperaturas médias obtidas nestas análises foram de $762 \pm 47^{\circ} \mathrm{C}$ no ${ }^{49} \mathrm{Ti}$ e $764 \pm 49^{\circ} \mathrm{C}$ no ${ }^{50} \mathrm{Ti}$ (Figura 68A). Outro cristal teve sua análise descartada devido ao alto conteúdo de Ti (428.7 ppm de ${ }^{49} \mathrm{Ti}$ e 435.8 ppm de ${ }^{50} \mathrm{Ti}$ ).

Os isótopos de Lu-Hf foram analisados por LA-MC-ICPMS em 12 grãos de zircão. Os valores de ${ }^{176} \mathrm{Hf} /{ }^{177} \mathrm{Hf}_{\mathrm{o}}$ obtidos variam no intervalo de 0.282727 a 0.282641 , com valores de $\varepsilon_{\mathrm{Hfo}}$ correspondentes variando entre -2.05 e -5.09, e valor médio de -3.14. Quando os dados de Hf são analisados em conjunto com a idade concórdia de $355 \mathrm{Ma}$ desta amostra foram obtidos valores de ${ }^{176} \mathrm{Hf} /{ }^{177} \mathrm{Hf}_{\mathrm{i}}$ variando entre 0.282725 e 0.28264 . Os valores de $\varepsilon_{\mathrm{Hfi}}$ correspondentes variam entre -1.34 e -4.36 , com valor médio de -2.4 (Figura 68B). Os resultados individuais de $\varepsilon_{\mathrm{Hfi}}$, bem como os resultados de U-Pb e de Tiem-zircão, podem ser vistos na Figura 67. 


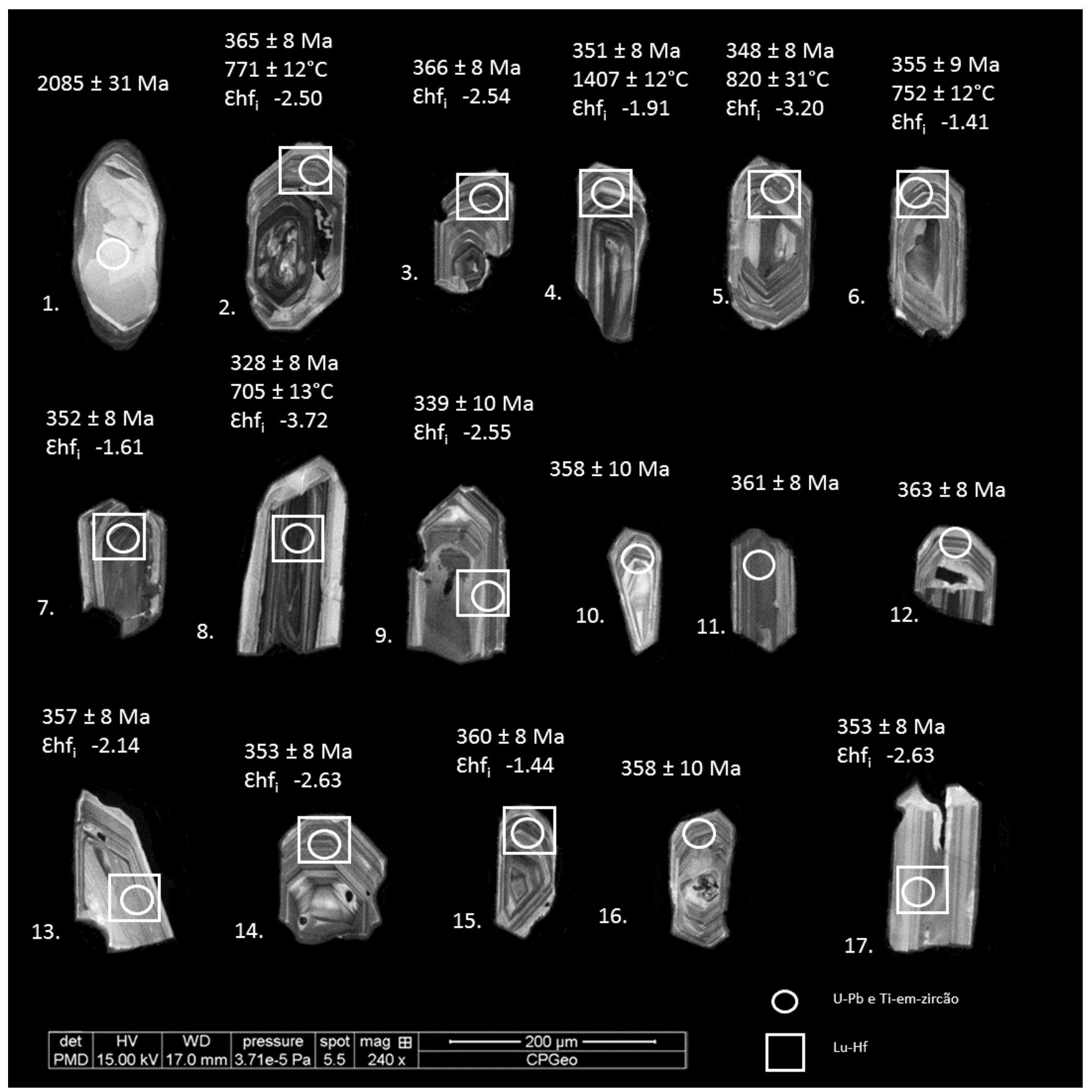

Figura 67. Composição das imagens de CL com os resultados individuais das análises efetuadas na população de zircão da amostra ZA-3 

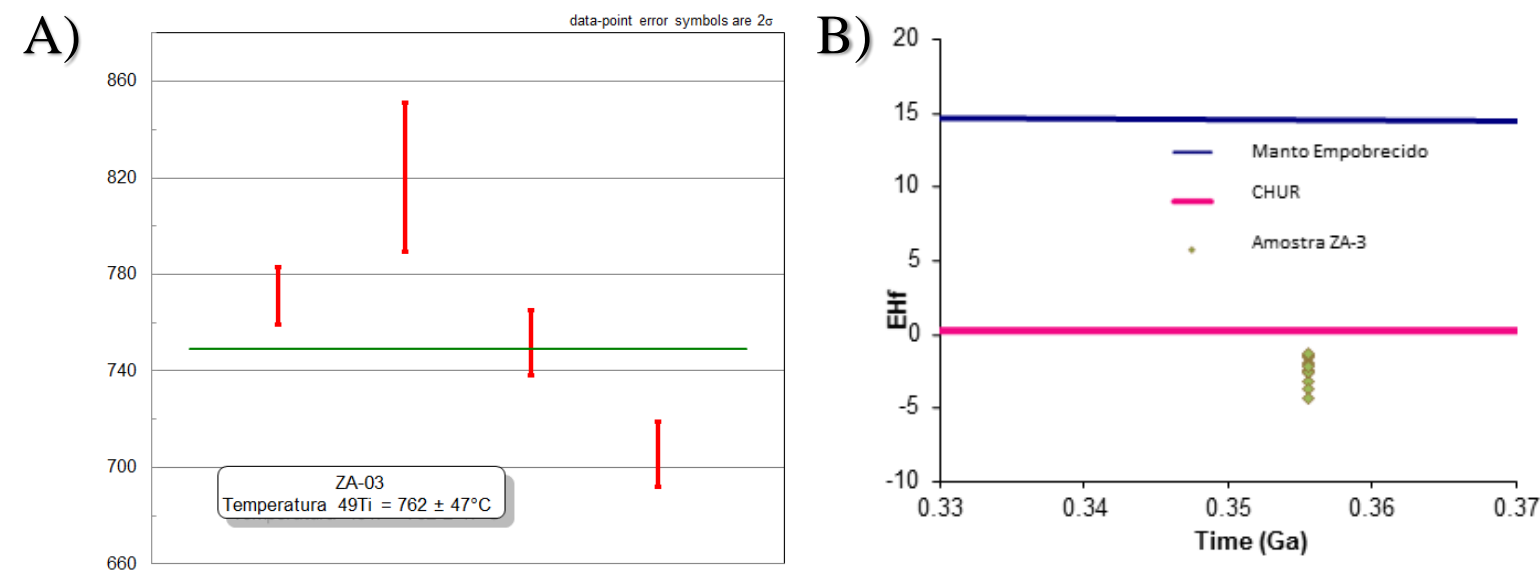

Figura 68. A) Temperaturas ${ }^{49}$ Ti e B) valores de $\varepsilon_{H f i}$ obtidos na amostra ZA-3

A amostra ZA-4 também é um dacito altamente afetado pela alteração hidrotermal composta por filossilicatos (sericita e clorita), além de sulfetos, que nesta amostra são raros. Em geral os cristais de zircão catalogados por CL são prismáticos, com comprimento entre 120 e $250 \mu \mathrm{m}$. Estes cristais são mais compridos e finos que os cristais da amostra ZA-3. Assim como ocorre na população de ZA-3, os grãos de ZA-4 apresentam um zoneamento oscilatório bem marcado, o que implica em variabilidade composicional no magma ao longo da cristalização destas populações. Diversos cristais apresentam bordas corroídas e/ou bordas esbranquiçadas de modo similar a população de ZA-3.

Nesta população foram executadas 20 análises de U-Pb via SHRIMP em 19 cristais de zircão. As análises são caracterizadas por uma grande variação nos conteúdos de U (161 - 748 ppm) e razões Th/U entre 0.42 e 1.04, razões que são típicas de grãos de zircão ígneos. As análises de 17 cristais apresentaram idades ${ }^{206} \mathrm{~Pb} /{ }^{238} \mathrm{U}$ variando entre 343 Ma e 368 Ma e gerou uma idade concórdia de $355 \pm 4$ Ma com valor de MSWD de 0.36 (Figura 69B). Outros 2 cristais apresentaram idades ${ }^{206} \mathrm{~Pb} /{ }^{238} \mathrm{U}$ de $322 \pm 8$ Ma e 377 \pm 9 Ma (Figura 69A), sendo que a idade de 322 Ma é um núcleo aparentemente afetado por alteração tardi-magmática de um cristal que possuía aparência de borda e núcleo de eventos distintos. Este cristal também foi datado na borda, que apresenta idade ${ }^{206} \mathrm{~Pb} /{ }^{238} \mathrm{U}$ de $368 \pm 8$ Ma.

Os isótopos de Ti da amostra ZA-4 foram estudados com 10 cristais de zircão. Nove análises apresentaram razão média de ${ }^{50} \mathrm{Ti} /{ }^{49} \mathrm{Ti}$ de 0.95 , com conteúdo médio de ${ }^{49} \mathrm{Ti}$ de 7.4 ppm e conteúdo médio de ${ }^{50} \mathrm{Ti}$ de $7.34 \mathrm{ppm}$. As temperaturas médias obtidas nessas 9 análises foram de $746 \pm 39^{\circ} \mathrm{C}$ no ${ }^{49} \mathrm{Ti}$ e $745 \pm 37^{\circ} \mathrm{C}$ no ${ }^{50} \mathrm{Ti}$ (Figura $70 \mathrm{~A}$ ). Um dos cristais 
teve suas análises descartadas devido ao alto conteúdo de Ti (93.4 ppm de ${ }^{49} \mathrm{Ti}$ e 91.5 ppm de $\left.{ }^{50} \mathrm{Ti}\right)$. Quando as duas populações de zircão de ZA-3 e ZA-4 são analisadas em conjunto são obtidas temperaturas de $747 \pm 39^{\circ} \mathrm{C}$ no ${ }^{49} \mathrm{Ti}$ e $746 \pm 39^{\circ} \mathrm{C}$ no ${ }^{50} \mathrm{Ti}$ (Figura $72 \mathrm{~A})$.
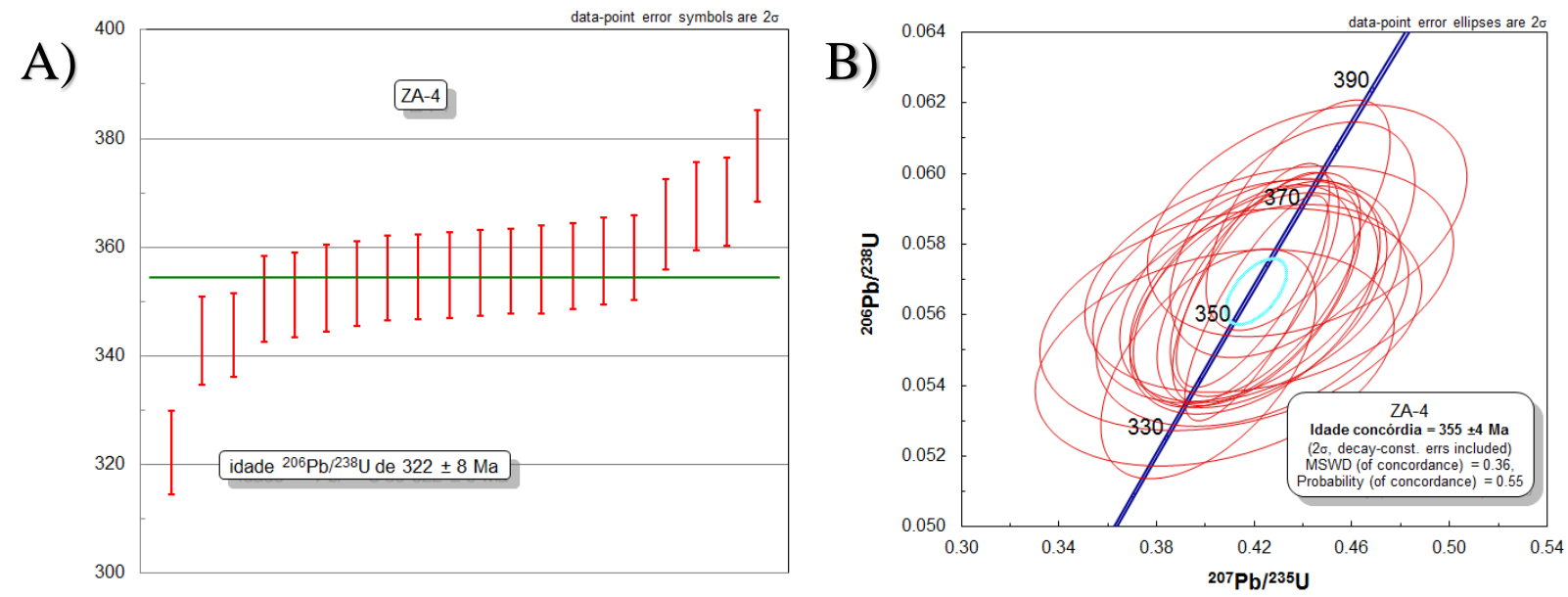

Figura 69. A) Dados U-Pb e B) idade concórdia obtida na amostra ZA-4

Os isótopos de Lu-Hf foram analisados via LA-MC-ICPMS nesta amostra em 17 grãos de zircão. Estes cristais apresentaram valores de ${ }^{176} \mathrm{Hf} /{ }^{177} \mathrm{Hf}_{\mathrm{o}}$ entre $0.282793 \mathrm{e}$ 0.282645 , com os valores de $\varepsilon_{\text {Hfo }}$ correspondente variando entre 0.28 e -4.95 , e valor médio de -3.42. Quando os dados de Lu-Hf são analisados junto com a idade concórdia de $355 \mathrm{Ma}$ obtida nesta amostra os valores de ${ }^{176} \mathrm{Hf} /{ }^{177} \mathrm{Hf}_{\mathrm{i}}$ iniciais obtidos variaram entre 0.282791 e 0.282687 . Os valores de $\varepsilon_{\mathrm{Hfi}}$ correspondentes variam entre 1.01 e -4.21 , com valor médio de -2.68. Todos os resultados individuais das análises podem ser vistos na Figura 70B abaixo.
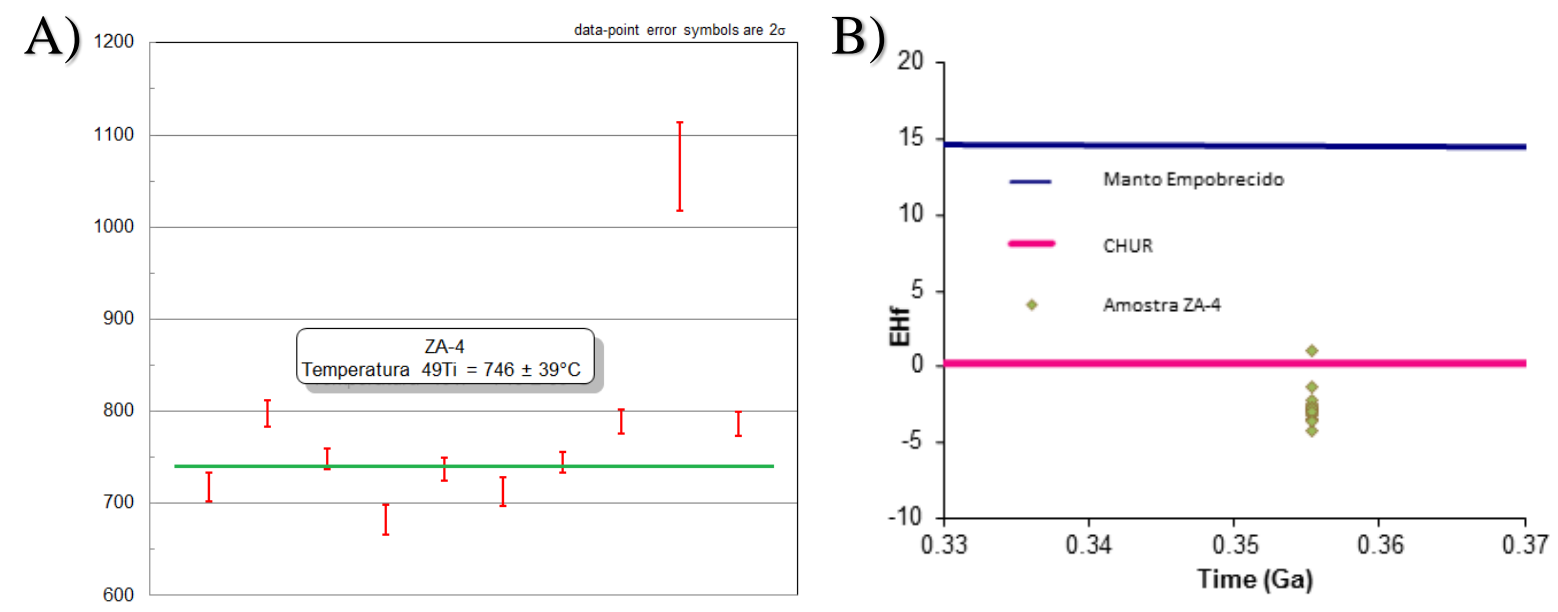

Figura 70. A) Temperaturas ${ }^{49}$ Ti e B) valores de $\varepsilon_{H f i}$ obtidos na amostra ZA-4 


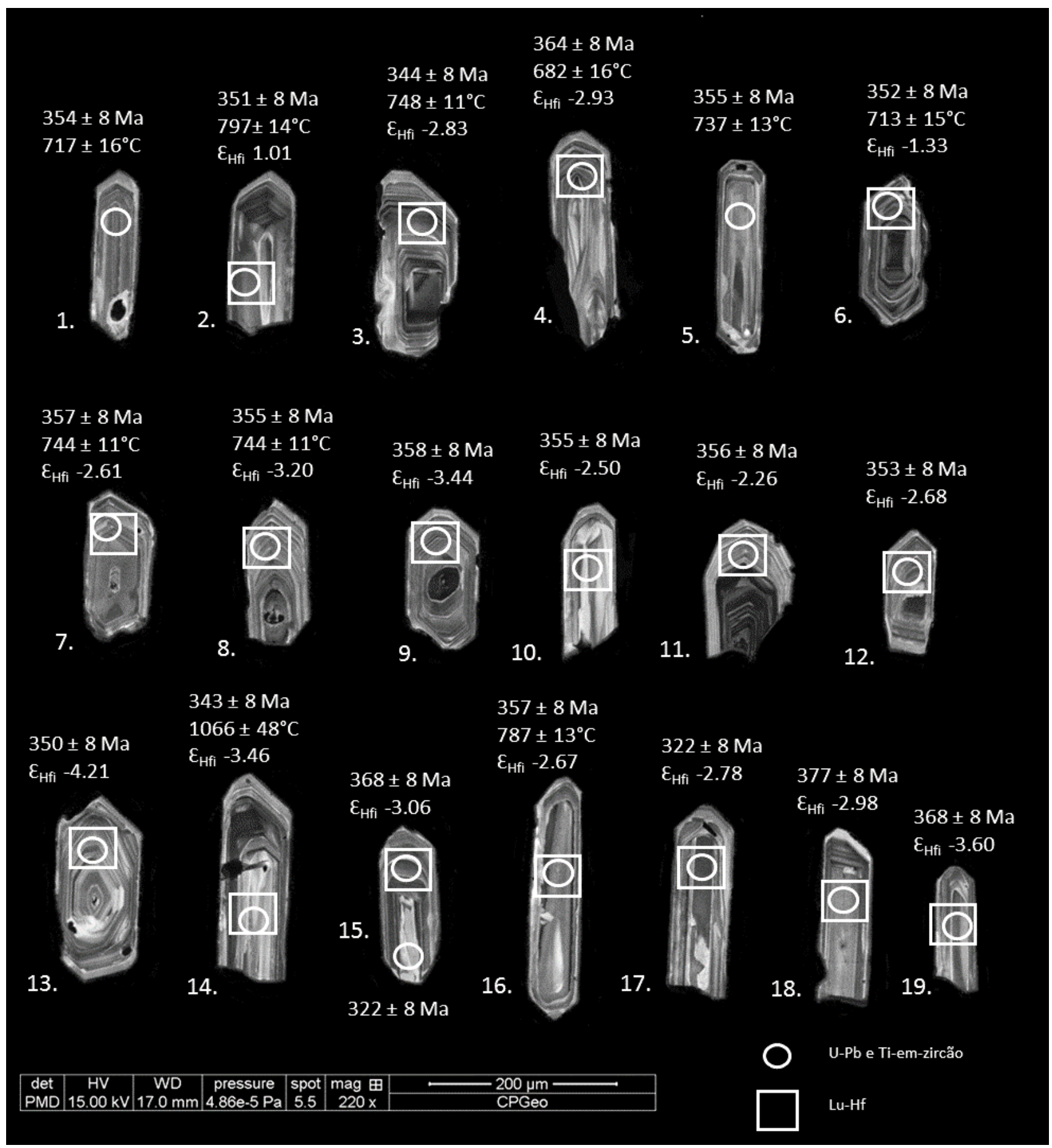

Figura 71. Composição de imagens de CL da população de zircão da amostra ZA-4 com os dados individuais 


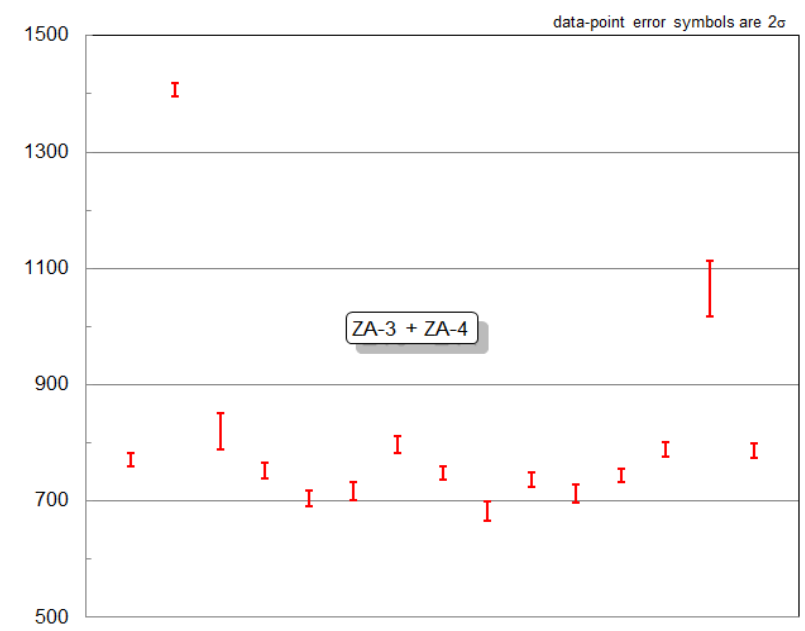

Figura 72. Temperaturas ${ }^{49}$ Ti obtidas nas amostras ZA-3 e ZA-4 e plotadas em conjunto

\section{$\underline{\text { Rio Tinto }}$}

Na região de Rio Tinto foram estudadas 5 amostras associadas a distintos estágios de evolução do magmatismo na região. Destas 5 amostras, 3 foram coletadas no próprio depósito de Rio Tinto, enquanto 2 amostras foram coletadas em Zarandas, uma localidade próxima ao depósito de Rio Tinto que apresenta a mesma geologia sem as alterações hidrotermais, o que permite uma melhor compreensão das relações geológicas entre os litotipos (Conde, 2016).

A amostra RT-02 representa o riolito tardio (Figura 73) que corta os litotipos principais da parte norte do depósito de Rio Tinto, como a rocha encaixante aos sulfetos disseminados de Filón Norte (Figura 74). Os cristais de zircão concentrados nesta amostra apresentam morfologia prismática, com tamanho entre $80-300 \mu \mathrm{m}$. O zoneamento oscilatório é bem marcado, indicando variabilidade composicional neste magma ao longo da cristalização destes cristais de zircão. Bordas reabsorvidas são uma característica comum nesta população, indicando insaturação de Zr no magma pós-cristalização dos cristais. Alguns cristais apresentam regiões esbranquiçadas, especialmente as bordas, indicando que estes cristais sofreram alteração tardi-magmática. 


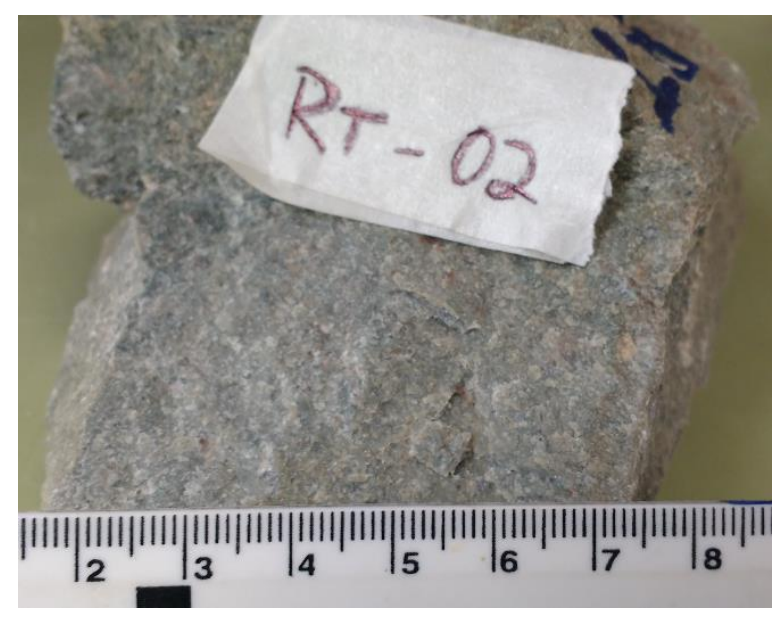

Figura 73. Amostra RT-02, o riolito posterior de Rio Tinto

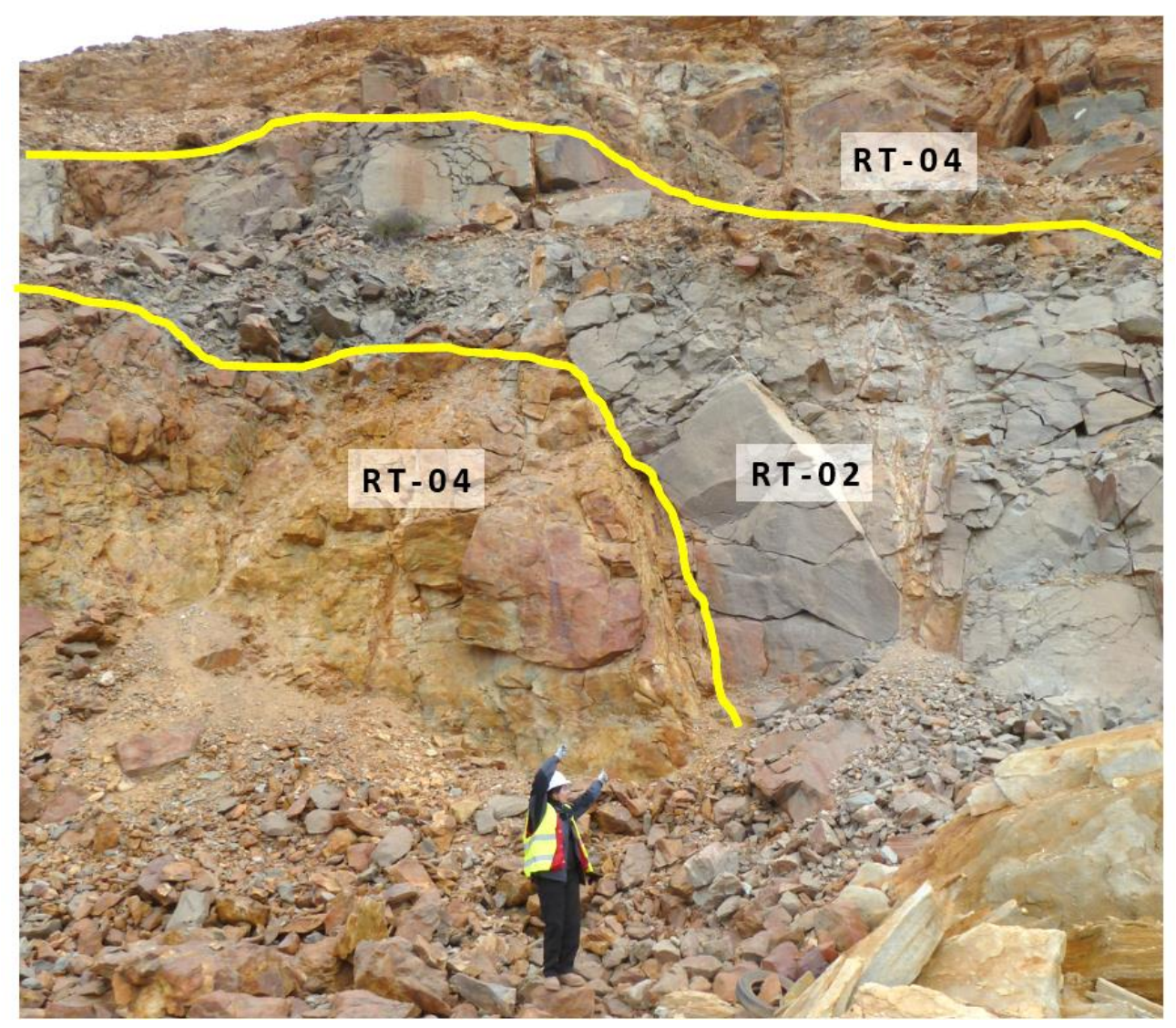

Figura 74. Contato entre o litotipo alterado hidrotermalmente de Filón Norte (RT-04) e uma intrusão tardia sem alteração (RT-02),

Nesta amostra 20 análises de U-Pb foram executadas em 20 cristais de zircão. As análises são caracterizadas por uma grande variação nos conteúdos de U (200 - 1599 ppm) e razões Th/U entre 0.38 e 0.93 , razões que são típicas de cristais de zircão ígneos. As análises variam em idades ${ }^{206} \mathrm{~Pb} /{ }^{238} \mathrm{U}$ entre $331 \mathrm{Ma}$ e $362 \mathrm{Ma}$ (Figura 75A). Um dos cristais apresentou alto teor de $\mathrm{Pb}$ comum (7.65ppm) e foi descartado, enquanto os 19 
cristais gerariam uma idade concórdia de $346 \pm 3$ Ma com valor de MSWD de 3.8 (Figura 75B). Entretanto, levando a geologia regional, a idade concórdia obtida para a amostra SP-03, e a geologia local em conta estas 19 análises foram separadas em 2 populações distintas:

I) uma população de antecristais composta por 10 cristais, com idades ${ }^{206} \mathrm{~Pb} /{ }^{238} \mathrm{U}$ entre 345 Ma e 362 Ma e idade concórdia de $352 \pm 3$ Ma, com valor de MSWD de 2.0 (Figura 75C).

II) uma população de autocristais composta por 9 cristais, com idades ${ }^{206} \mathrm{~Pb} /{ }^{238} \mathrm{U}$ entre 331 Ma e 344 Ma e idade concórdia de $339 \pm 3$ Ma, com valor de MSWD de 0.71 (Figura 75D).

Essas populações são morfologicamente similares e são indistinguíveis via geoquímica ou nas imagens de CL
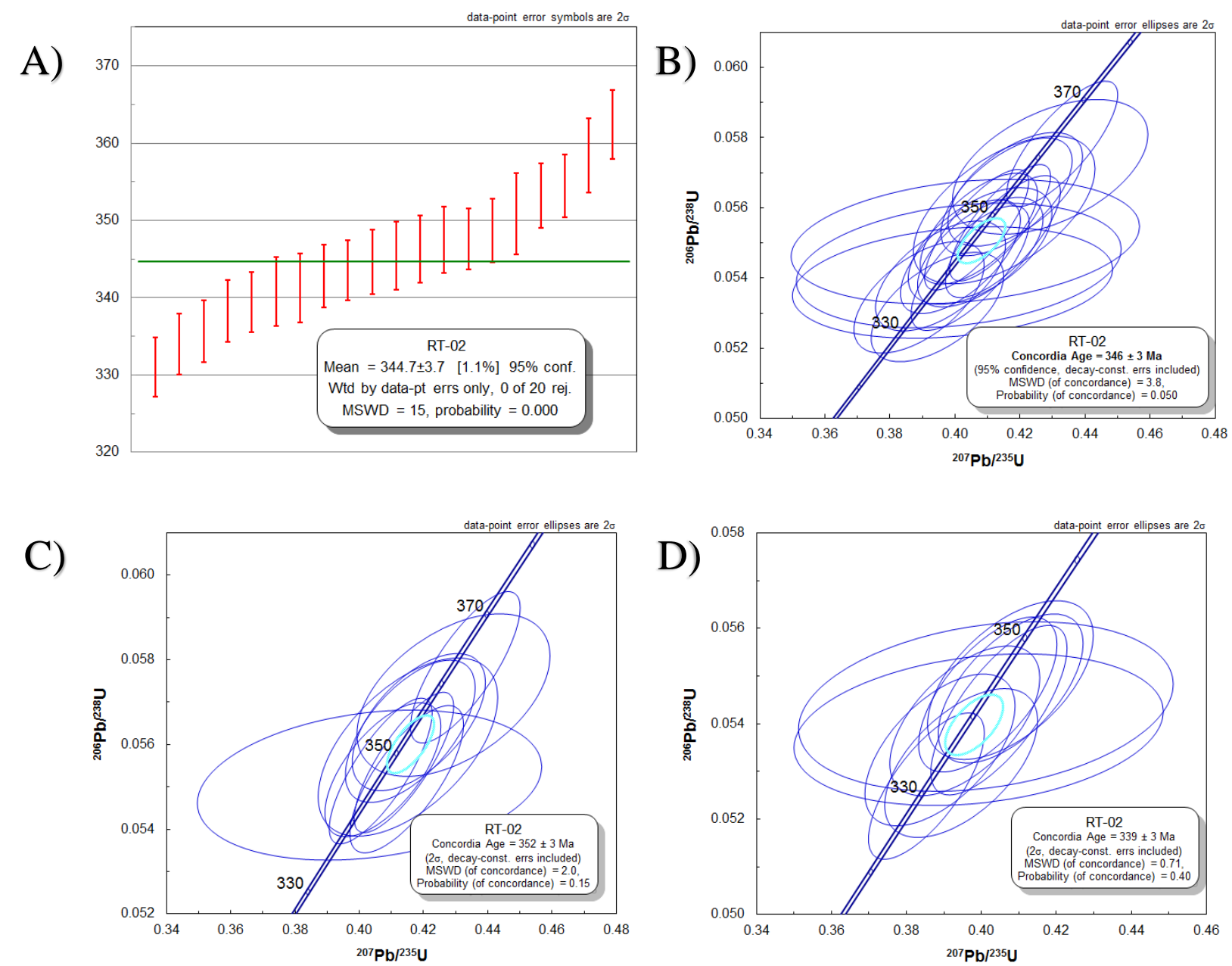

Figura 75. A) todos os dados U-Pb obtidos, B) idade concórdia única gerada com esta população. C) Idade concórdia dos antecristais e D) idade concórdia dos autocristais da amostra RT-02 
A amostra RT-02 apresenta duas populações distintas, os antecristais e os autocristais de zircão. Ambas tiveram o seu conteúdo de Ti analisado. A população de antecristais de 352 Ma teve 9 cristais de zircão analisados. Destas, 8 análises apresentaram razão média de 0.97 conteúdo médio de ${ }^{49} \mathrm{Ti}$ de 5.8 ppm e conteúdo médio de ${ }^{50} \mathrm{Ti}$ de 5.9 ppm. As temperaturas médias obtidas nestas 8 análises foram de $714 \pm 61^{\circ} \mathrm{C}$ no ${ }^{49} \mathrm{Ti}$ e $713 \pm 64^{\circ} \mathrm{C}$ no ${ }^{50} \mathrm{Ti}$. Uma análise foi descartada por apresentar temperatura de $604 \pm 15$ no ${ }^{49} \mathrm{Ti}$ e $607 \pm 14$ no ${ }^{49} \mathrm{Ti}$, que são temperaturas irreais para magmas félsicos (Siégel et al., 2018). A população de autocristais de 339 Ma também teve 9 cristais de zircão analisados e nela 7 análises apresentaram razão média de ${ }^{50} \mathrm{Ti} /{ }^{49} \mathrm{Ti}$ de 0.95 , com conteúdo médio de ${ }^{49} \mathrm{Ti}$ de $5.0 \mathrm{ppm}$ e conteúdo médio de ${ }^{50} \mathrm{Ti}$ de $4.9 \mathrm{ppm}$. As temperaturas médias obtidas nestas 7 análises foram de $712 \pm 29^{\circ} \mathrm{C}$ no ${ }^{49} \mathrm{Ti}$ e $717 \pm 35^{\circ} \mathrm{C}$ no ${ }^{50} \mathrm{Ti}$. Outras duas análises foram descaradas por estarem enriquecidas em Ti (25.3 e 88.7 ppm de ${ }^{49} \mathrm{Ti}$ e 25.7 e $84.2 \mathrm{ppm} \mathrm{de}{ }^{50} \mathrm{Ti}$ respectivamente). Analisando todos os cristais de zircão da amostra RT-02 em conjunto seriam obtidas temperaturas médias de $713 \pm 48^{\circ} \mathrm{C}$ no ${ }^{49} \mathrm{Ti}$ e $712 \pm$ $51^{\circ} \mathrm{C}$ no ${ }^{50} \mathrm{Ti}$.
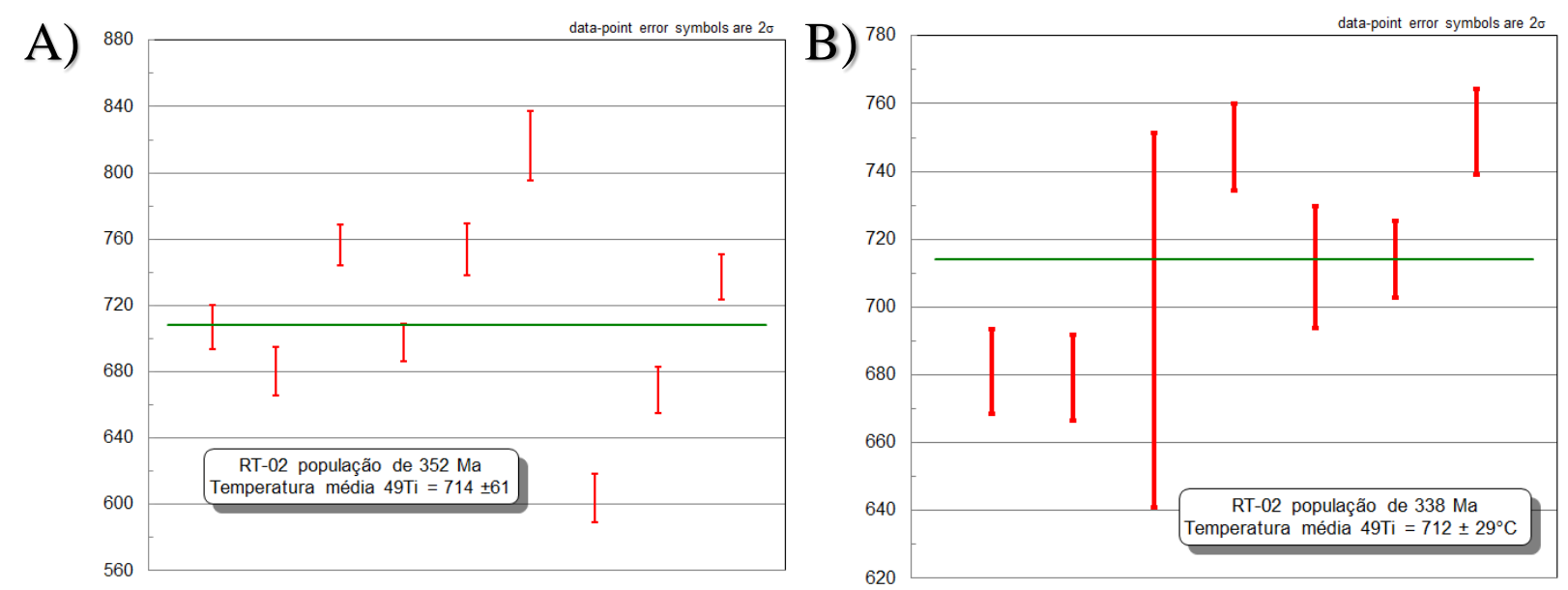


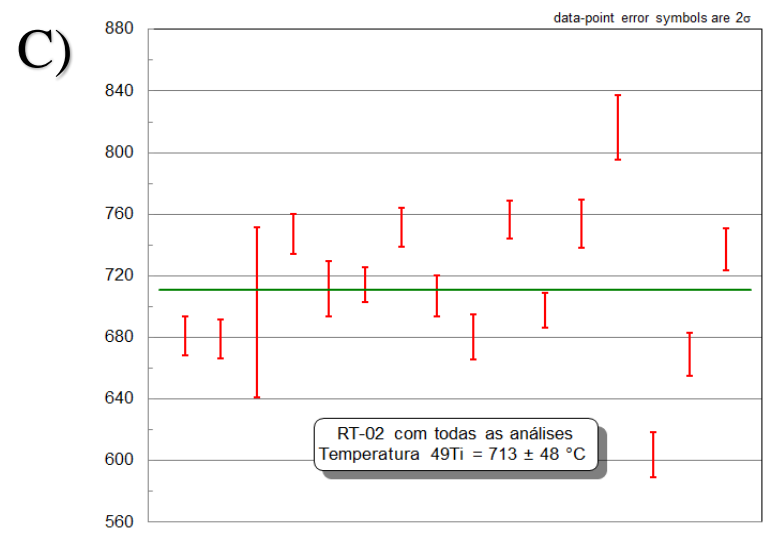

Figura 76. A) Temperaturas ${ }^{49} \mathrm{Ti}$ da população de antecristais e B) temperaturas ${ }^{49} \mathrm{Ti}$ da população de autocristais da amostra RT-02. C) mostra todas as idades sendo interpretadas em conjunto nesta amostra.

A maioria dos cristais de zircão da amostra RT-02 foram perdidos em uma fase de polimento e somente 6 cristais de zircão tiveram seus isótopos de Lu-Hf analisados. A população de antecristais de 352 Ma estava representada por 3 cristais de zircão nestas análises e seu conteúdo de ${ }^{176} \mathrm{Hf} /{ }^{177} \mathrm{Hf}_{\mathrm{o}}$ variou entre 0.282761 a 0.282669 , e com o $\varepsilon_{\mathrm{Hfo}}$ correspondente variando entre -0.85 e -4.1 , com valor médio de -2.78 . Quando a idade concórdia de 352 Ma é utilizada para obter os valores iniciais de Hf os valores de ${ }^{176} \mathrm{Hf} /{ }^{177} \mathrm{Hf}$ i variam entre 0.282759 e 0.282668 , sendo que os valores de $\varepsilon_{\mathrm{Hfi}}$ correspondente variam entre -0.18 e -3.39 , com valor médio de -2.09 . A população de autocristais de zircão de idade 339 Ma também foi representada por 3 cristais de zircão que apresentaram conteúdo de ${ }^{176} \mathrm{Hf} /{ }^{177} \mathrm{Hf}_{\mathrm{o}}$ entre 0.282705 e 0.282655 , com o $\varepsilon_{\text {Hfo }}$ correspondente variando entre -2.83 e -4.6, com valor médio de -3.96. Usando a idade de $339 \mathrm{Ma}$ os valores iniciais de ${ }^{176} \mathrm{Hf} /{ }^{177} \mathrm{Hf}_{\mathrm{i}}$ variaram entre 0.282704 e 0.282654 , com os valores de $\varepsilon_{\mathrm{Hfi}}$ correspondentes variando entre -2.13 e -3.87, e com valor médio de -3.25 (Figura 77). Todas as análises individuais de U-Pb, Ti-em-zircão e Lu-Hf executada nos cristais de zircão da amostra RT-02 estão plotadas na Figura 78. 


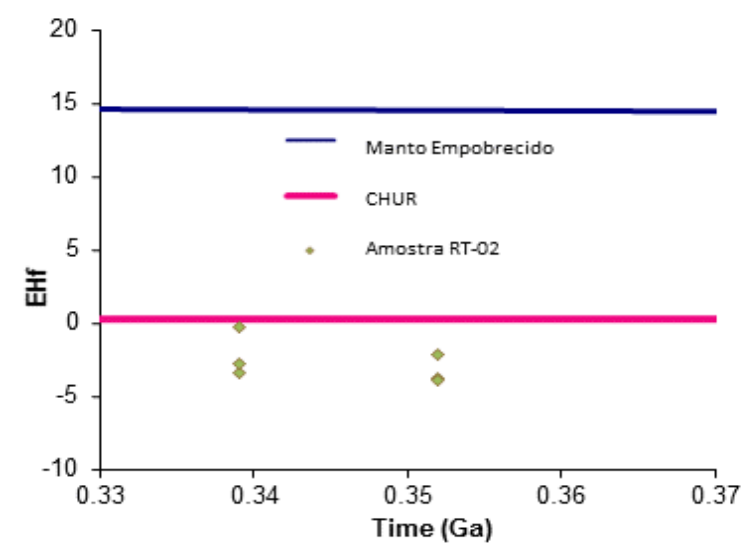

Figura 77. Valores de $\mathcal{E}_{H f i}$ obtidos nos cristais de zircão da amostra RT-02 


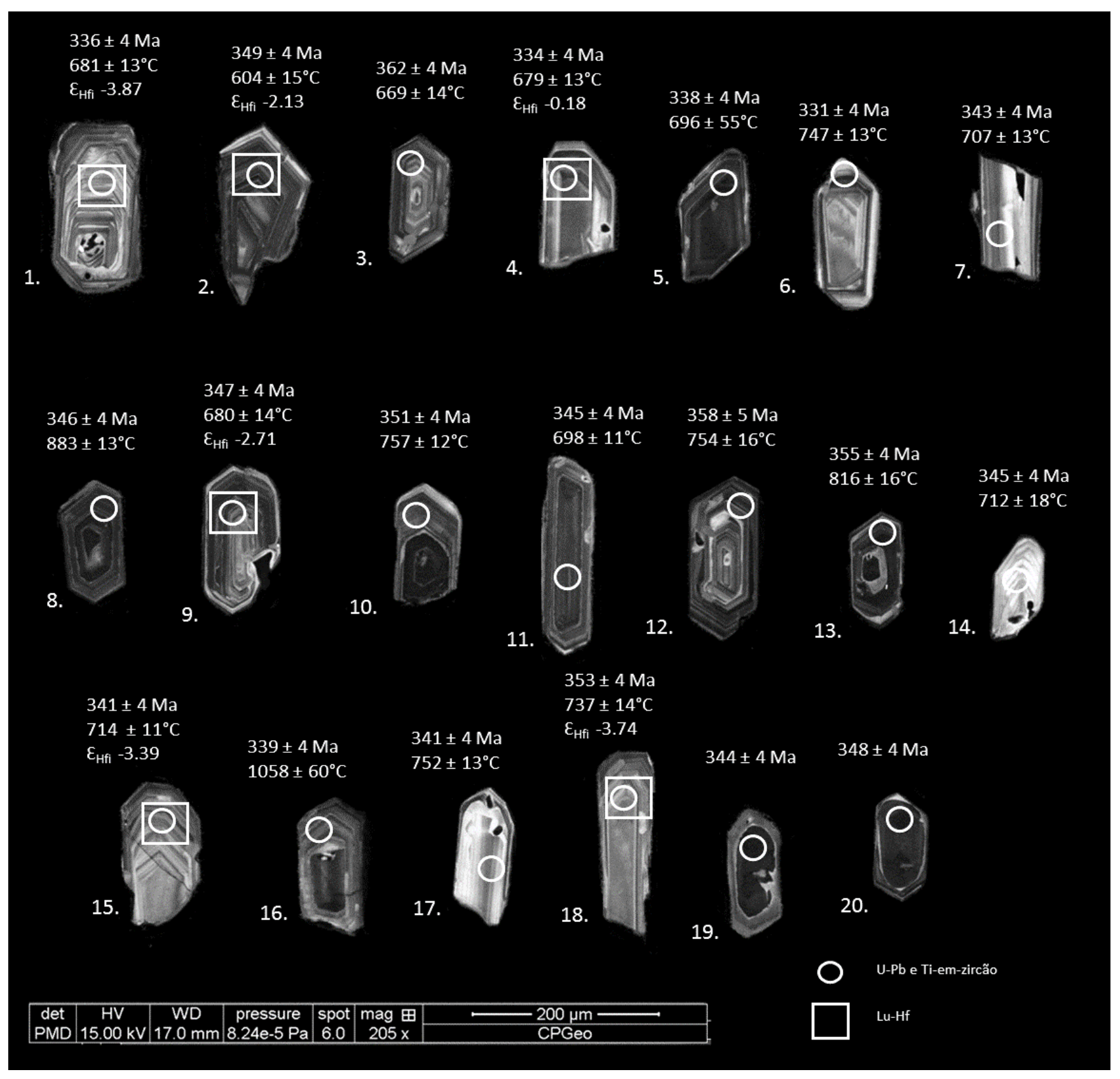

Figura 78. Composição de imagens CL dos cristais da amostra RT-02 com os dados das análises individuais de $\mathrm{U}$-Pb, Ti-em-zircão e $\mathrm{Lu}$-Hf.

A amostra RT-04 é um riodacito maciço intensamente alterado hidrotermalmente coletado em Filón Norte, na região norte do depósito de Rio Tinto. Nela veios de quartzo centimétricos cortam a amostra e geram um amplo processo de alteração hidrotermal relacionado com a mineralização. A rocha apresenta sulfetos semi maciços de substituição, feição típica de depósitos de VMS formados a partir de substituição de litologias vulcânicas reativas abaixo da superfície (Tornos et al., 2015a; Figura 79). 


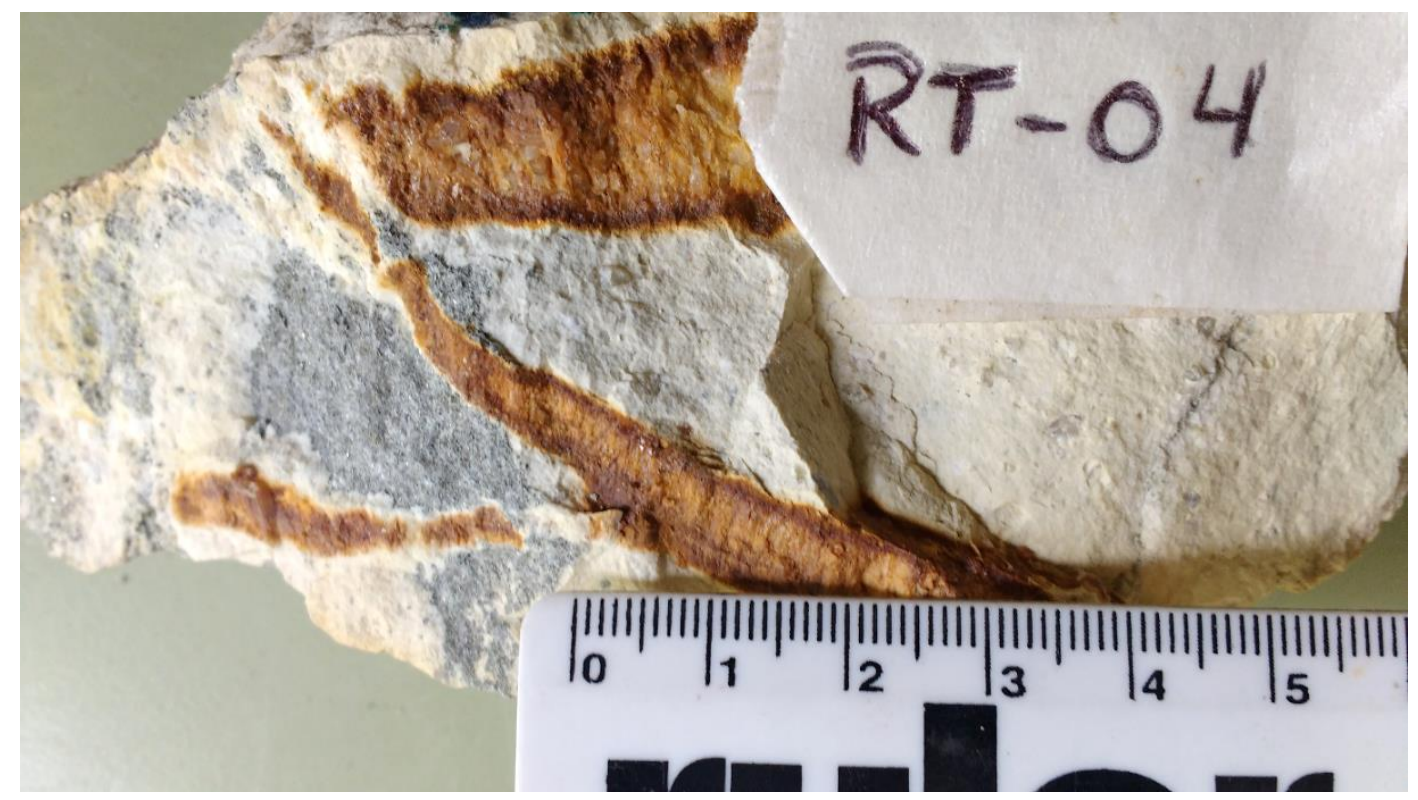

Figura 79. Amostra RT-04 de Filón Norte, Rio Tinto.

Os cristais de zircão concentrados nesta população foram imageados via CL e são prismáticos. O tamanho destes grãos de zircão varia entre 80 e $500 \mu \mathrm{m}$. A maioria desta população apresenta zoneamento oscilatório bem definido, indicando variabilidade composicional no magma ao longo da cristalização dos cristais. Bordas reabsorvidas são comuns em diversos cristais desta população, assim como regiões com recristalização tardi-magmática. Inclusões minerais são observadas em alguns dos cristais e, geralmente, estão associadas a zonas de annealing. Um dos cristais é diferente dos demais e apresenta coloração mais clara na imagem de CL, com zoneamento oscilatório imperceptível gradando para um zoneamento por setor leve.

Neste riodacito do Filón Norte foram executadas 23 análises em 23 cristais de zircão (Figura 80A). As análises foram executadas nos zoneamentos oscilatórios e são caracterizadas por uma grande variação nos conteúdos de U (71 - 1033 ppm) e razões Th/U entre 0.4 e 0.96, razões estas típicas de grãos ígneos. Com 17 análises que variaram entre 366 Ma e 340 Ma foi calculada uma idade concórdia de $352 \pm 3$ Ma com valor de MSWD com valor de 4.4 (Figura 80C). Uma das análises apresentou 65.99\% de $\mathrm{Pb}$ comum e foi descartada, enquanto outros 4 cristais apresentaram idades individuais ${ }^{238} \mathrm{U} /{ }^{206} \mathrm{~Pb}$ de $166 \pm 21 \mathrm{Ma}, 330 \pm 5 \mathrm{Ma}, 333 \pm 4 \mathrm{Ma}, 335 \pm 4 \mathrm{Ma}, 391 \pm 5 \mathrm{Ma}$, além de outro cristal com idade Cadomiana de $571 \pm 8 \mathrm{Ma}$ (Figura 80B). Os resultados de $333 \mathrm{Ma}$ e 335 Ma apresentam também valores anômalos de Ti-em-zircão, enquanto que o zircão 
com 330 Ma não foi analisado via Ti-em-zircão, mas apresenta recristalização tardimagmática que provavelmente afetou a análise.
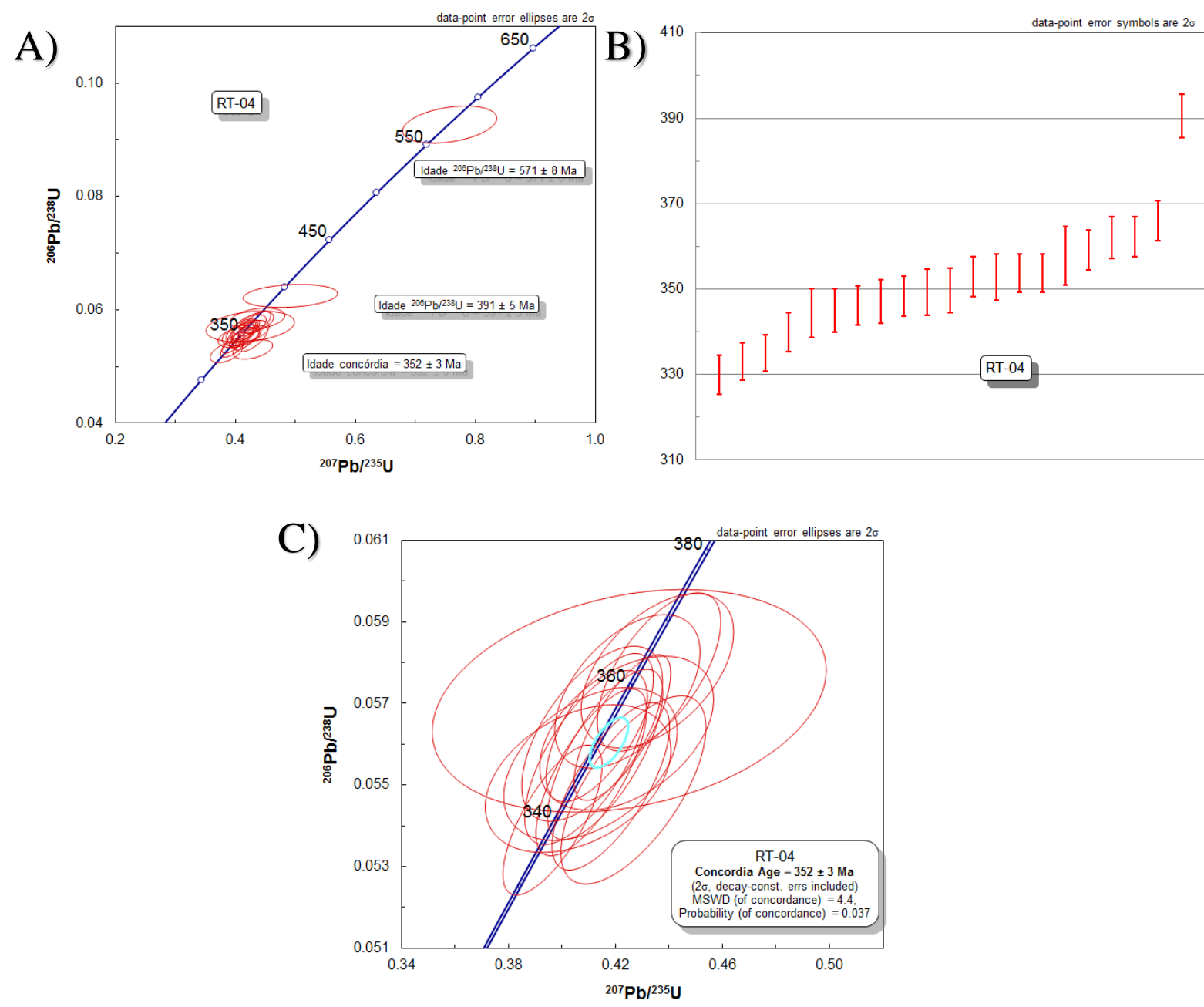

Figura 80. A) Todos os dados de U-Pb obtidos, B) dados mais próximos ao evento da FPI e C) idade concórdia obtida para a população de zircão da amostra RT-04

A amostra RT-04 foi analisada com 14 cristais de zircão. Em 3 análises o conteúdo de Ti foi anômalo, com valores de 56.1, 144.2 e 1456.6 ppm de ${ }^{49} \mathrm{Ti}$ e 57.1, 146.0 e 1407.2 ppm de ${ }^{50} \mathrm{Ti}$ respectivamente. As outras 11 análises apresentaram razão média de ${ }^{50} \mathrm{Ti} /{ }^{49} \mathrm{Ti}$ de 0.96 , com conteúdo médio de ${ }^{49} \mathrm{Ti}$ de 5.8 ppm e conteúdo médio de ${ }^{50} \mathrm{Ti}$ de 5.4 ppm. As temperaturas médias obtidas nestas 11 análises foram de $712 \pm 29^{\circ} \mathrm{C}$ no ${ }^{49} \mathrm{Ti}$ e $717 \pm$ $35^{\circ} \mathrm{C}$ no ${ }^{50} \mathrm{Ti}$ (Figura $\left.82 \mathrm{~A}\right)$.

Os isótopos de Lu-Hf foram analisados por LA-MC-ICPMS em 10 grãos de zircão desta amostra. Em 9 análises os valores de ${ }^{176} \mathrm{Hf} /{ }^{177} \mathrm{Hf}_{\mathrm{o}}$ presentes variaram entre 0.282830 e 0.282562 , o que corresponde a valores de $\varepsilon_{\text {Hfo }}$ variando entre -1.1 e -7.89 , com valor médio de -3.83. Utilizando a idade concórdia de 352 Ma obtida nesta amostra os valores 
calculados de ${ }^{176} \mathrm{Hf} /{ }^{177} \mathrm{Hf}_{\mathrm{i}}$ variam entre 0.282827 e 0.282561 , com valores de $\varepsilon_{\mathrm{Hfi}}$ entre 0.38 e -7.14, e média de -3.1 (Figura 82B). Um dos cristais apresentou valores outliers e, ao observar a imagem de CL dele é possível constatar que a análise atingiu uma inclusão. Todos os resultados das análises isotópicas individuais de U-Pb, Ti e Lu-Hf estão plotados nos cristais de zircão analisados na Figura 81.

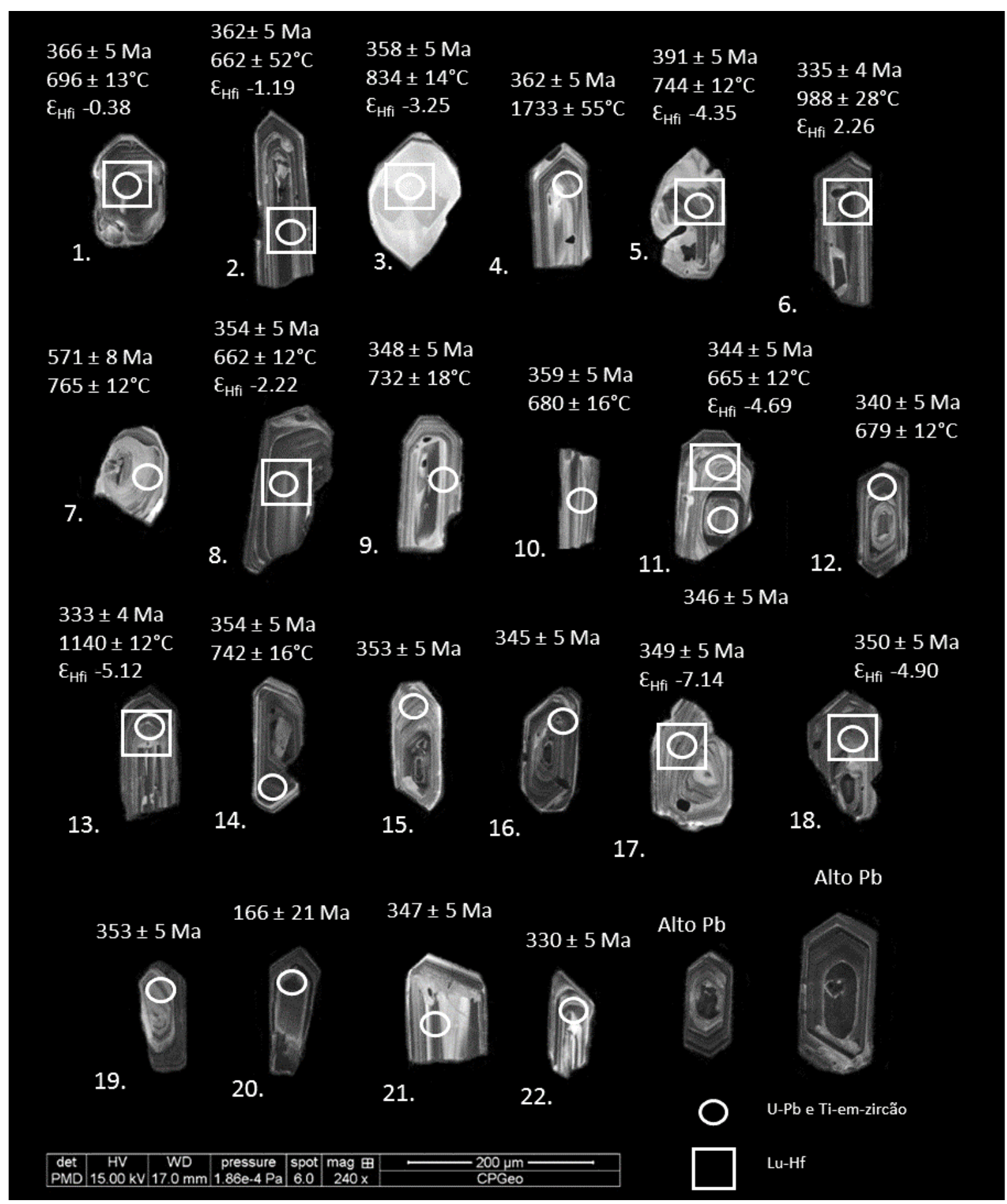

Figura 81. Composição de imagens CL da população de zircão presente na amostra RT-04 com os dados das análises individuais de U-Pb, Ti-em-zircão e Lu-Hf. 

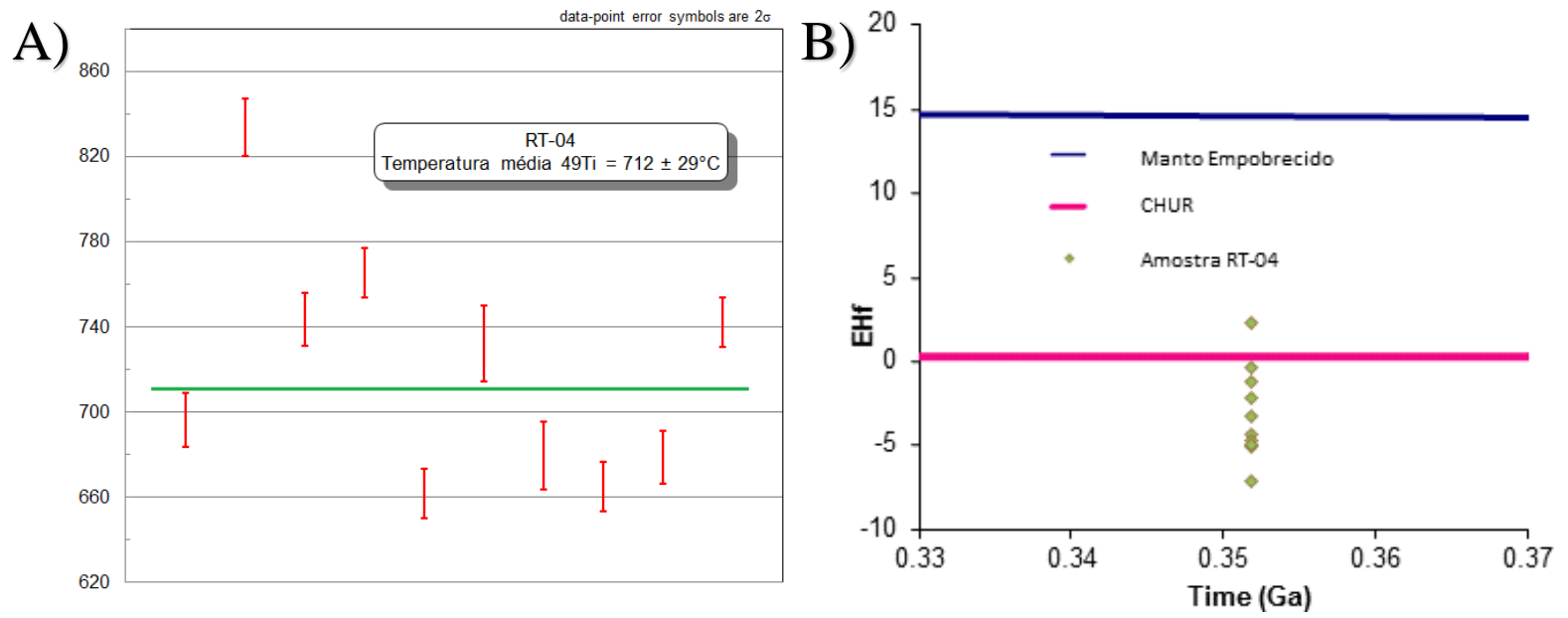

Figura 82. A) Temperaturas ${ }^{49}$ Ti e B) valores de $\mathcal{E}_{H f i}$ obtidos na amostra RT-04

Os grãos de zircão concentrados a partir do riodacito da cava de Atalaya (RT-05, Figura 83) apresentam grãos de zircão com morfologia prismática, tamanho variando entre 80 e $500 \mu \mathrm{m}$. Os cristais dessa população apresentam zoneamento oscilatório com variação marcada entre bandas claras mais espessas e bandas escuras mais finas. Alguns cristais apresentam bordas reabsorvidas indicativas de um período de insaturação de $\mathrm{Zr}$ no magma pós cristalização destes grãos.

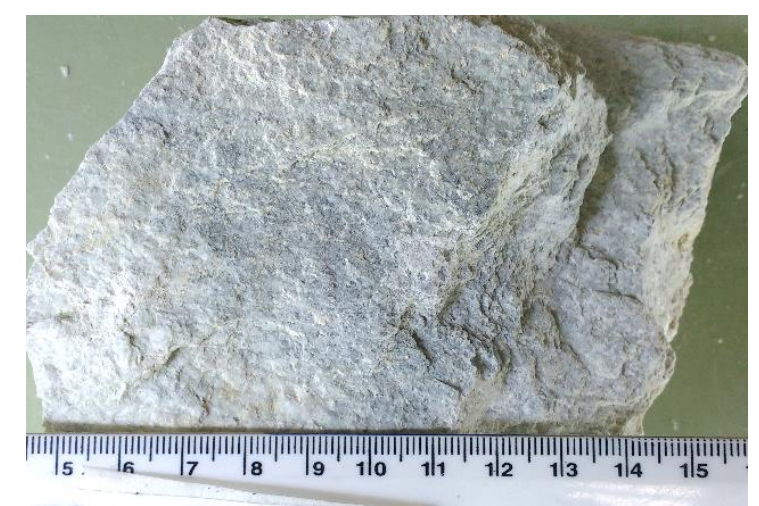

Figura 83. Amostra RT-05 do rio(dacito) da cava de Atalaya.

Para a datação desta população por U-Pb via SHRIMP foram efetuadas 16 análises em 16 cristais de zircão (Figura 84A). As análises são caracterizadas por variação intermediária nos conteúdos de U (189 - 715 ppm) e razões Th/U entre 0.34 e 0.83 , razões que são típicas de grãos de zircão ígneos. Com 13 análises com idades individuais ${ }^{238} \mathrm{U} /{ }^{206} \mathrm{~Pb}$ entre $338 \mathrm{Ma}$ a $356 \mathrm{Ma}$ foi calculada a idade concórdia de $348 \pm 3 \mathrm{Ma}$, com valor de MSWD de 2.3 (Figura 84B). 
A amostra RT-05 foi analisada com 14 cristais de zircão que apresentam razão média de ${ }^{50} \mathrm{Ti} /{ }^{49} \mathrm{Ti}$ de 0.96 , com conteúdo médio de ${ }^{49} \mathrm{Ti}$ de $6.1 \mathrm{ppm}$ e conteúdo médio de ${ }^{50} \mathrm{Ti}$ de $5.8 \mathrm{ppm}$. As temperaturas médias obtidas nestas 14 análises foram de $726 \pm 40^{\circ} \mathrm{C}$ no ${ }^{49} \mathrm{Ti}$ e $723 \pm 36^{\circ} \mathrm{C}$ no ${ }^{50} \mathrm{Ti}$ (Figura $85 \mathrm{~A}$ ).
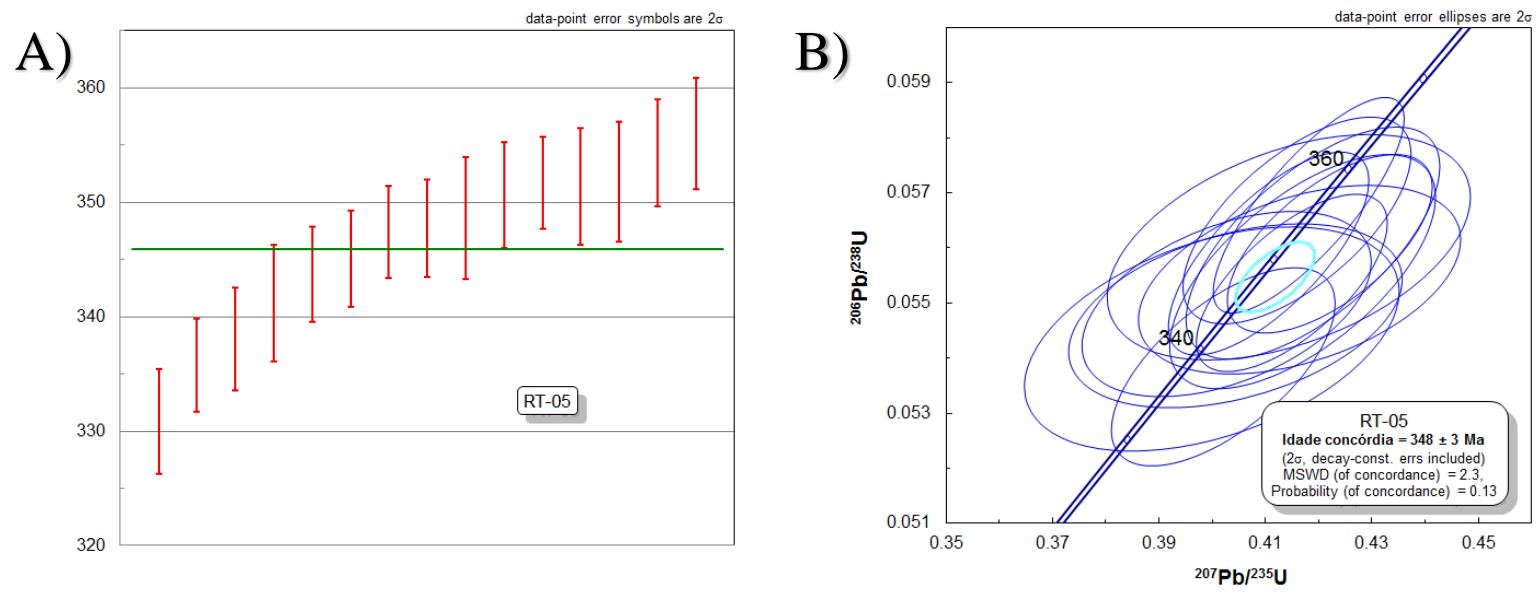

Figura 84. A) Dados da amostra RT-05 e B) idade concórdia obtida nos cristais de zircão estudados nesta amostra.

Os isótopos de Lu-Hf foram estudados por LA-MC-ICPMS em 16 cristais de zircão. Estes cristais apresentaram conteúdo de ${ }^{176} \mathrm{Hf} /{ }^{177} \mathrm{Hf}_{\mathrm{o}}$ variando entre $0.282638 \mathrm{e}$ 0.282526 , com os valores de $\varepsilon_{\mathrm{Hfo}}$ correspondentes variando entre -5.2 e -9.55 , e valor médio de -7.76. Quando estes dados são analisados em conjunto com a idade concórdia de $348 \mathrm{Ma}$ foram obtidos valores de ${ }^{176} \mathrm{Hf} /{ }^{177} \mathrm{Hf}_{\mathrm{i}}$ que variam entre 0.282636 e 0.282524 . Os valores de $\varepsilon_{\mathrm{Hfi}}$ correspondente variam entre -4.48 e -8.81 , com valor médio de -7.04 (Figura 85B). Os resultados individuais de todas as análises de U-Pb, Ti-em-zircão e LuHf podem ser consultados na Figura 86.
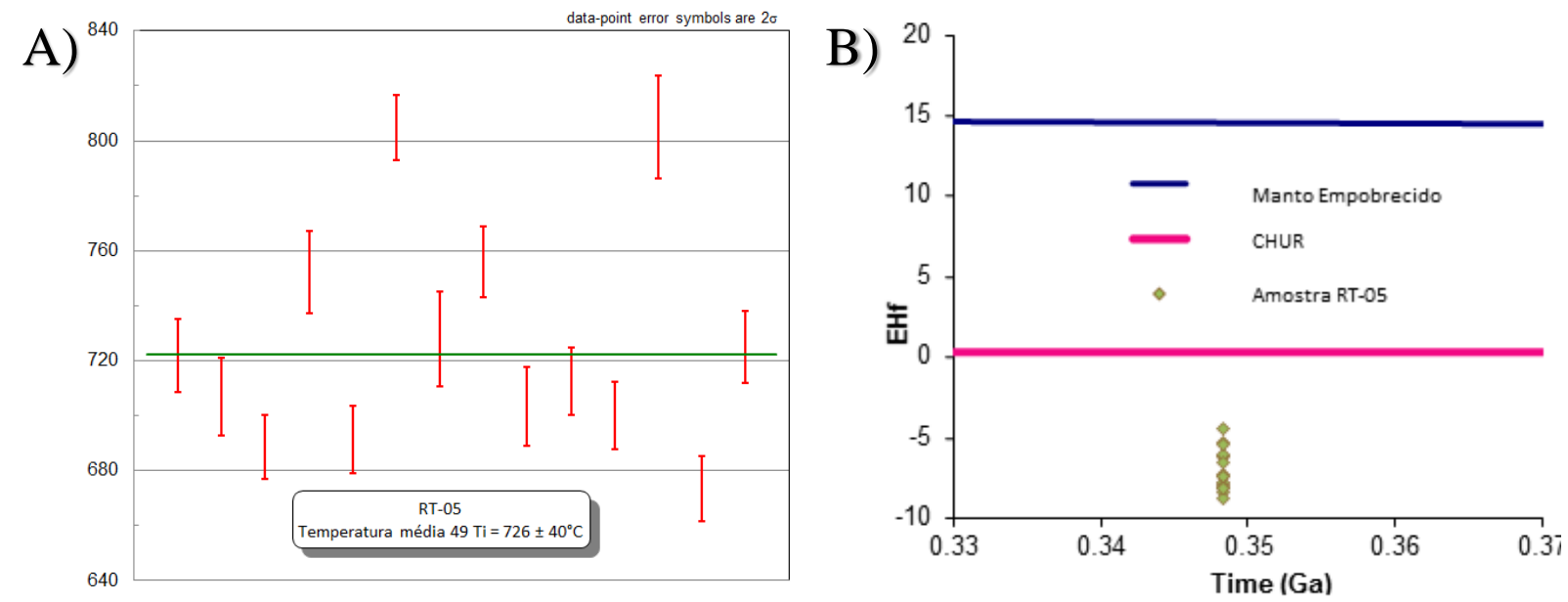

Figura 85. A) Temperaturas ${ }^{49}$ Ti e B) valores de $\varepsilon_{H f i}$ obtidos na população de zircão de RT-05 


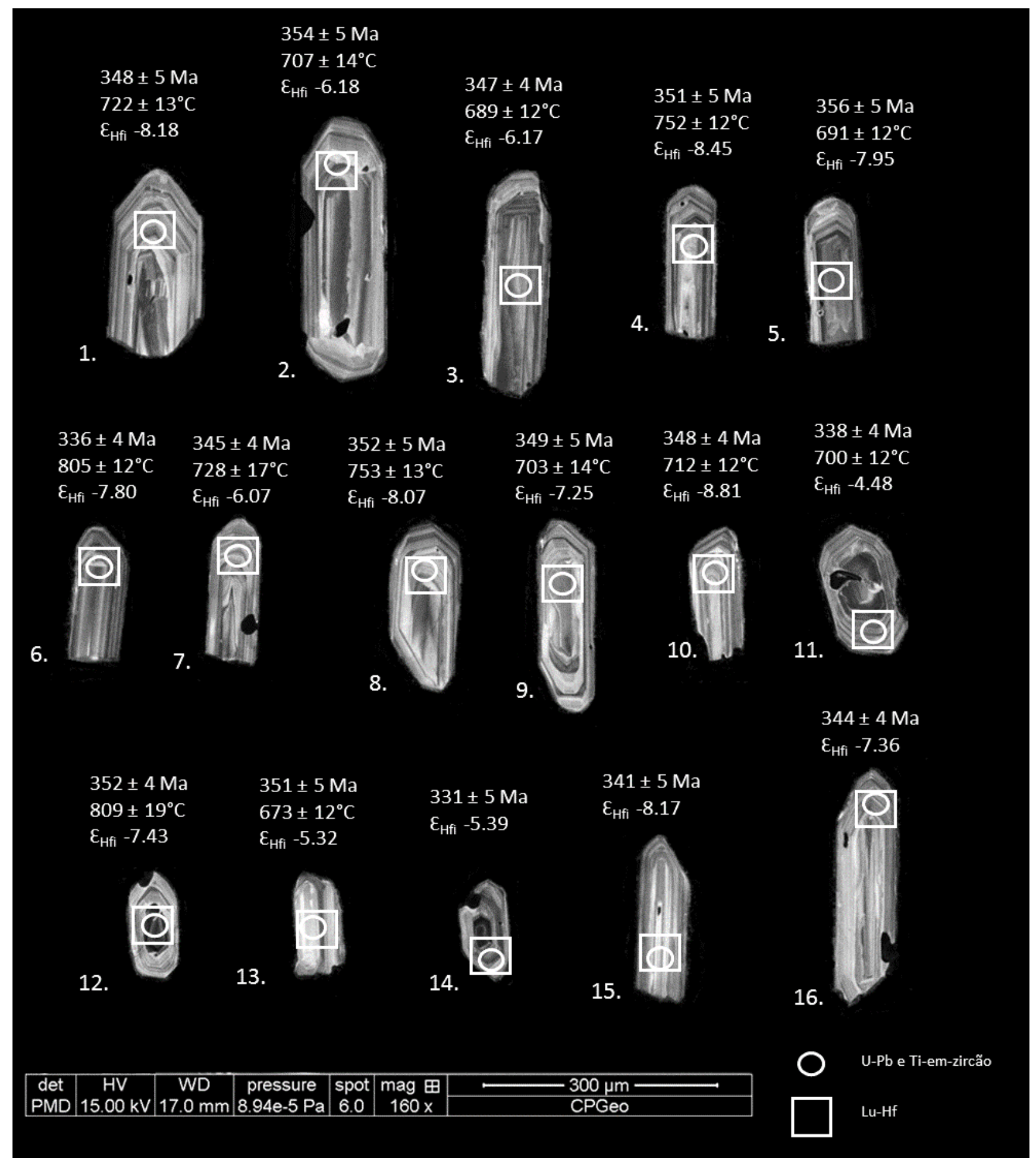

Figura 86. Composição com as imagens de CL da população zircão estudada na amostra RT-05 com os resultados individuais obtidos em cada análise plotados nos cristais dessa população. 
A amostra ZN-01 coletada na localidade de Zarandas é um arenito vulcanoclástico que é interpretado como o início do magmatismo félsico na região de Rio Tinto (Conde, 2016; Figura 87).

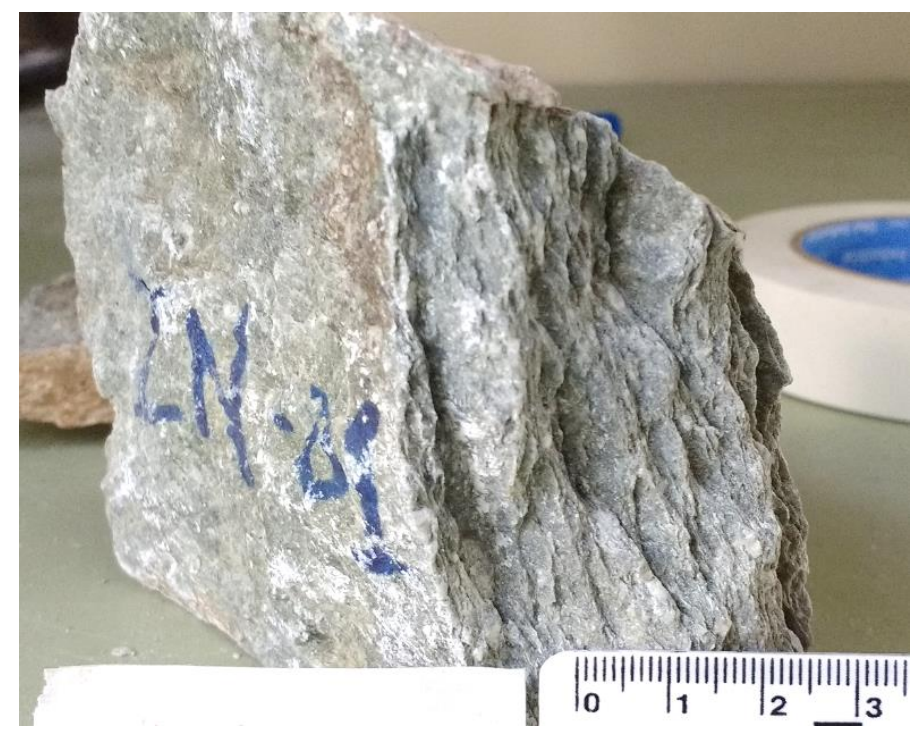

Figura 87. Amostra do arenito vulcanoclástico de Zarandas.

Os cristais deste arenito vulcanoclástico são pequenos e variando entre 80 e 300 $\mu \mathrm{m}$. As imagens obtidas via CL mostram cristais prismático com cristais relativamente heterogêneos entre si. Alguns cristais são menores e mais escuros nas imagens de CL, enquanto que os cristais maiores tendem a ser mais claros e apresentarem feições mais complexas, sendo que um zircão apresenta núcleo herdado. Os zoneamentos oscilatórios destes cristais geralmente são degrade o que indica baixa variação composicional ao longo da cristalização destes grãos. Diversos cristais apresentam bordas reabsorvidas, indicando residência pós-cristalização em um magma insaturado em zircão. Alguns cristais apresentam leves esbranquiçamentos, possivelmente proveniente de alteração tardi-magmáticas.

Os isótopos de U-Pb foram analisados por SHRIMP nesta amostra a partir de 24 análises em 23 cristais de zircão. As análises são caracterizadas por uma grande variação nos conteúdos de U (125 - 1085 ppm) e razões Th/U entre 0.23 e 0.85 , razões típicas de grãos de zircão ígneos. Com 22 análises, que variaram entre 373 Ma e 342 Ma (Figura 88B), foi calculada uma idade concórdia de $358 \pm 2$ Ma com o valor de MSWD de 0.0064 (Figura 88C). Duas idades ${ }^{238} \mathrm{U} /{ }^{206} \mathrm{~Pb}$ obtidas, uma delas em um xenocristal e a outra em um núcleo herdado, apresentaram idades Neoproterozoicas de $699 \pm 10$ Ma e $662 \pm 8$ Ma (Figura 88A). 

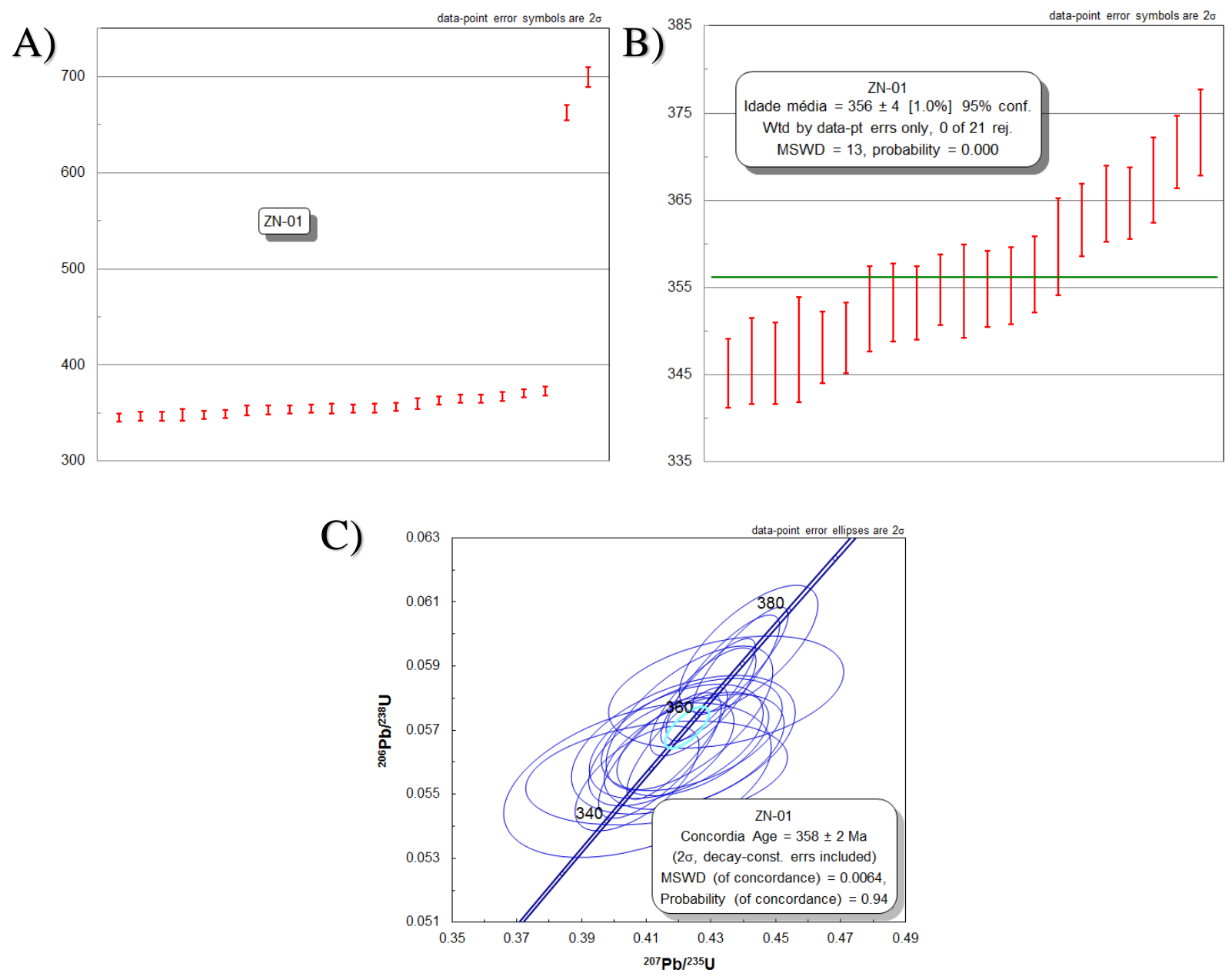

Figura 88. A) Dados de U-Pb obtidos, B) idade ${ }^{238} \mathrm{U}^{206} \mathrm{~Pb}$ média e C) idade concórdia da população $\mathrm{ZN}-01$

Os teores de Ti da amostra ZN-01 foram analisados em 18 cristais de zircão. Com um conjunto de 16 análises foi calculada a razão média de ${ }^{50} \mathrm{Ti} /{ }^{49} \mathrm{Ti}$ de 0.97 , com conteúdo médio de ${ }^{49} \mathrm{Ti}$ de 4.8 ppm e conteúdo médio de ${ }^{50} \mathrm{Ti}$ de $4.9 \mathrm{ppm}$. As temperaturas médias obtidas com estes dados são de $705 \pm 39^{\circ} \mathrm{C}$ no ${ }^{49} \mathrm{Ti}$ e $706 \pm 39^{\circ} \mathrm{C}$ no ${ }^{50} \mathrm{Ti}$ (Figura 89A). A análise do xenocristal de $699 \mathrm{Ma}$ apresentou um alto teor de Ti $\left(23.44 \mathrm{ppm}\right.$ de ${ }^{49} \mathrm{Ti}$ e 21.07 ppm de ${ }^{50} \mathrm{Ti}$ ), o que significa temperaturas de $874 \pm 21{ }^{\circ} \mathrm{C}$ no ${ }^{49} \mathrm{Ti}$ e $861 \pm 21^{\circ} \mathrm{C}$ no ${ }^{50} \mathrm{Ti}$. Uma outra análise apresentou valor de ${ }^{50} \mathrm{Ti} /{ }^{49} \mathrm{Ti}$ de 0.91 , valor inferior ao 0.94 considerado mínimo para a razão ${ }^{50} \mathrm{Ti} /{ }^{49} \mathrm{Ti}$ e foi descartada.

Nesta população 15 cristais da amostra do arenito vulcanoclástico de Zarandas também tiveram os isótopos de Lu-Hf analisados por LA-MC-ICPMS. Os valores de ${ }^{176} \mathrm{Hf} /{ }^{177} \mathrm{Hf}_{\mathrm{o}}$ variaram entre 0.282880 e 0.282531 , com valores de $\varepsilon_{\mathrm{Hfo}}$ correspondentes variando entre 3.36 e -8.98, e valor médio de -3.7. Quando os dados de Lu-Hf são analisados em conjunto com a idade concórdia de 358 Ma são obtidos valores iniciais de 
${ }^{176} \mathrm{Hf} /{ }^{177} \mathrm{Hf}_{\mathrm{i}}$ variando entre 0.28287 e 0.28253 , sendo que os valores de $\varepsilon_{\mathrm{Hfi}}$ correspondentes variam entre 4.05 e -8.22 , com valor médio de -2.96 (Figura 89B). O resultado das análises individuais de $\mathrm{U}-\mathrm{Pb}$, Ti-em-zircão e Lu-Hf podem ser vistos na Figura 90.
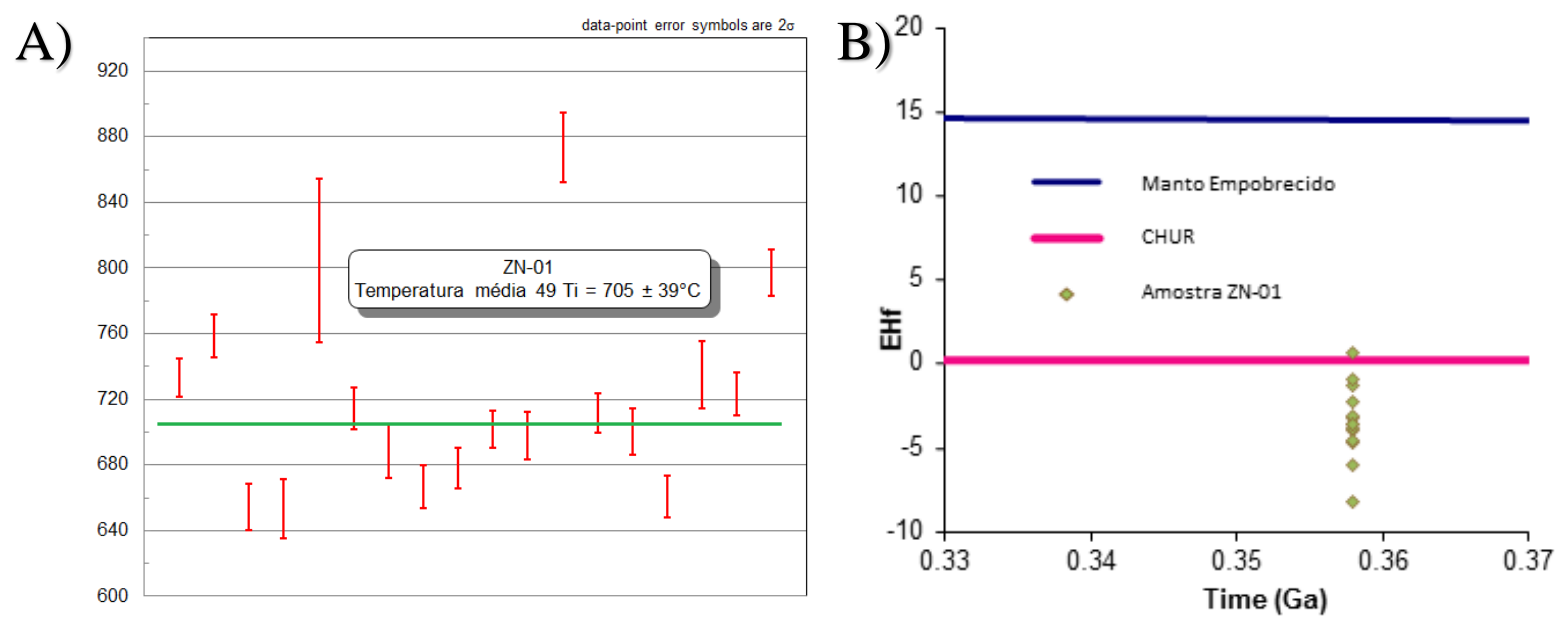

Figura 89. A) Temperaturas ${ }^{49}$ Ti e B) valores de $\varepsilon_{H f i}$ obtidos na amostra $\mathrm{ZN}$-01 


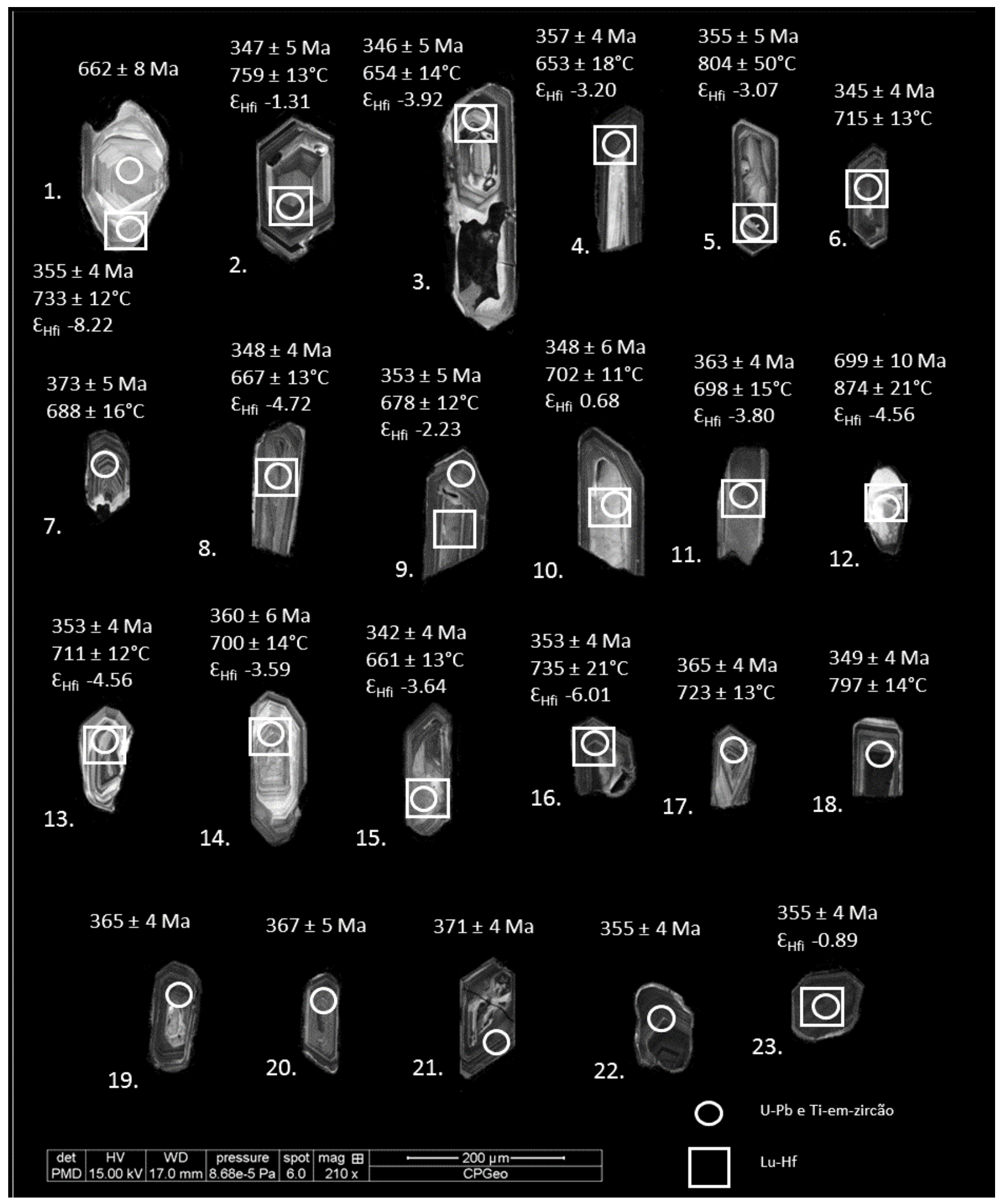

Figura 90. Composição com as imagens de CL obtidas com os cristais de zircão estudados na amostra ZN-01 com os resultados individuais de cada análise plotados nos cristais analisados. 
A outra amostra coletada na localidade de Zarandas foi a amostra ZN-02, um riodacito sem mineralizações ou alterações hidrotermais associadas (Figura 91). Os cristais de zircão catalogados via CL nesta amostra apresentam morfologia prismático, com cristais individuais variando entre 80 e $500 \mu \mathrm{m}$ de comprimento. Esta população de zircão é mais homogênea que a população de ZN-01. Os cristais de zircão apresentam zoneamento oscilatório bem definido, indicando variação composicional ao longo do processo de cristalização. Existem evidências sutis de alteração tardi-magmática em alguns cristais, como bordas mais esbranquiçadas e também esbranquiçamento em torno de inclusões minerais.

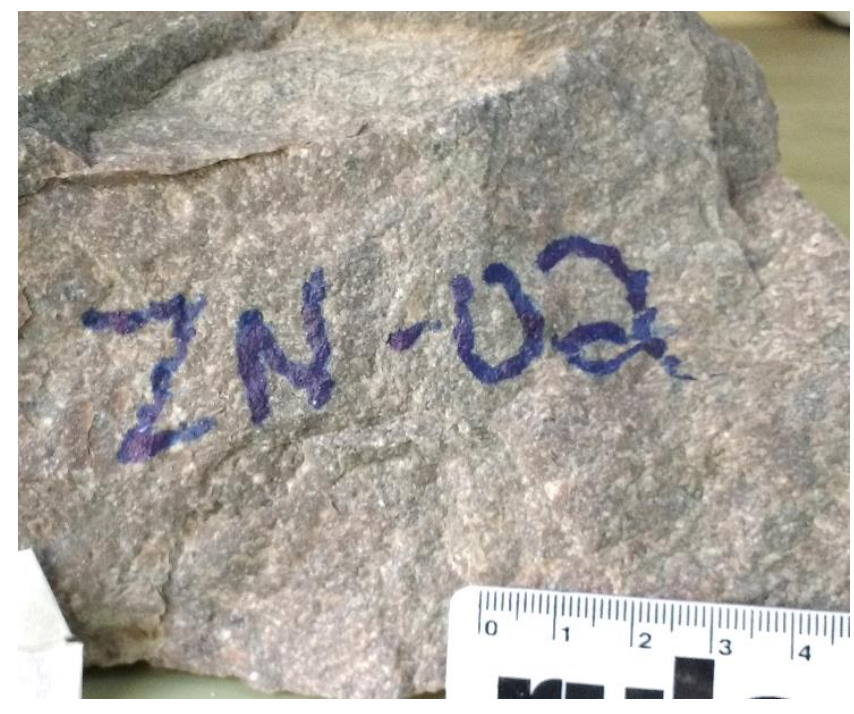

Figura 91. Fotografia do dacito maciço amostrado em Zarandas (ZN-02)

Nesta amostra os isótopos de U-Pb foram analisados por SHIRMP com 22 análises em 22 cristais de zircão. As análises são caracterizadas por uma grande variação nos conteúdos de U (167 - 1503 ppm) e razões Th/U entre 0.44 e 0.77, razões típicas de cristais de zircão ígneos. Com 14 análises desta população, que possuem idades individuais ${ }^{206} \mathrm{~Pb} /{ }^{238} \mathrm{U}$ variando entre $356 \mathrm{Ma}$ e $343 \mathrm{Ma}$, foi calculada uma idade concórdia de $351 \pm$ 2 Ma com um valor de MSWD de 0.43 (Figura 92C). Outras 5 análises presentaram alto teor de $\mathrm{Pb}$ e tiveram suas análises abortadas, enquanto que 3 cristais desta população apresentaram idades ${ }^{238} \mathrm{U} /{ }^{206} \mathrm{~Pb}$ de $259 \pm 9 \mathrm{Ma}, 326 \pm 4$ e $340 \pm 4 \mathrm{Ma}$ (Figura 92A, B).

Os isótopos de Ti foram analisados via SHRIMP em 18 cristais de zircão desta população. Destas análises, 13 apresentaram razão média de ${ }^{50} \mathrm{Ti} /{ }^{49} \mathrm{Ti}$ de 0.98 , com conteúdo médio de ${ }^{49} \mathrm{Ti}$ de $5.2 \mathrm{ppm}$ e conteúdo médio de ${ }^{50} \mathrm{Ti}$ de $5.3 \mathrm{ppm}$. As temperaturas médias de ${ }^{49} \mathrm{Ti}$ e ${ }^{50} \mathrm{Ti}$ obtidas nessas análises foram de, respectivamente, $707 \pm 53^{\circ} \mathrm{C}$ e 
$708 \pm 54^{\circ} \mathrm{C}$ (Figura 94A). Duas outras análises apresentaram razões de ${ }^{50} \mathrm{Ti} /{ }^{49} \mathrm{Ti}$ fora do intervalo (1.9 e 0.88) e tiveram suas análises descartadas. Outro zircão apresentou alto $\mathrm{Pb}$ na análise de U-Pb e enriquecimento anômalo de Ti em comparação as demais análises desta população $(25.05$ e $25.82 \mathrm{ppm}$, gerando respectivamente temperaturas de $882 \pm$ $13^{\circ} \mathrm{C}$ no ${ }^{49} \mathrm{Ti}$ e $885 \pm 15^{\circ} \mathrm{C}$ no ${ }^{50} \mathrm{Ti}$ ). Outra análise foi descartada pois ela também apresentou enriquecimento em $\mathrm{Pb}$, mas com empobrecimento em $\mathrm{Ti}$, gerando temperatura ${ }^{49} \mathrm{Ti}$ de $614 \pm 14^{\circ} \mathrm{C}$ e temperatura ${ }^{50} \mathrm{Ti}$ de $618 \pm 17^{\circ} \mathrm{C}$, temperaturas questionáveis para magmas félsicos (Síegel et al., 2018). Uma outra análise apresentou o erro da medida de ${ }^{49}$ Ti muito alto (2.58 ppm com desvio padrão de 1.74) e também foi descartada.
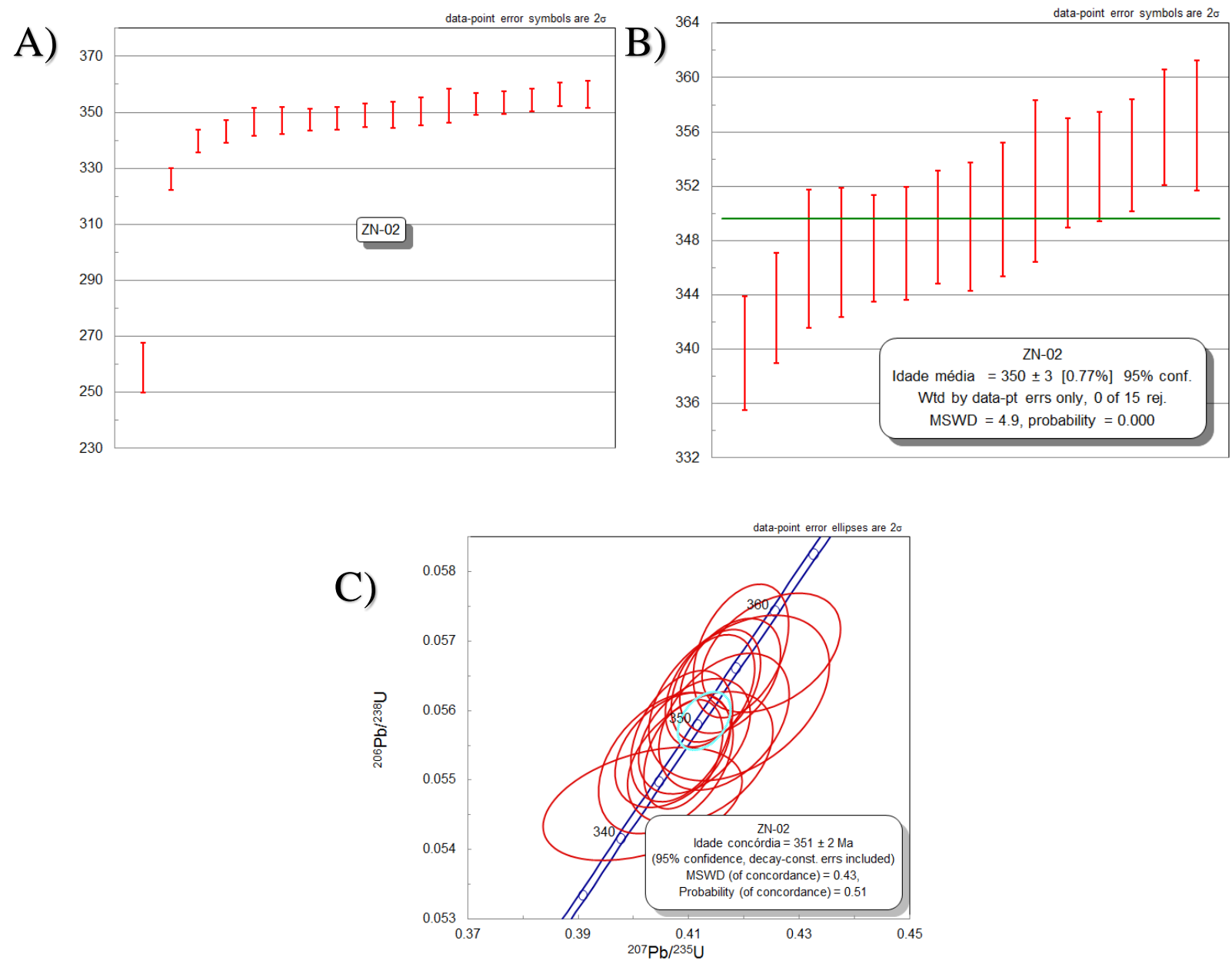

Figura 92. A) dados de $\mathrm{U}$-Pb obtidos, B) idade ${ }^{238} \mathrm{U}^{206} \mathrm{~Pb}$ média e C) idade concórdia obtida na população de zircão estudada em $\mathrm{ZN}-02$

A grande maioria dos cristais desta população foi perdida na etapa de polimento antes da análise dos isótopos de Lu-Hf e diversos dos cristais de zircão remanescentes ficaram muito finos que, quando analisados LA-MC-ICPMS, acabaram sendo atravessados pelo feixe de laser, o que impossibilitou a integração destes dados. Assim, 
diversas análises desta população atravessaram os cristais e tiveram que ser descartadas. Dos cristais analisados apenas 4 análises foram mantidas após a integração dos resultados via Iolite. Estes 4 cristais tiveram valores presentes ${ }^{176} \mathrm{Hf} /{ }^{177} \mathrm{Hf}_{\mathrm{o}}$ variando entre 0.282635 e 0.282758 , estes valores geraram valores de $\varepsilon_{\text {Hfo }}$ que variam entre -5.30 e -0.95 . Quando os valores de Hf são calculados a partir da idade concórdia desta população foram obtidos valores ${ }^{176} \mathrm{Hf} /{ }^{177} \mathrm{Hf}_{\mathrm{i}}$ variando entre 0.282634 e 0.282756 , com valores de $\varepsilon_{\mathrm{Hfi}}$ correspondentes que variam entre -4.57 e -0.26, e valor médio de -2.25 (Figura 94B). Todos os resultados isotópicos das análises individuais de U-Pb, Ti e Lu-Hf obtidos nesta população pode ser consultados na Figura 93.

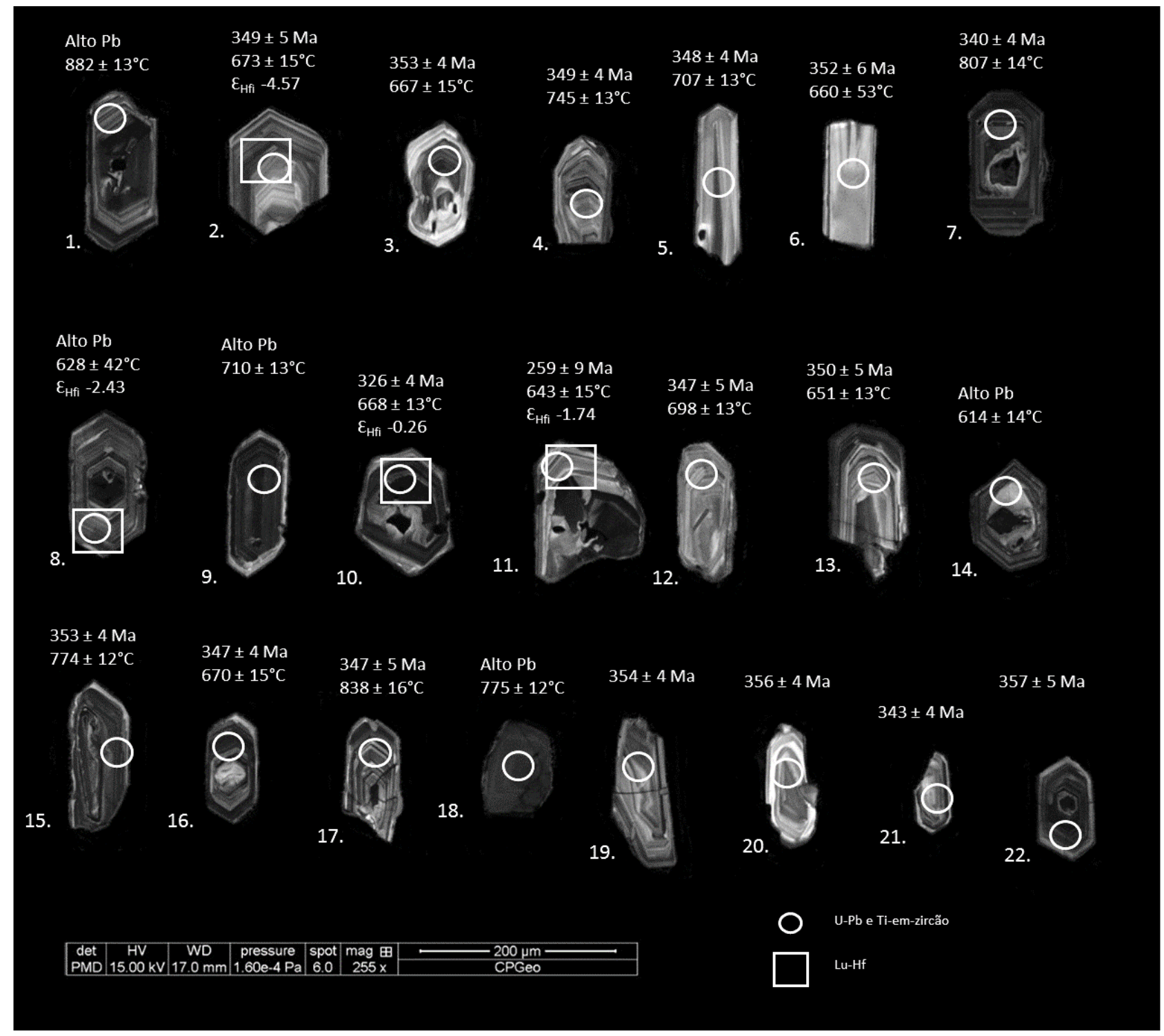

Figura 93. Imagens de CL obtidas na população de zircão da amostra ZN-02 com os resultados individuais das análises de U-Pb, Ti-em-zircão e Lu-Hf plotados nos cristais analisados. 

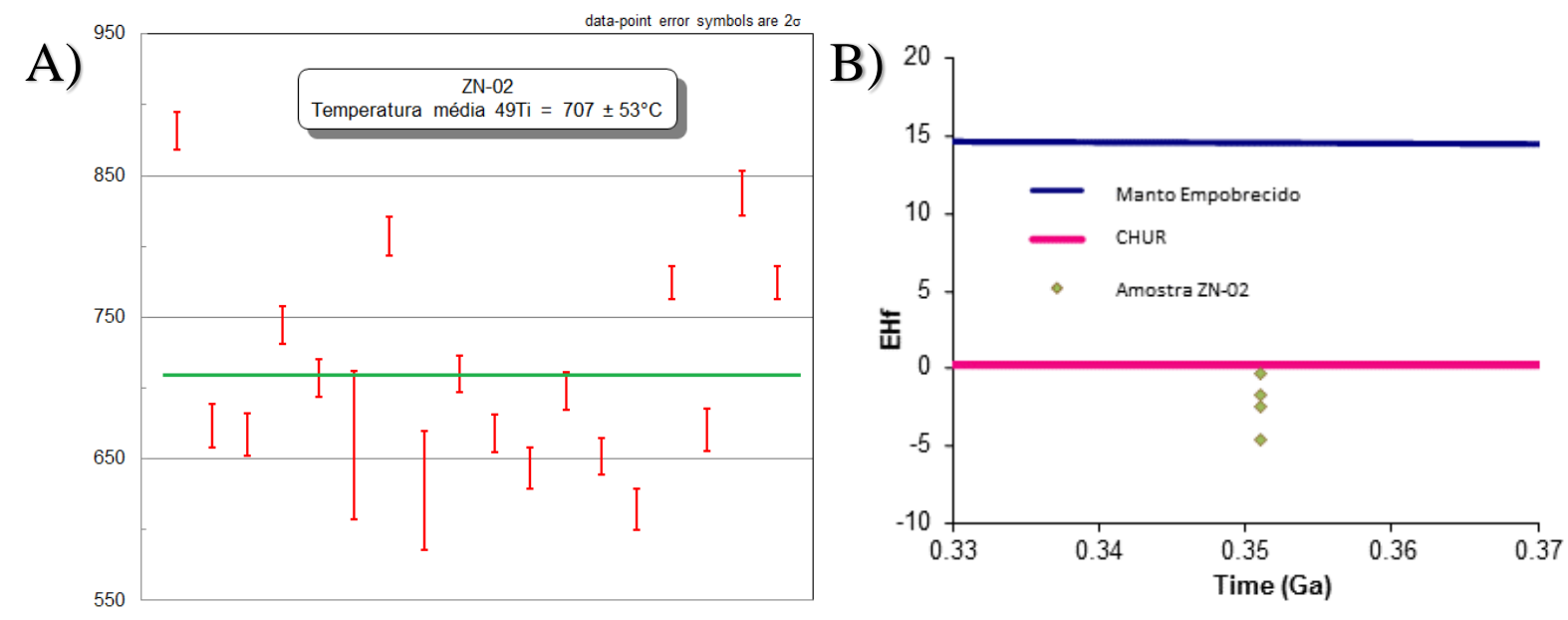

Figura 94. A) Temperaturas ${ }^{49}$ Ti e B) valores de $\varepsilon_{H f i}$ da amostra $\mathrm{ZN}-02$

\section{Aglomerado del Cerro}

O Aglomerado del Cerro, também conhecido como Dacito El Cerro, foi amostrado na beira da estrada A-485, a $3.5 \mathrm{~km}$ da vila de El Cerro de Andévalo e 4.2km do depósito de La Zarza. Esta amostra representa o vulcanismo félsico estéril do Complexo VS no Setor Central e foi analisada para comparações. O Aglomerado del Cerro é composto por clastos subarredondada a subangulosos, de textura afanítica. Estes clastos são suportados pela matriz (Figura 95). A amostra AC-01 representa estes clastos, enquanto que a amostra AC-02 representa a matriz que suporta eles.

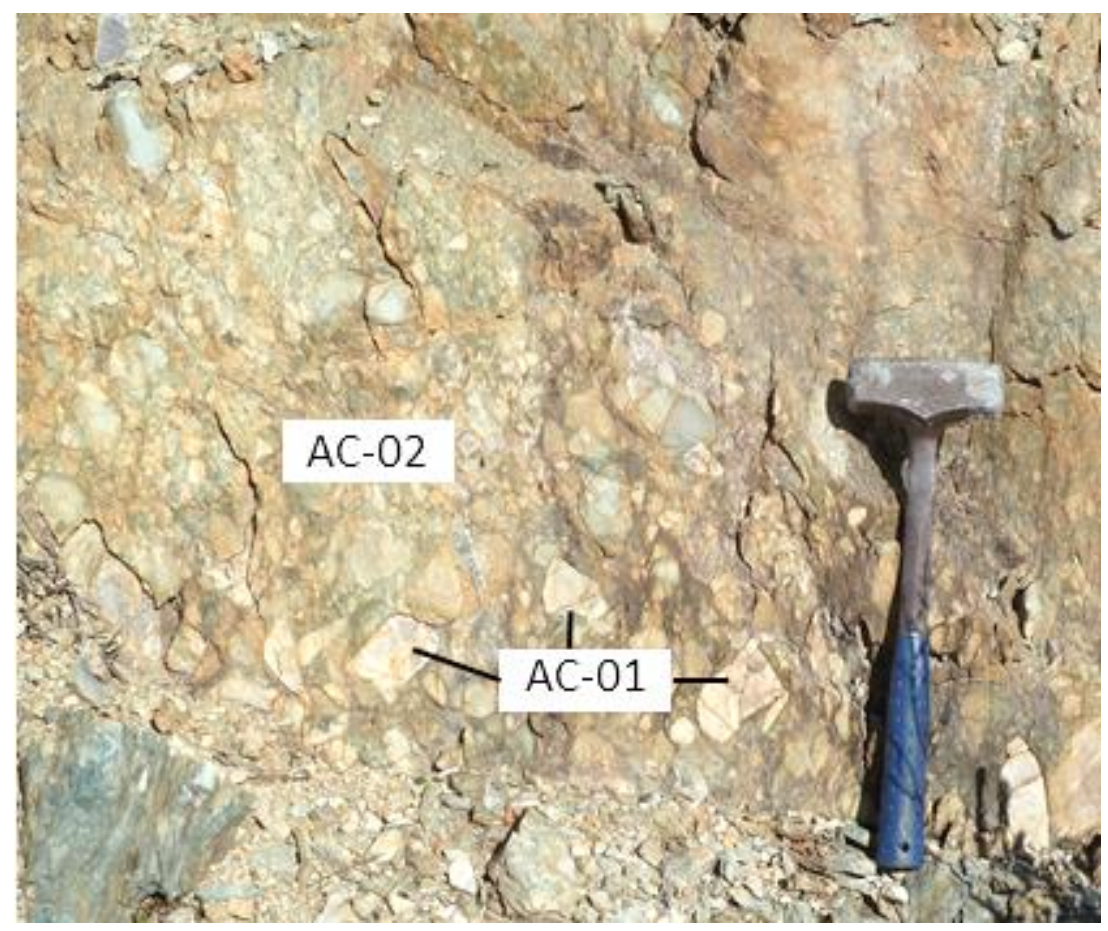

Figura 95. Afloramento do Dacito El Cerro 


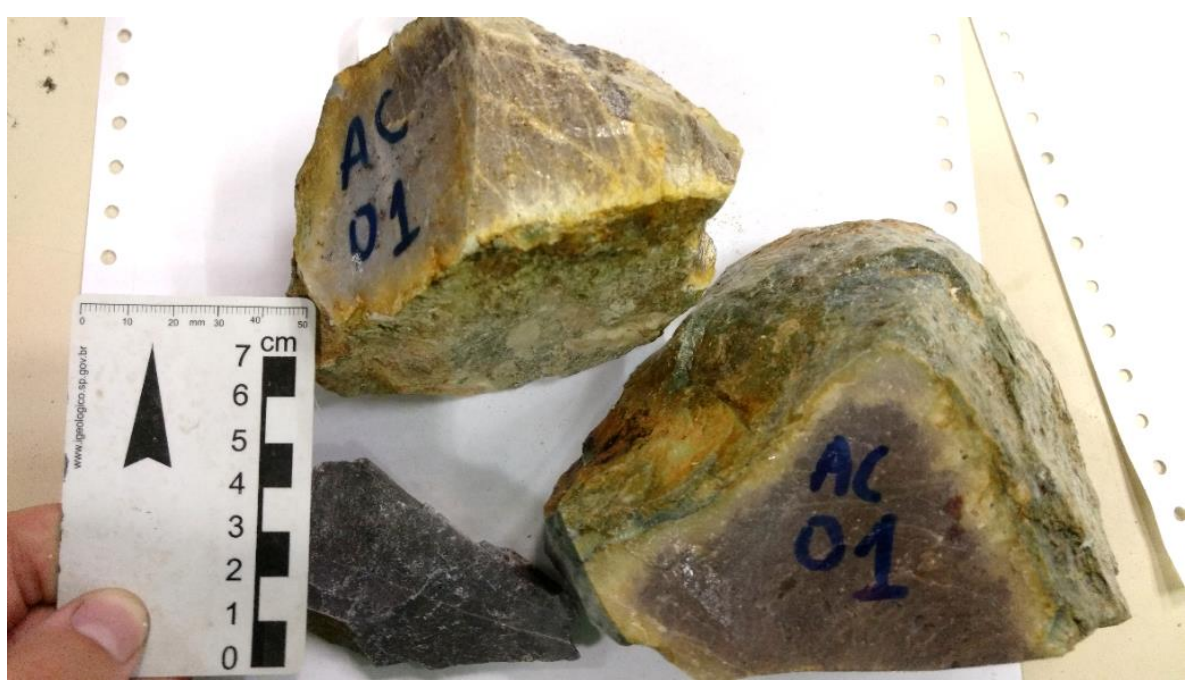

Figura 96. Fotografia da amostra AC-01

Em geral os cristais de zircão observados via imagens de CL da amostra AC-01 são prismáticos, com comprimento variando entre 120 e $220 \mu \mathrm{m}$. O zoneamento oscilatório apresenta pouco contraste, em geral sendo um degrade leve, o que indica pouca variabilidade composicional no magma ao longo da cristalização destes minerais. Alguns cristais apresentam um leve zoneamento setorial. Nesta população alguns cristais apresentam bordas levemente reabsorvidas, indicando um breve período de residência em condições de insaturação de $\mathrm{Zr}$ no magma.

Nesta amostra foram executadas 20 análises de U-Pb via SHRIMP em 20 cristais de zircão. As análises são caracterizadas por uma pequena variação nos conteúdos de U (98 - 365 ppm) e razões Th/U entre 0.46 e 0.94, razões típicas de grãos de zircão ígneos. A idade média obtida nesta população de zircão foi de $353 \pm 2$ Ma (Figura 97A). Um dos cristais apresentou idade ${ }^{206} \mathrm{~Pb} /{ }^{238} \mathrm{U}$ de $345 \pm 3$ Ma e os 19 cristais restantes tiveram idades individuais ${ }^{206} \mathrm{~Pb} /{ }^{238} \mathrm{U}$ variando entre $347 \mathrm{Ma}$ e $358 \mathrm{Ma}$. Estes 19 cristais restantes definiram uma idade concórdia de $354 \pm 2$ Ma com valores de MSWD de 0.046 (Figura 97B). 

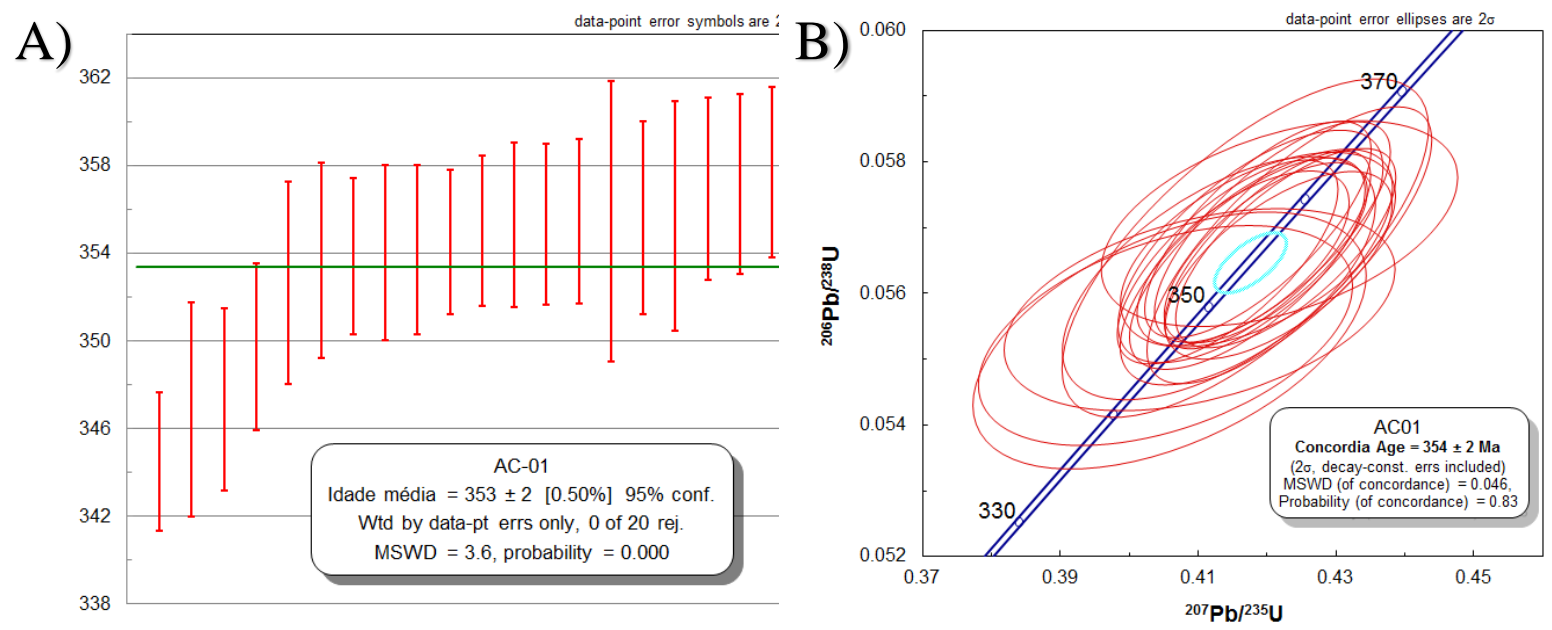

Figura 97. A) Idade ${ }^{206} \mathrm{~Pb} /{ }^{238} U$ média e B) idade concórdia da população de zircão de AC-01

Os isótopos de Ti foram analisados por SHRIMP em 18 cristais de zircão desta população e 17 análises apresentaram razão média de ${ }^{50} \mathrm{Ti} /{ }^{49} \mathrm{Ti}$ de 0.96 , com conteúdo médio de ${ }^{49} \mathrm{Ti}$ de $9.6 \mathrm{ppm}$ e conteúdo médio de ${ }^{50} \mathrm{Ti}$ de $9.5 \mathrm{ppm}$. As temperaturas médias obtidas nestes 17 cristais de zircão foram de $773 \pm 29^{\circ} \mathrm{C}$ no ${ }^{49} \mathrm{Ti}$ e $771 \pm 31^{\circ} \mathrm{C}$ no ${ }^{50} \mathrm{Ti}$ (Figura 98A). Outra análise apresentou valores de erro padrão nas medidas de quantidade de Ti superiores a $50 \%$ do valor em ppm medido $\left(21.2 \pm 13.4\right.$ ppm de ${ }^{49} \mathrm{Ti}$ e $20.4 \pm 14.2$ ppm de ${ }^{50} \mathrm{Ti}$ ) e foi descartada.

Os isótopos de Lu-Hf foram estudados por LA-MC-ICPMS em 20 cristais de zircão desta população. Estes grãos de zircão apresentaram conteúdo de ${ }^{176} \mathrm{Hf} /{ }^{177} \mathrm{Hf}_{\mathrm{o}}$ variando entre 0.282717 e 0.282645 , com os valores de $\varepsilon_{\mathrm{Hfo}}$ correspondente variando entre -2.4 e -4.95, e valor médio de -3.52. Quando a idade concórdia de 354 Ma é usada são obtidos valores de ${ }^{176} \mathrm{Hf} /{ }^{177} \mathrm{Hf}_{\mathrm{i}}$ variando entre 0.282715 e 0.282644 , sendo que os valores de $\varepsilon_{\mathrm{Hfi}}$ correspondentes variam entre -1.69 e -4.21, com média de -2.79 (Figura 98B). Os resultados individuais das análises isotópicas de U-Pb, Ti e Lu-Hf podem ser vistos na Figura 99. 

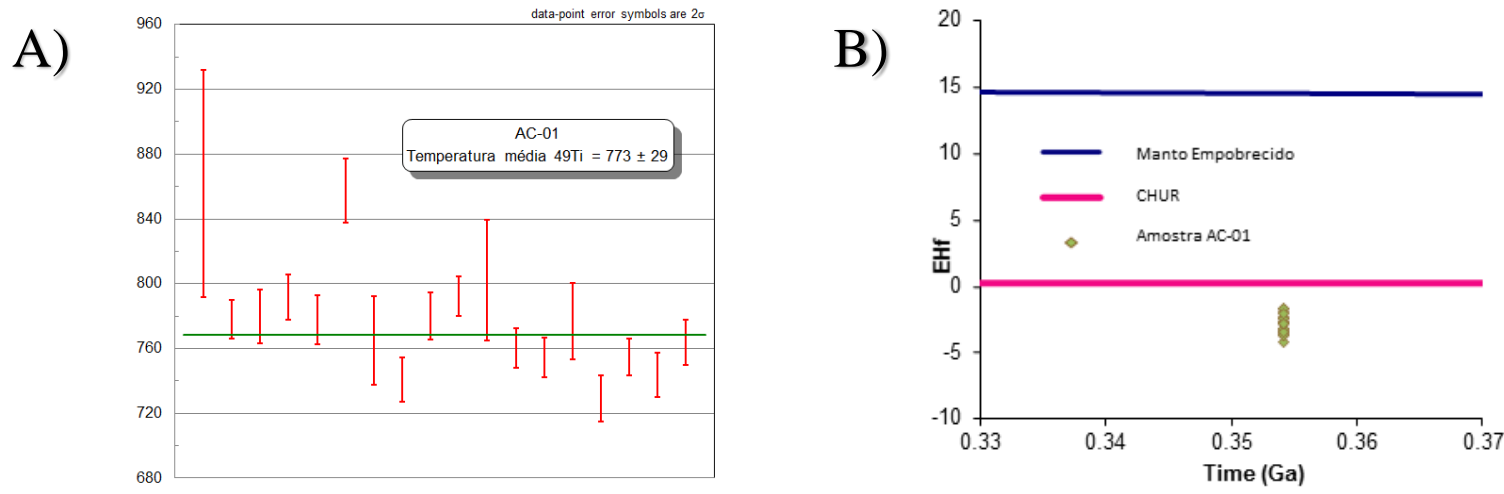

Figura 98. A) Temperaturas ${ }^{49}$ Ti e B) valores de $\mathcal{E}_{H f i}$ obtidos na amostra AC-01 


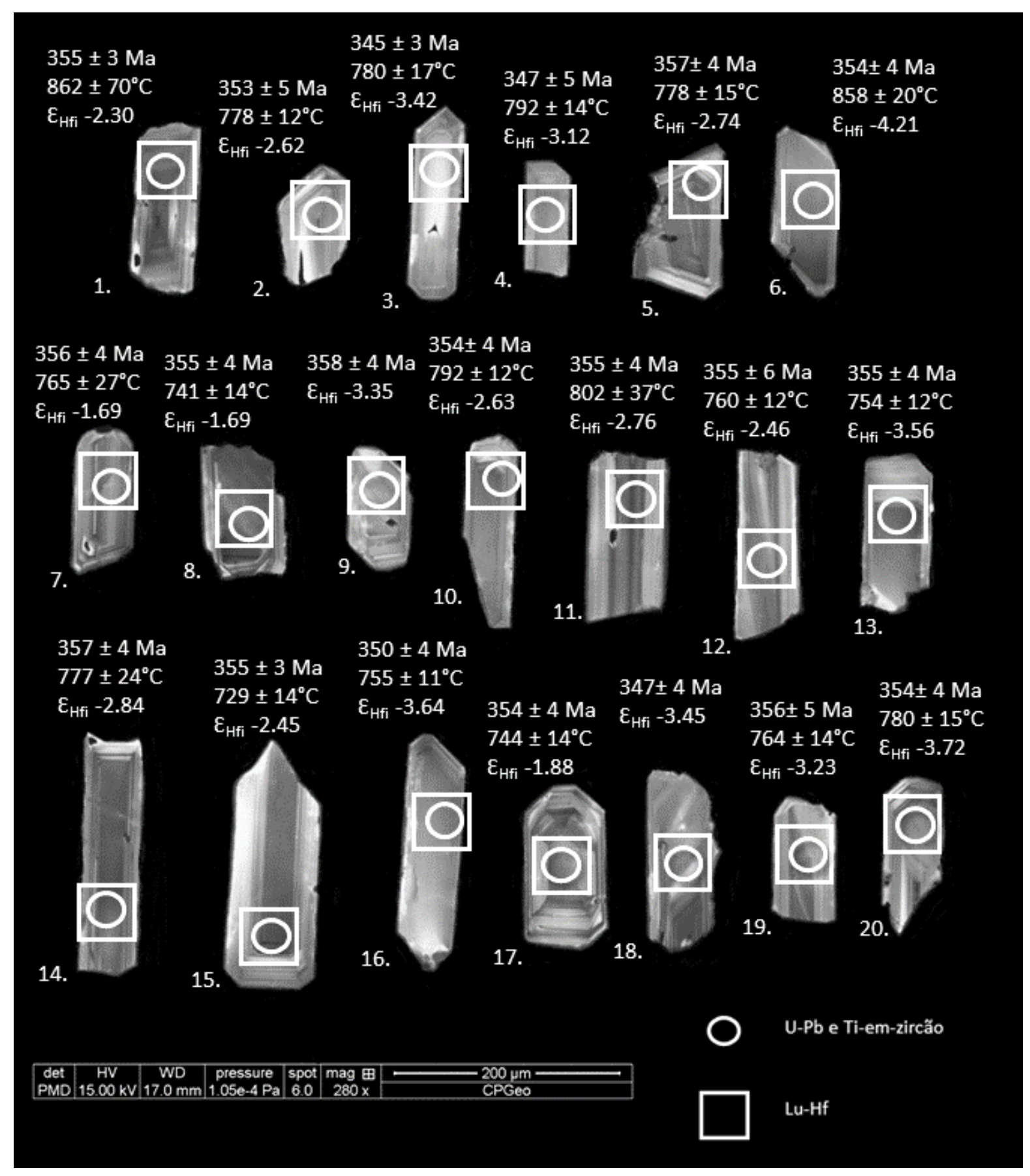

Figura 99. Imagens de CL obtidas na população de zircão da amostra AC-01 com os resultados das análises de U-Pb, Ti-em-zircão e Lu-Hf plotados nos cristais analisados.

A amostra AC-02 representa a matriz do conglomerado do Dacito El Cerro (Figura 100). Em geral os cristais de zircão catalogados via imagens de CL da amostra AC-02 são bastante similares aos cristais de zircão presentes na amostra AC-01. Estes cristais são prismáticos, com comprimento variando entre 80 e $220 \mu \mathrm{m}$. Assim como na amostra AC-01, os zoneamentos oscilatórios são relativamente sutis em relação a outras amostras 
estudadas, com bandas largas e homogêneas. Nesta população, entretanto, ocorrem mais porções esbranquiçadas indicando que esta população foi afetada por alterações tardimagmáticas, além de inclusões minerais grandes (de até $80 \mu \mathrm{m}$ ) e bordas corroídas e reabsorvidas.
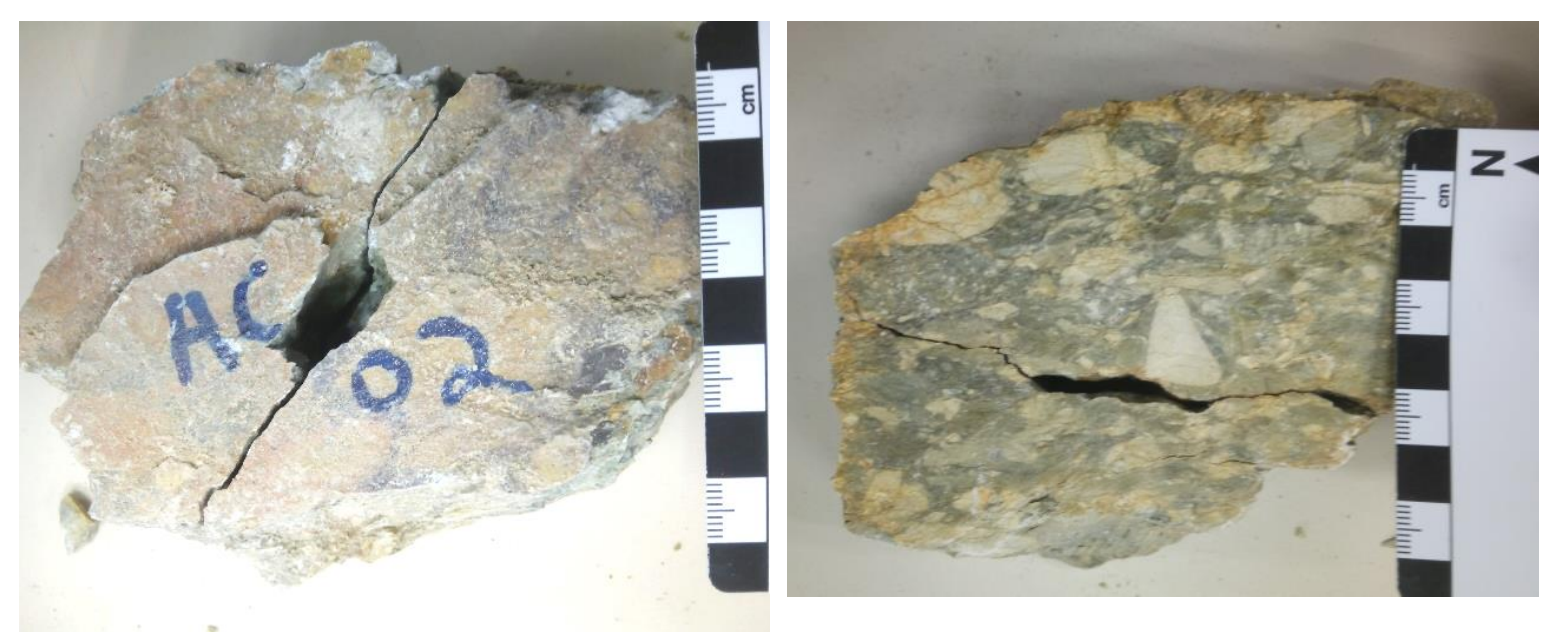

Figura 100. Fotografias da amostra AC-02 em dois ângulos diferentes

Nesta amostra foram executadas 20 análises em 20 cristais de zircão por SHRIMP. As análises são caracterizadas por uma pequena variação nos conteúdos de U (133- 450 ppm) e razões Th/U entre 0.49 e 0.94 , razões que são típicas de grãos de zircão ígneos. Destas análises, 17 foram utilizadas no cálculo da idade concórdia. Elas variaram entre 344 e 362 Ma e definiram uma idade concórdia de $352 \pm 4$ Ma, com valor de MSWD de 0.042 (Figura 101C). Outra das análises se mostrou um xenocristal e apresentou idade ${ }^{206} \mathrm{~Pb} /{ }^{238} \mathrm{U}$ de $395 \pm 3 \mathrm{Ma}$ (Figura 101A). Outras duas análises não foram utilizadas para o cálculo da concórdia e geraram idades individuais ${ }^{206} \mathrm{~Pb} /{ }^{238} \mathrm{U}$ de $340 \pm 4$ Ma e $362 \pm 5$ Ma. 

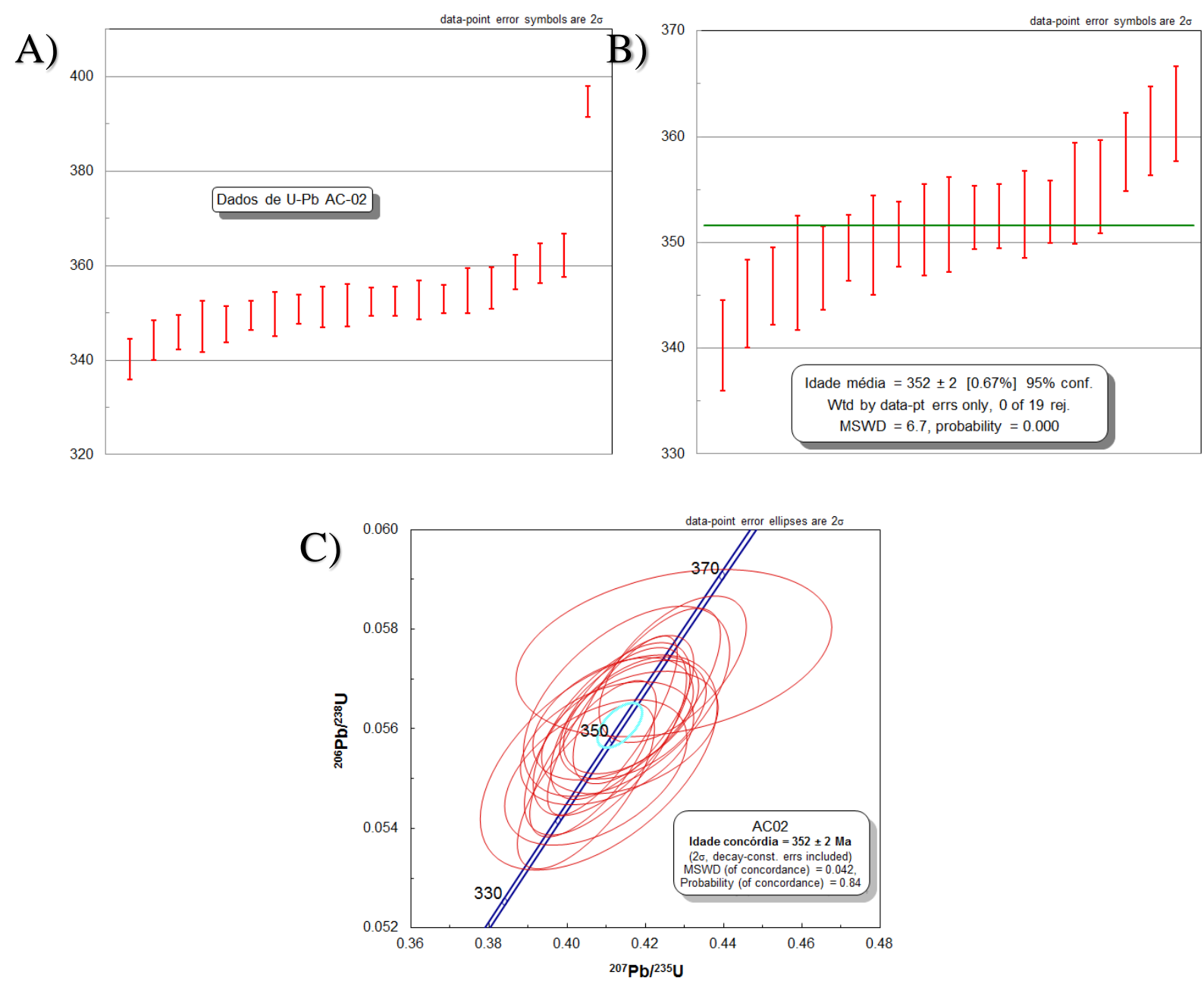

Figura 101. A) dados de $\mathrm{U}-\mathrm{Pb}, \mathrm{B})$ idade ${ }^{238} \mathrm{U}^{206} \mathrm{~Pb}$ média e C) idade concórdia obtida na população de zircão de AC-02

Os isótopos de Ti foram analisados com 12 análises nesta amostra. Uma análise foi descartada devido ao alto conteúdo de Ti $\left(35.2 \mathrm{ppm}\right.$ e $35.3 \mathrm{ppm}$ de ${ }^{49} \mathrm{Ti}$ e ${ }^{50} \mathrm{Ti}$ respectivamente) enquanto que as outras 11 apresentaram uma razão média de ${ }^{50} \mathrm{Ti} /{ }^{49} \mathrm{Ti}$ de 0.95 , com conteúdo médio de ${ }^{49} \mathrm{Ti}$ de 10.8 ppm e conteúdo médio de ${ }^{50} \mathrm{Ti}$ de 10.7 ppm. As temperaturas médias obtidas nestes 11 cristais de zircão foram de $785 \pm 29^{\circ} \mathrm{C}$ no ${ }^{49} \mathrm{Ti}$ e $784 \pm 27^{\circ} \mathrm{C}$ no ${ }^{50} \mathrm{Ti}$ (Figura $103 \mathrm{~A}$ ).

As análises de isótopos de Lu-Hf por LA-MC-ICPMS foram executados em 21 cristais de zircão da amostra AC-02. Estes cristais apresentaram valores de ${ }^{176} \mathrm{Hf} /{ }^{177} \mathrm{Hf}_{\mathrm{o}}$ entre 0.282747 e 0.282669 , com valores de $\varepsilon_{\mathrm{Hfo}}$ correspondentes variando entre -1.34 e 4.1, e valor médio de -3.32. Quando os dados de Hf são analisados em conjunto com a idade concórdia de 352 Ma são obtidos valores de ${ }^{176} \mathrm{Hf} /{ }^{177} \mathrm{Hf}_{\mathrm{i}}$ variando entre 0.282745 e 0.282668 , sendo que os valores de $\varepsilon_{\mathrm{Hfi}}$ correspondentes variam entre -0.64 e -3.36 , com 
média de -2.59 (Figura 103B). Os resultados individuais das análises executadas nesta população podem ser consultados na Figura 102.

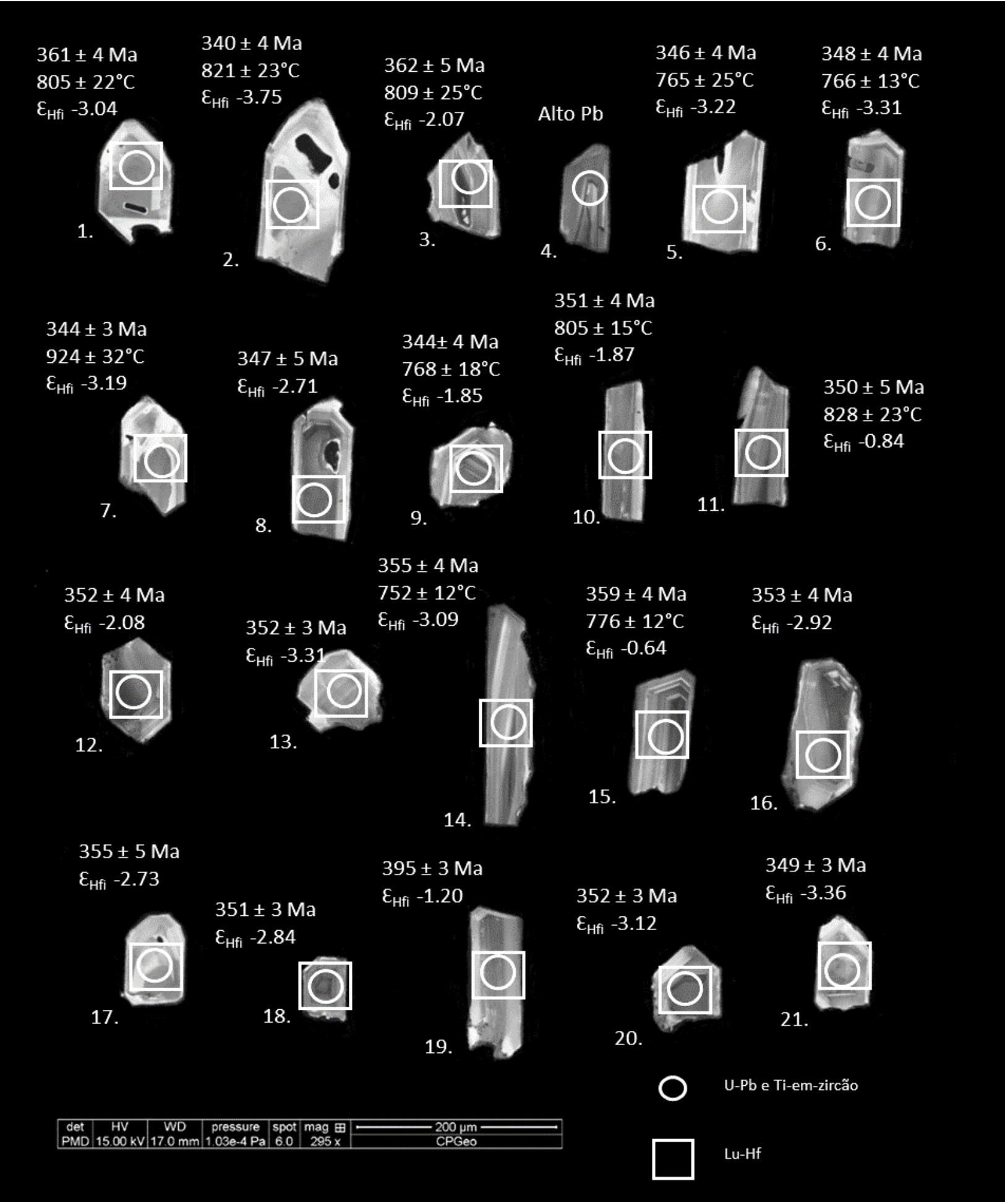

Figura 102. População de cristais com os resultados individuais das análises de U-Pb, Ti-emzircão e Lu-Hf plotados 

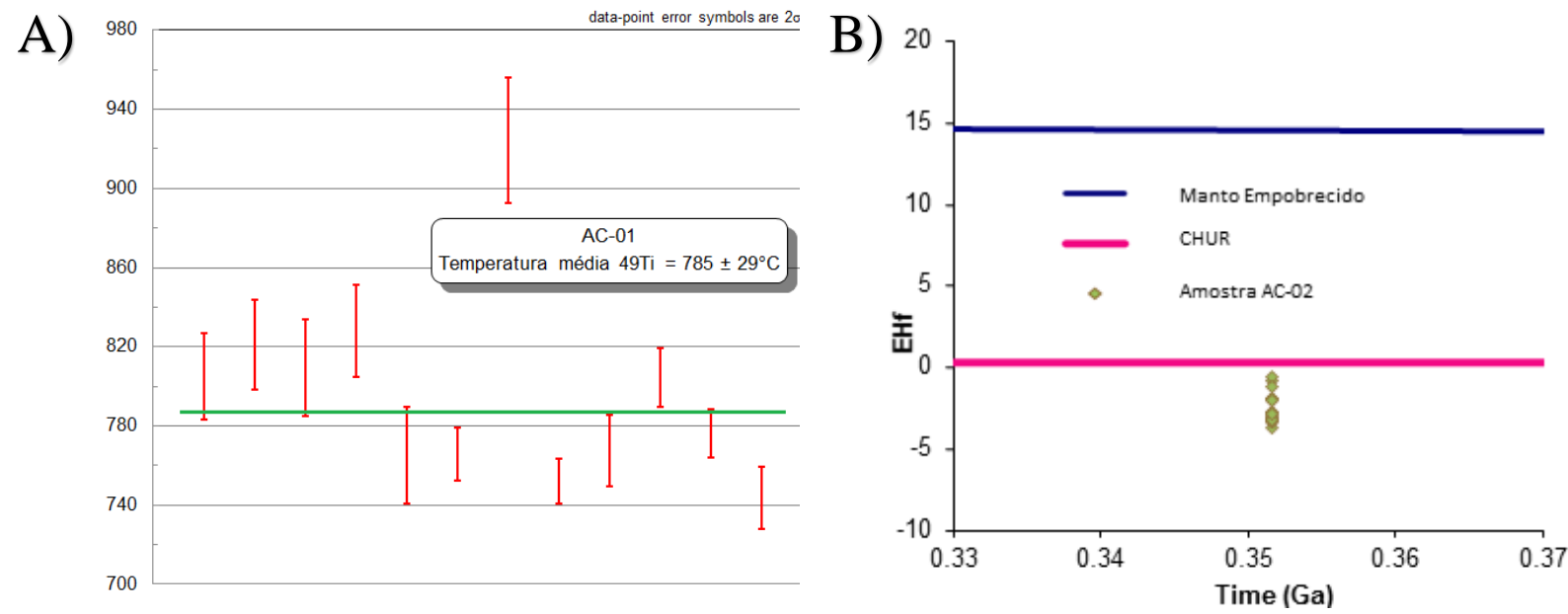

Figura 103. A) Temperaturas de ${ }^{49}$ Ti e B) valores de $\mathcal{E}_{H f i}$ obtidos na população de zircão da amostra AC-02
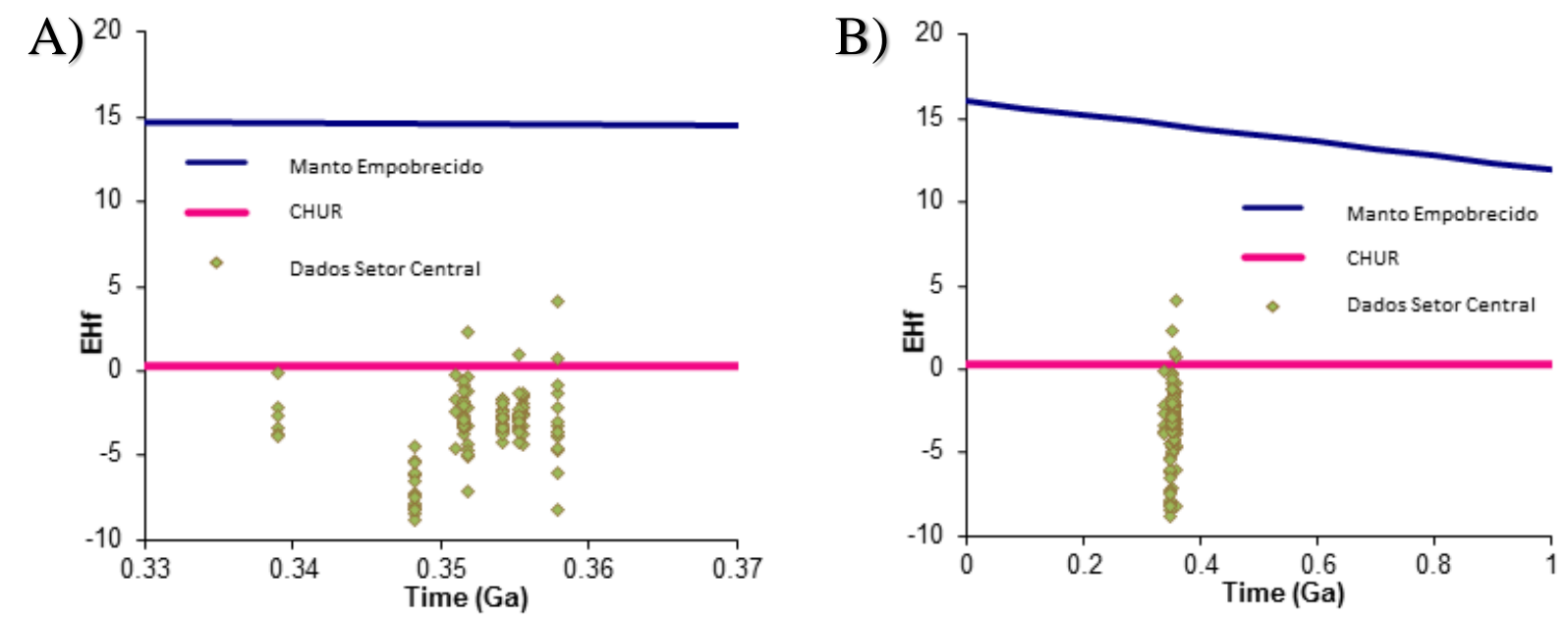

Figura 104. A) e B) apresentam os valores de $\mathcal{E}_{H f i}$ obtidos no Setor Central plotados na escala dos eventos geológicos regionais (0.33-0.37 Ga) e na escala geralmente utilizada em outros trabalhos (0.0-

$1.0 \mathrm{Ga})$

As idades concórdia obtidas no Setor Central variam entre $358 \pm 2$ Ma e $339 \pm 3$ Ma. A idade obtida no riolito tardio de Rio Tinto é de $339 \pm 3$ Ma, o que é coerente com a idade obtida em SP-03. A idade de $358 \pm 2$ Ma foi obtida em Zarandas e representa o início do magmatismo na região de Rio Tinto. Levando em conta somente amostras relacionadas a mineralizações de sulfeto maciço, o intervalo de idades obtidas variou entre 357 - 348 Ma.

No Setor Central as duas idades de La Zarza associadas a mineralização (357 $355 \mathrm{Ma}$ ) são diferentes das idades de Rio Tinto associadas a mineralização (352 - 348 
Ma). Assim como acontece com os depósitos do Cinturão Norte, as idades obtidas são idades do Tournaisiano. As rochas estéreis do Dacito El Cerro apresentam idades de 354 e 352 Ma e mostram que este corpo representa um vulcanismo contemporâneo aos vulcanismos de La Zarza e Rio Tinto.

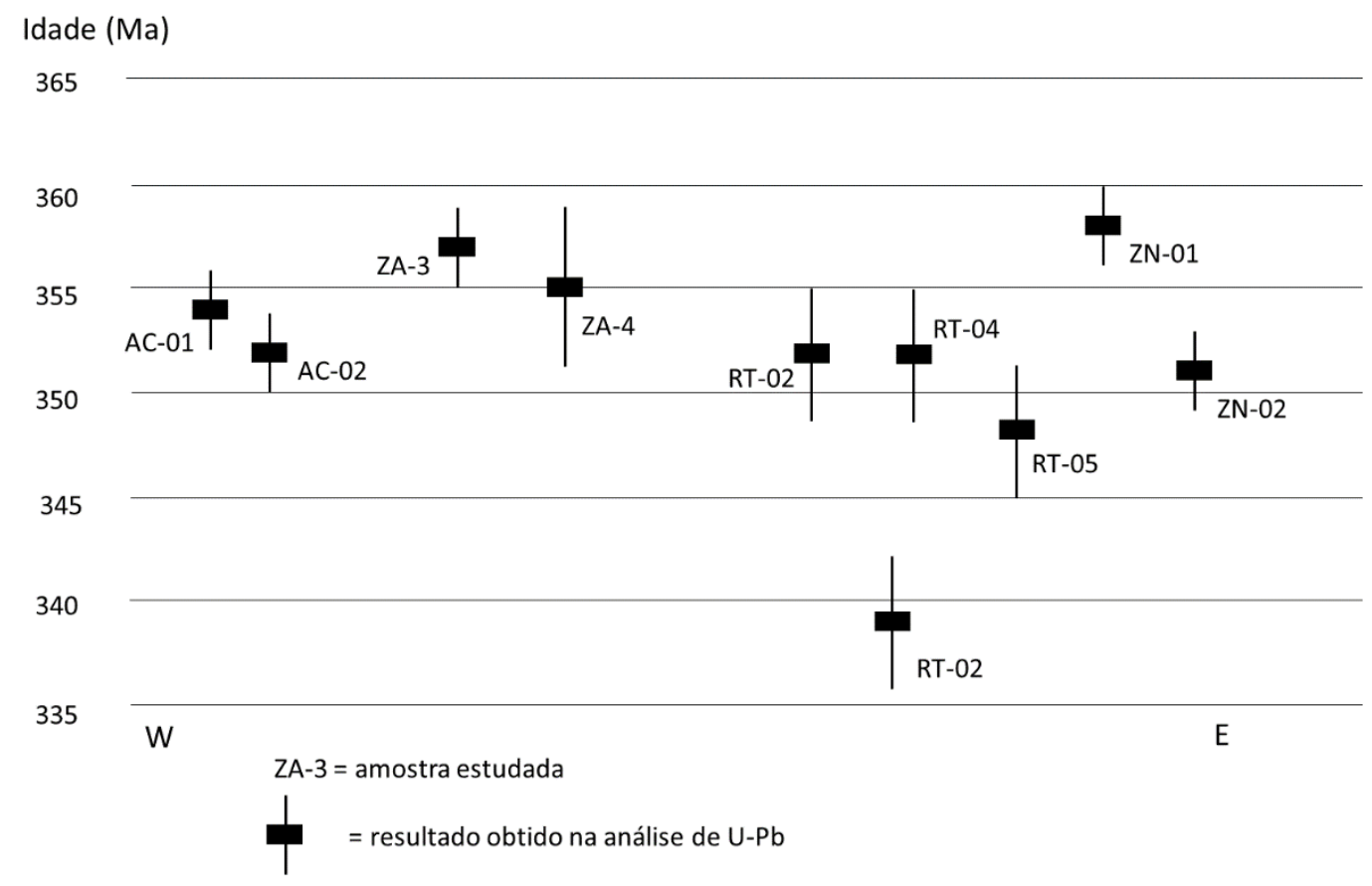

Figura 105. Régua de idades concórdia obtidas nos depósitos do Setor Central.

No Setor Central foram estudadas 9 amostras via isótopos de Ti. As amostras do Dacito del Cerro apresentaram temperaturas entre $775^{\circ} \mathrm{C}$ e $785^{\circ} \mathrm{C}$, com temperatura média de $780^{\circ} \mathrm{C}$. Enquanto isso as amostras de localidades com mineralizações apresentaram temperaturas mais frias: La Zarza apresentou temperaturas de $746^{\circ} \mathrm{C}$ e $729^{\circ} \mathrm{C}$, com temperatura média de $738^{\circ} \mathrm{C}$ enquanto Rio Tinto apresentou temperaturas variando entre $692^{\circ} \mathrm{C}$ e $727^{\circ} \mathrm{C}$, com temperatura média de $713^{\circ} \mathrm{C}$, as temperaturas mais frias registradas na FPI.

Os dados de U-Pb mostram que o depósito de La Zarza é um pouco mais antigo que o depósito de Rio Tinto (375 - 355 Ma e 352 - 348 Ma, respectivamente) e os dados isotópicos de Ti complementam a análise ao mostrarem que o depósito de La Zarza também apresenta temperaturas um pouco mais elevadas que o depósito de Rio Tinto. 


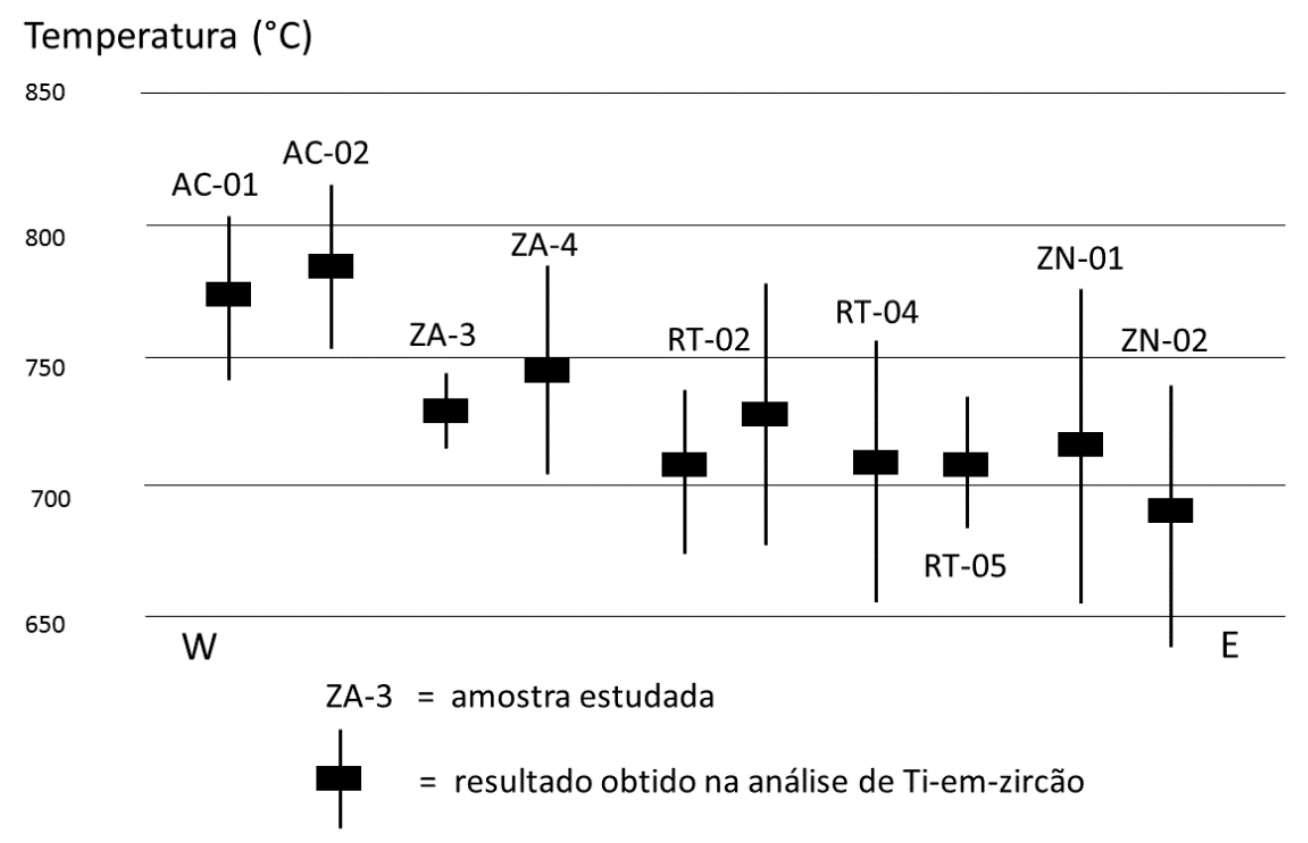

Figura 106. Temperaturas ${ }^{49}$ Ti obtidas nas amostras do Setor Central

Diferente do que ocorre no Cinturão Norte, os valores de $\varepsilon_{\mathrm{Hfi}}$ obtidos no Setor Central apresentam valores negativos que variam entre -2.09 e -7.04, com valor médio de $\varepsilon_{\mathrm{Hfi}}=-3.26$, uma assinatura mais crustal que a assinatura das rochas do Cinturão Norte. Poucas análises individuais estão acima de $\varepsilon_{\mathrm{Hfi}}=0$ nesta região, o que também mostra que a contribuição de material mantélico é reduzida nesta região em comparação ao Cinturão Norte.
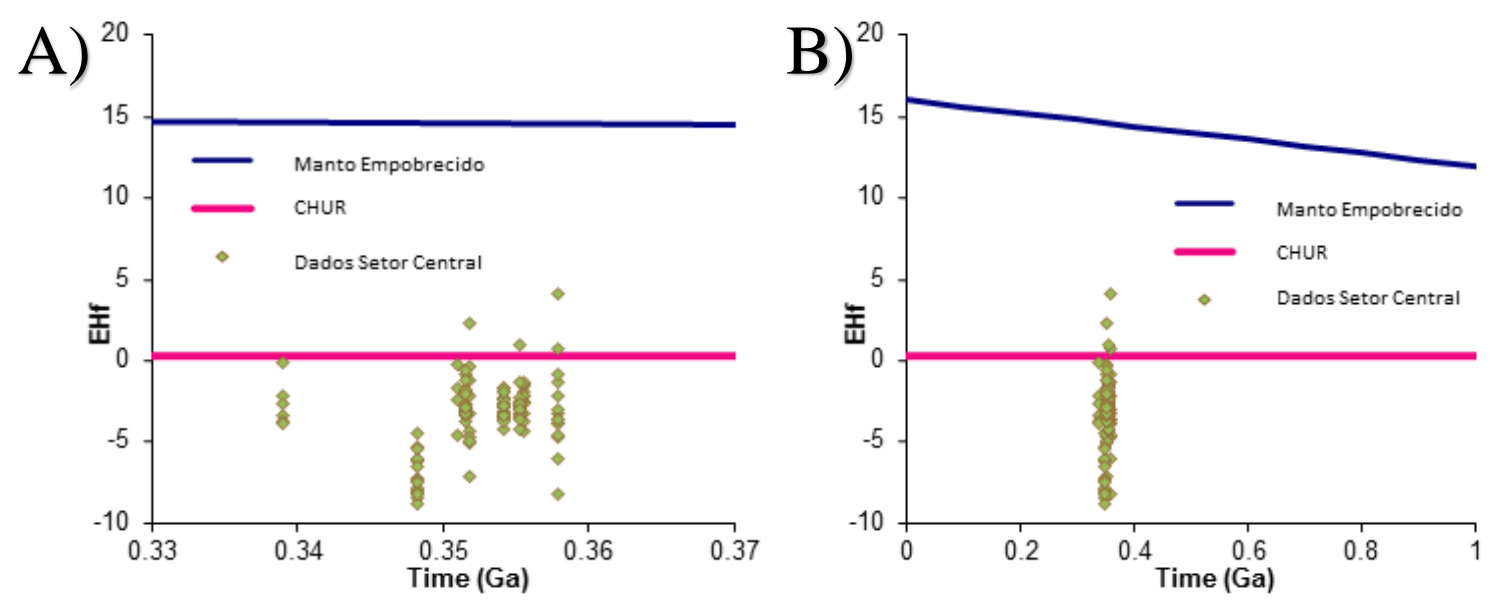

Figura 107. A) e B) Valores de $\varepsilon_{H f i}$ obtidos no Setor Central da FPI, que são mais negativos do que os valores do Cinturão Norte. 


\subsection{REGIÃO SUL}

Nesta tese a região denominada Região Sul compreende todo o sul da FPI espanhola, que é dividida na região Puebla de Guzman, onde o depósito gigante de Tharsis está inserido e região de Valverde-Aznalcóllar, onde existem 3 depósitos gigantes (Sotiel-Migollas, Valverde e Aznalcóllar) e o de classe mundial de Las Cruces (Tornos, 2006). Os depósitos portugueses também são desta região, mas estes não foram estudados nesta tese.

\section{$\underline{\text { Tharsis }}$}

O depósito de Tharsis um dos melhores exemplos de depósitos associados a folhelhos do sul da FPI. Este depósito originalmente continha mais de 133 Mt de sulfetos, tendo sido explotado deste tempos pré-romanos e atualmente se encontra exaurido. Nesta localidade o Complexo VS possui espessura que varia entre 100 e $150 \mathrm{~m}$, composta basicamente por uma monótona sucessão de folhelhos que é cavalgada por um riodacito intensamente sericitizado. Além destas rochas félsicas também ocorrem rochas vulcanoclásticas félsicas sem continuidade lateral e com camadas de até $1 \mathrm{~m}$ intercaladas com arenitos e folhelhos contemporâneas as mineralizações em uma posição distal (Tornos et al., 2008). A amostra TH-04 representa o riodacito sericitizado que cavalga por cima da mineralização (Figura 108), que tem como rocha encaixante os folhelhos, que Tornos et al. (2008) denomina Upper Unit.
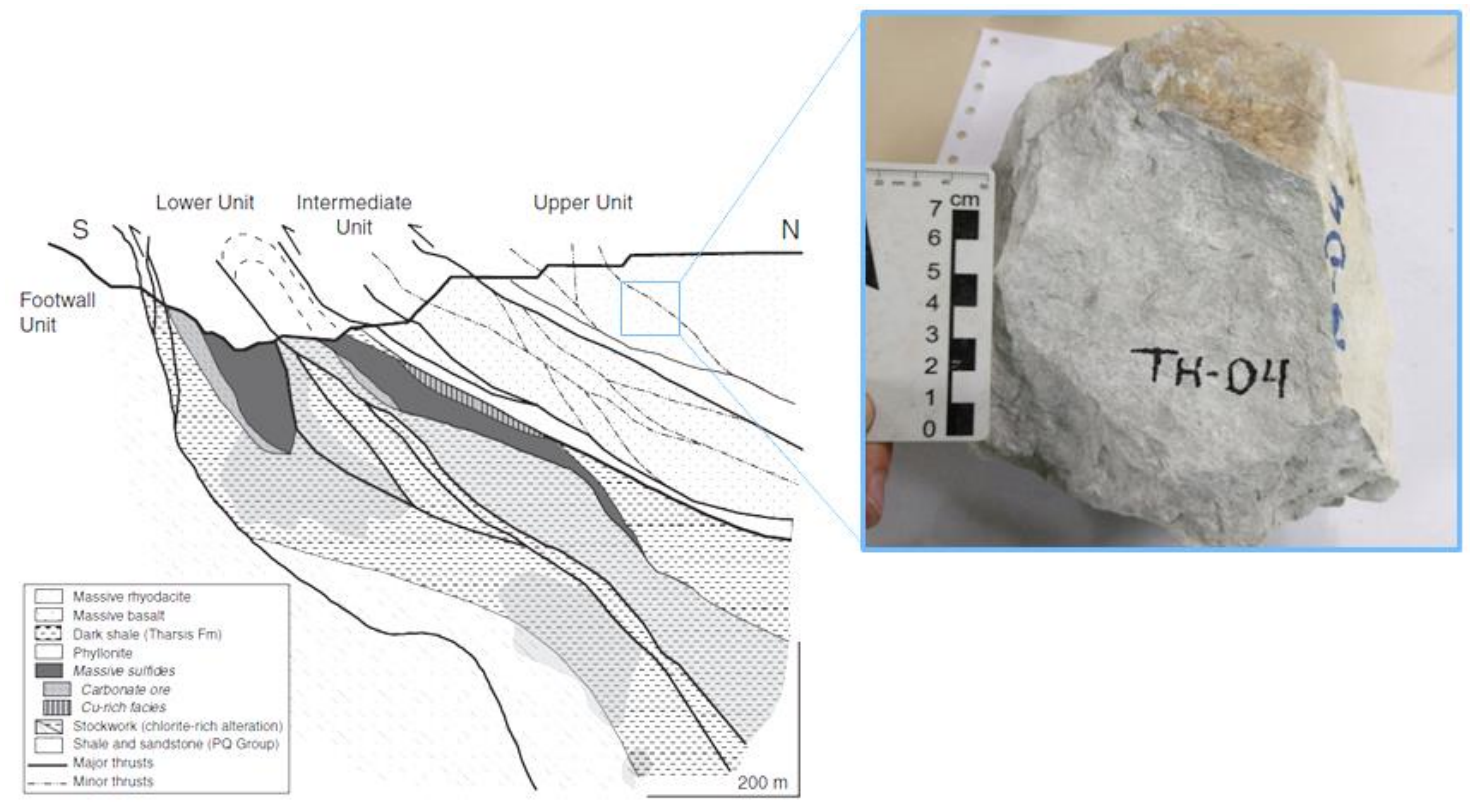

Figura 108. Sessão geológica de Tharsis (Tornos et al. 2008) com fotografia da amostra TH-04 em detalhe 
Os cristais de zircão são prismáticos, com comprimento variando entre 100 e 300 $\mu \mathrm{m}$. O zoneamento oscilatório é sutil, indicando certa homogeneidade composicional no magma ao longo da cristalização destes minerais. Um dos cristais de zircão claros apresenta zoneamento setorial. Alguns minerais apresentam bordas reabsorvidas, refletindo condições de insaturação de $\mathrm{Zr}$ pós-cristalização dos grãos de zircão. Alguns cristais apresentam esbranquiçamentos sutis, evidenciando que esta população foi afetada com pouca intensidade por alterações tardi-magmáticas e, por vezes, essas regiões esbranquiçadas apresentam inclusões minerais associadas.

O estudo dos isótopos de U-Pb por SHRIMP foi executado com 21 análises em uma população de 21 cristais (Figura 109A). As análises são caracterizadas por uma grande variação nos conteúdos de U (82 - 841 ppm) e razões Th/U entre 0.37 e 1.19, razões que são típicas de grãos de zircão ígneos. Em um diagrama concórdia, 10 análises com idades individuais ${ }^{206} \mathrm{~Pb} /{ }^{238} \mathrm{U}$ entre $361 \mathrm{Ma}$ e $371 \mathrm{Ma}$ definiram uma idade concórdia $365 \pm 2 \mathrm{Ma}$ (Figura 109C). Outras 6 análises apresentaram idades ${ }^{206} \mathrm{~Pb} /{ }^{238} \mathrm{U}$ de $350 \pm 7$ Ma, $352 \pm 7 \mathrm{Ma}, 376 \pm 6 \mathrm{Ma}$ (zircão 10), $376 \pm 6 \mathrm{Ma}$ (zircão 20), $385 \pm 8 \mathrm{Ma}$ e $430 \pm 8$ Ma. O conjunto de 16 análises, que variam entre 350 Ma e 376 Ma, definiram uma idade ${ }^{206} \mathrm{~Pb} /{ }^{238} \mathrm{U}$ média de $365 \pm 2 \mathrm{Ma}$ (Figura 109B). Outras 4 análises foram descartadas devido ao conteúdo de $\mathrm{Pb}$ comum elevado (o valor de $\mathrm{Pb}$ comum $>2.5 \%$ foi utilizado como critério de corte nesta amostra). 

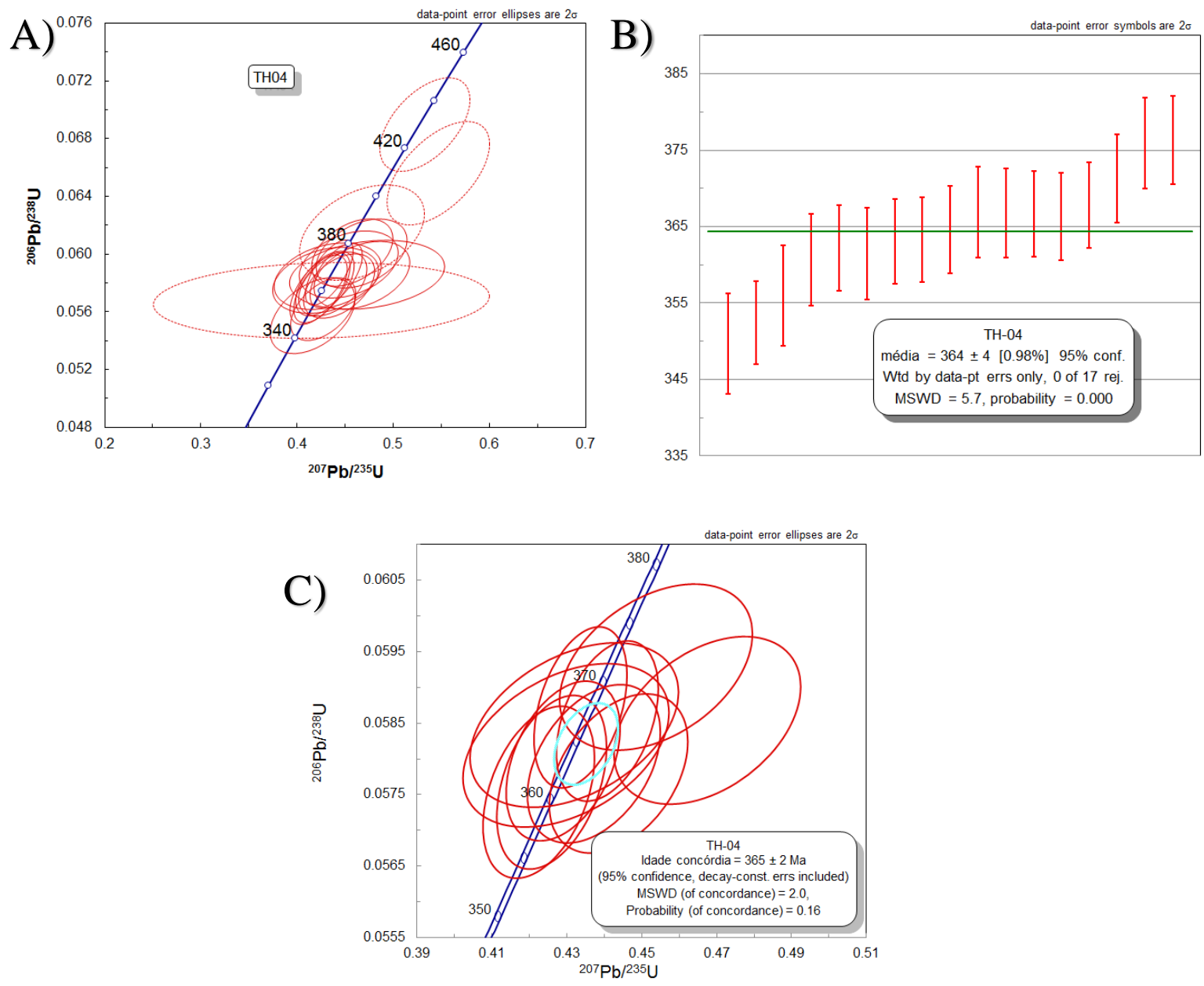

Figura 109. A) Dados de U-Pb obtidos em $\mathrm{TH}-04, \mathrm{~B})$ idade ${ }^{206} \mathrm{~Pb} /{ }^{238} \mathrm{U}$ média e C) idade concórdia obtida nesta população de zircão

O Ti-em-zircão foi estudado por SHRIMP em 10 grãos de zircão desta amostra. Nesta população as 10 análises apresentam razão média de ${ }^{50} \mathrm{Ti} /{ }^{49} \mathrm{Ti}$ de 0.96 , com conteúdo médio de $14.1 \mathrm{ppm}$ de ${ }^{49} \mathrm{Ti}$ e $14.3 \mathrm{ppm}$ de ${ }^{50} \mathrm{Ti}$. As temperaturas médias obtidas são de $804 \pm 59^{\circ} \mathrm{C}$ no ${ }^{49} \mathrm{Ti}$ e $806 \pm 59^{\circ} \mathrm{C}$ no ${ }^{50} \mathrm{Ti}$ (Figura $110 \mathrm{~A}$ ).

Nesta população 19 cristais de zircão tiveram seu conteúdo de Lu-Hf estudados por LA-MC-ICPMS. Estes cristais apresentaram valores presentes de ${ }^{176} \mathrm{Hf} /{ }^{177} \mathrm{Hf}_{\mathrm{o}}$ entre 0.282775 e 0.282631 , com os valores de $\varepsilon_{\text {Hfo }}$ correspondentes variando entre -0.35 e 5.45, e com valor médio de -3.01. Usando a idade concórdia de $365 \mathrm{Ma}$ obtida nesta população os valores de ${ }^{176} \mathrm{Hf} /{ }^{177} \mathrm{Hf}_{\mathrm{i}}$ variaram entre 0.282773 e 0.282629 , sendo que os valores de $\varepsilon_{\mathrm{Hfi}}$ correspondentes variam entre 0.40 e -4.69 , com média de -2.26 (Figura 
110B). Os resultados individuais das análises de isótopos de U-Pb, Ti e Lu-Hf executadas na amostra TH-04 podem ser consultados na Figura 111 abaixo.
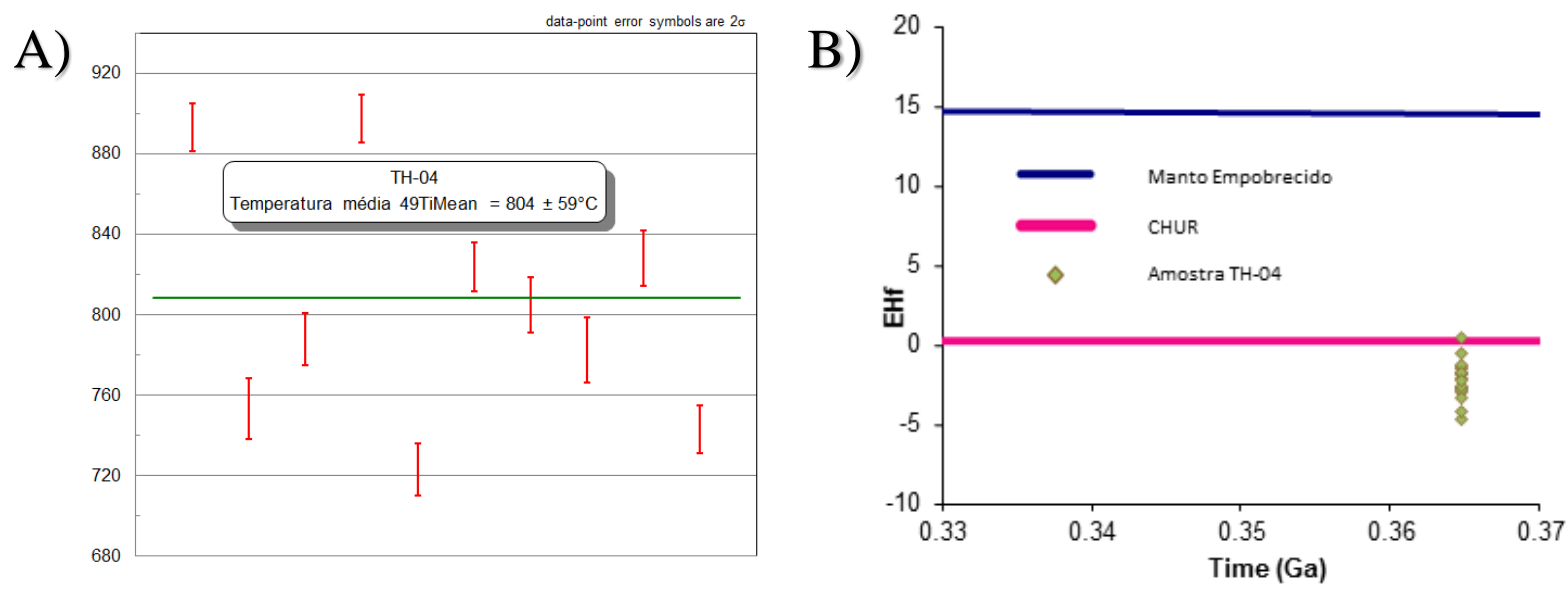

Figura 110. A) Temperaturas ${ }^{49}$ Ti e B) valores de $\varepsilon_{H f i}$ obtidos na amostra $\mathrm{TH}-04$ 


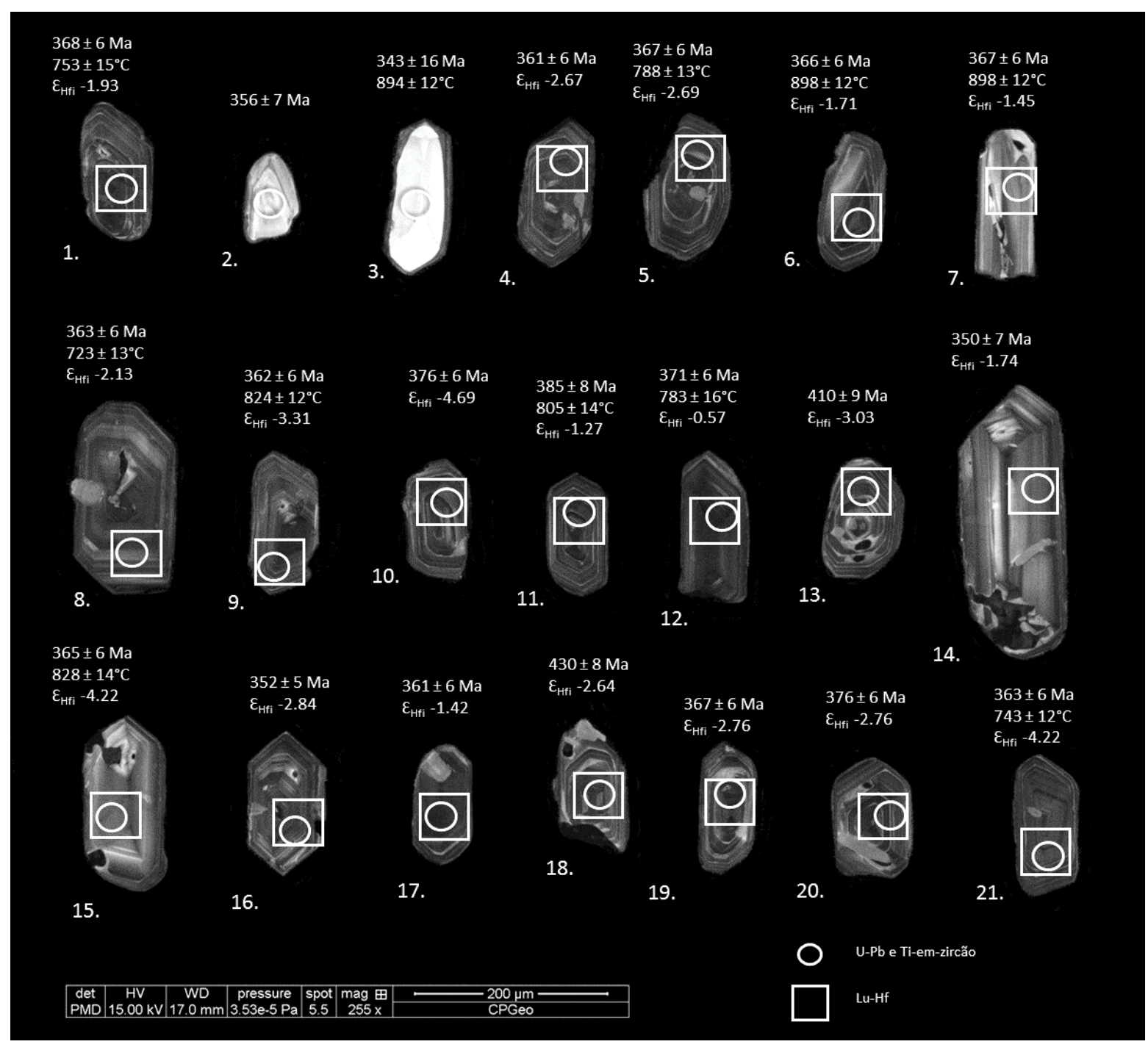

Figura 111. Resultados das análises de U-Pb, Ti-em-zircão e Lu-Hf executados na amostra TH-

04.

\section{Las Cruces}

O depósito de Las Cruces é diferente dos outros depósitos estudados nesta tese pois ele apresenta uma zona de cimentação secundária como o principal mineral de minério. De qualquer forma, a gênese dos sulfetos maciços primário está associada as rochas vulcânicas do Complexo VS, que aqui é um dacito maciço com intenso processo de sericitização (LC-07). Em Las Cruces um dacito distal sem indícios de alteração hidrotermal (LC-09) também foi estudado (Figura 112; Figura 113). Existem diversos estudos distintos executados em Las Cruces que tratam da geologia básica, formação relacionada com atividade de microrganismos, gossans e processos supérgenos e modelo geológico de formação do depósito (Knight 2000, Blake 2008, Tornos et al., 2014a, b; Yesares et al., 2014; Yesares et al., 2015 e Tornos et al., 2017). 


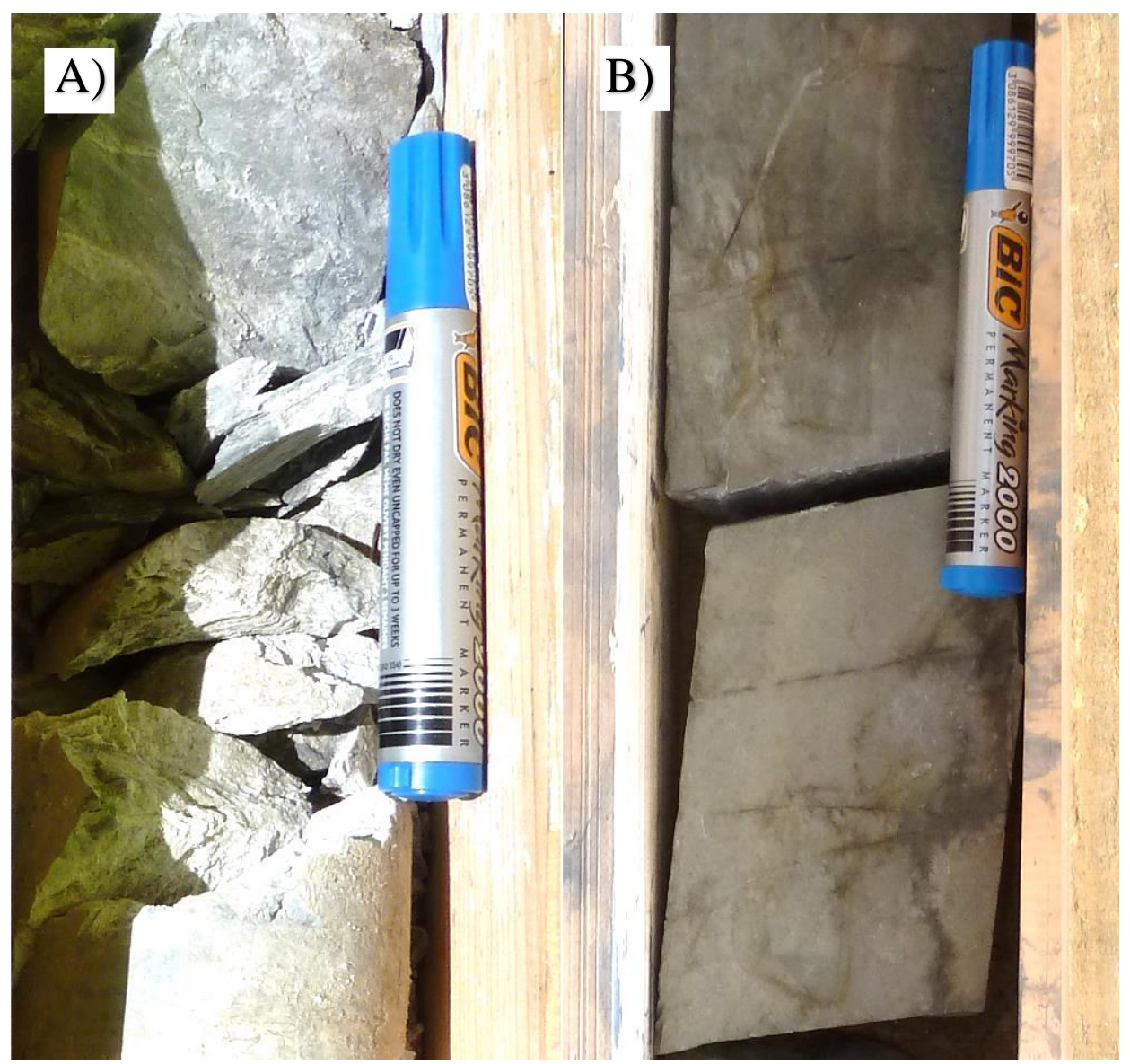

Figura 112. Fotografia dos testemunhos de sondagem amostrado em Las Cruces. A) é a amostra LC-07, que representa a rocha encaixante à mineralização de Las Cruces, com intensa alteração sericítica e B) é o dacito distal (LC-09) sem relação com a mineralização.

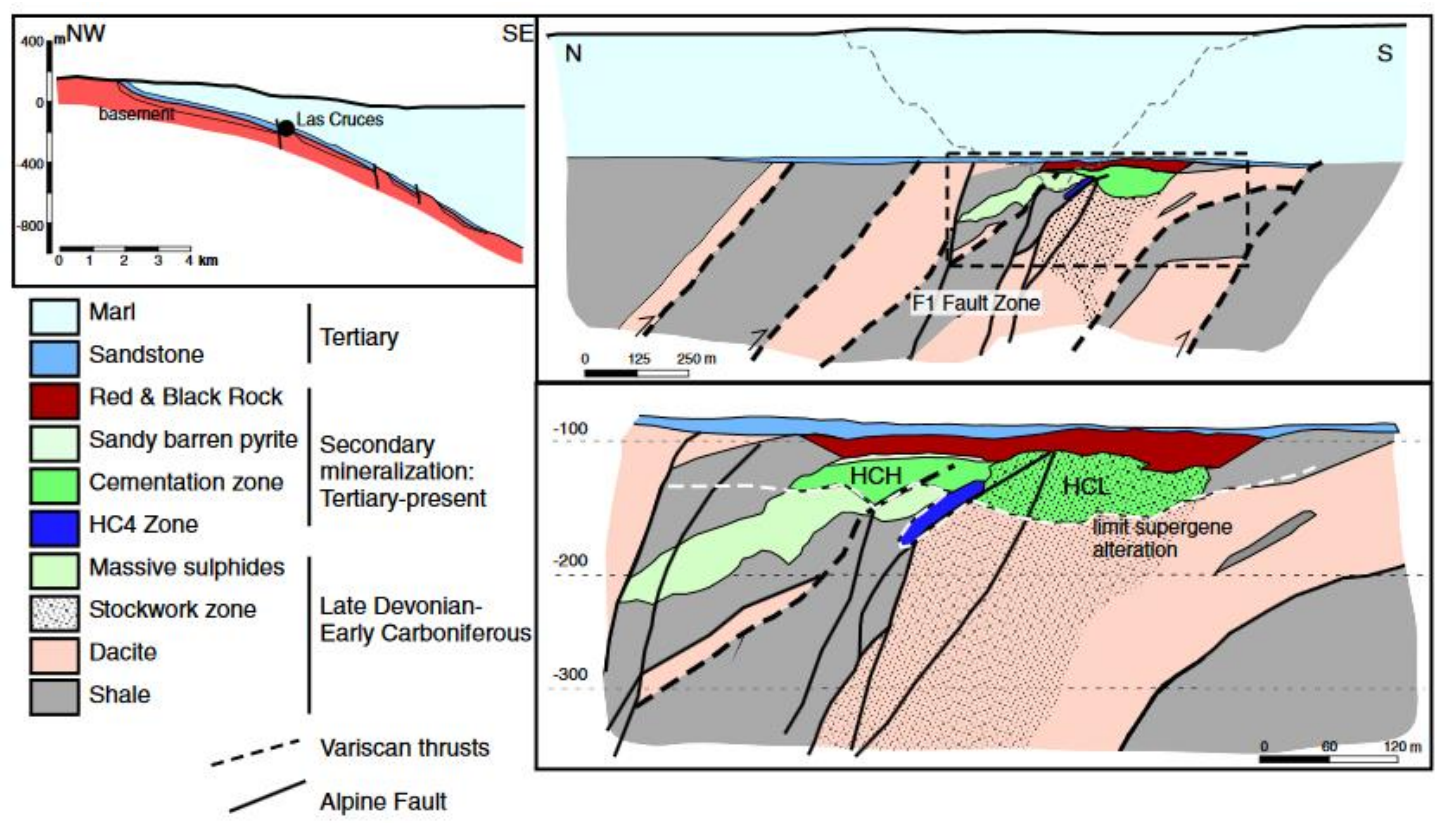

Figura 113. Sessão esquemática do depósito de Las Cruces com a zona de cimentação secundária. HCH e HCL são nomenclaturas utilizadas pela companhia First Quantum de acordo com o teor de Cu. 
A população de zircão concentrada no dacito sericitizado (LC-07) foi catalogada por imagens de CL e possui minerais subeuhedrais, geralmente arredondados. Nestes cristais ocorrem zoneamentos oscilatórios pouco marcado, indicando que o magma manteve a composição relativamente estável ao longo da cristalização destes minerais. Diversos cristais apresentam zoneamento setorial e outros cristais desta população apresentam núcleo e bordas bem definidos. Alguns cristais regiões esbranquiçadas, indicando que esta população sofreu processo de alteração tardi-magmática. As faces da maioria destes cristais são arredondadas, com algumas delas sofrendo reabsorção o que, de acordo com Corfu et al. (2003), está relacionado a recristalização relacionada a metamorfismo de alto grau. De fato, a comparação entre os cristais de zircão da população de LC-07 com as imagens de $\mathrm{Cl}$ dos cristais de zircão do Atlas de Texturas de Zircão de Corfu et al. (2003) associa os cristais de Las Cruces com as feições de recristalização em alto grau metamórfico.

Os estudos de U-Pb via SHRIMP foram feitos com 34 análises em 20 cristais desta população devido ao número de cristais com borda e núcleo (Figura 114A). As análises são caracterizadas por uma pequena variação nos conteúdos de U (83 - 303 ppm) e razões Th/U entre 0.31 e 0.60 , razões que são típicas de cristais de zircão ígneos. Os resultados individuais destas análises podem ser consultados na Figura 115 mais adiante. Todas as análises apresentaram alto conteúdo de $\mathrm{Pb}$ comum, com teores entre $1.65 \%$ a $24.80 \%$, e média de $5.19 \%$. Adotando o corte em $5 \%$ de $\mathrm{Pb}$ comum 11 análises foram descartadas.

Com 10 análises, que variaram entre 350 Ma e 368 Ma, foi calculada uma idade concórdia de $359 \pm 3 \mathrm{Ma}$, com valor de MSWD de 0.93 (Figura 114D). Apesar da aparência dos grãos de zircão indicarem núcleos e bordas nenhum significado geológico foi interpretado a partir da datação destas zonas com aparências distintas. As outras 13 análises apresentam um grande intervalo de idades, entre 295 Ma e 372 Ma (Figura 114 B, C; Figura 117). Porém levando em conta as características desta amostra (alto Pb, morfologia de alto grau metamórfico com recristalização), a geologia regional (idades dos outros depósitos estudados nesta tese e em demais trabalhos), além da geologia local observada por Barrie et al. (2002) e dos resultados obtidos outra amostra (LC-09, que é discutida adiante) 8 destas análises, com idades entre 295 Ma e 334 Ma, também foram descartadas. Outras 2 análises apresentaram idades ${ }^{238} \mathrm{U} /{ }^{206} \mathrm{~Pb}$ de $344 \pm 6$ Ma e $372 \pm 6$ Ma. 
As análises de Ti-em-zircão foram executados no SHIRMP em 10 cristais de zircão. Com 9 análises, que apresentaram razão média de ${ }^{50} \mathrm{Ti} /{ }^{49} \mathrm{Ti}$ de 0.96 e conteúdo médio de 16.7 ppm de ${ }^{49} \mathrm{Ti}$ e $16.8 \mathrm{ppm}$ de ${ }^{50} \mathrm{Ti}$, foram obtidas temperaturas médias de 833 $\pm 18^{\circ} \mathrm{C}$ no ${ }^{49} \mathrm{Ti}$ e $834 \pm 18^{\circ} \mathrm{C}$ no ${ }^{50} \mathrm{Ti}$ (Figura $116 \mathrm{~A}$ ). Outra análise foi descartada devido ao alto conteúdo de Ti (1093.7 ppm e 1089.8 ppm de ${ }^{49} \mathrm{Ti} \mathrm{e}{ }^{50} \mathrm{Ti}$ respectivamente).
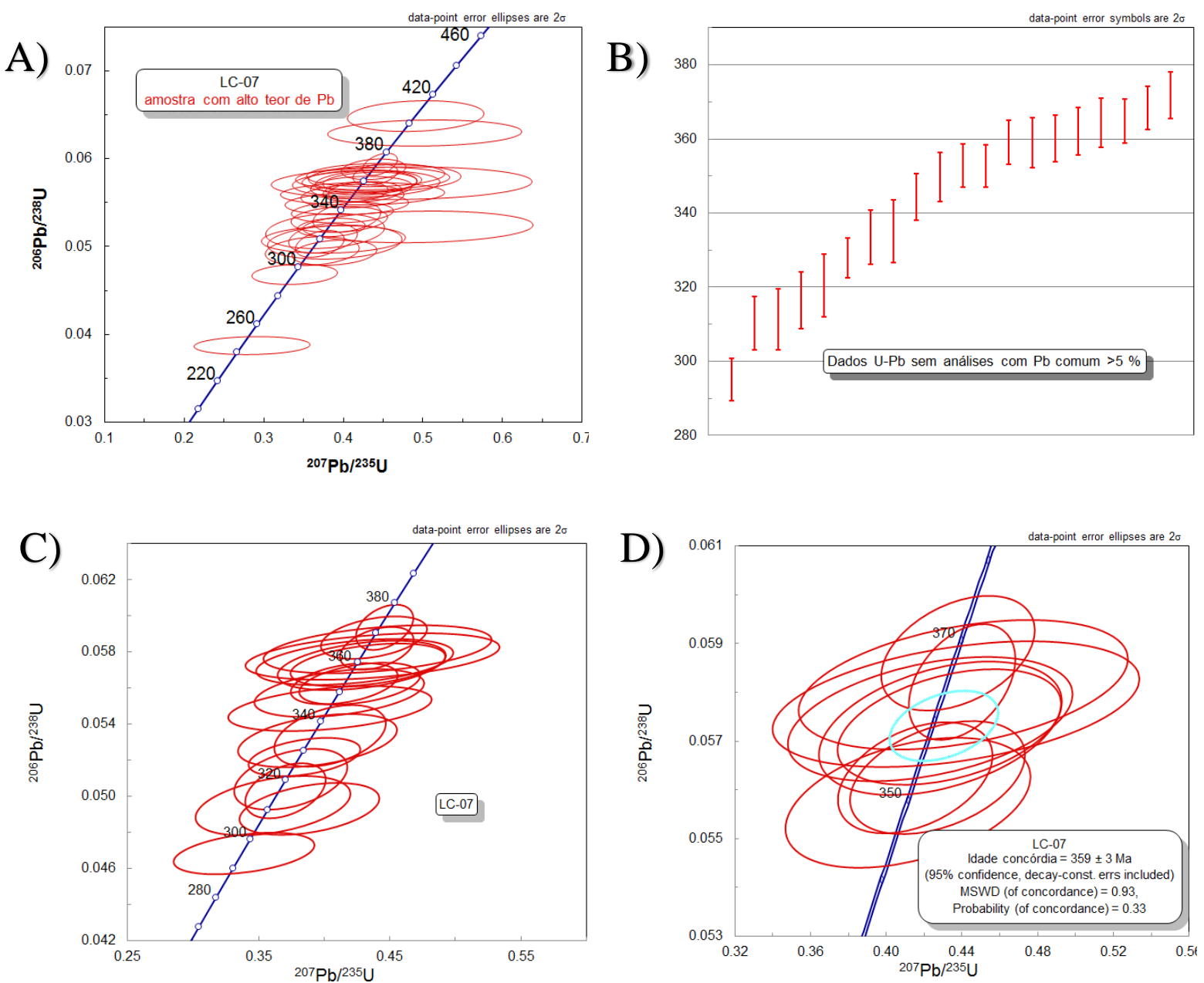

Figura 114. A) Todos os dados de U-Pb obtidos nesta amostra. B) e C) Dados U-Pb após a exclusão de minerais com alto Pb comum. D) Idade concórdia obtida na amostra LC-07 
A população de zircão da amostra LC-07 que teve seus isótopos de Lu-Hf analisada é composta por 18 cristais de zircão. Estes grãos apresentam variação no conteúdo de ${ }^{176} \mathrm{Hf} /{ }^{177} \mathrm{Hf}_{\mathrm{o}}$ entre 0.282693 e 0.282586 , com os valores de $\varepsilon_{\mathrm{Hfo}}$ correspondentes variando entre -3.25 e -7.04, com valor médio de -6.36. Quando os dados de Hf são analisados em conjunto com a idade concórdia de 363 Ma desta amostra foram obtidos valores iniciais de ${ }^{176} \mathrm{Hf} /{ }^{177} \mathrm{Hf}_{\mathrm{i}}$ que variam entre 0.282693 e 0.282585 , com valores de $\varepsilon_{\mathrm{Hfi}}$ correspondentes variando entre -2.46 e -6.25, e com valor médio de -5.58 (Figura 116B). Os valores individuais das análises isotópicas de Ti e Lu-Hf podem ser observados adiante na Figura 118. 


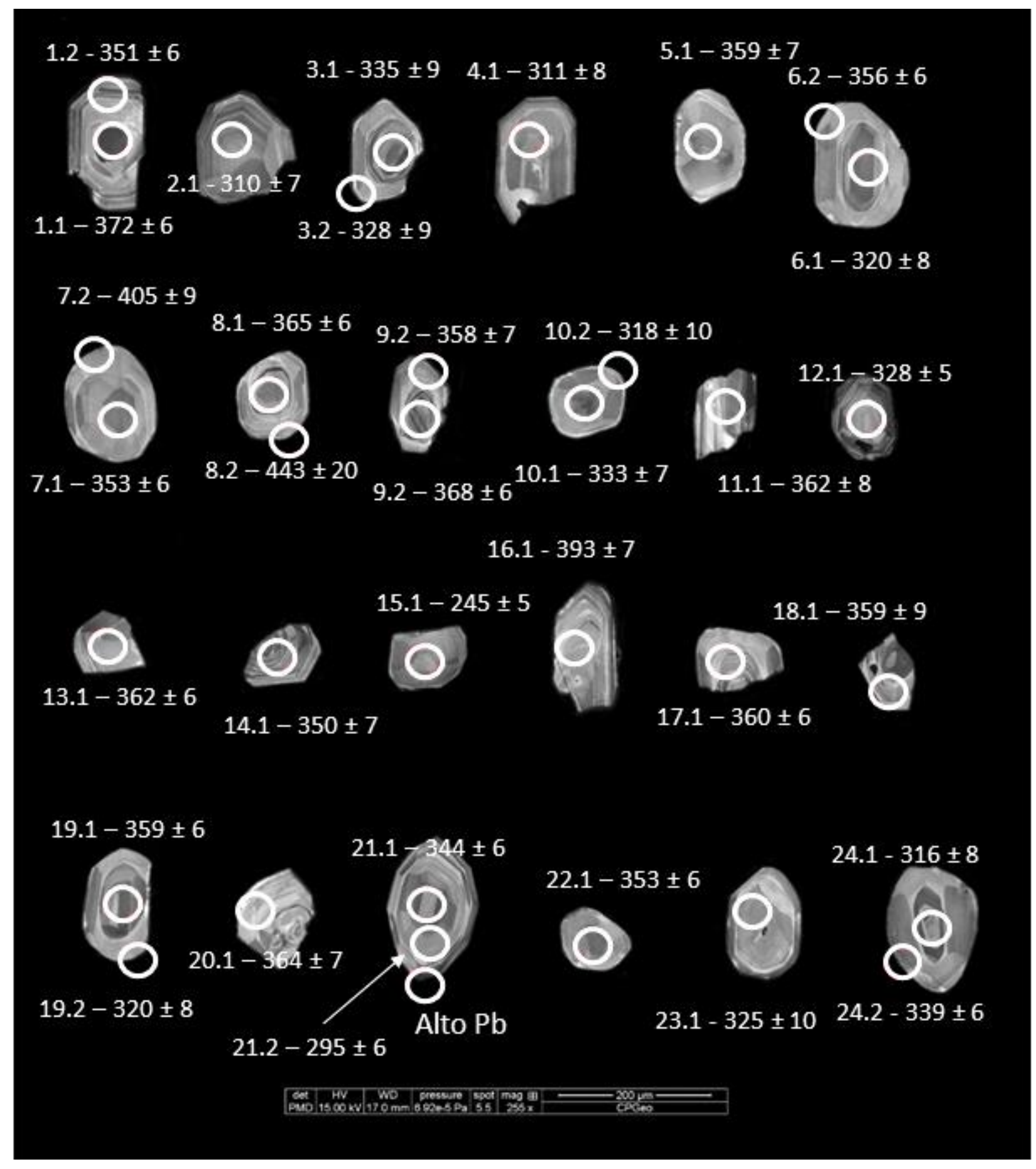

Figura 115. Todos os dados de U-Pb obtidos na amostra LC-07 

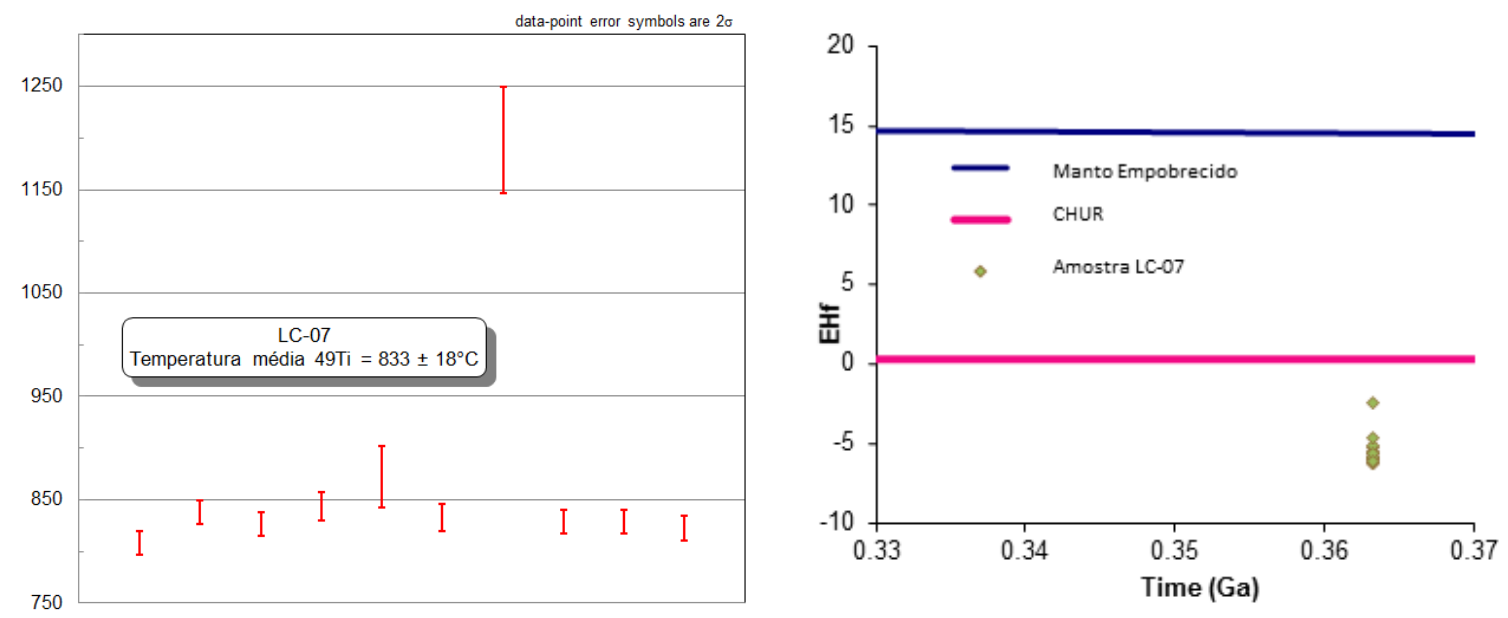

Figura 116. A) Temperaturas ${ }^{49}$ Ti e B) valores de $\varepsilon_{H f i}$ obtidos na amostra

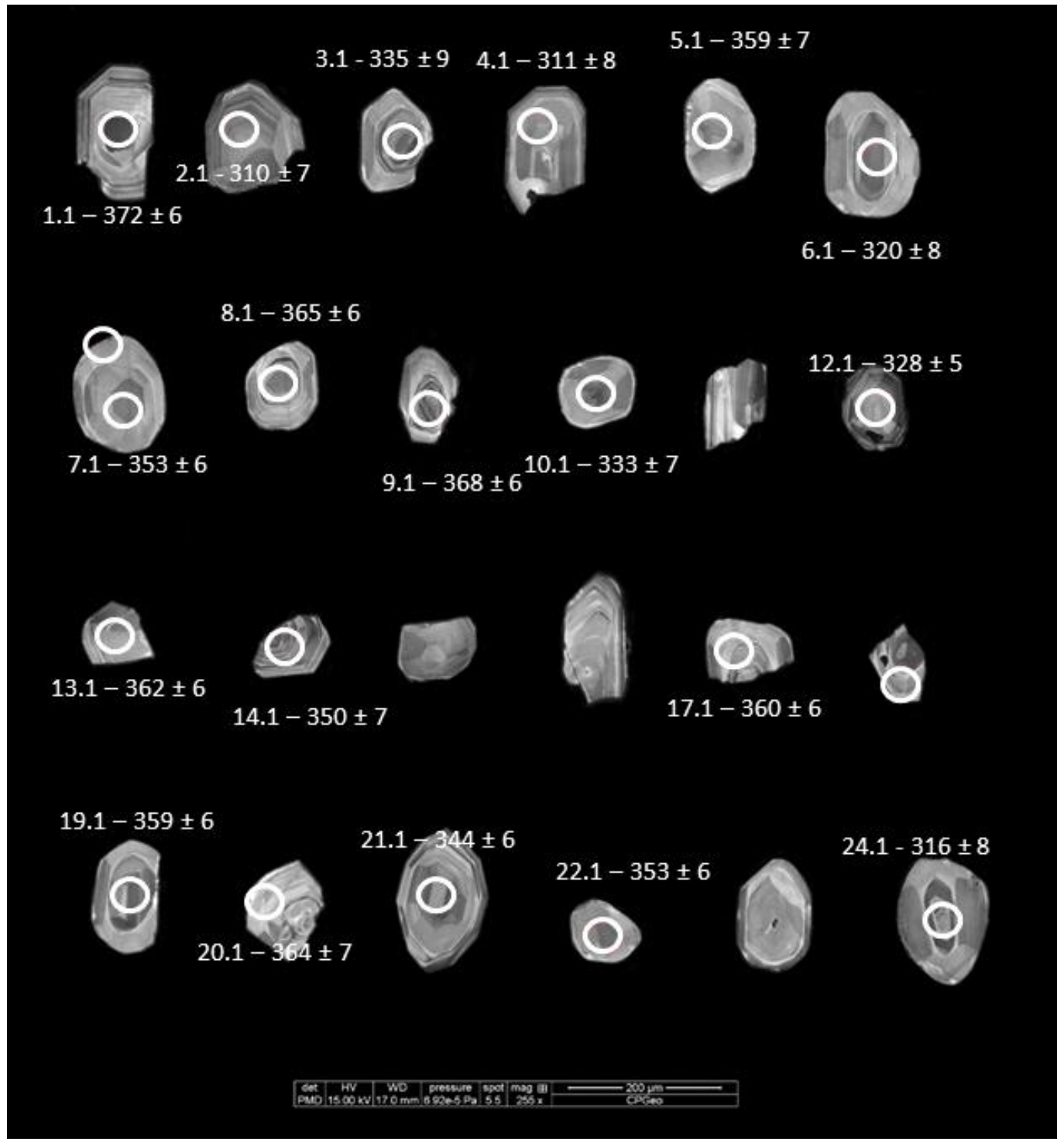

Figura 117. Dados de U-Pb que não foram descartados por alto teor de Pb nesta população de zircão. 


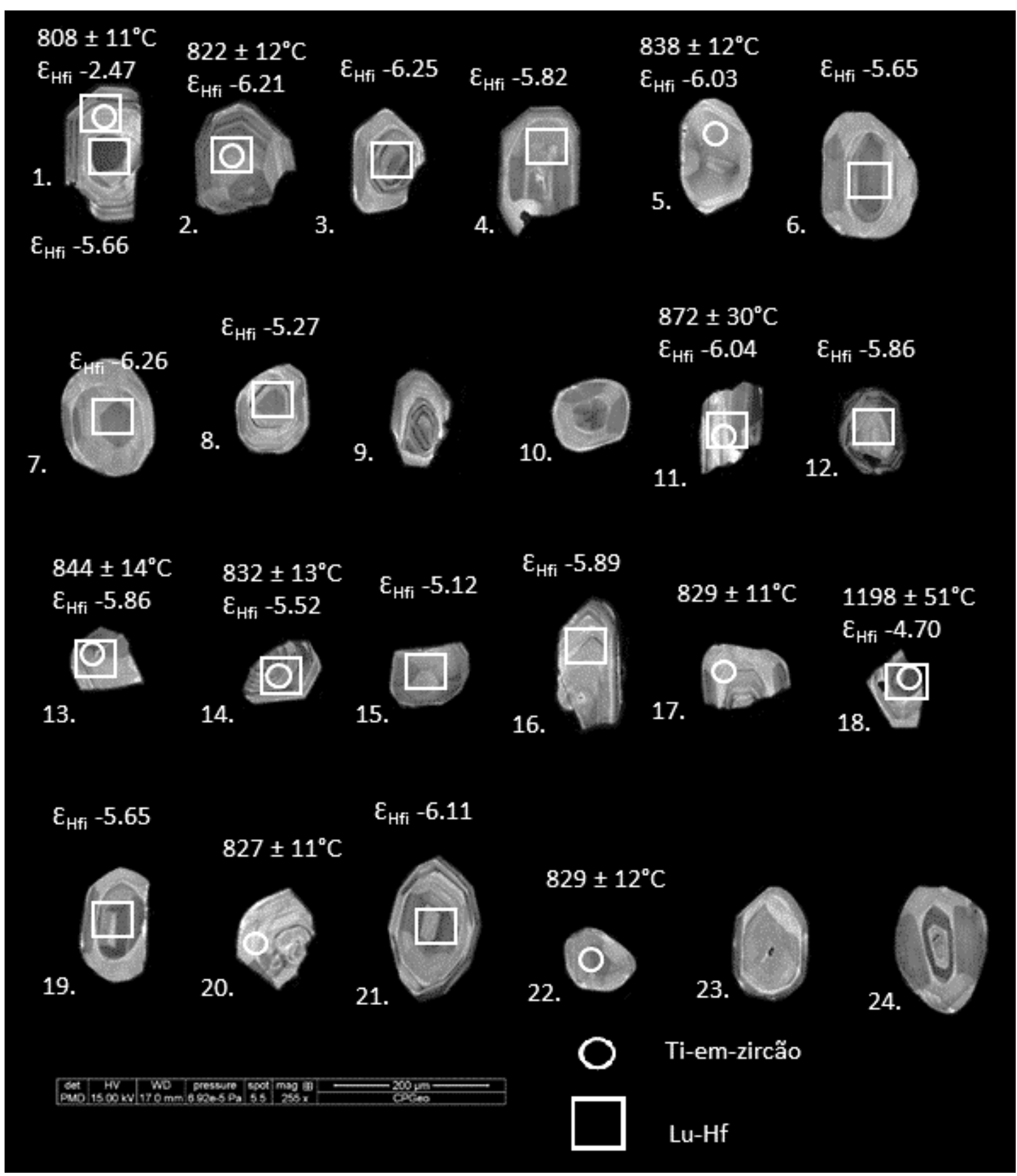

Figura 118. Dados de Ti-em-zircão e $\mathcal{E}_{H f i}$ da população de zircão da amostra LC-07

$\mathrm{Na}$ região da mina de Las Cruces ocorrem outros corpos vulcânicos e subvulcânicos que não estão necessariamente associados a mineralização. Um destes corpos também foi amostrado via testemunho de sondagem cedido pela First Quantum Minerals LTD. Esta amostra (LC-09) representa um domo de riodacito distal a mineralização sem indícios de alteração hidrotermal (Figura 112B). Os cristais de zircão concentrados nesta amostra (LC-09) são prismáticos, com comprimento variando entre 150 e $250 \mu \mathrm{m}$. Esta população é bastante homogênea e diferente da população de LC-07. 
Os zoneamentos oscilatórios são bem marcados, com aspecto quase rítmico que intercala bandas claras e bandas escuras. Bordas reabsorvidas são comuns. Alguns cristais apresentam regiões esbranquiçadas associadas a recristalização tardi-magmática.

Nesta população os isótopos de U-Pb foram analisados por SHRIMP com 18 análises em 18 grãos de zircão (Figura 119A). As análises são caracterizadas por uma pequena variação nos conteúdos de U (231 - 569 ppm) e razões Th/U entre 0.27 e 0.67 , razões que são típicas de grãos de zircão ígneos. As análises foram executadas no interior dos cristais nos zoneamentos oscilatórios. Com 15 análises, que variaram entre $347 \mathrm{Ma} \mathrm{e}$ $356 \mathrm{Ma}$, a idade concórdia foi calculada em $352 \pm 2$ Ma, com valor de MSWD de 0.49, para esta população (Figura 120). Outras 3 análises, com idades individuais ${ }^{206} \mathrm{~Pb} /{ }^{238} \mathrm{U}$ de $339 \pm 4 \mathrm{Ma}, 342 \pm 5 \mathrm{Ma}, 362 \pm 5 \mathrm{Ma}$, também foram utilizadas para o cálculo da idade média desta população, que é $351 \pm 4$ Ma (Figura 119B).

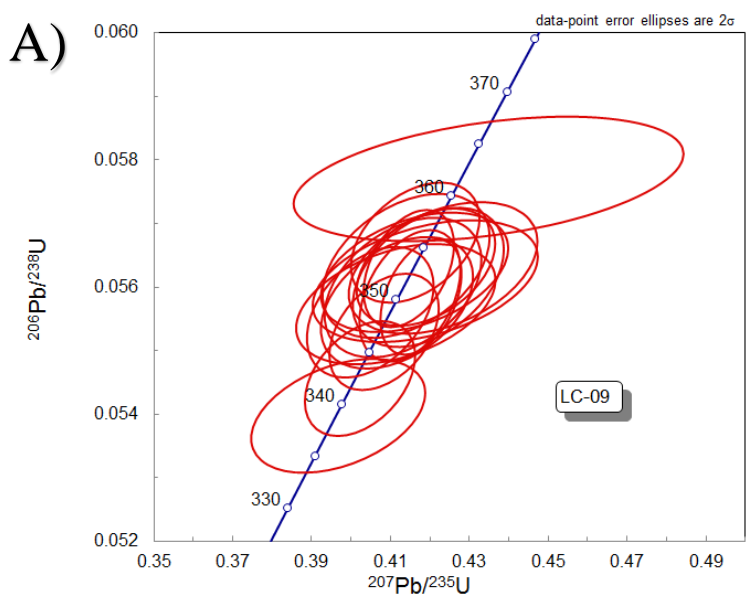

B)

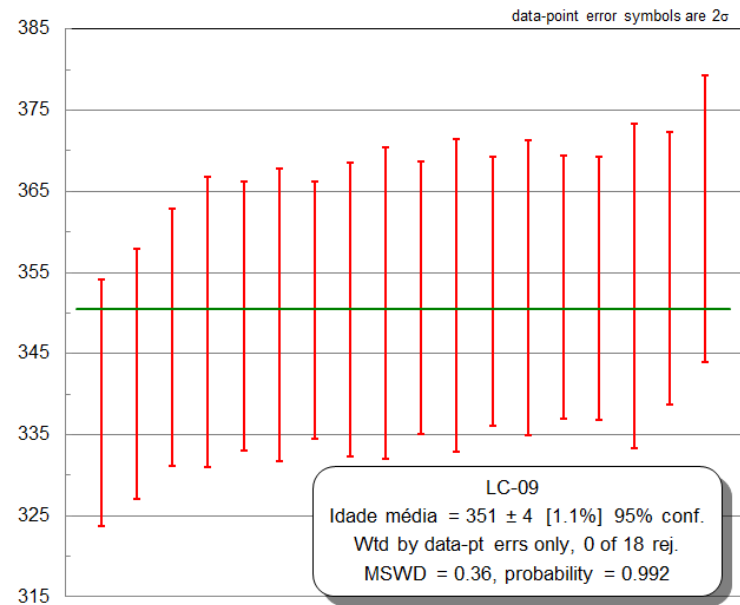

Figura 119. A) Dados de U-Pb e B) idade ${ }^{206} \mathrm{~Pb}^{238} \mathrm{U}$ média obtida na amostra LC-09 


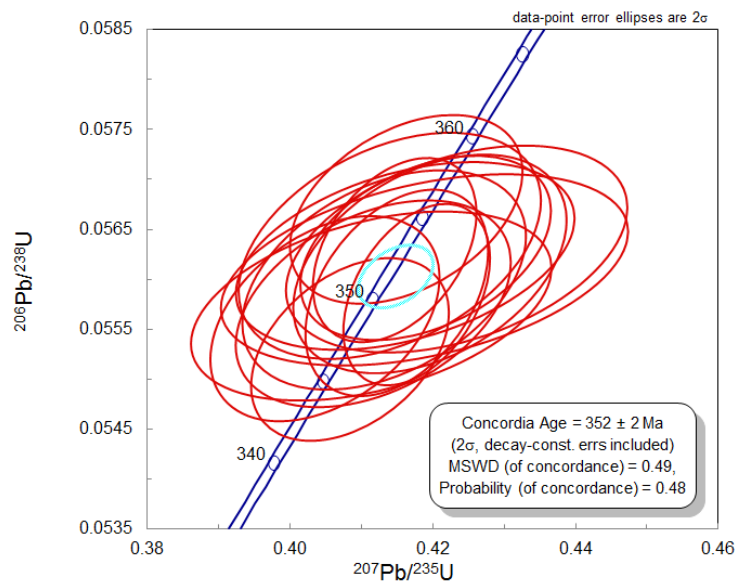

Figura 120. Idade concórdia obtida com a população de zircão da amostra LC-09

Nesta amostra os isótopos de Ti foram estudados por SHRIMP em 10 grãos de zircão que apresentaram uma razão média de ${ }^{50} \mathrm{Ti} /{ }^{49} \mathrm{Ti}$ de 0.97 , com conteúdo médio de ${ }^{49} \mathrm{Ti}$ de $8.3 \mathrm{ppm}$ e conteúdo médio de ${ }^{50} \mathrm{Ti}$ de $8.2 \mathrm{ppm}$. As temperaturas médias obtidas nestes 10 cristais analisados foram de $760 \pm 21^{\circ} \mathrm{C}$ no ${ }^{49} \mathrm{Ti}$ e $759 \pm 17^{\circ} \mathrm{C}$ no ${ }^{50} \mathrm{Ti}$ (Figura 121A).

Os isótopos de Lu-Hf foram estudados por LA-MC-ICPMS em 18 cristais de zircão. Os resultados obtidos mostram que os valores de ${ }^{176} \mathrm{Hf} /{ }^{177} \mathrm{Hf}_{\mathrm{o}}$ variam no intervalo de 0.282597 e 0.282503 , com os valores de $\varepsilon_{\mathrm{Hfo}}$ correspondentes variando entre -6.65 e -9.97, e com valor médio de $\varepsilon_{\mathrm{Hfo}}$ de -8.75 . Quando os dados de Hf são analisados em conjunto com a idade concórdia de $352 \mathrm{Ma}$ são obtidos valores iniciais de ${ }^{176} \mathrm{Hf} /{ }^{177} \mathrm{Hf}_{\mathrm{i}}$ variando entre 0.282596 e 0.282502 . Os valores de $\varepsilon_{\mathrm{Hfi}}$ correspondentes variam entre -5.9 e -9.22, com valores médios de $\varepsilon_{\mathrm{Hfi}}$ de -7.79 (Figura 121B). Os resultados individuais obtidos nas análises de U-Pb, Ti-em-zircão e Lu-Hf podem ser observadas na Figura 122. 
A)

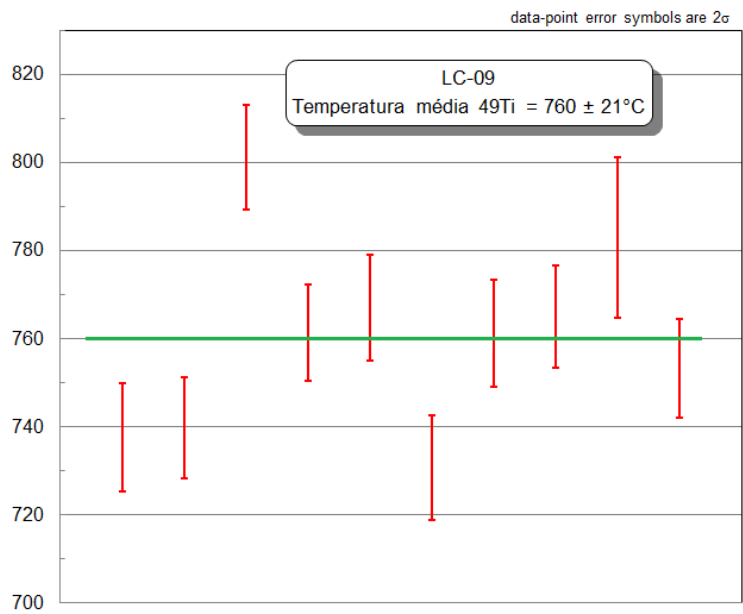

B)

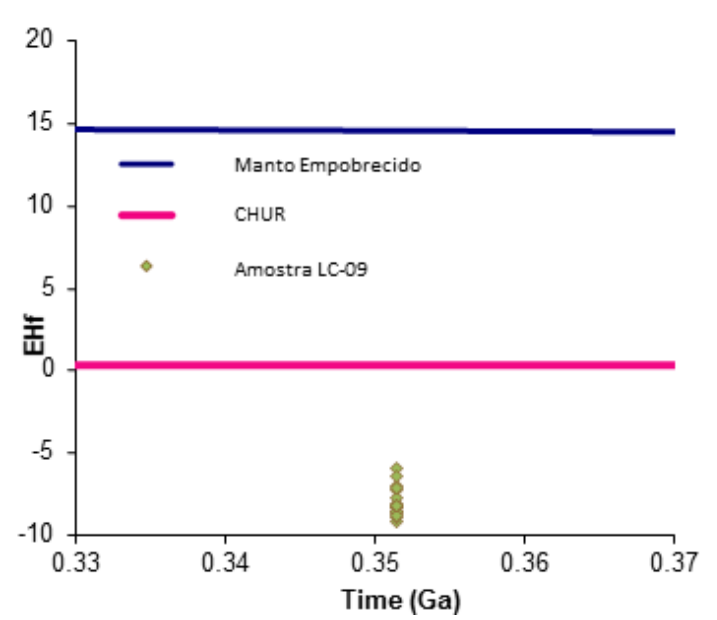

Figura 121. A) Temperaturas ${ }^{49}$ Ti e B) valores de $\varepsilon_{H f i}$ obtidos na amostra LC-09 


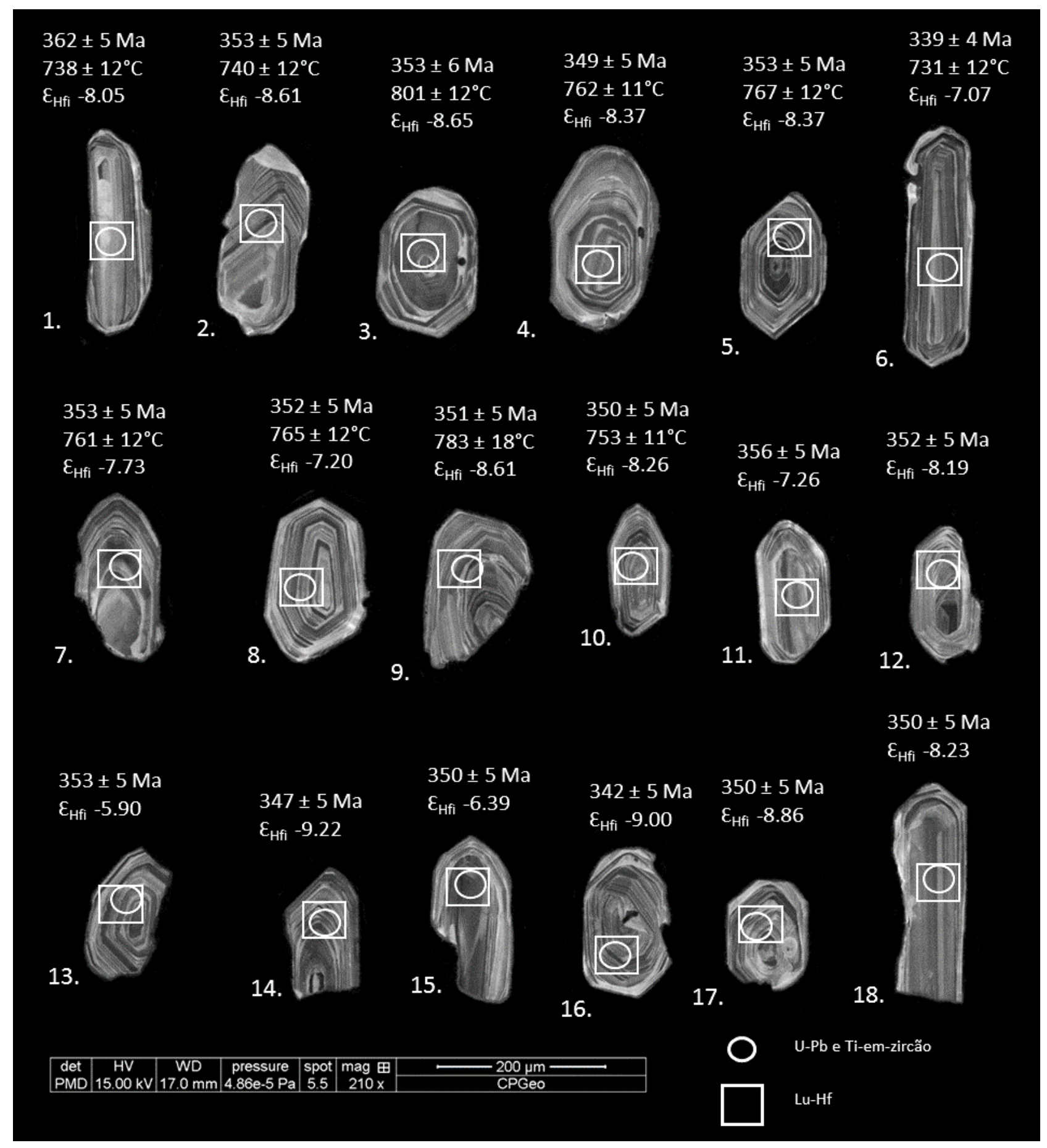

Figura 122. Resultados individuais obtidos nas análises de U-Pb, Ti-em-zircão e Lu-Hf executadas na população da amostra LC-09. 


\section{Gerena}

Os litotipos do Maciço de Gerena estudados representam um dos poucos afloramentos de rochas plutônicas conhecidas na FPI. A amostra GR-01 é um granodiorito que ocorre associado a enclaves tonalíticos, de onde a amostra GR-02 foi colhida. A população de zircão catalogada por CL em GR-01 é composta por cristais prismáticos, com comprimento variando entre 100 e $400 \mu \mathrm{m}$. Os zoneamentos oscilatórios são sutis na maioria dos grãos de zircão. Nesta população núcleos herdados estão presentes em alguns dos cristais, enquanto que bordas reabsorvidas são comuns como um todo.

Os isótopos de U-Pb do granodiorito representado pela amostra GR-01 foram analisados por SHRIMP com 19 análises em 18 cristais de zircão. As análises são caracterizadas por uma grande variação nos conteúdos de U (379 - 1132 ppm) e razões Th/U entre 0.14 e 0.91, razões típicas de cristais ígneos. Em um diagrama concórdia 14 análises, com idades individuais ${ }^{206} \mathrm{~Pb} /{ }^{238} \mathrm{U}$ entre $337 \mathrm{Ma}$ e $359 \mathrm{Ma}$, definiram uma idade concórdia de $349 \pm 2 \mathrm{Ma}$, com valor de MSWD de 0.071 Figura 123). Outras análises, 3 apresentaram teores de $\mathrm{Pb}$ comum elevados ( $\mathrm{Pb}$ comum $>2 \%$ nesta amostra), e foram descartadas. Nesta população dois núcleos herdados foram datados e apresentam idades ${ }^{206} \mathrm{~Pb} /{ }^{238} \mathrm{U}$ de $1583 \pm 21 \mathrm{Ma}, 639 \pm 7 \mathrm{Ma}$, sendo o zircão que possui núcleo de $1583 \pm 21$ Ma possui borda de $334 \pm 4$ Ma e ambas análises apresentam teores de $\mathrm{Pb}$ comum $>2 \%$. Outro xenocristal apresentou idade individual ${ }^{206} \mathrm{~Pb} /{ }^{238} \mathrm{U}$ de $571 \pm 7 \mathrm{Ma}$.
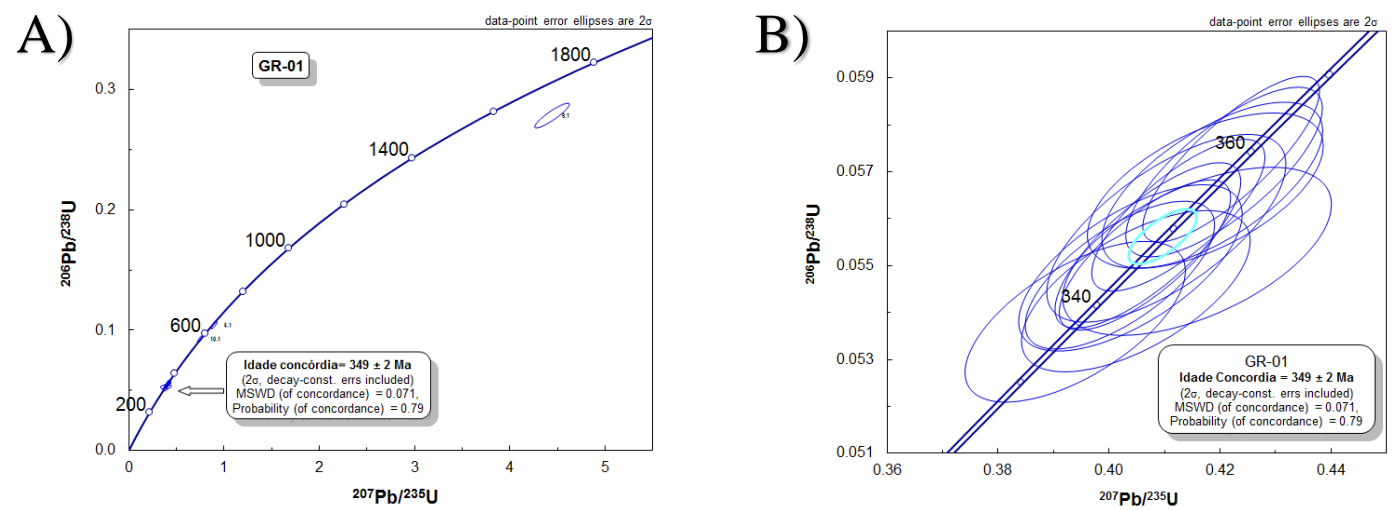

Figura 123. A) todos os dados de U-Pb obtidos nesta amostra e B) idade concórdia obtida a partir dos cristais de zircão de GR-01.

As análises isotópicas de Ti foram efetuadas por SHRIMP em 18 grãos de zircão da população de GR-01. Nesta população 14 análises apresentaram razão média de ${ }^{50} \mathrm{Ti} /{ }^{49} \mathrm{Ti}$ de 0.97 , com conteúdo médio de ${ }^{49} \mathrm{Ti}$ de $7.5 \mathrm{ppm}$ e conteúdo médio de ${ }^{50} \mathrm{Ti}$ de7.5 
ppm. As temperaturas médias obtidas foram de $745 \pm 43^{\circ} \mathrm{C}$ no ${ }^{49} \mathrm{Ti}$ e $744 \pm 46^{\circ} \mathrm{C}$ no ${ }^{50} \mathrm{Ti}$ (Figura 124A). Uma das análises apresentou razão ${ }^{50} \mathrm{Ti} /{ }^{49} \mathrm{Ti}$ de 0.89 e foi descarta, outras 3 apresentaram enriquecimento em Ti e também foram descartadas.

A análise dos isótopos de Lu-Hf foi feita por LA-MC-ICPMS em 13 grãos de zircão. Destas, 12 análises apresentaram a razão de ${ }^{176} \mathrm{Hf} /{ }^{177} \mathrm{Hf}_{\mathrm{o}}$ variando no intervalo de 0.282741 e 0.282588 , com os valores de $\varepsilon_{\text {Hfo }}$ correspondentes variando entre -1.56 e 6.97, e com valor médio de -4.47. Quando os dados de Hf são analisados com a idade concórdia de $348 \mathrm{Ma}$ desta amostra foi obtido um valor de ${ }^{176} \mathrm{Hf} /{ }^{177} \mathrm{Hf}_{\mathrm{i}}$ variando entre 0.282737 e 0.282586 . Os valores de $\varepsilon_{\mathrm{Hfi}}$ correspondentes variam entre -0.91 e -6.25 , com valor médio de -3.77 (Figura 124B). Uma destas análises foi de um xenocristal Cadomiano e apresentou ${ }^{176} \mathrm{Hf} /{ }^{177} \mathrm{Hf}_{\mathrm{o}}$ de 0.282489 , com $\varepsilon_{\mathrm{Hfo}}$ de -10.47 . Utilizando a idade ${ }^{206} \mathrm{~Pb} /{ }^{238} \mathrm{U}$ de $571 \mathrm{Ma}$ o valor ${ }^{176} \mathrm{Hf} /{ }^{177} \mathrm{Hf}_{\mathrm{i}}$ é de 0.282487 , com $\varepsilon_{\mathrm{Hfi}}$ de -9.27 . Esses resultados individuais, bem como os resultados das análises de U-Pb e Ti-em-zircão via SHRIMP podem ser consultados na Figura 125.
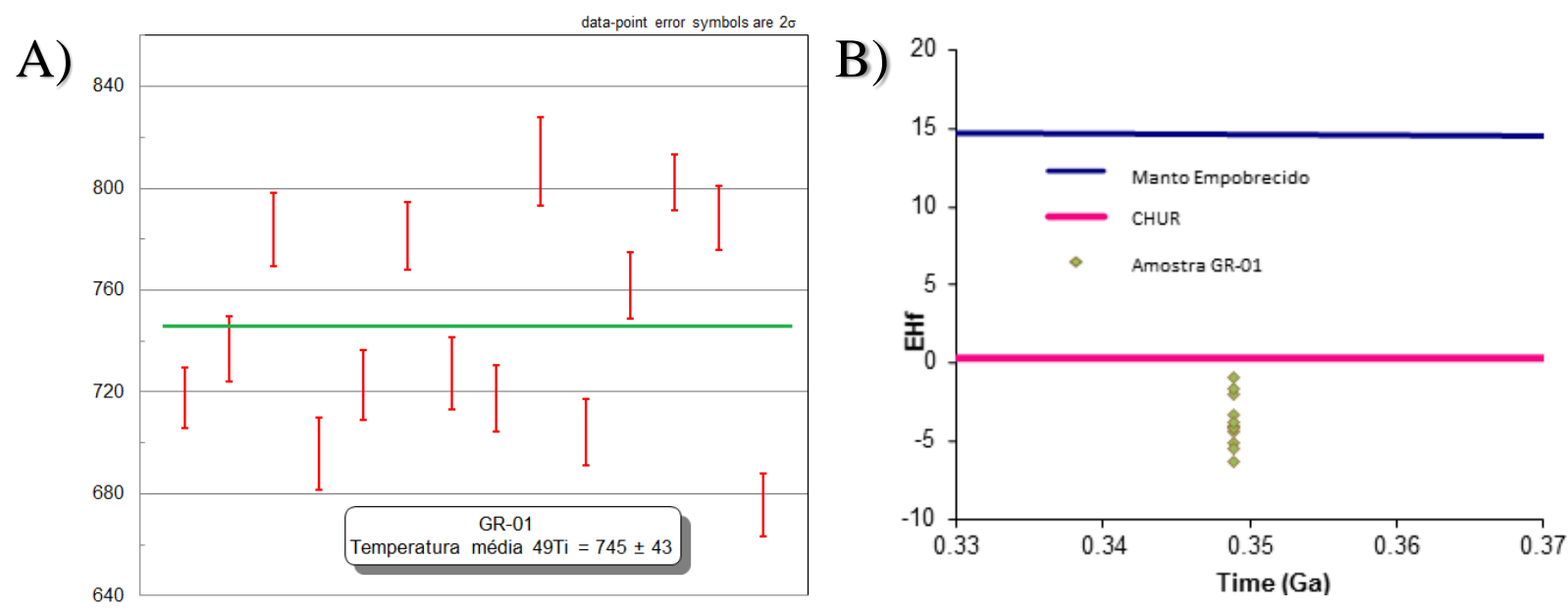

Figura 124. A) Temperaturas ${ }^{49}$ Ti e B) valores de $\mathcal{E}_{H f i}$ obtidos na população de zircão da amostra GR-01 


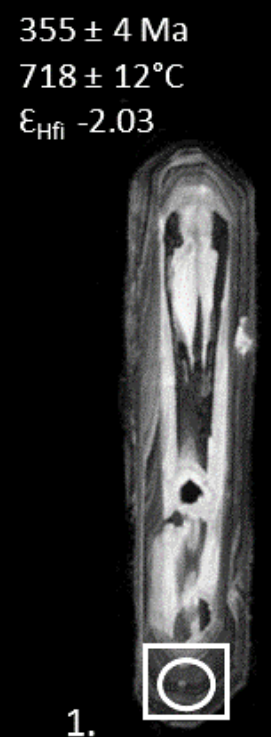

$350 \pm 5 \mathrm{Ma}$ $723 \pm 14^{\circ} \mathrm{C}$ $\varepsilon_{\mathrm{Hfi}}-4.04$

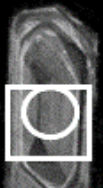

7.

$352 \pm 4 \mathrm{Ma}$ $781 \pm 13^{\circ} \mathrm{C}$ $\varepsilon_{\mathrm{Hfi}}-5.48$

8.

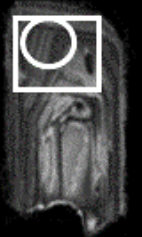

2.

3.

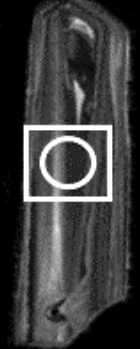

$338 \pm 4 \mathrm{Ma}$ $727 \pm 14^{\circ} \mathrm{C}$ $\varepsilon_{\mathrm{Hi}}-4.17$ $\varepsilon_{\mathrm{Hi}}-5.48$
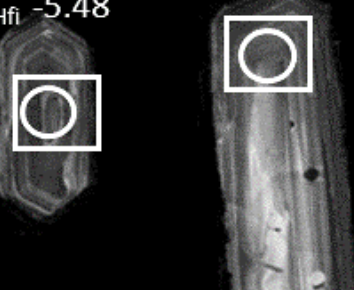

9.

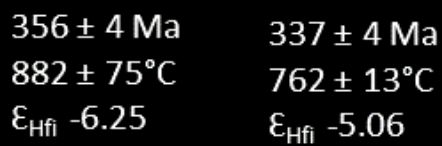

13.

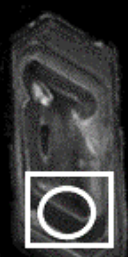

14.

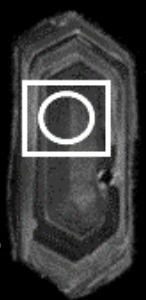

$344 \pm 4 \mathrm{Ma}$ $908 \pm 13^{\circ} \mathrm{C}$ $\varepsilon_{\mathrm{Hfi}}-3.26$
4.

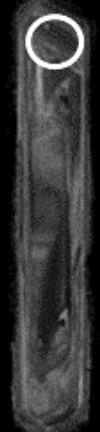

5.

$$
\begin{aligned}
& 350 \pm 5 \mathrm{Ma} \\
& 784 \pm 14^{\circ} \mathrm{C} \\
& \varepsilon_{\mathrm{Hfi}}-4.34
\end{aligned}
$$

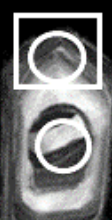

$639 \pm 7 \mathrm{Ma}$

$$
\begin{aligned}
& 571 \pm 7 \mathrm{Ma} \\
& 718 \pm 13^{\circ} \mathrm{C} \\
& \varepsilon_{\mathrm{Hfi}}-9.74
\end{aligned}
$$

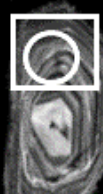

10.

$347 \pm 4 \mathrm{Ma}$
$810 \pm 17^{\circ} \mathrm{C}$
$\varepsilon_{\text {Hfi }}-0.91$

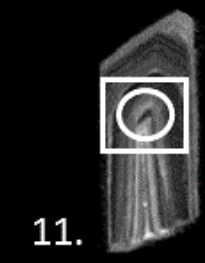

$802 \pm 11^{\circ} \mathrm{C}$
$342 \pm 4 \mathrm{Ma}$ $788 \pm 13^{\circ} \mathrm{C}$ $\varepsilon_{\mathrm{Hfi}}-3.83$

17.

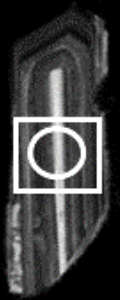

$359 \pm 4 \mathrm{Ma}$ $704 \pm 13^{\circ} \mathrm{C}$ $\varepsilon_{\mathrm{Hfi}}-4.19$

12.

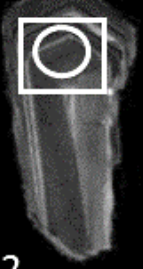

$348 \pm 4 \mathrm{Ma}$ $676 \pm 12^{\circ} \mathrm{C}$

$334 \pm 4 \mathrm{Ma}$ $696 \pm 14^{\circ} \mathrm{C}$

6.

$1582 \pm 21 \mathrm{Ma}$

18.

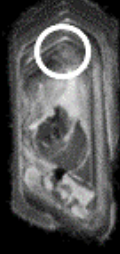

\begin{tabular}{c|c|c|c|c|c|c} 
det & HV & WD & pressure & spot & mag $⿴ 囗 十)$ & 300 $\mu \mathrm{m}$ \\
\cline { 2 - 5 } PMD & $15.00 \mathrm{kV}$ & $17.0 \mathrm{~mm}$ & $9.55 \mathrm{e}-5 \mathrm{~Pa}$ & 6.0 & $200 \mathrm{x}$ & CPGeo \\
\hline
\end{tabular}

U-Pb e Ti-em-zircão

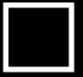

Lu-Hf

Figura 125. Imagens de CL da população de zircão da amostra GR-01 com os resultados individuais de cada análise plotados nos spots de cada análise. 
Na amostra GR-02 foram catalogadas duas populações de zircão distintas nas imagens de CL. Uma destas populações apresenta cristais claros subeuhedrais com faces arredondadas enquanto a outra população é escura e apresenta faces mais retas. A população clara apresenta cristais de zircão que variam entre 100 e $200 \mu \mathrm{m}$. Os cristais apresentam zoneamentos oscilatórios bem definidos, mas com pouca variação composicional. Diversos cristais desta população aparentam uma história complexa de cristalização, com núcleos e bordas. As bordas de alguns dos cristais são escuras, indicando um estágio posterior de cristalização. A outra população com cristais de zircão escuros apresenta cristais prismáticos que variam entre 150 e $300 \mu \mathrm{m}$. Estes cristais são escuros e não é possível ver zoneamento oscilatório neles. Algumas bordas desta população são esbranquiçadas, denotando alteração relacionada a alteração tardimagmática. Esta segunda população apresenta bordas mais reabsorvidas que a população de cristais claros.

Nessa amostra 22 cristais de zircão tiveram os isótopos de U-Pb analisados via SHRIMP, sendo que 8 são da população escura e 14 da população clara. Como as feições destas populações indicam estes cristais apresentam origens distintas:

(I população escura de autocristais de zircão e

(II população clara de xenocristais (Figura 126A).

Na população escura as análises são caracterizadas por uma pequena variação nos conteúdos de U (1842 - 2578 ppm) e razões Th/U entre 0.59 e 0.98, razões que são típicas de cristais de zircão ígneos. Nesta amostra 3 análises foram interrompidas pelo alto conteúdo de $\mathrm{Pb}$, além de apresentar outras 2 análises com teor elevado de $\mathrm{Pb}$ comum $(4.56 \%$ e $7.05 \%)$. Como foram obtidos poucos dados desta população estas duas análises com alto $\mathrm{Pb}$ comum foram utilizadas no cálculo de uma idade concórdia em conjunto com outras 3 análises com teores baixos de $\mathrm{Pb}$ comum. A idade concórdia obtida foi de $351 \pm$ 6 Ma (Figura 126B), com valor de MSWD de 0.059 a partir de 5 análises que variaram individualmente entre 363 Ma e 341 Ma.

A população de xenocristais claros apresentou análises caracterizadas por uma variação nos conteúdos de U entre 171 - 594 ppm e razões Th/U entre 0.19 e 0.58 , razões que são típicas de cristais de zircão ígneos. As 14 análises apresentaram idades ${ }^{207} \mathrm{~Pb} /{ }^{206} \mathrm{~Pb}$ variando entre $1888 \pm 9$ Ma e $2188 \pm 8$ Ma. Destas 14 análises, 7 apresentam teores de $\mathrm{Pb}$ comum elevado (nesta população $\mathrm{Pb}$ comum $>2 \%$ ), justamente as análises com idades 
inferiores a 2.0 Ga. Estas análises foram descartadas e com as outras 7 análises foi possível estabelecer uma idade ${ }^{207} \mathrm{~Pb} /{ }^{206} \mathrm{~Pb}$ média de $2163 \pm 14 \mathrm{Ma}$, com valor de MSWD de 4.9. Utilizando uma reta discórdia para levar em conta os cristais enriquecidos em $\mathrm{Pb}$ foi estabelecida uma reta com 2 interceptos com os dados desta população clara: o intercepto superior apresentou idade de $2195 \pm 7 \mathrm{Ma}$, enquanto que o intercepto inferior apresentou idade de $587 \pm 29$ Ma. Estas idades de intercepto da população clara apresentaram valor de MSWD de 1.3 (Figura 126C). Estas idades mostram que a população de xenocristais do tonalito é de idade Riaciana, em cerca de $2.2 \mathrm{Ga}$ e que esta população foi afetada pela Orogenia Cadomiana (650-500 Ma) que é representada pela idade de 587 Ma do intercepto inferior.
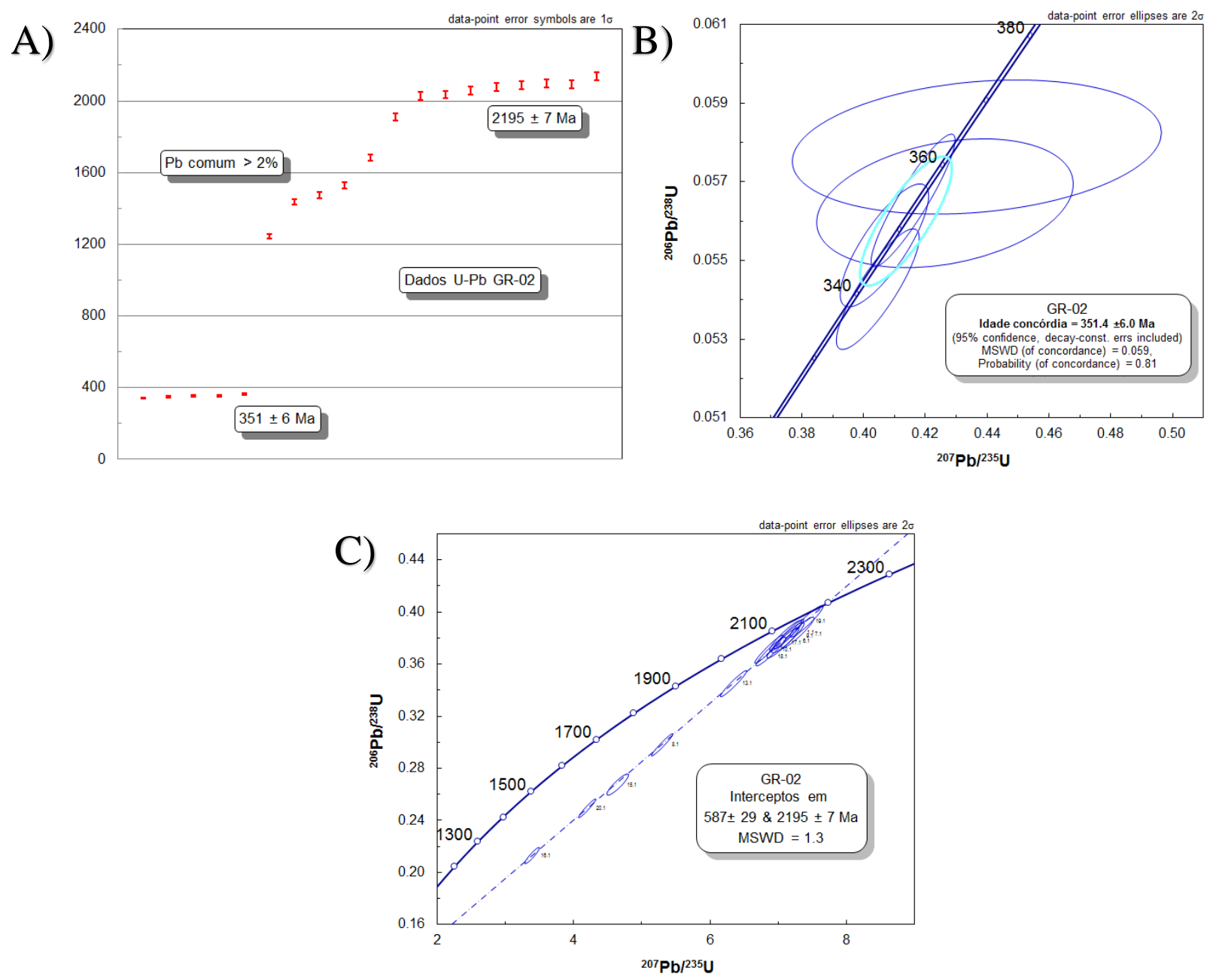

Figura 126. A) Todos os dados obtidos na amostra GR-02. B) Idade concórdia obtida com 5 autocristais desta população e C) idades da população de xenocristais 
Esta amostra apresenta duas populações distintas de cristais de zircão: uma população de xenocristais ( $2.2 \mathrm{Ga})$ e uma população de autocristais ( 351 Ma). Os isótopos de Ti foram estudados por SHRIMP em 8 cristais de zircão da população de autocristais e em 10 cristais da população de xenocristais. A população de autocristais apresentou 6 análises enriquecidas em Ti que tiveram que ser descartadas (conteúdo superior a $25 \mathrm{ppm}$ com alto conteúdo de $\mathrm{V}$ associado). As 2 análises restantes apresentaram a razão média de ${ }^{50} \mathrm{Ti} /{ }^{49} \mathrm{Ti}$ de 0.97 e conteúdo médio de ${ }^{49} \mathrm{Ti}$ de $6.9 \mathrm{ppm}$ e conteúdo médio de ${ }^{50} \mathrm{Ti}$ de $6.8 \mathrm{ppm}$. As temperaturas médias obtidas foram de $743 \pm 29^{\circ} \mathrm{C}$ no ${ }^{49} \mathrm{Ti}$ e $740 \pm 33^{\circ} \mathrm{C}$ no ${ }^{50} \mathrm{Ti}$.

Cinco análises da população de xenocristais apresentaram razão média de ${ }^{50} \mathrm{Ti} /{ }^{49} \mathrm{Ti}$ de 0.97 e conteúdo médio de ${ }^{49} \mathrm{Ti}$ de $9.1 \mathrm{ppm}$ e conteúdo médio de ${ }^{50} \mathrm{Ti}$ de $9.3 \mathrm{ppm}$. As temperaturas médias obtidas foram de $763 \pm 54^{\circ} \mathrm{C}$ no ${ }^{49} \mathrm{Ti}$ e $765 \pm 53^{\circ} \mathrm{C}$ no ${ }^{50} \mathrm{Ti}$. Outras 5 analises tiveram que ser excluídas por diversas razões: uma análise apresentou razão ${ }^{50} \mathrm{Ti} /{ }^{49} \mathrm{Ti}$ de 2.13 , outra apresentou razão ${ }^{50} \mathrm{Ti} /{ }^{49} \mathrm{Ti}$ de 0.84 , enquanto que as outras 3 análises foram excluídas por apresentarem conteúdo de $\mathrm{V}$ elevado.

Diversos cristais de zircão desta amostra foram perdidos quando o mount foi polido antes das análises isotópicas de Lu-Hf por LA-MC-ICPMS. A maioria dos xenocristais (que tendem a ser menores) foi perdida e essa população não foi estudada. A população de autocristais teve 8 grãos de zircão analisados. Os resultados obtidos mostram que os valores de ${ }^{176} \mathrm{Hf} /{ }^{177} \mathrm{Hf}_{\mathrm{o}}$ variam no intervalo de 0.282741 e 0.282627 , com os valores de $\varepsilon_{\mathrm{Hfo}}$ correspondentes variando entre -1.56 e -5.59 , e com valor médio de 4.22. Utilizando a idade concórdia de $351 \mathrm{Ma}$ os valores de ${ }^{176} \mathrm{Hf} /{ }^{177} \mathrm{Hf}_{\mathrm{i}}$ calculados variam entre 0.282737 e 0.282586 . Os valores de $\varepsilon_{\mathrm{Hfi}}$ correspondentes variam entre -0.91 e -4.89 , com valor médio de $\varepsilon_{\mathrm{Hfi}}$ de -3.52 (Figura 128). As análises individuais de U-Pb, Ti-emzircão e Lu-Hf efetuadas na amostra GR-02 e seus respectivos resultados se encontram plotados na Figura 130. Na Figura 129A e B todos os valores de $\varepsilon_{\mathrm{Hfi}}$ obtidos são apresentados em conjunto. 

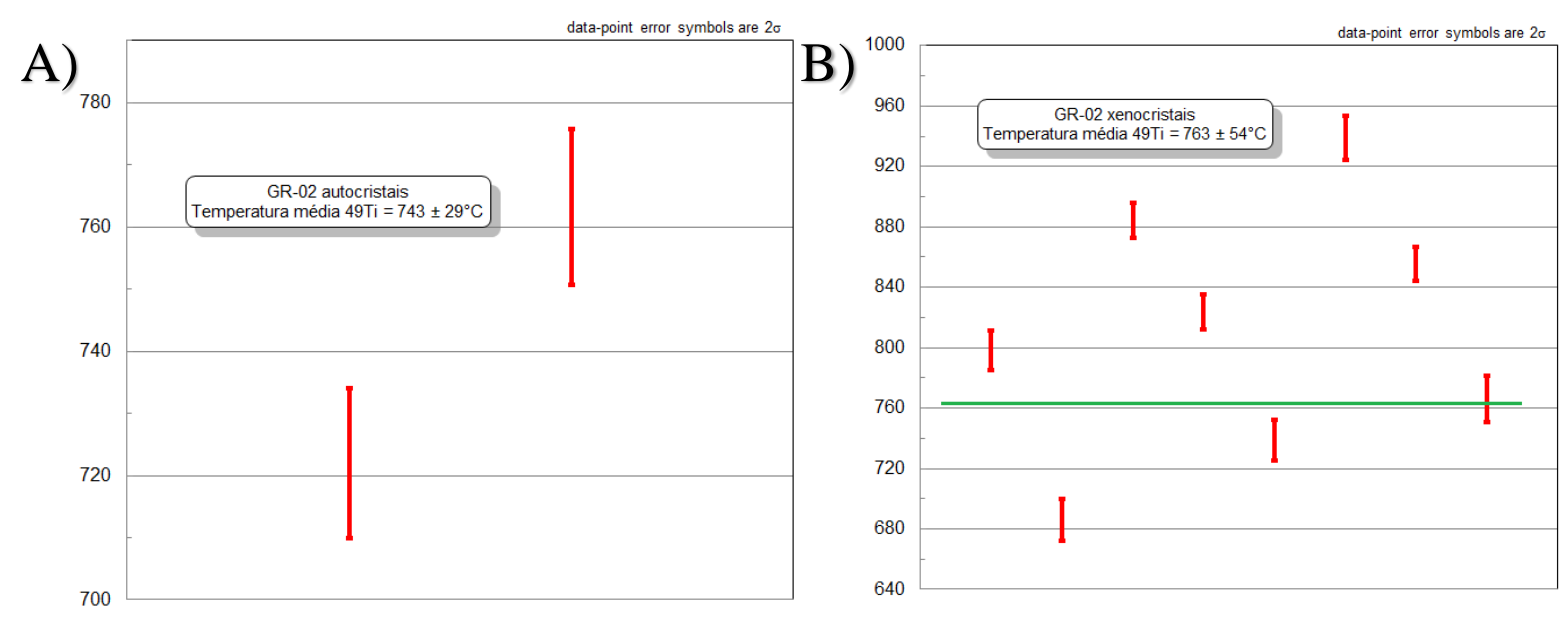

Figura 127. A) Temperaturas ${ }^{49}$ Ti obtidas nos autocristais e nos xenocristais da amostra GR-02.

B) valores de $\mathcal{E}_{H f i}$ obtidos na população de autocristais e C)

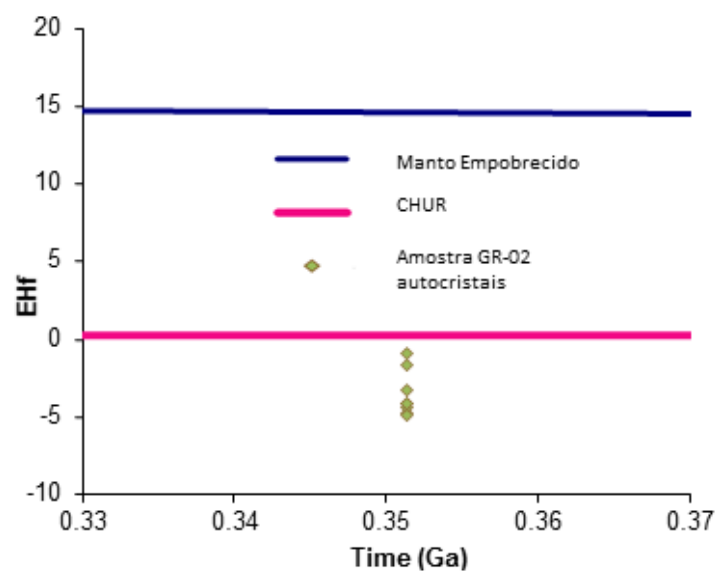

Figura 128. Assinatura de $\varepsilon_{H f}$ da população de autocristais de GR-02
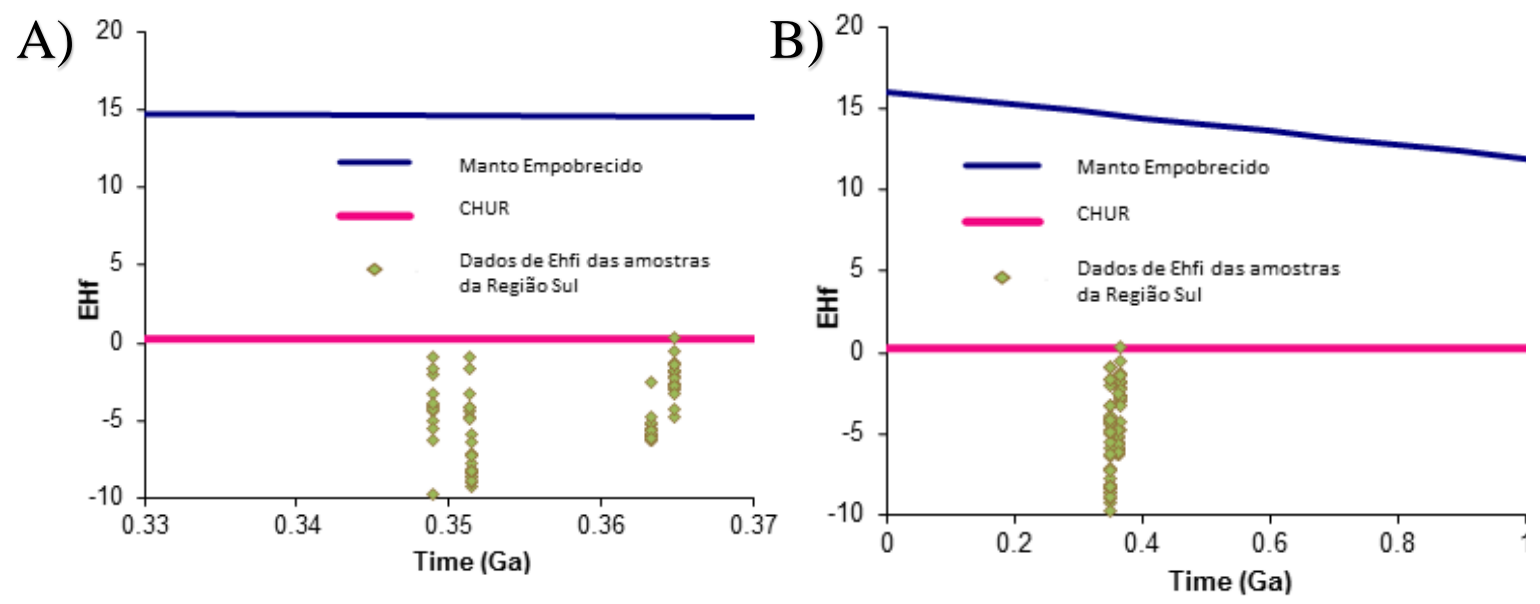

Figura 129. A) e B) apresentam os valores de $\varepsilon_{H f i}$ obtidos no Região Sul plotados na escala dos eventos geológicos regionais (0.33-0.37 Ga) e na escala geralmente utilizada em outros trabalhos (0.0- 


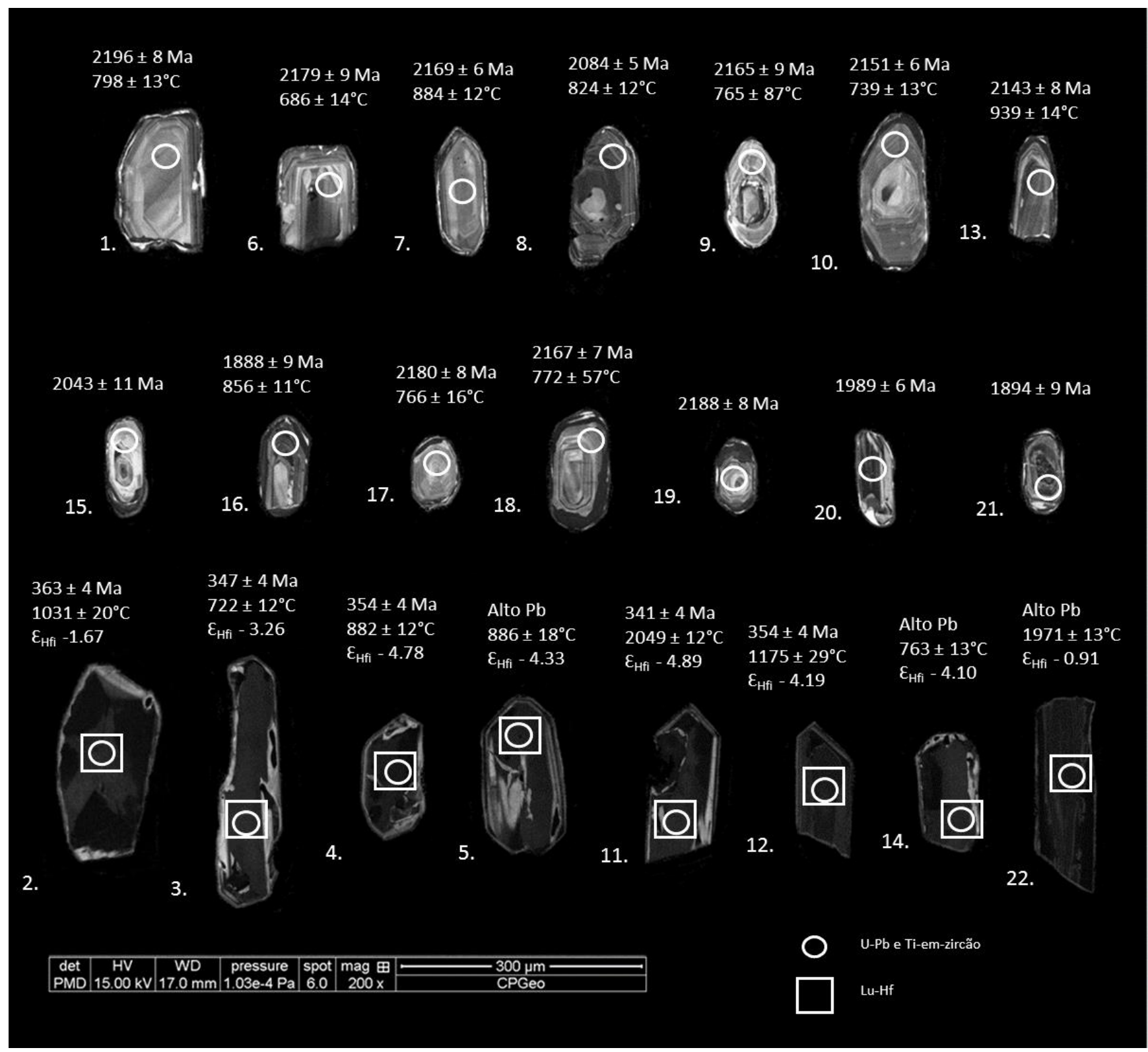

Figura 130. Populações de zircão da amostra GR-02 com os resultados individuais das análises de U-Pb, Ti-em-zircão e Lu-Hf plotados nos cristais de zircão.

As idades obtidas na Região Sul variam entre $365 \pm 2$ Ma e $348 \pm 1$ Ma quando todas as amostras estudadas são levadas em consideração. Entretanto, as idades das rochas vulcânicas associadas aos sulfetos maciços foram de $359 \pm 3$ para Las Cruces (LC-07) e $365 \pm 2$ para Tharsis (TH-04), que são idades do Struniano (Famenniano Superior). Em Las Cruces também foi obtida uma idade tardia de $352 \pm 2$ Ma em amostra de um domo de riodacito estéril distal a mineralização de sulfeto maciço.

As rochas plutônicas estudadas em Gerena também apresentam idades na faixa dos $350 \mathrm{Ma}$, com o granodiorito (GR-01) apresentando idade de $348 \pm 1$ Ma e o tonalito 
(GR-02) apresentando idade de $351 \pm 6$, além de uma população de xenocristais que registrou idade do intercepto superior de $2195 \pm 7$ Ma e idade do intercepto inferior de $587 \pm 29 \mathrm{Ma}$, o que indica que esta população de zircão foi gerada no Riaciano e possivelmente foi afetada ao longo da Orogenia Cadomiana.

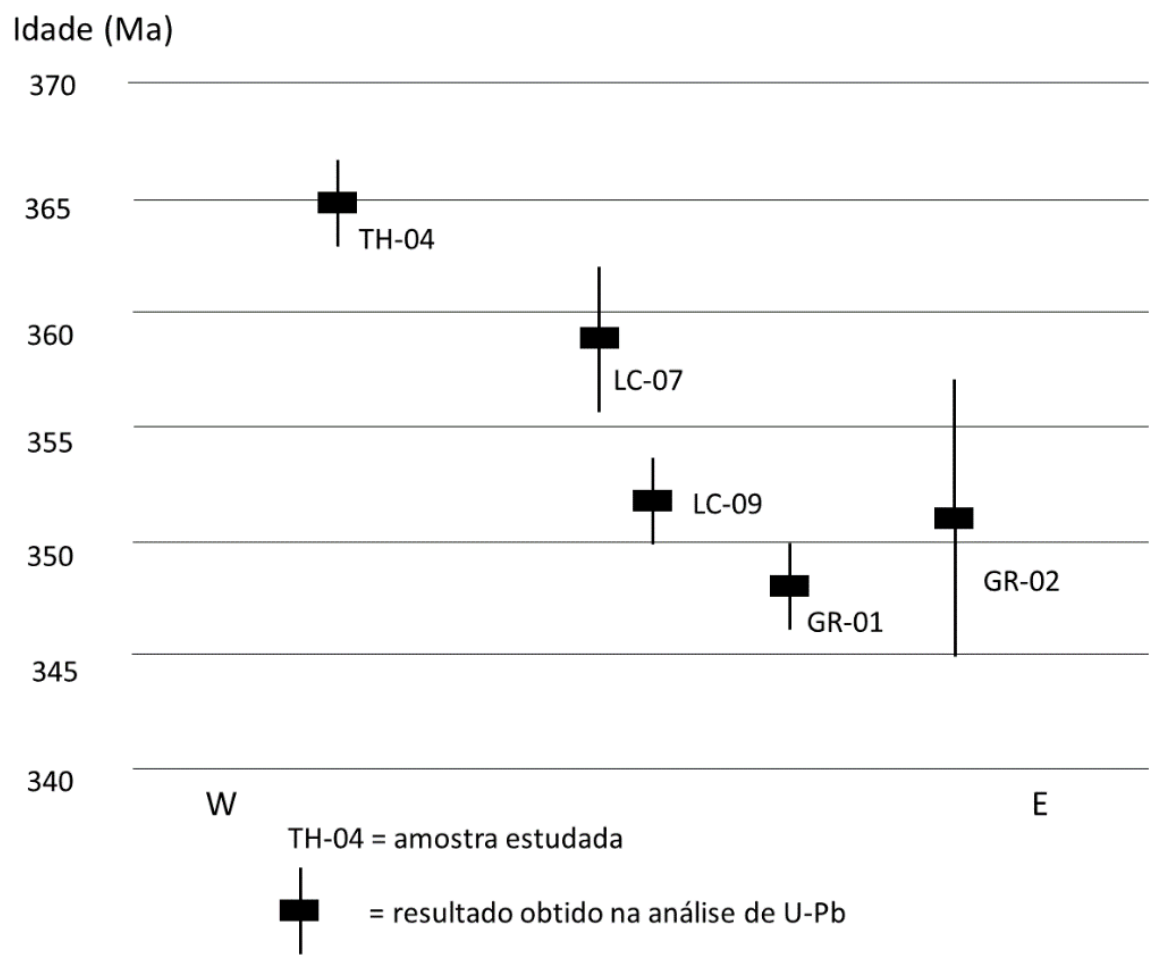

Figura 131. Régua de idades concórdia obtidas em dois depósitos, uma rocha estéril e duas rochas plutônicas da Região Sul

A Região Sul foi estudada em 5 amostras. As amostras relacionadas as mineralizações em de Tharsis (TH-04) e Las Cruces (LC-07), apresentaram temperaturas de $804^{\circ} \mathrm{C}$ e $836^{\circ} \mathrm{C}$ respectivamente. Outro corpo subvulcânico distal a mineralização foi estudado em Las Cruces (LC-09) e apresentou temperatura de $760^{\circ} \mathrm{C}$. As duas rochas plutônicas de Gerena (GR-01 e GR-02) apresentaram temperaturas de $743^{\circ} \mathrm{C}$ e $743^{\circ} \mathrm{C}$. A população de xenocristais Riacianos $(2.2 \mathrm{Ga})$ de GR-02 apresentou temperatura de $763^{\circ} \mathrm{C}$. Estas temperaturas inferiores a $800^{\circ} \mathrm{C}$ estão sempre relacionadas aos corpos Tournaisianos da Região Sul, enquanto que as temperaturas superiores a $800^{\circ} \mathrm{C}$ obtidas tanto neste trabalho como por Codeço et al. (2015) estão relacionadas aos corpos Strunianos (Famenniano Superior). 


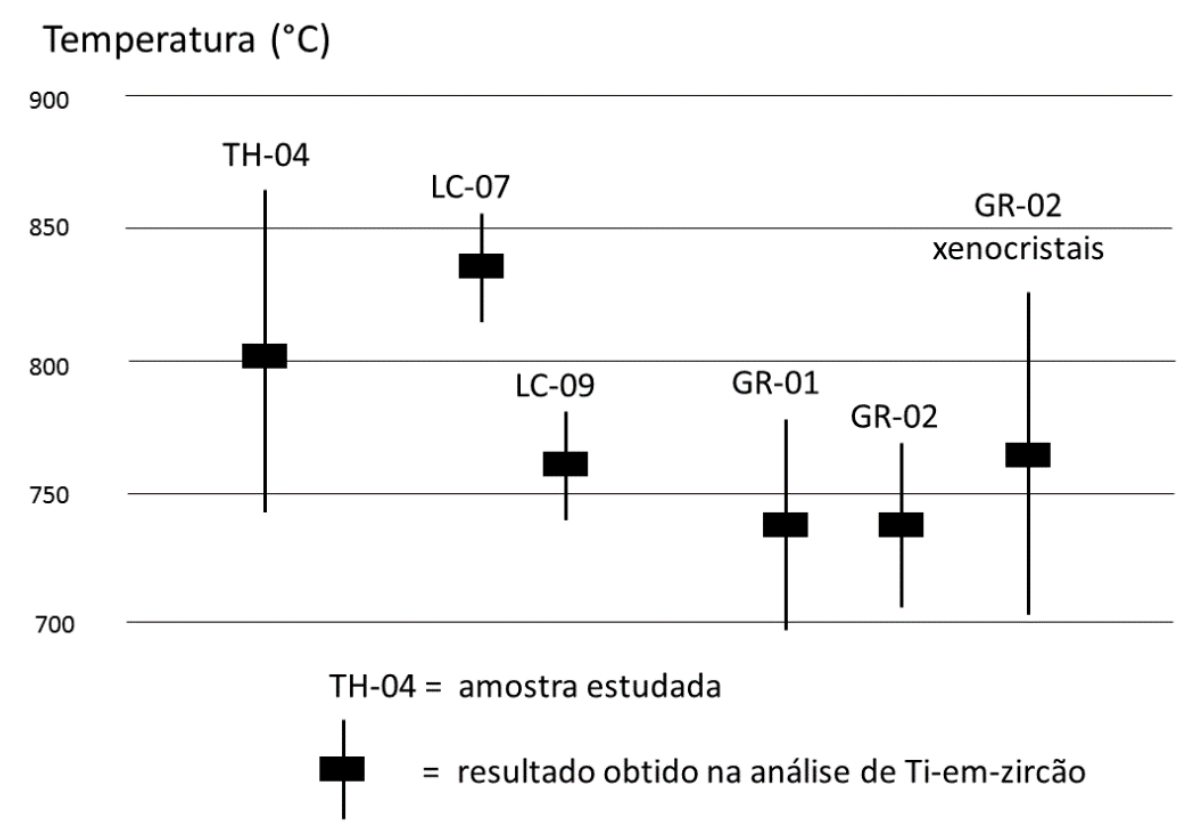

Figura 132. Temperaturas ${ }^{49}$ Ti obtidas nas amostras da Região Sul

As 5 amostras estudadas na Região $\mathrm{Sul}$ apresentam valores de $\varepsilon_{\mathrm{Hfi}}$ que variam entre -2.26 e -8.00 , com valor médio de -5.25 , valores mais crustais que mostram que a influência mantélica está restrita ao Cinturão Norte. Dos resultados obtidos na Região Sul chama a atenção a amostra LC-09 apresentar $\mathcal{E}_{\mathrm{Hfi}}$ de -8.00 enquanto as rochas plutônicas contemporâneas e geograficamente próximas do Maciço de Gerena (GR-01 e GR-02) apresentaram valores de $\varepsilon_{\mathrm{Hfi}} \mathrm{de}-4.23$ e -3.52 , indicando fonte crustal mais significativa.
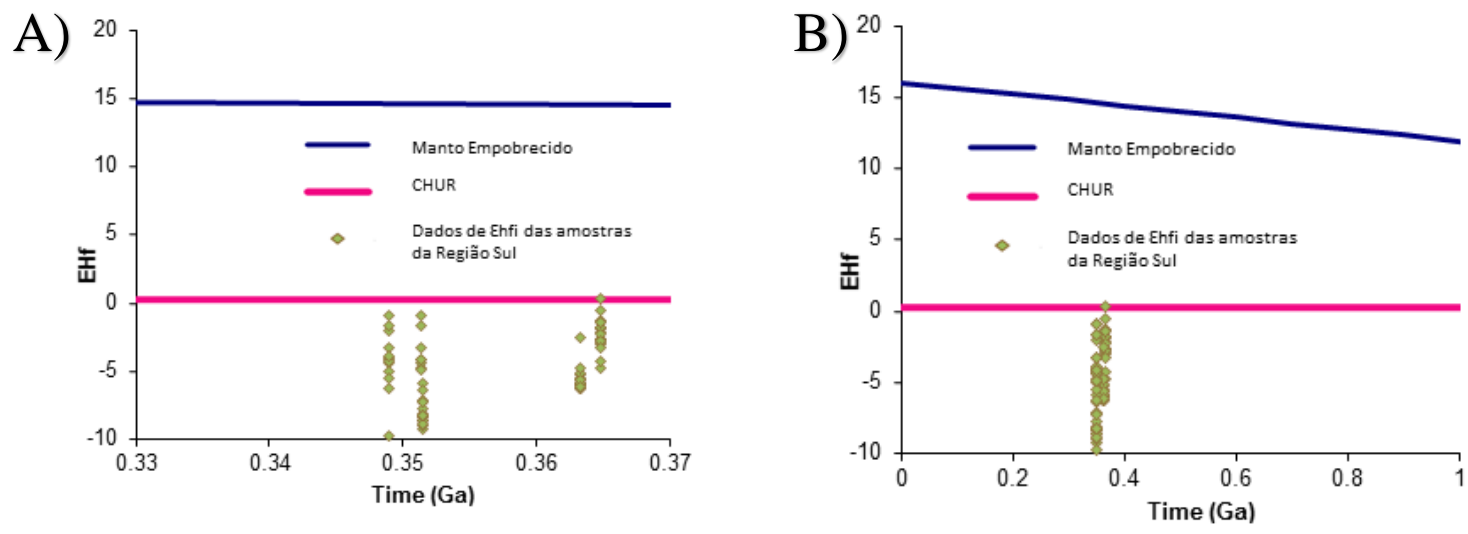

Figura 133. Valores de $\varepsilon_{H f i}$ obtidos na Região Sul da FPI, que são os valores mais negativos obtidos nesta tese

Nesta tese a geocronologia, a termometria e a origem das rochas vulcânicas do Complexo VS da Faixa Piritosa Ibérica espanhola foram analisadas em 23 amostras 
vulcânicas associadas aos corpos de sulfeto maciço, rochas estéreis vulcânicas e rochas plutônicas. Os resultados obtidos nas análises isotópicas de U-Pb, Ti e Lu-Hf em 23 amostras da FPI estão sintetizados na Tabela 4

Tabela 4. Síntese dos resultados isotópicos de U-Pb e Ti-em-zircão por SHIRMP e Lu-Hf por LAMC-ICPMS obtidos em cada amostra analisada nesta tese.

\begin{tabular}{|c|c|c|c|c|c|}
\hline Região & Depósito & Amostra & $\begin{array}{l}\text { Idade concórdia } \\
\text { (Ma) }\end{array}$ & $\begin{array}{c}\text { Ti-em- } \\
\text { zircão }\left({ }^{\circ} \mathrm{C}\right)\end{array}$ & $\mathrm{E}_{\mathrm{Hf}}$ \\
\hline \multirow{9}{*}{ 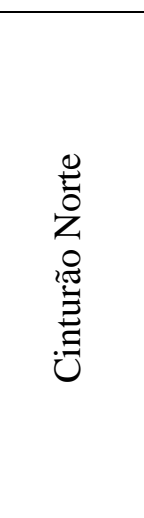 } & San Telmo & ST-01 & $347 \pm 2$ & $742 \pm 25$ & 3.28 \\
\hline & $\begin{array}{l}\text { Aguas } \\
\text { Tenidas }\end{array}$ & AT-01 & $352 \pm 3$ & $759 \pm 42$ & 0.01 \\
\hline & & AT-03 & $349 \pm 2$ & $737 \pm 40$ & -0.22 \\
\hline & Magdalena & MA-01 & $354 \pm 2$ & . & 1.98 \\
\hline & San Miguel & SM-12 & $353 \pm 2$ & $739 \pm 49$ & -0.63 \\
\hline & Concepcion & $\mathrm{CO}-04$ & $354 \pm 3$ & $731 \pm 22$ & -0.83 \\
\hline & San Platon & SP-03 & $338 \pm 3$ & $726 \pm 9$ & -2.07 \\
\hline & Solo Viejo & SV-01 & $349 \pm 2$ & $711 \pm 33$ & -4.54 \\
\hline & & SV-02 & $349 \pm 2$ & $740 \pm 16$ & 1.42 \\
\hline \multirow{10}{*}{ 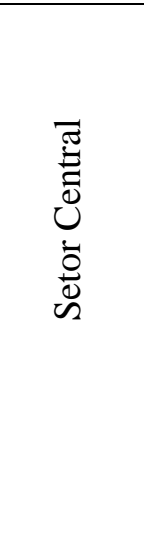 } & La Zarza & ZA-3 & $357 \pm 2$ & $729 \pm 13$ & -2.4 \\
\hline & & ZA-4 & $355 \pm 4$ & $746 \pm 39$ & -2.68 \\
\hline & Rio Tinto & RT-02 & $339 \pm 3$ & $712 \pm 29$ & -2.09 \\
\hline & & RT-02 & $352 \pm 3$ & $727 \pm 49$ & -3.25 \\
\hline & & RT-04 & $352 \pm 3$ & $715 \pm 54$ & -3.1 \\
\hline & & RT-05 & $348 \pm 3$ & $713 \pm 25$ & -7.04 \\
\hline & Zarandas & $\mathrm{ZN}-01$ & $358 \pm 2$ & $720 \pm 58$ & -2.96 \\
\hline & & $\mathrm{ZN}-02$ & $351 \pm 2$ & $692 \pm 49$ & -2.25 \\
\hline & Dacito El & AC-01 & $354 \pm 2$ & $775 \pm 31$ & -2.79 \\
\hline & Cerro & AC-02 & $352 \pm 2$ & $785 \pm 29$ & -2.59 \\
\hline \multirow{6}{*}{ 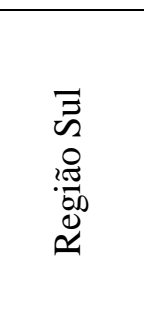 } & Tharsis & TH-04 & $365 \pm 2$ & $804 \pm 59$ & -2.26 \\
\hline & Las Cruces & LC-07 & $359 \pm 3$ & $836 \pm 21$ & -5.58 \\
\hline & & LC-09 & $352 \pm 2$ & $760 \pm 21$ & -8 \\
\hline & Gerena & GR-01 & $348 \pm 1$ & $743 \pm 42$ & -4.23 \\
\hline & & GR-02 & $351 \pm 6$ & $743 \pm 29$ & -3.52 \\
\hline & & GR-02 & $2195 \pm 7$ & $763 \pm 54$ & . \\
\hline
\end{tabular}


370

Idade (Ma)

365

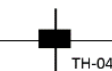

360

355

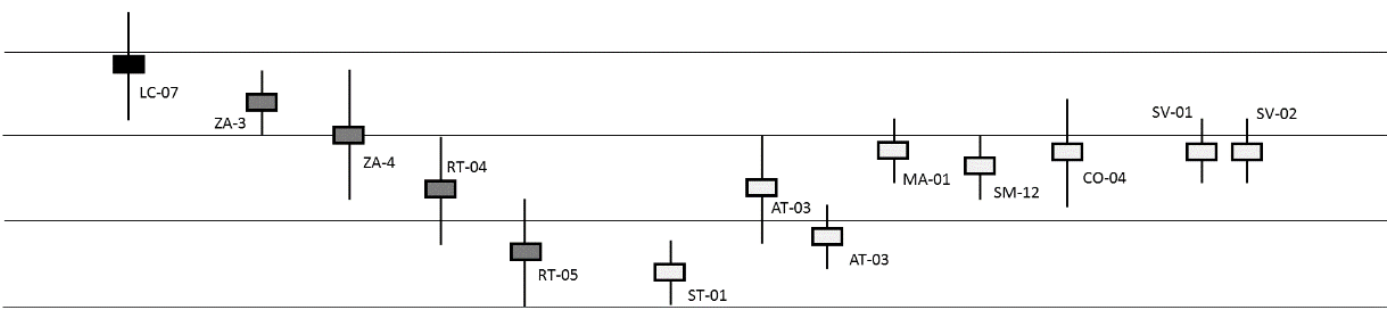

340

335

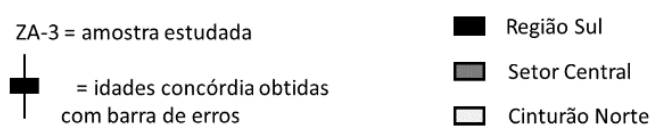

Figura 134. Idades concórdias obtidas nos depósitos de sulfeto maciço estudados tanto na Região Sul quanto na Região Norte e seus subsetores (Setor Central e Cinturão Norte). 
Idade (Ma)

365

360

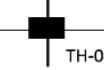

355

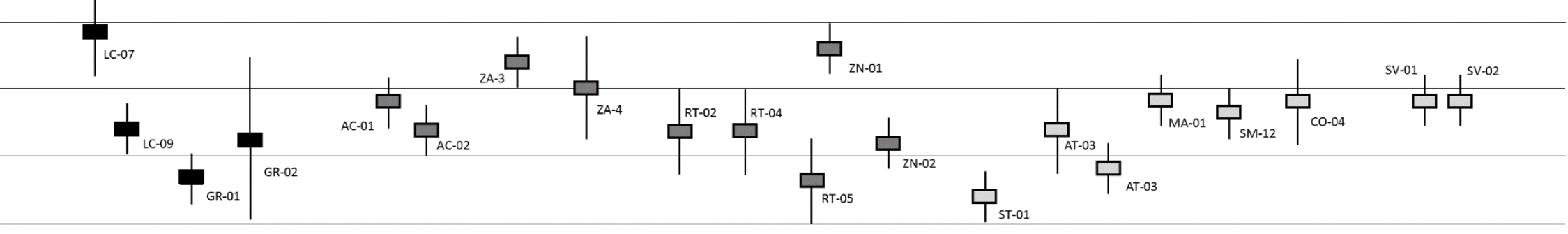

340

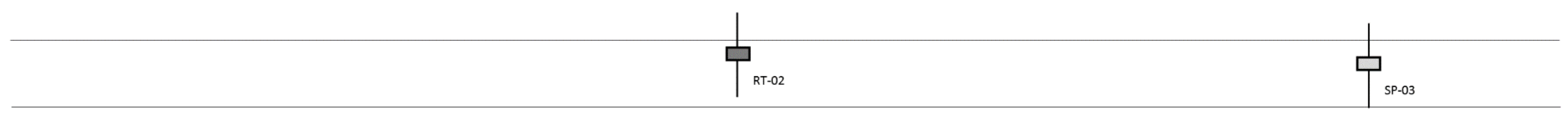

$\mathrm{ZA}-3=$ amostra estudada

1 = idades concórdia obtidas

- Região Sul

com barra de erros

$\square$ Setor Central

$\square$ Cinturão Norte

Figura 135. Idades concórdias obtidas nas análises U-Pb efetuadas. As diferentes regiões analisadas estão marcadas em cores diferentes. As rochas associadas as mineralizações de sulfeto maciço da Região Norte como um todo (Setor Central e Cinturão Norte) são formadas entre o intervalo de 355-347 Ma, idade Tournaisiana, enquanto que as rochas associadas as mineralizações de sulfeto maciço da Região Sul são mais antigas e estão associadas ao intervalo $365-359$ Ma, idade Struniana. 


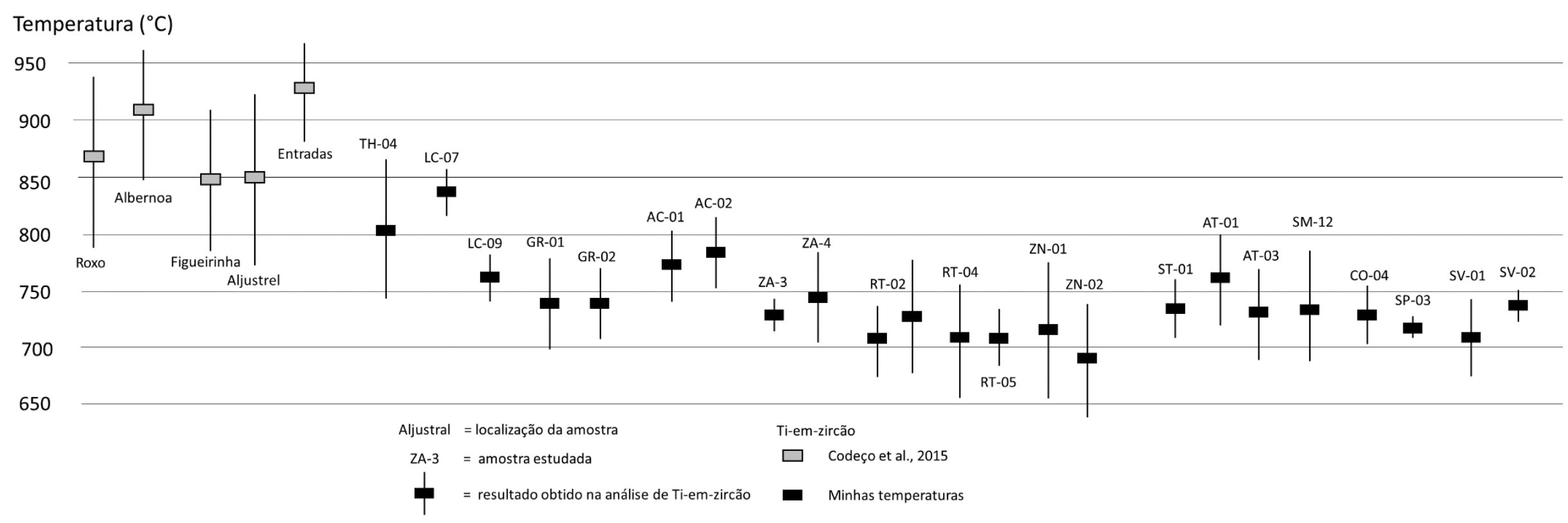

Figura 136. Todas as temperaturas de Ti-em-zircão e isótopos de Ti obtidas na FPI. As temperaturas desta tese foram obtidas na Espanha enquanto as temperaturas obtidas por Codeço et al. (2015) e Codeço et al. (2018) são de Portugal. 
Tabela 5. Resultados de Ti-em-zircão obtidos nas amostras estudadas nesta tese.

\begin{tabular}{|c|c|c|c|c|c|c|c|c|}
\hline Região & Amostra & $50 / 49$ médios & ${ }^{49} \mathrm{Ti}$ média (ppm) & ${ }^{50} \mathrm{Ti}$ média (ppm) & $\begin{array}{c}\text { T média }\left({ }^{\circ} \mathrm{C}\right) \\
{ }^{49} \mathrm{Ti}\end{array}$ & $2 \sigma$ & $\begin{array}{c}\text { T média }\left({ }^{\circ} \mathrm{C}\right) \\
{ }^{50} \mathrm{Ti}\end{array}$ & $2 \sigma$ \\
\hline \multirow{8}{*}{ 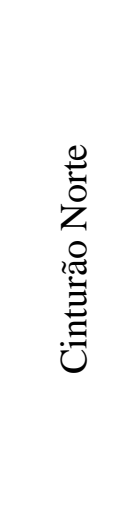 } & ST-01 & 0.962 & 6.89 & 6.65 & 742 & 25 & 739 & 23 \\
\hline & AT-01 & 0.95 & 8.57 & 8.61 & 759 & 42 & 759 & 42 \\
\hline & AT-03 & 0.95 & 6.737 & 6.41 & 737 & 40 & 734 & 35 \\
\hline & SM-12 & 0.96 & 7.3 & 7.6 & 739 & 49 & 741 & 54 \\
\hline & $\mathrm{CO}-04$ & 0.961 & 6.1 & 6 & 731 & 22 & 729 & 21 \\
\hline & SP-03 & 0.96 & 5.7 & 5.5 & 726 & 9 & 724 & 5 \\
\hline & SV-01 & 0.949 & 5.02 & 5.09 & 711 & 33 & 713 & 31 \\
\hline & SV-02 & 0.969 & 6.62 & 6.66 & 740 & 16 & 741 & 13 \\
\hline \multicolumn{9}{|c|}{ Temperatura ${ }^{49} \mathrm{Ti}$ média Cinturão Norte $=736 \pm 30^{\circ} \mathrm{C}$} \\
\hline \multirow{9}{*}{ 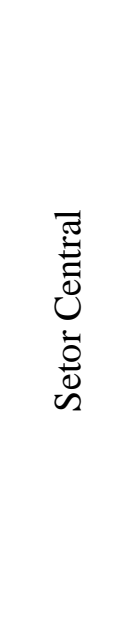 } & $\mathrm{ZA}-3$ & 0.96 & 6 & 6.1 & 729 & 13 & 730 & 11 \\
\hline & $\mathrm{ZA}-4$ & 0.951 & 7.46 & 7.34 & 746 & 39 & 745 & 37 \\
\hline & RT-02 (339) & 0.954 & 4.99 & 4.91 & 712 & 29 & 717 & 35 \\
\hline & RT-02 (350) & 0.971 & 5.78 & 5.88 & 727 & 49 & 727 & 54 \\
\hline & RT-04 & 0.9625 & 5.77 & 5.39 & 715 & 54 & 712 & 48 \\
\hline & RT-05 & 0.958 & 5.04 & 4.96 & 713 & 25 & 712 & 25 \\
\hline & $\mathrm{ZN}-01$ & 0.974 & 4.81 & 4.87 & 720 & 58 & 720 & 55 \\
\hline & $\mathrm{ZN}-02$ & 0.977 & 4.35 & 4.43 & 692 & 49 & 693 & 50 \\
\hline & AC-01 & 0.949 & 11.17 & 10.97 & 775 & 31 & 773 & 32 \\
\hline
\end{tabular}


$\mathrm{AC}-02$

0.951

10.8

10.65

785

29

784

27

Temperatura ${ }^{49} \mathrm{Ti}$ média Setor Central associado a sulfetos maciços $=720 \pm 38^{\circ} \mathrm{C}$

Temperatura ${ }^{49} \mathrm{Ti}$ média Setor Central regional $=780 \pm 30^{\circ} \mathrm{C}$

\begin{tabular}{|c|c|c|c|c|c|c|c|c|}
\hline Região & Amostra & 50/49 médios & ${ }^{49} \mathrm{Ti}$ média (ppm) & ${ }^{50} \mathrm{Ti}$ média (ppm) & $\begin{array}{c}\mathrm{T} \text { média }\left({ }^{\circ} \mathrm{C}\right) \\
{ }^{49} \mathrm{Ti}\end{array}$ & $2 \sigma$ & $\begin{array}{c}\mathrm{T} \text { média }\left({ }^{\circ} \mathrm{C}\right) \\
{ }^{50} \mathrm{Ti}\end{array}$ & $2 \sigma$ \\
\hline \multirow{6}{*}{ 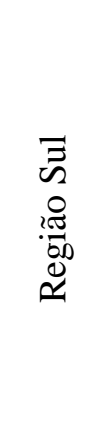 } & TH-04 & 0.962 & 14.08 & 14.33 & 804 & 59 & 806 & 59 \\
\hline & LC-07 & 0.96 & 16.1 & 16.4 & 836 & 21 & 836 & 22 \\
\hline & LC-09 & 0.969 & 8.28 & 8.16 & 760 & 21 & 759 & 17 \\
\hline & GR-01 & 0.959 & 7.5 & 7.5 & 743 & 42 & 742 & 45 \\
\hline & $\begin{array}{c}\text { GR-02 } \\
(350)\end{array}$ & 0.97 & 6.89 & 6.78 & 743 & 29 & 740 & 33 \\
\hline & $\begin{array}{c}\text { GR-02 } \\
(2 \mathrm{Ga})\end{array}$ & 0.97 & 9.14 & 9.32 & 763 & 54 & 765 & 53 \\
\hline
\end{tabular}

Temperatura ${ }^{49} \mathrm{Ti}$ média Região Sul associado a sulfetos maciços $=820 \pm 40^{\circ} \mathrm{C}$

Temperatura ${ }^{49} \mathrm{Ti}$ média Setor Central $=749 \pm 37^{\circ} \mathrm{C}$ 
Tabela 6. Resultados obtidos nas análises de U-Pb e Lu-Hf nas amostras estudadas nesta tese.

\begin{tabular}{|c|c|c|c|c|c|c|c|c|c|c|c|c|c|c|}
\hline \multirow{2}{*}{ Região } & \multirow{2}{*}{ Amostra } & \multirow{2}{*}{$\begin{array}{c}\text { Idade } \\
\text { Concórdia } \\
\text { (Ma) }\end{array}$} & \multicolumn{3}{|c|}{ Valor atual ${ }^{176} \mathrm{Hf} /{ }^{177} \mathrm{Hf}$} & \multicolumn{3}{|c|}{$\varepsilon$ Hfo } & \multicolumn{3}{|c|}{${ }^{176} \mathrm{Hf} /{ }^{177} \mathrm{Hf}$ inicial } & \multicolumn{3}{|c|}{$\varepsilon \mathrm{Hfi}$} \\
\hline & & & Máx & $\min$ & Média & máx & $\min$ & média & máx & $\min$ & Média & $\max$ & $\min$ & média \\
\hline \multirow{9}{*}{ 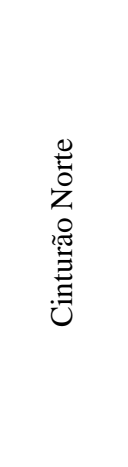 } & ST-01 & 347 & 0.282895 & 0.282823 & 0.282857 & 3.89 & 1.34 & 2.55 & 0.282893 & 0.282822 & 0.282856 & 4.59 & 2.08 & 3.28 \\
\hline & AT-01 & 352 & 0.282795 & 0.282698 & 0.282765 & 0.35 & -3.08 & -0.71 & 0.282793 & 0.282697 & 0.282697 & 1.07 & -2.33 & 0.01 \\
\hline & AT-03 & 350 & 0.282866 & 0.282630 & 0.282759 & 2.86 & -5.48 & -0.93 & 0.282863 & 0.282628 & 0.282757 & 3.55 & -4.77 & -0.22 \\
\hline & MA-01 & 354 & 0.282886 & 0.282744 & 0.28282 & 3.57 & -1.45 & 1.24 & 0.282884 & 0.282743 & 0.282819 & 4.3 & -0.71 & 1.98 \\
\hline & SM-12 & 353 & 0.282815 & 0.282691 & 0.282746 & 1.06 & -3.32 & -1.36 & 0.282813 & 0.28269 & 0.282745 & 1.76 & -2.58 & -0.63 \\
\hline & $\mathrm{CO}-04$ & 354 & 0.282883 & 0.282703 & 0.282785 & 3.47 & -2.9 & -0.02 & 0.282881 & 0.282701 & 0.282784 & 4.18 & -2.18 & -0.83 \\
\hline & SP-03 & 338 & 0.282737 & 0.282684 & 0.282707 & -1.7 & -3.57 & -2.78 & 0.282735 & 0.282684 & 0.282705 & -1 & -2.87 & -2.07 \\
\hline & SV-01 & 349 & 0.282821 & 0.282485 & 0.282636 & 1.27 & -10.61 & -5.27 & 0.282818 & 0.282484 & 0.282635 & 1.95 & -9.87 & -4.54 \\
\hline & SV-02 & 349 & 0.282815 & 0.282485 & 0.282805 & 1.06 & 0.18 & 0.7 & 0.282812 & 0.282484 & 0.282803 & 1.73 & 0.92 & 1.42 \\
\hline \multicolumn{2}{|c|}{ Média do Cinturão Norte* } & 350 & & & & & & -0.73 & & & & & & -0.18 \\
\hline \multirow{10}{*}{ 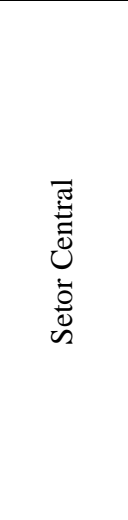 } & ZA-3 & 356 & 0.282727 & 0.282641 & 0.282696 & -2.05 & -5.09 & -3.14 & 0.282725 & 0.28264 & 0.282696 & -1.34 & -4.36 & -2.4 \\
\hline & ZA-4 & 355 & 0.282793 & 0.282645 & 0.282688 & 0.28 & -4.95 & -3.42 & 0.282791 & 0.282687 & 0.282687 & 1.01 & -4.21 & -2.68 \\
\hline & RT-02 & 339 & 0.282761 & 0.282669 & 0.282706 & -0.85 & -4.1 & -2.78 & 0.282759 & 0.282668 & 0.282705 & -0.18 & -3.39 & -2.09 \\
\hline & RT-02 & 352 & 0.282705 & 0.282655 & 0.282673 & -2.83 & -4.6 & -3.96 & 0.282704 & 0.282654 & 0.282672 & -2.13 & -3.87 & -3.25 \\
\hline & RT-04 & 352 & 0.28283 & 0.282562 & 0.282677 & -1.1 & -7.89 & -3.83 & 0.282827 & 0.282561 & 0.282675 & -0.38 & -7.14 & -3.1 \\
\hline & RT-05 & 348 & 0.282638 & 0.282526 & 0.282565 & -5.2 & -9.55 & -7.76 & 0.282636 & 0.282524 & 0.282564 & -4.48 & -8.81 & -7.04 \\
\hline & $\mathrm{ZN}-01$ & 358 & 0.28288 & 0.282531 & 0.28268 & 3.36 & -8.98 & -3.7 & 0.28287 & 0.28253 & 0.282679 & 4.05 & -8.22 & -2.96 \\
\hline & $\mathrm{ZN}-02$ & 350 & 0.282758 & 0.282635 & 0.282701 & -0.95 & -5.3 & -2.97 & 0.282756 & 0.282633 & 0.282699 & -0.26 & -4.57 & -2.25 \\
\hline & AC-01 & 354 & 0.282717 & 0.282645 & 0.282685 & -2.4 & -4.95 & -3.52 & 0.282715 & 0.282644 & 0.282684 & -1.69 & -4.21 & -2.79 \\
\hline & AC-02 & 352 & 0.282747 & 0.282669 & 0.282691 & -1.34 & -4.1 & -3.32 & 0.282745 & 0.282668 & 0.28269 & -0.64 & -3.36 & -2.59 \\
\hline \multicolumn{2}{|c|}{ Média Setor Central* } & 352 & & & & & & -3.99 & & & & & & -3.26 \\
\hline
\end{tabular}


Continuação da Tabela 5

\begin{tabular}{|c|c|c|c|c|c|c|c|c|c|c|c|c|c|c|}
\hline \multirow{2}{*}{ Região } & \multirow{2}{*}{ Amostra } & \multirow{2}{*}{$\begin{array}{c}\text { Idade } \\
\text { Concórdia } \\
(\mathrm{Ma}) \\
\end{array}$} & \multicolumn{3}{|c|}{ Valor atual ${ }^{176} \mathrm{Hf} /{ }^{177} \mathrm{Hf}$} & \multicolumn{3}{|c|}{$\varepsilon_{\mathrm{Hfo}}$} & \multicolumn{3}{|c|}{${ }^{176} \mathrm{Hf} /{ }^{177} \mathrm{Hf}$ inicial } & \multicolumn{3}{|c|}{$\varepsilon_{\mathrm{Hfi}}$} \\
\hline & & & Máx. & Min & Média & Máx. & Min & Média & Máx. & Min & Média & Max & Min & Média \\
\hline \multirow{5}{*}{ 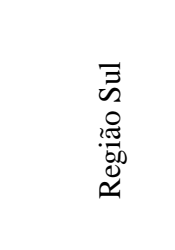 } & TH-04 & 365 & 0.282775 & 0.282631 & 0.2827 & -0.35 & -5.45 & -3.01 & 0.282773 & 0.282629 & 0.282698 & 0.4 & -4.69 & -2.26 \\
\hline & LC-07 & 359 & 0.282693 & 0.282586 & 0.282605 & -3.25 & -7.04 & -6.36 & 0.282693 & 0.282585 & 0.282604 & -2.46 & -6.25 & -5.58 \\
\hline & LC-09 & 352 & 0.282597 & 0.282503 & 0.282537 & -6.65 & -9.97 & -8.75 & 0.282596 & 0.282502 & 0.282536 & -5.9 & -9.22 & -8 \\
\hline & GR-01 & 348 & 0.282741 & 0.282588 & 0.282645 & -1.56 & -10.47 & -4.93 & 0.282737 & 0.282586 & 0.282643 & -0.91 & -9.74 & -4.23 \\
\hline & GR-02 & 351 & 0.282741 & 0.282627 & 0.282666 & -1.56 & -5.59 & -4.22 & 0.282737 & 0.282586 & 0.282664 & -0.91 & -4.89 & -3.52 \\
\hline \multicolumn{2}{|c|}{$\begin{array}{l}\text { Média relacionados a sulfetos } \\
\text { maciços }\end{array}$} & 362 & & & & & & -4.69 & & & & & & -4.71 \\
\hline \multicolumn{2}{|c|}{ Média Região Sul outros } & 350 & & & & & & -5.97 & & & & & & -5.25 \\
\hline
\end{tabular}

* desconsiderando SP-03 que é considerada posterior

** desconsiderando ZN-01 que não é considerada de outra unidade e população de autocristais de RT-02 


\section{DISCUSSÕES (chamar as imagens nas discussões)}

\subsection{MORFOLOGIA DOS CRISTAIS DE ZIRCÃO}

As populações de zircão estudadas nos diversos depósitos apresentam grande heterogeneidade em suas características morfológicas, mas todas as populações observadas são ígneas. Assim como Barrie et al. (2002) destaca na discussão sobre o trabalho de Nesbitt et al. (1999), não foram observadas populações de zircão hidrotermal.

Nesta tese 23 populações de zircão foram analisadas e as populações estudadas apresentam padrões distintos de zoneamento oscilatório que são característicos de grãos de zircão com origem magmática. Os zoneamentos oscilatórios presentes podem ser bem demarcados, mais sutis, sem grande diferença composicional ou praticamente ausente. Estas feições são indicativas de variações composicionais no ambiente em que as populações de zircão se cristalizaram.

A maioria das populações estudadas apresentaram poucas ou nenhuma herança visível na forma de núcleos herdados e somente uma amostra, o tonalito do Maciço de Gerena (GR-02), apresentou duas populações claramente distintas nas imagens de CL. Nesta amostra uma população é composta por pequenos cristais com bordas arredondadas e coloração clara e zoneamento oscilatório enquanto que a outra população é composta por cristais escuros de maior tamanho, sem zoneamento oscilatório visível e com faces sem arredondamento. Como a largura dos spots é muito superior a espessura das bandas individuais do zoneamento oscilatório, o resultado da geocronologia é uma aproximação que homogeneíza o período de cristalização em uma idade representativa da época de cristalização do zircão no magma.

Alterações tardi-magmáticas são comuns e afetam diversas análises, em especial a rocha vulcânica encaixante em Las Cruces (LC-07), mas em menor escala na grande maioria das populações estudadas. Em diversas populações de zircão estas alterações podem ser observadas em bordas esbranquiçadas dos cristais de zircão ou mesmo no interior dos cristais. Diversos cristais de zircão apresentam annealing em torno de suas inclusões minerais, o que indica troca e reequilíbrio químico entre as inclusões e os cristais de zircão (Corfu et al., 2003). Estas inclusões com annealing ocorrem tanto em amostras de depósitos da Região Norte como da Região Sul. Diversos cristais também apresentam danos internos a suas estruturas relacionados a metamitização. 
A morfologia da amostra LC-07 é distinta das demais e apresenta características relacionadas a recristalização em alto grau metamórfico. Essa morfologia, em conjunto com as idades perturbadas obtidas indicam que, diferentemente do restante da FPI onde o grau metamórfico é mais baixo, a região de Las Cruces esteve exposta a um alto grau metamórfico ao longo da orogenia Variscana.

\subsection{IDADES NO CONTEXTO REGIONAL DA FPI}

Como citado ao longo do item 3.3, existem diversas datações U-Pb efetuadas na FPI (Nesbitt et al., 1999; Barrie et al., 2002; Rosa et al., 2009; Valenzuela et al., 2011; Solá et al., 2015). Entretanto estas datações não foram executadas de uma maneira representativa em toda a FPI e, com exceção da localidade de Rio Tinto, as rochas associadas aos depósitos da Região Norte da FPI não foram datadas por trabalhos anteriores. As demais idades previamente obtidas na FPI apontam para formação dos depósitos de sulfeto maciço no Struniano ( 362-359 Ma).

As idades obtidas nesta tese tanto no Cinturão Norte como no Setor Central da Região Norte da FPI mostram que o depósito de Rio Tinto não é uma exceção de idade Tournaisiana em uma província composta somente por depósitos do Struniano (Famenniano Superior), mas sim que a FPI é uma província com duas regiões formadas em idades distintas. A FPI é dividida entre a Região Sul, com depósitos associados a folhelhos e Região Norte com depósitos de sub-seafloor replacement em rochas vulcânicas félsicas. As idades de formação dos depósitos da Região Sul estão associadas ao Struniano enquanto que as idades obtidas nesta tese para os depósitos da Região Norte mostram que estes depósitos são Tournaisianos. O Cinturão Norte apresenta rochas vulcânicas com idades no intervalo de 354-347 Ma e no Setor Central o depósito de La Zarza possui idades entre 357 - 355 Ma enquanto que Rio Tinto tem idades relacionadas aos sulfetos maciços entre 352-348 Ma, todas idades Tournaisianas. Esta divisão entre dois intervalos temporais de magmatismo também é descrita em Neves Corvos por Solá et al. (2015), mas lá o vulcanismo Struniano está associado aos corpos de sulfeto maciço enquanto que o vulcanismo Tournaisiano é estéril.

Não existem idades palinológicas nesta região, com exceção da idade Tournaisiana observada nos folhelhos do Complexo VS em Rio Tinto (Pereira \& Gonzalez-Clavijo, 2007). Com exceção da Mina de Atalaya, em Rio Tinto, não são descritas outras mineralizações associadas a folhelhos, que compõe menos de $5 \%$ das rochas do Complexo VS na Região Norte. 
A coluna estratigráfica modelo da região do Cinturão Norte da FPI foi estabelecida por Conde (2016) e Conde \& Tornos, (2019) (Figura 137). Nestes trabalhos os autores discutem que devido ao alto tectonismo da região a unidade UFU (Upper Felsic Unit Unidade Félsica Superior) pode ser uma repetição da unidade LFU (Lower Felsic Unit Unidade Félsica Inferior). Estas duas unidades apresentam contatos tectônicos, o que dificulta o estabelecimento das relações geológicas entre as unidades.

O depósito de San Telmo ocorre associado a UFU enquanto que Aguas Tenidas, San Platon, San Miguel, Magdalena e Concepcion estão associados a LFU (Conde \& Tornos, 2019). Estas unidades possuem litotipos similares, com complexos de domos riodacíticos e dacíticos com hialoclastitos associados. A geoquímica destas unidades também é semelhante, o que levou Conde (2016) e Conde \& Tornos (2019) a proporem que estas duas unidades são partes desmembradas de um mesmo complexo vulcânico.

A geocronologia U-Pb efetuada nesta tese mostra que as rochas hospedeiras aos depósitos associados a LFU (Aguas Tenidas, San Miguel, Magdalena e Concepcion) possuem idades que variam entre 354 - 349 Ma. A idade concórdia obtida em San Platon (338 Ma \pm 3) não permite confirmar que este depósito em específico pertence a LFU, pois a amostra datada é interpretada como tardia e sem relação com a mineralização de sulfeto maciço deste depósito, tal qual ocorre com o riolito tardio de Rio Tinto. A idade concórdia obtida em San Telmo (347 \pm 2 Ma) indica que, diferente da interpretação de Conde \& Tornos (2019), a UFU deve ser uma unidade distinta da unidade LFU. Entretanto, a idade de San Telmo (347 $\pm 2 \mathrm{Ma}$ ) apresenta certa sobreposição com as idades mais jovens da LFU (AT-03 - $349 \pm 2$ Ma e AT-01 - $352 \pm 3$ Ma) ainda apresentam sobreposição e a interpretação de Conde \& Tornos (2019) e Conde (2016) de que ambas unidades (UFU e LFU) são a mesma unidade desmembrada não pode ser descartada. Esta questão está além da resolução do SHRIMP e poderia ser resolvida com a utilização da geocronologia U$\mathrm{Pb}$ por ID-TIMS, equipamento com uma precisão supeior ao SHRIMP. O depósito de Solo Viejo não foi estudado por Conde (2016) e Conde \& Tornos (2019) e a relação com as unidades UFU e LFU não é conhecida. De acordo com Tornos et al., (2005), Solo Viejo ocorre na parte superior da coluna estratigráfica, o que é coerente com as duas idades de 349 Ma observadas nesta localidade. A síntese das idades obtidas pode ser observada na Figura 140. 


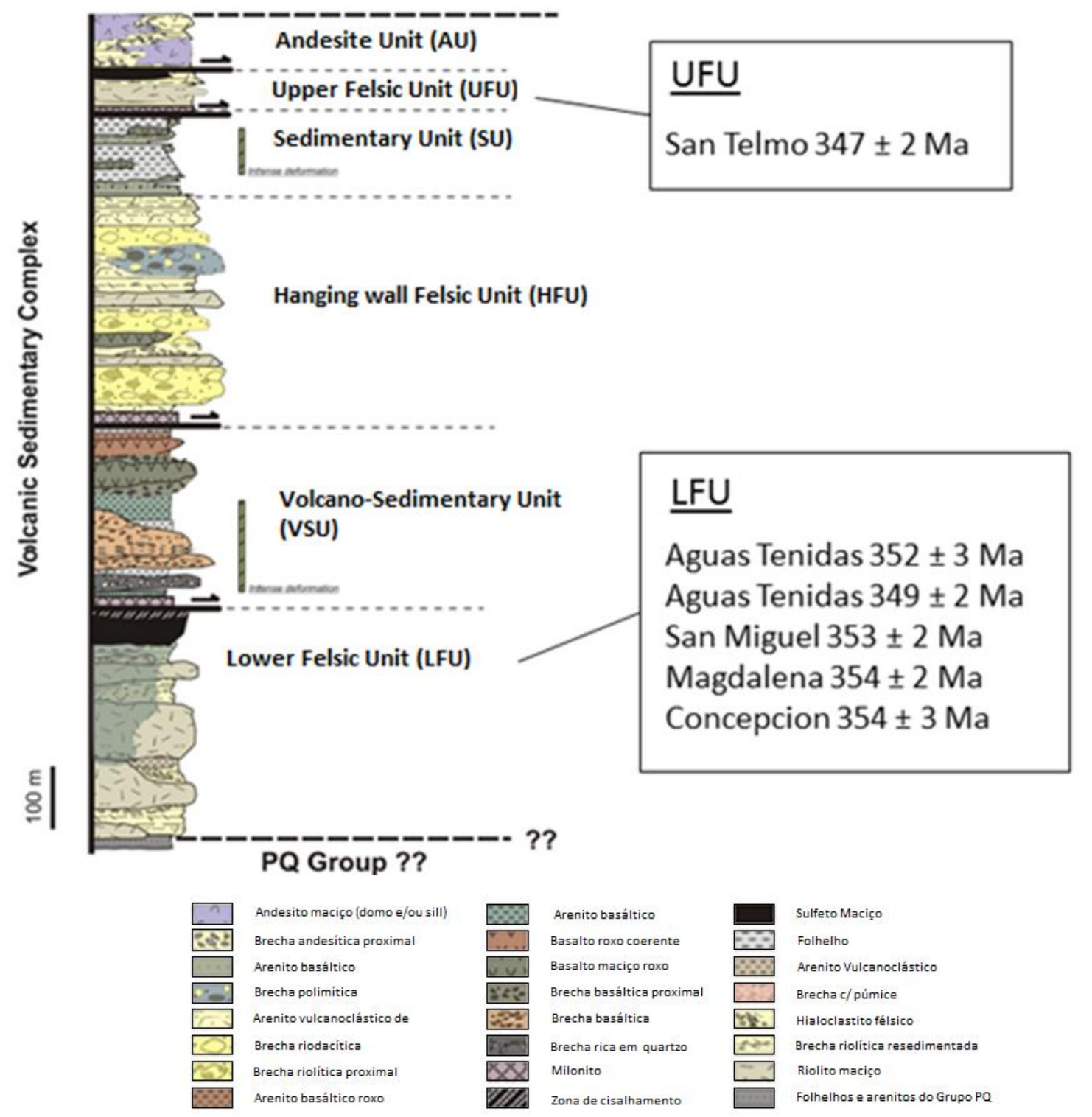

Figura 137. Coluna estratigráfica do Cinturão Norte proposta por Conde (2016) e Conde \& Tornos (2019) com as idades obtidas nos depósitos associados às unidades LFU e UFU

Como dito anteriormente, Martin Izard et al. (2016) separa a FPI de acordo com suas estruturas tectônicas e as rochas vulcânicas associadas aos depósitos, com resultado um pouco distinto a separação de Tornos (2006). Para Martin Izard et al. (2016) a Região Norte é composta por bacias de pull apart e grabens e os depósitos estão na parte superior do vulcanismo félsico VSC2. A Região Central de Martin Izard et al. (2016) é composta pelo que esta tese chamou de Região Sul e inclui os depósitos associados a folhelhos descritos por Tornos (2006). Martin Izard et al. (2016) associa estes depósitos a rochas andesíticas de $\mathrm{VSC}_{0}$ e sequencias sedimentares, o que vai de encontro com as interpretações de Conde \& Tornos (2019) sobre a dispersão de rochas andesíticas ao longo 
da FPI. A Região Sul de Martin Izard et al. (2016) é composta por Neves Corvos e está associado a rochas vulcânicas félsicas de $\mathrm{VSC}_{0}$ relacionadas ao Struniano (Famenniano Superior). Levando em consideração a terminologia utilizada por Martin Izard et al. (2016), as idades obtidas nesta tese confirmam que o magmatismo de $\mathrm{VSC}_{0}$ está relacionado ao Struniano (365-359 Ma), enquanto que as rochas de $\mathrm{VSC}_{2}$ estão relacionadas ao Tournaisiano (357-348 Ma).

Para Martin Izard et al. (2016), o depósito de Neves Corvo representa uma região distinta da FPI. Entretanto neste depósito diversas características semelhantes aos depósitos da Região Sul são observadas e Neves Corvo também é um depósito associado a folhelhos e precipitado na superfície marinha. Outras características de Neves Corvos são distintas em relação à FPI, como o alto teor de estanho $(\mathrm{Sn})$ e assinaturas isotópicas que indicam múltiplas fontes de fluidos mineralizantes (Relvas et al., 2001), mas a interpretação desta tese e de Tornos (2006) é que Neves Corvos representa um outlier, como ocorre com Las Cruces, e não uma região distinta como é proposto por Marin Izard et al. (2016).

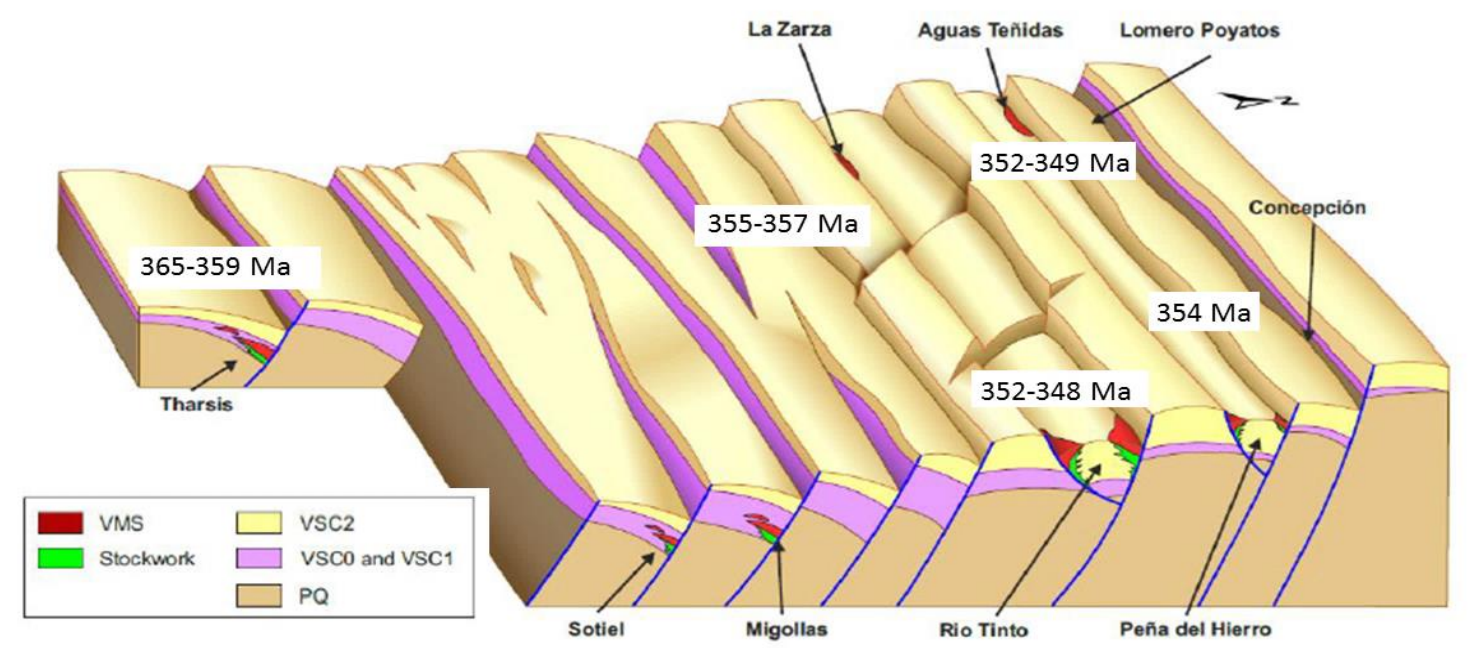

Figura 138. Idades obtidas nesta tese plotadas na seção geológica apresentada por Martin Izard et al. (2016) com os diferentes intervalos magmáticos mineralizados $V_{S C}$ e $V_{S C}$.

A idade de $354 \pm 1$ Ma obtida por Barrie et al. (2002) via TIMS em Las Cruces deve ser vista com ressalvas. Nesta tese os cristais de zircão do dacito encaixante de Las Cruces apresentam enriquecimento em $\mathrm{Pb}$ comum e diversas análises tiveram que ser descartadas. Esta amostra é da mesma unidade do dacito encaixante datado por Barrie et al. (2002). Barrie et al. (2002) analisou uma população de apenas 6 cristais de zircão com 
baixo conteúdo de $\mathrm{Pb}$ comum. Os enriquecimentos de $\mathrm{Pb}$ por vezes são locais, o que significa dizer que em um zircão com assinatura média de $\mathrm{Pb}$ que não apresente enriquecimento de $\mathrm{Pb}$ os dados do zircão já podem estar alterados. De fato, diversos cristais de zircão com enriquecimento de $\mathrm{Pb}$ estudados nesta tese apresentam idades mais jovens que $359 \pm 3 \mathrm{Ma}$, o que indica que este enriquecimento gera idades mais jovens. A idade é de $354 \pm 1 \mathrm{Ma}, 5 \mathrm{Ma}$ mais jovem que a idade obtida nesta tese para o dacito encaixante de Las Cruces. As imagens de CL apresentadas nos RESULTADOS (Figura 115) mostram que diversas regiões dos cristais estão afetadas por alterações tardimagmáticas e mesmo que o conteúdo médio de $\mathrm{Pb}$ comum não assinale um valor suficientemente alto que fazer estas análises serem eliminadas por Barrie et el. (2002) estas alterações e recristalizações já afetaram as idades obtidas. De fato, quando as imagens da CL apresentadas por Barrie et al. (2002) (Figura 139) são comparadas com as obtidas nesta tese é perceptível que foram estudados cristais com alterações tardimagmática que não eram facilmente perceptíveis devido a resolução das imagens de CL e não foram descritas.

Quando as análises de U-Pb por TIMS foram executadas essas regiões devem ter sido homogeneizadas e a assinatura de $\mathrm{U}-\mathrm{Pb}$ ficou alterada.
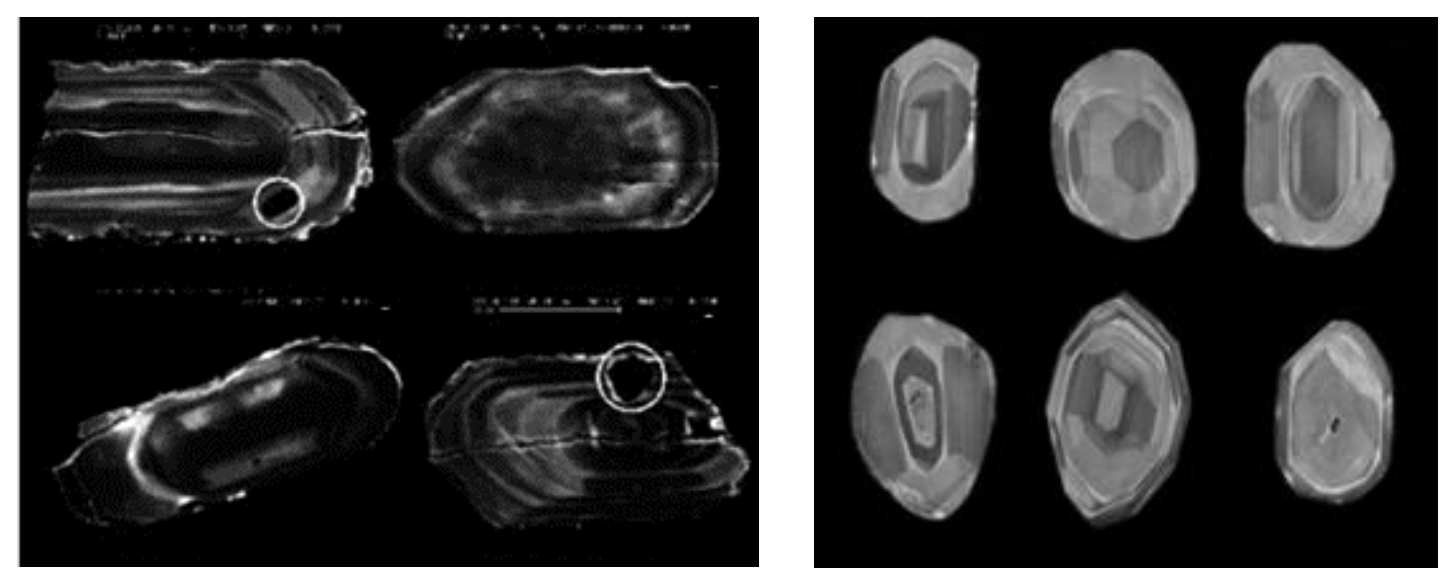

Figura 139. Imagens de CL de baixa resolução dos cristais de zircão estudados por Barrie et al. (2002) são comparadas com as imagens de CL obtidas nesta tese. Os círculos brancos nas imagens de CL de Barrie et al. (2002) são inclusões.

Diversas análises individuais em xenocristais de zircão preservados apresentaram idades Cadomianas, uma orogenia Neoproterozoica que ocorreu entre $\sim 650-550$ Ma e que foi o último de uma sequência de eventos que formou o embasamento cristalino da Europa (Plant et al., 2003). Da mesma maneira a idade obtida no intercepto inferior da população de xenocristais do tonalito 
do Maciço de Gerena aponta uma idade Cadomiana de $587 \pm 29$ Ma. Esta população de xenocristais do tonalito do Maciço de Gerena também apresentou idades Riacianas de $2195 \pm 7$ Ma para o intercepto superior.

A Orogenia Cadomiana afeta grande parte da Europa e evidências geofísicas, petrológicas, estruturais e geoquímicas confirmam que a Zona de Ossa Morena foi amplamente afetada por essa orogenia (Egiuluz \& Abalos, 1992; Egiuluz et al., 2000; Bandres et al., 2002; Pin et al., 2002; Ribeiro et al., 2009). Na Zona Sul Portuguesa, onde está inserida a FPI, existem algumas heranças observadas em cristais de zircão, mas além disso pouco se sabe a respeito da influência da Orogenia Cadomiana na região.

Nesta tese foram obtidas diversos cristais de zircão herdados que apontam para o Cadomiano, que também já foram observadas em outros trabalhos ao longo da FPI. Rosa et al. (2009), por exemplo, descreve herança de idades ${ }^{207} \mathrm{~Pb} /{ }^{235} \mathrm{U}$ Cadomianas de $607 \pm 8 \mathrm{Ma}, 603 \pm 10$ Ma e $606 \pm 12$ Ma em Aljustrel; $585 \pm 14$ Ma, $626 \pm 14$ Ma, $627 \pm 12$ Ma em Lousal. Estes autores também apresentam idades Riacianas de $2271 \pm 52 \mathrm{Ma}, 2079 \pm 48 \mathrm{Ma}, 2067 \pm 38 \mathrm{Ma}$, $2471 \pm 56$ Ma em Lousal. Valenzuela et al. (2011) também observa herança Cadomiana de idade ${ }^{207} \mathrm{~Pb} /{ }^{235} \mathrm{U} 564 \pm 1$ Ma no riolito associada ao corpo de San Dionísio. Barrie et al. (2002) também descrevem herança de $537 \pm 3$ Ma em Aljustrel

Estas idades vulcânicas Cadomianas, em conjunto com a idade de intercepto inferior obtida em rocha plutônica, mostram que a Orogenia Cadomiana também afeta a Zona Sul Portuguesa, mesmo que em intensidade bem menor do que a intensidade que esta orogenia afeta a Zona de Ossa Morena 


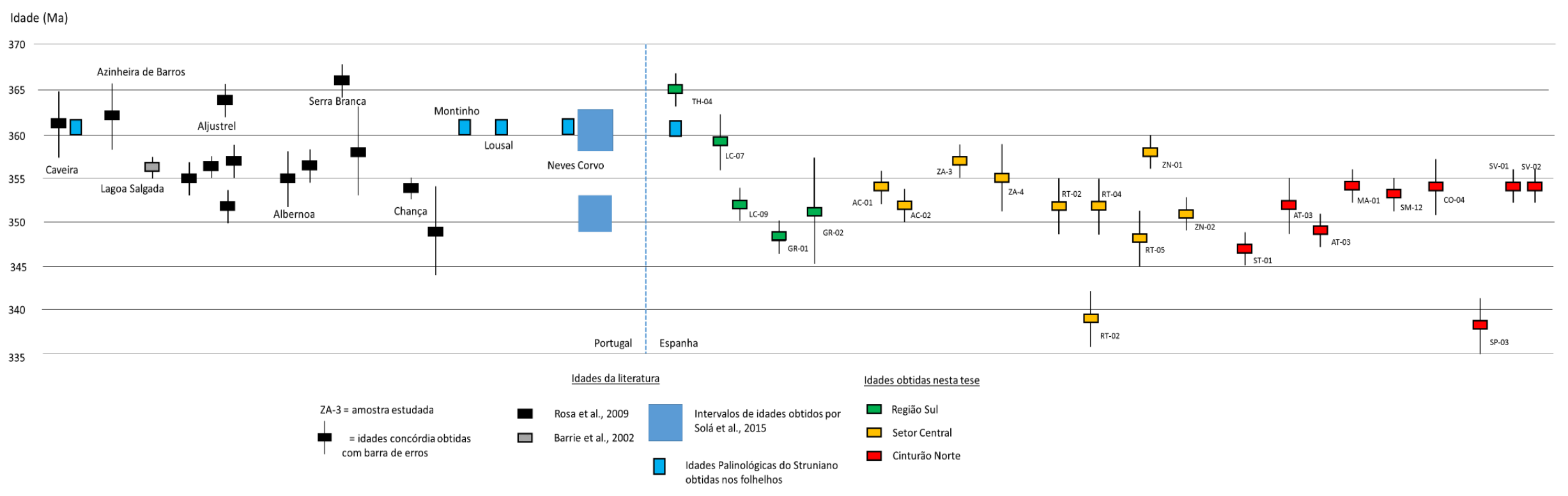

Figura 140. Idades obtidas nesta tese plotadas em conjunto com idades obtidas na FPI portuguesa. 


\subsection{TEMPERATURAS DE CRISTALIZAÇÃO DO ZIRCÃO NO CONTEXTO REGIONAL DA FPI}

Codeço et al., (2015) e Codeço et al., (2018) estudaram a temperatura de saturação de zircão no magma e as compararam com as temperaturas obtidas a partir da utilização do Ti-em-zircão na parte portuguesa da Faixa Piritosa Ibérica. De acordo com os resultados de Ti-em-zircão destes trabalhos, os magmas riolíticos relacionados aos centros vulcânicos que estão associados a corpos de sulfeto maciço são o produto de magmas com temperaturas de cristalização de zircão acima de $800^{\circ} \mathrm{C}$. Em contraste, as sequências vulcânicas estéreis estão associadas a magmas riodacíticos a dacíticos gerados em temperaturas mais baixas (menor que $800^{\circ} \mathrm{C}$, com cluster entre $700-750^{\circ} \mathrm{C}$ ) (Codeço et al., 2015).

Codeço et al. (2015) e Codeço et al. (2018) utilizam tanto Ti-em-zircão quanto temperaturas de saturação de zircão. Essas temperaturas de saturação de zircão obtidas também indicam que nos riolitos estudados por estes autores estas temperaturas eram elevadas $\left(\mathrm{T}\left({ }^{\circ} \mathrm{C}\right)\right.$ de sat $\left.>800^{\circ} \mathrm{C}\right)$. Por sua vez os rio(dacitos) apresentam as temperaturas de saturação mais frias $\left(\mathrm{T}\left(^{\circ}\right)\right.$ de sat $\left.<775^{\circ} \mathrm{C}\right)$. As temperaturas de saturação de zircão no magma também foram utilizadas para estimar temperaturas em torno dos $820^{\circ} \mathrm{C} \mathrm{e} 770^{\circ} \mathrm{C}$ para as rochas félsicas do depósito de Serra Branca (Rosa et al., 2006) e em torno de $780^{\circ} \mathrm{C}$ para as rochas félsicas do depósito de Albernoa (Rosa et al., 2004). Os dados de temperaturas de saturação de zircão e Ti-em-zircão obtidos por Codeço et al. (2018) e Codeço et al. (2018) sempre apresentam diferenças de temperatura, sendo que as temperaturas de saturação de zircão subestimam as temperaturas de cristalização do zircão (Codeço et al., 2018).

Temperaturas de saturação de zircão (Watson e Harrison, 1983) devem ser observadas com ressalvas pois são temperaturas teóricas que indicam o início da cristalização de zircão em um magma e não devem ser utilizadas como análogos para temperaturas magmáticas ou de fusão parcial (Siégel et al., 2018). Na realidade para que as temperaturas de saturação de zircão tenham significado como um geotermômetro, elas só poderiam ser aplicadas para rochas com composições próximas a composição química no momento que o zircão está cristalizando (Hanchar e Watson, 2003). A temperatura de saturação é uma variável dinâmica que muda ao longo da cristalização do magma e, na realidade, aumenta conforme a cristalização fracionada avança, enquanto que a temperatura do magma está diminuindo (Siégel et al., 2018). Siégel et al. (2018) 
apresentam um extenso exemplo de como esta temperatura é uma variável dinâmica utilizando dados do Monte Kilauea para ilustrar a discussão.

Resumidamente, pode-se dizer que novos cristais de zircão se cristalizam quando a temperatura de saturação de zircão no magma é superior a temperatura do magma e que estes dois valores (temperaturas de saturação e temperatura do magma) só são equivalentes em conteúdos muito específicos de Si no magma. Como consequência podese dizer que qualquer zircão herdado residindo em um magma insaturado em zircão está fora de equilíbrio e deve ser reabsorvido se o tempo de residência no magma permitir. Uma conclusão fundamental que este raciocínio implica é que a cristalização de novos cristais de zircão está sempre associada a magmas de composição graníticas/riolíticas (até magmas de composição andesítica) e, portanto, não se deve assumir que nenhum cristal residindo em outras rochas seja um autocristal (Siégel et al., 2018).

Os resultados obtidos nesta tese para a Região Norte (Cinturão Norte e Setor Central) ampliam o cenário proposto por Codeço et al. (2015), e mostram que estas temperaturas de cristalização de zircão superiores a $800^{\circ} \mathrm{C}$ relacionadas as rochas félsicas associadas aos corpos de sulfeto maciço são representativas apenas da Região Sul da FPI. Enquanto isso, todas as rochas associadas as mineralizações da Região Norte apresentam temperaturas inferiores a $760^{\circ} \mathrm{C}$ (Figura 141). O depósito de Rio Tinto, que é o maior depósito da FPI, apresenta as menores temperaturas obtidas nesta tese, com temperatura de cristalização de zircão nos litotipos vulcânicos félsico associados as mineralizações (RT-04 e RT-05) de $715 \pm 54^{\circ} \mathrm{C}$ e $713 \pm 25^{\circ} \mathrm{C}$.

Se ao invés de um valor fixo de $\alpha \mathrm{TiO}_{2}=0.7$ (conforme discutido em MATERIAIS E MÉTODOS) o intervalo dos valores de rocha total de $\mathrm{TiO}_{2}$ obtidos for utilizado os resultados não variariam significativamente (Codeço et al. 2018). Como a amostragem desta tese foi enxuta, focando estudos isotópicos, um estudo geoquímico não foi executado e com isso o valor $\alpha \mathrm{TiO}_{2}=0.7$ foi utilizado para os cálculos termométricos. Este valor fixo em 0.7 ainda permite que os dados da literatura sejam comparados com os dados desta tese. 


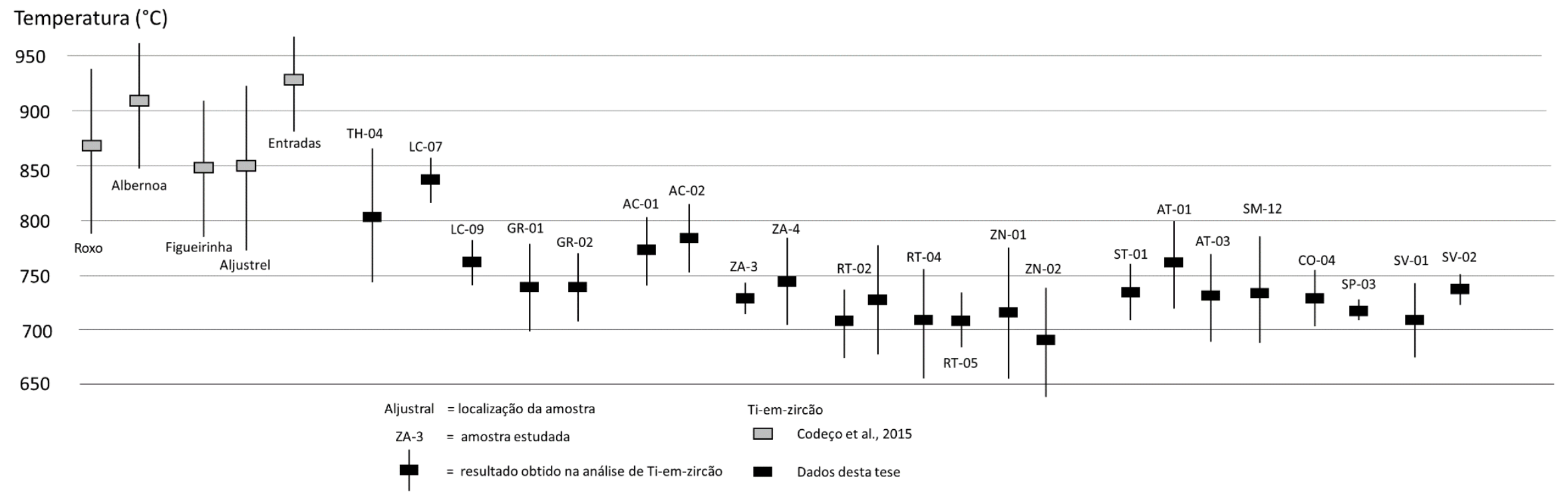

Figura 141. Todas as temperaturas de Ti-em-zircão e de isótopos de Ti obtidas na FPI como um todo. As temperaturas obtidas nesta tese são de localidades espanholas, enquanto as temperaturas obtidas por Codeço et al. $(2015,2018)$ são de Portugal. 


\subsection{ORIGEM CRUSTAL DO MAGMATISMO DA FPI}

Os depósitos portugueses da FPI tiveram os isótopos de Lu-Hf estudados por Rosa et al. (2009). Nesta tese os dados individuais de cada análise efetuada por Rosa et al. (2009) foram utilizados e os valores de $\varepsilon_{\mathrm{Hf}}$ foram recalculados (Anexo III). Os depósitos de Portugal estudados por Rosa et al. (2009) variaram entre -13.07 e 1.14, com média de -7.97 (Figura 142) e dois outliers com valores de $\varepsilon_{\mathrm{Hfi}}$ de -22.34 e -57.89 , e, portanto, as assinaturas de $\varepsilon_{\mathrm{Hfi}}$ destes depósitos são crustais. Estas assinaturas mostram que a Região Sul portuguesa apresenta assinatura ainda mais crustal se comparado ao valor de $\varepsilon_{\mathrm{Hfi}} \mathrm{de}$ 5.2 da Região Sul espanhola.

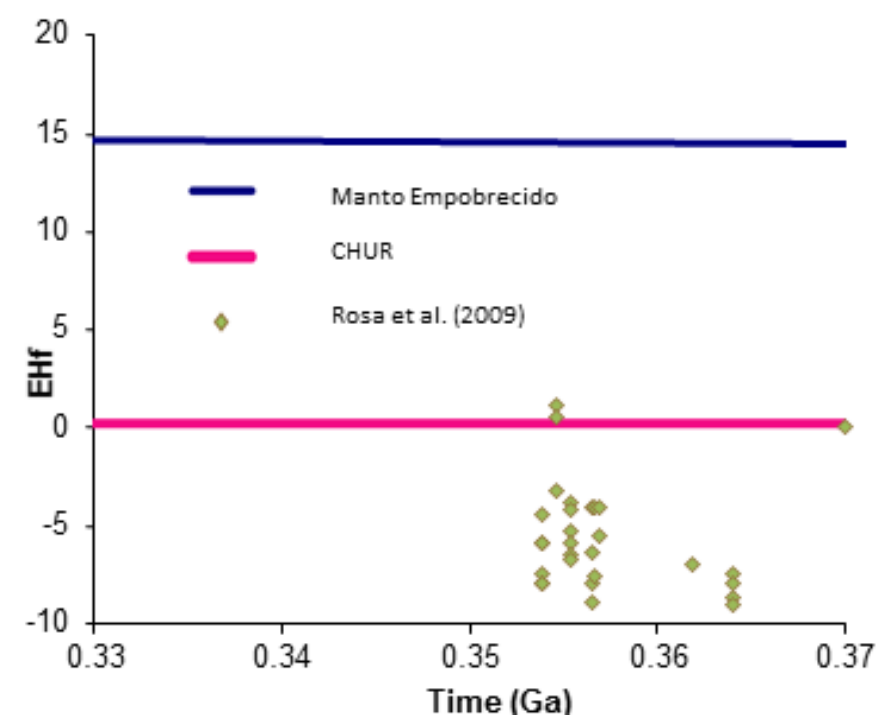

Figura 142. Valores de $\mathcal{E}_{H f i}$ obtidos por Rosa et al. (2009) para depósitos portugueses da FPI

Comparando os valores de $\varepsilon_{\mathrm{Hfi}}$ das distintas regiões analisadas nesta tese fica claro que o Cinturão Norte apresenta contribuição mantélica, enquanto que a Setor Central apresentou menor grau de contribuição mantélica e maior contribuição crustal. A Região Sul espanhola apresentou assinaturas de $\varepsilon_{\mathrm{Hfi}}$ mais próximas as recalculadas para a parte portuguesa da FPI e são essencialmente crustais.

A contribuição de material mantélico na geração do vulcanismo félsico varia de acordo com a região da FPI. O Cinturão Norte da Região Norte apresenta assinatura média de $\varepsilon_{\mathrm{Hf}} \sim-0.2$, enquanto que o Setor Central da Região Norte apresenta assinatura média de $\varepsilon_{\mathrm{Hf}} \sim-3.2$ e a Região Sul possui assinatura média de $\varepsilon_{\mathrm{Hf}} \sim$-5.2. Ou seja, as assinaturas de $\varepsilon_{\mathrm{Hf}}$ mostram maior quantidade de contribuição de material mantélico na formação das rochas vulcânicas do Cinturão Norte e menor contribuição de mantélico na Região Sul (Figura 143). Andesitos essão presentes em quantidade relevante exclusivamente no 
Cinturão Norte (Conde, 2016; Conde \& Tornos, 2019) e comprovam essa maior interação na região.

O único litotipo de composição diferente de riolito-dacito estudado nesta tese é o tonalito do Maciço de Gerena (GR-02), que para Castro et al. (1990) tem origem na assimilação de diques sin-plutônicos máficos em uma câmara magmática félsica. Este tonalito apresenta assinaturas crustais $\left(\varepsilon_{\mathrm{Hfi}}=-3.52\right)$, além de estar geograficamente localizado ao lado do depósito de Las Cruces na Região Sul, indicando que a fonte máfica deste tonalito é crustal, e, portanto, distinta da fonte com assinatura mantélica do Cinturão Norte.
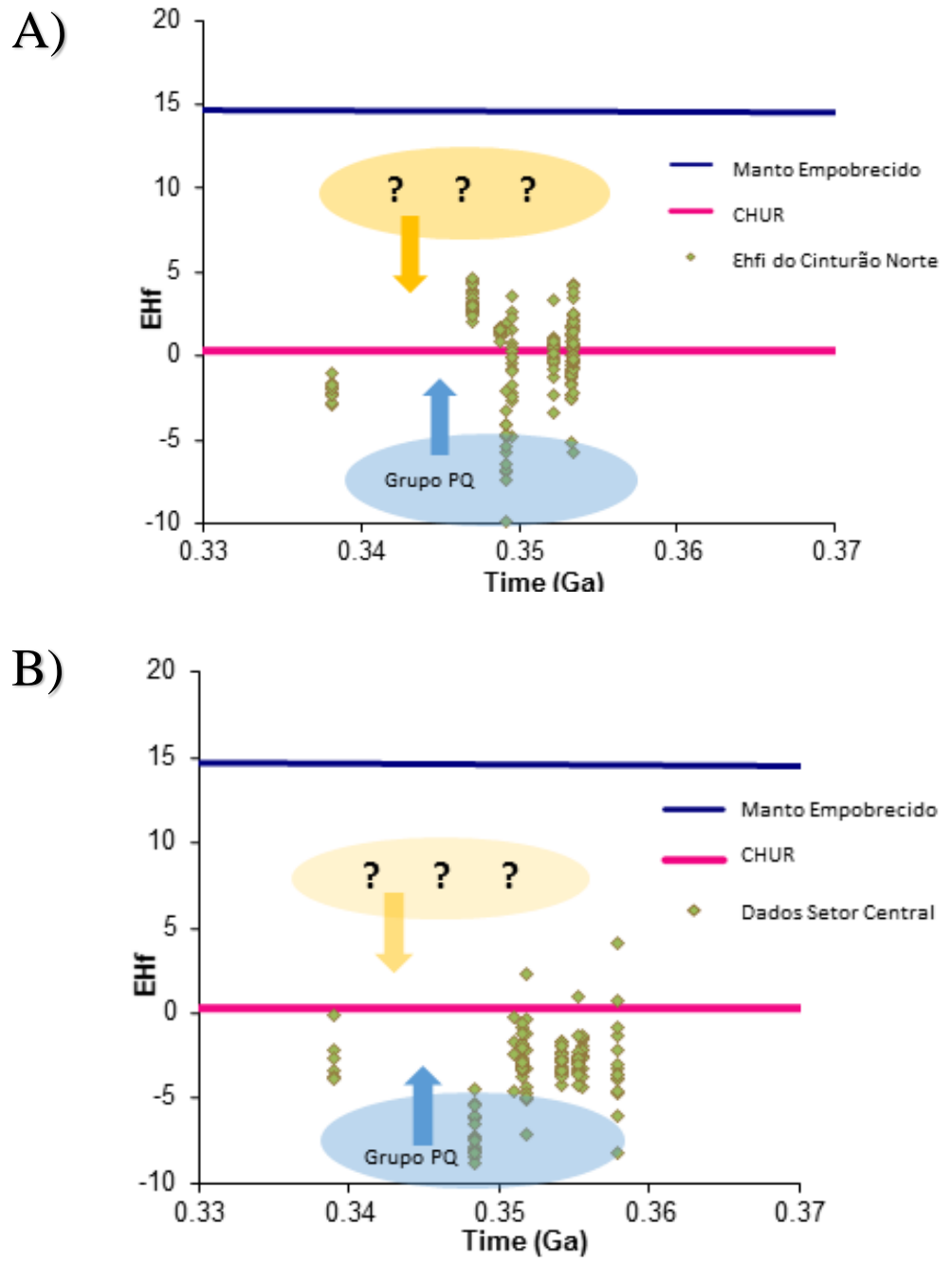

Figura 143. Interpretação das assinaturas de $\varepsilon_{H f i}$ nas duas porções da Região Norte. Em A) o Cinturão Norte apresenta valor de $\varepsilon_{H f i}$ médio de -0.18, indicando uma significativa contribuição mantélica enquanto que em B) mostra que a assinatura de Hf do Setor Central apresenta uma contribuição mantélica menor, apresentando valor de $\varepsilon_{H f i}$ médio de -3.26. 
Simancas et al. (2003) considera que a atividade magmática da Zona de Ossa Morena foi gerada por uma pluma mantélica que atuou entre 355-335 Ma. Até o presente não existem evidências de que está pluma afetou diretamente a Zona Sul Portuguesa, mas os resultados obtidos nesta tese mostram um aporte significativo de material de derivação mantélica na formação das rochas magmáticas do Complexo VS na Região Norte, especialmente no Cinturão Norte, que é a região da Zona Sul Portuguesa mais próxima da Zona de Ossa Morena. Estes dados apontam que esta pluma poderia ter influenciado também na geração do magmatismo da Zona Sul Portuguesa, possivelmente sendo responsável pela fusão dos litotipos do Grupo FQ em sua base.

O embasamento da Região Norte da FPI é pouco conhecido, mas tanto os dados de $\varepsilon_{\text {Hf }}$ quanto a geologia da região, com presença abundante de andesitos, indicam que o embasamento da Região Norte apresenta mais interação com as rochas máficas, o que pode estar associado a uma taxa maior de extensão nesta região.

\subsection{DIFERENÇAS ENTRE A REGIÃO NORTE E A REGIÃO SUL DA FPI}

As diferenças litológicas e estratigráficas entre a Região Norte e a Região Sul da FPI espanhola já foram descritas em outros trabalhos (Tornos, 2006; Martin Izard et al 2016, Conde, 2016). Basicamente a FPI apresenta duas regiões com processos geológicos e metalogenéticos distintos. A Região Sul da FPI espanhola apresenta continuidade lateral com a parte portuguesa da FPI enquanto que a Região Norte é praticamente restrita a Espanha.

Os depósitos de sulfeto maciço da Região Sul da FPI são formados através da exalação de fluidos ricos em metais e pobres em enxofre em depressões no assoalho oceânico (Tornos, 2006; Tornos et al., 2008; Menor-Salván et al., 2010; Tornos et al., 2015a). Estas mineralizações estão associadas a folhelhos e rochas vulcânicas ocorrem com pouco expressão nestas localidades. Já os depósitos da Região Norte da FPI são formados pela substituição abaixo da superfície gerada pelos fluidos hidrotermais em rochas vulcanossedimentares (Tornos et al., 2015a; Conde, 2016; Conde \& Tornos, 2019). Na Região Norte rochas sedimentares são escassas ou ausentes e só ocorrem em porções distais dos centros vulcânicos.

A idade de formação dos depósitos de sulfeto maciço é diferente em cada uma das regiões. Os depósitos de sulfeto maciço da Região Sul da FPI ocorrem associados ao magmatismo Struniano (Famenniano Superior), o que é inferido a partir de idades 
palinológicas obtidas em folhelhos e idades isotópicas de $\mathrm{U}-\mathrm{Pb}$ obtidas nas rochas vulcânicas associadas. Enquanto que os depósitos da Região Norte da FPI ocorrem associados ao magmatismo Tournaisiano, idade obtida em uma idade palinológica obtida em Rio Tinto e em diversas idades isotópicas de U-Pb obtidas no Cinturão do Norte e no Setor Central da Região Norte.

As temperaturas obtidas para as rochas do Tournaisiano são claramente mais frias, o que ocorre em todas as temperaturas da Região Norte e nas amostras da Região Sul de 350 Ma. Considerando os dados isotópicos de Ti apresentados nesta tese em conjunto com os dados de Ti-em-zircão de Codeço et al. (2015) nota-se que as rochas magmáticas do Struniano (Famenniano Superior) apresentam sempre temperaturas superiores a $800^{\circ} \mathrm{C}$, enquanto que as amostras do Tournaisiano apresentam temperaturas inferiores a $785^{\circ} \mathrm{C}$. Desconsiderando as duas amostras estéreis do Dacito El Cerro, as amostras do Tournaisiano restantes associadas as mineralizações apresentam temperaturas inferiores a $760^{\circ} \mathrm{C}$, temperaturas significativamente inferiores as temperaturas de $800^{\circ} \mathrm{C}$ observadas no magmatismo Struniano.

Apesar das análises de isótopos de Ti, assim como as análises de Ti-em-zircão, apresentarem um erro elevado, por vezes de até $50^{\circ} \mathrm{C}$, elas ainda conseguem marcar a diferença de temperatura entre o vulcanismo Struniano e o vulcanismo Tournaisiano, o que ocorre na Figura 144 em que os dados as idades individuais ${ }^{206} \mathrm{~Pb} /{ }^{238} \mathrm{U}$ estão plotadas junto com as temperaturas de Ti-em-zircão. Os dados em azul nesta figura são uma composição das idades U-Pb obtidas por Rosa et al. (2009) com as temperaturas obtidas por Codeço et al. (2015). A diferença entre rochas férteis e estéreis no vulcanismo Tournaisiano também é bem demarcado no Cinturão Norte, mesmo com esse erro elevado, e a temperatura média das rochas estéreis da Região Norte é de $780^{\circ} \mathrm{C}$ enquanto que as rochas associadas à corpos de sulfeto maciço apresentam temperatura média de $717^{\circ} \mathrm{C}$. 


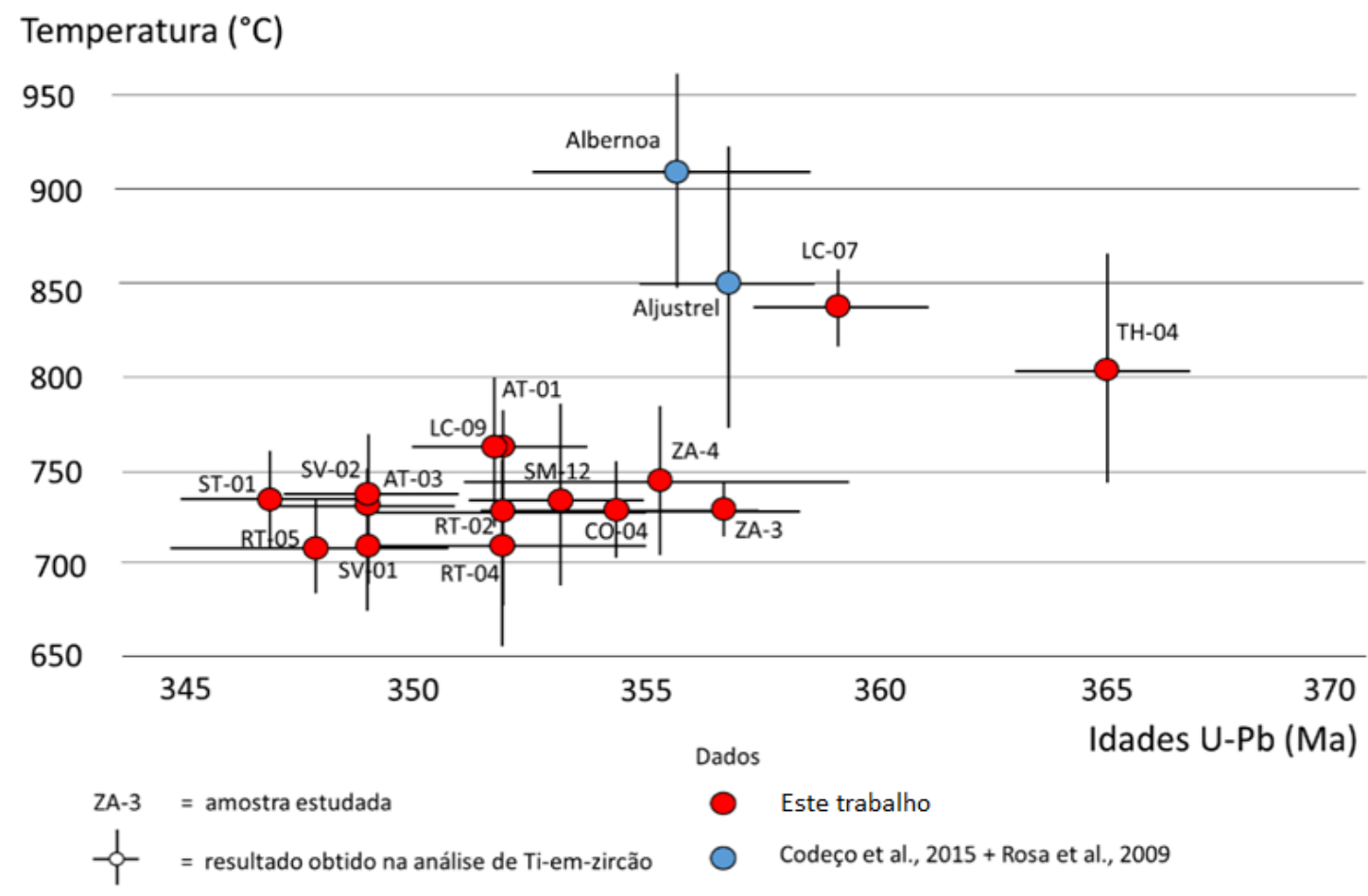

Figura 144. Dados de U-Pb e Ti-em-zircão obtidos nesta tese e na literatura (Codeço et al., 2015 realizou as análises de Ti-em-zircão e Rosa et al., 2009 realizou as análises de $U$-Pb). As amostras representam os rochas encaixantes dos seguintes depósitos: TH-04 - Tharsis; LC-07 e LC-09 - Las Cruces; ZA-4 e ZA-3, La Zarza; CO-04 - Concepcion; SM-12 - San Miguel; AT-01 e AT-03 - Aguas

Tenidas;RT-02, RT-04 e RT-05 - Rio Tinto; SV-01 e SV-02 - Soloviejo; ST-01 - San Telmo

As análises de Lu-Hf efetuadas em diversas localidades da FPI espanhola e portuguesa também indicam diferença entre as diferentes regiões desta província. As assinaturas de $\varepsilon_{\mathrm{Hfi}}$ da Região Sul e dos depósitos de Portugal apresentam uma assinatura marcadamente crustal, enquanto que as assinaturas de $\varepsilon_{\mathrm{Hfi}}$ obtidas no Cinturão Norte apresentam assinatura mista indicando que além de fonte crustal esta região também possui fonte mantélica associada ao magmatismo. As assinaturas do Setor Central da Região Norte são mais crustais que as assinaturas do Cinturão Norte, mas não tanto quanto as demais assinaturas mais a sul (Região Sul e Portugal), indicando que esta região também recebe uma contribuição de material mantélico em menor escala na geração do seu vulcanismo. A ausência de andesitos na Região Sul, presença subordinada no Setor Central e maior expressão no Cinturão Norte também indicam uma diferença na contribuição de magmas máficos mantélicos e magmas félsicos relacionados a fusão da base do Grupo FQ.

As regiões da FPI apresentam depósitos com características econômicas distintas. Os depósitos do Cinturão Norte apresentam menores tonelagens que os depósitos do Setor Central e que os depósitos da Região Sul espanhola. Em compensação estes depósitos 
apresentam teores mais elevados de metais base, $\mathrm{Ag}$ e $\mathrm{Au}$, fato associado a remobilização dos metais ao longo da orogenia variscana, que afeta mais intensamente os depósitos da Região Norte (Sánchez-Espana et al., 2000). A remobilização é maior no Cinturão Norte devido ao maior grau de tectnismo observado na região. Já os depósitos da Região Sul são compostos basicamente por pirita, com teores inferiores de metais de base, $\mathrm{Ag}$ e $\mathrm{Au}$. Las Cruces é uma exceção e apresenta um enriquecimento supérgeno associado a zona de cimentação secundária formada a partir da lixiviação do gossan associado ao corpo de sulfeto maciço (Tornos et al., 2017).

Os depósitos portugueses apresentam características similares as características de Tharsis e também são formados por precipitação e em associação com folhelhos. Martin Izard et al. (2016) considera que o depósito de Neves Corvo representa uma região distinta da FPI. Porém Neves Corvo apresenta diversas características semelhantes aos depósitos da Região Sul e também é um depósito associado a folhelhos e precipitado na superfície marinha. Algumas características de Neves Corvos de fato divergem do restante da FPI, como o alto teor de estanho $(\mathrm{Sn})$ e assinaturas isotópicas que indicam múltiplas fontes de fluidos mineralizantes (Relvas et al., 2001), mas para o autor desta tese isto deveria levar este depósito a ser visto como um outlier, como é o caso de Las Cruces, e não como uma nova região distinta. A Figura 145 mostra esquematicamente as características do magmatismo Tournaisiano por volta de $\sim 350$ Ma de acordo com as análises isotópicas.

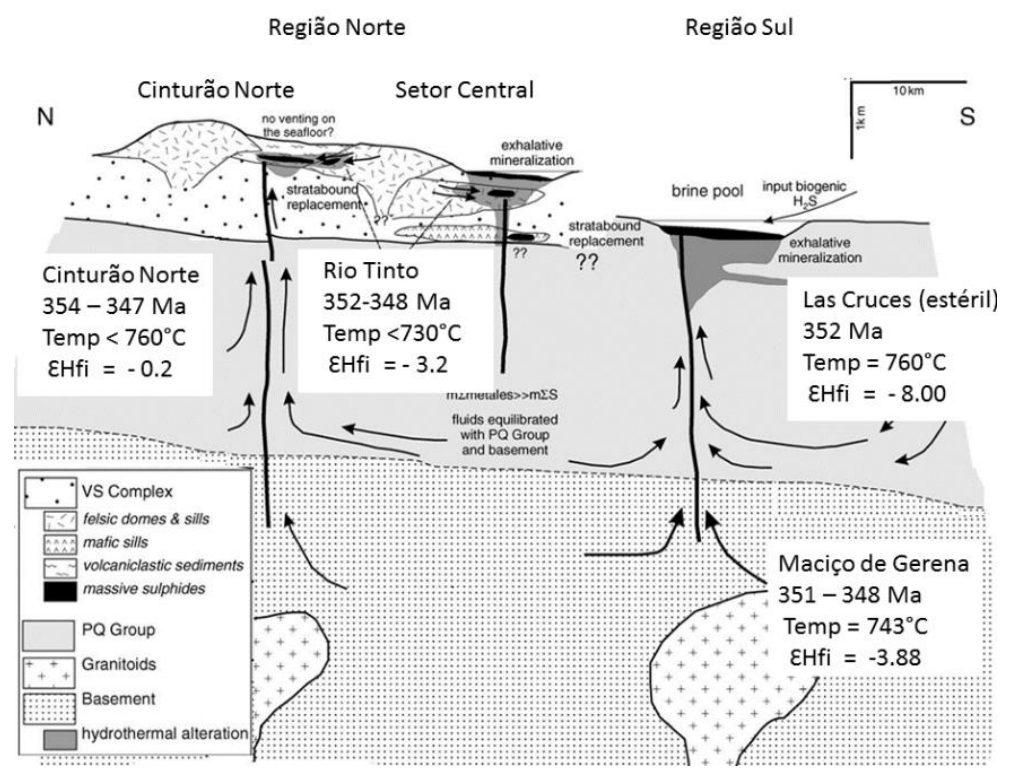

Figura 145. Características do magmatismo em $\sim 350$ Ma, o auge do evento magmático

Tournaisiano na FPI espanhola, plotadas no modelo esquemático da FPI apresentado por Tornos 
Tabela 7. Tabela comparativa entre a Região Norte e Região Sul da FPI de acordo com os resultados isotópicos obtidos nesta tese.

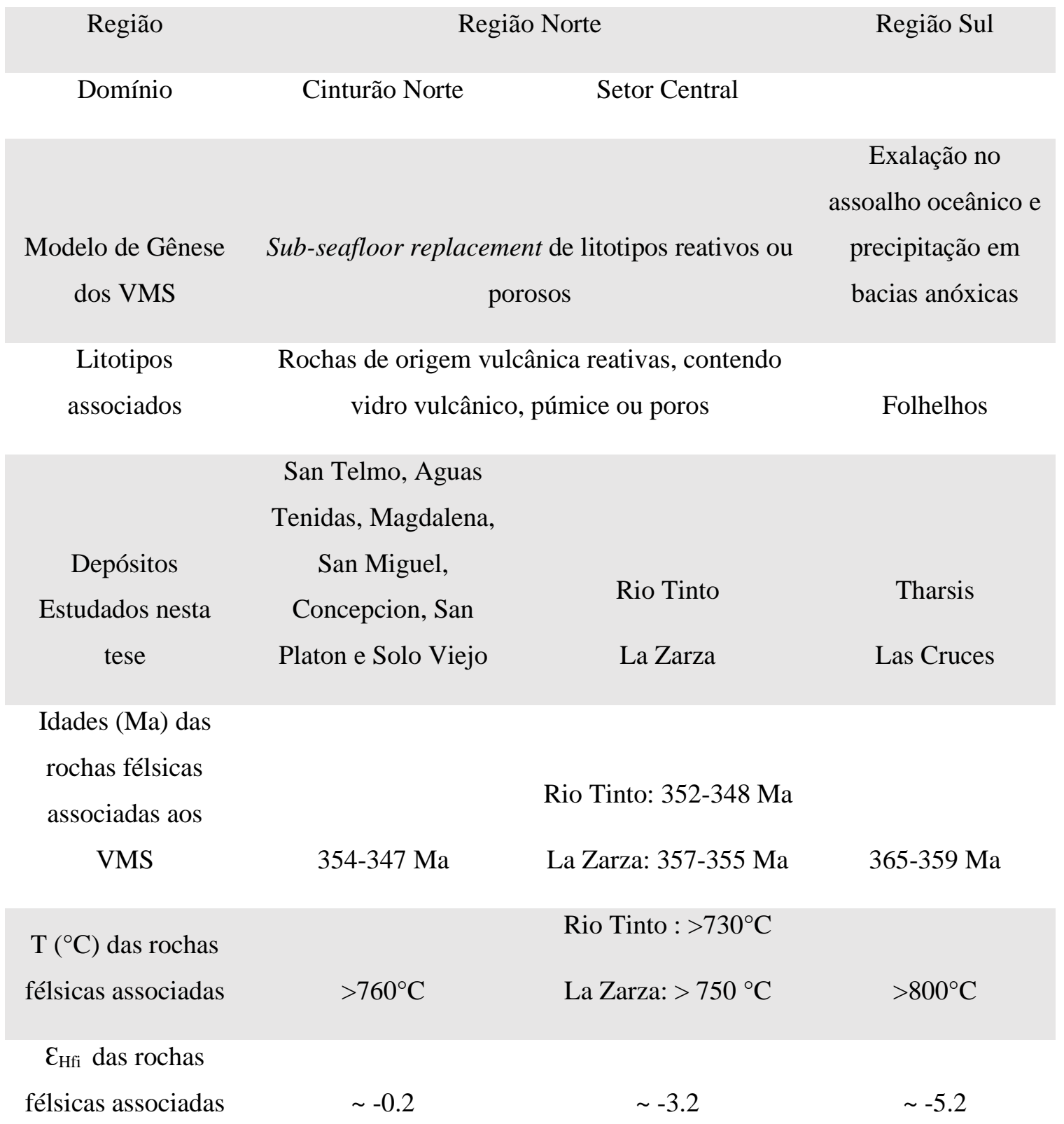

\subsection{RIO TINTO}

O depósito de Rio Tinto foi estudado a partir de 5 amostras nesta tese e os resultados, em conjunto com os dados de mapeamento e análises geoquímicas efetuadas por Conde (2016), geraram um manuscrito em processo de submissão. Sintetizando, a partir da datação de distintos litotipos pertencentes a Unidade Félsica, unidade definida por Conde (2016) que está associada as mineralizações de sulfeto maciço no Complexo VS, foi possível estabelecer a geocronologia dos eventos magmáticos da região de Rio Tinto. 
O vulcanismo da Unidade Félsica teve início em $358 \pm 2$ Ma, idade obtida através da datação de cristais de zircão provenientes de um arenito vulcanoclástico rico em púmice com pouca distância de transporte. Este episódio foi nomeado de Unidade Félsica I (Felsic Unit I). As rochas félsica associadas a duas das lentes de sulfeto maciço de Rio Tinto (San Dionísio e Filón Norte) apresentaram idades de $348 \pm 3$ e $352 \pm 3$ Ma, intervalo denominado Unidade Félsica II (Felsic Unit II). Em Rio Tinto existe um pulso de riolito tardio que corta as demais rochas da região. Este litotipo apresentou duas populações de zircão, uma de antecristais de idade $352 \pm 3$ Ma e outra de autocristais de idade $339 \pm 3$ Ma. Esta idade de 339 Ma representa a Unidade Félsica III (Felsic Unit III) e é cronologicamente correlacionada com a idade de 338 Ma obtida em San Platon (Figura 147).

Estes dados aumentam a duração do magmatismo félsico na região de Rio Tinto para 19 Ma com início em 358 Ma e término em 339 Ma. Esta atividade magmática apresenta duração maior do que os 7 e 9 Ma obtidos por Rosa et al (2009) nos depósitos de Aljustrel e Serra Branca da FPI portuguesa. Este longo intervalo de tempo mostra que o magmatismo do Complexo VS ocorreu intermitentemente por um longo período - maior do que já descrito anteriormente em qualquer depósito da FPI e em outras províncias VMS - e que a formação dos sulfetos maciços ocorre associada ao magmatismo Tournaisiano, assim como as demais rochas da Região Norte.

Em Rio Tinto a temperatura do magmatismo teve variação sempre abaixo dos $750^{\circ} \mathrm{C}$. Estas temperaturas confirmam a observação de Conde (2016) de que rochas félsicas de Rio Tinto devem ser relativamente frias por possuírem conteúdo de Zr baixo $(<200 \mathrm{ppm}$ nas rochas associadas aos sulfetos maciços e >200 ppm em rochas estéreis) e mostram que em Rio Tinto as rochas associadas as mineralizações apresentam temperaturas mais baixas. De fato, as rochas da região de Rio Tinto são as rochas com menores temperaturas analisadas nesta tese, com temperatura média de $713^{\circ} \mathrm{C}$, temperatura significativamente inferior a temperatura média de $741^{\circ} \mathrm{C}$ do Cinturão Norte (Figura 146). 


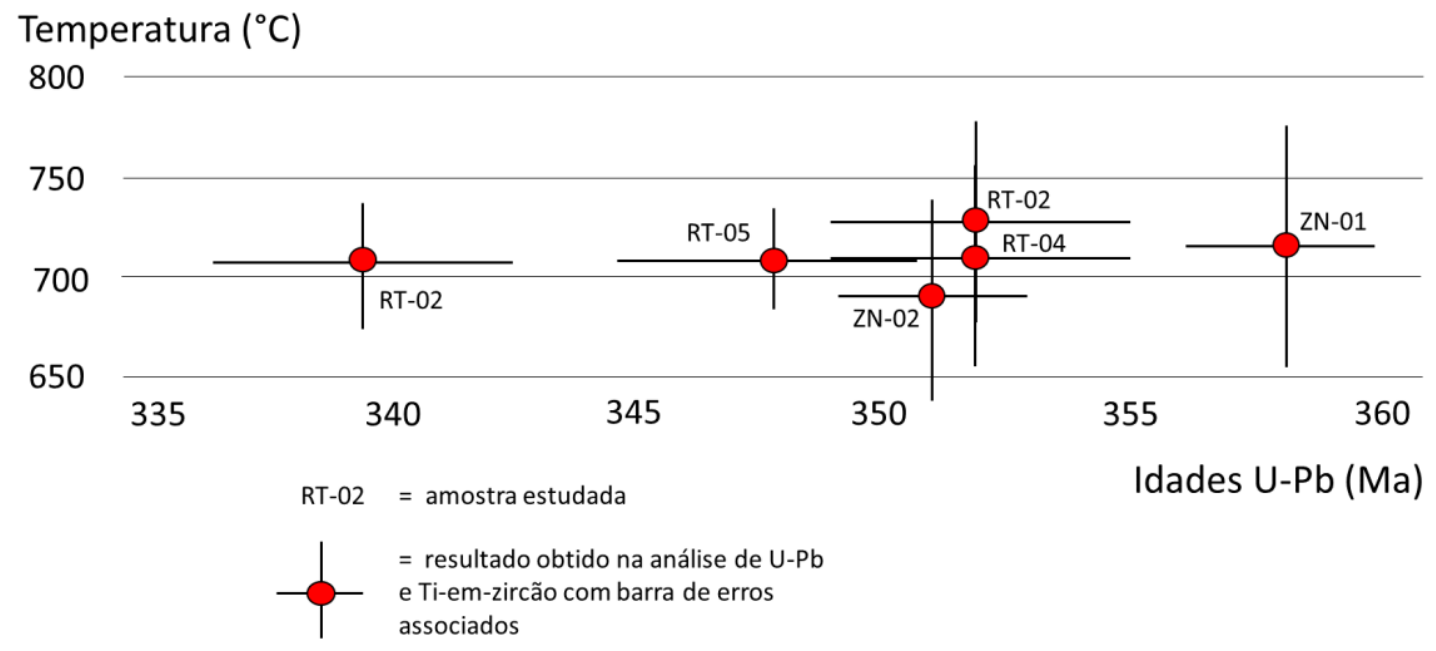

Figura 146. Dados de U-Pb e Ti-em-zircão obtidos em Rio Tinto e Zarandas, mostrando como a temperatura do magmatismo do Complexo VS nesta região se manteve abaixo dos $750^{\circ} \mathrm{C}$ ao longo de toda sua duração 


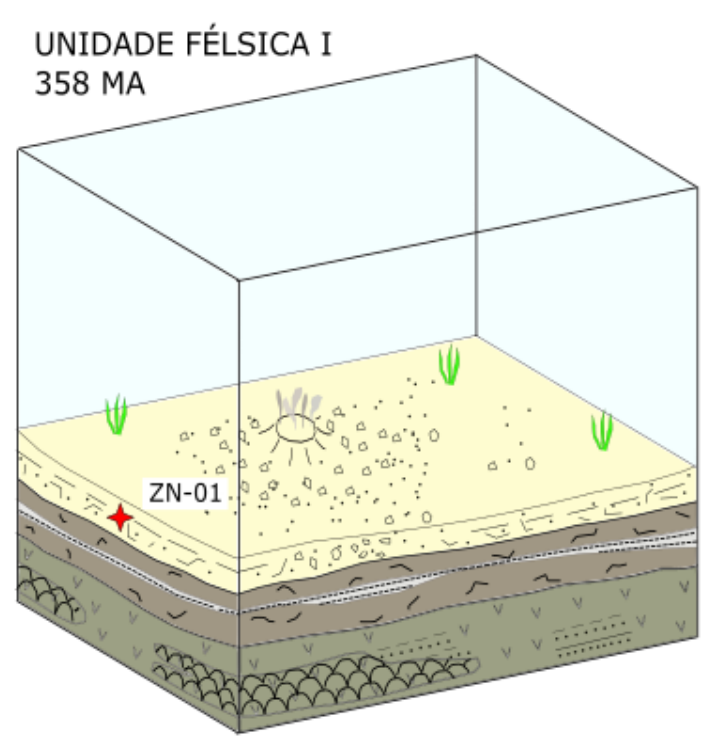

\section{Unidades}

Unidade Sedimentar Superior USS

\section{Unidade Félsica - UF}

Unidade Sedimentar Inferior USI

Unidade Máfica Siliciclástica UMS

Litotipos
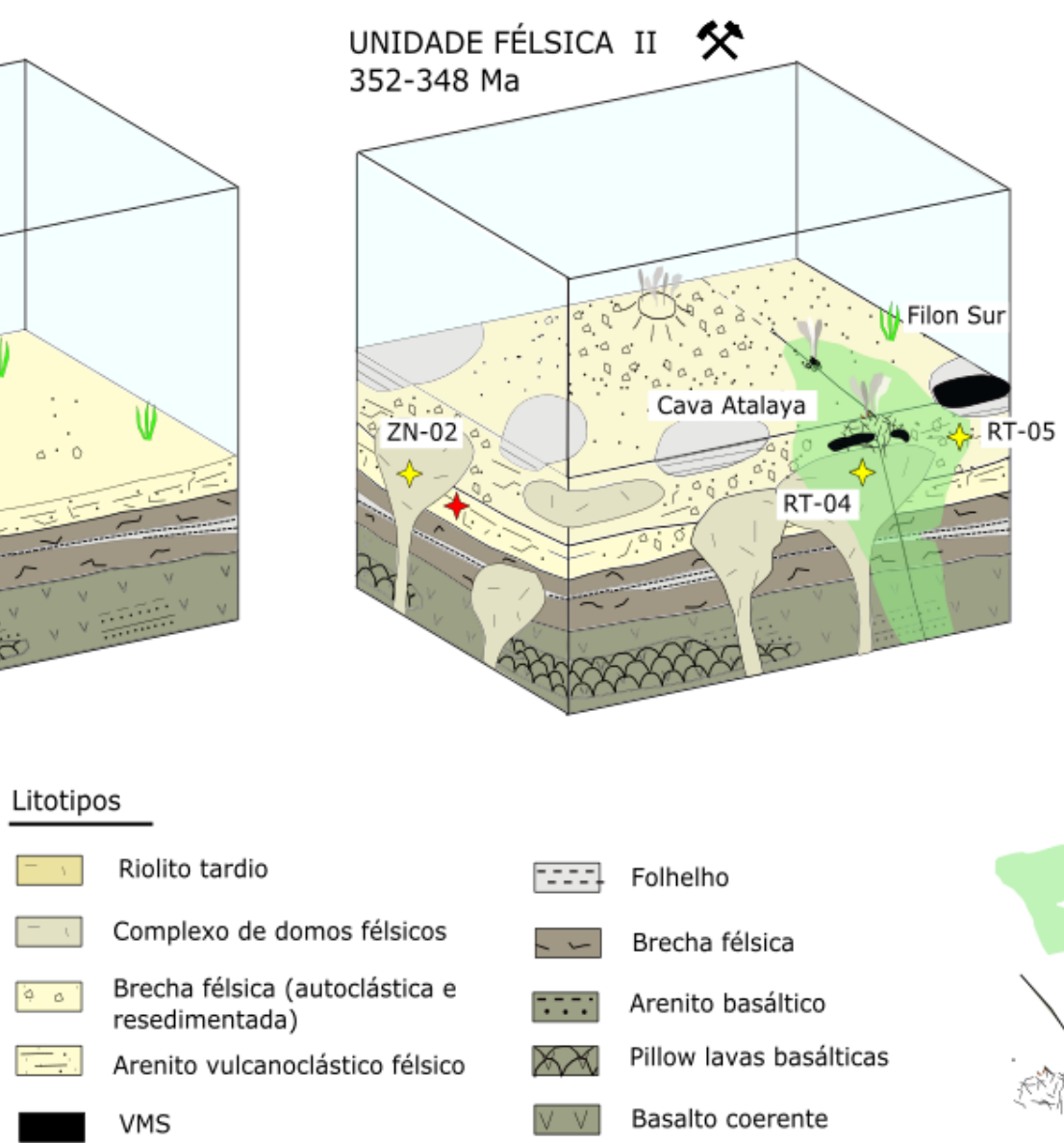

UNIDADE FÉLSICA III

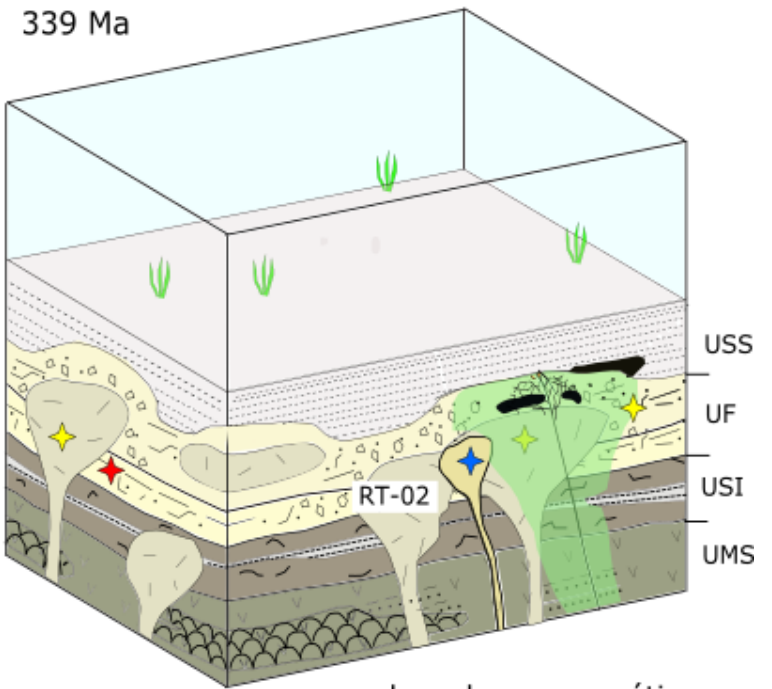

desenho esquemático

sem escala

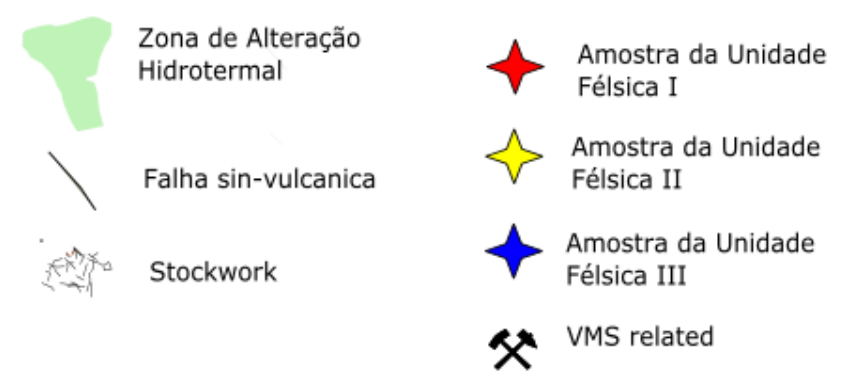

Figura 147. Evolução geocronológica do depósito de Rio Tinto com os 3 estágios de evolução (de Mello et al., in prep.) 


\subsection{MACIÇO DE GERENA E AS RAÌZES DO MAGMATISMO}

Existem poucas rochas plutônicas aflorando na FPI e com isso pouco é conhecido sobre as raízes do magmatismo do Complexo VS. Barrie et al. (2002) estudou o plúton de Campofrio, um plúton de $346 \pm 1$ Ma localizado a $3.5 \mathrm{~km}$ de Rio Tinto e com assinatura química semelhante. Nesta tese foram estudadas duas amostras plutônicas do Maciço de Gerena, um granodiorito (GR-01) e um tonalito (GR-02). Estas duas amostras apresentaram idades, temperaturas e valores de $\varepsilon_{\mathrm{Hfi}}$, similares aos valores obtidos em um dacito estéril de Las Cruces (LC-09) e demais amostras Tournaisianas da Região Norte.

A formação do Maciço de Gerena está relacionado a intrusão de diques sinplutônicos máficos em um corpo granítico. Uma diferença de $200^{\circ} \mathrm{C}$ é estimada entre o tonalito e o granodiorito (Rosa, 1992; Castro et al., 1990). As temperaturas dos isótopos de Ti indicam que a cristalização de zircão ocorreu somente no estágio final do resfriamento do tonalito, quando as temperaturas já entraram em equilíbrio. A cristalização desta população de zircão em um tonalito ocorre associada a assimilação de Zr do magma félsico pelo magma máfico, pois de acordo com Siebel et al. (2018) magmas de composições mais máficas não cristalizam zircão.

Isto indica que as rochas plutônicas do Maciço de Gerena estão relacionadas e podem ser consideradas as raízes plutônicas do vulcanismo Tournaisiano do Complexo VS da Região Sul. Nesta região o magmatismo Tournaisiano é estéril e o magmatismo Struniano (Famenniano Superior) está relacionado com o depósito de Las Cruces. Assim como o Plúton de Campofrio, na região de Rio Tinto, o Maciço de Gerena também não pode ser associado diretamente com o vulcanismo relacionado a depósitos minerais da FPI. No caso do Maciço de Gerena até existe a associação geocronológica com uma rocha vulcânica félsica de Las Cruces, mas esta rocha é distal e não está associada aos sulfetos maciços e rochas encaixantes (Figura 148).

A população de autocristais de zircão do tonalito do Maciço de Gerena (GR-02) foi cristalizada somente depois do contato e assimilação dos diques sin-plutônicos máficos no magma félsico. É possível inferir isto, pois magmas máficos são insaturados em Zr e não cristalizam zircão (Siégel et al., 2018). A cristalização desta população está relacionada a assimilação de $\mathrm{Zr}$ proveniente do magma félsico. 


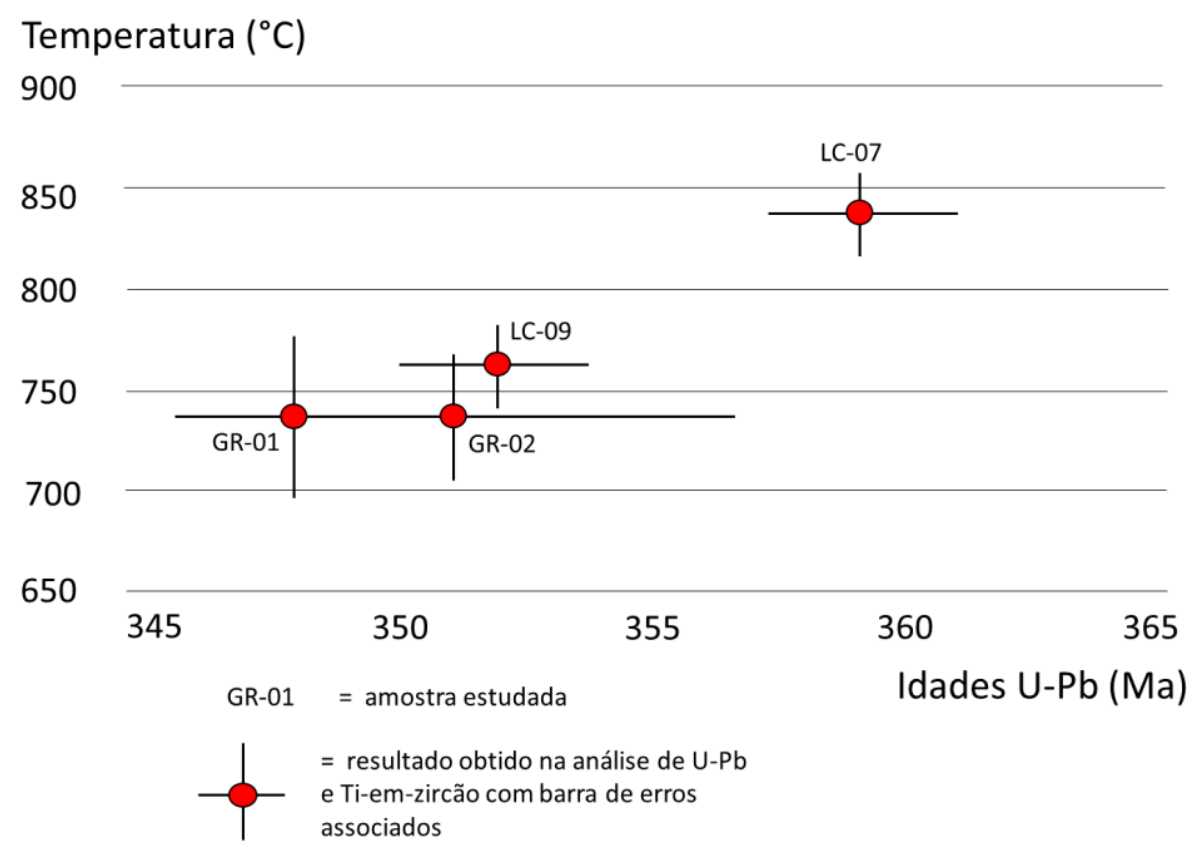

Figura 148. Dados de U-Pb e Ti-em-zircão obtidos em Las Cruces e Gerena mostrando como as rochas de Gerena estão associadas ao magmatismo Tournaisiano $\left[T\left({ }^{\circ} \mathrm{C}\right)<785^{\circ} \mathrm{C}\right]$, enquanto que as mineralizações estão associadas ao magmatismo Struniano $\left[\mathrm{T}\left({ }^{\circ} \mathrm{C}\right)>800^{\circ} \mathrm{C}\right]$.

\subsection{TEMPERATURAS DO MAGMA EM DEPÓSITOS VMS}

A maioria dos distritos de sulfeto maciço vulcanogênicos e subclasses de depósitos VMS estão associados a rochas máficas e félsicas que são específicas de magmatismo de alta temperatura $\left(\mathrm{T}>800^{\circ} \mathrm{C}\right.$ ) (Piercey 2007, 2010, 2011). As intrusões subvucânicas que ocorrem em diversos níveis crustais também são produtos de um elevado regime térmico comum aos ambientes que abrigam depósitos VMS. Estas intrusões são consideradas bons indícios de ambiente propício a depósitos VMS, mas não podem ser consideradas responsáveis pelo conteúdo de metais e pela geração do hidrotermalismo, que é gerado em rochas mais profundas, entre $3-10 \mathrm{~km}$ de profundidade (Piercey 2011).

A presença de rochas máficas associadas as rochas félsicas mineralizadas é marcante em depósitos VMS associados a rochas félsicas e está relacionada com as temperaturas elevadas (Piercey, 2011). Na FPI o Complexo VS inclui sequencias complexas de rochas máficas e félsicas intercalas com folhelhos e sedimentos químicos. Nos centros vulcânicos as sequencias são predominantemente compostas por rochas félsicas (60\%), com proporção menor de rochas máficas (20\%) e folhelhos (20\%). Estas 
rochas máficas ocorrem como sills basálticos ou pequenos stocks, além de localmente como lavas (Tornos, 2006).

Dados geoquímicos (alto conteúdo de $\mathrm{Zr}, \mathrm{Ga}$, ETR leves e pesados, Y, Nb) de ambientes crustais indicam que com a geração das rochas félsicas associadas aos depósitos de VMS ocorre a partir de fusão parcial de material crustal a temperaturas elevadas $\left(\mathrm{T}>900^{\circ} \mathrm{C}\right)$ devido a ascensão de magmas basálticos em ambientes extensionais de riftes (Lentz, 1998, 1999; Whalen et al., 1998, Piercey et al., 2001, Piercey, 2003, Piercey, 2008, Piercey, 2011). Para Piercey (2011), em ambientes de depósitos de VMS máficos e félsicos, o magmatismo é de alta temperatura gerado em níveis superficiais rasos.

Para Piercey (2011) a fusão de terrenos máficos/andesíticos, que possuem baixo conteúdo de $\mathrm{Zr}$ gera rochas com baixo conteúdo de $\mathrm{Zr}$. Isto explicaria as baixas assinaturas de $\mathrm{Zr}(<50-100 \mathrm{ppm})$ nos distritos VMS de Flin Flon, partes de Snow Lake e Rambler (Piercey, 2011). Adicionalmente, fusão parcial de alta temperatura em rochas granulíticas também podem gerar melts graníticos com baixo Zr (Villaseca et al., 2007).

Mais recentemente alguns depósitos associados a rochas félsicas com conteúdo de Zr baixos têm sido descritos, como os depósitos VMS de Boundary (Piercey et al., 2014) e de Ming (Pilote \& Piercey, 2018) nas Montanhas Apalaches em Newfoundland, Canadá, além do depósito de Rio Tinto e depósitos do Cinturão Norte (Conde, 2016). O depósito de Ming está associado a um complexo de domos félsicos com assinaturas de $\mathrm{Zr}$ entre 60-80 ppm nas rochas félsicas e 105-120 ppm nas rochas máficas. Por sua vez o depósito de Boundary está associado a sub-seafloor replacement em lavas riolíticas e rochas vulcanoclásticas associadas, com conteúdo de Zr variando entre 110-170 ppm nestas rochas félsicas. Conde (2016) e Conde \& Tornos (2019) observaram valores de Zr menores que 200ppm nas rochas encaixantes as mineralizações nos depósitos do Cinturão Norte e em Rio Tinto, enquanto que as rochas estéreis apresentaram valores superiores a 200ppm.

Para Piercey (2011) os intervalos de magmatismo de longa duração (Bieldeman Bay - 14 Ma; VMS de Noranda - 3 Ma; e VMS de Wolverine - 5 Ma), também indicariam um gradiente geotérmico elevado associado a estes depósitos. O depósito de Aljustrel, na FPI portuguesa, é um depósito com intervalo de 15 Ma que possui temperaturas estimadas em $829 \pm 73^{\circ} \mathrm{C}$ via temperatura de saturação do zircão e $851 \pm 78^{\circ} \mathrm{C}$ via Ti-em-zircão (Codeço et al., 2015, Codeço et al., 2018). 
As temperaturas isotópicas de $\mathrm{Ti}$ obtidas nesta tese complementam o modelo vigente para as temperaturas das rochas vulcânicas associadas aos depósitos VMS (Piercey 2011 e referências); concordam com os trabalhos mais recentes (Piercey et al., 2014; Conde, 2016, Pilote \& Piercey, 2018) e mostram que de fato existem diversos depósitos de VMS, associados a magmatismo de temperatura mais baixa ( $\mathrm{T}<760^{\circ} \mathrm{C}$ ). $\mathrm{O}$ depósito de Rio Tinto, por exemplo, possui as temperaturas mais baixas observadas nesta tese $\left(\mathrm{T}<725^{\circ} \mathrm{C}\right)$ e é fruto de uma atividade magmática com amplo intervalo de duração, indicando também que a manutenção de uma atividade magmática de longa duração não é exclusividade de ambientes com alto gradiente geotérmico e temperaturas superiores a $800^{\circ} \mathrm{C}$.

$\mathrm{Na}$ realidade a interpretação de altas temperaturas reflete mais um enviesamento de dados dos depósitos que já foram estudados do que realmente uma necessidade de altas temperaturas para a formação dos depósitos VMS, possivelmente refletindo mais as características dos depósitos VMS dos Apalaches, onde a maioria dos estudos do Prof. Piercey foram realizados (Piercey, comunicação oral).

Isso reforça o argumento a favor da utilização de modelos de gênese que levem em conta os processos geológicos e não modelos descritivos que levam em conta depósitos análogos. Mesmo que os modelos descritivos sejam úteis e auxiliem na pesquisa mineral, eles só permitem descobertas de depósitos que apresentem características similares aos já descritos, deixando de lado a possibilidade de novas descobertas (McCuaig et al., 2010).

A abordagem de sistemas minerais, por outro lado, permite focar nos processos mineralizantes e, com isso, reflete melhor os processos genéticos relacionados com a formação destes depósitos (McCuaig et al., 2007; McCuaig et al., 2010; McCuaig \& Hronsky, 2014). Em depósitos magmáticos hidrotermais continentais já ocorre uma mudança de pensamento em relação aos depósitos epitermais (low, intermediate e high sulfidation), tipo pórfiro e skarns, que nada mais são que feições distintas desenvolvidas em um ambiente vulcânico-hidrotermal (Hedenquist et al., 2000; Sillitoe, 2010, Mello, 2015). Em depósitos VMS esta mudança também está ocorrendo e a revisão mais recente sobre estes depósitos leva em conta os processos mineralizantes e não as feições descritivas destes depósitos (Tornos et al., 2015a). 
As temperaturas obtidas nesta tese mostram que depósitos de VMS podem ser formados associados a rochas félsicas de temperaturas elevadas $\left(>800^{\circ} \mathrm{C}\right)$ e mais brandas $\left(<760^{\circ} \mathrm{C}\right)$ e que, portanto, a temperatura não é um critério confiável para se estabelecer quais rochas félsicas podem estar associadas aos depósitos de VMS.

Nesta tese a região com assinatura de $\varepsilon_{\mathrm{Hf}}$ mais mantélica (a Região Norte) apresenta justamente as temperaturas abaixo de $775^{\circ} \mathrm{C}$, enquanto que as assinaturas de $\varepsilon_{\mathrm{Hf}}$ mais crustais estão associadas justamente aos depósitos da Região Sul, onde as rochas félsicas registram temperaturas mais elevadas $\left(\mathrm{T}>800^{\circ} \mathrm{C}\right)$. Ou seja, a presença deste material mantélico na Região Norte, assim como sua maior proximidade com a pluma descrita na Zona de Ossa Morena, não implicou em temperaturas mais elevadas.

\subsection{IMPLICAÇÕES EXPLORATÓRIAS}

Os resultados obtidos nesta tese trazem implicações exploratórias interessantes. Localmente, na FPI, um novo intervalo de mineralizações VMS foi comprovado como um intervalo metalogenético relevante. Antes a literatura só considerava o depósito de Rio Tinto como um depósito formado no Tournaisiano. Nesta tese foi demonstrado que na realidade todos os depósitos da Região Norte estão associados ao Tournaisiano, mais especificamente entre 357Ma e 348 Ma.

As implicações exploratórias globais são ainda mais relevantes. Antes deste trabalho poucos depósitos de VMS foram descritos em associação com rochas vulcânicas "frias", com temperaturas abaixo dos $800^{\circ} \mathrm{C}$. Conde (2016), bem como Piercey et al. ( 2014) e Pilote \& Piercey (2018) observaram depósitos associados a rochas vulcânicas com teores de $\mathrm{Zr}$ abaixo de 200 ppm, o que para estes autores indicaria temperaturas mais frias. Entretanto não existia nenhum trabalho que utilizasse um geotermômetro robusto e comprovasse estas temperaturas "frias". Com os resultados obtidos nesta tese, entretanto, fica claro que existem diversos depósitos VMS associados a temperaturas inferiores a $800^{\circ} \mathrm{C}$. Estas temperaturas podem estar associadas, inclusive, a depósitos VMS gigantes como La Zarza e Rio Tinto.

Com isso a paradigma de que os depósitos VMS estão associados a temperaturas elevadas $\left(>800^{\circ} \mathrm{C}\right.$, Piercey, 2011) deve ser desconsiderado. A consequência principal é que foi aberto um novo horizonte de exploração, as rochas vulcânicas "frias", ampliando significativamente o espectro de ambientes que podem abrigar depósitos VMS. 


\section{CONCLUSÕES}

A Faixa Piritosa Ibérica pode ser dividida em duas regiões distintas, a Região Norte e a Região Sul. As duas regiões possuem ambientes de formação distintos para os corpos de sulfeto maciço, a substituição que ocorre abaixo do assoalho oceânico da Região Norte e a precipitação em bacias anóxicas da Região Sul. Esta tese executou um extenso estudo geocronológico, de temperatura de cristalização dos cristais de zircão no magma e da origem dos litotipos félsicos associados aos corpos de sulfeto maciço.

Os resultados geocronológicos obtidos ampliam o que já havia sido descrito no depósito de Rio Tinto (Barrie et al., 2002; Valenzuela et al., 2011) e demonstraram que o magmatismo de toda a Região Norte ocorreu no Tournaisiano, entre 358-347 Ma. O magmatismo associado a Região Sul apresenta idades associadas ao Struniano (Famenniano Superior), entre 365-359 Ma, conforme já foi detalhado em outros trabalhos. Tornos et al. (2015b) infere que a migração a norte do magmatismo no intervalo Tournaisiano está relacionado a mudança de ângulo da subducção que ocorria concomitantemente

O Cinturão Norte apresenta rochas félsicas associadas aos sulfetos maciços no intervalo entre 354-347 Ma, enquanto que La Zarza, no Setor Central apresenta idades de 357-355 Ma. Em Rio Tinto o estudo geocronológico foi mais aprofundado e caracterizou um amplo intervalo de pulsos intermitentes de vulcanismo que teve início em $358 \mathrm{Ma}$ com um magmatismo de pouco expressão datado em rochas vulcanoclásticas de Zarandas. O pico da atividade vulcânica ocorreu entre 352 e 348 Ma, idade que está associada aos corpos de sulfeto maciço da localidade, enquanto o término da atividade vulcânica ocorre em 339 Ma, totalizando um intervalo de 19 Ma. Este magmatismo intermitente gera hidrotermalismo intermitente e o hidrotermalismo associado ao vulcanismo de 352-348 Ma está associado aos depósitos de VMS. O intervalo de $19 \mathrm{Ma}$ é superior aos intervalos conhecidos de outras províncias de VMS mundiais (Bieldeman Bay - 14 Ma; VMS de Noranda - 3 Ma; e VMS de Wolverine - 5 Ma; Piercey, 2011), indicando que a duração da atividade vulcânica pode estar diretamente relacionada ao tamanho dos depósitos gerados. No caso de Rio Tinto o vulcanismo sin-mineralização ocorreu em um intervalo de 4 Ma.

A Região Sul apresentou idades U-Pb associadas aos corpos de sulfeto maciço entre 365-359 Ma. Outras idades entre 352-348 Ma também são observadas na Região Sul em rochas plutônicas e em uma rocha vulcânica estéril em Las Cruces, o que mostra 
que o padrão de dois intervalos vulcânicos (363-358 Ma e 353-349 Ma) com corpos de sulfeto maciço associadas ao primeiro intervalo descrito por Solá et al. (2015) em Neves Corvo se repete ao longo da Região Sul.

Os dados isotópicos de Ti confirmaram as observações de Conde (2016) de que as rochas félsicas associadas aos corpos de sulfeto maciço da Região Norte são relativamente frias, o que as difere das rochas félsicas da Região Sul. Na Região Norte as temperaturas calculadas para a cristalização dos cristais de zircão rochas vulcânicas estéreis são de $\sim 780^{\circ} \mathrm{C}$ enquanto que a cristalização dos cristais de zircão das rochas associadas aos corpos de sulfeto maciço apresentam temperaturas $<760^{\circ} \mathrm{C}$ no Cinturão Norte e em La Zarza e temperaturas $<730^{\circ} \mathrm{C}$ em Rio Tinto. Estes resultados discordam do modelo atual de temperatura das rochas félsicas associadas a depósitos VMS (Piercey, 2011) e concordam com alguns trabalhos mais recentes que mostram corpos de VMS associados a rochas félsicas mais frias (Piercey et al., 2014; Pilote \& Piercey, 2018; Conde, 2016; Conde \& Tornos, 2019). Na Região Sul as temperaturas de cristalização de zircão das rochas vulcânicas associadas aos sulfetos maciços são sempre superior à $800^{\circ} \mathrm{C}$. Na FPI as rochas vulcânicas podem ser consideradas as fontes de calor que geram a circulação do fluido hidrotermal. Essas rochas não são fonte importante de metais e nem de fluidos, ambos associados ao Grupo FQ.

A contribuição de material mantélico na geração dos litotipos félsicos também varia de acordo com a região da FPI. As amostras do Cinturão Norte apresentam assinatura de $\varepsilon_{\mathrm{Hf}} \sim-0.2$, enquanto que o Setor Central apresenta $\varepsilon_{\mathrm{Hf}} \sim$-3.2. A Região Sul possui $\varepsilon_{H f} \sim-5.2$ na porção espanhola e $\varepsilon_{H f} \sim-7.97$ na porção portuguesa. Ou seja, as assinaturas de $\varepsilon_{\mathrm{Hf}}$ mostram maior quantidade de contribuição de material mantélico na formação das rochas vulcânicas do Cinturão Norte e menor contribuição de mantélico na Região Sul. Andesitos ocorrem em quantidade somente no Cinturão Norte e comprovam essa maior interação nesta região. Esta interação com rochas máficas possivelmente indica a influência do material de derivação mantélica da pluma atuante na Zona de Ossa Morena na geração do magmatismo do Complexo VS na Região Norte, com maior interação no Cinturão Norte.

As rochas plutônicas do Maciço de Gerena apresentaram dados geocronológicos, termométricos e de $\varepsilon_{\mathrm{Hf}}$ que mostram que estas rochas podem ser consideradas parte da raiz plutônica da atividade magmática do Complexo VS da Região Sul ao longo do vulcanismo Tournaisiano. Uma das amostras do Maciço de Gerena também registra uma população de zircão Riaciana, com idade de $2.2 \mathrm{Ga}$. Esta população de xenocristais 
também registra a Orogenia Cadomiana através da idade do intercepto inferior de 587 Ma. 


\section{REFERÊNCIAS}

Abalos, B., Ibarguchi, J. G., \& Eguiluz, L. (1991). Cadomian subduction/collision and Variscan transpression in the Badajoz-Córdoba shear belt, southwest Spain. Tectonophysics, 199(1), 51-72.

Amelin, Y., Der-Chuen, L., Halliday, A. N., \& Pidgeon, R. T. (1999). Nature of the Earth's earliest crust from hafnium isotopes in single detrital zircons. Nature, 399(6733), 252.

Anderson, J. L., Barth, A. P., Wooden, J. L., \& Mazdab, F. (2008). Thermometers and thermobarometers in granitic systems., Reviews in Mineralogy and Geochemistry, 69(1), 121-142.

Andrew, R.L (2000) Short Course in Evaluation of Gossans in Mineral Exploration, ADIMB, Brasilia, 57pp

Anschutz, P., Blanc, G., Monnin, C., \& Boulègue, J. (2000). Geochemical dynamics of the Atlantis II Deep (Red Sea): II. Composition of metalliferous sediment pore waters. Geochimica et Cosmochimica Acta, 64(23), 39954006.

Aranda, S. M., \& del Villar, J. R. C. (1995). Metodología de investigación aplicada a los yacimientos de Manganeso en Huelva. Boletín geológico y minero, 106(2), 21-31.

Arthur, M. A., \& Sageman, B. B. (1994). Marine black shales: depositional mechanisms and environments of ancient deposits. Annual Review of Earth and Planetary Sciences, 22(1), 499-551.

Baldwin, J. A., Brown, M., \& Schmitz, M. D. (2007). First application of titanium-in-zircon thermometry to ultrahigh-temperature metamorphism. Geology, 35(4), 295-298.

Baker, E. T. (2009). Relationships between hydrothermal activity and axial magma chamber distribution, depth, and melt content. Geochemistry, Geophysics, Geosystems, 10(6)

Bandrés, A., Eguíluz, L., Ibarguchi, J. G., \& Palacios, T. (2002). Geodynamic evolution of a Cadomian arc region: the northern Ossa-Morena zone, Iberian massif. Tectonophysics, 352(1-2), 105-120.

Bard, J. P. (1969). Le metamorphisme regional progressif des Sierras de Aracena en Andalousie occidentale (Espagne): sa place dans le segment hercynien sub-iberique.

Barriga, F. J. A. S., \& Fyfe, W. S. (1997). Multi-phase water-rhyolite interaction and ore fluid generation at Aljustrel, Portugal. Mineralium Deposita, 33(1-2), 188-207.

Barrie, T. C., Amelin, Y., \& Pascual, E. (2002). U-Pb geochronology of VMS mineralization in the Iberian Pyrite Belt. Mineralium Deposita, 37(8), 684-703.

Barrie, C. T., \& Hannington, M. D. (1999). Classification of volcanic-associated massive sulfide deposits based on host-rock composition. Reviews in Economic Geology, 8, 1-11.

Bea, F., Montero, P. G., Gonzalez-Lodeiro, F., Talavera, C., Molina, J. F., Scarrow, J. H., ... \& Zinger, T. (2006). Zircon thermometry and U-Pb ion-microprobe dating of the gabbros and associated migmatites of the Variscan Toledo Anatectic Complex, Central Iberia. Journal of the Geological Society, 163(5), 847-855.

Belousova, E., Griffin, W. L., O'Reilly, S. Y., \& Fisher, N. L. (2002). Igneous zircon: trace element composition as an indicator of source rock type. Contributions to mineralogy and petrology, 143(5), 602-622.

Black, L.P., Kamo, S.L., Allen, C.M., Davis, D.W., Aleinikoff, J.N., Valley, J.W., Mundil, R., Campbell, I.H., Korsch, R.J., Williams, I.S., Foudoulis, C., 2004. Improved Pb-206/U-218 microprobe geochronology by the monitoring of a trace-element-related matrix effect; SHRIMP, ID-TIMS, ELA-ICP-MS and oxygen isotope documentation for a series of zircon standards. Chemical Geology 205, 115-140. 
Blake, C. (2008). Mineralogical characterisation and interpretation of a precious metal-bearing fossil gossan, Las Cruces, Spain. Cardiff University (United Kingdom).

Bobrowicz, G. L. (1995) Mineralogy, geochemistry and alteration as exploration guides at Aguas Teñidas Este, Pyrite Belt, Spain. Phd Thesis University of Birmingham

Boulter, C. D. (1993). Comparison of Rio Tinto, Spain, and Guaymas Basin, Gulf of California: An explanation of a supergiant massive sulfide deposit in an ancient sill-sediment complex. Geology, 21(9), 801-804.

Boulter, C. (2005). Comment on "A new geodynamic interpretation for the South Portuguese Zone (SW Iberia) and the Iberian Pyrite Belt genesis" by J. Onézime et al. Tectonics, 24(1).

Bouvier, A., Vervoort, J. D., \& Patchett, P. J. (2008). The Lu-Hf and Sm-Nd isotopic composition of CHUR: constraints from unequilibrated chondrites and implications for the bulk composition of terrestrial planets. Earth and Planetary Science Letters, 273(1-2), 48-57.

Bryan, S. E., Ferrari, L., Reiners, P. W., Allen, C. M., Petrone, C. M., Ramos-Rosique, A., \& Campbell, I. H. (2007). New insights into crustal contributions to large-volume rhyolite generation in the mid-Tertiary Sierra Madre Occidental province, Mexico, revealed by U-Pb geochronology. Journal of Petrology, 49(1), 47-77.

Capdevila, R., Corretge, G., \& Floor, P. (1973). Les granitoides varisques de la Meseta Ibérique. Bulletin de la Société géologique de France, 7(3-4), 209-228.

Caplan, M. L., \& Bustin, R. M. (1999). Devonian-Carboniferous Hangenberg mass extinction event, widespread organic-rich mudrock and anoxia: causes and consequences. Palaeogeography, Palaeoclimatology, Palaeoecology, 148(4), 187-207.

Cambridge Mineral Resources, Internal Report, (2004). Mineralogy, geochemistry and alteration as exploration guides at Aguas Teñidas Este, Pyrite Belt, Spain. PhD Thesis University of Birmigham.

Camus, F., \& Dilles, J. H. (2001). A special issue devoted to porphyry copper deposits of northern Chile. Economic Geology, 96(2), 233-237.

Castro, A., Jesús, D., \& Stephens, W. E. (1990). Magma mixing in the subvolcanic environment: petrology of the Gerena interaction zone near Seville, Spain. Contributions to Mineralogy and Petrology, 106(1), 9-26.

Castroviejo, R., Quesada, C., \& Soler, M. (2011). Post-depositional tectonic modification of VMS deposits in Iberia and its economic significance. Mineralium Deposita, 46(5-6), 615-637.

Cherniak, D. J., Hanchar, J. M., \& Watson, E. B. (1997). Diffusion of tetravalent cations in zircon. Contributions to Mineralogy and Petrology, 127(4), 383-390.

Chu, N. C., Taylor, R. N., Chavagnac, V., Nesbitt, R. W., Boella, R. M., Milton, J. A., ... \& Burton, K. (2002). $\mathrm{Hf}$ isotope ratio analysis using multi-collector inductively coupled plasma mass spectrometry: an evaluation of isobaric interference corrections. Journal of Analytical Atomic Spectrometry, 17(12), 1567-1574.

Claiborne, L. L., Miller, C. F., Walker, B. A., Wooden, J. L., Mazdab, F. K., \& Bea, F. (2006). Tracking magmatic processes through $\mathrm{Zr} / \mathrm{Hf}$ ratios in rocks and $\mathrm{Hf}$ and Ti zoning in zircons: an example from the Spirit Mountain batholith, Nevada. Mineralogical Magazine, 70(5), 517-543

Codeço, M. S., Mateus, A., Figueiras, J., Rodrigues, P., \& Gonçalves, L. (2018). Development of the ErvidelRoxo and Figueirinha-Albernoa volcanic sequences in the Iberian pyrite Belt, Portugal: Metallogenic and geodynamic implications. Ore Geology Reviews, 98, 80-108. 
Codeço, M., Mateus, A., Figueiras, J., Rodrigues, P., \& Gonçalves, L (2015). Zircon as a magma monitor: examples of zircon saturation and Ti-in-zircon thermometry applied to felsic volcanics of the Iberian Pyrite Belt. X Congresso Ibérico de Geoquímica/XVIII Semana de Geoquímica, Conference Paper,

Conde, C. (2016) Geology and hydrothermal evolution of massive sulphides of the Iberian Pyrite Belt. Tese de Doutorado, Universidad de Salamanca, Espanha.

Conde, C., \& Tornos, F. (2019). Geochemistry and architecture of the host sequence of the massive sulfides in the northern Iberian Pyrite Belt. Ore Geology Reviews, 103042.

Conde, C., Tornos, F., Fernandez, J., Doyle, M (2003) Encuadre estratigráfico de los sulfurus massivos de la parte Surroriental de La Faja Piritica: Aznalcollar-Los Frailes y Las Cruces. Boletin Sociedad Española Mineralogia 26-A: 161-162

Coogan, L. A., \& Hinton, R. W. (2006). Do the trace element compositions of detrital zircons require Hadean continental crust?. Geology, 34(8), 633-636.

Corfu, F., Hanchar, J. M., Hoskin, P. W., \& Kinny, P. (2003). Atlas of zircon textures. Reviews in mineralogy and geochemistry, 53(1), 469-500.

Doyle, M.(1996) Las Cruces copper proyect, Pyrite Belt, Spain. Boletín geológico y minero, 107:681-683

Doyle, M.G., Allen, R.L., 2003. Subsea-floor replacement in volcanic-hosted massive sulfide deposits. Ore Geology Reviews 23, 183-222.

Dunning, G. R., Díez Montes, A., Matas, J., Martín Parra, L. M., Almarza, J., \& Donaire, M. (2002). Geocronología U/Pb del volcanismo ácido y granitoides de la Faja Pirítica Ibérica (Zona Surportuguesa). Geogaceta $32,127-130$.

Eguíluz, L., Abalos, B. (1992). Tectonic setting of Cadomian low-pressure metamorphism in the central OssaMorena Zone (Iberian Massif, SW Spain). Precambrian Research, 56(1-2), 113-137.

Egiuluz, L., Ibarguchi, J. G., Abalos, B., \& Apraiz, A. (2000). Superposed Hercynian and Cadomian orogenic cycles in the Ossa-Morena zone and related areas of the Iberian Massif. Geological Society of America Bulletin, 112(9), 1398-1413.

Faure, G., \& Mensing, T. M. (2005). Isotopes: principles and applications. John Wiley \& Sons Inc

Ferry, J. M., \& Watson, E. B. (2007). New thermodynamic models and revised calibrations for the Ti-inzircon and Zr-in-rutile thermometers. Contributions to Mineralogy and Petrology, 154(4), 429-437.

Fletcher, R. (2012) NI43-101 TECHNICAL REPORT ON THE LOMERO-POYATOS Au-Cu-Pb-Zn MINE IN ANDALUSIA, SPAIN. https://www.sec.gov/Archives/edgar/data/947121/000117625612000719/exhibit99-1.htm

Fisher, C. M., Hanchar, J. M., Samson, S. D., Dhuime, B., Blichert-Toft, J., Vervoort, J. D., \& Lam, R. (2011). Synthetic zircon doped with hafnium and rare earth elements: A reference material for in situ hafnium isotope analysis. Chemical Geology, 286(1-2), 32-47.

Franklin JM, Gibson HL, Jonasson IR, and Galley AG (2005) Volcanogenic massive sulfide deposits. In: Hedenquist JW, Thompson JFH, Goldfarb RJ, and Richards JP (eds.) 100th Anniversary Volume

Fu, B., Page, F. Z., Cavosie, A. J., Fournelle, J., Kita, N. T., Lackey, J. S., ... \& Valley, J. W. (2008). Ti-inzircon thermometry: applications and limitations. Contributions to Mineralogy and Petrology, 156(2), 197-215. 
Ghiorso, M. S., \& Gualda, G. A. (2013). A method for estimating the activity of titania in magmatic liquids from the compositions of coexisting rhombohedral and cubic iron-titanium oxides.Contributions to Mineralogy and Petrology, 165(1), 73-81.

González Clavijo, E. J., \& Díez Montes, A. (2010). Propuesta de estructura geológica para el depósito gigante de sulfuros masivos volcanogénicos de Río Tinto, Faja Pirítica Ibérica. Geogaceta, 48, 203-206.

Gonzalez, F., Moreno, C., Saez, R., \& Clayton, G. (2002). Ore genesis age of the Tharsis Mining District (Iberian Pyrite Belt): a palynological approach. Journal of the Geological Society, 159(3), 229-232.

Goodfellow, W. D., McCutcheon, S. R., \& Peter, J. M. (2003). Massive sulfide deposits of the Bathurst mining camp, New Brunswick and northern Maine: Introduction and summary of findings. Economic Geology, 11, 116.

Granda, A., Granda, T., Pons, J. M., \& Videira, J. C. (2016). The leading role of geophysical methods in the discovery of the La Magdalena VMS deposit in the Pyrite Belt, Huelva. First Break, 34(8), 67-78.

Groves, D. I., Condie, K. C., Goldfarb, R. J., Hronsky, J. M. A., \& Vielreicher, R. M. (2005). Secular changes in global tectonic processes and their influence on the temporal distribution of gold-bearing mineral deposits. Economic Geology, 100(2), 203-224.

Hanchar, J. M., Finch, R. J., Hoskin, P. W., Watson, E. B., Cherniak, D. J., \& Mariano, A. N. (2001). Rare earth elements in synthetic zircon: Part 1. Synthesis, and rare earth element and phosphorus doping. American Mineralogist, 86(5-6), 667-680.

Hanchar, J. M., \& Miller, C. F. (1993). Zircon zonation patterns as revealed by cathodoluminescence and backscattered electron images: implications for interpretation of complex crustal histories. Chemical geology, 110(13), 1-13.

Hanchar, J. M., \& Watson, E. B. (2003). Zircon saturation thermometry. Reviews in mineralogy and geochemistry, 53(1), 89-112.

Harrison, T. M., Aikman, A., Holden, P., Walker, A. M., McFarlane, C., Rubatto, D., \& Watson, E. B. (2005). Testing the Ti-in-zircon thermometer. In AGU Fall Meeting Abstracts.

Harrison, T. M., Watson, E. B., \& Aikman, A. B. (2007). Temperature spectra of zircon crystallization in plutonic rocks. Geology, 35(7), 635-638.

Hedenquist, J. W., \& Lowenstern, J. B. (1994). The role of magmas in the formation of hydrothermal ore deposits. Nature, 370(6490), 519-527.

Hedenquist, J. W., Arribas, A. \& Gonzalez-Urien, E. (2000). Exploration for epithermal gold deposits. Reviews in Economic Geology, 13(2), 45-77.

Heinrich, C. A., \& Neubauer, F. (2002). Cu-Au-Pb-Zn-Ag metallogeny of the Alpine-Balkan-CarpathianDinaride geodynamic province. Mineralium Deposita, 37(6), 533-540.

Herzig, P. M., \& Hannington, M. D. (1995). Polymetallic massive sulfides at the modern seafloor a review. Ore Geology Reviews, 10(2), 95-115.

Hoskin, P. W., \& Schaltegger, U. (2003). The composition of zircon and igneous and metamorphic petrogenesis. Reviews in mineralogy and geochemistry, 53(1), 27-62. 
Huston, D. L., Pehrsson, S., Eglington, B. M., \& Zaw, K. (2010). The geology and metallogeny of volcanichosted massive sulfide deposits: Variations through geologic time and with tectonic setting. Economic Geology, 105(3), 571-591.

Klein, C. (2002) The 22nd Edition of the Manual Of Mineral Science. 642p.

Knight, F. C. (2000). The mineralogy, geochemistry and genesis of the secondary sulphide mineralisation of the Las Cruces deposit, Spain. Tese de Doutorado, University of Wales, País de Gales.

Koski, R. A. \& Mosier, D. I. 2012. Deposit type and associated commodities in volcanogenic massive sulfide occurence model, U.S. Geological Survey Scientific Investigations Report 2010-5070-C chap 2.

Jorge, R. C. G. S., Relvas, J. M. R. S., \& Barriga, F. J. A. S. (2005). Silica gel microtextures in siliceous exhalites at the Soloviejo manganese deposit, Spain. In Mineral deposit research: Meeting the global challenge (pp. 631-634). Springer, Berlin, Heidelberg.

Laznicka, P. (1999). Quantitative relationships among giant deposits of metals. Economic Geology, 94(4), 455-473.

Leistel, J. M., Marcoux, E., Thiéblemont, D., Quesada, C., Sánchez, A., Almodóvar, G. R., ... \& Sáez, R. (1997). The volcanic-hosted massive sulphide deposits of the Iberian Pyrite Belt Review and preface to the Thematic Issue. Mineralium Deposita, 33(1), 2-30.

Lentz, D. R. (1998). Petrogenetic and geodynamic implications of extensional regimes in the phanerozoic subduction zones and their relationship to VMS-forming systems. Ore Geology Reviews, 12, 289-327.

Lentz, D. R. (1999). Petrology, geochemistry, and oxygen isotope interpretation of felsic volcanic and related rocks hosting the Brunswick 6 and 12 massive sulfide deposits (Brunswick Belt), Bathurst mining camp, New Brunswick, Canada. Economic Geology, 94(1), 57-86.

Ludwig, K. R. (2009). Isoplot. A Geochronological Toolkit for Microsoft Excel. Ver. 3.71. 09.05. 23nx.

Luz, F., Mateus, A., Figueiras, J., Tassinari, C. C., Ferreira, E., \& Gonçalves, L. (2019). Recognizing metasedimentary sequences potentially hosting concealed massive sulfide accumulations in the Iberian Pyrite Belt using geochemical fingerprints. Ore Geology Reviews, 107, 973-998.

McCuaig, T. C., Beresford, S., \& Hronsky, J. (2010). Translating the mineral systems approach into an effective exploration targeting system. Ore Geology Reviews, 38(3), 128-138.

McCuaig, T. C., \& Hronsky, J. M. (2014). The mineral system concept: the key to exploration targeting. Society of Economic Geologists Special Publication, 18, 153-175.

McCuaig, T. C., Kreuzer, O. P., Brown, W. M. (2007). Fooling ourselves-dealing with model uncertainty in a mineral systems approach to exploration. In Mineral Exploration and Research: Digging Deeper: Proceedings of the 9th Biennial SGA Meeting, Dublin (pp. 1435-1438).

Mantero, E. M., García Navarro, E., Alonso Chaves, F. M., Martín Parra, L. M., Matas, J., \& Azor, A. (2007). La Zona Sudportuguesa: propuesta para la división de un bloque continental en dominios. Geogaceta, 43, 27-30.

Mantero, E. M., Alonso-Chaves, F. M., García-Navarro, E., \& Azor, A. (2011). Tectonic style and structural analysis of the Puebla de Guzmán Antiform (Iberian Pyrite Belt, South Portuguese Zone, SW Spain). Geological Society, London, Special Publications, 349(1), 203-222. 
Marcoux, E. (1997). Lead isotope systematics of the giant massive sulphide deposits in the Iberian Pyrite Belt. Mineralium Deposita, 33(1-2), 45-58.

Marti, J., Soriano, C., \& Dingwell, D. B. (1999). Tube pumices as strain markers of the ductile-brittle transition during magma fragmentation. Nature, 402(6762), 650.

Maslennikov, V. V., Maslennikova, S. P., Large, R. R., Danyushevsky, L. V., Herrington, R. J., Ayupova, N. R., ... \& Tessalina, S. G. (2017). Chimneys in Paleozoic massive sulfide mounds of the Urals VMS deposits: Mineral and trace element comparison with modern black, grey, white and clear smokers. Ore Geology Reviews, 85, 64-106.

Matte, P. (2001). The Variscan collage and orogeny (480-290 Ma) and the tectonic definition of the Armorica microplate: a review. Terra nova, 13(2), 122-128.

Mathur, R., Ruiz, J., \& Tornos, F. (1999). Age and sources of the ore at Tharsis and Rio Tinto, Iberian pyrite belt, from Re-Os isotopes. Mineralium Deposita, 34(8), 790-793.

Matos, J. X., Pereira, Z., Rosa, C. J., Rosa, D., Oliveira, J. T., \& Relvas, J. M. (2011). Late Strunian age: a key time frame for VMS deposit exploration in the Iberian Pyrite Belt. In 11th SGA Biennial Meeting: Let's Talk Ore Deposits.

McCuaig, T. C., Beresford, S., \& Hronsky, J. (2010). Translating the mineral systems approach into an effective exploration targeting system. Ore Geology Reviews, 38(3), 128-138.

McCuaig, T. C., \& Hronsky, J. M. (2014). The mineral system concept: the key to exploration targeting. Society of Economic Geologists, Special Publication, 18, 153-175.

Mello C. R (2015) Características Isotópicas de Pb da Mineralização Aurífera de Marmato, Colombia; Implicações para Identificação e Caracterização de Domínios Transicionais entre Sistemas Epitermais e do tipo Pórfiro. Dissertação de Mestrado, Instituto de Geociências, Universidade de São Paulo, Brasil.

Mello, C. R., Tassinari, C. C. G., Conde, C., Tornos, F. 2017 U/Pb Geochronology of the igneous rocks associated to the Rio Tinto VMS deposit. Conference Paper $14^{\text {th }}$ Biennial Meeting SGA Quebec.

Menor-Salván, C., Tornos, F., Fernández-Remolar, D., \& Amils, R. (2010). Association between catastrophic paleovegetation changes during Devonian-Carboniferous boundary and the formation of giant massive sulfide deposits. Earth and Planetary Science Letters, 299(3), 398-408.

Moecher, D. P., McDowell, S. M., Samson, S. D., \& Miller, C. F. (2014). Ti-in-zircon thermometry and crystallization modeling support hot Grenville granite hypothesis. Geology, 42(3), 267-270.

Mojzsis, S. J., Harrison, T. M., \& Pidgeon, R. T. (2001). Oxygen-isotope evidence from ancient zircons for liquid water at the Earth's surface 4,300 Myr ago. Nature, 409(6817), 178.

Miller, J. S., Matzel, J. E., Miller, C. F., Burgess, S. D., \& Miller, R. B. (2007). Zircon growth and recycling during the assembly of large, composite arc plutons. Journal of Volcanology and Geothermal Research, 167(1), 282299.

Moreno, C. (1993). Postvolcanic Paleozoic of the Iberian Pyrite Belt: an example of basin morphologic control on sediment distribution in a turbidite basin. Journal of Sedimentary Research, 63(6).

Moreno, C., Capitan, M.A., Doyle, M., Nieto, J.M, Ruiz, F., Saez, R. (2003) Edad mínima del gossan de Las Cruces: implicaciones sobre la edad del inicio de los ecossistemas extremos em la Faja Pirítica Ibérica; Geogaceta 33:67-70. 
Moreno, C., Sierra, S., \& Sáez, R. (1996). Evidence for catastrophism at the Famennian-Dinantian boundary in the Iberian Pyrite Belt. Geological Society, London, Special Publications, 107(1), 153-162.

Mosier, D. L. B., Singer, V. I., \& Donald, A. (2009). Volcanogenic massive sulfide deposits of the world: Database and grade and tonnage models. U. S. Geological Survey Open-File Report 2009-1034, 50 p.

Mitjavila, J., Marti, J., \& Soriano, C. (1997). Magmatic evolution and tectonic setting of the Iberian Pyrite Belt volcanism. Journal of Petrology, 38(6), 727-755.

Munhá, J. (1983). Low grade regional metamorphism in the Iberian Pyrite Belt. Comunicação. Serviço Geológico. Português, 69, 3-35.

Munhá, J. (1990). Metamorphic evolution of the south Portuguese/Pulo do Lobo zone. In Pre-mesozoic geology of Iberia (pp. 363-368). Springer Berlin Heidelberg.

Nesbitt, R.W., Pascual, E., Fanning, C. M., Toscano, M., Saez, R., Almodovar, G. R. (1999) U-Pb dating of stockwork zircons from the eastern Iberian Pyrite Belt. Journal of the Geological Society 156, 7-10.

Ochsner, A. (1993). U-Pb Geochronology of the Upper Proterozoic-Lower Paleozoic geodynamic evolution in the Ossa-Morena Zone (SW Iberia): Constraints on the timing of the cadomian orogeny (Doctoral dissertation, ETH Zurich).

Ohmoto, H. (1996). Formation of volcanogenic massive sulfide deposits: the Kuroko perspective. Ore geology reviews, 10(3-6), 135-177.

Oliveira, J.T, 1990. South Portuguese Zone. In: Dallmeyer, R.D., Martinez Garcia, E. (Eds.), Pre-mesozoic geology of Iberia. Springer-Verlag, Berlin Heidelberg New York, pp. 333-346.

Oliveira, J. T., \& Quesada, C. (1998). A comparison of stratigraphy, structure, and palaeogeography of the South Portuguese Zone and southwest England, European Variscides. Proceedings of the Ussher Society, 9(3), 141150 .

Onézime, J., Charvet, J., Faure, M., Bourdier, J. L., \& Chauvet, A. (2003). A new geodynamic interpretation for the South Portuguese Zone (SW Iberia) and the Iberian Pyrite Belt genesis. Tectonics, 22(4).

Page, F. Z., Fu, B., Kita, N. T., Fournelle, J., Spicuzza, M. J., Schulze, D. J., .. \& V Valley, J. W. (2007). Zircons from kimberlite: new insights from oxygen isotopes, trace elements, and Ti in zircon thermometry. Geochimica et Cosmochimica Acta, 71(15), 3887-3903.

Patchett, P. J., \& Tatsumoto, M. (1980). Lu-Hf total-rock isochron for the eucrite meteorites. Nature, $288(5791), 571$.

Pereira, Z., Gonzalez-CLavijo, E. (2007). New palynological ages improving the geologic background of the Rio Tinto mine área (Spanish part of the Iberian Pyrite Belt). In CIMP 2007 Lisbon General Meeting, Abstract Book.

Pereira, Z., Matos, J. X., Fernandes, P. M. C., \& Oliveira, J. T. (2008). Palynostratigraphy and systematic palynology of the Devonian and Carboniferous successions of the South Portuguese Zone, Portugal. Instituto Nactional de Engenharia, Tecnologia e Inovação.

Pereira, Z., Matos, J. X., Fernandes, P., \& Oliveira, J. T. (2010). Palynostratigraphic study of the Caveira mine, NW sector of the Iberian Pyrite Belt, Portugal. In CIMP 2010 General Meeting, Abstract Book. 
Pereira, Z., Sáez Ramos, R., Pons, J. M., Oliveira, J. T., \& Moreno Garrido, M. C. (1996). Edad devónica (Struniense) de las mineralizaciones de Aznalcóllar (Faja Pirítica Ibérica) en base a palinología. Geogaceta 20(7), 16091612 .

Piercey, S. J. (2007). Volcanogenic massive sulphide (VMS) deposits of the Newfoundland Appalachians: an overview of their setting, classification, grade-tonnage data, and unresolved questions. Newfoundland and Labrador Department of Natural Resources, Geological Survey, Report, 07-1.

Piercey, S. J. (2010). An overview of petrochemistry in the regional exploration for volcanogenic massive sulphide (VMS) deposits. Geochemistry: Exploration, Environment, Analysis (2010) 10 (2): 119-136.

Piercey, S. J. (2011). The setting, style, and role of magmatism in the formation of volcanogenic massive sulfide deposits. Mineralium Deposita, 46(5-6), 449-471.

Piercey, S. J. (2015). A semipermeable interface model for the genesis of subseafloor replacement-type volcanogenic massive sulfide (VMS) deposits. Economic Geology, 110(7), 1655-1660.

Piercey SJ, Mortensen JK, Creaser RA (2003) Neodymium isotope geochemistry of felsic volcanic and intrusive rocks from the Yukon-Tanana terrane in the Finlayson Lake region, Yukon, Canada. Canada Journal of Earth Science 40:77-97

Piercey, S. J., Paradis, S., Murphy, D. C., \& Mortensen, J. K. (2001). Geochemistry and paleotectonic setting of felsic volcanic rocks in the Finlayson Lake volcanic-hosted massive sulfide district, Yukon, Canada. Economic Geology, 96(8), 1877-1905.

Piercey S.J., Peter J.M., Mortensen J.K., Paradis S., Murphy D.C., Tucker T.L. (2008) Petrology and U-Pb geochronology of footwall porphyritic rhyolites from the wolverine volcanogenic massive sulfide deposit, Yukon, Canada: implications for the genesis of massive sulfide deposits in continental margin environments. Economic Geology 103:5-33

Piercey, S. J., Squires, G. C., \& Brace, T. D. (2014). Lithostratigraphic, hydrothermal, and tectonic setting of the Boundary volcanogenic massive sulfide deposit, Newfoundland Appalachians, Canada: Formation by subseafloor replacement in a Cambrian rifted arc. Economic Geology, 109(3), 661-687.

Pilote, J. L., \& Piercey, S. J. (2018). Petrogenesis of the Rambler Rhyolite Formation: controls on the Ming VMS deposit and geodynamic implications for the Taconic Seaway, Newfoundland Appalachians, Canada. American Journal of Science, 318(6), 640-683.

Pin, C., Liñán, E., Pascual, E., Donaire, T., \& Valenzuela, A. (2002). Late Neoproterozoic crustal growth in the European Variscides: Nd isotope and geochemical evidence from the Sierra de Córdoba andesites (Ossa-Morena Zone, Southern Spain). Tectonophysics, 352(1-2), 133-151.

Prior, G. J., Gibson, H. L., Watkinson, D. H., Cook, R. E., \& Hannington, M. D. (1999). Rare earth and high field strength element geochemistry of the Kidd Creek rhyolites, Abitibi greenstone belt, Canada: Evidence for Archean felsic volcanism and volcanogenic massive sulfide ore formation in an Iceland-style rift environment. Economic Geology Monograph, 10, 457-484.

Pufahl, P. K., \& Hiatt, E. E. (2012). Oxygenation of the Earth's atmosphere-ocean system: a review of physical and chemical sedimentologic responses. Marine and Petroleum Geology, 32(1), 1-20.

Quesada, C. (1997). A reappraisal of the structure of the Spanish segment of the Iberian Pyrite Belt. Mineralium Deposita, 33(1-2), 31-44. 
Quesada, C., Fonseca, P. E., Munhá, J., Oliveira, J. T., \& Ribeiro, A. (1994). The Beja-Acebuches Ophiolite (Southern Iberia Variscan fold belt): geological characterization and geodynamic significance. Boletín Geológico y Minero, 105(1), 3-49.

Reid, M. R., Vazquez, J. A., \& Schmitt, A. K. (2011). Zircon-scale insights into the history of a Supervolcano, Bishop Tuff, Long Valley, California, with implications for the Ti-in-zircon geothermometer. Contributions to Mineralogy and Petrology, 161(2), 293-311.

Relvas, J. M. (2000) Geology and metallogenesis at the Neves Corvo deposit, Portugla. Tese de doutorado, Universitade de Lisboa, Portugal.

Relvas, J. M., Tassinari, C. C., Munhá, J., \& Barriga, F. J. (2001). Multiple sources for ore-forming fluids in the Neves Corvo VHMS Deposit of the Iberian Pyrite Belt (Portugal): strontium, neodymium and lead isotope evidence. Mineralium Deposita, 36(5), 416-427.

Relvas, J. M., Barriga, F. J., Ferreira, A., Noiva, P. C., Pacheco, N., \& Barriga, G. (2006). Hydrothermal alteration and mineralization in the Neves-Corvo volcanic-hosted massive sulfide deposit, Portugal. I. Geology, mineralogy, and geochemistry. Economic Geology, 101(4), 753-790.

Rollinson, H. R. (1993). Discriminating between tectonic environments using geochemical data. Using Geochemical Data: Evaluation, Presentation, Interpretation. Longman Scientific \& Technical, Essex, UK, 171-214.

Rosa, D. R. N., Finch, A. A., Andersen, T., \& Inverno, C. M. C. (2009). U-Pb geochronology and Hf isotope ratios of magmatic zircons from the Iberian Pyrite Belt. Mineralogy and Petrology, 95(1-2), 47.

Rosa, D. R., Inverno, C. M., Oliveira, V. M., \& Rosa, C. J. (2004). Geochemistry of volcanic rocks, Albernoa area, Iberian pyrite belt, Portugal. International Geology Review, 46(4), 366-383.

Rosa, D. R., Inverno, C. M., Oliveira, V. M., \& Rosa, C. J. (2006). Geochemistry and geothermometry of volcanic rocks from Serra Branca, Iberian pyrite belt, Portugal. Gondwana Research, 10(3-4), 328-339.

Rosa, C. J., McPhie, J., \& Relvas, J. M. (2010). Type of volcanoes hosting the massive sulfide deposits of the Iberian Pyrite Belt. Journal of Volcanology and Geothermal Research, 194(4), 107-126.

Routhier, P., Aye, F., Boyer, C., Lecolle, M., Moliere, P., Picot, P., and Roger, G. (1980) Le ceinture sudiberique a amas sulfures dans sa partie espagnole mediane: Orleans, BRGM, 265 p.

Ribeiro, A., Munhá, J., Mateus, A., Fonseca, P., Pereira, E., Noronha, F., .. \& Ferreira, N. (2009). Mechanics of thick-skinned Variscan overprinting of Cadomian basement (Iberian Variscides). Comptes Rendus Geoscience, $341(2-3), 127-139$

Sánchez-España, J., Velasco, F., \& Yusta, I. (2000). Hydrothermal alteration of felsic volcanic rocks associated with massive sulphide deposition in the northern Iberian Pyrite Belt (SW Spain). Applied Geochemistry, 15(9), 1265-1290.

Sanchez España, J. (2000): Mineralogía y geoquímica de los yacimientos de sulfuros masivos en el área Nor-Oriental de la Faja Pirítica Ibérica (San Telmo-San Miguel-Peña del Hierro), Norte de Huelva, Espanhaa. Tese de Doutorado, Universidad del Pais Vasco, 307 pp

Sáez, R., Almodóvar, G. R., \& Pascual, E. (1996). Geological constraints on massive sulphide genesis in the Iberian Pyrite Belt. Ore Geology Reviews, 11(6), 429-451.

Sáez, R., Pascual, E., Toscano, M., \& Almodóvar, G. R. (1999). The Iberian type of volcano-sedimentary massive sulphide deposits. Mineralium Deposita, 34(5-6), 549-570. 
Salman, K. (2004). The timing of the Cadomian and Variscan cycles in the Ossa-Morena Zone, SW Iberia: granitic magmatism from subduction to extension. Journal of Iberian Geology, 30, 119-132.

Sato, K., Tassinari, C. C. G., Mateus, A., Siga Jr, O., Basei, M. A. S., \& Onoe, A. T. (2018). Ti-in-Zircon with SHRIMP at IG-USP-BRAZIL: analytical technique for determination of titanium concentration using 49Ti / $91 \mathrm{Zr}$ ++ and $50 \mathrm{Ti} / 91 \mathrm{Zr}++$ ratios and its relevance in geothermometry approaches. ${ }^{\mathrm{TH}}$ International SHRIMP Workshop, Korea Basic Science Institute and Gyeongju National Museum.

Sato, K., Tassinari, C. C. G., Basei, M. A. S., Siga Jr, O., Onoe, A. T., \& Souza, M. (2014). Sensitive high resolution ion microprobe (SHRIMP IIe/MC) of the Institute of Geosciences of the University of São Paulo, Brazil: analytical method and first results. Geologia USP, Série Científica, 14(3), 3-14.

Scaillet, B., Holtz, F., \& Pichavant, M. (2016). Experimental constraints on the formation of silicic magmas. Elements, 12(2), 109-114.

Schardt, C., \& Large, R. R. (2009). New insights into the genesis of volcanic-hosted massive sulfide deposits on the seafloor from numerical modeling studies. Ore Geology Reviews, 35(3), 333-351

Schulz, K. J., 2012. Regional environment in volcanogenic massive sulfide occurence model: U.S. Geological Survey Scientific Investigations Report 2010-5070-C chap 4.

Segal, I., Halicz, L., \& Platzner, I. T. (2003). Accurate isotope ratio measurements of ytterbium by multiple collection inductively coupled plasma mass spectrometry applying erbium and hafnium in an improved double external normalization procedure. Journal of Analytical Atomic Spectrometry, 18(10), 1217-1223.

Shanks, W. C., \& Thurston, R. (Eds.). 2012. Volcanogenic massive sulfide occurrence model. US Geological Survey Scientific Investigations Report 2010-5070-C, 345 p.

Schardt, C., and Large, R.R., 2009, New insights into the genesis of volcanichosted massive sulfide deposits on the seafloor from numerical modeling studies: Ore Geology Reviews, 35, 333-351.

Schulz, K.J. 2012 Regional environment in volcanogenic massive sulfide occurence model: US Geological Survey Scientific Investigations Report 2010-5070-C, chap 4.

Segal, I., Halicz, L., \& Platzner, I. T. (2003). Accurate isotope ratio measurements of ytterbium by multiple collection inductively coupled plasma mass spectrometry applying erbium and hafnium in an improved double external normalization procedure. Journal of Analytical Atomic Spectrometry, 18(10), 1217-1223.

Sepkoski, J. J. (1996). Patterns of Phanerozoic extinction: a perspective from global data bases. In Global events and event stratigraphy in the Phanerozoic (pp. 35-51). Springer, Berlin, Heidelberg.

Sláma, J., Košler, J., Condon, D. J., Crowley, J. L., Gerdes, A., Hanchar, J. M., ... \& Schaltegger, U. (2008). Plešovice zircon—a new natural reference material for $\mathrm{U}-\mathrm{Pb}$ and $\mathrm{Hf}$ isotopic microanalysis. Chemical Geology, 249(12), 1-35.

Siégel, C., Bryan, S. E., Allen, C. M., \& Gust, D. A. (2018). Use and abuse of zircon-based thermometers: a critical review and a recommended approach to identify antecrystic zircons. Earth-Science Reviews, 176, 87-116

Sillitoe, R. H. 2010. Porphyry Copper Systems. Economic Geology 10, 3-41.

Sillitoe, R. H., Hannington, M. D., \& Thompson, J. F. (1996). High sulfidation deposits in the volcanogenic massive sulfide environment. Economic Geology, 91(1), 204-212.

Simancas, J. F., Carbonell, R., González Lodeiro, F., Pérez Estaún, A., Juhlin, C., Ayarza, P., ... \& Pascual, E. (2003). Crustal structure of the transpressional Variscan orogen of SW Iberia: SW Iberia deep seismic reflection profile (IBERSEIS). Tectonics, 22(6). 
Solá, A. R., Salgueiro, R., Pereira, Z., Matos, J. X., Rosa, C., Araújo, V., ... \& Lains, J. A. (2015). Evolução temporal do complexo vulcano sedimentar associado ao depósito de Neves-Corvo. In X Congresso Ibérico de Geoquímica: XVIII Semana de Geoquímica. Laboratório Nacional de Energia e Geologia.

Solomon, M., \& Quesada, C. (2003). Zn-Pb-Cu massive sulfide deposits: Brine-pool types occur in collisional orogens, black smoker types occur in backarc and/or arc basins. Geology, 31(12), 1029-1032.

Solomon, M., Tornos, F., \& Gaspar, O. C. (2002). Explanation for many of the unusual features of the massive sulfide deposits of the Iberian pyrite belt. Geology, 30(1), 87-90.

Solomon, M., Tornos, F., Large, R. R., Badham, J. N. P., Both, R. A., \& Zaw, K. (2004). Zn-Pb-Cu volcanichosted massive sulphide deposits: criteria for distinguishing brine pool-type from black smoker-type sulphide deposition. Ore Geology Reviews, 25(3), 259-283.

Soriano, C., \& Casas, J. (2002). Variscan tectonics in the Iberian pyrite belt, South Portuguese Zone. International Journal of Earth Sciences, 91(5), 882-896

Steiger, R., \& Jäger, E. (1977). Subcommission on geochronology: convention on the use of decay constants in geo-and cosmochronology. Earth and planetary science letters, 36(3), 359-362.

Streel, M., Brice, D., \& Mistiaen, B. (2006). Strunian. Geologica Belgica, 9(1/2), 105-109.

Taylor, D. J., McKeegan, K. D., \& Harrison, T. M. (2009). Lu-Hf zircon evidence for rapid lunar differentiation. Earth and Planetary Science Letters, 279(3), 157-164.

Thiéblemont, D., Pascual, E., \& Stein, G. (1997). Magmatism in the Iberian Pyrite Belt: petrological constraints on a metallogenic model. Mineralium Deposita, 33(1-2), 98-110.

Tornos, F., Clavijo, E. G., \& Spiro, B. (1997). The Filón Norte orebody (Tharsis, Iberian Pyrite Belt): a proximal low-temperature shale-hosted massive sulphide in a thin-skinned tectonic belt. Mineralium Deposita, 33(12), 150-169.

Tornos, F., Spiro, B., \& Stanley, C. (1999). The genesis of shale-hosted massive sulphides in the Iberian Pyrite Belt. Mineral deposits: Processes to processing: Rotterdam, Balkema, 605-608.

Tornos, F., Barriga, F. J. A. S., Marcoux, E., Pascual, E., Pons, J. M., Relvas, J. M. R. S., \& Velasco, F. (2000). The Iberian pyrite belt. Database on global VMS districts: CODES-GEODE, 19-52.

Tornos, F., Casquet, C., Galindo, C., Velasco, F., \& Canales, A. (2001). A new style of Ni-Cu mineralization related to magmatic breccia pipes in a transpressional magmatic arc, Aguablanca, Spain. Mineralium Deposita, 36(7), 700-706.

Tornos, F., Casquet, C., Relvas, J. M., Barriga, F. J., \& Sáez, R. (2002). The relationship between ore deposits and oblique tectonics: the SW Iberian Variscan Belt. Geological Society, London, Special Publications, 204(1), 179198.

Tornos, F. (2003): The Concepción Mine. Field Trip Guide, GEODE-GCMS Workshop. Iberian Pyrite Belt, April, 2003 In: The Iberian Pyrite Belt. Field Trip Guide. $9^{\text {th }}$ Biennual SGA Meeting

Tornos, F. (2003): The La Zarza Mine. Field Trip Guide, GEODE-GCMS Workshop. Iberian Pyrite Belt, April, 2003 In: The Iberian Pyrite Belt. Field Trip Guide. $9^{\text {th }}$ Biennual SGA Meeting

Tornos, F., Casquet, C., \& Relvas, J. M. (2005). 4: Transpressional tectonics, lower crust decoupling and intrusion of deep mafic sills: a model for the unusual metallogenesis of SW Iberia. Ore Geology Reviews, 27(1-4), 133163.

Tornos, F. (2006). Environment of formation and styles of volcanogenic massive sulfides: The Iberian Pyrite Belt. Ore Geology Reviews, v. 28, p. 259-307 
Tornos, F. (2007) Field Guide to the geology of ore deposits of SW Iberia, IGME.

Tornos, F., \& Heinrich, C. A. (2008). Shale basins, sulfur-deficient ore brines and the formation of exhalative base metal deposits. Chemical Geology, 247(1-2), 195-207.

Tornos, F., Solomon, M., Conde, C., \& Spiro, B. F. (2008). Formation of the Tharsis massive sulfide deposit, Iberian Pyrite Belt: geological, lithogeochemical, and stable isotope evidence for deposition in a brine pool. Economic Geology, 103(1), 185-214.

Tornos, F., Solomon, M., Conde, C., \& Spiro, B. F. (2008). Formation of the Tharsis massive sulfide deposit, Iberian Pyrite Belt: geological, lithogeochemical, and stable isotope evidence for deposition in a brine pool. Economic Geology, 103(1), 185-214.

Tornos, F., Velasco, F., Menor-Salván, C., Delgado, A., Slack, J. F., \& Escobar, J. M. (2014). Formation of recent $\mathrm{Pb}$-Ag-Au mineralization by potential sub-surface microbial activity. Nature communications, 5, 4600

Tornos, F., Conde, C., Chiaradia, M., Velasco, F. (2015). Evolving subduction-related basins control de formation of VMS deposits in the Iberian Pyrite Belt. Society of Economic Geology Conference "World-Class Ore Deposits: Discovery to Recovery" Poster.

Tornos, F., Peter, J. M., Allen, R., \& Conde, C. (2015). Controls on the siting and style of volcanogenic massive sulphide deposits. Ore Geology Reviews, 68, 142-163.

Tornos, F., Velasco, F., Menor-Salván, C., Delgado, A., \& Escobar, J. M. (2014). El Control Microbiológico de las Paragénesis Secundarias del Depósito de Las Cruces. Revista de la Sociedad Española de mineralogia, 19.

Tornos, F., Velasco, F., Slack, J. F., Delgado, A., Gomez-Miguelez, N., Escobar, J. M., \& Gomez, C. (2017). The high-grade Las Cruces copper deposit, Spain: a product of secondary enrichment in an evolving basin. Mineralium Deposita, 52(1), 1-34.

Valenzuela, A., Donaire, T., Pin, C., Toscano, M., Hamilton, M. A., \& Pascual, E. (2011). Geochemistry and $\mathrm{U}-\mathrm{Pb}$ dating of felsic volcanic rocks in the Riotinto-Nerva unit, Iberian Pyrite Belt, Spain: crustal thinning, progressive crustal melting and massive sulphide genesis. Journal of the Geological Society, 168(3), 717-732.

Vervoort, J. D. (2010). Hf analysis in zircon by LA-MC-ICPMS: promise and pitfalls. Geological Society of America. Annual Meeting. 42, 286-289

Velasco, F., Herrero, J. M., Suárez, S., Yusta, I., Alvaro, A., \& Tornos, F. (2013). Supergene features and evolution of gossans capping massive sulphide deposits in the Iberian Pyrite Belt. Ore Geology Reviews, 53, 181-203.

Villaseca, C., Orejana, D., Paterson, B.A., 2007. Zr-LREE rich minerals in residual peraluminous granulites, another factor in the origin of low Zr-LREE granitic melts? Lithos 96 (3-4), 375-386.

Watson, E. B., \& Harrison, T. M. (1983). Zircon saturation revisited: temperature and composition effects in a variety of crustal magma types. Earth and Planetary Science Letters, 64(2), 295-304.

Watson, E. B., \& Harrison, T. M. (2005). Zircon thermometer reveals minimum melting conditions on earliest Earth. Science, 308(5723), 841-844.

Watson, E. B., Wark, D. A., \& Thomas, J. B. (2006). Crystallization thermometers for zircon and rutile. Contributions to Mineralogy and Petrology, 151(4), 413.

Wark, D. A., Hildreth, W., Spear, F. S., Cherniak, D. J., \& Watson, E. B. (2007). Pre-eruption recharge of the Bishop magma system. Geology, 35(3), 235-238. 
Whalen, J. B., Rogers, N., van Staal, C. R., Longstaffe, F. J., Jenner, G. A., \& Winchester, J. A. (1998). Geochemical and isotopic (Nd, O) data from Ordovician felsic plutonic and volcanic rocks of the Miramichi Highlands: petrogenetic and metallogenic implications for the Bathurst Mining Camp. Canadian Journal of Earth Sciences, 35(3), 237-252.

White, N. C., \& Hedenquist, J. W. (1995). Epithermal gold deposits: styles, characteristics and exploration. SEG newsletter, 23(1), 9-13.

Woodhead, J. D., \& Hergt, J. M. (2005). A preliminary appraisal of seven natural zircon reference materials for in situ Hf isotope determination. Geostandards and Geoanalytical Research, 29(2), 183-195.

Wopenka, B., Jolliff, B. L., Zinner, E., \& Kremser, D. T. (1996). Trace element zoning and incipient metamictization in a lunar zircon: application of three microprobe techniques. American Mineralogist, 81(7-8), 902912.

Yesares, L., Sáez, R., Nieto, J. M., De Almodovar, G. R., Gómez, C., \& Escobar, J. M. (2015). The Las Cruces deposit, Iberian Pyrite Belt, Spain. Ore Geology Reviews, 66, 25-46.

Yesares, L., Sáez, R., Nieto, J. M., de Almodóvar, G. R., \& Cooper, S. (2014). Supergene enrichment of precious metals by natural amalgamation in the Las Cruces weathering profile (Iberian Pyrite Belt, SW Spain). Ore Geology Reviews, 58, 14-26. 


\section{ANEXO I}

\section{Isótopos de U-Pb por SHRIMP}

\begin{tabular}{|c|c|c|c|c|c|c|c|c|c|c|c|c|c|c|c|c|c|c|c|}
\hline Local & Spot & $\stackrel{\mathrm{ppm}}{\mathrm{U}}$ & $\begin{array}{l}\text { ppm } \\
\text { Th }\end{array}$ & $\begin{array}{l}232 \mathrm{Th} \\
/ 238 \mathrm{U}\end{array}$ & $\begin{array}{l}\text { 7-corr } \\
\% \text { com } \\
206\end{array}$ & $\begin{array}{c}206 \mathrm{~Pb} \\
/ 238 \mathrm{U} \\
\mathrm{Age}\end{array}$ & $\begin{array}{l}1 \sigma \\
\text { err }\end{array}$ & $\begin{array}{c}207 \mathrm{~Pb} \\
/ 206 \mathrm{~Pb} \\
\mathrm{Age}\end{array}$ & $\begin{array}{l}1 \sigma \\
\text { err }\end{array}$ & $\begin{array}{c}\% \\
\text { Dis- } \\
\text { cor- } \\
\text { dant }\end{array}$ & $\begin{array}{c}238 \\
/ 206^{*}\end{array}$ & $\begin{array}{l}\% \\
\text { err }\end{array}$ & $\begin{array}{l}207^{*} \\
/ 206^{*}\end{array}$ & $\begin{array}{l}\% \\
\text { err }\end{array}$ & $\begin{array}{l}207^{*} \\
/ 235\end{array}$ & $\begin{array}{l}\% \\
\text { err }\end{array}$ & $\begin{array}{l}206^{*} \\
/ 238\end{array}$ & $\begin{array}{l}\% \\
\text { err }\end{array}$ & $\begin{array}{l}\text { err } \\
\text { corr }\end{array}$ \\
\hline \multirow{20}{*}{ 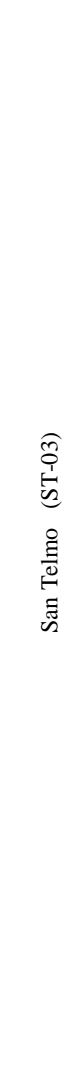 } & ST03-1.1 & 86 & 42 & 0.508 & 0.347 & 341 & 6 & 343 & 76 & +1 & 18.41 & 1.9 & 0.05334 & 3.3 & 0.3994 & 3.9 & 0.05431 & 1.9 & 0.5 \\
\hline & ST03-1.2 & 117 & 61 & 0.538 & 0.539 & 347 & 3 & 360 & 101 & +4 & 18.06 & 0.9 & 0.05374 & 4.5 & 0.4104 & 4.6 & 0.05538 & 0.9 & 0.2 \\
\hline & ST03-2.1 & 129 & 80 & 0.641 & 0.213 & 341 & 4 & 357 & 47 & +5 & 18.39 & 1.2 & 0.05367 & 2.1 & 0.4023 & 2.4 & 0.05437 & 1.2 & 0.5 \\
\hline & ST03-3.1 & 173 & 124 & 0.742 & 0.086 & 349 & 3 & 336 & 39 & -4 & 17.97 & 0.9 & 0.05317 & 1.7 & 0.4079 & 1.9 & 0.05564 & 0.9 & 0.5 \\
\hline & ST03-4.1 & 102 & 55 & 0.555 & 0.199 & 339 & 3 & 336 & 57 & -1 & 18.51 & 0.9 & 0.05318 & 2.5 & 0.3961 & 2.7 & 0.05402 & 0.9 & 0.4 \\
\hline & ST03-5.1 & 163 & 101 & 0.639 & -0.243 & 350 & 4 & 334 & 46 & -5 & 17.93 & 1.1 & 0.05312 & 2.0 & 0.4084 & 2.3 & 0.05576 & 1.1 & 0.5 \\
\hline & ST03-6.1 & 167 & 102 & 0.632 & 0.356 & 346 & 3 & 355 & 53 & +3 & 18.12 & 0.9 & 0.05362 & 2.4 & 0.4080 & 2.5 & 0.05518 & 0.9 & 0.4 \\
\hline & ST03-7.1 & 120 & 73 & 0.629 & 0.108 & 347 & 4 & 363 & 42 & +4 & 18.07 & 1.2 & 0.05380 & 1.8 & 0.4105 & 2.2 & 0.05534 & 1.2 & 0.5 \\
\hline & ST03-8.1 & 107 & 60 & 0.575 & 0.515 & 358 & 3 & 346 & 78 & -3 & 17.53 & 1.0 & 0.05340 & 3.4 & 0.4201 & 3.6 & 0.05705 & 1.0 & 0.3 \\
\hline & ST03-9.1 & 79 & 34 & 0.450 & 0.122 & 345 & 5 & 356 & 53 & +3 & 18.19 & 1.5 & 0.05363 & 2.3 & 0.4064 & 2.8 & 0.05496 & 1.5 & 0.5 \\
\hline & ST03-10.1 & 109 & 57 & 0.542 & 0.220 & 350 & 4 & 356 & 55 & +2 & 17.93 & 1.3 & 0.05363 & 2.4 & 0.4125 & 2.8 & 0.05578 & 1.3 & 0.5 \\
\hline & ST03-11.1 & 147 & 88 & 0.620 & 0.485 & 335 & 5 & 329 & 65 & -2 & 18.77 & 1.4 & 0.05300 & 2.9 & 0.3893 & 3.2 & 0.05328 & 1.4 & 0.4 \\
\hline & ST03-12.1 & 250 & 188 & 0.776 & 0.013 & 345 & 4 & 331 & 27 & -4 & 18.19 & 1.2 & 0.05304 & 1.2 & 0.4020 & 1.7 & 0.05497 & 1.2 & 0.7 \\
\hline & ST03-13.1 & 134 & 73 & 0.563 & 0.024 & 349 & 5 & 340 & 37 & -3 & 17.98 & 1.3 & 0.05326 & 1.6 & 0.4083 & 2.1 & 0.05561 & 1.3 & 0.6 \\
\hline & ST03-14.1 & 126 & 71 & 0.582 & 0.122 & 342 & 3 & 328 & 66 & -4 & 18.37 & 0.9 & 0.05298 & 2.9 & 0.3976 & 3.1 & 0.05443 & 0.9 & 0.3 \\
\hline & ST03-15.1 & 111 & 58 & 0.535 & -0.122 & 351 & 5 & 353 & 47 & +1 & 17.89 & 1.4 & 0.05356 & 2.1 & 0.4129 & 2.5 & 0.05591 & 1.4 & 0.6 \\
\hline & ST03-16.1 & 124 & 73 & 0.608 & 0.429 & 347 & 3 & 349 & 80 & +0 & 18.08 & 0.9 & 0.05347 & 3.5 & 0.4078 & 3.7 & 0.05532 & 0.9 & 0.2 \\
\hline & ST03-17.1 & 125 & 70 & 0.575 & -0.018 & 346 & 4 & 340 & 35 & -2 & 18.12 & 1.2 & 0.05327 & 1.5 & 0.4054 & 2.0 & 0.05520 & 1.2 & 0.6 \\
\hline & ST03-18.1 & 78 & 34 & 0.447 & 0.300 & 348 & 3 & 356 & 70 & +2 & 18.04 & 1.0 & 0.05364 & 3.1 & 0.4100 & 3.3 & 0.05542 & 1.0 & 0.3 \\
\hline & ST03-19.1 & 104 & 52 & 0.521 & 0.127 & 346 & 3 & 343 & 50 & -1 & 18.13 & 0.9 & 0.05333 & 2.2 & 0.4056 & 2.4 & 0.05516 & 0.9 & 0.4 \\
\hline
\end{tabular}




\begin{tabular}{|c|c|c|c|c|c|c|c|c|c|c|c|c|c|c|c|c|c|c|c|}
\hline & ST03-20.1 & 134 & 76 & 0.588 & -0.028 & 350 & 5 & 340 & 55 & -3 & 17.94 & 1.6 & 0.05327 & 2.4 & 0.4094 & 2.9 & 0.05574 & 1.6 & 0.5 \\
\hline & ST03-21.1 & 172 & 114 & 0.684 & 0.056 & 346 & 5 & 337 & 35 & -3 & 18.15 & 1.5 & 0.05318 & 1.6 & 0.4039 & 2.2 & 0.05508 & 1.5 & 0.7 \\
\hline & ST03-22.1 & 197 & 144 & 0.756 & 0.003 & 351 & 4 & 364 & 44 & +4 & 17.86 & 1.2 & 0.05383 & 2.0 & 0.4155 & 2.3 & 0.05599 & 1.2 & 0.5 \\
\hline & ST03-23.1 & 183 & 123 & 0.695 & -0.026 & 344 & 4 & 335 & 28 & -3 & 18.24 & 1.3 & 0.05315 & 1.2 & 0.4018 & 1.8 & 0.05483 & 1.3 & 0.7 \\
\hline \multirow{16}{*}{ 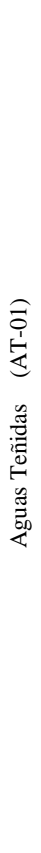 } & АТ01-1.1 & 123 & 97 & 0.81 & 22.82 & 363 & 17 & 383 & 1425 & +5 & 17.26 & 4.8 & 0.05430 & 63.4 & 0.4338 & 63.6 & 0.05795 & 4.8 & 0.1 \\
\hline & АT01-2.1 & 229 & 110 & 0.50 & 1.35 & 434 & 7 & 447 & 150 & +3 & 14.35 & 1.8 & 0.05587 & 6.8 & 0.5370 & 7.0 & 0.06971 & 1.8 & 0.3 \\
\hline & АТ01-3.1 & 158 & 114 & 0.75 & 1.61 & 353 & 6 & 361 & 138 & +2 & 17.78 & 1.8 & 0.05376 & 6.1 & 0.4167 & 6.4 & 0.05623 & 1.8 & 0.3 \\
\hline & АT01-4.1 & 241 & 163 & 0.70 & 0.81 & 353 & 5 & 324 & 105 & -9 & 17.78 & 1.4 & 0.05289 & 4.6 & 0.4101 & 4.8 & 0.05623 & 1.4 & 0.3 \\
\hline & АT01-5.1 & 222 & 181 & 0.84 & 2.21 & 358 & 7 & 391 & 287 & +9 & 17.51 & 1.9 & 0.05447 & 12.8 & 0.4290 & 12.9 & 0.05712 & 1.9 & 0.1 \\
\hline & АT01-6.1 & 295 & 198 & 0.69 & 1.85 & 346 & 5 & 380 & 157 & +9 & 18.14 & 1.4 & 0.05422 & 7.0 & 0.4121 & 7.1 & 0.05512 & 1.4 & 0.2 \\
\hline & AT01-7.1 & 229 & 167 & 0.75 & 0.91 & 358 & 5 & 355 & 117 & -1 & 17.52 & 1.4 & 0.05361 & 5.2 & 0.4218 & 5.4 & 0.05707 & 1.4 & 0.3 \\
\hline & AT01-8.1 & 304 & 177 & 0.60 & 1.09 & 311 & 8 & 355 & 114 & +13 & 20.22 & 2.7 & 0.05362 & 5.1 & 0.3656 & 5.7 & 0.04945 & 2.7 & 0.5 \\
\hline & АТ01-9.1 & 275 & 167 & 0.63 & 0.73 & 358 & 5 & 347 & 73 & -3 & 17.49 & 1.4 & 0.05342 & 3.2 & 0.4212 & 3.5 & 0.05718 & 1.4 & 0.4 \\
\hline & АT01-10.1 & 492 & 486 & 1.02 & 0.57 & 352 & 5 & 395 & 50 & +11 & 17.83 & 1.3 & 0.05458 & 2.2 & 0.4220 & 2.6 & 0.05608 & 1.3 & 0.5 \\
\hline & AT01-11.1 & 457 & 429 & 0.97 & 0.41 & 352 & 5 & 337 & 42 & -5 & 17.82 & 1.3 & 0.05318 & 1.8 & 0.4115 & 2.3 & 0.05612 & 1.3 & 0.6 \\
\hline & AT01-12.1 & 186 & 135 & 0.75 & 1.44 & 335 & 5 & 325 & 129 & -3 & 18.74 & 1.4 & 0.05291 & 5.7 & 0.3894 & 5.9 & 0.05338 & 1.4 & 0.2 \\
\hline & АТ01-13.1 & 453 & 435 & 0.99 & 0.91 & 350 & 5 & 397 & 52 & +12 & 17.92 & 1.5 & 0.05463 & 2.3 & 0.4204 & 2.8 & 0.05581 & 1.5 & 0.5 \\
\hline & AT01-14.1 & 479 & 450 & 0.97 & 0.65 & 347 & 5 & 332 & 69 & -5 & 18.10 & 1.5 & 0.05307 & 3.0 & 0.4042 & 3.4 & 0.05524 & 1.5 & 0.4 \\
\hline & AT01-15.1 & 509 & 532 & 1.08 & 0.50 & 351 & 5 & 322 & 61 & -9 & 17.89 & 1.4 & 0.05284 & 2.7 & 0.4073 & 3.1 & 0.05590 & 1.4 & 0.5 \\
\hline & AT01-16.1 & 380 & 238 & 0.65 & 10.14 & 308 & 5 & 344 & 442 & +11 & 20.44 & 1.8 & 0.05335 & 19.5 & 0.3599 & 19.6 & 0.04892 & 1.8 & 0.1 \\
\hline \multirow{7}{*}{ 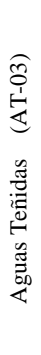 } & АТ03-1.1 & 1174 & 836 & 0.735 & 0.35 & 343 & 6 & 396 & 22 & +14 & 18.30 & 1.7 & 0.05460 & 1.0 & 0.411 & 1.9 & 0.0546 & 1.7 & 0.9 \\
\hline & AT03-2.1 & 511 & 393 & 0.795 & 0.38 & 351 & 6 & 325 & 56 & -8 & 17.86 & 1.7 & 0.05292 & 2.5 & 0.409 & 3.0 & 0.0560 & 1.7 & 0.6 \\
\hline & АT03-3.1 & 257 & 173 & 0.692 & 1.21 & 335 & 8 & 334 & 115 & -0 & 18.76 & 2.4 & 0.05311 & 5.1 & 0.390 & 5.6 & 0.0533 & 2.4 & 0.4 \\
\hline & АТ03-4.1 & 663 & 633 & 0.987 & 0.24 & 354 & 6 & 332 & 33 & -7 & 17.71 & 1.7 & 0.05307 & 1.5 & 0.413 & 2.2 & 0.0565 & 1.7 & 0.8 \\
\hline & АТ03-5.1 & 417 & 359 & 0.888 & 1.23 & 353 & 6 & 351 & 110 & -1 & 17.76 & 1.7 & 0.05351 & 4.9 & 0.416 & 5.2 & 0.0563 & 1.7 & 0.3 \\
\hline & AT03-6.1 & 444 & 261 & 0.607 & 0.55 & 356 & 6 & 349 & 51 & -2 & 17.63 & 1.7 & 0.05347 & 2.2 & 0.418 & 2.8 & 0.0567 & 1.7 & 0.6 \\
\hline & АТ03-7.1 & 331 & 218 & 0.680 & 36.38 & 362 & 8 & 522 & 507 & +31 & 17.30 & 2.3 & 0.05779 & 23.1 & 0.461 & 23.2 & 0.0578 & 2.3 & 0.1 \\
\hline
\end{tabular}




\begin{tabular}{|c|c|c|c|c|c|c|c|c|c|c|c|c|c|c|c|c|c|c|c|}
\hline & АТ03-8.1 & 320 & 242 & 0.780 & 1.04 & 353 & 6 & 394 & 83 & +11 & 17.76 & 1.7 & 0.05455 & 3.7 & 0.424 & 4.1 & 0.0563 & 1.7 & 0.4 \\
\hline & АТ03-9.1 & 301 & 185 & 0.635 & 0.48 & 348 & 6 & 345 & 58 & -1 & 18.03 & 1.7 & 0.05338 & 2.6 & 0.408 & 3.1 & 0.0555 & 1.7 & 0.6 \\
\hline & АТ03-10.1 & 451 & 382 & 0.874 & 0.46 & 351 & 6 & 363 & 59 & +3 & 17.85 & 1.8 & 0.05381 & 2.6 & 0.416 & 3.2 & 0.0560 & 1.8 & 0.6 \\
\hline & AT03-11.1 & 318 & 243 & 0.790 & 1.23 & 348 & 6 & 504 & 88 & +32 & 18.03 & 1.7 & 0.05733 & 4.0 & 0.438 & 4.4 & 0.0555 & 1.7 & 0.4 \\
\hline & AT03-12.1 & 599 & 659 & 1.137 & 0.46 & 347 & 6 & 378 & 38 & +8 & 18.07 & 1.7 & 0.05416 & 1.7 & 0.413 & 2.4 & 0.0554 & 1.7 & 0.7 \\
\hline & АT03-13.1 & 473 & 427 & 0.932 & 0.54 & 349 & 6 & 338 & 73 & -3 & 17.96 & 1.9 & 0.05322 & 3.2 & 0.409 & 3.7 & 0.0557 & 1.9 & 0.5 \\
\hline & AT03-14.1 & 422 & 201 & 0.492 & 0.91 & 343 & 6 & 386 & 84 & +11 & 18.27 & 1.7 & 0.05436 & 3.7 & 0.410 & 4.1 & 0.0547 & 1.7 & 0.4 \\
\hline & AT03-15.1 & 529 & 411 & 0.803 & 2.25 & 351 & 6 & 424 & 142 & +18 & 17.87 & 1.8 & 0.05530 & 6.4 & 0.427 & 6.6 & 0.0560 & 1.8 & 0.3 \\
\hline & AT03-16.1 & 426 & 300 & 0.726 & 0.73 & 342 & 6 & 369 & 66 & +7 & 18.33 & 1.7 & 0.05395 & 2.9 & 0.406 & 3.4 & 0.0545 & 1.7 & 0.5 \\
\hline & AT03-17.1 & 487 & 462 & 0.980 & 2.58 & 346 & 6 & 452 & 104 & +24 & 18.16 & 1.7 & 0.05599 & 4.7 & 0.425 & 5.0 & 0.0551 & 1.7 & 0.3 \\
\hline \multirow{17}{*}{ 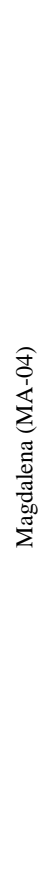 } & MA-01.1 & 131 & 60 & 0.470 & 0.97 & 402 & 5 & 397 & 119 & -1 & 15.54 & 1.4 & 0.05464 & 5.3 & 0.4847 & 5.5 & 0.0643 & 1.4 & 0.2 \\
\hline & MA-01.2 & 197 & 194 & 1.019 & 0.69 & 350 & 3 & 340 & 68 & -3 & 17.93 & 0.9 & 0.05326 & 3.0 & 0.4097 & 3.1 & 0.0558 & 0.9 & 0.3 \\
\hline & MA-2.1 & 159 & 122 & 0.791 & 0.16 & 356 & 4 & 370 & 44 & +4 & 17.60 & 1.2 & 0.05397 & 2.0 & 0.4227 & 2.3 & 0.0568 & 1.2 & 0.5 \\
\hline & MA- 2.2 & 171 & 121 & 0.731 & 0.17 & 362 & 4 & 342 & 52 & -6 & 17.32 & 1.1 & 0.05330 & 2.3 & 0.4242 & 2.6 & 0.0577 & 1.1 & 0.4 \\
\hline & MA-3.1 & 149 & 114 & 0.788 & 0.21 & 358 & 5 & 347 & 55 & -3 & 17.50 & 1.4 & 0.05342 & 2.4 & 0.4209 & 2.8 & 0.0571 & 1.4 & 0.5 \\
\hline & MA-3.2 & 315 & 153 & 0.502 & -0.05 & 356 & 3 & 341 & 26 & -5 & 17.61 & 0.8 & 0.05328 & 1.1 & 0.4173 & 1.4 & 0.0568 & 0.8 & 0.6 \\
\hline & MA-4.1 & 104 & 63 & 0.624 & 0.06 & 353 & 3 & 344 & 83 & -3 & 17.79 & 1.0 & 0.05336 & 3.7 & 0.4136 & 3.8 & 0.0562 & 1.0 & 0.3 \\
\hline & MA-5.1 & 120 & 97 & 0.839 & 0.34 & 339 & 5 & 332 & 69 & -2 & 18.53 & 1.4 & 0.05308 & 3.0 & 0.3950 & 3.4 & 0.0540 & 1.4 & 0.4 \\
\hline & MA-6.1 & 127 & 72 & 0.580 & 0.29 & 360 & 4 & 361 & 62 & +0 & 17.44 & 1.2 & 0.05376 & 2.7 & 0.4251 & 3.0 & 0.0574 & 1.2 & 0.4 \\
\hline & MA-6.2 & 120 & 85 & 0.733 & 0.18 & 362 & 5 & 351 & 58 & -3 & 17.29 & 1.5 & 0.05353 & 2.6 & 0.4269 & 3.0 & 0.0578 & 1.5 & 0.5 \\
\hline & MA-7.1 & 268 & 304 & 1.169 & -0.04 & 345 & 3 & 332 & 27 & -4 & 18.19 & 1.0 & 0.05309 & 1.2 & 0.4024 & 1.5 & 0.0550 & 1.0 & 0.6 \\
\hline & MA-8.1 & 204 & 177 & 0.898 & 0.05 & 346 & 4 & 363 & 30 & +5 & 18.14 & 1.1 & 0.05381 & 1.3 & 0.4091 & 1.7 & 0.0551 & 1.1 & 0.6 \\
\hline & MA- 8.2 & 504 & 377 & 0.773 & 0.00 & 502 & 25 & 501 & 39 & -0 & 12.35 & 5.2 & 0.05723 & 1.8 & 0.6391 & 5.5 & 0.0810 & 5.2 & 0.9 \\
\hline & MA-9.1 & 102 & 65 & 0.657 & 0.47 & 353 & 4 & 351 & 78 & -0 & 17.79 & 1.2 & 0.05352 & 3.5 & 0.4148 & 3.6 & 0.0562 & 1.2 & 0.3 \\
\hline & MA-9.2 & 178 & 96 & 0.558 & -0.01 & 435 & 5 & 431 & 39 & -1 & 14.34 & 1.1 & 0.05545 & 1.8 & 0.5332 & 2.1 & 0.0697 & 1.1 & 0.5 \\
\hline & MA-10.1 & 125 & 108 & 0.891 & 0.37 & 354 & 5 & 338 & 71 & -5 & 17.71 & 1.6 & 0.05321 & 3.1 & 0.4142 & 3.5 & 0.0565 & 1.6 & 0.4 \\
\hline & MA-11.1 & 372 & 303 & 0.841 & 0.00 & 355 & 4 & 342 & 23 & -4 & 17.68 & 1.0 & 0.05331 & 1.0 & 0.4157 & 1.4 & 0.0566 & 1.0 & 0.7 \\
\hline
\end{tabular}




\begin{tabular}{|c|c|c|c|c|c|c|c|c|c|c|c|c|c|c|c|c|c|c|c|}
\hline & MA-11.2 & 117 & 66 & 0.580 & -0.19 & 410 & 7 & 415 & 88 & +1 & 15.22 & 1.8 & 0.05506 & 3.9 & 0.4988 & 4.3 & 0.0657 & 1.8 & 0.4 \\
\hline & MA-12.1 & 134 & 82 & 0.637 & 0.30 & 406 & 6 & 396 & 69 & -2 & 15.38 & 1.5 & 0.05461 & 3.1 & 0.4895 & 3.4 & 0.0650 & 1.5 & 0.4 \\
\hline \multirow{24}{*}{ 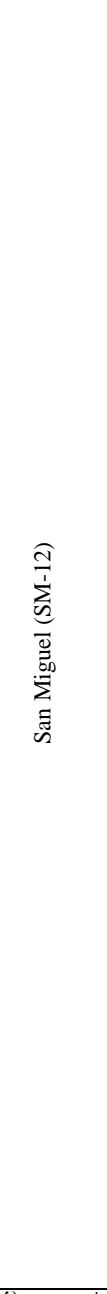 } & SM12-1.1 & 420 & 379 & 0.933 & 0.42 & 352 & 3 & 375 & 53 & +6 & 17.83 & 0.9 & 0.05409 & 2.4 & 0.4183 & 2.5 & 0.0561 & 0.9 & 0.4 \\
\hline & SM12-2.1 & 285 & 216 & 0.783 & 0.83 & 318 & 4 & 333 & 60 & +5 & 19.80 & 1.4 & 0.05310 & 2.6 & 0.3699 & 3.0 & 0.0505 & 1.4 & 0.5 \\
\hline & SM12-3.1 & 242 & 158 & 0.676 & 0.42 & 350 & 3 & 367 & 45 & +5 & 17.90 & 0.8 & 0.05391 & 2.0 & 0.4152 & 2.2 & 0.0559 & 0.8 & 0.4 \\
\hline & SM12-4.1 & 131 & 51 & 0.401 & -0.09 & 351 & 3 & 340 & 38 & -3 & 17.86 & 0.9 & 0.05326 & 1.7 & 0.4113 & 1.9 & 0.0560 & 0.9 & 0.5 \\
\hline & SM12-5.1 & 588 & 363 & 0.637 & 0.14 & 361 & 3 & 378 & 19 & +5 & 17.36 & 1.0 & 0.05416 & 0.8 & 0.4301 & 1.3 & 0.0576 & 1.0 & 0.8 \\
\hline & SM12-6.1 & 852 & 1123 & 1.361 & 0.03 & 355 & 4 & 339 & 16 & -5 & 17.68 & 1.1 & 0.05324 & 0.7 & 0.4152 & 1.3 & 0.0566 & 1.1 & 0.8 \\
\hline & SM12-7.1 & 473 & 327 & 0.714 & 0.03 & 357 & 4 & 348 & 20 & -3 & 17.56 & 1.1 & 0.05345 & 0.9 & 0.4197 & 1.4 & 0.0570 & 1.1 & 0.8 \\
\hline & SM12-8.1 & 256 & 111 & 0.448 & 0.20 & 353 & 4 & 343 & 37 & -3 & 17.78 & 1.1 & 0.05334 & 1.6 & 0.4138 & 2.0 & 0.0563 & 1.1 & 0.6 \\
\hline & SM12-9.1 & 520 & 324 & 0.643 & 0.06 & 354 & 3 & 335 & 22 & -6 & 17.71 & 0.9 & 0.05313 & 1.0 & 0.4136 & 1.3 & 0.0565 & 0.9 & 0.7 \\
\hline & SM12-10.1 & 888 & 555 & 0.645 & -0.44 & 502 & 14 & 379 & 30 & -34 & 12.36 & 2.9 & 0.05418 & 1.3 & 0.6046 & 3.2 & 0.0809 & 2.9 & 0.9 \\
\hline & SM12-11.1 & 326 & 162 & 0.514 & 0.18 & 374 & 10 & 358 & 35 & -5 & 16.73 & 2.9 & 0.05370 & 1.5 & 0.4425 & 3.3 & 0.0598 & 2.9 & 0.9 \\
\hline & SM12-12.1 & 716 & 498 & 0.718 & 0.01 & 477 & 6 & 453 & 28 & -5 & 13.03 & 1.3 & 0.05601 & 1.3 & 0.5927 & 1.8 & 0.0767 & 1.3 & 0.7 \\
\hline & SM12-13.1 & 292 & 170 & 0.599 & 0.11 & 353 & 4 & 340 & 32 & -4 & 17.78 & 1.2 & 0.05326 & 1.4 & 0.4131 & 1.9 & 0.0563 & 1.2 & 0.7 \\
\hline & SM12-14.1 & 298 & 198 & 0.687 & 0.00 & 352 & 4 & 342 & 25 & -3 & 17.80 & 1.2 & 0.05332 & 1.1 & 0.4130 & 1.6 & 0.0562 & 1.2 & 0.7 \\
\hline & SM12-15.1 & 330 & 200 & 0.625 & 0.15 & 355 & 3 & 353 & 29 & -1 & 17.65 & 0.9 & 0.05356 & 1.3 & 0.4183 & 1.6 & 0.0566 & 0.9 & 0.6 \\
\hline & SM12-16.1 & 424 & 319 & 0.776 & 0.33 & 344 & 4 & 354 & 32 & +3 & 18.22 & 1.2 & 0.05360 & 1.4 & 0.4057 & 1.9 & 0.0549 & 1.2 & 0.7 \\
\hline & SM12-17.1 & 228 & 162 & 0.733 & 0.12 & 349 & 3 & 334 & 38 & -5 & 17.96 & 1.0 & 0.05311 & 1.7 & 0.4078 & 2.0 & 0.0557 & 1.0 & 0.5 \\
\hline & SM12-19.1 & 459 & 303 & 0.682 & 0.31 & 372 & 3 & 359 & 36 & -4 & 16.84 & 0.8 & 0.05372 & 1.6 & 0.4399 & 1.8 & 0.0594 & 0.8 & 0.5 \\
\hline & SM12-20.1 & 663 & 404 & 0.630 & 0.15 & 368 & 3 & 352 & 34 & -5 & 17.04 & 0.8 & 0.05355 & 1.5 & 0.4334 & 1.7 & 0.0587 & 0.8 & 0.5 \\
\hline & SM12-21.1 & 337 & 214 & 0.656 & 0.01 & 353 & 3 & 350 & 22 & -1 & 17.78 & 0.8 & 0.05351 & 1.0 & 0.4151 & 1.3 & 0.0563 & 0.8 & 0.6 \\
\hline & SM12-22.1 & 1018 & 947 & 0.961 & 1.24 & 327 & 5 & 343 & 80 & +5 & 19.19 & 1.4 & 0.05333 & 3.6 & 0.3831 & 3.8 & 0.0521 & 1.4 & 0.4 \\
\hline & SM12-23.1 & 370 & 192 & 0.537 & 0.12 & 369 & 4 & 384 & 26 & +4 & 16.96 & 1.0 & 0.05432 & 1.1 & 0.4417 & 1.5 & 0.0590 & 1.0 & 0.7 \\
\hline & SM12-24.1 & 1444 & 942 & 0.674 & 0.69 & 391 & 9 & 401 & 70 & +3 & 16.01 & 2.4 & 0.05473 & 3.1 & 0.4714 & 3.9 & 0.0625 & 2.4 & 0.6 \\
\hline & SM12-25.1 & 326 & 192 & 0.610 & 0.04 & 357 & 5 & 353 & 26 & -1 & 17.57 & 1.6 & 0.05357 & 1.2 & 0.4205 & 2.0 & 0.0569 & 1.6 & 0.8 \\
\hline 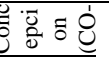 & CO04-1.1 & 153 & 103 & 0.693 & 0.81 & 330 & 6 & 351 & 80 & +6 & 19.06 & 1.8 & 0.05352 & 3.5 & 0.387 & 4.0 & 0.0525 & 1.8 & 0.4 \\
\hline
\end{tabular}




\begin{tabular}{|c|c|c|c|c|c|c|c|c|c|c|c|c|c|c|c|c|c|c|c|}
\hline & $\mathrm{CO} 04-2.1$ & 162 & 116 & 0.738 & 1.14 & 322 & 7 & 365 & 117 & +12 & 19.50 & 2.1 & 0.05384 & 5.2 & 0.381 & 5.6 & 0.0513 & 2.1 & 0.4 \\
\hline & CO04-3.1 & 200 & 158 & 0.818 & 0.93 & 339 & 6 & 322 & 82 & -5 & 18.54 & 1.7 & 0.05285 & 3.6 & 0.393 & 4.0 & 0.0539 & 1.7 & 0.4 \\
\hline & $\mathrm{CO} 04-3.2$ & 125 & 38 & 0.310 & 2.35 & 335 & 6 & 372 & 205 & +10 & 18.73 & 1.9 & 0.05403 & 9.1 & 0.398 & 9.3 & 0.0534 & 1.9 & 0.2 \\
\hline & CO04-4.1 & 128 & 62 & 0.501 & 1.52 & 356 & 8 & 356 & 171 & -0 & 17.60 & 2.2 & 0.05363 & 7.6 & 0.420 & 7.9 & 0.0568 & 2.2 & 0.3 \\
\hline & CO04-5.1 & 160 & 86 & 0.554 & 1.68 & 352 & 6 & 333 & 145 & -6 & 17.80 & 1.8 & 0.05310 & 6.4 & 0.411 & 6.6 & 0.0562 & 1.8 & 0.3 \\
\hline & CO04-6.1 & 163 & 91 & 0.572 & 1.57 & 346 & 7 & 384 & 150 & +10 & 18.15 & 2.0 & 0.05431 & 6.7 & 0.413 & 7.0 & 0.0551 & 2.0 & 0.3 \\
\hline & CO04-7.1 & 225 & 142 & 0.653 & 1.20 & 355 & 6 & 356 & 122 & +0 & 17.68 & 1.8 & 0.05363 & 5.4 & 0.418 & 5.7 & 0.0566 & 1.8 & 0.3 \\
\hline & CO04-8.1 & 196 & 107 & 0.568 & 1.30 & 350 & 6 & 355 & 105 & +1 & 17.90 & 1.8 & 0.05362 & 4.7 & 0.413 & 5.0 & 0.0559 & 1.8 & 0.4 \\
\hline & CO04-9.1 & 211 & 135 & 0.658 & 2.04 & 361 & 6 & 377 & 171 & +4 & 17.36 & 1.8 & 0.05414 & 7.6 & 0.430 & 7.8 & 0.0576 & 1.8 & 0.2 \\
\hline & CO04-10.1 & 313 & 161 & 0.531 & 1.74 & 400 & 9 & 399 & 246 & -0 & 15.62 & 2.3 & 0.05467 & 11.0 & 0.482 & 11.2 & 0.0640 & 2.3 & 0.2 \\
\hline & CO04-11.1 & 142 & 77 & 0.560 & 2.54 & 358 & 7 & 378 & 249 & +5 & 17.50 & 1.9 & 0.05418 & 11.1 & 0.427 & 11.2 & 0.0571 & 1.9 & 0.2 \\
\hline & CO04-12.1 & 752 & 514 & 0.706 & 0.75 & 358 & 7 & 395 & 94 & +10 & 17.49 & 2.0 & 0.05458 & 4.2 & 0.430 & 4.7 & 0.0572 & 2.0 & 0.4 \\
\hline & CO04-13.1 & 221 & 147 & 0.689 & 1.26 & 359 & 6 & 388 & 119 & +8 & 17.47 & 1.8 & 0.05442 & 5.3 & 0.429 & 5.6 & 0.0572 & 1.8 & 0.3 \\
\hline & CO04-14.1 & 318 & 200 & 0.649 & 1.03 & 364 & 6 & 354 & 98 & -3 & 17.23 & 1.7 & 0.05359 & 4.3 & 0.429 & 4.7 & 0.0580 & 1.7 & 0.4 \\
\hline & CO04-15.1 & 135 & 82 & 0.624 & 2.90 & 365 & 7 & 390 & 232 & +6 & 17.15 & 2.1 & 0.05445 & 10.3 & 0.438 & 10.5 & 0.0583 & 2.1 & 0.2 \\
\hline & CO04-16.1 & 193 & 130 & 0.698 & 1.32 & 350 & 6 & 375 & 132 & +7 & 17.92 & 1.8 & 0.05409 & 5.9 & 0.416 & 6.1 & 0.0558 & 1.8 & 0.3 \\
\hline & CO04-17.1 & 1451 & 965 & 0.687 & 2.23 & 340 & 6 & 362 & 223 & +6 & 18.46 & 1.8 & 0.05379 & 9.9 & 0.402 & 10.1 & 0.0542 & 1.8 & 0.2 \\
\hline & CO04-18.1 & 192 & 125 & 0.674 & 1.62 & 352 & 6 & 337 & 125 & -5 & 17.80 & 1.8 & 0.05318 & 5.5 & 0.412 & 5.8 & 0.0562 & 1.8 & 0.3 \\
\hline & CO04-19.1 & 231 & 183 & 0.820 & 1.31 & 354 & 7 & 396 & 148 & +11 & 17.70 & 1.9 & 0.05459 & 6.6 & 0.425 & 6.9 & 0.0565 & 1.9 & 0.3 \\
\hline & CO04-20.1 & 206 & 143 & 0.717 & 0.88 & 356 & 6 & 337 & 133 & -6 & 17.62 & 1.8 & 0.05318 & 5.9 & 0.416 & 6.2 & 0.0567 & 1.8 & 0.3 \\
\hline & CO04-21.1 & 216 & 159 & 0.761 & 1.60 & 356 & 6 & 376 & 147 & +6 & 17.62 & 1.8 & 0.05413 & 6.5 & 0.424 & 6.8 & 0.0568 & 1.8 & 0.3 \\
\hline & CO04-22.1 & 218 & 156 & 0.740 & 1.10 & 354 & 6 & 336 & 129 & -5 & 17.71 & 1.8 & 0.05318 & 5.7 & 0.414 & 5.9 & 0.0565 & 1.8 & 0.3 \\
\hline \multirow{5}{*}{ 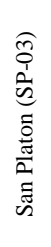 } & SP03-1.1 & 113 & 71 & 0.650 & 4.61 & 341 & 7 & 397 & 369 & +14 & 18.41 & 2.2 & 0.05462 & 16.5 & 0.409 & 16.6 & 0.0543 & 2.2 & 0.1 \\
\hline & SP03-2.1 & 254 & 190 & 0.773 & 7.37 & 396 & 8 & 620 & 320 & +37 & 15.79 & 2.0 & 0.06045 & 14.8 & 0.528 & 15.0 & 0.0633 & 2.0 & 0.1 \\
\hline & SP03-3.1 & 205 & 141 & 0.712 & 1.52 & 343 & 6 & 342 & 155 & -0 & 18.28 & 1.8 & 0.05332 & 6.8 & 0.402 & 7.1 & 0.0547 & 1.8 & 0.3 \\
\hline & SP03-3.2 & 159 & 87 & 0.565 & 1.73 & 340 & 6 & 356 & 149 & +5 & 18.46 & 1.8 & 0.05364 & 6.6 & 0.401 & 6.9 & 0.0542 & 1.8 & 0.3 \\
\hline & SP03-4.1 & 211 & 144 & 0.705 & 1.32 & 347 & 6 & 370 & 102 & +6 & 18.10 & 1.9 & 0.05397 & 4.5 & 0.411 & 4.9 & 0.0553 & 1.9 & 0.4 \\
\hline
\end{tabular}




\begin{tabular}{|c|c|c|c|c|c|c|c|c|c|c|c|c|c|c|c|c|c|c|c|}
\hline & SP03-5.1 & 166 & 98 & 0.613 & 1.71 & 339 & 6 & 319 & 194 & -6 & 18.51 & 1.8 & 0.05278 & 8.5 & 0.393 & 8.7 & 0.0540 & 1.8 & 0.2 \\
\hline & SP03-6.1 & 238 & 265 & 1.151 & 5.19 & 346 & 7 & 342 & 284 & -1 & 18.12 & 2.1 & 0.05331 & 12.5 & 0.406 & 12.7 & 0.0552 & 2.1 & 0.2 \\
\hline & SP03-7.1 & 154 & 95 & 0.636 & 1.16 & 352 & 6 & 383 & 116 & +8 & 17.82 & 1.8 & 0.05430 & 5.2 & 0.420 & 5.5 & 0.0561 & 1.8 & 0.3 \\
\hline & SP03-8.1 & 106 & 59 & 0.574 & 3.23 & 327 & 7 & 353 & 272 & +7 & 19.20 & 2.3 & 0.05357 & 12.1 & 0.385 & 12.3 & 0.0521 & 2.3 & 0.2 \\
\hline & SP03-9.1 & 152 & 88 & 0.594 & 1.86 & 350 & 7 & 388 & 178 & +10 & 17.90 & 2.0 & 0.05440 & 7.9 & 0.419 & 8.2 & 0.0559 & 2.0 & 0.2 \\
\hline & SP03-10.1 & 293 & 270 & 0.953 & 5.97 & 337 & 6 & 394 & 257 & +15 & 18.64 & 1.8 & 0.05455 & 11.5 & 0.403 & 11.6 & 0.0536 & 1.8 & 0.2 \\
\hline & SP03-11.1 & 159 & 92 & 0.597 & 2.13 & 342 & 7 & 427 & 182 & +20 & 18.34 & 2.1 & 0.05537 & 8.1 & 0.416 & 8.4 & 0.0545 & 2.1 & 0.2 \\
\hline & SP03-12.1 & 124 & 78 & 0.649 & 2.20 & 328 & 7 & 345 & 202 & +5 & 19.14 & 2.1 & 0.05338 & 8.9 & 0.385 & 9.2 & 0.0522 & 2.1 & 0.2 \\
\hline & SP03-13.1 & 195 & 119 & 0.632 & 1.80 & 285 & 7 & 295 & 148 & +3 & 22.15 & 2.5 & 0.05221 & 6.5 & 0.325 & 6.9 & 0.0452 & 2.5 & 0.4 \\
\hline & SP03-14.1 & 102 & 59 & 0.600 & 1.83 & 330 & 8 & 348 & 208 & +5 & 19.05 & 2.4 & 0.05345 & 9.2 & 0.387 & 9.5 & 0.0525 & 2.4 & 0.3 \\
\hline & SP03-15.1 & 100 & 61 & 0.633 & 3.29 & 319 & 6 & 379 & 271 & +16 & 19.72 & 1.9 & 0.05419 & 12.1 & 0.379 & 12.2 & 0.0507 & 1.9 & 0.2 \\
\hline & SP03-16.1 & 138 & 102 & 0.762 & 2.21 & 319 & 6 & 353 & 150 & +10 & 19.69 & 1.8 & 0.05356 & 6.6 & 0.375 & 6.9 & 0.0508 & 1.8 & 0.3 \\
\hline & SP03-17.1 & 170 & 99 & 0.603 & 1.61 & 328 & 6 & 356 & 171 & +8 & 19.18 & 1.8 & 0.05365 & 7.6 & 0.386 & 7.8 & 0.0521 & 1.8 & 0.2 \\
\hline & SP03-18.1 & 142 & 86 & 0.623 & 1.24 & 325 & 6 & 349 & 120 & +7 & 19.34 & 1.8 & 0.05348 & 5.3 & 0.381 & 5.6 & 0.0517 & 1.8 & 0.3 \\
\hline \multirow{13}{*}{ 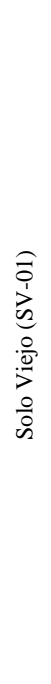 } & SV-01-1.1 & 177 & 110 & 0.64 & 0.93 & 348 & 6 & 356 & 138 & +2 & 18.04 & 1.6 & 0.05363 & 6.1 & 0.4100 & 6.3 & 0.05544 & 1.6 & 0.3 \\
\hline & SV-01-2.1 & 69 & 43 & 0.65 & 1.35 & 606 & 9 & 593 & 164 & -2 & 10.15 & 1.6 & 0.05969 & 7.5 & 0.8106 & 7.7 & 0.09849 & 1.6 & 0.2 \\
\hline & SV-01-3.1 & 367 & 168 & 0.47 & 0.34 & 354 & 5 & 375 & 42 & +6 & 17.71 & 1.3 & 0.05409 & 1.9 & 0.4211 & 2.3 & 0.05647 & 1.3 & 0.6 \\
\hline & SV-01-4.1 & 315 & 181 & 0.59 & 0.24 & 344 & 4 & 382 & 51 & +10 & 18.24 & 1.3 & 0.05426 & 2.3 & 0.4101 & 2.6 & 0.05481 & 1.3 & 0.5 \\
\hline & SV-01-5.1 & 176 & 94 & 0.55 & 0.90 & 344 & 5 & 347 & 119 & +1 & 18.23 & 1.4 & 0.05342 & 5.3 & 0.4040 & 5.4 & 0.05485 & 1.4 & 0.3 \\
\hline & SV-01-6.1 & 318 & 168 & 0.55 & 0.24 & 351 & 5 & 342 & 46 & -3 & 17.88 & 1.3 & 0.05332 & 2.0 & 0.4112 & 2.4 & 0.05593 & 1.3 & 0.6 \\
\hline & SV-01-7.1 & 348 & 150 & 0.45 & 0.47 & 345 & 5 & 366 & 47 & +6 & 18.20 & 1.4 & 0.05389 & 2.1 & 0.4083 & 2.5 & 0.05495 & 1.4 & 0.6 \\
\hline & SV-01-8.1 & 356 & 167 & 0.48 & 0.37 & 353 & 5 & 381 & 43 & +7 & 17.75 & 1.3 & 0.05423 & 1.9 & 0.4213 & 2.3 & 0.05634 & 1.3 & 0.6 \\
\hline & SV-01-9.1 & 351 & 162 & 0.48 & 0.18 & 353 & 5 & 337 & 40 & -5 & 17.79 & 1.3 & 0.05319 & 1.8 & 0.4122 & 2.2 & 0.05621 & 1.3 & 0.6 \\
\hline & SV-01-10.1 & 360 & 156 & 0.45 & 0.21 & 350 & 5 & 331 & 41 & -6 & 17.91 & 1.3 & 0.05305 & 1.8 & 0.4085 & 2.2 & 0.05584 & 1.3 & 0.6 \\
\hline & SV-01-11.1 & 111 & 66 & 0.62 & 1.48 & 342 & 5 & 374 & 159 & +9 & 18.35 & 1.5 & 0.05407 & 7.1 & 0.4064 & 7.2 & 0.05450 & 1.5 & 0.2 \\
\hline & SV-01-12.1 & 403 & 189 & 0.48 & 0.48 & 354 & 5 & 411 & 51 & +14 & 17.69 & 1.3 & 0.05497 & 2.3 & 0.4284 & 2.6 & 0.05652 & 1.3 & 0.5 \\
\hline & SV-01-13.1 & 378 & 489 & 1.33 & 0.25 & 340 & 4 & 388 & 33 & +13 & 18.46 & 1.3 & 0.05442 & 1.5 & 0.4064 & 2.0 & 0.05416 & 1.3 & 0.7 \\
\hline
\end{tabular}




\begin{tabular}{|c|c|c|c|c|c|c|c|c|c|c|c|c|c|c|c|c|c|c|c|}
\hline & SV-01-14.1 & 383 & 179 & 0.48 & 0.26 & 350 & 5 & 368 & 58 & +5 & 17.90 & 1.3 & 0.05392 & 2.6 & 0.4152 & 2.9 & 0.05585 & 1.3 & 0.5 \\
\hline & SV-01-15.1 & 425 & 204 & 0.50 & 0.15 & 347 & 4 & 360 & 31 & +4 & 18.08 & 1.3 & 0.05375 & 1.4 & 0.4099 & 1.9 & 0.05531 & 1.3 & 0.7 \\
\hline & SV-01-16.1 & 385 & 250 & 0.67 & 0.32 & 348 & 4 & 363 & 42 & +4 & 18.02 & 1.3 & 0.05380 & 1.9 & 0.4117 & 2.3 & 0.05551 & 1.3 & 0.6 \\
\hline & SV-01-17.1 & 258 & 110 & 0.44 & 0.80 & 322 & 4 & 353 & 67 & +9 & 19.50 & 1.4 & 0.05357 & 2.9 & 0.3788 & 3.3 & 0.05129 & 1.4 & 0.4 \\
\hline & SV-01-18.1 & 388 & 325 & 0.87 & 1.29 & 361 & 5 & 397 & 112 & +9 & 17.38 & 1.5 & 0.05463 & 5.0 & 0.4333 & 5.2 & 0.05752 & 1.5 & 0.3 \\
\hline & SV-01-18.2 & 729 & 292 & 0.41 & 4.06 & 622 & 9 & 1355 & 28 & +57 & 9.87 & 1.5 & 0.08677 & 1.5 & 1.2120 & 2.1 & 0.10131 & 1.5 & 0.7 \\
\hline & SV-01-19.1 & 374 & 258 & 0.71 & 0.75 & 343 & 4 & 335 & 83 & -3 & 18.29 & 1.3 & 0.05314 & 3.6 & 0.4007 & 3.9 & 0.05469 & 1.3 & 0.3 \\
\hline & SV-01-20.1 & 413 & 216 & 0.54 & 0.55 & 350 & 5 & 359 & 64 & +3 & 17.90 & 1.3 & 0.05372 & 2.8 & 0.4137 & 3.1 & 0.05586 & 1.3 & 0.4 \\
\hline & SV-01-21.1 & 382 & 210 & 0.57 & 0.41 & 352 & 5 & 370 & 43 & +5 & 17.80 & 1.3 & 0.05397 & 1.9 & 0.4180 & 2.3 & 0.05617 & 1.3 & 0.6 \\
\hline & SV-01-22.1 & 1031 & 935 & 0.94 & 2.42 & 334 & 6 & 341 & 177 & +2 & 18.83 & 1.8 & 0.05329 & 7.8 & 0.3903 & 8.0 & 0.05312 & 1.8 & 0.2 \\
\hline & SV-01-23.1 & 469 & 234 & 0.51 & 0.22 & 351 & 4 & 388 & 30 & +10 & 17.86 & 1.3 & 0.05441 & 1.3 & 0.4200 & 1.9 & 0.05598 & 1.3 & 0.7 \\
\hline \multirow{16}{*}{ 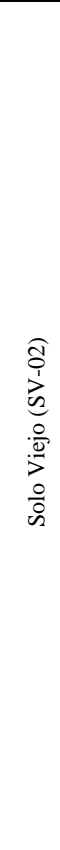 } & SV-02-1.1 & 204 & 156 & 0.79 & 0.40 & 352 & 5 & 358 & 90 & +2 & 17.83 & 1.4 & 0.05370 & 4.0 & 0.4152 & 4.2 & 0.05608 & 1.4 & 0.3 \\
\hline & SV-02-2.1 & 326 & 765 & 2.42 & 20.10 & 480 & 15 & 1623 & 490 & +73 & 12.94 & 3.2 & 0.09995 & 26.3 & 1.0651 & 26.5 & 0.07728 & 3.2 & 0.1 \\
\hline & SV-02-2.2 & 310 & 224 & 0.75 & 0.31 & 344 & 5 & 337 & 49 & -2 & 18.26 & 1.5 & 0.05319 & 2.1 & 0.4016 & 2.6 & 0.05475 & 1.5 & 0.6 \\
\hline & SV-02-3.1 & 121 & 90 & 0.77 & 4.41 & 366 & 7 & 706 & 343 & +50 & 17.10 & 1.8 & 0.06295 & 16.1 & 0.5075 & 16.2 & 0.05847 & 1.8 & 0.1 \\
\hline & SV-02-3.2 & 442 & 360 & 0.84 & 0.10 & 349 & 4 & 338 & 33 & -3 & 17.96 & 1.3 & 0.05322 & 1.4 & 0.4085 & 2.0 & 0.05568 & 1.3 & 0.7 \\
\hline & SV-02-4.1 & 175 & 129 & 0.76 & 0.21 & 349 & 5 & 324 & 64 & -8 & 17.97 & 1.6 & 0.05290 & 2.8 & 0.4060 & 3.2 & 0.05566 & 1.6 & 0.5 \\
\hline & SV-02-4.2 & 629 & 658 & 1.08 & 0.07 & 332 & 4 & 324 & 28 & -3 & 18.90 & 1.3 & 0.05289 & 1.2 & 0.3859 & 1.8 & 0.05291 & 1.3 & 0.7 \\
\hline & SV- $02-2.3$ & 105 & 49 & 0.49 & 1.40 & 340 & 5 & 344 & 162 & +1 & 18.49 & 1.5 & 0.05337 & 7.2 & 0.3980 & 7.3 & 0.05409 & 1.5 & 0.2 \\
\hline & SV-02-5.1 & 603 & 467 & 0.80 & 0.11 & 346 & 4 & 340 & 29 & -2 & 18.11 & 1.3 & 0.05326 & 1.3 & 0.4055 & 1.8 & 0.05522 & 1.3 & 0.7 \\
\hline & SV-02-5.2 & 124 & 74 & 0.62 & 1.17 & 338 & 5 & 486 & 136 & +31 & 18.59 & 1.5 & 0.05685 & 6.2 & 0.4218 & 6.3 & 0.05380 & 1.5 & 0.2 \\
\hline & SV-02-6.1 & 254 & 145 & 0.59 & 15.62 & 546 & 14 & 1108 & 405 & +53 & 11.32 & 2.7 & 0.07650 & 20.3 & 0.9319 & 20.5 & 0.08835 & 2.7 & 0.1 \\
\hline & SV-02-6.2 & 756 & 732 & 1.00 & 0.26 & 350 & 5 & 357 & 29 & +2 & 17.90 & 1.4 & 0.05367 & 1.3 & 0.4133 & 1.9 & 0.05585 & 1.4 & 0.7 \\
\hline & SV-02-7.1 & 379 & 291 & 0.79 & 0.61 & 344 & 4 & 360 & 57 & +4 & 18.24 & 1.3 & 0.05373 & 2.5 & 0.4062 & 2.9 & 0.05483 & 1.3 & 0.5 \\
\hline & SV-02-8.1 & 99 & 56 & 0.59 & 2.22 & 346 & 7 & 346 & 183 & -0 & 18.12 & 2.0 & 0.05339 & 8.1 & 0.4062 & 8.3 & 0.05518 & 2.0 & 0.2 \\
\hline & SV-02-9.1 & 214 & 126 & 0.61 & 0.33 & 351 & 5 & 346 & 64 & -1 & 17.88 & 1.4 & 0.05341 & 2.8 & 0.4119 & 3.1 & 0.05594 & 1.4 & 0.4 \\
\hline & SV-02-9.2 & 542 & 502 & 0.96 & 0.35 & 350 & 4 & 395 & 34 & +12 & 17.90 & 1.3 & 0.05458 & 1.5 & 0.4204 & 2.0 & 0.05587 & 1.3 & 0.7 \\
\hline
\end{tabular}




\begin{tabular}{|c|c|c|c|c|c|c|c|c|c|c|c|c|c|c|c|c|c|c|c|}
\hline & SV-02-10.1 & 186 & 139 & 0.78 & 0.70 & 350 & 5 & 383 & 74 & +9 & 17.93 & 1.4 & 0.05429 & 3.3 & 0.4176 & 3.6 & 0.05578 & 1.4 & 0.4 \\
\hline & SV-02-11.1 & 573 & 584 & 1.05 & 0.58 & 347 & 4 & 366 & 57 & +5 & 18.06 & 1.3 & 0.05387 & 2.5 & 0.4112 & 2.8 & 0.05536 & 1.3 & 0.5 \\
\hline & SV-02-12.1 & 239 & 168 & 0.73 & 0.45 & 352 & 5 & 331 & 64 & -6 & 17.84 & 1.4 & 0.05305 & 2.8 & 0.4100 & 3.1 & 0.05605 & 1.4 & 0.4 \\
\hline & SV-02-13.1 & 124 & 70 & 0.58 & 1.42 & 351 & 7 & 357 & 134 & +2 & 17.87 & 2.1 & 0.05368 & 5.9 & 0.4142 & 6.3 & 0.05597 & 2.1 & 0.3 \\
\hline & SV-02-14.1 & 415 & 340 & 0.85 & 0.32 & 350 & 5 & 361 & 57 & +3 & 17.91 & 1.3 & 0.05376 & 2.5 & 0.4139 & 2.9 & 0.05584 & 1.3 & 0.5 \\
\hline & SV-02-15.1 & 146 & 94 & 0.66 & 1.27 & 344 & 5 & 336 & 115 & -2 & 18.27 & 1.4 & 0.05317 & 5.1 & 0.4013 & 5.3 & 0.05474 & 1.4 & 0.3 \\
\hline & SV-02-16.1 & 749 & 469 & 0.65 & 0.07 & 354 & 4 & 344 & 25 & -3 & 17.74 & 1.3 & 0.05337 & 1.1 & 0.4148 & 1.7 & 0.05637 & 1.3 & 0.8 \\
\hline & SV-02-17.1 & 438 & 272 & 0.64 & 0.69 & 349 & 5 & 367 & 52 & +5 & 17.96 & 1.3 & 0.05391 & 2.3 & 0.4139 & 2.7 & 0.05569 & 1.3 & 0.5 \\
\hline & SV-02-18.1 & 197 & 141 & 0.74 & 0.49 & 347 & 5 & 349 & 88 & +0 & 18.07 & 1.4 & 0.05346 & 3.9 & 0.4080 & 4.1 & 0.05534 & 1.4 & 0.3 \\
\hline \multirow{17}{*}{ 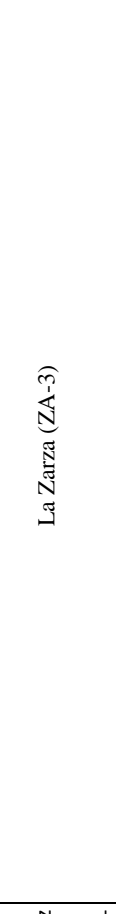 } & ZA03-1.1 & 46 & 29 & 0.65 & 0.53 & 2085 & 31 & 2090 & 22 & +0 & 2.62 & 1.7 & 0.12944 & 1.2 & 6.8142 & 2.1 & 0.38180 & 1.7 & 0.8 \\
\hline & ZA03-2.1 & 345 & 229 & 0.687 & 1.70 & 365 & 8 & 386 & 120 & +6 & 17.14 & 2.3 & 0.05437 & 5.4 & 0.4373 & 5.8 & 0.05834 & 2.3 & 0.4 \\
\hline & ZA03-3.1 & 378 & 240 & 0.656 & 0.72 & 366 & 8 & 352 & 72 & -4 & 17.12 & 2.3 & 0.05354 & 3.2 & 0.4313 & 3.9 & 0.05842 & 2.3 & 0.6 \\
\hline & ZA03-4.1 & 392 & 270 & 0.712 & 2.55 & 351 & 8 & 382 & 156 & +8 & 17.85 & 2.3 & 0.05427 & 6.9 & 0.4192 & 7.3 & 0.05601 & 2.3 & 0.3 \\
\hline & ZA03-5.1 & 237 & 120 & 0.524 & 1.54 & 348 & 8 & 377 & 137 & +8 & 18.02 & 2.3 & 0.05413 & 6.1 & 0.4142 & 6.5 & 0.05550 & 2.3 & 0.3 \\
\hline & ZA03-6.1 & 187 & 99 & 0.544 & 1.87 & 355 & 9 & 363 & 137 & +2 & 17.64 & 2.7 & 0.05381 & 6.1 & 0.4207 & 6.7 & 0.05669 & 2.7 & 0.4 \\
\hline & ZA03-7.1 & 339 & 120 & 0.367 & 0.66 & 352 & 8 & 371 & 71 & +5 & 17.81 & 2.3 & 0.05400 & 3.2 & 0.4180 & 3.9 & 0.05613 & 2.3 & 0.6 \\
\hline & ZA03-8.1 & 660 & 385 & 0.603 & 0.71 & 328 & 8 & 377 & 50 & +13 & 19.15 & 2.4 & 0.05414 & 2.2 & 0.3898 & 3.3 & 0.05222 & 2.4 & 0.7 \\
\hline & ZA03-9.1 & 211 & 114 & 0.557 & 1.77 & 339 & 9 & 353 & 159 & +4 & 18.53 & 2.6 & 0.05358 & 7.0 & 0.3987 & 7.5 & 0.05397 & 2.6 & 0.4 \\
\hline & ZA03-10.1 & 125 & 69 & 0.570 & 1.95 & 358 & 10 & 347 & 242 & -3 & 17.50 & 2.8 & 0.05343 & 10.7 & 0.4210 & 11.1 & 0.05714 & 2.8 & 0.3 \\
\hline & ZA03-11.1 & 329 & 272 & 0.854 & 0.68 & 361 & 8 & 355 & 68 & -2 & 17.35 & 2.3 & 0.05362 & 3.0 & 0.4261 & 3.8 & 0.05763 & 2.3 & 0.6 \\
\hline & ZA03-12.1 & 293 & 184 & 0.647 & 0.85 & 363 & 8 & 386 & 103 & +6 & 17.25 & 2.3 & 0.05436 & 4.6 & 0.4345 & 5.1 & 0.05797 & 2.3 & 0.4 \\
\hline & ZA03-13.1 & 135 & 51 & 0.392 & 1.28 & 357 & 8 & 354 & 212 & -1 & 17.56 & 2.3 & 0.05359 & 9.4 & 0.4209 & 9.7 & 0.05696 & 2.3 & 0.2 \\
\hline & ZA03-14.1 & 230 & 113 & 0.509 & 1.27 & 353 & 8 & 350 & 114 & -1 & 17.78 & 2.3 & 0.05350 & 5.0 & 0.4148 & 5.5 & 0.05624 & 2.3 & 0.4 \\
\hline & ZA03-15.1 & 288 & 193 & 0.691 & 0.86 & 360 & 8 & 389 & 59 & +8 & 17.42 & 2.4 & 0.05444 & 2.6 & 0.4308 & 3.6 & 0.05740 & 2.4 & 0.7 \\
\hline & ZA03-16.1 & 200 & 89 & 0.461 & 1.48 & 353 & 8 & 384 & 169 & +8 & 17.75 & 2.4 & 0.05432 & 7.5 & 0.4219 & 7.9 & 0.05634 & 2.4 & 0.3 \\
\hline & ZA03-17.1 & 214 & 95 & 0.457 & 3.17 & 356 & 8 & 385 & 210 & +8 & 17.63 & 2.3 & 0.05433 & 9.4 & 0.4249 & 9.6 & 0.05672 & 2.3 & 0.2 \\
\hline$\Xi \underset{N}{\pi} \sigma \stackrel{\frac{N}{N}}{N}$ & ZA04-1.1 & 244 & 145 & 0.613 & 1.04 & 354 & 8 & 376 & 103 & +6 & 17.69 & 2.3 & 0.05411 & 4.6 & 0.4217 & 5.1 & 0.05652 & 2.3 & 0.4 \\
\hline
\end{tabular}




\begin{tabular}{|c|c|c|c|c|c|c|c|c|c|c|c|c|c|c|c|c|c|c|c|}
\hline & ZA04-2.1 & 180 & 130 & 0.745 & 1.21 & 351 & 8 & 384 & 130 & +9 & 17.86 & 2.3 & 0.05431 & 5.8 & 0.4193 & 6.2 & 0.05599 & 2.3 & 0.4 \\
\hline & ZA04-3.1 & 355 & 302 & 0.878 & 1.41 & 344 & 8 & 348 & 160 & +1 & 18.25 & 2.3 & 0.05345 & 7.1 & 0.4038 & 7.4 & 0.05479 & 2.3 & 0.3 \\
\hline & ZA04-4.1 & 246 & 117 & 0.488 & 0.72 & 364 & 8 & 386 & 92 & +6 & 17.20 & 2.3 & 0.05436 & 4.1 & 0.4357 & 4.7 & 0.05812 & 2.3 & 0.5 \\
\hline & ZA04-5.1 & 196 & 101 & 0.530 & 1.09 & 355 & 8 & 344 & 130 & -3 & 17.65 & 2.3 & 0.05336 & 5.7 & 0.4169 & 6.2 & 0.05667 & 2.3 & 0.4 \\
\hline & ZA04-6.1 & 396 & 273 & 0.712 & 0.52 & 352 & 8 & 386 & 38 & +9 & 17.80 & 2.3 & 0.05435 & 1.7 & 0.4211 & 2.9 & 0.05619 & 2.3 & 0.8 \\
\hline & ZA04-7.1 & 217 & 88 & 0.420 & 0.81 & 357 & 8 & 378 & 67 & +6 & 17.59 & 2.3 & 0.05416 & 3.0 & 0.4246 & 3.8 & 0.05686 & 2.3 & 0.6 \\
\hline & ZA04-8.1 & 217 & 106 & 0.502 & 0.81 & 355 & 8 & 343 & 87 & -3 & 17.69 & 2.3 & 0.05334 & 3.8 & 0.4158 & 4.5 & 0.05653 & 2.3 & 0.5 \\
\hline & ZA04-9.1 & 748 & 752 & 1.038 & 0.34 & 358 & 8 & 340 & 46 & -5 & 17.51 & 2.3 & 0.05326 & 2.0 & 0.4195 & 3.1 & 0.05712 & 2.3 & 0.7 \\
\hline & ZA04-10.1 & 182 & 94 & 0.532 & 0.76 & 355 & 8 & 373 & 75 & +5 & 17.67 & 2.3 & 0.05405 & 3.3 & 0.4218 & 4.0 & 0.05660 & 2.3 & 0.6 \\
\hline & ZA04-11.1 & 544 & 501 & 0.953 & 0.58 & 356 & 8 & 360 & 53 & +1 & 17.61 & 2.3 & 0.05373 & 2.3 & 0.4206 & 3.3 & 0.05677 & 2.3 & 0.7 \\
\hline & ZA04-12.1 & 249 & 125 & 0.518 & 1.04 & 353 & 8 & 374 & 99 & +6 & 17.75 & 2.3 & 0.05407 & 4.4 & 0.4199 & 4.9 & 0.05633 & 2.3 & 0.5 \\
\hline & ZA04-13.1 & 182 & 93 & 0.525 & 1.54 & 350 & 8 & 340 & 169 & -3 & 17.90 & 2.3 & 0.05327 & 7.4 & 0.4104 & 7.8 & 0.05588 & 2.3 & 0.3 \\
\hline & ZA04-14.1 & 161 & 79 & 0.504 & 0.91 & 343 & 8 & 341 & 86 & -0 & 18.31 & 2.4 & 0.05329 & 3.8 & 0.4013 & 4.5 & 0.05462 & 2.4 & 0.5 \\
\hline & ZA04-15.1 & 228 & 115 & 0.521 & 1.08 & 322 & 8 & 318 & 115 & -1 & 19.51 & 2.5 & 0.05276 & 5.1 & 0.3728 & 5.6 & 0.05125 & 2.5 & 0.4 \\
\hline & ZA04-16.1 & 177 & 129 & 0.755 & 1.36 & 357 & 8 & 380 & 155 & +6 & 17.54 & 2.3 & 0.05421 & 6.9 & 0.4261 & 7.2 & 0.05701 & 2.3 & 0.3 \\
\hline & ZA04-15.2 & 275 & 191 & 0.715 & 0.36 & 368 & 8 & 371 & 61 & +1 & 17.00 & 2.3 & 0.05400 & 2.7 & 0.4380 & 3.5 & 0.05882 & 2.3 & 0.6 \\
\hline & ZA04-17.1 & 254 & 196 & 0.796 & 0.90 & 356 & 8 & 350 & 106 & -2 & 17.63 & 2.3 & 0.05349 & 4.7 & 0.4182 & 5.2 & 0.05671 & 2.3 & 0.4 \\
\hline & ZA04-18.1 & 362 & 307 & 0.874 & 1.39 & 377 & 8 & 379 & 143 & +1 & 16.61 & 2.3 & 0.05420 & 6.3 & 0.4499 & 6.7 & 0.06020 & 2.3 & 0.3 \\
\hline & ZA04-19.1 & 226 & 138 & 0.632 & 1.43 & 368 & 8 & 396 & 126 & +7 & 17.05 & 2.3 & 0.05461 & 5.6 & 0.4417 & 6.1 & 0.05867 & 2.3 & 0.4 \\
\hline & RT-02-1.1 & 305 & 112 & 0.38 & 0.10 & 336 & 4 & 319 & 39 & -5 & 18.71 & 1.2 & 0.05278 & 1.7 & 0.389 & 2.1 & 0.0535 & 1.2 & 0.6 \\
\hline & RT-02-2.1 & 883 & 374 & 0.44 & 0.19 & 349 & 4 & 372 & 21 & +6 & 17.99 & 1.2 & 0.05401 & 0.9 & 0.414 & 1.5 & 0.0556 & 1.2 & 0.8 \\
\hline & RT-02-3.1 & 638 & 292 & 0.47 & 0.11 & 362 & 4 & 384 & 22 & +6 & 17.29 & 1.3 & 0.05431 & 1.0 & 0.433 & 1.6 & 0.0578 & 1.3 & 0.8 \\
\hline 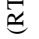 & RT-02-4.1 & 450 & 302 & 0.69 & 0.43 & 334 & 4 & 363 & 39 & +8 & 18.81 & 1.2 & 0.05382 & 1.7 & 0.395 & 2.1 & 0.0532 & 1.2 & 0.6 \\
\hline$\Xi$ & xTEM-16.1 & 311 & 89 & 0.30 & 0.07 & 408 & 5 & 413 & 30 & +1 & 15.29 & 1.2 & 0.05502 & 1.3 & 0.496 & 1.8 & 0.0654 & 1.2 & 0.7 \\
\hline $\bar{q}$ & RT-02-5.1 & 879 & 647 & 0.76 & 7.65 & 338 & 4 & 361 & 110 & +6 & 18.55 & 1.2 & 0.05376 & 4.9 & 0.400 & 5.0 & 0.0539 & 1.2 & 0.2 \\
\hline & RT-02-6.1 & 670 & 456 & 0.70 & 0.10 & 331 & 4 & 330 & 26 & -0 & 18.98 & 1.2 & 0.05304 & 1.1 & 0.385 & 1.6 & 0.0527 & 1.2 & 0.7 \\
\hline & RT-02-7.1 & 351 & 233 & 0.69 & -0.05 & 343 & 4 & 344 & 32 & +0 & 18.31 & 1.2 & 0.05335 & 1.4 & 0.402 & 1.9 & 0.0546 & 1.2 & 0.6 \\
\hline
\end{tabular}




\begin{tabular}{|c|c|c|c|c|c|c|c|c|c|c|c|c|c|c|c|c|c|c|c|}
\hline & RT-02-8.1 & 1292 & 736 & 0.59 & 0.66 & 346 & 4 & 392 & 26 & +12 & 18.12 & 1.3 & 0.05451 & 1.2 & 0.415 & 1.7 & 0.0552 & 1.3 & 0.7 \\
\hline & RT-02-9.1 & 970 & 399 & 0.42 & 0.16 & 347 & 4 & 340 & 22 & -2 & 18.06 & 1.3 & 0.05326 & 1.0 & 0.407 & 1.6 & 0.0554 & 1.3 & 0.8 \\
\hline & RT-02-10.1 & 200 & 122 & 0.63 & 0.20 & 351 & 5 & 364 & 51 & +4 & 17.88 & 1.5 & 0.05382 & 2.3 & 0.415 & 2.7 & 0.0559 & 1.5 & 0.6 \\
\hline & RT-02-11.1 & 836 & 513 & 0.63 & 0.66 & 345 & 4 & 365 & 41 & +6 & 18.21 & 1.2 & 0.05385 & 1.8 & 0.408 & 2.2 & 0.0549 & 1.2 & 0.6 \\
\hline & RT-02-12.1 & 1244 & 827 & 0.69 & 1.02 & 358 & 5 & 390 & 56 & +8 & 17.49 & 1.4 & 0.05447 & 2.5 & 0.429 & 2.9 & 0.0572 & 1.4 & 0.5 \\
\hline & RT-02-13.1 & 1198 & 868 & 0.75 & 0.71 & 355 & 4 & 358 & 37 & +1 & 17.69 & 1.2 & 0.05370 & 1.6 & 0.419 & 2.0 & 0.0565 & 1.2 & 0.6 \\
\hline & RT-02-14.1 & 158 & 68 & 0.44 & 0.88 & 345 & 4 & 334 & 119 & -3 & 18.17 & 1.3 & 0.05313 & 5.3 & 0.403 & 5.4 & 0.0550 & 1.3 & 0.2 \\
\hline & RT-02-15.1 & 438 & 202 & 0.48 & 0.14 & 341 & 4 & 374 & 28 & +9 & 18.42 & 1.3 & 0.05407 & 1.3 & 0.405 & 1.8 & 0.0543 & 1.3 & 0.7 \\
\hline & RT-02-16.1 & 605 & 358 & 0.61 & 0.09 & 339 & 4 & 332 & 38 & -2 & 18.50 & 1.2 & 0.05307 & 1.7 & 0.396 & 2.1 & 0.0541 & 1.2 & 0.6 \\
\hline & RT-02-17.1 & 146 & 92 & 0.65 & 1.13 & 341 & 4 & 351 & 111 & +3 & 18.39 & 1.3 & 0.05353 & 4.9 & 0.401 & 5.1 & 0.0544 & 1.3 & 0.3 \\
\hline & RT-02-18.1 & 317 & 130 & 0.42 & 0.06 & 353 & 4 & 353 & 35 & -0 & 17.76 & 1.2 & 0.05356 & 1.6 & 0.416 & 2.0 & 0.0563 & 1.2 & 0.6 \\
\hline & RT-02-19.1 & 1140 & 778 & 0.71 & 0.73 & 344 & 4 & 372 & 35 & +8 & 18.27 & 1.2 & 0.05403 & 1.5 & 0.408 & 1.9 & 0.0547 & 1.2 & 0.6 \\
\hline & RT-02-20.1 & 1599 & 1434 & 0.93 & 0.69 & 348 & 4 & 343 & 31 & -2 & 18.05 & 1.2 & 0.05332 & 1.4 & 0.407 & 1.8 & 0.0554 & 1.2 & 0.6 \\
\hline \multirow{14}{*}{ 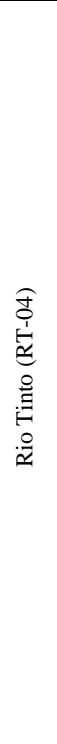 } & RT-04-1.1 & 669 & 481 & 0.74 & 0.69 & 366 & 5 & 382 & 91 & +4 & 17.12 & 1.3 & 0.05426 & 4.0 & 0.4371 & 4.3 & 0.05843 & 1.3 & 0.3 \\
\hline & RT-04-2.1 & 1033 & 742 & 0.74 & 0.59 & 362 & 5 & 403 & 37 & +10 & 17.31 & 1.4 & 0.05477 & 1.7 & 0.4363 & 2.2 & 0.05777 & 1.4 & 0.6 \\
\hline & RT-04-3.1 & 71 & 32 & 0.46 & 1.17 & 358 & 7 & 372 & 153 & +4 & 17.52 & 2.0 & 0.05403 & 6.8 & 0.4251 & 7.1 & 0.05707 & 2.0 & 0.3 \\
\hline & RT-04-4.1 & 351 & 170 & 0.50 & 0.59 & 362 & 5 & 399 & 52 & +9 & 17.30 & 1.3 & 0.05466 & 2.3 & 0.4357 & 2.7 & 0.05780 & 1.3 & 0.5 \\
\hline & RT-04-5.1 & 809 & 665 & 0.85 & 2.77 & 391 & 5 & 496 & 141 & +22 & 16.01 & 1.3 & 0.05712 & 6.4 & 0.4919 & 6.6 & 0.06246 & 1.3 & 0.2 \\
\hline & RT-04-6.1 & 666 & 617 & 0.96 & 0.53 & 335 & 4 & 359 & 35 & +7 & 18.74 & 1.3 & 0.05372 & 1.6 & 0.3952 & 2.0 & 0.05336 & 1.3 & 0.6 \\
\hline & RT-04-7.1 & 119 & 52 & 0.45 & 0.58 & 571 & 8 & 577 & 87 & +1 & 10.79 & 1.4 & 0.05927 & 4.0 & 0.7574 & 4.2 & 0.09267 & 1.4 & 0.3 \\
\hline & RT-04-8.1 & 460 & 316 & 0.71 & 0.12 & 354 & 5 & 339 & 34 & -4 & 17.73 & 1.3 & 0.05324 & 1.5 & 0.4141 & 2.0 & 0.05641 & 1.3 & 0.7 \\
\hline & RT-04-9.1 & 186 & 129 & 0.72 & 0.48 & 348 & 5 & 356 & 66 & +2 & 18.01 & 1.4 & 0.05365 & 2.9 & 0.4107 & 3.2 & 0.05552 & 1.4 & 0.4 \\
\hline & RT-04-10.1 & 311 & 181 & 0.60 & 0.38 & 359 & 5 & 360 & 51 & +0 & 17.45 & 1.3 & 0.05373 & 2.2 & 0.4245 & 2.6 & 0.05730 & 1.3 & 0.5 \\
\hline & RT-04-11.1 & 282 & 188 & 0.69 & 0.24 & 346 & 5 & 345 & 73 & -0 & 18.13 & 1.3 & 0.05339 & 3.2 & 0.4060 & 3.5 & 0.05516 & 1.3 & 0.4 \\
\hline & RT-04-11.2 & 269 & 105 & 0.40 & 0.60 & 344 & 6 & 468 & 43 & +27 & 18.22 & 1.7 & 0.05639 & 1.9 & 0.4267 & 2.6 & 0.05488 & 1.7 & 0.7 \\
\hline & RT-04-12.1 & 616 & 294 & 0.49 & 0.11 & 340 & 5 & 333 & 30 & -2 & 18.47 & 1.4 & 0.05310 & 1.3 & 0.3964 & 1.9 & 0.05414 & 1.4 & 0.7 \\
\hline & RT-04-13.1 & 500 & 392 & 0.81 & 2.17 & 333 & 4 & 557 & 62 & +41 & 18.86 & 1.3 & 0.05873 & 2.9 & 0.4294 & 3.1 & 0.05303 & 1.3 & 0.4 \\
\hline
\end{tabular}




\begin{tabular}{|c|c|c|c|c|c|c|c|c|c|c|c|c|c|c|c|c|c|c|c|}
\hline & RT-04-14.1 & 899 & 597 & 0.69 & 0.36 & 354 & 4 & 385 & 26 & +8 & 17.73 & 1.3 & 0.05433 & 1.2 & 0.4226 & 1.7 & 0.05641 & 1.3 & 0.7 \\
\hline & RT-04-15.1 & 257 & 134 & 0.54 & 0.76 & 353 & 5 & 399 & 63 & +12 & 17.77 & 1.4 & 0.05467 & 2.8 & 0.4242 & 3.1 & 0.05627 & 1.4 & 0.4 \\
\hline & RT-04-16.1 & 978 & 820 & 0.87 & 0.77 & 345 & 5 & 420 & 34 & +18 & 18.19 & 1.5 & 0.05518 & 1.5 & 0.4182 & 2.1 & 0.05497 & 1.5 & 0.7 \\
\hline & RT-04-17.1 & 293 & 161 & 0.57 & 0.05 & 349 & 5 & 341 & 38 & -3 & 17.96 & 1.6 & 0.05328 & 1.7 & 0.4090 & 2.3 & 0.05568 & 1.6 & 0.7 \\
\hline & RT-04-18.1 & 592 & 343 & 0.60 & 0.32 & 350 & 5 & 377 & 33 & +7 & 17.94 & 1.5 & 0.05413 & 1.5 & 0.4161 & 2.1 & 0.05575 & 1.5 & 0.7 \\
\hline & RT-04-19.1 & 297 & 110 & 0.38 & 0.21 & 353 & 5 & 330 & 48 & -7 & 17.78 & 1.6 & 0.05302 & 2.1 & 0.4113 & 2.6 & 0.05626 & 1.6 & 0.6 \\
\hline & RT-04-20.1 & 1111 & 2151 & 2.00 & 64.39 & 166 & 21 & 2866 & 773 & +95 & 38.27 & 12.6 & 0.20491 & 47.5 & 0.7383 & 49.2 & 0.02613 & 12.6 & 0.3 \\
\hline & RT-04-21.1 & 395 & 349 & 0.91 & 0.11 & 347 & 5 & 366 & 32 & +5 & 18.08 & 1.5 & 0.05388 & 1.4 & 0.4109 & 2.1 & 0.05531 & 1.5 & 0.7 \\
\hline & RT-04-22.1 & 402 & 305 & 0.78 & 0.79 & 330 & 5 & 339 & 57 & +3 & 19.04 & 1.4 & 0.05323 & 2.5 & 0.3854 & 2.9 & 0.05251 & 1.4 & 0.5 \\
\hline \multirow{16}{*}{ 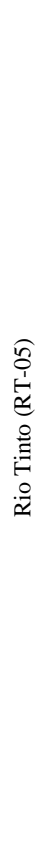 } & RT-05- 1.1 & 229 & 79 & 0.36 & -0.02 & 348 & 5 & 355 & 39 & +2 & 18.03 & 1.5 & 0.05361 & 1.7 & 0.410 & 2.3 & 0.0555 & 1.5 & 0.6 \\
\hline & RT-05-2.1 & 252 & 107 & 0.44 & 0.04 & 354 & 5 & 345 & 36 & -3 & 17.70 & 1.4 & 0.05339 & 1.6 & 0.416 & 2.1 & 0.0565 & 1.4 & 0.6 \\
\hline & RT-05-3.1 & 496 & 216 & 0.45 & 0.26 & 347 & 4 & 386 & 29 & +10 & 18.06 & 1.2 & 0.05436 & 1.3 & 0.415 & 1.8 & 0.0554 & 1.2 & 0.7 \\
\hline & RT-05-4.1 & 471 & 168 & 0.37 & 0.05 & 351 & 5 & 341 & 29 & -3 & 17.89 & 1.3 & 0.05327 & 1.3 & 0.411 & 1.9 & 0.0559 & 1.3 & 0.7 \\
\hline & RT-05-5.1 & 530 & 174 & 0.34 & -0.03 & 356 & 5 & 346 & 24 & -3 & 17.61 & 1.4 & 0.05341 & 1.0 & 0.418 & 1.8 & 0.0568 & 1.4 & 0.8 \\
\hline & RT-05-6.1 & 238 & 191 & 0.83 & 0.46 & 336 & 4 & 336 & 61 & -0 & 18.70 & 1.3 & 0.05316 & 2.7 & 0.392 & 3.0 & 0.0535 & 1.3 & 0.4 \\
\hline & RT-05-7.1 & 248 & 96 & 0.40 & 0.31 & 345 & 4 & 334 & 56 & -3 & 18.19 & 1.2 & 0.05312 & 2.5 & 0.403 & 2.8 & 0.0550 & 1.2 & 0.5 \\
\hline & RT-05-8.1 & 254 & 99 & 0.40 & 0.16 & 352 & 5 & 378 & 39 & +7 & 17.83 & 1.5 & 0.05417 & 1.7 & 0.419 & 2.3 & 0.0561 & 1.5 & 0.7 \\
\hline & RT-05-9.1 & 253 & 107 & 0.44 & 0.27 & 349 & 5 & 389 & 42 & +11 & 18.00 & 1.6 & 0.05442 & 1.9 & 0.417 & 2.4 & 0.0556 & 1.6 & 0.6 \\
\hline & RT-05-10.1 & 211 & 81 & 0.40 & 0.48 & 348 & 4 & 391 & 60 & +11 & 18.04 & 1.3 & 0.05449 & 2.7 & 0.416 & 3.0 & 0.0554 & 1.3 & 0.4 \\
\hline & RT-05-11.1 & 328 & 146 & 0.46 & 0.28 & 338 & 4 & 378 & 37 & +11 & 18.57 & 1.4 & 0.05416 & 1.6 & 0.402 & 2.1 & 0.0538 & 1.4 & 0.6 \\
\hline & RT-05-12.1 & 715 & 383 & 0.55 & 0.39 & 352 & 4 & 396 & 32 & +11 & 17.83 & 1.2 & 0.05459 & 1.4 & 0.422 & 1.9 & 0.0561 & 1.2 & 0.6 \\
\hline & RT-05-13.1 & 189 & 100 & 0.55 & 0.45 & 351 & 5 & 357 & 68 & +2 & 17.85 & 1.5 & 0.05365 & 3.0 & 0.414 & 3.4 & 0.0560 & 1.5 & 0.4 \\
\hline & RT-05-14.1 & 513 & 271 & 0.55 & 0.30 & 331 & 5 & 353 & 35 & +6 & 18.99 & 1.4 & 0.05356 & 1.6 & 0.389 & 2.1 & 0.0527 & 1.4 & 0.7 \\
\hline & RT-05-15.1 & 213 & 103 & 0.50 & 0.68 & 341 & 5 & 345 & 74 & +1 & 18.40 & 1.5 & 0.05337 & 3.3 & 0.400 & 3.6 & 0.0544 & 1.5 & 0.4 \\
\hline & RT-05-16.1 & 249 & 115 & 0.48 & 0.33 & 344 & 4 & 352 & 66 & +2 & 18.26 & 1.2 & 0.05355 & 2.9 & 0.404 & 3.2 & 0.0548 & 1.2 & 0.4 \\
\hline \multirow{2}{*}{ 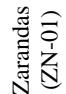 } & ZN-01-1.1 & 128 & 70 & 0.57 & 0.10 & 662 & 8 & 646 & 39 & -3 & 9.24 & 1.3 & 0.06119 & 1.8 & 0.913 & 2.2 & 0.1082 & 1.3 & 0.6 \\
\hline & $\mathrm{ZN}-01-2.1$ & 422 & 280 & 0.69 & 0.82 & 347 & 5 & 375 & 53 & +8 & 18.10 & 1.5 & 0.05409 & 2.3 & 0.412 & 2.8 & 0.0552 & 1.5 & 0.5 \\
\hline
\end{tabular}




\begin{tabular}{|c|c|c|c|c|c|c|c|c|c|c|c|c|c|c|c|c|c|c|c|}
\hline & ZN-01-3.1 & 640 & 328 & 0.53 & 0.08 & 346 & 5 & 345 & 26 & -0 & 18.12 & 1.4 & 0.05338 & 1.1 & 0.406 & 1.8 & 0.0552 & 1.4 & 0.8 \\
\hline & $\mathrm{ZN}-01-1.2$ & 168 & 38 & 0.23 & 0.13 & 355 & 4 & 357 & 51 & +1 & 17.65 & 1.3 & 0.05367 & 2.3 & 0.419 & 2.6 & 0.0567 & 1.3 & 0.5 \\
\hline & ZN-01-4.1 & 873 & 433 & 0.51 & 0.59 & 357 & 4 & 375 & 54 & +5 & 17.59 & 1.3 & 0.05409 & 2.4 & 0.424 & 2.7 & 0.0569 & 1.3 & 0.5 \\
\hline & ZN-01-5.1 & 768 & 468 & 0.63 & 2.28 & 355 & 5 & 373 & 67 & +5 & 17.68 & 1.6 & 0.05405 & 3.0 & 0.421 & 3.3 & 0.0566 & 1.6 & 0.5 \\
\hline & ZN-01-6.1 & 651 & 403 & 0.64 & 0.79 & 345 & 4 & 378 & 40 & +9 & 18.18 & 1.2 & 0.05416 & 1.8 & 0.411 & 2.1 & 0.0550 & 1.2 & 0.6 \\
\hline & ZN-01-7.1 & 847 & 476 & 0.58 & 0.23 & 373 & 5 & 363 & 32 & -3 & 16.80 & 1.4 & 0.05380 & 1.4 & 0.442 & 2.0 & 0.0595 & 1.4 & 0.7 \\
\hline & ZN-01-8.1 & 379 & 158 & 0.43 & 0.07 & 348 & 4 & 338 & 34 & -3 & 18.02 & 1.2 & 0.05321 & 1.5 & 0.407 & 1.9 & 0.0555 & 1.2 & 0.6 \\
\hline & ZN-01-9.1 & 394 & 147 & 0.38 & -0.01 & 353 & 5 & 348 & 27 & -1 & 17.79 & 1.4 & 0.05345 & 1.2 & 0.414 & 1.9 & 0.0562 & 1.4 & 0.8 \\
\hline & ZN-01-10.1 & 185 & 69 & 0.39 & 0.82 & 348 & 6 & 341 & 85 & -2 & 18.04 & 1.8 & 0.05328 & 3.7 & 0.407 & 4.1 & 0.0554 & 1.8 & 0.4 \\
\hline & $\mathrm{ZN}-01-11.1$ & 602 & 490 & 0.84 & -0.01 & 363 & 4 & 353 & 23 & -3 & 17.28 & 1.2 & 0.05357 & 1.0 & 0.428 & 1.6 & 0.0579 & 1.2 & 0.8 \\
\hline & $\mathrm{ZN}-01-12.1$ & 125 & 75 & 0.62 & 0.17 & 699 & 10 & 725 & 33 & +4 & 8.73 & 1.6 & 0.06349 & 1.6 & 1.003 & 2.2 & 0.1146 & 1.6 & 0.7 \\
\hline & ZN-01-13.1 & 281 & 128 & 0.47 & 0.15 & 353 & 4 & 345 & 42 & -2 & 17.75 & 1.2 & 0.05339 & 1.8 & 0.415 & 2.2 & 0.0563 & 1.2 & 0.6 \\
\hline & ZN-01-14.1 & 209 & 118 & 0.59 & 0.06 & 360 & 6 & 350 & 43 & -3 & 17.43 & 1.6 & 0.05351 & 1.9 & 0.423 & 2.5 & 0.0574 & 1.6 & 0.6 \\
\hline & ZN-01-15.1 & 662 & 450 & 0.70 & 0.40 & 342 & 4 & 353 & 34 & +3 & 18.34 & 1.2 & 0.05358 & 1.5 & 0.403 & 1.9 & 0.0545 & 1.2 & 0.6 \\
\hline & ZN-01-16.1 & 717 & 393 & 0.57 & 1.34 & 353 & 4 & 400 & 52 & +12 & 17.75 & 1.3 & 0.05470 & 2.3 & 0.425 & 2.7 & 0.0563 & 1.3 & 0.5 \\
\hline & ZN-01-17.1 & 453 & 273 & 0.62 & 1.21 & 365 & 4 & 378 & 72 & +4 & 17.18 & 1.2 & 0.05418 & 3.2 & 0.435 & 3.4 & 0.0582 & 1.2 & 0.4 \\
\hline & ZN-01-18.1 & 747 & 503 & 0.70 & 2.28 & 349 & 4 & 364 & 86 & +4 & 17.96 & 1.2 & 0.05384 & 3.8 & 0.413 & 4.0 & 0.0557 & 1.2 & 0.3 \\
\hline & ZN-01-19.1 & 1044 & 602 & 0.60 & -0.07 & 365 & 4 & 349 & 17 & -5 & 17.18 & 1.2 & 0.05347 & 0.8 & 0.429 & 1.4 & 0.0582 & 1.2 & 0.8 \\
\hline & xTEM-11.2 & 615 & 200 & 0.34 & -0.03 & 443 & 5 & 433 & 18 & -2 & 14.07 & 1.3 & 0.05551 & 0.8 & 0.544 & 1.5 & 0.0711 & 1.3 & 0.8 \\
\hline & ZN-01-20.1 & 680 & 397 & 0.60 & -0.05 & 367 & 5 & 356 & 21 & -3 & 17.06 & 1.4 & 0.05364 & 0.9 & 0.434 & 1.7 & 0.0586 & 1.4 & 0.8 \\
\hline & ZN-01-21.1 & 1257 & 525 & 0.43 & 0.03 & 371 & 4 & 364 & 17 & -2 & 16.90 & 1.2 & 0.05382 & 0.7 & 0.439 & 1.4 & 0.0592 & 1.2 & 0.8 \\
\hline & $\mathrm{ZN}-01-22.1$ & 990 & 817 & 0.85 & 0.90 & 355 & 4 & 388 & 43 & +9 & 17.68 & 1.2 & 0.05441 & 1.9 & 0.424 & 2.3 & 0.0566 & 1.2 & 0.5 \\
\hline & ZN-01-23.1 & 1085 & 394 & 0.37 & 0.08 & 355 & 4 & 361 & 19 & +2 & 17.67 & 1.3 & 0.05377 & 0.8 & 0.420 & 1.5 & 0.0566 & 1.3 & 0.8 \\
\hline \multirow{5}{*}{ 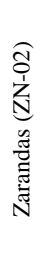 } & ZN-02-2.1 & 489 & 262 & 0.55 & 0.04 & 349 & 5 & 341 & 27 & -2 & 17.98 & 1.4 & 0.05328 & 1.2 & 0.409 & 1.8 & 0.0556 & 1.4 & 0.8 \\
\hline & ZN-02-3.1 & 676 & 401 & 0.61 & 0.05 & 353 & 4 & 345 & 24 & -2 & 17.74 & 1.2 & 0.05339 & 1.1 & 0.415 & 1.6 & 0.0564 & 1.2 & 0.7 \\
\hline & ZN-02-4.1 & 313 & 148 & 0.49 & 0.08 & 349 & 4 & 354 & 36 & +1 & 17.98 & 1.2 & 0.05358 & 1.6 & 0.411 & 2.0 & 0.0556 & 1.2 & 0.6 \\
\hline & ZN-02-5.1 & 312 & 227 & 0.75 & 0.08 & 348 & 4 & 340 & 39 & -2 & 18.04 & 1.2 & 0.05326 & 1.7 & 0.407 & 2.1 & 0.0554 & 1.2 & 0.6 \\
\hline & ZN-02-6.1 & 167 & 73 & 0.45 & 0.31 & 352 & 6 & 375 & 60 & +6 & 17.80 & 1.7 & 0.05410 & 2.7 & 0.419 & 3.2 & 0.0562 & 1.7 & 0.5 \\
\hline
\end{tabular}




\begin{tabular}{|c|c|c|c|c|c|c|c|c|c|c|c|c|c|c|c|c|c|c|c|}
\hline & $\mathrm{ZN}-02-7.1$ & 1060 & 696 & 0.68 & 0.20 & 340 & 4 & 357 & 22 & +5 & 18.48 & 1.3 & 0.05366 & 1.0 & 0.400 & 1.6 & 0.0541 & 1.3 & 0.8 \\
\hline & $\mathrm{ZN}-02-10.1$ & 1503 & 950 & 0.65 & 0.51 & 326 & 4 & 382 & 22 & +15 & 19.27 & 1.3 & 0.05425 & 1.0 & 0.388 & 1.6 & 0.0519 & 1.3 & 0.8 \\
\hline & $\mathrm{ZN}-02-11.1$ & 354 & 241 & 0.70 & 1.30 & 259 & 9 & 409 & 62 & +38 & 24.42 & 3.5 & 0.05493 & 2.8 & 0.310 & 4.5 & 0.0410 & 3.5 & 0.8 \\
\hline & ZN-02-12.1 & 263 & 126 & 0.50 & 0.14 & 347 & 5 & 341 & 44 & -2 & 18.10 & 1.5 & 0.05328 & 1.9 & 0.406 & 2.4 & 0.0552 & 1.5 & 0.6 \\
\hline & ZN-02-13.1 & 338 & 146 & 0.44 & 0.30 & 350 & 5 & 374 & 41 & +7 & 17.91 & 1.4 & 0.05408 & 1.8 & 0.416 & 2.3 & 0.0558 & 1.4 & 0.6 \\
\hline & ZN-02-15.1 & 770 & 577 & 0.77 & 0.13 & 353 & 4 & 343 & 24 & -3 & 17.77 & 1.2 & 0.05332 & 1.1 & 0.414 & 1.6 & 0.0563 & 1.2 & 0.7 \\
\hline & ZN-02-16.1 & 1317 & 806 & 0.63 & 0.16 & 347 & 4 & 353 & 19 & +2 & 18.06 & 1.2 & 0.05357 & 0.8 & 0.409 & 1.4 & 0.0554 & 1.2 & 0.8 \\
\hline & ZN-02-17.1 & 603 & 347 & 0.59 & 0.47 & 347 & 5 & 372 & 49 & +7 & 18.08 & 1.4 & 0.05402 & 2.2 & 0.412 & 2.6 & 0.0553 & 1.4 & 0.5 \\
\hline & ZN-02-19.1 & 527 & 266 & 0.52 & 0.13 & 354 & 4 & 354 & 30 & -0 & 17.70 & 1.2 & 0.05359 & 1.3 & 0.417 & 1.8 & 0.0565 & 1.2 & 0.7 \\
\hline & ZN-02-20.1 & 264 & 150 & 0.59 & 0.30 & 356 & 4 & 380 & 46 & +6 & 17.59 & 1.2 & 0.05422 & 2.1 & 0.425 & 2.4 & 0.0568 & 1.2 & 0.5 \\
\hline & ZN-02-21.1 & 344 & 198 & 0.59 & 0.64 & 343 & 4 & 341 & 78 & -0 & 18.30 & 1.2 & 0.05330 & 3.5 & 0.402 & 3.7 & 0.0547 & 1.2 & 0.3 \\
\hline & ZN-02-22.1 & 1415 & 917 & 0.67 & 0.22 & 357 & 5 & 350 & 22 & -2 & 17.59 & 1.4 & 0.05350 & 1.0 & 0.419 & 1.7 & 0.0569 & 1.4 & 0.8 \\
\hline \multirow{15}{*}{ 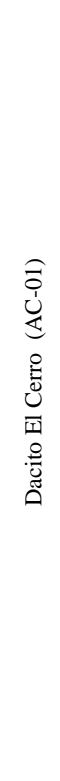 } & AC01-1.1 & 262 & 191 & 0.753 & 0.008 & 355 & 3 & 347 & 26 & -2 & 17.69 & 1.0 & 0.05344 & 1.2 & 0.4165 & 1.5 & 0.05654 & 1.0 & 0.6 \\
\hline & AC01-2.1 & 168 & 107 & 0.658 & 0.099 & 353 & 5 & 340 & 41 & -4 & 17.78 & 1.3 & 0.05327 & 1.8 & 0.4130 & 2.2 & 0.05623 & 1.3 & 0.6 \\
\hline & AC01-3.1 & 98 & 60 & 0.632 & 0.489 & 345 & 3 & 353 & 120 & +3 & 18.22 & 0.9 & 0.05358 & 5.3 & 0.4055 & 5.4 & 0.05490 & 0.9 & 0.2 \\
\hline & AC01-4.1 & 152 & 95 & 0.648 & 0.324 & 347 & 5 & 339 & 56 & -2 & 18.09 & 1.4 & 0.05324 & 2.5 & 0.4059 & 2.9 & 0.05529 & 1.4 & 0.5 \\
\hline & AC01-5.1 & 213 & 152 & 0.737 & -0.007 & 357 & 4 & 354 & 26 & -1 & 17.56 & 1.2 & 0.05360 & 1.1 & 0.4208 & 1.7 & 0.05694 & 1.2 & 0.7 \\
\hline & AC01-6.1 & 221 & 149 & 0.697 & 0.108 & 354 & 4 & 379 & 27 & +7 & 17.72 & 1.0 & 0.05420 & 1.2 & 0.4217 & 1.6 & 0.05643 & 1.0 & 0.6 \\
\hline & AC01-7.1 & 260 & 180 & 0.717 & 0.087 & 356 & 4 & 346 & 31 & -3 & 17.63 & 1.3 & 0.05340 & 1.4 & 0.4176 & 1.9 & 0.05672 & 1.3 & 0.7 \\
\hline & AC01-8.1 & 363 & 277 & 0.789 & 0.039 & 355 & 4 & 361 & 22 & +2 & 17.65 & 1.1 & 0.05377 & 1.0 & 0.4201 & 1.5 & 0.05666 & 1.1 & 0.7 \\
\hline & AC01-9.1 & 152 & 68 & 0.459 & 0.243 & 358 & 4 & 355 & 51 & -1 & 17.52 & 1.1 & 0.05361 & 2.2 & 0.4218 & 2.5 & 0.05706 & 1.1 & 0.4 \\
\hline & AC01-10.1 & 219 & 164 & 0.774 & 0.100 & 354 & 4 & 363 & 32 & +3 & 17.73 & 1.3 & 0.05381 & 1.4 & 0.4185 & 1.9 & 0.05640 & 1.3 & 0.7 \\
\hline & AC01-11.1 & 355 & 320 & 0.932 & 0.122 & 355 & 4 & 374 & 25 & +5 & 17.64 & 1.1 & 0.05408 & 1.1 & 0.4227 & 1.5 & 0.05669 & 1.1 & 0.7 \\
\hline & AC01-12.1 & 163 & 112 & 0.707 & 0.101 & 355 & 6 & 343 & 41 & -4 & 17.64 & 1.9 & 0.05333 & 1.8 & 0.4169 & 2.6 & 0.05669 & 1.9 & 0.7 \\
\hline & AC01-13.1 & 191 & 116 & 0.628 & 0.083 & 355 & 4 & 354 & 37 & -0 & 17.65 & 1.1 & 0.05359 & 1.6 & 0.4187 & 1.9 & 0.05667 & 1.1 & 0.5 \\
\hline & AC01-14.1 & 300 & 222 & 0.764 & -0.072 & 357 & 4 & 342 & 25 & -5 & 17.55 & 1.2 & 0.05330 & 1.1 & 0.4187 & 1.6 & 0.05697 & 1.2 & 0.7 \\
\hline & AC01-15.1 & 365 & 333 & 0.940 & 0.080 & 355 & 3 & 362 & 23 & +2 & 17.66 & 1.0 & 0.05378 & 1.0 & 0.4198 & 1.4 & 0.05662 & 1.0 & 0.7 \\
\hline
\end{tabular}




\begin{tabular}{|c|c|c|c|c|c|c|c|c|c|c|c|c|c|c|c|c|c|c|c|}
\hline & AC01-16.1 & 200 & 139 & 0.718 & 0.100 & 350 & 4 & 344 & 59 & -2 & 17.94 & 1.1 & 0.05337 & 2.6 & 0.4102 & 2.8 & 0.05575 & 1.1 & 0.4 \\
\hline & AC01-17.1 & 242 & 157 & 0.669 & 0.055 & 354 & 4 & 354 & 27 & -0 & 17.71 & 1.2 & 0.05359 & 1.2 & 0.4172 & 1.7 & 0.05646 & 1.2 & 0.7 \\
\hline & AC01-18.1 & 146 & 88 & 0.624 & 0.269 & 347 & 4 & 333 & 55 & -4 & 18.06 & 1.2 & 0.05309 & 2.4 & 0.4053 & 2.7 & 0.05536 & 1.2 & 0.5 \\
\hline & AC01-19.1 & 205 & 141 & 0.711 & 0.024 & 356 & 5 & 376 & 29 & +5 & 17.63 & 1.5 & 0.05411 & 1.3 & 0.4233 & 2.0 & 0.05673 & 1.5 & 0.8 \\
\hline & AC01-20.1 & 227 & 166 & 0.753 & -0.049 & 354 & 4 & 337 & 25 & -5 & 17.71 & 1.1 & 0.05320 & 1.1 & 0.4143 & 1.6 & 0.05648 & 1.1 & 0.7 \\
\hline \multirow{20}{*}{ 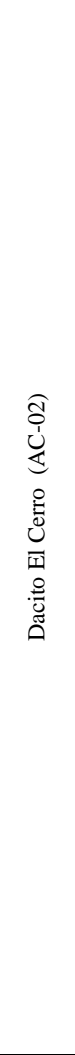 } & AC02-1.1 & 133 & 63 & 0.490 & 0.732 & 361 & 4 & 366 & 83 & +2 & 17.38 & 1.2 & 0.05388 & 3.7 & 0.4274 & 3.9 & 0.05752 & 1.2 & 0.3 \\
\hline & AC02-2.1 & 218 & 172 & 0.816 & 0.250 & 340 & 4 & 333 & 38 & -2 & 18.45 & 1.3 & 0.05310 & 1.7 & 0.3969 & 2.1 & 0.05420 & 1.3 & 0.6 \\
\hline & AC02-3.1 & 188 & 127 & 0.697 & 0.189 & 362 & 5 & 363 & 40 & +0 & 17.30 & 1.3 & 0.05382 & 1.8 & 0.4288 & 2.2 & 0.05779 & 1.3 & 0.6 \\
\hline & AC02-5.1 & 144 & 88 & 0.626 & 0.253 & 346 & 4 & 354 & 47 & +2 & 18.14 & 1.1 & 0.05360 & 2.1 & 0.4074 & 2.3 & 0.05512 & 1.1 & 0.5 \\
\hline & AC02-6.1 & 247 & 185 & 0.773 & 0.002 & 348 & 4 & 339 & 26 & -3 & 18.05 & 1.2 & 0.05324 & 1.1 & 0.4066 & 1.6 & 0.05540 & 1.2 & 0.7 \\
\hline & AC02-7.1 & 176 & 109 & 0.640 & -0.064 & 353 & 3 & 357 & 33 & +1 & 17.77 & 0.9 & 0.05366 & 1.5 & 0.4164 & 1.7 & 0.05627 & 0.9 & 0.5 \\
\hline & AC02-8.1 & 351 & 293 & 0.864 & 0.770 & 347 & 5 & 350 & 58 & +1 & 18.07 & 1.6 & 0.05350 & 2.6 & 0.4081 & 3.0 & 0.05533 & 1.6 & 0.5 \\
\hline & AC02-9.1 & 214 & 134 & 0.648 & 0.055 & 344 & 4 & 352 & 29 & +2 & 18.23 & 1.2 & 0.05353 & 1.3 & 0.4048 & 1.8 & 0.05485 & 1.2 & 0.7 \\
\hline & AC02-10.1 & 270 & 199 & 0.761 & 0.164 & 351 & 4 & 341 & 35 & -3 & 17.86 & 1.3 & 0.05329 & 1.5 & 0.4114 & 2.0 & 0.05599 & 1.3 & 0.6 \\
\hline & AC02-11.1 & 238 & 164 & 0.713 & 0.111 & 350 & 5 & 342 & 35 & -2 & 17.94 & 1.4 & 0.05332 & 1.5 & 0.4098 & 2.1 & 0.05575 & 1.4 & 0.7 \\
\hline & AC02-12.1 & 450 & 410 & 0.941 & 0.018 & 352 & 4 & 339 & 23 & -4 & 17.84 & 1.3 & 0.05324 & 1.0 & 0.4116 & 1.6 & 0.05607 & 1.3 & 0.8 \\
\hline & AC02-13.1 & 151 & 96 & 0.658 & 0.052 & 352 & 3 & 335 & 41 & -5 & 17.79 & 0.9 & 0.05314 & 1.8 & 0.4118 & 2.0 & 0.05620 & 0.9 & 0.4 \\
\hline & AC02-14.1 & 312 & 273 & 0.903 & -0.085 & 355 & 4 & 363 & 30 & +2 & 17.65 & 1.3 & 0.05381 & 1.3 & 0.4204 & 1.8 & 0.05666 & 1.3 & 0.7 \\
\hline & AC02-15.1 & 188 & 125 & 0.687 & 0.099 & 359 & 4 & 377 & 33 & +5 & 17.48 & 1.1 & 0.05415 & 1.5 & 0.4270 & 1.8 & 0.05720 & 1.1 & 0.6 \\
\hline & AC02-16.1 & 185 & 126 & 0.706 & -0.018 & 353 & 4 & 347 & 31 & -2 & 17.78 & 1.2 & 0.05342 & 1.4 & 0.4141 & 1.8 & 0.05623 & 1.2 & 0.7 \\
\hline & AC02-17.1 & 140 & 75 & 0.557 & 0.090 & 355 & 5 & 340 & 50 & -5 & 17.68 & 1.4 & 0.05325 & 2.2 & 0.4152 & 2.6 & 0.05655 & 1.4 & 0.5 \\
\hline & AC02-18.1 & 157 & 94 & 0.621 & 0.215 & 351 & 3 & 369 & 46 & +5 & 17.88 & 0.9 & 0.05396 & 2.0 & 0.4161 & 2.2 & 0.05593 & 0.9 & 0.4 \\
\hline & AC02-19.1 & 290 & 228 & 0.814 & 0.490 & 395 & 3 & 391 & 57 & -1 & 15.84 & 0.9 & 0.05449 & 2.5 & 0.4744 & 2.7 & 0.06314 & 0.9 & 0.3 \\
\hline & AC02-20.1 & 212 & 159 & 0.772 & 0.149 & 352 & 3 & 363 & 36 & +3 & 17.80 & 0.9 & 0.05381 & 1.6 & 0.4169 & 1.8 & 0.05619 & 0.9 & 0.5 \\
\hline & AC02-21.1 & 147 & 78 & 0.545 & 0.109 & 349 & 3 & 346 & 45 & -1 & 17.95 & 0.9 & 0.05341 & 2.0 & 0.4102 & 2.2 & 0.05571 & 0.9 & 0.4 \\
\hline \multirow{2}{*}{ 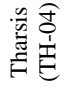 } & TH04-1.1 & 477 & 269 & 0.58 & 0.47 & 368 & 6 & 352 & 39 & -4 & 17.03 & 1.6 & 0.0536 & 1.7 & 0.434 & 2.3 & 0.0587 & 1.6 & 0.7 \\
\hline & TH04-2.1 & 82 & 47 & 0.59 & 4.06 & 356 & 7 & 387 & 375 & +8 & 17.61 & 1.9 & 0.0544 & 16.7 & 0.426 & 16.8 & 0.0568 & 1.9 & 0.1 \\
\hline
\end{tabular}




\begin{tabular}{|c|c|c|c|c|c|c|c|c|c|c|c|c|c|c|c|c|c|c|c|}
\hline & TH04-3.1 & 103 & 62 & 0.62 & 2.98 & 343 & 16 & 326 & 518 & -5 & 18.28 & 4.7 & 0.0529 & 22.8 & 0.399 & 23.3 & 0.0547 & 4.7 & 0.2 \\
\hline & TH04-4.1 & 479 & 304 & 0.66 & 0.58 & 361 & 6 & 353 & 50 & -3 & 17.34 & 1.7 & 0.0536 & 2.2 & 0.426 & 2.8 & 0.0577 & 1.7 & 0.6 \\
\hline & TH04-5.1 & 545 & 489 & 0.93 & 0.85 & 367 & 6 & 397 & 44 & +8 & 17.08 & 1.6 & 0.0546 & 2.0 & 0.441 & 2.5 & 0.0585 & 1.6 & 0.6 \\
\hline & TH04-6.1 & 266 & 96 & 0.37 & 1.24 & 366 & 6 & 353 & 113 & -4 & 17.10 & 1.6 & 0.0536 & 5.0 & 0.432 & 5.3 & 0.0585 & 1.6 & 0.3 \\
\hline & TH04-7.1 & 242 & 280 & 1.19 & 3.90 & 367 & 6 & 551 & 148 & +34 & 17.07 & 1.7 & 0.0586 & 6.8 & 0.473 & 7.0 & 0.0586 & 1.7 & 0.2 \\
\hline & TH04-8.1 & 367 & 200 & 0.56 & 0.59 & 363 & 6 & 357 & 55 & -2 & 17.25 & 1.6 & 0.0537 & 2.4 & 0.429 & 2.9 & 0.0580 & 1.6 & 0.5 \\
\hline & TH04-9.1 & 421 & 289 & 0.71 & 1.12 & 362 & 6 & 440 & 67 & +18 & 17.30 & 1.6 & 0.0557 & 3.0 & 0.444 & 3.4 & 0.0578 & 1.6 & 0.5 \\
\hline & TH04-10.1 & 542 & 332 & 0.63 & 1.74 & 376 & 6 & 469 & 84 & +20 & 16.65 & 1.6 & 0.0564 & 3.8 & 0.467 & 4.1 & 0.0600 & 1.6 & 0.4 \\
\hline & TH04-11.1 & 841 & 509 & 0.62 & 2.50 & 385 & 8 & 419 & 116 & +8 & 16.26 & 2.2 & 0.0552 & 5.2 & 0.468 & 5.6 & 0.0615 & 2.2 & 0.4 \\
\hline & TH04-12.1 & 526 & 297 & 0.58 & 1.47 & 371 & 6 & 433 & 97 & +15 & 16.87 & 1.6 & 0.0555 & 4.4 & 0.454 & 4.6 & 0.0593 & 1.6 & 0.3 \\
\hline & TH04-13.1 & 816 & 663 & 0.84 & 3.06 & 410 & 9 & 621 & 71 & +35 & 15.24 & 2.2 & 0.0605 & 3.3 & 0.547 & 4.0 & 0.0656 & 2.2 & 0.6 \\
\hline & TH04-14.1 & 238 & 195 & 0.85 & 1.04 & 350 & 7 & 377 & 87 & +8 & 17.94 & 1.9 & 0.0542 & 3.9 & 0.416 & 4.3 & 0.0557 & 1.9 & 0.4 \\
\hline & ТH04-15.1 & 230 & 183 & 0.82 & 0.88 & 365 & 6 & 353 & 112 & -3 & 17.18 & 1.6 & 0.0536 & 5.0 & 0.430 & 5.2 & 0.0582 & 1.6 & 0.3 \\
\hline & TH04-16.1 & 420 & 335 & 0.82 & 1.00 & 352 & 5 & 418 & 63 & +16 & 17.80 & 1.6 & 0.0552 & 2.8 & 0.427 & 3.2 & 0.0562 & 1.6 & 0.5 \\
\hline & TH04-17.1 & 506 & 421 & 0.86 & 0.40 & 361 & 6 & 340 & 52 & -6 & 17.38 & 1.7 & 0.0533 & 2.3 & 0.422 & 2.9 & 0.0575 & 1.7 & 0.6 \\
\hline & TH04-18.1 & 602 & 392 & 0.67 & 1.26 & 430 & 8 & 456 & 68 & +6 & 14.50 & 1.9 & 0.0561 & 3.1 & 0.533 & 3.6 & 0.0690 & 1.9 & 0.5 \\
\hline & ТH04-19.1 & 589 & 503 & 0.88 & 2.08 & 367 & 6 & 527 & 89 & +31 & 17.08 & 1.6 & 0.0579 & 4.0 & 0.468 & 4.4 & 0.0585 & 1.6 & 0.4 \\
\hline & TH04-20.1 & 390 & 195 & 0.52 & 0.75 & 376 & 6 & 420 & 77 & +11 & 16.64 & 1.6 & 0.0552 & 3.4 & 0.457 & 3.8 & 0.0601 & 1.6 & 0.4 \\
\hline & TH04-21.1 & 617 & 375 & 0.63 & 0.86 & 363 & 6 & 401 & 66 & +10 & 17.26 & 1.6 & 0.0547 & 2.9 & 0.437 & 3.3 & 0.0579 & 1.6 & 0.5 \\
\hline & LCO7-1.1 & 303 & 170 & 0.58 & 1.65 & 372 & 6 & 391 & 81 & +5 & 16.84 & 1.7 & 0.0545 & 3.6 & 0.446 & 4.0 & 0.0594 & 1.7 & 0.4 \\
\hline & LCO7-1.2 & 93 & 30 & 0.33 & 5.10 & 352 & 6 & 408 & 442 & +14 & 17.84 & 1.9 & 0.0549 & 19.8 & 0.424 & 19.9 & 0.0560 & 1.9 & 0.1 \\
\hline & LCO7-2.1 & 181 & 49 & 0.28 & 3.06 & 310 & 7 & 498 & 241 & +39 & 20.28 & 2.4 & 0.0572 & 10.9 & 0.389 & 11.2 & 0.0493 & 2.4 & 0.2 \\
\hline 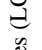 & LCO7-3.1 & 161 & 64 & 0.41 & 4.10 & 335 & 9 & 411 & 183 & +19 & 18.74 & 2.6 & 0.0550 & 8.2 & 0.405 & 8.6 & 0.0534 & 2.6 & 0.3 \\
\hline है & LCO7-3.2 & 121 & 44 & 0.37 & 9.87 & 329 & 9 & 884 & 492 & +64 & 19.13 & 2.8 & 0.0685 & 23.8 & 0.494 & 23.9 & 0.0523 & 2.8 & 0.1 \\
\hline 單 & LCO7-4.1 & 120 & 39 & 0.33 & 4.45 & 312 & 8 & 324 & 297 & +4 & 20.20 & 2.7 & 0.0529 & 13.1 & 0.361 & 13.4 & 0.0495 & 2.7 & 0.2 \\
\hline & LCO7-5.1 & 103 & 36 & 0.36 & 2.80 & 359 & 7 & 383 & 271 & +6 & 17.46 & 2.0 & 0.0543 & 12.1 & 0.429 & 12.2 & 0.0573 & 2.0 & 0.2 \\
\hline & LCO7-6.1 & 177 & 86 & 0.50 & 2.21 & 320 & 8 & 342 & 204 & +6 & 19.62 & 2.7 & 0.0533 & 9.0 & 0.375 & 9.4 & 0.0510 & 2.7 & 0.3 \\
\hline
\end{tabular}




\begin{tabular}{|c|c|c|c|c|c|c|c|c|c|c|c|c|c|c|c|c|c|c|c|}
\hline & LCO7-6.2 & 165 & 77 & 0.48 & 6.45 & 356 & 6 & 372 & 275 & +4 & 17.62 & 1.8 & 0.0540 & 12.2 & 0.423 & 12.3 & 0.0568 & 1.8 & 0.1 \\
\hline & LCO7-7.1 & 160 & 78 & 0.50 & 1.79 & 353 & 6 & 352 & 178 & -0 & 17.78 & 1.7 & 0.0535 & 7.9 & 0.415 & 8.0 & 0.0563 & 1.7 & 0.2 \\
\hline & LCO7-7.2 & 126 & 49 & 0.41 & 5.03 & 405 & 9 & 408 & 316 & +1 & 15.42 & 2.2 & 0.0549 & 14.1 & 0.491 & 14.3 & 0.0649 & 2.2 & 0.2 \\
\hline & LCO7-8.1 & 144 & 70 & 0.50 & 1.61 & 365 & 6 & 405 & 111 & +10 & 17.18 & 1.7 & 0.0548 & 4.9 & 0.440 & 5.2 & 0.0582 & 1.7 & 0.3 \\
\hline & LCO7-8.2 & 210 & 103 & 0.51 & 24.83 & 443 & 20 & 1276 & 444 & +68 & 14.07 & 4.6 & 0.0833 & 22.8 & 0.816 & 23.2 & 0.0711 & 4.6 & 0.2 \\
\hline & LCO7-9.1 & 208 & 110 & 0.54 & 1.81 & 368 & 6 & 371 & 166 & +1 & 17.00 & 1.6 & 0.0540 & 7.4 & 0.438 & 7.6 & 0.0588 & 1.6 & 0.2 \\
\hline & LCO7-9.2 & 133 & 49 & 0.38 & 7.22 & 359 & 7 & 387 & 394 & +8 & 17.48 & 2.1 & 0.0544 & 17.5 & 0.429 & 17.7 & 0.0572 & 2.1 & 0.1 \\
\hline & LCO7-10.1 & 185 & 78 & 0.43 & 3.39 & 334 & 7 & 369 & 278 & +10 & 18.83 & 2.3 & 0.0539 & 12.3 & 0.395 & 12.5 & 0.0531 & 2.3 & 0.2 \\
\hline & LCO7-10.2 & 140 & 57 & 0.42 & 6.62 & 318 & 10 & 448 & 388 & +30 & 19.79 & 3.1 & 0.0559 & 17.4 & 0.389 & 17.7 & 0.0505 & 3.1 & 0.2 \\
\hline & LCO7-11.1 & 103 & 40 & 0.40 & 6.16 & 362 & 8 & 480 & 380 & +25 & 17.29 & 2.1 & 0.0567 & 17.2 & 0.452 & 17.3 & 0.0578 & 2.1 & 0.1 \\
\hline & LCO7-12.1 & 155 & 49 & 0.32 & 2.02 & 328 & 5 & 350 & 201 & +6 & 19.16 & 1.7 & 0.0535 & 8.9 & 0.385 & 9.1 & 0.0522 & 1.7 & 0.2 \\
\hline & LCO7-13.1 & 104 & 37 & 0.36 & 4.81 & 362 & 6 & 406 & 403 & +11 & 17.31 & 1.8 & 0.0549 & 18.0 & 0.437 & 18.1 & 0.0578 & 1.8 & 0.1 \\
\hline & LCO7-14.1 & 164 & 49 & 0.31 & 3.26 & 350 & 7 & 352 & 287 & +1 & 17.94 & 2.0 & 0.0535 & 12.7 & 0.412 & 12.9 & 0.0557 & 2.0 & 0.2 \\
\hline & LCO7-15.1 & 147 & 49 & 0.35 & 4.99 & 245 & 5 & 348 & 469 & +30 & 25.80 & 2.2 & 0.0534 & 20.7 & 0.286 & 20.9 & 0.0388 & 2.2 & 0.1 \\
\hline & LCO7-16.1 & 121 & 40 & 0.34 & 5.96 & 394 & 7 & 525 & 433 & +26 & 15.89 & 1.9 & 0.0579 & 19.8 & 0.502 & 19.8 & 0.0629 & 1.9 & 0.1 \\
\hline & LCO7-17.1 & 94 & 32 & 0.35 & 3.66 & 360 & 6 & 347 & 326 & -4 & 17.40 & 1.8 & 0.0534 & 14.4 & 0.423 & 14.5 & 0.0575 & 1.8 & 0.1 \\
\hline & LCO7-18.1 & 115 & 43 & 0.38 & 13.77 & 359 & 9 & 604 & 609 & +42 & 17.46 & 2.6 & 0.0600 & 28.1 & 0.474 & 28.3 & 0.0573 & 2.6 & 0.1 \\
\hline & LCO7-19.1 & 147 & 71 & 0.50 & 2.80 & 359 & 6 & 406 & 246 & +12 & 17.45 & 1.7 & 0.0549 & 11.0 & 0.433 & 11.1 & 0.0573 & 1.7 & 0.2 \\
\hline & LCO7-20.1 & 83 & 25 & 0.32 & 4.85 & 364 & 7 & 410 & 358 & +11 & 17.19 & 1.9 & 0.0550 & 16.0 & 0.441 & 16.1 & 0.0582 & 1.9 & 0.1 \\
\hline & LCO7-21.1 & 148 & 58 & 0.40 & 3.00 & 344 & 6 & 348 & 352 & +1 & 18.22 & 1.9 & 0.0534 & 15.6 & 0.404 & 15.7 & 0.0549 & 1.9 & 0.1 \\
\hline & LCO7-21.2 & 165 & 51 & 0.32 & 2.29 & 295 & 6 & 306 & 291 & +4 & 21.35 & 2.0 & 0.0525 & 12.8 & 0.339 & 13.0 & 0.0468 & 2.0 & 0.2 \\
\hline & LCO7-22.1 & 159 & 58 & 0.38 & 3.11 & 353 & 6 & 415 & 194 & +15 & 17.77 & 1.7 & 0.0551 & 8.7 & 0.427 & 8.8 & 0.0563 & 1.7 & 0.2 \\
\hline & LCO7-23.1 & 138 & 48 & 0.36 & 5.68 & 326 & 10 & 321 & 361 & -1 & 19.30 & 3.1 & 0.0528 & 15.9 & 0.377 & 16.2 & 0.0518 & 3.1 & 0.2 \\
\hline & LCO7-19.2 & 111 & 51 & 0.48 & 8.83 & 320 & 8 & 425 & 421 & +25 & 19.66 & 2.5 & 0.0553 & 18.9 & 0.388 & 19.1 & 0.0509 & 2.5 & 0.1 \\
\hline & LCO7-24.1 & 155 & 60 & 0.40 & 1.88 & 316 & 8 & 346 & 142 & +9 & 19.87 & 2.5 & 0.0534 & 6.3 & 0.370 & 6.8 & 0.0503 & 2.5 & 0.4 \\
\hline & LCO7-24.2 & 218 & 127 & 0.60 & 6.34 & 339 & 6 & 357 & 293 & +5 & 18.54 & 1.8 & 0.0537 & 13.0 & 0.399 & 13.1 & 0.0539 & 1.8 & 0.1 \\
\hline 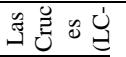 & LCO9-1.1 & 316 & 109 & 0.36 & 1.98 & 362 & 5 & 398 & 206 & +9 & 17.33 & 1.4 & 0.05466 & 9.2 & 0.4349 & 9.3 & 0.05771 & 1.4 & 0.1 \\
\hline
\end{tabular}




\begin{tabular}{|c|c|c|c|c|c|c|c|c|c|c|c|c|c|c|c|c|c|c|c|}
\hline & LCO9-2.1 & 331 & 85 & 0.27 & 1.08 & 353 & 5 & 393 & 98 & +10 & 17.76 & 1.5 & 0.05453 & 4.4 & 0.4234 & 4.6 & 0.05631 & 1.5 & 0.3 \\
\hline & LCO9-3.1 & 310 & 103 & 0.34 & 1.03 & 353 & 6 & 341 & 87 & -4 & 17.75 & 1.6 & 0.05329 & 3.8 & 0.4140 & 4.2 & 0.05634 & 1.6 & 0.4 \\
\hline & LCO9-4.1 & 302 & 125 & 0.43 & 0.57 & 349 & 5 & 320 & 65 & -9 & 17.98 & 1.5 & 0.05281 & 2.9 & 0.4049 & 3.2 & 0.05561 & 1.5 & 0.5 \\
\hline & LCO9-5.1 & 478 & 204 & 0.44 & 0.57 & 353 & 5 & 369 & 71 & +5 & 17.76 & 1.3 & 0.05396 & 3.2 & 0.4190 & 3.4 & 0.05632 & 1.3 & 0.4 \\
\hline & LCO9-6.1 & 377 & 148 & 0.41 & 0.82 & 339 & 4 & 342 & 98 & +1 & 18.53 & 1.4 & 0.05331 & 4.3 & 0.3968 & 4.5 & 0.05398 & 1.4 & 0.3 \\
\hline & LCO9-7.1 & 445 & 182 & 0.42 & 0.34 & 353 & 5 & 347 & 41 & -2 & 17.76 & 1.3 & 0.05342 & 1.8 & 0.4146 & 2.3 & 0.05629 & 1.3 & 0.6 \\
\hline & LCO9-8.1 & 310 & 135 & 0.45 & 0.79 & 352 & 5 & 379 & 76 & +7 & 17.81 & 1.6 & 0.05419 & 3.4 & 0.4196 & 3.7 & 0.05616 & 1.6 & 0.4 \\
\hline & LCO9-9.1 & 245 & 70 & 0.29 & 0.63 & 351 & 5 & 351 & 81 & -0 & 17.86 & 1.6 & 0.05352 & 3.6 & 0.4132 & 3.9 & 0.05600 & 1.6 & 0.4 \\
\hline & LCO9-10.1 & 249 & 69 & 0.29 & 0.97 & 350 & 5 & 351 & 109 & +1 & 17.94 & 1.4 & 0.05353 & 4.8 & 0.4114 & 5.0 & 0.05574 & 1.4 & 0.3 \\
\hline & LCO9-11.1 & 340 & 119 & 0.36 & 0.78 & 356 & 5 & 339 & 66 & -5 & 17.64 & 1.4 & 0.05324 & 2.9 & 0.4163 & 3.2 & 0.05670 & 1.4 & 0.4 \\
\hline & LCO9-12.1 & 231 & 64 & 0.29 & 0.83 & 352 & 5 & 377 & 121 & +7 & 17.83 & 1.4 & 0.05415 & 5.4 & 0.4188 & 5.6 & 0.05610 & 1.4 & 0.3 \\
\hline & LCO9-13.1 & 315 & 108 & 0.35 & 0.76 & 353 & 5 & 357 & 101 & +1 & 17.78 & 1.4 & 0.05367 & 4.5 & 0.4161 & 4.7 & 0.05624 & 1.4 & 0.3 \\
\hline & LCO9-14.1 & 362 & 133 & 0.38 & 0.64 & 347 & 5 & 353 & 55 & +2 & 18.08 & 1.4 & 0.05356 & 2.4 & 0.4084 & 2.8 & 0.05530 & 1.4 & 0.5 \\
\hline & LCO9-15.1 & 567 & 368 & 0.67 & 0.44 & 350 & 5 & 381 & 34 & +8 & 17.91 & 1.3 & 0.05425 & 1.5 & 0.4177 & 2.0 & 0.05585 & 1.3 & 0.7 \\
\hline & LCO9-16.1 & 394 & 126 & 0.33 & 0.68 & 342 & 5 & 349 & 56 & +2 & 18.33 & 1.4 & 0.05347 & 2.5 & 0.4023 & 2.8 & 0.05456 & 1.4 & 0.5 \\
\hline & LCO9-17.1 & 496 & 147 & 0.31 & 0.56 & 350 & 5 & 366 & 45 & +4 & 17.90 & 1.5 & 0.05387 & 2.0 & 0.4149 & 2.5 & 0.05587 & 1.5 & 0.6 \\
\hline & LCO9-18.1 & 290 & 121 & 0.43 & 0.73 & 350 & 5 & 352 & 79 & +1 & 17.94 & 1.5 & 0.05355 & 3.5 & 0.4117 & 3.8 & 0.05576 & 1.5 & 0.4 \\
\hline \multirow{10}{*}{ 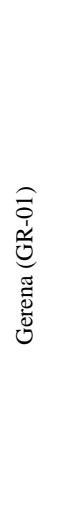 } & GR-01-1.1 & 448 & 106 & 0.24 & 0.33 & 355 & 4 & 349 & 38 & -2 & 17.67 & 1.2 & 0.05348 & 1.7 & 0.417 & 2.1 & 0.0566 & 1.2 & 0.6 \\
\hline & GR-01-2.1 & 586 & 99 & 0.17 & 0.00 & 347 & 4 & 345 & 23 & -1 & 18.11 & 1.2 & 0.05338 & 1.0 & 0.406 & 1.6 & 0.0552 & 1.2 & 0.8 \\
\hline & GR-01-3.1 & 773 & 680 & 0.91 & 0.27 & 344 & 4 & 337 & 29 & -2 & 18.25 & 1.2 & 0.05320 & 1.3 & 0.402 & 1.7 & 0.0548 & 1.2 & 0.7 \\
\hline & GR-01-4.1 & 494 & 78 & 0.16 & 0.00 & 357 & 5 & 352 & 26 & -2 & 17.54 & 1.3 & 0.05354 & 1.1 & 0.421 & 1.7 & 0.0570 & 1.3 & 0.8 \\
\hline & GR-01-5.1 & 738 & 104 & 0.14 & 0.23 & 639 & 7 & 687 & 14 & +7 & 9.60 & 1.2 & 0.06238 & 0.7 & 0.896 & 1.3 & 0.1042 & 1.2 & 0.9 \\
\hline & GR-01-5.2 & 379 & 110 & 0.30 & 0.15 & 350 & 5 & 343 & 35 & -2 & 17.92 & 1.5 & 0.05333 & 1.6 & 0.410 & 2.1 & 0.0558 & 1.5 & 0.7 \\
\hline & GR-01-6.1 & 419 & 222 & 0.55 & 2.66 & 1582 & 21 & 1893 & 13 & +18 & 3.59 & 1.5 & 0.11582 & 0.7 & 4.443 & 1.7 & 0.2782 & 1.5 & 0.9 \\
\hline & GR-01-6.2 & 939 & 338 & 0.37 & 4.20 & 334 & 4 & 337 & 134 & +1 & 18.81 & 1.3 & 0.05320 & 5.9 & 0.390 & 6.1 & 0.0532 & 1.3 & 0.2 \\
\hline & GR-01-7.1 & 381 & 121 & 0.33 & 0.14 & 345 & 4 & 342 & 35 & -1 & 18.20 & 1.3 & 0.05330 & 1.6 & 0.404 & 2.0 & 0.0550 & 1.3 & 0.6 \\
\hline & GR-01-8.1 & 711 & 266 & 0.39 & 0.05 & 352 & 4 & 344 & 23 & -2 & 17.83 & 1.2 & 0.05335 & 1.0 & 0.412 & 1.5 & 0.0561 & 1.2 & 0.8 \\
\hline
\end{tabular}




\begin{tabular}{|c|c|c|c|c|c|c|c|c|c|c|c|c|c|c|c|c|c|c|c|}
\hline & GR-01-9.1 & 398 & 240 & 0.62 & 0.18 & 338 & 4 & 333 & 36 & -2 & 18.59 & 1.3 & 0.05310 & 1.6 & 0.394 & 2.1 & 0.0538 & 1.3 & 0.6 \\
\hline & GR-01-10.1 & 587 & 400 & 0.70 & 0.00 & 571 & 7 & 553 & 18 & -3 & 10.80 & 1.3 & 0.05861 & 0.8 & 0.748 & 1.5 & 0.0926 & 1.3 & 0.8 \\
\hline & GR-01-11.1 & 1027 & 356 & 0.36 & 1.65 & 347 & 4 & 393 & 44 & +12 & 18.08 & 1.3 & 0.05453 & 2.0 & 0.416 & 2.4 & 0.0553 & 1.3 & 0.6 \\
\hline & GR-01-12.1 & 852 & 297 & 0.36 & 0.03 & 359 & 4 & 348 & 20 & -3 & 17.46 & 1.3 & 0.05344 & 0.9 & 0.422 & 1.5 & 0.0573 & 1.3 & 0.8 \\
\hline & GR-01-13.1 & 1132 & 417 & 0.38 & 0.70 & 356 & 4 & 351 & 33 & -1 & 17.63 & 1.3 & 0.05353 & 1.5 & 0.419 & 1.9 & 0.0567 & 1.3 & 0.7 \\
\hline & GR-01-14.1 & 737 & 310 & 0.43 & 0.35 & 337 & 4 & 335 & 48 & -1 & 18.62 & 1.2 & 0.05314 & 2.1 & 0.393 & 2.4 & 0.0537 & 1.2 & 0.5 \\
\hline & GR-01-15.1 & 976 & 751 & 0.80 & 2.24 & 321 & 4 & 379 & 55 & +16 & 19.58 & 1.2 & 0.05420 & 2.5 & 0.382 & 2.7 & 0.0511 & 1.2 & 0.4 \\
\hline & GR-01-17.1 & 607 & 132 & 0.22 & 0.55 & 342 & 4 & 368 & 37 & +7 & 18.36 & 1.3 & 0.05392 & 1.6 & 0.405 & 2.1 & 0.0545 & 1.3 & 0.6 \\
\hline & GR-01-18.1 & 642 & 143 & 0.23 & 0.06 & 348 & 4 & 339 & 24 & -3 & 18.04 & 1.3 & 0.05325 & 1.1 & 0.407 & 1.7 & 0.0554 & 1.3 & 0.8 \\
\hline \multirow{18}{*}{ 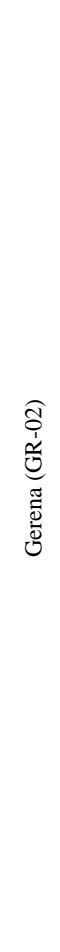 } & GR-02-1.1 & 171 & 97 & 0.58 & 1.37 & 2096 & 23 & 2196 & 8 & +5 & 2.60 & 1.3 & 0.13753 & 0.5 & 7.284 & 1.4 & 0.3841 & 1.3 & 0.9 \\
\hline & GR-02-2.1 & 1954 & 1826 & 0.97 & 7.02 & 363 & 4 & 401 & 122 & +10 & 17.27 & 1.2 & 0.05472 & 5.5 & 0.437 & 5.6 & 0.0579 & 1.2 & 0.2 \\
\hline & GR-02-3.1 & 2077 & 1701 & 0.85 & 0.00 & 347 & 4 & 340 & 19 & -2 & 18.06 & 1.2 & 0.05326 & 0.9 & 0.407 & 1.4 & 0.0554 & 1.2 & 0.8 \\
\hline & GR-02-4.1 & 2578 & 1469 & 0.59 & 4.53 & 354 & 4 & 403 & 85 & +12 & 17.71 & 1.2 & 0.05478 & 3.8 & 0.426 & 4.0 & 0.0565 & 1.2 & 0.3 \\
\hline & GR-02-6.1 & 182 & 67 & 0.38 & 1.47 & 2077 & 22 & 2179 & 9 & +5 & 2.63 & 1.3 & 0.13617 & 0.5 & 7.138 & 1.4 & 0.3802 & 1.3 & 0.9 \\
\hline & GR-02-7.1 & 314 & 126 & 0.42 & 1.02 & 2091 & 22 & 2169 & 6 & +4 & 2.61 & 1.2 & 0.13541 & 0.4 & 7.155 & 1.3 & 0.3832 & 1.2 & 1.0 \\
\hline & GR-02-8.1 & 561 & 189 & 0.35 & 3.82 & 1682 & 18 & 2084 & 5 & +22 & 3.36 & 1.2 & 0.12897 & 0.3 & 5.300 & 1.2 & 0.2980 & 1.2 & 1.0 \\
\hline & GR-02-9.1 & 192 & 75 & 0.40 & 1.10 & 2085 & 22 & 2165 & 9 & +4 & 2.62 & 1.3 & 0.13507 & 0.5 & 7.110 & 1.4 & 0.3818 & 1.3 & 0.9 \\
\hline & GR-02-10.1 & 381 & 134 & 0.36 & 1.41 & 2036 & 21 & 2151 & 6 & +6 & 2.69 & 1.2 & 0.13402 & 0.3 & 6.864 & 1.2 & 0.3714 & 1.2 & 1.0 \\
\hline & GR-02-11.1 & 1842 & 1557 & 0.87 & 0.24 & 341 & 4 & 374 & 16 & +9 & 18.43 & 1.2 & 0.05407 & 0.7 & 0.405 & 1.4 & 0.0543 & 1.2 & 0.9 \\
\hline & GR-02-12.1 & 1923 & 1832 & 0.98 & -0.05 & 354 & 4 & 345 & 12 & -3 & 17.69 & 1.2 & 0.05338 & 0.5 & 0.416 & 1.3 & 0.0565 & 1.2 & 0.9 \\
\hline & GR-02-13.1 & 390 & 209 & 0.55 & 2.60 & 1910 & 20 & 2143 & 6 & +13 & 2.90 & 1.2 & 0.13341 & 0.3 & 6.345 & 1.2 & 0.3450 & 1.2 & 1.0 \\
\hline & GR-02-15.1 & 184 & 53 & 0.30 & 4.59 & 1528 & 17 & 2043 & 11 & +28 & 3.74 & 1.3 & 0.12602 & 0.6 & 4.647 & 1.4 & 0.2674 & 1.3 & 0.9 \\
\hline & GR-02-16.1 & 416 & 80 & 0.20 & 4.70 & 1245 & 14 & 1888 & 9 & +37 & 4.70 & 1.2 & 0.11555 & 0.5 & 3.393 & 1.3 & 0.2130 & 1.2 & 0.9 \\
\hline & GR-02-17.1 & 177 & 73 & 0.43 & 1.54 & 2059 & 22 & 2180 & 8 & +6 & 2.66 & 1.3 & 0.13623 & 0.5 & 7.068 & 1.4 & 0.3763 & 1.3 & 0.9 \\
\hline & GR-02-18.1 & 263 & 147 & 0.58 & 1.68 & 2028 & 21 & 2167 & 7 & +7 & 2.70 & 1.2 & 0.13521 & 0.4 & 6.892 & 1.3 & 0.3697 & 1.2 & 0.9 \\
\hline & GR-02-19.1 & 191 & 97 & 0.53 & 0.73 & 2136 & 23 & 2188 & 8 & +3 & 2.55 & 1.3 & 0.13687 & 0.5 & 7.413 & 1.3 & 0.3928 & 1.3 & 0.9 \\
\hline & GR-02-20.1 & 594 & 336 & 0.58 & 4.50 & 1434 & 15 & 1989 & 6 & +31 & 4.01 & 1.2 & 0.12223 & 0.3 & 4.200 & 1.2 & 0.2492 & 1.2 & 1.0 \\
\hline
\end{tabular}




\section{ANEXO II}

Isótopos de Ti por SHRIMP

\begin{tabular}{|c|c|c|c|c|c|c|c|c|c|c|c|}
\hline Amostra & análise & $\begin{array}{c}50 \mathrm{Ti} / \\
49 \mathrm{Ti}\end{array}$ & $\begin{array}{c}\mathbf{V} \\
(\mathbf{p p m})\end{array}$ & $\begin{array}{c}\text { 49Ti } \\
(\mathbf{p p m})\end{array}$ & Std & $\begin{array}{c}\text { 50Ti } \\
(\mathbf{p p m})\end{array}$ & Std & $\begin{array}{c}\text { T }\left({ }^{\circ} \mathrm{C}\right) \\
\text { 49Ti }\end{array}$ & $\begin{array}{l}\text { Std } \\
(2 \sigma)\end{array}$ & $\begin{array}{c}\text { T }\left({ }^{\circ} \mathbf{C}\right) \\
50 \mathrm{Ti}\end{array}$ & $\begin{array}{l}\text { Std } \\
(2 \sigma)\end{array}$ \\
\hline & & & & & & & & \multicolumn{4}{|c|}{ Ferry \& Watson (2007) } \\
\hline \multirow{13}{*}{ 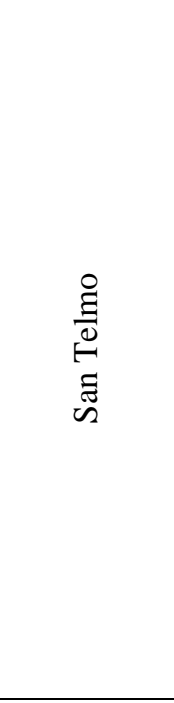 } & ST01-1.1 & 0.95 & & 6.0 & 0.4 & 6.1 & 0.4 & 732 & 15 & 732 & 16 \\
\hline & ST01-2.1 & 0.95 & & 5.2 & 0.1 & 5.2 & 0.1 & 718 & 11 & 718 & 11 \\
\hline & ST01-3.1 & 0.96 & & 7.9 & 0.6 & 6.2 & 0.7 & 757 & 17 & 735 & 20 \\
\hline & ST01-4.1 & 0.97 & & 5.6 & 0.2 & 5.7 & 0.2 & 725 & 13 & 728 & 13 \\
\hline & ST01-5.1 & 0.96 & & 11.2 & 0.2 & 11.4 & 0.4 & 792 & 12 & 794 & 14 \\
\hline & ST01-6.1 & 0.99 & & 6.6 & 0.2 & 6.9 & 0.3 & 740 & 13 & 745 & 15 \\
\hline & ST01-7.1 & 0.95 & & 69.4 & 16.6 & 70.0 & 13.0 & 1019 & 43 & 1020 & 36 \\
\hline & ST01-8.1 & 0.96 & & 8.5 & 0.2 & 6.9 & 0.1 & 764 & 13 & 745 & 11 \\
\hline & ST01-9.1 & 0.97 & & 5.9 & 0.4 & 6.1 & 0.6 & 731 & 16 & 734 & 19 \\
\hline & ST01-10.1 & 0.96 & & 5.2 & 0.3 & 5.3 & 0.4 & 719 & 15 & 720 & 17 \\
\hline & ST01-11.1 & 0.93 & & 5.6 & 0.1 & 5.6 & 0.3 & 726 & 12 & 725 & 15 \\
\hline & ST01-12.1 & 0.95 & & 6.5 & 0.1 & 6.5 & 0.1 & 738 & 12 & 739 & 12 \\
\hline & ST01-13.1 & 0.95 & & 6.4 & 0.2 & 6.4 & 0.1 & 737 & 12 & 737 & 12 \\
\hline \multirow{3}{*}{ 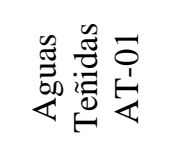 } & AT01-1.1 & 0.99 & & 15.2 & 0.3 & 15.8 & 1.0 & 824 & 12 & 828 & 17 \\
\hline & AT01-2.1 & 0.96 & & 3.4 & 0.1 & 3.4 & 0.1 & 681 & 13 & 682 & 13 \\
\hline & AT01-3.1 & 0.90 & & 10.3 & 0.7 & 9.7 & 0.6 & 783 & 17 & 778 & 16 \\
\hline
\end{tabular}




\begin{tabular}{|c|c|c|c|c|c|c|c|c|c|c|}
\hline & AT01-4.1 & 0.97 & 6.4 & 0.3 & 6.5 & 0.2 & 737 & 14 & 739 & 12 \\
\hline & AT01-5.1 & 0.94 & 7.0 & 0.2 & 6.9 & 0.3 & 745 & 13 & 744 & 14 \\
\hline & AT01-6.1 & 0.94 & 10.4 & 0.2 & 10.3 & 0.2 & 785 & 12 & 783 & 12 \\
\hline & AT01-7.1 & 0.97 & 4.6 & 0.3 & 4.7 & 0.1 & 708 & 15 & 710 & 12 \\
\hline & AT01-8.1 & 0.93 & 7.6 & 2.3 & 8.0 & 1.9 & 753 & 36 & 758 & 31 \\
\hline & AT01-9.1 & 0.95 & 11.3 & 1.5 & 11.3 & 1.7 & 793 & 23 & 793 & 25 \\
\hline & AT01-10.1 & 0.95 & 9.6 & 1.6 & 9.6 & 1.6 & 776 & 26 & 776 & 25 \\
\hline \multirow{5}{*}{ 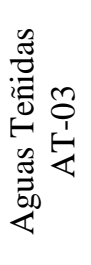 } & AT03-1.1 & 0.96 & 3.5 & 0.1 & 3.6 & 0.2 & 686 & 13 & 687 & 14 \\
\hline & AT03-2.1 & 0.96 & 5.6 & 0.5 & 5.7 & 0.8 & 726 & 17 & 727 & 23 \\
\hline & AT03-3.1 & 0.94 & 8.9 & 0.3 & 7.6 & 0.2 & 769 & 13 & 753 & 13 \\
\hline & AT03-4.1 & 0.94 & 8.9 & 0.2 & 8.8 & 0.1 & 769 & 13 & 768 & 11 \\
\hline & AT03-5.1 & 0.96 & 29.4 & 2.7 & 29.8 & 2.7 & 901 & 21 & 903 & 21 \\
\hline \multirow{15}{*}{ 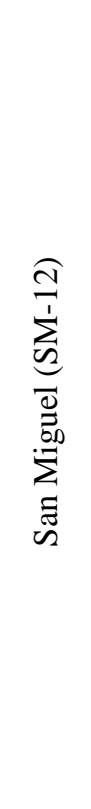 } & SM12-1.1 & 0.98 & 6.1 & 0.2 & 6.3 & 0.3 & 733 & 13 & 737 & 15 \\
\hline & SM12-2.1 & 0.96 & 4.5 & 0.1 & 4.5 & 0.1 & 705 & 11 & 706 & 12 \\
\hline & SM12-3.1 & 0.97 & 6.6 & 0.4 & 5.9 & 0.4 & 741 & 16 & 730 & 16 \\
\hline & SM12-4.1 & 1.00 & 3.7 & 0.2 & 3.9 & 0.1 & 690 & 14 & 694 & 12 \\
\hline & SM12-5.1 & 0.96 & 5.9 & 0.3 & 5.9 & 0.2 & 730 & 14 & 731 & 13 \\
\hline & SM12-6.1 & 0.95 & 8.0 & 0.2 & 8.1 & 0.2 & 759 & 13 & 760 & 12 \\
\hline & SM12-7.1 & 0.98 & 72.3 & 11.9 & 75.1 & 13.0 & 1025 & 34 & 1031 & 35 \\
\hline & SM12-8.1 & 0.96 & 18.6 & 1.1 & 23.6 & 1.7 & 846 & 17 & 875 & 19 \\
\hline & SM12-9.1 & 0.96 & 17.9 & 0.6 & 18.2 & 0.6 & 842 & 14 & 844 & 13 \\
\hline & SM12-10.1 & 0.98 & 4.2 & 0.3 & 4.3 & 0.3 & 700 & 15 & 703 & 16 \\
\hline & SM12-11.1 & 0.93 & 7.0 & 0.3 & 6.9 & 0.4 & 746 & 14 & 744 & 16 \\
\hline & SM12-12.1 & 0.91 & 4.5 & 0.2 & 4.4 & 0.1 & 707 & 14 & 703 & 12 \\
\hline & SM12-13.1 & 0.93 & 5.6 & 0.2 & 4.8 & 0.1 & 726 & 14 & 711 & 12 \\
\hline & SM12-14.1 & 0.98 & 4.3 & 0.5 & 4.4 & 0.6 & 702 & 20 & 705 & 21 \\
\hline & SM12-15.1 & 0.98 & 5.6 & 0.4 & 5.8 & 0.5 & 725 & 17 & 728 & 17 \\
\hline
\end{tabular}




\begin{tabular}{|c|c|c|c|c|c|c|c|c|c|c|}
\hline \multirow{10}{*}{ 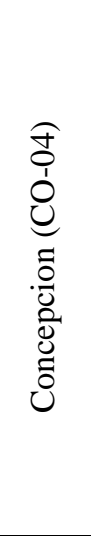 } & CO04-1.1 & 0.96 & 4.7 & 0.1 & 4.7 & 0.2 & 709 & 11 & 710 & 13 \\
\hline & $\mathrm{CO} 04-2.1$ & 0.92 & 10.0 & 2.0 & 9.6 & 1.6 & 780 & 29 & 777 & 25 \\
\hline & $\mathrm{CO} 04-3.1$ & 0.96 & 5.7 & 0.2 & 5.0 & 0.1 & 727 & 13 & 715 & 12 \\
\hline & CO04-4.1 & 0.95 & 5.4 & 0.1 & 5.4 & 0.0 & 722 & 12 & 722 & 11 \\
\hline & $\mathrm{CO} 04-5.1$ & 0.97 & 4.6 & 0.0 & 4.7 & 0.1 & 707 & 11 & 709 & 13 \\
\hline & CO04-6.1 & 0.90 & 15.7 & 4.6 & 14.9 & 4.2 & 828 & 39 & 822 & 38 \\
\hline & CO04-7.1 & 0.96 & 5.7 & 0.2 & 5.8 & 0.2 & 727 & 13 & 728 & 13 \\
\hline & CO04-8.1 & 0.98 & 6.1 & 0.3 & 5.7 & 0.1 & 734 & 14 & 726 & 12 \\
\hline & CO04-9.1 & 0.97 & 7.0 & 0.2 & 7.1 & 0.3 & 745 & 12 & 748 & 14 \\
\hline & CO04-10.1 & 0.98 & 5.5 & 0.1 & 5.7 & 0.1 & 724 & 12 & 728 & 12 \\
\hline \multirow{5}{*}{ 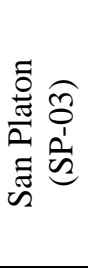 } & SP03-1.1 & 0.97 & 20.6 & 1.9 & 21.1 & 2.4 & 859 & 20 & 861 & 22 \\
\hline & SP03-2.1 & 0.94 & 42.8 & 6.9 & 42.3 & 7.9 & 950 & 31 & 948 & 34 \\
\hline & SP03-3.1 & 0.95 & 6.2 & 0.2 & 5.6 & 0.2 & 735 & 14 & 725 & 13 \\
\hline & SP03-4.1 & 0.98 & 5.6 & 0.1 & 5.8 & 0.1 & 726 & 12 & 729 & 11 \\
\hline & SP03-5.1 & 0.96 & 5.1 & 0.2 & 5.2 & 0.0 & 717 & 13 & 718 & 10 \\
\hline \multirow{12}{*}{ 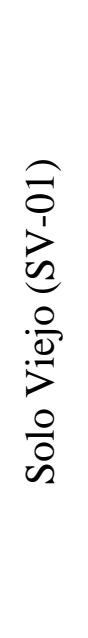 } & SV01-1.1 & 0.9600 & 4.27 & 0.04 & 4.32 & 0.13 & 701 & 11 & 703 & 13 \\
\hline & SV01-2.1 & 0.9500 & 6.15 & 0.08 & 6.14 & 0.20 & 734 & 11 & 734 & 13 \\
\hline & SV01-3.1 & 0.9500 & 7.68 & 0.17 & 6.73 & 0.15 & 755 & 12 & 742 & 12 \\
\hline & SV01-4.1 & 0.9700 & 8.03 & 0.13 & 8.18 & 0.16 & 759 & 12 & 761 & 12 \\
\hline & SV01-5.1 & 0.9600 & 2.81 & 0.11 & 2.85 & 0.11 & 667 & 13 & 668 & 13 \\
\hline & SV01-6.1 & 0.9500 & 6.32 & 0.31 & 6.32 & 0.19 & 736 & 14 & 736 & 13 \\
\hline & SV01-7.1 & 0.9000 & 4.63 & 2.15 & 4.39 & 1.67 & 708 & 44 & 704 & 39 \\
\hline & SV01-8.1 & 0.9800 & 3.02 & 0.08 & 3.14 & 0.25 & 673 & 12 & 676 & 16 \\
\hline & SV01-9.1 & 0.8800 & 4.00 & 0.74 & 5.37 & 0.39 & 696 & 25 & 722 & 16 \\
\hline & SV01-10.1 & 0.9500 & 6040.97 & 106.90 & 6105.89 & 128.96 & 2431 & 22 & 2438 & 24 \\
\hline & SV01-11.1 & 1.0000 & 3.30 & 0.14 & 3.50 & 0.05 & 680 & 13 & 685 & 11 \\
\hline & SV01-12.1 & 0.9500 & 28342.81 & 492.99 & 28506.48 & 502.56 & 4076 & 40 & 4086 & 40 \\
\hline
\end{tabular}




\begin{tabular}{|c|c|c|c|c|c|c|c|c|c|c|}
\hline \multirow{12}{*}{ 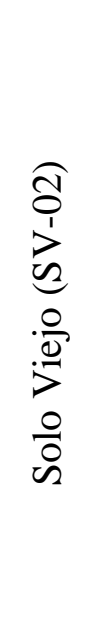 } & SV02-1.1 & 1.5082 & 4.43 & 6.87 & 7.08 & 8.51 & 705 & 98 & 747 & 90 \\
\hline & SV02-2.1 & 0.9735 & 25.10 & 1.58 & 25.92 & 1.49 & 882 & 17 & 886 & 17 \\
\hline & SV02-3.1 & 0.9558 & 8.88 & 0.40 & 8.07 & 0.13 & 769 & 14 & 759 & 12 \\
\hline & SV02-4.1 & 0.9522 & 5.62 & 0.11 & 5.68 & 0.13 & 726 & 12 & 727 & 12 \\
\hline & SV02-5.1 & 1.0251 & 5.86 & 0.13 & 6.37 & 0.23 & 729 & 12 & 737 & 13 \\
\hline & SV02-6.1 & 0.9549 & 12.46 & 3.65 & 12.62 & 4.37 & 803 & 38 & 804 & 42 \\
\hline & SV02-7.1 & 0.9544 & 7.07 & 0.20 & 7.13 & 0.67 & 747 & 13 & 748 & 19 \\
\hline & SV02-8.1 & 0.9529 & 5.41 & 0.15 & 5.45 & 0.16 & 722 & 12 & 723 & 13 \\
\hline & SV02-9.1 & 0.7706 & 6.53 & 0.23 & 4.64 & 2.48 & 739 & 13 & 709 & 49 \\
\hline & SV02-10.1 & 0.9967 & 5.70 & 0.12 & 6.01 & 0.23 & 727 & 12 & 732 & 13 \\
\hline & SV02-11.1 & 0.9705 & 6.86 & 0.11 & 7.04 & 0.10 & 744 & 11 & 746 & 11 \\
\hline & SV02-12.1 & 0.9457 & 7.55 & 0.27 & 7.54 & 0.24 & 753 & 13 & 753 & 13 \\
\hline \multirow{5}{*}{ 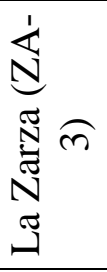 } & ZA03-1.1 & 0.95 & 7.8 & 0.2 & 7.8 & 0.4 & 771 & 12 & 771 & 15 \\
\hline & ZA03-2.1 & 0.96 & 428.7 & 3.4 & 435.8 & 4.8 & 1407 & 12 & 1411 & 13 \\
\hline & ZA03-3.1 & 1.00 & 12.5 & 2.6 & 13.1 & 3.3 & 820 & 31 & 825 & 35 \\
\hline & ZA03-4.1 & 0.98 & 6.4 & 0.2 & 6.6 & 0.1 & 752 & 13 & 755 & 11 \\
\hline & ZA03-5.1 & 0.95 & 3.8 & 0.2 & 3.8 & 0.1 & 705 & 13 & 706 & 13 \\
\hline \multirow{10}{*}{ 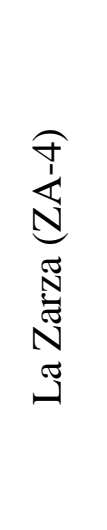 } & ZA04-1.1 & 0.94 & 5.1 & 0.3 & 5.1 & 0.2 & 717 & 16 & 717 & 13 \\
\hline & ZA04-2.1 & 0.95 & 11.8 & 0.5 & 11.9 & 0.5 & 797 & 14 & 798 & 14 \\
\hline & ZA04-3.1 & 0.98 & 7.2 & 0.1 & 7.1 & 0.3 & 748 & 11 & 747 & 14 \\
\hline & ZA04-4.1 & 0.97 & 3.4 & 0.3 & 3.5 & 0.2 & 682 & 16 & 685 & 14 \\
\hline & ZA04-5.1 & 0.96 & 6.4 & 0.2 & 6.5 & 0.4 & 737 & 13 & 739 & 15 \\
\hline & ZA04-6.1 & 0.94 & 4.9 & 0.3 & 4.8 & 0.2 & 713 & 15 & 712 & 13 \\
\hline & ZA04-7.1 & 0.97 & 6.9 & 0.1 & 7.0 & 0.2 & 744 & 11 & 746 & 12 \\
\hline & ZA04-8.1 & 0.93 & 10.8 & 0.3 & 9.9 & 0.4 & 789 & 13 & 779 & 14 \\
\hline & ZA04-9.1 & 0.93 & 93.4 & 24.1 & 91.5 & 26.2 & 1066 & 48 & 1062 & 52 \\
\hline & ZA04-10.1 & 0.92 & 10.6 & 0.3 & 10.3 & 0.3 & 787 & 13 & 784 & 13 \\
\hline
\end{tabular}




\begin{tabular}{|c|c|c|c|c|c|c|c|c|c|c|}
\hline \multirow{18}{*}{ 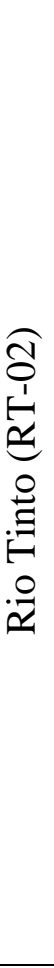 } & RT02-1.1 & 0.928 & 3.35 & 0.10 & 3.27 & 0.09 & 681 & 13 & 679 & 12 \\
\hline & RT02-2.1 & 0.998 & 1.20 & 0.08 & 1.27 & 0.08 & 604 & 15 & 607 & 14 \\
\hline & RT02-3.1 & 0.950 & 2.89 & 0.14 & 2.49 & 0.12 & 669 & 14 & 657 & 14 \\
\hline & RT02-4.1 & 0.964 & 3.27 & 0.11 & 3.33 & 0.08 & 679 & 13 & 680 & 12 \\
\hline & RT02-5.1 & 0.929 & 4.01 & 2.66 & 3.92 & 2.72 & 696 & 55 & 694 & 57 \\
\hline & RT02-6.1 & 0.936 & 7.10 & 0.20 & 7.00 & 0.19 & 747 & 13 & 746 & 12 \\
\hline & RT02-7.1 & 0.952 & 4.56 & 0.18 & 4.59 & 0.03 & 707 & 13 & 708 & 11 \\
\hline & RT02-8.1 & 0.963 & 25.31 & 0.72 & 25.76 & 0.66 & 883 & 13 & 885 & 13 \\
\hline & RT02-9.1 & 0.946 & 3.32 & 0.18 & 2.95 & 0.28 & 680 & 14 & 671 & 17 \\
\hline & RT02-10.1 & 0.976 & 7.84 & 0.19 & 8.08 & 0.32 & 757 & 12 & 760 & 14 \\
\hline & RT02-11.1 & 0.949 & 4.09 & 0.06 & 4.10 & 0.22 & 698 & 11 & 698 & 14 \\
\hline & RT02-12.1 & 0.981 & 7.63 & 0.46 & 7.90 & 0.69 & 754 & 16 & 757 & 18 \\
\hline & RT02-13.1 & 0.999 & 14.12 & 1.54 & 14.90 & 1.76 & 816 & 21 & 822 & 22 \\
\hline & RT02-14.1 & 0.991 & 4.81 & 0.45 & 5.04 & 0.46 & 712 & 18 & 716 & 18 \\
\hline & RT02-15.1 & 0.929 & 4.93 & 0.08 & 3.97 & 0.11 & 714 & 11 & 695 & 12 \\
\hline & RT02-16.1 & 0.899 & 88.69 & 30.90 & 84.19 & 26.87 & 1057 & 60 & 1049 & 55 \\
\hline & RT02-17.1 & 1.000 & 7.45 & 0.21 & 7.87 & 0.10 & 752 & 13 & 757 & 11 \\
\hline & RT02-18.1 & 0.985 & 6.38 & 0.25 & 6.63 & 0.24 & 737 & 14 & 741 & 13 \\
\hline \multirow{9}{*}{ 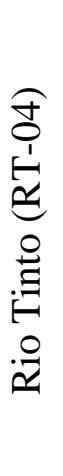 } & RT04-1.1 & 0.9778 & 4.02 & 0.13 & 4.15 & 0.08 & 696 & 13 & 699 & 12 \\
\hline & RT04-2.1 & 1.0005 & 2.63 & 1.76 & 2.78 & 1.95 & 662 & 52 & 666 & 54 \\
\hline & RT04-3.1 & 0.9753 & 16.60 & 0.56 & 12.47 & 0.15 & 834 & 14 & 803 & 11 \\
\hline & RT04-4.1 & 0.9149 & 1456.65 & 187.37 & 1407.20 & 198.67 & 1733 & 55 & 1721 & 59 \\
\hline & RT04-5.1 & 0.9888 & 6.85 & 0.18 & 7.16 & 0.15 & 744 & 12 & 748 & 12 \\
\hline & RT04-6.1 & 0.9643 & 56.10 & 7.40 & 57.12 & 6.20 & 988 & 28 & 990 & 25 \\
\hline & RT04-7.1 & 0.9539 & 8.59 & 0.14 & 8.63 & 0.20 & 765 & 12 & 766 & 12 \\
\hline & RT04-8.1 & 0.9818 & 2.64 & 0.06 & 2.73 & 0.19 & 662 & 12 & 665 & 15 \\
\hline & RT04-9.1 & 0.9495 & 6.05 & 0.53 & 5.36 & 0.45 & 732 & 18 & 721 & 17 \\
\hline
\end{tabular}




\begin{tabular}{|c|c|c|c|c|c|c|c|c|c|c|}
\hline & RT04-10.1 & 1.0510 & 3.29 & 0.25 & 3.64 & 0.18 & 680 & 16 & 688 & 14 \\
\hline & RT04-11.1 & 0.9455 & 2.74 & 0.05 & 2.73 & 0.15 & 665 & 12 & 665 & 14 \\
\hline & RT04-12.1 & 0.7793 & 3.25 & 0.10 & 2.67 & 1.86 & 679 & 12 & 663 & 54 \\
\hline & RT04-13.1 & 0.9614 & 144.12 & 1.44 & 145.97 & 0.77 & 1140 & 12 & 1142 & 11 \\
\hline & RT04-14.1 & 0.9840 & 6.74 & 0.12 & 6.99 & 0.58 & 742 & 12 & 746 & 17 \\
\hline \multirow{14}{*}{ 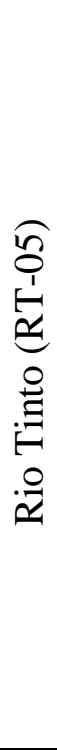 } & RT05-1.1 & 0.996 & 5.39 & 0.19 & 4.03 & 0.11 & 722 & 13 & 696 & 12 \\
\hline & RT05-2.1 & 0.973 & 4.55 & 0.22 & 4.69 & 0.28 & 707 & 14 & 710 & 15 \\
\hline & RT05-3.1 & 0.937 & 3.67 & 0.07 & 3.64 & 0.16 & 689 & 12 & 688 & 14 \\
\hline & RT05-4.1 & 0.949 & 7.48 & 0.39 & 7.50 & 0.28 & 752 & 15 & 752 & 13 \\
\hline & RT05-5.1 & 0.978 & 3.79 & 0.10 & 3.92 & 0.14 & 691 & 12 & 694 & 13 \\
\hline & RT05-6.1 & 0.954 & 12.65 & 0.22 & 9.89 & 0.23 & 805 & 12 & 779 & 12 \\
\hline & RT05-7.1 & 0.974 & 5.76 & 0.48 & 5.93 & 0.53 & 728 & 17 & 731 & 18 \\
\hline & RT05-8.1 & 0.929 & 7.78 & 0.24 & 7.64 & 0.42 & 756 & 13 & 754 & 15 \\
\hline & RT05-9.1 & 0.954 & 4.36 & 0.22 & 4.39 & 0.16 & 703 & 14 & 704 & 13 \\
\hline & RT05-10.1 & 0.938 & 4.85 & 0.12 & 4.81 & 0.10 & 712 & 12 & 712 & 12 \\
\hline & RT05-11.1 & 0.961 & 4.19 & 0.11 & 4.26 & 0.16 & 700 & 12 & 701 & 13 \\
\hline & RT05-12.1 & 0.961 & 12.67 & 1.08 & 11.46 & 0.83 & 805 & 19 & 794 & 17 \\
\hline & RT05-13.1 & 0.963 & 3.05 & 0.07 & 3.11 & 0.21 & 673 & 12 & 675 & 15 \\
\hline & RT05-14.1 & 0.944 & 5.58 & 0.19 & 5.58 & 0.29 & 725 & 13 & 725 & 15 \\
\hline \multirow{8}{*}{ 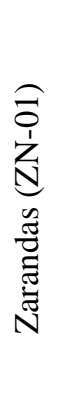 } & ZN01-1.1 & 0.988 & 6.10 & 0.12 & 6.37 & 0.09 & 733 & 12 & 737 & 11 \\
\hline & ZN01-2.1 & 0.973 & 8.02 & 0.25 & 8.25 & 0.21 & 759 & 13 & 762 & 12 \\
\hline & ZN01-3.1 & 0.944 & 2.40 & 0.14 & 2.40 & 0.13 & 654 & 14 & 654 & 14 \\
\hline & ZN01-4.1 & 0.985 & 2.36 & 0.25 & 2.46 & 0.25 & 653 & 18 & 656 & 17 \\
\hline & ZN01-5.1 & 0.908 & 12.60 & 5.56 & 12.09 & 4.44 & 804 & 50 & 800 & 44 \\
\hline & ZN01-6.1 & 0.999 & 4.96 & 0.15 & 4.16 & 0.10 & 715 & 13 & 699 & 12 \\
\hline & ZN01-7.1 & 0.967 & 3.66 & 0.27 & 3.74 & 0.19 & 688 & 16 & 690 & 14 \\
\hline & ZN01-8.1 & 0.950 & 2.82 & 0.11 & 2.83 & 0.12 & 667 & 13 & 667 & 13 \\
\hline
\end{tabular}




\begin{tabular}{|c|c|c|c|c|c|c|c|c|c|c|}
\hline & ZN01-9.1 & 0.964 & 3.23 & 0.09 & 3.30 & 0.12 & 678 & 12 & 680 & 13 \\
\hline & ZN01-10.1 & 0.990 & 4.29 & 0.07 & 4.49 & 0.23 & 702 & 11 & 706 & 14 \\
\hline & ZN01-11.1 & 1.036 & 4.09 & 0.23 & 4.48 & 0.29 & 698 & 15 & 706 & 15 \\
\hline & ZN01-12.1 & 0.971 & 23.44 & 2.31 & 21.07 & 2.07 & 874 & 21 & 861 & 21 \\
\hline & ZN01-13.1 & 0.969 & 4.79 & 0.11 & 4.91 & 0.31 & 711 & 12 & 714 & 15 \\
\hline & ZN01-14.1 & 0.946 & 4.20 & 0.21 & 4.20 & 0.25 & 700 & 14 & 700 & 15 \\
\hline & ZN01-15.1 & 0.992 & 2.61 & 0.09 & 2.74 & 0.19 & 661 & 13 & 665 & 15 \\
\hline & ZN01-16.1 & 0.984 & 6.23 & 0.75 & 6.51 & 0.16 & 735 & 21 & 739 & 12 \\
\hline & ZN01-17.1 & 0.945 & 5.47 & 0.19 & 5.50 & 0.28 & 723 & 13 & 724 & 15 \\
\hline & ZN01-18.1 & 0.956 & 11.76 & 0.51 & 11.54 & 0.63 & 797 & 14 & 795 & 16 \\
\hline \multirow{17}{*}{ 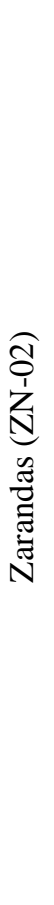 } & ZN02-1.1 & 0.970 & 25.05 & 0.70 & 25.82 & 1.07 & 882 & 13 & 885 & 15 \\
\hline & ZN02-2.1 & 0.999 & 3.04 & 0.20 & 3.23 & 0.07 & 673 & 15 & 678 & 12 \\
\hline & ZN02-3.1 & 1.029 & 2.81 & 0.18 & 3.07 & 0.10 & 667 & 15 & 674 & 13 \\
\hline & ZN02-4.1 & 0.985 & 6.91 & 0.24 & 7.26 & 0.46 & 745 & 13 & 749 & 16 \\
\hline & ZN02-5.1 & 0.991 & 4.55 & 0.16 & 4.81 & 0.16 & 707 & 13 & 712 & 13 \\
\hline & ZN02-6.1 & 1.016 & 2.58 & 1.74 & 2.56 & 0.82 & 660 & 53 & 659 & 32 \\
\hline & ZN02-7.1 & 0.960 & 12.99 & 0.45 & 13.29 & 0.66 & 807 & 14 & 810 & 15 \\
\hline & ZN02-8.1 & 1.942 & 1.69 & 0.89 & 3.49 & 0.83 & 628 & 42 & 684 & 28 \\
\hline & ZN02-9.1 & 0.950 & 4.70 & 0.14 & 4.76 & 0.18 & 710 & 13 & 711 & 13 \\
\hline & ZN02-10.1 & 0.922 & 2.87 & 0.12 & 2.79 & 0.43 & 668 & 13 & 666 & 21 \\
\hline & ZN02-11.1 & 0.914 & 2.08 & 0.13 & 2.01 & 0.33 & 643 & 15 & 641 & 22 \\
\hline & ZN02-12.1 & 0.995 & 4.11 & 0.16 & 3.25 & 0.17 & 698 & 13 & 678 & 14 \\
\hline & ZN02-13.1 & 0.939 & 2.31 & 0.09 & 2.29 & 0.62 & 651 & 13 & 651 & 29 \\
\hline & ZN02-14.1 & 0.994 & 1.40 & 0.09 & 1.47 & 0.14 & 614 & 14 & 618 & 17 \\
\hline & ZN02-15.1 & 0.977 & 9.38 & 0.15 & 9.69 & 0.19 & 774 & 12 & 777 & 12 \\
\hline & ZN02-16.1 & 1.032 & 2.94 & 0.18 & 3.21 & 0.29 & 670 & 15 & 678 & 17 \\
\hline & ZN02-17.1 & 0.884 & 17.15 & 0.91 & 16.06 & 2.38 & 838 & 16 & 830 & 25 \\
\hline
\end{tabular}




\begin{tabular}{|c|c|c|c|c|c|c|c|c|c|c|}
\hline & ZN02-18.1 & 0.977 & 9.43 & 0.15 & 9.75 & 0.19 & 775 & 12 & 778 & 12 \\
\hline \multirow{18}{*}{ 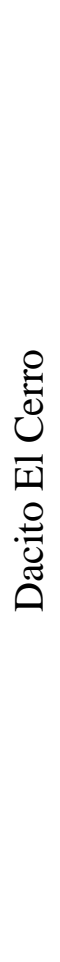 } & AC01-1.1 & 0.91 & 21.2 & 13.4 & 20.4 & 14.2 & 862 & 70 & 857 & 75 \\
\hline & AC01-2.1 & 0.94 & 9.8 & 0.2 & 9.7 & 0.1 & 778 & 12 & 777 & 11 \\
\hline & AC01-3.1 & 0.94 & 9.9 & 0.7 & 8.1 & 0.7 & 780 & 17 & 760 & 18 \\
\hline & AC01-4.1 & 0.97 & 11.2 & 0.4 & 11.4 & 0.4 & 792 & 14 & 794 & 13 \\
\hline & AC01-5.1 & 0.97 & 9.7 & 0.5 & 9.9 & 0.4 & 778 & 15 & 780 & 14 \\
\hline & AC01-6.1 & 0.97 & 20.5 & 1.8 & 21.0 & 2.7 & 858 & 20 & 861 & 24 \\
\hline & AC01-7.1 & 0.91 & 8.5 & 1.6 & 8.2 & 1.4 & 765 & 27 & 761 & 26 \\
\hline & AC01-8.1 & 0.95 & 6.6 & 0.3 & 6.6 & 0.5 & 741 & 14 & 741 & 17 \\
\hline & AC01-9.1 & 0.96 & 10.0 & 0.5 & 10.1 & 0.3 & 780 & 15 & 781 & 13 \\
\hline & AC01-10.1 & 0.96 & 11.2 & 0.2 & 10.2 & 0.5 & 792 & 12 & 783 & 14 \\
\hline & AC01-11.1 & 0.95 & 12.4 & 3.6 & 12.4 & 2.7 & 802 & 37 & 802 & 31 \\
\hline & AC01-12.1 & 0.97 & 8.1 & 0.2 & 8.3 & 0.2 & 760 & 12 & 762 & 12 \\
\hline & AC01-13.1 & 0.96 & 7.7 & 0.2 & 7.8 & 0.2 & 754 & 12 & 756 & 12 \\
\hline & AC01-14.1 & 0.94 & 9.6 & 1.4 & 9.6 & 0.9 & 777 & 24 & 777 & 19 \\
\hline & AC01-15.1 & 0.98 & 5.8 & 0.3 & 6.0 & 0.2 & 729 & 14 & 732 & 13 \\
\hline & AC01-16.1 & 0.96 & 7.7 & 0.1 & 7.8 & 0.1 & 755 & 11 & 756 & 11 \\
\hline & AC01-17.1 & 0.98 & 6.8 & 0.3 & 5.8 & 0.1 & 744 & 14 & 729 & 12 \\
\hline & AC01-18.1 & 0.95 & 8.4 & 0.3 & 8.5 & 0.1 & 764 & 14 & 764 & 11 \\
\hline \multirow{8}{*}{ 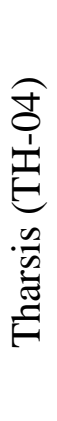 } & TH04-1.1 & 0.97 & 27.6 & 0.4 & 28.3 & 0.2 & 894 & 12 & 896 & 11 \\
\hline & TH04-2.1 & 0.98 & 7.6 & 0.4 & 7.8 & 0.5 & 753 & 15 & 756 & 16 \\
\hline & TH04-3.1 & 0.95 & 10.8 & 0.3 & 10.3 & 0.2 & 788 & 13 & 784 & 12 \\
\hline & TH04-4.1 & 0.97 & 28.6 & 0.4 & 29.3 & 0.3 & 898 & 12 & 901 & 11 \\
\hline & TH04-5.1 & 0.97 & 5.5 & 0.2 & 5.6 & 0.1 & 723 & 13 & 725 & 12 \\
\hline & ТH04-6.1 & 0.95 & 15.2 & 0.3 & 15.3 & 0.5 & 824 & 12 & 825 & 14 \\
\hline & TH04-7.1 & 0.97 & 12.7 & 0.5 & 13.0 & 0.4 & 805 & 14 & 807 & 13 \\
\hline & TH04-8.1 & 0.95 & 10.2 & 0.6 & 10.7 & 1.1 & 783 & 16 & 788 & 20 \\
\hline
\end{tabular}




\begin{tabular}{|c|c|c|c|c|c|c|c|c|c|c|}
\hline & TH04-9.1 & 0.97 & 15.8 & 0.5 & 16.1 & 0.3 & 828 & 14 & 831 & 12 \\
\hline & TH04-10.1 & 0.95 & 6.8 & 0.1 & 6.9 & 0.1 & 743 & 12 & 744 & 12 \\
\hline \multirow{10}{*}{ 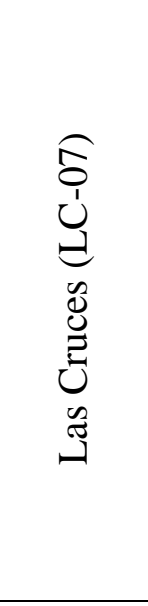 } & LC07-1.1 & 0.95 & 13.1 & 0.1 & 13.1 & 0.4 & 808 & 11 & 808 & 13 \\
\hline & LC07-2.1 & 0.96 & 17.1 & 0.3 & 17.4 & 0.2 & 838 & 12 & 839 & 12 \\
\hline & LC07-3.1 & 0.98 & 15.6 & 0.2 & 15.5 & 0.3 & 827 & 11 & 827 & 12 \\
\hline & LC07-4.1 & 0.95 & 18.1 & 0.6 & 18.1 & 0.4 & 844 & 14 & 844 & 13 \\
\hline & LC07-5.1 & 0.95 & 23.2 & 4.2 & 23.2 & 3.7 & 872 & 30 & 872 & 28 \\
\hline & LC07-6.1 & 0.96 & 16.4 & 0.5 & 16.6 & 0.2 & 832 & 13 & 834 & 12 \\
\hline & LC07-7.1 & 0.93 & 196.6 & 44.6 & 191.8 & 50.3 & 1198 & 51 & 1193 & 57 \\
\hline & LC07-8.1 & 0.96 & 15.8 & 0.2 & 15.6 & 0.1 & 829 & 11 & 827 & 10 \\
\hline & LC07-9.1 & 0.97 & 15.8 & 0.2 & 16.2 & 0.4 & 829 & 12 & 831 & 13 \\
\hline & $\begin{array}{c}\text { LC07- } \\
10.1 \\
\end{array}$ & 0.97 & 14.9 & 0.3 & 15.2 & 0.2 & 822 & 12 & 824 & 12 \\
\hline \multirow{10}{*}{ 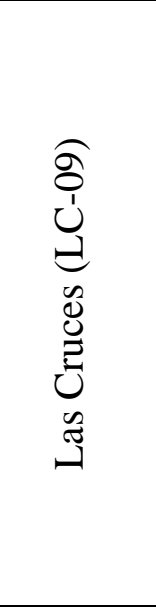 } & LC09-1.1 & 0.98 & 6.4 & 0.2 & 6.6 & 0.1 & 738 & 12 & 741 & 12 \\
\hline & LC09-2.1 & 0.97 & 6.6 & 0.1 & 6.7 & 0.2 & 740 & 12 & 742 & 12 \\
\hline & LC09-3.1 & 0.96 & 12.2 & 0.2 & 10.6 & 0.3 & 801 & 12 & 786 & 13 \\
\hline & LC09-4.1 & 0.99 & 8.2 & 0.1 & 8.6 & 0.3 & 762 & 11 & 766 & 13 \\
\hline & LC09-5.1 & 0.97 & 8.7 & 0.2 & 8.9 & 0.2 & 767 & 12 & 769 & 12 \\
\hline & LC09-6.1 & 0.98 & 5.9 & 0.1 & 6.2 & 0.2 & 731 & 12 & 734 & 13 \\
\hline & LC09-7.1 & 0.95 & 8.2 & 0.2 & 8.2 & 0.2 & 761 & 12 & 761 & 12 \\
\hline & LC09-8.1 & 0.96 & 8.5 & 0.1 & 7.7 & 0.2 & 765 & 12 & 755 & 12 \\
\hline & LC09-9.1 & 0.95 & 10.3 & 0.9 & 10.3 & 1.4 & 783 & 18 & 783 & 23 \\
\hline & $\begin{array}{c}\text { LC09- } \\
10.1 \\
\end{array}$ & 0.97 & 7.6 & 0.1 & 7.8 & 0.2 & 753 & 11 & 756 & 12 \\
\hline \multirow{2}{*}{ 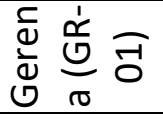 } & GR01-1.1 & 0.977 & 5.15 & 0.11 & 5.30 & 0.25 & 718 & 12 & 720 & 14 \\
\hline & GR01-2.1 & 0.976 & 6.34 & 0.19 & 6.53 & 0.21 & 737 & 13 & 739 & 13 \\
\hline
\end{tabular}




\begin{tabular}{|c|c|c|c|c|c|c|c|c|c|c|c|}
\hline & GR01-3.1 & 0.953 & & 30.92 & 0.85 & 31.10 & 1.19 & 908 & 13 & 908 & 15 \\
\hline & GR01-4.1 & 0.882 & & 5.63 & 0.73 & 5.24 & 0.66 & 726 & 21 & 719 & 21 \\
\hline & GR01-5.1 & 0.962 & & 10.32 & 0.46 & 10.47 & 0.52 & 784 & 14 & 785 & 15 \\
\hline & GR01-6.1 & 0.963 & & 3.99 & 0.20 & 3.48 & 0.21 & 696 & 14 & 684 & 15 \\
\hline & GR01-7.1 & 0.970 & & 5.44 & 0.22 & 5.57 & 0.22 & 723 & 14 & 725 & 14 \\
\hline & GR01-8.1 & 0.949 & & 10.07 & 0.35 & 10.08 & 0.47 & 781 & 13 & 781 & 15 \\
\hline & GR01-9.1 & 0.979 & & 5.71 & 0.26 & 5.90 & 0.11 & 727 & 14 & 730 & 12 \\
\hline & $\begin{array}{c}\text { GR01- } \\
10.1\end{array}$ & 0.968 & & 5.13 & 0.17 & 5.25 & 0.28 & 718 & 13 & 720 & 15 \\
\hline & $\begin{array}{c}\text { GR01- } \\
11.1\end{array}$ & 0.957 & & 13.36 & 0.95 & 13.51 & 0.72 & 810 & 17 & 812 & 16 \\
\hline & $\begin{array}{c}\text { GR01- } \\
12.1\end{array}$ & 0.954 & & 4.41 & 0.15 & 3.70 & 0.11 & 704 & 13 & 689 & 13 \\
\hline & $\begin{array}{c}\text { GR01- } \\
13.1\end{array}$ & 0.948 & & 25.16 & 16.83 & 25.18 & 17.46 & 882 & 75 & 882 & 77 \\
\hline & $\begin{array}{c}\text { GR01- } \\
14.1\end{array}$ & 0.961 & & 8.28 & 0.25 & 8.40 & 0.17 & 762 & 13 & 763 & 12 \\
\hline & $\begin{array}{c}\text { GR01- } \\
15.1\end{array}$ & 0.941 & & 40.12 & 4.26 & 39.87 & 3.22 & 941 & 24 & 941 & 20 \\
\hline & $\begin{array}{c}\text { GR01- } \\
16.1\end{array}$ & 0.954 & & 12.37 & 0.13 & 12.48 & 0.24 & 802 & 11 & 803 & 12 \\
\hline & $\begin{array}{c}\text { GR01- } \\
17.1\end{array}$ & 0.962 & & 10.80 & 0.30 & 10.98 & 0.18 & 788 & 13 & 790 & 12 \\
\hline & $\begin{array}{c}\text { GR01- } \\
18.1 \\
\end{array}$ & 0.978 & & 3.14 & 0.09 & 2.80 & 0.18 & 676 & 12 & 666 & 15 \\
\hline 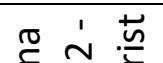 & GR02-2.1 & 0.967 & 8.14 & 75.07 & 5.22 & 76.76 & 4.78 & 1031 & 20 & 1035 & 19 \\
\hline 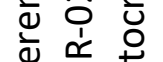 & GR02-3.1 & 0.983 & 0.22 & 5.39 & 0.13 & 5.09 & 0.11 & 722 & 12 & 717 & 12 \\
\hline 心 & GR02-4.1 & 0.960 & 2.83 & 25.21 & 0.43 & 25.60 & 0.31 & 882 & 12 & 884 & 11 \\
\hline
\end{tabular}




\begin{tabular}{|c|c|c|c|c|c|c|c|c|c|c|c|}
\hline & GR02-5.1 & 0.954 & 6.49 & 25.91 & 1.73 & 26.14 & 2.03 & 886 & 18 & 887 & 19 \\
\hline & $\begin{array}{c}\text { GR02- } \\
11.1\end{array}$ & 0.963 & 272.43 & 3084.65 & 15.50 & 3127.11 & 15.88 & 2049 & 12 & 2056 & 12 \\
\hline & $\begin{array}{c}\text { GR02- } \\
12.1\end{array}$ & 0.944 & 35.78 & 174.14 & 18.46 & 173.15 & 18.98 & 1175 & 29 & 1174 & 30 \\
\hline & $\begin{array}{c}\text { GR02- } \\
14.1\end{array}$ & 0.957 & 1.52 & 8.40 & 0.22 & 8.46 & 0.13 & 763 & 13 & 764 & 11 \\
\hline & $\begin{array}{c}\text { GR02- } \\
22.1\end{array}$ & 0.963 & 222.42 & 2611.30 & 16.62 & 2647.58 & 11.80 & 1971 & 13 & 1977 & 12 \\
\hline \multirow{10}{*}{ 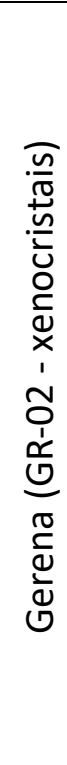 } & GR02-1.1 & 0.977 & 0.65 & 11.91 & 0.38 & 12.31 & 0.46 & 798 & 13 & 802 & 14 \\
\hline & GR02-6.1 & 0.988 & 0.23 & 3.55 & 0.18 & 3.71 & 0.17 & 686 & 14 & 690 & 14 \\
\hline & GR02-7.1 & 0.967 & 1.17 & 21.98 & 0.29 & 22.33 & 0.31 & 884 & 12 & 868 & 12 \\
\hline & GR02-8.1 & 0.967 & 0.57 & 15.12 & 0.25 & 15.36 & 0.27 & 824 & 12 & 825 & 12 \\
\hline & GR02-9.1 & 0.996 & 0.19 & 8.51 & 9.18 & 18.16 & 20.15 & 765 & 87 & 844 & 101 \\
\hline & $\begin{array}{c}\text { GR02- } \\
10.1\end{array}$ & 0.983 & 0.41 & 6.49 & 0.22 & 6.72 & 0.15 & 739 & 13 & 742 & 12 \\
\hline & $\begin{array}{c}\text { GR02- } \\
12.1\end{array}$ & 0.949 & 2.57 & 39.34 & 1.32 & 36.34 & 1.30 & 939 & 14 & 928 & 15 \\
\hline & $\begin{array}{c}\text { GR02- } \\
16.1\end{array}$ & 0.965 & 1.41 & 20.08 & 0.17 & 20.44 & 0.27 & 856 & 11 & 858 & 12 \\
\hline & $\begin{array}{c}\text { GR02- } \\
17.1\end{array}$ & 0.935 & 0.44 & 8.65 & 0.51 & 8.52 & 0.25 & 766 & 16 & 765 & 13 \\
\hline & $\begin{array}{c}\text { GR02- } \\
18.1\end{array}$ & 0.843 & 0.19 & 9.21 & 5.29 & 6.88 & 3.18 & 772 & 57 & 744 & 47 \\
\hline
\end{tabular}




\section{ANEXO III}

Isótopos de Lu-Hf por LA-MC-ICPMS

\begin{tabular}{|c|c|c|c|c|c|c|}
\hline Amostra & análise & $\begin{array}{c}\text { Idade } \\
\text { concórdia } \\
\text { da } \\
\text { amostra }\end{array}$ & $\begin{array}{l}{ }^{176} \mathrm{Lu} / \\
{ }^{177} \mathrm{Hfo}\end{array}$ & $\begin{array}{l}{ }^{176} \mathrm{Hf} / \\
{ }^{177} \mathrm{Hfo}\end{array}$ & ${ }^{176} \mathrm{Hf} /{ }^{177} \mathrm{Hfi}$ & $\varepsilon \mathrm{Hfo}$ \\
\hline
\end{tabular}

\begin{tabular}{|c|c|c|c|c|c|c|c|}
\hline San Telmo & ST-03-1.1 & 347 & 0.001312 & 0.282839 & 0.282838 & 1.91 & 2.65 \\
\hline \multirow[t]{23}{*}{ (ST-03) } & ST-03-3.1 & 347 & 0.001845 & 0.282874 & 0.282873 & 3.15 & 3.88 \\
\hline & ST-03-4.1 & 347 & 0.001852 & 0.282842 & 0.282841 & 2.02 & 2.74 \\
\hline & ST-03-5.1 & 347 & 0.001516 & 0.282861 & 0.282860 & 2.69 & 3.42 \\
\hline & ST-03.6.1 & 347 & 0.001930 & 0.282837 & 0.282836 & 1.84 & 2.57 \\
\hline & ST-03-7.1 & 347 & 0.002130 & 0.282872 & 0.282871 & 3.08 & 3.80 \\
\hline & ST-03-8.1 & 347 & 0.001393 & 0.282892 & 0.282891 & 3.78 & 4.52 \\
\hline & ST-03-9.1 & 347 & 0.001432 & 0.282888 & 0.282887 & 3.64 & 4.38 \\
\hline & ST-03-10.1 & 347 & 0.001135 & 0.282850 & 0.282849 & 2.30 & 3.04 \\
\hline & ST-03-12.1 & 347 & 0.002970 & 0.282862 & 0.282860 & 2.72 & 3.43 \\
\hline & ST-03-13.1 & 347 & 0.001707 & 0.282856 & 0.282855 & 2.51 & 3.24 \\
\hline & ST-03-14.1 & 347 & 0.001329 & 0.282853 & 0.282852 & 2.40 & 3.14 \\
\hline & ST-03-15.1 & 347 & 0.001356 & 0.282838 & 0.282837 & 1.87 & 2.61 \\
\hline & ST-03-16.1 & 347 & 0.002011 & 0.282841 & 0.282840 & 1.98 & 2.70 \\
\hline & ST-03-17.1 & 347 & 0.001269 & 0.282846 & 0.282845 & 2.16 & 2.90 \\
\hline & ST-03-18.1 & 347 & 0.001400 & 0.282853 & 0.282852 & 2.40 & 3.14 \\
\hline & ST-03-19.1 & 347 & 0.001301 & 0.282823 & 0.282822 & 1.34 & 2.08 \\
\hline & ST-03-20.1 & 347 & 0.001494 & 0.282831 & 0.282830 & 1.63 & 2.36 \\
\hline & ST-03-21.1 & 347 & 0.001740 & 0.282870 & 0.282869 & 3.01 & 3.74 \\
\hline & ST-03-22.1 & 347 & 0.001538 & 0.282862 & 0.282861 & 2.72 & 3.46 \\
\hline & ST-03-23.1 & 347 & 0.003464 & 0.282885 & 0.282883 & 3.54 & 4.23 \\
\hline & ST-03.X1 & 347 & 0.003110 & 0.282895 & 0.282893 & 3.89 & 4.59 \\
\hline & ST-03-X2 & 347 & 0.001734 & 0.282852 & 0.282851 & 2.37 & 3.10 \\
\hline & ST-03-X3 & 347 & 0.002909 & 0.282848 & 0.282846 & 2.23 & 2.93 \\
\hline Aguas Teñidas & AT-01-1.1 & 352 & 0.001930 & 0.282769 & 0.282768 & -0.57 & 0.17 \\
\hline \multirow[t]{12}{*}{ (AT-01) } & AT-01-2.1 & 352 & 0.001435 & 0.282670 & 0.282669 & -4.07 & -3.32 \\
\hline & AT-01-3.1 & 352 & 0.001780 & 0.282761 & 0.282760 & -0.85 & -0.11 \\
\hline & AT-01-4.1 & 352 & 0.002162 & 0.282769 & 0.282768 & -0.57 & 0.17 \\
\hline & AT-01-5.1 & 352 & 0.002930 & 0.282795 & 0.282793 & 0.35 & 1.07 \\
\hline & AT-01-6.1 & 352 & 0.002219 & 0.282751 & 0.282750 & -1.20 & -0.47 \\
\hline & AT-01-7.1 & 352 & 0.004101 & 0.282778 & 0.282775 & -0.25 & 0.44 \\
\hline & AT-01-8.1 & 352 & 0.003807 & 0.282730 & 0.282727 & -1.94 & -1.25 \\
\hline & AT-01-9.1 & 352 & 0.002269 & 0.282783 & 0.282782 & -0.07 & 0.66 \\
\hline & AT-01-10.1 & 352 & 0.002484 & 0.282760 & 0.282758 & -0.88 & -0.16 \\
\hline & AT-01-11.1 & 352 & 0.002458 & 0.282786 & 0.282784 & 0.04 & 0.76 \\
\hline & AT-01-12.1 & 352 & 0.002890 & 0.282782 & 0.282780 & -0.11 & 0.61 \\
\hline & AT-01-13.1 & 352 & 0.003072 & 0.282792 & 0.282790 & 0.25 & 0.96 \\
\hline
\end{tabular}




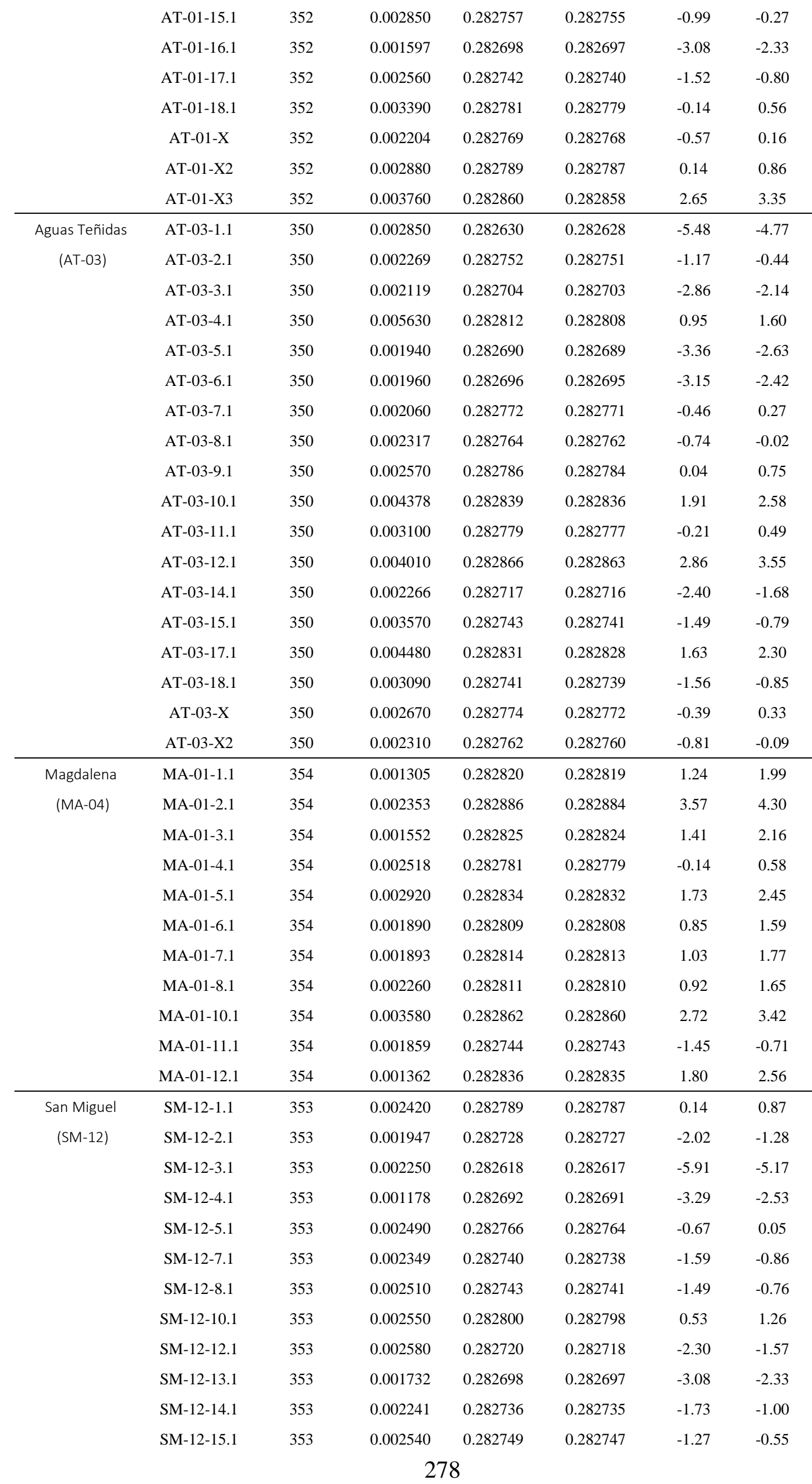




\begin{tabular}{|c|c|c|c|c|c|c|c|}
\hline & SM-12-16.1 & 353 & 0.001759 & 0.282699 & 0.282698 & -3.04 & -2.30 \\
\hline & SM-12-17.1 & 353 & 0.003469 & 0.282815 & 0.282813 & 1.06 & 1.76 \\
\hline & SM-12-18.1 & 353 & 0.002790 & 0.282811 & 0.282809 & 0.92 & 1.64 \\
\hline & SM-12-19.1 & 353 & 0.001923 & 0.282730 & 0.282729 & -1.94 & -1.21 \\
\hline & SM-12-20.1 & 353 & 0.002273 & 0.282729 & 0.282728 & -1.98 & -1.25 \\
\hline & SM-12-21.2 & 353 & 0.001824 & 0.282691 & 0.282690 & -3.32 & -2.58 \\
\hline & SM-12-22.1 & 353 & 0.005530 & 0.282805 & 0.282801 & 0.71 & 1.36 \\
\hline & SM-12-23.1 & 353 & 0.001559 & 0.282732 & 0.282731 & -1.87 & -1.13 \\
\hline & SM-12-24.1 & 353 & 0.002350 & 0.282778 & 0.282776 & -0.25 & 0.48 \\
\hline & SM-12-25.1 & 353 & 0.001138 & 0.282714 & 0.282713 & -2.51 & -1.75 \\
\hline & SM-12-X1 & 353 & 0.003028 & 0.282757 & 0.282755 & -0.99 & -0.28 \\
\hline \multirow{21}{*}{$\begin{array}{l}\text { Concepcion } \\
\text { (CO-04) }\end{array}$} & CO-04-1.1 & 354 & 0.002900 & 0.282791 & 0.282789 & 0.21 & 0.93 \\
\hline & CO-04-2.1 & 354 & 0.001493 & 0.282759 & 0.282758 & -0.92 & -0.17 \\
\hline & CO-04-3.1 & 354 & 0.003740 & 0.282817 & 0.282815 & 1.13 & 1.83 \\
\hline & CO-04-4.1 & 354 & 0.001327 & 0.282742 & 0.282741 & -1.52 & -0.77 \\
\hline & CO-04-5.1 & 354 & 0.001562 & 0.282754 & 0.282753 & -1.10 & -0.35 \\
\hline & CO-04-6.1 & 354 & 0.001469 & 0.282751 & 0.282750 & -1.20 & -0.45 \\
\hline & CO-04-7.1 & 354 & 0.002130 & 0.282779 & 0.282778 & -0.21 & 0.52 \\
\hline & CO-04-8.1 & 354 & 0.003060 & 0.282766 & 0.282764 & -0.67 & 0.04 \\
\hline & CO-04-9.1 & 354 & 0.002350 & 0.282776 & 0.282774 & -0.32 & 0.41 \\
\hline & CO-04-10.1 & 354 & 0.002550 & 0.282757 & 0.282755 & -0.99 & -0.27 \\
\hline & CO-04-11.1 & 354 & 0.002650 & 0.282783 & 0.282781 & -0.07 & 0.65 \\
\hline & CO-04-12.1 & 354 & 0.002590 & 0.282787 & 0.282785 & 0.07 & 0.79 \\
\hline & CO-04-13.1 & 354 & 0.002700 & 0.282767 & 0.282765 & -0.64 & 0.08 \\
\hline & CO-04-14.1 & 354 & 0.002321 & 0.282806 & 0.282804 & 0.74 & 1.47 \\
\hline & CO-04-16.1 & 354 & 0.002183 & 0.282822 & 0.282821 & 1.31 & 2.04 \\
\hline & CO-04.17.1 & 354 & 0.004590 & 0.282836 & 0.282833 & 1.80 & 2.48 \\
\hline & CO-04.18.1 & 354 & 0.002950 & 0.282883 & 0.282881 & 3.47 & 4.18 \\
\hline & CO-04.19.1 & 354 & 0.003030 & 0.282871 & 0.282869 & 3.04 & 3.76 \\
\hline & CO-04.20.1 & 354 & 0.002088 & 0.282784 & 0.282783 & -0.04 & 0.70 \\
\hline & CO-04-21.1 & 354 & 0.002880 & 0.282703 & 0.282701 & -2.90 & -2.18 \\
\hline & CO-04-22.1 & 354 & 0.001913 & 0.282760 & 0.282759 & -0.88 & -0.14 \\
\hline \multirow{12}{*}{$\begin{array}{c}\text { San Platon } \\
\text { (SP-03) }\end{array}$} & SP-03-1.1 & 338 & 0.002260 & 0.282684 & 0.282683 & -3.57 & -2.87 \\
\hline & SP-03-3.1 & 338 & 0.001305 & 0.282700 & 0.282699 & -3.01 & -2.28 \\
\hline & SP-03-5.1 & 338 & 0.001777 & 0.282708 & 0.282707 & -2.72 & -2.01 \\
\hline & SP-03-7.1 & 338 & 0.001529 & 0.282714 & 0.282713 & -2.51 & -1.79 \\
\hline & SP-03-8.1 & 338 & 0.001430 & 0.282704 & 0.282703 & -2.86 & -2.15 \\
\hline & SP-03-9.1 & 338 & 0.001391 & 0.282686 & 0.282685 & -3.50 & -2.78 \\
\hline & SP-03-11.1 & 338 & 0.001110 & 0.282699 & 0.282698 & -3.04 & -2.32 \\
\hline & SP-03-12.1 & 338 & 0.002648 & 0.282717 & 0.282715 & -2.40 & -1.71 \\
\hline & SP-03-13.1 & 338 & 0.001644 & 0.282701 & 0.282700 & -2.97 & -2.26 \\
\hline & SP-03-15.1 & 338 & 0.001599 & 0.282708 & 0.282707 & -2.72 & -2.01 \\
\hline & SP-03-17.1 & 338 & 0.001443 & 0.282719 & 0.282718 & -2.33 & -1.62 \\
\hline & SP-03-18.1 & 338 & 0.002390 & 0.282737 & 0.282735 & -1.70 & -1.00 \\
\hline \multirow{4}{*}{$\begin{array}{l}\text { Solo Viejo } \\
\text { (SV-01) }\end{array}$} & SV-01-1.1 & 349 & 0.001570 & 0.282804 & 0.282803 & 0.67 & 1.41 \\
\hline & SV-01-3.1 & 349 & 0.001457 & 0.282485 & 0.282484 & -10.61 & -9.87 \\
\hline & SV-01-5.1 & 349 & 0.001455 & 0.282629 & 0.282628 & -5.52 & -4.78 \\
\hline & SV-01-8.1 & 349 & 0.001256 & 0.282568 & 0.282567 & -7.67 & -6.93 \\
\hline
\end{tabular}




\begin{tabular}{|c|c|c|c|c|c|c|c|}
\hline & SV-01-9.1 & 349 & 0.001142 & 0.282603 & 0.282602 & -6.44 & -5.69 \\
\hline & SV-10.1 & 349 & 0.001377 & 0.282571 & 0.282570 & -7.57 & -6.82 \\
\hline & SV-01-11.1 & 349 & 0.004180 & 0.282821 & 0.282818 & 1.27 & 1.95 \\
\hline & SV-01-12.1 & 349 & 0.001617 & 0.282583 & 0.282582 & -7.14 & -6.41 \\
\hline & SV-01-14.1 & 349 & 0.003145 & 0.282649 & 0.282647 & -4.81 & -4.11 \\
\hline & SV-01-15.1 & 349 & 0.001962 & 0.282707 & 0.282706 & -2.76 & -2.03 \\
\hline & SV-01-16.1 & 349 & 0.001213 & 0.282555 & 0.282554 & -8.13 & -7.39 \\
\hline & SV-01-18.1 & 349 & 0.001772 & 0.282632 & 0.282631 & -5.41 & -4.68 \\
\hline & SV-01-20.1 & 349 & 0.001230 & 0.282612 & 0.282611 & -6.12 & -5.37 \\
\hline & SV-01-21.1 & 349 & 0.001880 & 0.282648 & 0.282647 & -4.84 & -4.11 \\
\hline & SV-01-22.1 & 349 & 0.001570 & 0.282673 & 0.282672 & -3.96 & -3.22 \\
\hline \multirow{8}{*}{$\begin{array}{l}\text { Solo Viejo } \\
\text { (SV-02) }\end{array}$} & SV-02-2.1 & 349 & 0.002103 & 0.282803 & 0.282802 & 0.64 & 1.36 \\
\hline & SV-02-3.2 & 349 & 0.004462 & 0.282815 & 0.282812 & 1.06 & 1.73 \\
\hline & SV-02-4.2 & 349 & 0.002600 & 0.282813 & 0.282811 & 0.99 & 1.70 \\
\hline & SV-02-5.1 & 349 & 0.002416 & 0.282805 & 0.282803 & 0.71 & 1.43 \\
\hline & SV-02-8.1 & 349 & 0.002940 & 0.282799 & 0.282797 & 0.50 & 1.20 \\
\hline & SV-02-9.1 & 349 & 0.001700 & 0.282805 & 0.282804 & 0.71 & 1.44 \\
\hline & SV-02-10.1 & 349 & 0.003660 & 0.282809 & 0.282807 & 0.85 & 1.54 \\
\hline & SV-02-12.1 & 349 & 0.001257 & 0.282790 & 0.282789 & 0.18 & 0.92 \\
\hline \multirow{23}{*}{$\begin{array}{c}\text { Aglomerado del } \\
\text { Cerro } \\
\text { (AC-01) }\end{array}$} & AC-01-1.1 & 354 & 0.003490 & 0.282700 & 0.282698 & -3.01 & -2.30 \\
\hline & AC-01-2.1 & 354 & 0.001909 & 0.282690 & 0.282689 & -3.36 & -2.62 \\
\hline & AC-01-4.1 & 354 & 0.002170 & 0.282676 & 0.282675 & -3.85 & -3.12 \\
\hline & AC-01-5.1 & 354 & 0.002426 & 0.282687 & 0.282685 & -3.47 & -2.74 \\
\hline & AC-01-6.1 & 354 & 0.002130 & 0.282645 & 0.282644 & -4.95 & -4.21 \\
\hline & AC-01-7.1 & 354 & 0.002850 & 0.282717 & 0.282715 & -2.40 & -1.69 \\
\hline & AC-01-8.1 & 354 & 0.003020 & 0.282717 & 0.282715 & -2.40 & -1.69 \\
\hline & AC-01-9.1 & 354 & 0.001617 & 0.282669 & 0.282668 & -4.10 & -3.35 \\
\hline & AC-01-10.1 & 354 & 0.002361 & 0.282690 & 0.282688 & -3.36 & -2.63 \\
\hline & AC-01-11.1 & 354 & 0.002010 & 0.282686 & 0.282685 & -3.50 & -2.76 \\
\hline & AC-01-12.1 & 354 & 0.002665 & 0.282695 & 0.282693 & -3.18 & -2.46 \\
\hline & AC-01-13.1 & 354 & 0.001305 & 0.282663 & 0.282662 & -4.31 & -3.56 \\
\hline & AC-01-14.1 & 354 & 0.002510 & 0.282684 & 0.282682 & -3.57 & -2.84 \\
\hline & AC-01-15.1 & 354 & 0.002173 & 0.282695 & 0.282694 & -3.18 & -2.45 \\
\hline & AC-01-16.1 & 354 & 0.001764 & 0.282661 & 0.282660 & -4.38 & -3.64 \\
\hline & AC-01-17.1 & 354 & 0.003490 & 0.282712 & 0.282710 & -2.58 & -1.88 \\
\hline & AC-01-19.1 & 354 & 0.002300 & 0.282673 & 0.282671 & -3.96 & -3.23 \\
\hline & AC-01-18.1 & 354 & 0.002860 & 0.282667 & 0.282665 & -4.17 & -3.45 \\
\hline & AC-01-20.1 & 354 & 0.001937 & 0.282659 & 0.282658 & -4.46 & -3.72 \\
\hline & AC-01-X1 & 354 & 0.002810 & 0.282668 & 0.282666 & -4.14 & -3.42 \\
\hline & AC-01-X2 & 354 & 0.003240 & 0.282717 & 0.282715 & -2.40 & -1.69 \\
\hline & AC-01-X3 & 354 & 0.001859 & 0.282685 & 0.282684 & -3.54 & -2.79 \\
\hline & AC-01-X4 & 354 & 0.002276 & 0.282708 & 0.282706 & -2.72 & -1.99 \\
\hline \multirow{21}{*}{$\begin{array}{c}\text { Aglomerado del } \\
\text { Cerro } \\
\text { (AC-02) }\end{array}$} & AC-02-1.1 & 352 & 0.001485 & 0.282678 & 0.282677 & -3.78 & -3.04 \\
\hline & AC-02-2.1 & 352 & 0.001830 & 0.282658 & 0.282657 & -4.49 & -3.75 \\
\hline & AC-02-3.1 & 352 & 0.002288 & 0.282706 & 0.282704 & -2.79 & -2.07 \\
\hline & AC-02-5.1 & 352 & 0.001860 & 0.282673 & 0.282672 & -3.96 & -3.22 \\
\hline & AC-02-6.1 & 352 & 0.002440 & 0.282671 & 0.282669 & -4.03 & -3.31 \\
\hline & AC-02-7.1 & 352 & 0.001870 & 0.282674 & 0.282673 & -3.93 & -3.19 \\
\hline & AC-02-8.1 & 352 & 0.002780 & 0.282688 & 0.282686 & -3.43 & -2.71 \\
\hline & AC-02-9.1 & 352 & 0.002222 & 0.282712 & 0.282711 & -2.58 & -1.85 \\
\hline & AC-02-10.1 & 352 & 0.002790 & 0.282712 & 0.282710 & -2.58 & -1.87 \\
\hline & AC-02-11.1 & 352 & 0.002630 & 0.282741 & 0.282739 & -1.56 & -0.84 \\
\hline & AC-02-12.1 & 352 & 0.002810 & 0.282706 & 0.282704 & -2.79 & -2.08 \\
\hline & AC-02-13.1 & 352 & 0.002322 & 0.282671 & 0.282669 & -4.03 & -3.31 \\
\hline & AC-02-15.1 & 352 & 0.003250 & 0.282747 & 0.282745 & -1.34 & -0.64 \\
\hline & AC-02-16.1 & 352 & 0.002425 & 0.282682 & 0.282680 & -3.64 & -2.92 \\
\hline & AC- $02-17.1$ & 352 & 0.001760 & 0.282687 & 0.282686 & -3.47 & -2.73 \\
\hline & AC-02-19.1 & 352 & 0.003087 & 0.282731 & 0.282729 & -1.91 & -1.20 \\
\hline & AC- $02-20.1$ & 352 & 0.002115 & 0.282676 & 0.282675 & -3.85 & -3.12 \\
\hline & AC-02-21.1 & 352 & 0.001676 & 0.282669 & 0.282668 & -4.10 & -3.36 \\
\hline & AC-02-X1 & 352 & 0.002160 & 0.282677 & 0.282676 & -3.82 & -3.09 \\
\hline & AC-02-X2 & 352 & 0.001812 & 0.282673 & 0.282672 & -3.96 & -3.22 \\
\hline & AC-02-X3 & 352 & 0.002034 & 0.282684 & 0.282683 & -3.57 & -2.84 \\
\hline La Zarza & ZA-3-2.1 & 357 & 0.001610 & 0.282693 & 0.282692 & -3.25 & -2.50 \\
\hline
\end{tabular}




\begin{tabular}{|c|c|c|c|c|c|c|c|}
\hline \multirow[t]{13}{*}{$(\mathrm{ZA}-3)$} & ZA-3-3.1 & 357 & 0.001800 & 0.282692 & 0.282691 & -3.29 & -2.54 \\
\hline & ZA-3-4.1 & 357 & 0.002076 & 0.282710 & 0.282709 & -2.65 & -1.91 \\
\hline & ZA-3-5.1 & 357 & 0.001414 & 0.282673 & 0.282672 & -3.96 & -3.20 \\
\hline & ZA-3-6.1 & 357 & 0.001700 & 0.282724 & 0.282723 & -2.16 & -1.41 \\
\hline & ZA-3-7.1 & 357 & 0.001470 & 0.282718 & 0.282717 & -2.37 & -1.61 \\
\hline & ZA-3-8.1 & 357 & 0.002050 & 0.282659 & 0.282658 & -4.46 & -3.72 \\
\hline & ZA-3-9.1 & 357 & 0.002119 & 0.282692 & 0.282691 & -3.29 & -2.55 \\
\hline & ZA-3-13.1 & 357 & 0.001155 & 0.282703 & 0.282702 & -2.90 & -2.14 \\
\hline & ZA-3-14.1 & 357 & 0.001193 & 0.282689 & 0.282688 & -3.39 & -2.63 \\
\hline & ZA-3-15.1 & 357 & 0.001756 & 0.282723 & 0.282722 & -2.19 & -1.44 \\
\hline & ZA-3-17.1 & 357 & 0.002240 & 0.282641 & 0.282640 & -5.09 & -4.36 \\
\hline & ZA-3-X & 356 & 0.003110 & 0.282727 & 0.282725 & -2.05 & -1.34 \\
\hline & ZA-3-X2 & 356 & 0.002040 & 0.282702 & 0.282701 & -2.94 & -2.19 \\
\hline \multirow{17}{*}{$\begin{array}{c}\text { La Zarza } \\
\text { (ZA-4) }\end{array}$} & ZA-4-2.1 & 355 & 0.002624 & 0.282793 & 0.282791 & 0.28 & 1.01 \\
\hline & ZA-4-3.1 & 355 & 0.001787 & 0.282684 & 0.282683 & -3.57 & -2.83 \\
\hline & ZA-4-4.1 & 355 & 0.001624 & 0.282681 & 0.282680 & -3.68 & -2.93 \\
\hline & ZA-4-6.1 & 355 & 0.002770 & 0.282727 & 0.282725 & -2.05 & -1.33 \\
\hline & ZA-4-7.1 & 355 & 0.001625 & 0.282690 & 0.282689 & -3.36 & -2.61 \\
\hline & ZA-4-8.1 & 355 & 0.001300 & 0.282673 & 0.282672 & -3.96 & -3.20 \\
\hline & ZA-4-9.1 & 355 & 0.002390 & 0.282667 & 0.282665 & -4.17 & -3.44 \\
\hline & ZA-4-10.1 & 355 & 0.001420 & 0.282693 & 0.282692 & -3.25 & -2.50 \\
\hline & ZA-4-11.1 & 355 & 0.001700 & 0.282700 & 0.282699 & -3.01 & -2.26 \\
\hline & ZA-4-12.1 & 355 & 0.001512 & 0.282688 & 0.282687 & -3.43 & -2.68 \\
\hline & ZA-4-13.1 & 355 & 0.002080 & 0.282645 & 0.282644 & -4.95 & -4.21 \\
\hline & ZA-4-14.1 & 355 & 0.001875 & 0.282666 & 0.282665 & -4.21 & -3.46 \\
\hline & ZA-4-15.1 & 355 & 0.001397 & 0.282677 & 0.282676 & -3.82 & -3.06 \\
\hline & ZA-4-16.1 & 355 & 0.002526 & 0.282689 & 0.282687 & -3.39 & -2.67 \\
\hline & ZA-4-17.1 & 355 & 0.001425 & 0.282685 & 0.282684 & -3.54 & -2.78 \\
\hline & ZA-4-18.1 & 355 & 0.002170 & 0.282680 & 0.282679 & -3.71 & -2.98 \\
\hline & ZA-4-19.1 & 355 & 0.001793 & 0.282662 & 0.282661 & -4.35 & -3.60 \\
\hline \multirow{6}{*}{$\begin{array}{l}\text { Rio Tinto } \\
\text { (RT-02) }\end{array}$} & RT-02-1.1 & 339 & 0.001304 & 0.282655 & 0.282654 & -4.60 & -3.87 \\
\hline & RT-02-2.1 & 339 & 0.002297 & 0.282705 & 0.282704 & -2.83 & -2.13 \\
\hline & RT-02-4.1 & 339 & 0.003840 & 0.282761 & 0.282759 & -0.85 & -0.18 \\
\hline & RT-02-9.1 & 339 & 0.003050 & 0.282689 & 0.282687 & -3.39 & -2.71 \\
\hline & RT-02-15.1 & 339 & 0.001685 & 0.282669 & 0.282668 & -4.10 & -3.39 \\
\hline & RT-02-18.1 & 339 & 0.001490 & 0.282659 & 0.282658 & -4.46 & -3.74 \\
\hline \multirow{10}{*}{$\begin{array}{l}\text { Rio Tinto } \\
\text { (RT-04) }\end{array}$} & RT-04-1.1 & 352 & 0.002900 & 0.282754 & 0.282752 & -1.10 & -0.38 \\
\hline & RT-04-2.1 & 352 & 0.002477 & 0.282731 & 0.282729 & -1.91 & -1.19 \\
\hline & RT-04-3.1 & 352 & 0.001374 & 0.282672 & 0.282671 & -4.00 & -3.25 \\
\hline & RT-04-5.1 & 352 & 0.001572 & 0.282641 & 0.282640 & -5.09 & -4.35 \\
\hline & RT-04-6.1 & 352 & 0.004640 & 0.282830 & 0.282827 & 1.59 & 2.26 \\
\hline & RT-04-8.1 & 352 & 0.002601 & 0.282702 & 0.282700 & -2.94 & -2.22 \\
\hline & RT-04-11.1 & 352 & 0.001189 & 0.282631 & 0.282630 & -5.45 & -4.69 \\
\hline & RT-04-13.1 & 352 & 0.001450 & 0.282619 & 0.282618 & -5.87 & -5.12 \\
\hline & RT-04-17.1 & 352 & 0.001340 & 0.282562 & 0.282561 & -7.89 & -7.14 \\
\hline & RT-04-18.1 & 352 & 0.002303 & 0.282626 & 0.282624 & -5.62 & -4.90 \\
\hline Rio Tinto & RT-05-1.1 & 348 & 0.001597 & 0.282533 & 0.282532 & -8.91 & -8.18 \\
\hline (RT-05) & RT-05-2.1 & 348 & 0.002580 & 0.282590 & 0.282588 & -6.90 & -6.18 \\
\hline
\end{tabular}




\begin{tabular}{|c|c|c|c|c|c|c|c|}
\hline & RT-05-3.1 & 348 & 0.001834 & 0.282590 & 0.282589 & -6.90 & -6.17 \\
\hline & RT-05-4.1 & 348 & 0.002840 & 0.282526 & 0.282524 & -9.16 & -8.45 \\
\hline & RT-05-5.1 & 348 & 0.002750 & 0.282540 & 0.282538 & -8.66 & -7.95 \\
\hline & RT-05-6.1 & 348 & 0.002103 & 0.282544 & 0.282543 & -8.52 & -7.80 \\
\hline & RT-05-7.1 & 348 & 0.002200 & 0.282593 & 0.282592 & -6.79 & -6.07 \\
\hline & RT-05-8.1 & 348 & 0.001532 & 0.282536 & 0.282535 & -8.81 & -8.07 \\
\hline & RT-05-9.1 & 348 & 0.001490 & 0.282559 & 0.282558 & -7.99 & -7.25 \\
\hline & RT-05-10.1 & 348 & 0.001595 & 0.282515 & 0.282514 & -9.55 & -8.81 \\
\hline & RT-05-11.1 & 348 & 0.002480 & 0.282638 & 0.282636 & -5.20 & -4.48 \\
\hline & RT-05-12.1 & 348 & 0.001578 & 0.282554 & 0.282553 & -8.17 & -7.43 \\
\hline & RT-05-13.1 & 348 & 0.002140 & 0.282614 & 0.282613 & -6.05 & -5.32 \\
\hline & RT-05-14.1 & 348 & 0.002100 & 0.282612 & 0.282611 & -6.12 & -5.39 \\
\hline & RT-05-15.1 & 348 & 0.001490 & 0.282533 & 0.282532 & -8.91 & -8.17 \\
\hline & RT-05-16.1 & 348 & 0.001426 & 0.282556 & 0.282555 & -8.10 & -7.36 \\
\hline \multirow{15}{*}{$\begin{array}{c}\text { Zarandas } \\
(\mathrm{ZN}-01)\end{array}$} & ZN-01-1.1 & 358 & 0.001420 & 0.282531 & 0.282530 & -8.98 & -8.22 \\
\hline & $\mathrm{ZN}-01-2.1$ & 358 & 0.002306 & 0.282727 & 0.282725 & -2.05 & -1.31 \\
\hline & $\mathrm{ZN}-01-3.1$ & 358 & 0.001918 & 0.282653 & 0.282652 & -4.67 & -3.92 \\
\hline & $\mathrm{ZN}-01-4.1$ & 358 & 0.002920 & 0.282674 & 0.282672 & -3.93 & -3.20 \\
\hline & $\mathrm{ZN}-01-5.1$ & 358 & 0.001740 & 0.282677 & 0.282676 & -3.82 & -3.07 \\
\hline & $\mathrm{ZN}-01-8.1$ & 358 & 0.001529 & 0.282630 & 0.282629 & -5.48 & -4.72 \\
\hline & $\mathrm{ZN}-01-9.1$ & 358 & 0.002145 & 0.282701 & 0.282700 & -2.97 & -2.23 \\
\hline & $\mathrm{ZN}-01-10.1$ & 358 & 0.003340 & 0.282784 & 0.282782 & -0.04 & 0.68 \\
\hline & ZN-01-11.1 & 358 & 0.001570 & 0.282656 & 0.282655 & -4.56 & -3.80 \\
\hline & $\mathrm{ZN}-01-12.1$ & 358 & 0.001995 & 0.282635 & 0.282634 & -5.30 & -4.56 \\
\hline & $\mathrm{ZN}-01-13.1$ & 358 & 0.001995 & 0.282635 & 0.282634 & -5.30 & -4.56 \\
\hline & ZN-01-14.1 & 358 & 0.001650 & 0.282662 & 0.282661 & -4.35 & -3.59 \\
\hline & $\mathrm{ZN}-01-15.1$ & 358 & 0.001952 & 0.282661 & 0.282660 & -4.38 & -3.64 \\
\hline & $\mathrm{ZN}-01-16.1$ & 358 & 0.002040 & 0.282594 & 0.282593 & -6.75 & -6.01 \\
\hline & $\mathrm{ZN}-01-23.1$ & 358 & 0.002560 & 0.282739 & 0.282737 & -1.63 & -0.89 \\
\hline \multirow{4}{*}{$\begin{array}{c}\text { Zarandas } \\
\text { (ZN-02) }\end{array}$} & $\mathrm{ZN}-02-2.1$ & 351 & 0.001737 & 0.282635 & 0.282634 & -5.30 & -4.57 \\
\hline & $\mathrm{ZN}-02-8.1$ & 351 & 0.002470 & 0.282696 & 0.282694 & -3.15 & -2.43 \\
\hline & $\mathrm{ZN}-02-10.1$ & 351 & 0.003470 & 0.282758 & 0.282756 & -0.95 & -0.26 \\
\hline & $\mathrm{ZN}-02-11.1$ & 351 & 0.001863 & 0.282715 & 0.282714 & -2.48 & -1.74 \\
\hline \multirow{15}{*}{$\begin{array}{l}\text { Aglomerado del } \\
\text { Cerro (AC-01) }\end{array}$} & AC-01-1.1 & 354 & 0.003490 & 0.282700 & 0.282698 & -3.01 & -2.30 \\
\hline & AC-01-2.1 & 354 & 0.001909 & 0.282690 & 0.282689 & -3.36 & -2.62 \\
\hline & AC-01-3.1 & 354 & 0.002276 & 0.282708 & 0.282706 & -2.72 & -1.99 \\
\hline & AC-01-4.1 & 354 & 0.002170 & 0.282676 & 0.282675 & -3.85 & -3.12 \\
\hline & AC-01-5.1 & 354 & 0.002426 & 0.282687 & 0.282685 & -3.47 & -2.74 \\
\hline & AC-01-6.1 & 354 & 0.002130 & 0.282645 & 0.282644 & -4.95 & -4.21 \\
\hline & AC-01-7.1 & 354 & 0.002850 & 0.282717 & 0.282715 & -2.40 & -1.69 \\
\hline & AC-01-8.1 & 354 & 0.002810 & 0.282668 & 0.282666 & -4.14 & -3.42 \\
\hline & AC-01-9.1 & 354 & 0.001617 & 0.282669 & 0.282668 & -4.10 & -3.35 \\
\hline & AC-01-10.1 & 354 & 0.002361 & 0.282690 & 0.282688 & -3.36 & -2.63 \\
\hline & AC-01-11.1 & 354 & 0.002010 & 0.282686 & 0.282685 & -3.50 & -2.76 \\
\hline & AC-01-12.1 & 354 & 0.002665 & 0.282695 & 0.282693 & -3.18 & -2.46 \\
\hline & AC-01-13.1 & 354 & 0.001305 & 0.282663 & 0.282662 & -4.31 & -3.56 \\
\hline & AC-01-14.1 & 354 & 0.002510 & 0.282684 & 0.282682 & -3.57 & -2.84 \\
\hline & AC-01-15.1 & 354 & 0.002173 & 0.282695 & 0.282694 & -3.18 & -2.45 \\
\hline
\end{tabular}




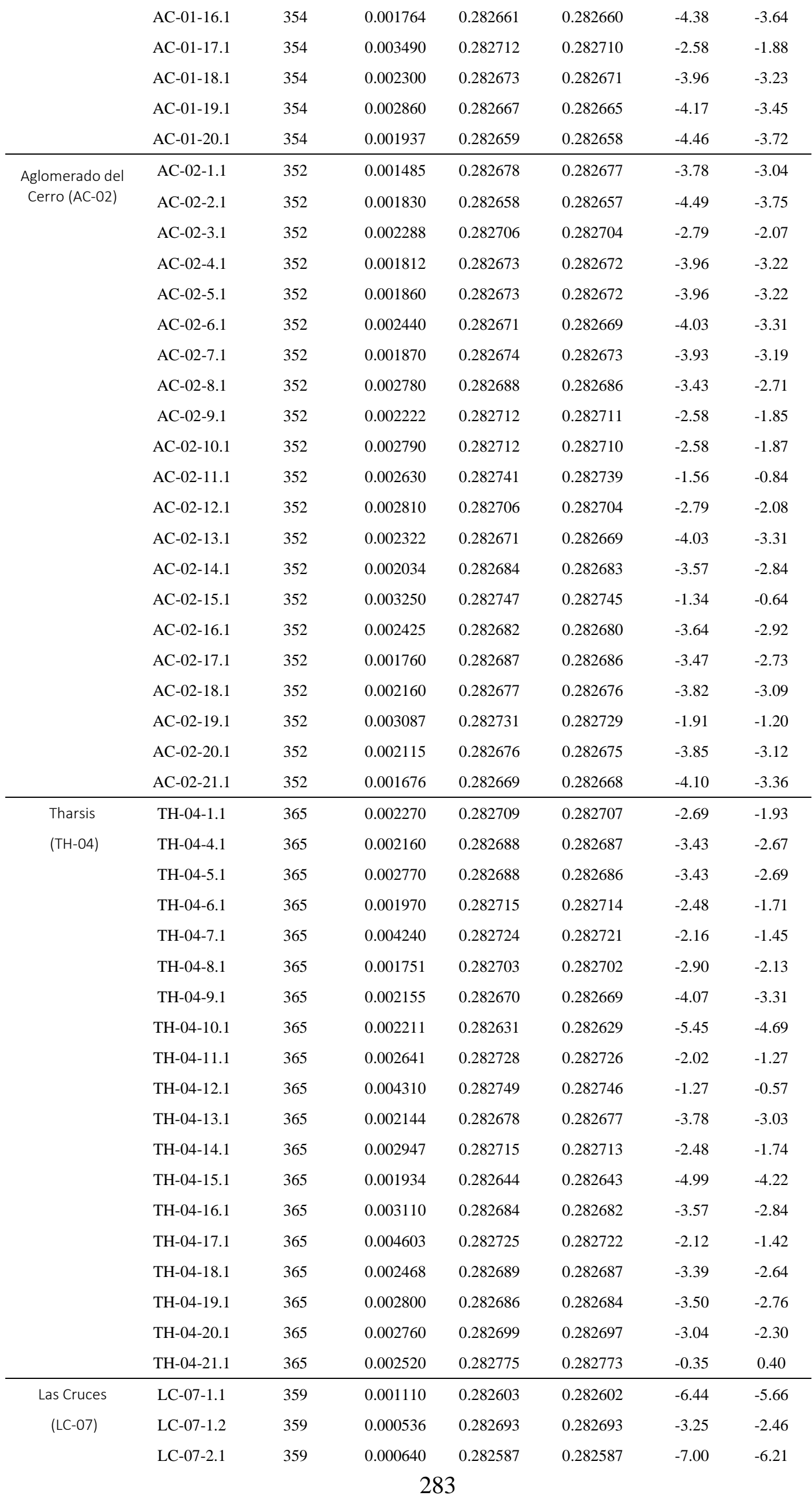




\begin{tabular}{|c|c|c|c|c|c|c|c|}
\hline & LC-07-3.1 & 359 & 0.000874 & 0.282586 & 0.282585 & -7.04 & -6.25 \\
\hline & LC-07-4.1 & 359 & 0.000652 & 0.282598 & 0.282598 & -6.61 & -5.82 \\
\hline & LC-07.5.1 & 359 & 0.000562 & 0.282592 & 0.282592 & -6.82 & -6.03 \\
\hline & LC-07-6.1 & 359 & 0.000918 & 0.282603 & 0.282602 & -6.44 & -5.65 \\
\hline & LC-07-7.1 & 359 & 0.001025 & 0.282586 & 0.282585 & -7.04 & -6.26 \\
\hline & LC-07-8.1 & 359 & 0.001131 & 0.282614 & 0.282613 & -6.05 & -5.27 \\
\hline & LC-07-11.1 & 359 & 0.000873 & 0.282592 & 0.282591 & -6.82 & -6.04 \\
\hline & LC-07-12.1 & 359 & 0.000926 & 0.282597 & 0.282596 & -6.65 & -5.86 \\
\hline & LC-07-13.1 & 359 & 0.000695 & 0.282597 & 0.282597 & -6.65 & -5.86 \\
\hline & LC-07-14.1 & 359 & 0.001130 & 0.282607 & 0.282606 & -6.29 & -5.52 \\
\hline & LC-07-15.1 & 359 & 0.000869 & 0.282618 & 0.282617 & -5.91 & -5.12 \\
\hline & LC-07-16.1 & 359 & 0.000540 & 0.282596 & 0.282596 & -6.68 & -5.89 \\
\hline & LC-07-18.1 & 359 & 0.001024 & 0.282630 & 0.282629 & -5.48 & -4.70 \\
\hline & LC-07-19.1 & 359 & 0.000868 & 0.282603 & 0.282602 & -6.44 & -5.65 \\
\hline & LC-07-21.1 & 359 & 0.000672 & 0.282590 & 0.282590 & -6.90 & -6.11 \\
\hline Las Cruces & LC-09-1.1 & 352 & 0.000919 & 0.282536 & 0.282535 & -8.81 & -8.05 \\
\hline (LC-09) & LC-09-2.1 & 352 & 0.000696 & 0.282520 & 0.282520 & -9.37 & -8.61 \\
\hline & LC-09-3.1 & 352 & 0.001027 & 0.282519 & 0.282518 & -9.41 & -8.65 \\
\hline & LC-09-4.1 & 352 & 0.001122 & 0.282527 & 0.282526 & -9.12 & -8.37 \\
\hline & LC-09-5.1 & 352 & 0.001056 & 0.282527 & 0.282526 & -9.12 & -8.37 \\
\hline & LC-09-6.1 & 352 & 0.001641 & 0.282564 & 0.282563 & -7.82 & -7.07 \\
\hline & LC-09-7.1 & 352 & 0.000871 & 0.282545 & 0.282544 & -8.49 & -7.73 \\
\hline & LC-09-8.1 & 352 & 0.001042 & 0.282560 & 0.282559 & -7.96 & -7.20 \\
\hline & LC-09-9.1 & 352 & 0.000927 & 0.282520 & 0.282519 & -9.37 & -8.61 \\
\hline & LC-09-10.1 & 352 & 0.000967 & 0.282530 & 0.282529 & -9.02 & -8.26 \\
\hline & LC-09-11.1 & 352 & 0.000620 & 0.282558 & 0.282558 & -8.03 & -7.26 \\
\hline & LC-09-12.1 & 352 & 0.000866 & 0.282532 & 0.282531 & -8.95 & -8.19 \\
\hline & LC-09-13.1 & 352 & 0.001394 & 0.282597 & 0.282596 & -6.65 & -5.90 \\
\hline & LC-09-14.1 & 352 & 0.000968 & 0.282503 & 0.282502 & -9.97 & -9.22 \\
\hline & LC-09-15.1 & 352 & 0.001318 & 0.282583 & 0.282582 & -7.14 & -6.39 \\
\hline & LC-09-16.1 & 352 & 0.000793 & 0.282509 & 0.282508 & -9.76 & -9.00 \\
\hline & LC-09-17.1 & 352 & 0.001011 & 0.282513 & 0.282512 & -9.62 & -8.86 \\
\hline & LC-09-18.1 & 352 & 0.001009 & 0.282531 & 0.282530 & -8.98 & -8.23 \\
\hline Gerena & GR-01-1.1 & 349 & 0.003549 & 0.282708 & 0.282705687 & -2.72 & -2.03 \\
\hline (GR-01) & GR-01-2.1 & 349 & 0.003606 & 0.282718 & 0.28271565 & -2.37 & -1.68 \\
\hline & GR-01-3.1 & 349 & 0.003207 & 0.282673 & 0.28267091 & -3.96 & -3.26 \\
\hline & GR-01-5.1 & 349 & 0.00243 & 0.282642 & 0.282640417 & -5.06 & -4.34 \\
\hline & GR-01-7.1 & 349 & 0.00344 & 0.282651 & 0.282648758 & -4.74 & -4.04 \\
\hline & GR-01-8.1 & 349 & 0.002786 & 0.28261 & 0.282608185 & -6.19 & -5.48 \\
\hline & GR-01-9.1 & 349 & 0.002851 & 0.282647 & 0.282645142 & -4.88 & -4.17 \\
\hline & GR-01-10.1 & 349 & 0.001942 & 0.282489 & 0.282487735 & -10.47 & -9.74 \\
\hline & GR-01-11.1 & 349 & 0.00562 & 0.282741 & 0.282737338 & -1.56 & -0.91 \\
\hline & GR-01-12.1 & 349 & 0.002295 & 0.282646 & 0.282644505 & -4.92 & -4.19 \\
\hline & GR-01-13.1 & 349 & 0.002491 & 0.282588 & 0.282586377 & -6.97 & -6.25 \\
\hline & GR-01-14.1 & 349 & 0.00287 & 0.282622 & 0.28262013 & -5.76 & -5.06 \\
\hline & GR-01-17.1 & 349 & 0.003204 & 0.282657 & 0.282654912 & -4.53 & -3.83 \\
\hline Gerena & GR-02-2.1 & 351 & 0.003606 & 0.282718 & 0.282715633 & -2.37 & -1.67 \\
\hline (GR-02) & GR-02-3.1 & 351 & 0.003207 & 0.282673 & 0.282670895 & -3.96 & -3.26 \\
\hline
\end{tabular}




\begin{tabular}{|c|c|c|c|c|c|c|c|}
\hline & GR-01-4.1 & 351 & 0.00318 & 0.28263 & 0.282627913 & -5.48 & -4.78 \\
\hline & GR-02-5.1 & 351 & 0.00243 & 0.282642 & 0.282640405 & -5.06 & -4.33 \\
\hline & GR-02-11.1 & 351 & 0.0037 & 0.282627 & 0.282624572 & -5.59 & -4.89 \\
\hline & GR-02-12.1 & 351 & 0.002295 & 0.282646 & 0.282644494 & -4.92 & -4.19 \\
\hline & GR-02-14.1 & 351 & 0.003226 & 0.282649 & 0.282646883 & -4.81 & -4.10 \\
\hline & GR-02-22.1 & 351 & 0.00562 & 0.282741 & 0.282737312 & -1.56 & -0.91 \\
\hline \multirow{32}{*}{$\begin{array}{l}\text { Dados de Rosa et } \\
\text { al. (2009) }\end{array}$} & CE4-zr116 & 370 & 0.001540 & 0.282765 & 0.282764 & -0.71 & 0.08 \\
\hline & AZ4zr2b & 361.8 & 0.001850 & 0.282565 & 0.282564 & -7.78 & -7.02 \\
\hline & FEV1-zr1b & 364 & 0.001030 & 0.282519 & 0.282518 & -9.41 & -8.62 \\
\hline & FEV1-zr8b & 364 & 0.000450 & 0.282506 & 0.282506 & -9.87 & -9.07 \\
\hline & FEV1-zr18b & 2639 & 0.000590 & 0.280986 & 0.280983 & -63.62 & -57.89 \\
\hline & FEV1-zr19b & 364 & 0.001700 & 0.282553 & 0.282552 & -8.20 & -7.44 \\
\hline & FEV1-zr34c & 364 & 0.000620 & 0.282538 & 0.282538 & -8.73 & -7.94 \\
\hline & FEV2-zr14b & 354.6 & 0.001510 & 0.282796 & 0.282795 & 0.39 & 1.14 \\
\hline & FEV2-zr31b & 354.6 & 0.001580 & 0.282674 & 0.282673 & -3.93 & -3.18 \\
\hline & FEV2-zr32b & 354.6 & 0.001330 & 0.282780 & 0.282779 & -0.18 & 0.58 \\
\hline & SJ1-zr3b & 356.5 & 0.001460 & 0.282649 & 0.282648 & -4.81 & -4.05 \\
\hline & SJ1-zr7b & 356.5 & 0.001430 & 0.282394 & 0.282393 & -13.83 & -13.07 \\
\hline & SJ1-zr15b & 356.5 & 0.001430 & 0.282132 & 0.282131 & -23.09 & -22.34 \\
\hline & SJ1-zr41b & 356.5 & 0.001370 & 0.282541 & 0.282540 & -8.63 & -7.87 \\
\hline & SJ1-zr42b & 356.5 & 0.000420 & 0.282510 & 0.282510 & -9.72 & -8.94 \\
\hline & SJ1-zr44b & 356.5 & 0.001170 & 0.282582 & 0.282581 & -7.18 & -6.42 \\
\hline & SJ2-zr3b & 356.6 & 0.001870 & 0.282549 & 0.282548 & -8.35 & -7.60 \\
\hline & SJ2-zr12b & 356.6 & 0.001710 & 0.282648 & 0.282647 & -4.84 & -4.09 \\
\hline & $\mathrm{CO} 5-\mathrm{zr} 2 \mathrm{~b}$ & 355.4 & 0.001860 & 0.282656 & 0.282655 & -4.56 & -3.82 \\
\hline & $\mathrm{CO} 5-\mathrm{zr} 4 \mathrm{~b}$ & 355.4 & 0.000930 & 0.282645 & 0.282644 & -4.95 & -4.18 \\
\hline & CO5-zr5b & 355.4 & 0.001320 & 0.282616 & 0.282615 & -5.98 & -5.22 \\
\hline & CO5-zr6b & 355.4 & 0.001670 & 0.282597 & 0.282596 & -6.65 & -5.90 \\
\hline & CO5-zr8c & 355.4 & 0.001370 & 0.282582 & 0.282581 & -7.18 & -6.42 \\
\hline & CO5-zr10c & 355.4 & 0.001150 & 0.282573 & 0.282572 & -7.50 & -6.74 \\
\hline & SB8-89,7zr1b & 356.9 & 0.001580 & 0.282608 & 0.282607 & -6.26 & -5.50 \\
\hline & SB8-89,7zr3b & 356.9 & 0.001560 & 0.282650 & 0.282649 & -4.77 & -4.02 \\
\hline & CH601-zr19b & 353.9 & 0.001270 & 0.282554 & 0.282553 & -8.17 & -7.41 \\
\hline & CH601-zr26b & 353.9 & 0.001150 & 0.282596 & 0.282595 & -6.68 & -5.93 \\
\hline & CH601-zr28b & 353.9 & 0.001010 & 0.282540 & 0.282539 & -8.66 & -7.90 \\
\hline & CH601-zr41b & 353.9 & 0.000990 & 0.282538 & 0.282537 & -8.73 & -7.97 \\
\hline & CH601-zr46 & 353.9 & 0.001370 & 0.282640 & 0.282639 & -5.13 & -4.37 \\
\hline & CH601-zr57 & 353.9 & 0.000960 & 0.282599 & 0.282598 & -6.58 & -5.82 \\
\hline
\end{tabular}

